UNIVERSIDADE DE SÃO PAULO

ESCOLA DE ENGENHARIA DE SÃO CARLOS

DEPARTAMENTO DE ENGENHARIA DE ESTRUTURAS

PAULO ROBERTO DE OLIVEIRA CARVALHO

ANÁLISE NUMÉRICA DE PEQUENAS PAREDES DE ALVENARIA ESTRUTURAL DE BLOCOS DE CONCRETO EM SITUAÇÃO DE INCÊNDIO: ÊNFASE NO COMPORTAMENTO TÉRMICO E TERMOESTRUTURAL

SÃO CARLOS 



\section{ANÁLISE NUMÉRICA DE PEQUENAS PAREDES DE ALVENARIA ESTRUTURAL DE BLOCOS DE CONCRETO EM SITUAÇÃO DE INCÊNDIO: ÊNFASE NO COMPORTAMENTO TÉRMICO E TERMOESTRUTURAL}

\section{VERSÃO CORRIGIDA}

A versão original encontra-se na Escola de Engenharia de São Carlos

Dissertação apresentada à Escola de Engenharia de São Carlos, Universidade de São Paulo, como parte dos requisitos para a obtenção do título de Mestre em Ciências.

Área de concentração: Engenharia Civil (Estruturas)

Orientador: Prof. Dr. Jorge Munaiar Neto 
AUTORIZO A REPRODUÇÃO TOTAL OU PARCIAL DESTE TRABALHO, POR QUALQUER MEIO CONVENCIONAL OU ELETRONNICO, PARA FINS DE ESTUDO E PESQUISA, DESDE QUE CITADA A FONTE.

Ficha catalográfica elaborada pela Biblioteca Prof. Dr. Sérgio Rodrigues Fontes da EESC/USP com os dados inseridos pelo(a) autor(a).

Carvalho, Paulo Roberto de Oliveira
C331a Análise numérica de pequenas par estrutural de blocos de concreto em situação de incêndio: ênfase no comportamento térmico e termoestrutural / Paulo Roberto de Oliveira Carvalho; orientador Jorge Munaiar Neto. São Carlos, 2019.

Dissertação (Mestrado) - Programa de Pós-Graduação em Engenharia Civil(Engenharia de Estruturas) e Área de Concentração em Estruturas -- Escola de Engenharia de São Carlos da Universidade de São Paulo, 2019.

1. Alvenaria estrutural. 2. Blocos de concreto. 3. Incêndio. 4. Método dos Elementos Finitos. 5. Modelo estrutural. 6. Modelo térmico. 7. Modelo termoestrutural. I. Título.

Eduardo Graziosi Silva - CRB - 8/8907 


\section{FOLHA DE JULGAMENTO}

Candidato: Engenheiro PAULO ROBERTO DE OLIVEIRACARVALHO.

Título da dissertação: "Análise numérica de pequenas paredes de alvenaria estrutural de blocos de concreto em situação de incêndio: ênfase no comportamento térmico e termoestrutural".

Data da defesa: 03/06/2019.

Comissão Julgadora:

Prof. Associado Jorge Munaiar Neto

(Orientador)

(Escola de Engenharia de São Carlos/EESC)

Prof. Dr. Roberto Marcio da Silva

(Universidade Federal de Minas Gerais/UFMG)

Prof. Dr. Armando Lopes Moreno Junior

(Universidade Estadual de Campinas/UNICAMP)
Resultado:
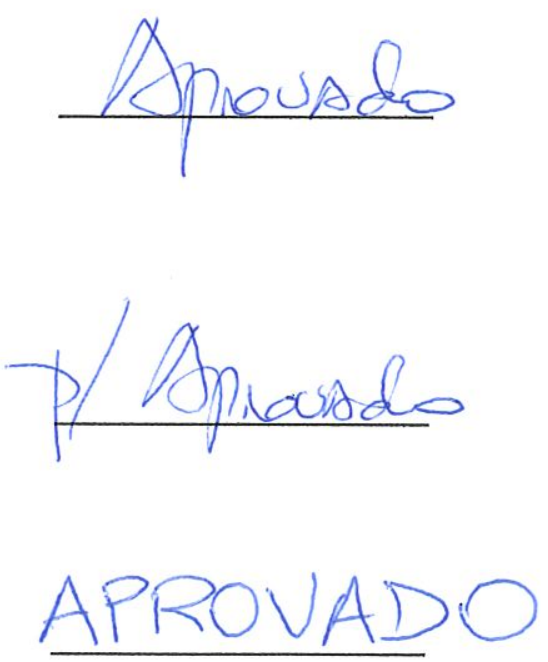

Coordenador do Programa de Pós-Graduação em Engenharia Civil (Engenharia de Estruturas):

Prof. Associado Vladimir Guilherme Haach

Presidente da Comissão de Pós-Graduação:

Prof. Titular Murilo Araujo Romero 

Aos meus pais, Paulo Carvalho e Sueleni Carvalho, meus avós, Maria Paes e Joaquim Celestino, minha namorada, Fernanda Oliveira, e aos meus pets, Tobby e Marley, com amor e gratidão. 



\section{AGRADECIMENTOS}

Primeiramente, agradeço a Deus por se fazer presente em cada instante de minha vida e por possibilitar meios para que os objetivos fossem alcançados.

Aos meus pais, Paulo e Sueleni, pelo apoio, carinho, dedicação, por me ensinarem os valores e princípios que busco seguir e por serem a base na qual me sustento.

Aos meus avós, Maria e Joaquim (in memoriam) por ensinar os conceitos mais valiosos da vida, por ajudar, apoiar e acreditar na minha capacidade.

À minha namorada, Fernanda, pelo carinho, cuidado, compreensão e apoio ao longo de todo o período acadêmico.

Aos meus cachorrinhos, Marley e Tobby (in memoriam), por transmitir a paz e a alegria independente dos momentos vividos.

Ao meu orientador, Jorge Munaiar Neto, pela confiança, atenção, sabedoria e disponibilidade em todos os momentos desta pós-graduação, além de sua amizade.

Aos professores Márcio Roberto Silva Corrêa (USP) e Armando Lopes Moreno Júnior (UNICAMP) pelas contribuições fornecidas no exame de qualificação. Aos professores Roberto Márcio da Silva (UFMG) e, novamente, Armando Moreno Júnior, pela participação, avaliação e grande contribuição na defesa deste trabalho.

Aos docentes e funcionários da Faculdade de Engenharia de Bauru (FEB/UNESP) e do Departamento de Estruturas (SET/USP) pelo incentivo e suporte ao longo do período acadêmico.

Ao Davi Leal pela grande ajuda no desenvolvimento deste trabalho, à Carol Santos, ao Yagho Simões, ao Fernando Gilio e ao Rafael Dupim pelo auxílio nas ferramentas do software ABAQUS. Aos meus colegas de sala, Lucas Antônio, Paula Ribeiro e Luniery Shiavon pelo apoio e amizade.

Aos meus amigos pessoais, Guilherme Barnabé, Moacyr Botelho, Ariovaldo Zonta, José Maurício Rapello, Luiz Saldanha e José Otávio Rapello, que, independente da distância, estão sempre presentes em todos os momentos.

Ao Conselho Nacional de Desenvolvimento Científico e Tecnológico, CNPq, pela bolsa concedida. 

"Talvez não tenha conseguido fazer o melhor, mas lutei para que o melhor fosse feito.

Não sou o que deveria ser, mas graças a Deus, não sou o que era antes".

(Martin Luther King) 



\section{RESUMO}

CARVALHO, P. R. O. Análise numérica de pequenas paredes de alvenaria estrutural de blocos de concreto em situação de incêndio: ênfase no comportamento térmico e termoestrutural. 2019. 313 p. Dissertação (Mestrado em Engenharia Civil (Estruturas)). Escola de Engenharia de São Carlos, Universidade de São Paulo, São Carlos, 2019.

A alvenaria estrutural vem sendo amplamente difundida em contexto nacional principalmente a partir da década de 90. Dentre as grandes vantagens do sistema construtivo podem ser citadas a economia de tempo e de material, além da redução do volume de resíduos. Para a segurança quanto ao uso da alvenaria, faz-se necessário o conhecimento do seu comportamento quando exposta a elevadas temperaturas em virtude da degradação das propriedades dos materiais, o que não é contemplado por normas nacionais. $\mathrm{O}$ uso de normas estrangeiras tem como referência propriedades e parâmetros dos materiais de suas respectivas abrangências. Em relação à modelagem numérica, esta é uma alternativa de grande eficiência e versatilidade em virtude dos elevados custos envolvidos nas análises experimentais e necessidade de infraestrutura adequada para os ensaios. O objetivo principal deste trabalho foi obter modelos numéricos a partir do software ABAQUS, versão 6.14, capazes de simular os comportamentos estrutural, térmico e termoestrutural de pequenas paredes de alvenaria estrutural constituídas de blocos de concreto. Para a modelagem numérica da pequena parede foram realizadas análises preliminares em prismas de três blocos com o intuito de simplificar e otimizar o processamento. Dentre as estratégias utilizadas foram considerados mecanismos de interação de contato entre os materiais para as análises estruturais e inserção de curvas de evolução de temperatura para as análises térmicas. O comportamento da pequena parede em temperatura ambiente sob carregamento de compressão, bem como, o gradiente de temperatura ao longo da seção transversal foi validado de acordo com os resultados experimentais existentes na literatura, sendo considerada a curva ISO 834-1:1999 para a situação de incêndio. Com estas validações, foi efetuado o modelo termoestrutural e analisado de forma qualitativa com os experimentos pertinentes. A tensão de ruptura e a distribuição de temperaturas do modelo numérico estiveram condizentes com os resultados experimentais, com desvios inferiores a 10\%. Em contexto termoestrutural, observou-se que a redução das restrições quanto ao giro e o aumento da intensidade do carregamento reduziram a resistência ao fogo das pequenas paredes em relação ao critério de resistência mecânica, o qual, por sua vez, apresentou-se superior em comparação com o critério de isolamento térmico.

Palavras-chave: Alvenaria estrutural. Blocos de concreto. Incêndio. Análise numérica. Método dos Elementos Finitos. Modelo estrutural. Modelo térmico. Modelo termoestrutural. 

CARVALHO, P. R. O. Numerical analysis of small walls of structural masonry of concrete blocks under fire situation: emphasis on thermal and thermo-structural behavior. 2019 . 313 p. Dissertation (M. Sc. in Structural Engineering (Structures)). São Carlos Engineering School, University of São Paulo, São Carlos, 2019.

Structural masonry has been widely used Brazil as well as in the rest of the world. Among the advantages of this building system, it is worth to be highlighted the saving of time and materials and the reduction of the construction waste. For safety in the use of masonry, it is necessary to know its behavior when exposed to high temperatures due to the degradation of the properties of the materials, which are not contemplated by Brazilian standards. So designers usually apply foreign standards, which are based on materials properties and other parameters inherent of their respective countries. Regarding numerical modeling, this is an alternative of great efficiency and versatility due to the high costs involved in the experimental analyses and the need for adequate infrastructure for the tests. This work aimed to develop numerical models from the software ABAQUS 6.14 capable of simulating the structural, thermal and thermostructural behavior of small walls of structural masonry of concrete blocks. For the numerical modeling of the small wall, preliminary analyses were carried out on three-block prisms in order to simplify and improve processing time. Among the strategies used were considered contact interaction between the materials for the structural analyses and insertion of temperature evolution curves for the thermal analyses. The behavior of the small wall at ambient temperature under load-bearing, as well as the temperature gradient along the cross section was validated according to the experimental tests available in literature, considering the ISO 834 standard fire curve. From these validations, the thermo-structural model was carried out and qualitatively analyzed with the available tests. The ultimate load and the distribution of the temperature of the numerical model were consistent with the experimental tests, with deviations less than $10 \%$. In the thermo-structural context, it was observed that the reduction of the rotational restraints and the increase of the load reduced the fire resistance of the small walls in relation to the load-bearing criterion, which, in turn, was higher compared with the thermal insulation criterion.

Keywords: Structural masonry. Concrete blocks. Fire. Numerical analysis. Finite Element Method. Structural model. Thermal model. Thermo-structural model. 



\section{LISTA DE FIGURAS}

Figura 1.1 - Distribuição de incêndio em 31 países de acordo com a origem (2015) 32

Figura 2.1 - Exemplos de construção em alvenaria estrutural de blocos de concreto e de blocos cerâmicos

Figura 2.2 - Famílias de blocos de concreto comuns

Figura 2.3 - Representação dos componentes da alvenaria estrutural 44

Figura 2.4 - Argamassamento total (a) e argamassamento parcial (b) 45

Figura 2.5 - Modo de ruptura de prismas de blocos de concreto com argamassamento parcial 46

Figura 2.6 - Influência da resistência da argamassa sobre a resistência da parede à compressão

Figura 2.7 - Arqueamento da parede em situação de incêndio 53

Figura 2.8 - Condição de contorno para vinculação de paredes 54

Figura 2.9 - Diagramas tensão-deformação comparativo para dois tipos de argamassa 55

Figura 2.10 - Ensaio de resistência à compressão para prismas de três blocos e pequena parede, ambos com argamassamento parcial 56

Figura 2.11 - Tensões principais mínimas obtidas numericamente para o prisma e para a parede

Figura 2.12 - Fator de redução das tensões de ruptura na compressão e na tração de acordo com a temperatura 58

Figura 2.13 - Modo de falha para o primeiro teste experimental. 58

Figura 2.14 - Comparação entre os resultados experimentais e numéricos para a deflexão lateral em função da temperatura para os testes 1 (a) e 2 (b)

Figura 2.15 - Deslocamento lateral em função da temperatura de acordo com os efeitos de restrição rotacional

Figura 2.16 - Subestruturas consideradas para a modelagem numérica com paredes centrais (a) e de canto (b)

Figura 2.17 - Deformação anterior à falha para configuração com fogo em dois pavimentos (a), e com fogo apenas no segundo pavimento (b)

Figura 2.18 - Aparato utilizado para inserção do carregamento na parede (a) e locação dos termopares ao longo da seção transversal da parede (b)

Figura 2.19 - Evolução da temperatura dos pontos de medição do bloco em função o tempo 63

Figura 2.20 - Distribuição das tensões principais e distribuição de temperatura 
Figura 2.21 - Locação dos termopares (a), distribuição de temperatura no bloco (b) e evolução da temperatura em função do tempo ao longo da espessura (c)

Figura 2.22 - Deslocamento lateral em função do tempo com variação do coeficiente de expansão térmica (a) e do módulo de elasticidade do bloco (b) 66

Figura 2.23 - Modelo do tijolo (a) e elementos de mola utilizados para a argamassa (b)....... 67 Figura 2.24 - Corpos-de-prova ensaiados sem preenchimento dos vazados (a), e com preenchimento dos vazados (b). 68

Figura 2.25 - Parede com revestimento após o ensaio (destaque para localização da fissura) 69 Figura 2.26 - Elevação de temperatura em função do tempo na face não exposta do bloco sem revestimento e sem preenchimento 70

Figura 2.27 - Elevação de temperatura em função do tempo na face não exposta do bloco com revestimento e com preenchimento.. 70

Figura 2.28 - Face exposta ao fogo após o incêndio da parede 2 (a), face não exposta ao fogo da parede 3 (b) e face não exposta ao fogo da parede 4 (c) 72 Figura 2.29 - Esquema de ensaio das pequenas paredes em temperaturas elevadas (a) e, fissuras

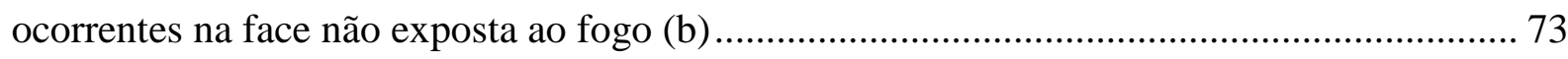

Figura 2.30 - Configurações dos quatro modelos criados ................................................... 74

Figura 2.31 - Resultados da análise estrutural: padrão de fissuras após análise térmica (fase 1)

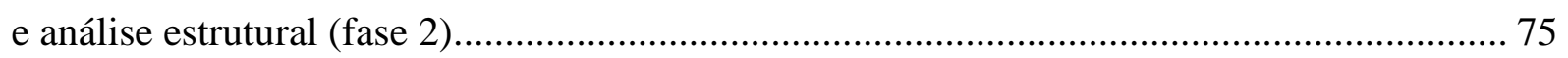

Figura 2.32 - Face exposta ao fogo do ensaio 2 após o ensaio.............................................. 76

Figura 2.33 - Geometria da malha de elementos finitos utilizada para a pequena parede e o prisma: comportamento à compressão $(\mathrm{a})$; e ao cisalhamento $(\mathrm{b})$......................................... 77 Figura 2.34 - Modelo de pequena parede utilizado para as simulações numéricas.................. 78 Figura 2.35 - Comparação dos diagramas tensão-deformação de prismas de três blocos e

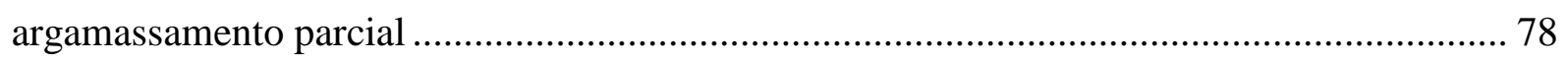

Figura 2.36 - Distribuição de tensões máximas para prisma de dois blocos e argamassamento

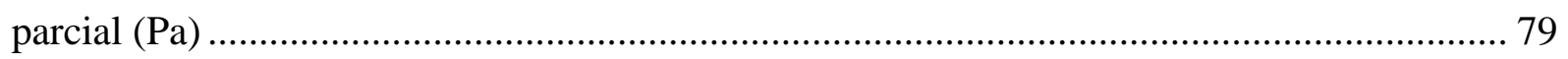

Figura 2.37 - Malhas utilizadas nas modelagens com blocos cerâmicos ................................. 80 Figura 2.38 - Elevação de temperatura em função do tempo na face não exposta ao fogo das

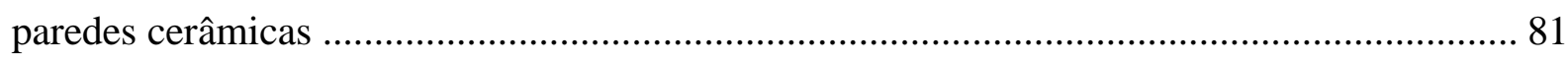

Figura 2.39 - Resumo das simulações numéricas pelo critério de resistência mecânica ......... 81

Figura 2.40 - Disposição dos corpos-de-prova da primeira fornada ...................................... 83

Figura 2.41 - Isolamento dos elementos com manta cerâmica............................................... 83 
Figura 2.42 - Instrumentação das pequenas paredes com as duas faces expostas ao fogo (a) e com uma face exposta ao fogo (b).

Figura 2.43 - Evolução da temperatura em função do tempo para ambas as faces expostas (a) e para uma única face exposta ao fogo (b).

Figura 3.1 - Esquematização das dimensões da pequena parede

Figura 3.2 - Técnicas de modelagem da alvenaria: (a) exemplar da alvenaria; (b) micromodelagem detalhada; (c) micromodelagem simplificada; (d) macromodelagem 89 Figura 3.3 - Comparação da malha com geometria tronco-cônica (a) e plana (b) dos blocos de concreto

Figura 3.4 - Comparação do diagrama tensão-deformação experimental de prismas de 3 blocos com os resultados numéricos

Figura 3.5 - Elementos sólidos: bloco (a), meio bloco (b), argamassa (c) e placa de reação (d)

Figura 3.6 - Discretizações realizadas nos blocos de concreto com 0,5 cm (a), 1,0 cm (b), 1,5 $\mathrm{cm}(\mathrm{c})$ e $3,0 \mathrm{~cm}(\mathrm{~d})$.

Figura 3.7 - Comparação do diagrama tensão-deformação experimental de prismas de 3 blocos com os resultados numéricos com diferentes malhas

Figura 3.8 - Malha das placas com alturas de $2 \mathrm{~cm}$ (a) e de $20 \mathrm{~cm}$ (b) 96 Figura 3.9 - Comparação do diagrama tensão-deformação experimental de prismas de 3 blocos com os resultados numéricos com diferentes mecanismos de contato.

Figura 3.10 - Comparação em escala aumentada da interface entre bloco e junta de argamassa utilizando a ferramenta tie (a) e interaction (b).... 98 Figura 3.11 - Comportamento do concreto para carregamento uniaxial para tração (a) e compressão (b)...

Figura 3.12 - Condições de contorno para a pequena parede 102

Figura 3.13 - Carregamento para a pequena parede 102

Figura 3.14 - Diagramas tensão-deformação experimentais relativas à compressão do bloco de concreto (a), do meio bloco (b) com espessuras de $14 \mathrm{~cm}$ e da argamassa (c) obtidos por Oliveira (2014)

Figura 3.15 - Diagrama força-deslocamento experimentais relativas à tração do bloco de concreto obtido por Izquierdo (2015) 104

Figura 3.16 - Diagramas tensão-deformação experimentais relativas à compressão do bloco de concreto (a) e do meio bloco (b) com espessuras de $14 \mathrm{~cm}$ de acordo com dados de Dupim (2019) 
Figura 3.17 - Diagramas tensão-deformação experimentais relativas à compressão do bloco de concreto (a) e do meio bloco (b) com espessuras de $19 \mathrm{~cm}$ de acordo com dados de Dupim (2019)

Figura 3.18 - Condições de contorno para as situações com exposição ao fogo em uma única face (a) e nas duas faces (b) 109

Figura 3.19 - Corpos-de-prova ensaiados com exposição ao fogo em apenas uma das faces e indicação do sentido da transferência de calor. 109

Figura 3.20 - Consideração quanto à contribuição para o aumento de temperatura dos gases

Figura 3.21 - Consideração acerca da transferência de calor . 110

Figura 3.22 - Indicação dos coeficientes de convecção e emissividades considerados ...... 111

Figura 3.23 - Calor específico calibrado para o material concreto 112

Figura 3.24 - Condutividade térmica calibrada para o material concreto 112

Figura 3.25 - Calor específico e condutividade térmica da argamassa 113 Figura 3.26 - Condições de contorno para comparação com os ensaios de Dupim (2019) nomeadas como CD1 (a) e CD2 (b).

Figura 3.27 - Condições de contorno para comparação com os ensaios de Lopes et al. (2018) nomeadas como CC1 (a), CC2 (b) e CC3 (c) 117

Figura 3.28 - Minoração da resistência à compressão do material concreto em função da temperatura. 118

Figura 3.29 - Diagrama tensão-deformação do bloco de concreto para diferentes temperaturas sem carregamento

Figura 3.30 - Diagrama tensão-deformação do bloco de concreto para diferentes temperaturas considerando carregamento.

Figura 4.1 - Modo de ruptura da pequena parede. 122

Figura 4.2 - Tensões principais mínimas do modelo numérico no momento da ruptura ....... 122

Figura 4.3 - Tensões principais máximas do modelo numérico no momento da ruptura ...... 123

Figura 4.4 - Tensões principais absolutas do modelo numérico pouco após a ruptura 123

Figura 4.5 - Tensões principais mínimas (a) e máximas (b) na argamassa no instante da ruptura

Figura 4.6 - Deformações elásticas (a) e plásticas (b) principais 124

Figura 4.7 - Comparação da curva tesão-deformação entre os valores experimentais e numérico 125

Figura 4.8 - Modo de ruptura da pequena parede obtido por Izquierdo (2015) 126 
Figura 4.9-I - Modo de ruptura da pequena parede obtido por Dupim (2019) ..................... 126

Figura 4.9-II - Modo de ruptura da pequena parede obtido por Dupim (2019) ..................... 127

Figura 4.10 - Tensões principais mínimas do modelo numérico no momento da ruptura.....127

Figura 4.11 - Tensões principais máximas do modelo numérico no momento da ruptura.... 128

Figura 4.12 - Tensões principais absolutas do modelo numérico pouco após a ruptura ........128

Figura 4.13 - Tensões principais mínimas (a) e máximas (b) na argamassa no instante da ruptura

Figura 4.14 - Deformações elásticas (a) e plásticas (b) principais ........................................130

Figura 4.15 - Comparação da curva tesão-deformação entre os valores experimentais e numérico

Figura 4.16-I - Modo de rupturada pequena parede obtido por Dupim (2019) ..................... 131

Figura 4.16-II - Modo de ruptura da pequena parede obtido por Dupim (2019)................... 132

Figura 4.17 - Tensões principais mínimas do modelo numérico no momento da ruptura.....132

Figura 4.18 - Tensões principais máximas do modelo numérico no momento da ruptura.... 133

Figura 4.19 - Tensões principais absolutas do modelo numérico pouco após a ruptura ........134

Figura 4.20 - Tensões principais mínimas (a) e máximas (b) na argamassa no instante da ruptura

Figura 4.21 - Deformações elásticas (a) e plásticas (b) principais

Figura 4.22 - Comparação da curva tesão-deformação entre os valores experimentais e numérico

Figura 4.23-I - Corpos-de-prova antes da elevação de temperatura (a).... 136

Figura 4.23-II - Corpos-de-prova durante (b) e após a elevação de temperatura (c).

Figura 4.24 - Evolução da temperatura em função da espessura da parede de acordo com os tempos de incêndio indicados. 138

Figura 4.25 - Comparação da elevação da temperatura em função do tempo para a distância de $5 \mathrm{~mm}$ da face exposta 140

Figura 4.26 - Comparação da elevação da temperatura em função do tempo para a distância de $20 \mathrm{~mm}$ da face exposta 140

Figura 4.27 - Comparação da elevação da temperatura em função do tempo para a distância de $70 \mathrm{~mm}$ da face exposta 141

Figura 4.28 - Comparação da elevação da temperatura em função do tempo para a distância de $120 \mathrm{~mm}$ da face exposta 141

Figura 4.29 - Comparação da elevação da temperatura em função do tempo para a distância de $135 \mathrm{~mm}$ da face exposta 
Figura 4.30 - Comparação da elevação da temperatura em função do tempo para a distância de $5 \mathrm{~mm}$ da face exposta.

Figura 4.31 - Comparação da elevação da temperatura em função do tempo para a distância de $20 \mathrm{~mm}$ da face exposta. 143

Figura 4.32 - Pequenas paredes após incêndio 145

Figura 4.33 - Curvatura da parede após o ensaio 146

Figura 4.34 - Gradiente de temperatura em 70 minutos de incêndio 146

Figura 4.35 - Tensões mínimas obtidas numericamente para as condições de contorno CD1 (1) e CD2 (2)

Figura 4.36 - Tensões máximas obtidas numericamente para as condições de contorno CD1 (1) e CD2 (2) 147

Figura 4.37 - Tensões principais mínimas (a) e máximas (b) na argamassa em 70 minutos de incêndio para a condição de contorno CD1 148 Figura 4.38 - Curvatura da parede no instante de 70 minutos em comparação com estado inicial para as condições de contorno CD1 (a) e CD2 (b)

Figura 4.39 - Magnitude dos deslocamentos ocorrentes no modelo numérico para as condições de contorno CD1 (1) e CD2 (2)

Figura 4.40 - Deslocamentos ocorrentes no modelo numérico na direção x para as condições de contorno CD1 (1) e CD2 (2) 150 Figura 4.41 - Deslocamentos ocorrentes no modelo numérico na direção y para as condições de contorno CD1 (1) e CD2 (2) 150 Figura 4.42 - Deslocamentos ocorrentes no modelo numérico na direção z para as condições de contorno CD1 (1) e CD2 (2) 151 Figura 4.43 - Deformações elásticas principais para as condições de contorno CD1 (1) e CD2 (2)

Figura 4.44 - Deformações plásticas principais para as condições de contorno CD1 (1) e CD2 (2)

Figura 4.45 - Bloco e meio bloco utilizados no ensaio 153 Figura 4.46 - Deformação axial em função do tempo para as diferentes condições de contorno consideradas em comparação com os resultados experimentais 154 Figura 4.47 - Deslocamento lateral em função do tempo para as diferentes condições de contorno consideradas em comparação com os resultados experimentais 155 
Figura 4.48 - Imagens no instante da ruptura da face oposta ao fogo (a), de sua da lateral (b) e da face exposta (c), e, distribuição de tensões para a condição de contorno CC1 (d), CC2 (e) e CC3 (f) para a face oposta (1) e exposta ao fogo (2).

Figura 5.1 - Diagrama tensão-deformação para diferentes discretizações 160

Figura 5.2 - Comparação das tensões máximas absolutas entre as discretizações com 1,0 (a), 1,5 (b) e $3,0 \mathrm{~cm}(\mathrm{c})$

Figura 5.3 - Diagrama tensão-deformação com variação do argamassamento para os parâmetros de Oliveira (2014)

Figura 5.4 - Comparação das tensões mínimas entre as paredes com argamassamento total (esquerda) e argamassamento parcial (direita)

Figura 5.5 - Comparação das tensões máximas entre as paredes com argamassamento total (esquerda) e argamassamento parcial (direita) 163

Figura 5.6 - Diagrama tensão-deformação com variação do argamassamento para os parâmetros de Dupim (2019) para parede com espessura de $14 \mathrm{~cm}$ 164 Figura 5.7 - Comparação das tensões mínimas entre as paredes de $14 \mathrm{~cm}$ de espessura com argamassamento total (esquerda) e argamassamento parcial (direita)

Figura 5.8 - Comparação das tensões máximas entre as paredes de $14 \mathrm{~cm}$ de espessura com argamassamento total (esquerda) e argamassamento parcial (direita) 165

Figura 5.9 - Diagrama tensão-deformação com variação do argamassamento para os parâmetros de Dupim (2019) para parede com espessura de $19 \mathrm{~cm}$ 166

Figura 5.10 - Comparação das tensões mínimas entre as paredes de $19 \mathrm{~cm}$ de espessura com argamassamento total (esquerda) e argamassamento parcial (direita)

Figura 5.11 - Comparação das tensões máximas entre as paredes de $19 \mathrm{~cm}$ de espessura com argamassamento total (esquerda) e argamassamento parcial (direita)

Figura 5.12 - Modo de ruptura de pequenas paredes com argamassamento parcial (a) e total (b)

Figura 5.13 - Comparação entre os diagramas tensão-deformação para paredes com espessura de $14 \mathrm{~cm}$ com e sem consideração de dano

Figura 5.14 - Comparação entre os diagramas tensão-deformação para paredes com espessura de $19 \mathrm{~cm}$ com e sem consideração de dano

Figura 5.15 - Curvas tensão-deformação para modelos com variação do ângulo de dilatância do concreto 171

Figura 5.16 - Esquematização do gradiente de temperatura com diferentes discretizações para 15 (a), 30 (b), 45 (c) e 60 (d) minutos de incêndio 
Figura 5.17 - Elevação da temperatura em função do tempo para os refinamentos estudados

Figura 5.18 - Evolução de temperatura em função do tempo para paredes com blocos de 14 e $19 \mathrm{~cm}$ de espessura. 176

Figura 5.19-I - Temperatura ao longo da espessura para o tempo de 15 minutos (a) para parede com blocos de $19 \mathrm{~cm}$ e uma face exposta ao fogo 176

Figura 5.19-II - Temperatura ao longo da espessura para os tempos de 30 (b), 45 (c), 60 (d) e 90 minutos (e) para parede com blocos de $19 \mathrm{~cm}$ de espessura

Figura 5.20 - Evolução da temperatura em função da espessura da parede de acordo com os tempos de incêndio indicados 178

Figura 5.21 - Evolução da temperatura em função do tempo utilizando o Eurocode 2 e a calibração para os parâmetros térmicos ..... 179 Figura 5.22 - Evolução da temperatura em função do tempo utilizando o Eurocode 6 e a calibração para os parâmetros térmicos 179 Figura 5.23 - Evolução de temperatura em função do tempo para a variação da condição de contorno na face oposta ao incêndio

Figura 5.24 - Evolução de temperatura em função do tempo da parede com uma face exposta ao fogo...

Figura 5.25 - Evolução de temperatura em função do tempo da parede com as duas faces expostas ao fogo 185

Figura 5.26 - Evolução de temperatura em função do tempo ao longo da espessura da parede 186

Figura 5.27-I - Temperatura ao longo da espessura para os tempos de exposição iguais a 15 (a), 30 (b), 60 (c) e 120 minutos (d) para parede com uma face exposta ao fogo 187

Figura 5.27-II - Temperatura ao longo da espessura para os tempos de 180 (e) e 240 minutos (f) para parede com uma face exposta ao fogo 188

Figura 5.28 - Evolução de temperatura em função do tempo ao longo da espessura da parede 188

Figura 5.29-I - Temperatura ao longo da espessura para os tempos de 15 (a), 30 (b), 60 (c) e 120 (d) minutos para parede com duas faces expostas ao fogo

Figura 5.29-II - Temperatura ao longo da espessura para os tempos de 180 (e) e 240 (f) minutos para parede com duas faces expostas ao fogo..... 190

Figura 5.30 - Deformação axial em função do tempo de incêndio para as condições de contorno avaliadas. 191 
Figura 5.31 - Distribuição de temperatura aos 25 (a), 50 (b), 75 (c) e 100 minutos (d) ........ 192 Figura 5.32 - Deformada para as condições de contorno CC1 (1), CC2 (2) e CC3 (3) para os tempos de 25 (a), 50 (b), 75 (c) e 100 minutos (d) de incêndio

Figura 5.33 - Deformação axial em função do tempo para as condições de contorno CC1 (a), CC2 (b) e CC3 (c) de acordo com a distância em relação à face exposta ao fogo

Figura 5.34 - Deslocamento lateral em função do tempo para as condições de contono CC1, $\mathrm{CC} 2$ e CC3.

Figura 5.35 - Distribuição de tensões absolutas na face exposta (1) e oposta (2) para os tempos de 25 (a), 50 (b), 75 (c) e 100 minutos (d) para a condição de contorno CC1

Figura 5.36 - Distribuição de deformações na face exposta (1) e oposta (2) para os tempos de 25 (a), 50 (b), 75 (c) e 100 minutos (d) para a condição de contorno CC1

Figura 5.37 - Distribuição de tensões absolutas na face exposta (1) e oposta (2) para os tempos de 25 (a), 50 (b), 75 (c) e 100 minutos (d) para a condição de contorno CC2 198

Figura 5.38 - Distribuição de deformações na face exposta (1) e oposta (2) para os tempos de 25 (a), 50 (b), 75 (c) e 100 minutos (d) para a condição de contorno CC2

Figura 5.39 - Distribuição de tensões absolutas na face exposta (1) e oposta (2) para os tempos de 25 (a), 50 (b), 75 (c) e 100 minutos (d) para a condição de contorno CC3 200 Figura 5.40 - Distribuição de deformações na face exposta (1) e oposta (2) para os tempos de 25 (a), 50 (b), 75 (c) e 100 minutos (d) para a condição de contorno CC3 201 Figura 5.41 - Evolução da temperatura em função do tempo para as duas situações de confinamento dos gases para a face oposta ao fogo 202

Figura 5.42 - Deformação axial em função do tempo para as três condições de contorno estudadas considerando o confinamento dos gases 203 Figura 5.43 - Comparação da deformação axial em função do tempo para diferentes condições de confinamento dos gases para as condições de contorno CC1 (a), CC2 (b) e CC3 (c).......204 Figura 5.44 - Deslocamento lateral em função do tempo para as condições de contono CC1, CC2 e CC3 com confinamento dos gases na face oposta 205

Figura 5.45-I - Comparação entre os deslocamentos laterais em função do tempo para diferentes condições de confinamento dos gases para as condições de contorno CC1 (a) e CC2 (b) ....205 Figura 5.45-II - Comparação entre os deslocamentos laterais em função do tempo para diferentes condições de confinamento dos gases para a condição de contorno CC3 (c)........206 Figura 5.46 - Deformação axial em função do tempo para a condição de contorno CC1 para diferentes carregamentos 
Figura 5.47 - Deformação axial em função do tempo para a condição de contorno CC2 para

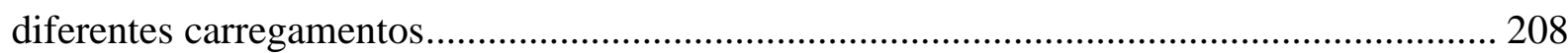
Figura 5.48 - Deslocamento lateral em função do tempo para a condição de contorno CC1 para

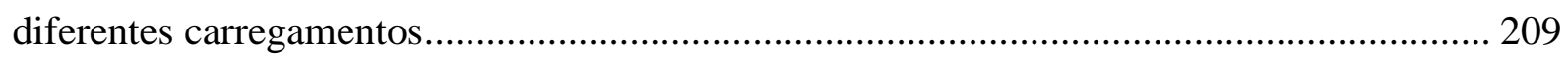
Figura 5.49 - Deslocamento lateral em função do tempo para a condição de contorno CC2 para

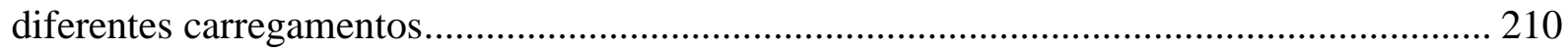


Tabela 2.1 - Redução da resistência à compressão das pequenas paredes em relação à

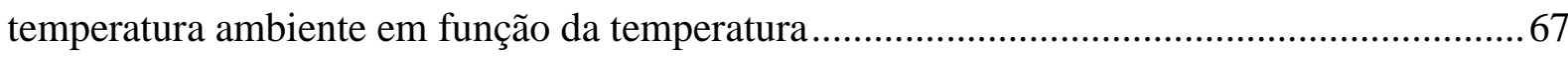

Tabela 2.2 - Resumo dos resultados obtidos por Nguyen e Meftah (2012)........................... 71

Tabela 2.3 - Resumo dos resultados obtidos por Russo e Sciarretta (2014) ........................... 74

Tabela 2.4 - Compilação dos resultados obtidos pelo IPT ..................................................... 76

Tabela 2.5 - Resultados obtidos para prismas de blocos de concreto de acordo com o critério

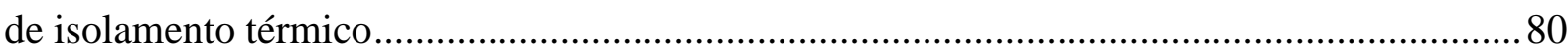

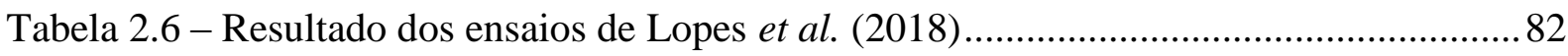

Tabela 3.1 - Comparação entre as discretizações realizadas nos prismas de 3 blocos ............ 95

Tabela 3.2 - Comparação dos resultados obtidos por cada malha em relação à tensão de ruptura e respectiva deformação .95

Tabela 3.3 - Comparação dos resultados obtidos por cada mecanismo de contato em relação à tensão de ruptura e respectiva deformação

Tabela 3.4 - Valores de massa específica utilizadas na modelagem numérica

Tabela 3.5 - Resumo das referências acerca dos parâmetros utilizados na modelagem térmica

Tabela 3.6 - Tensões de compressão e de tração do concreto de acordo com a temperatura para as situações sem carregmento e com carregamento de $40 \%$ da carga máxima

Tabela 4.1 - Comparação dos valores médios obtidos por Oliveira (2014) com o numérico 125 Tabela 4.2 - Comparação dos valores médios obtidos por Dupim (2019) com o numérico.. 131 Tabela 4.3 - Comparação dos valores médios obtidos por Dupim (2019) com o numérico.. 136 Tabela 4.4 - Temperaturas atingidas em função da distância em relação à face exposta e do tempo de incêndio.

Tabela 4.5 - Comparação entre os valores obtidos para o critério de isolamento térmico, em minutos

Tabela 4.6 - Temperaturas atingidas em função da distância em relação à face exposta e do tempo de incêndio. 144

Tabela 5.1 - Comparação dos valores de tensão e deformação entre as diferentes discretizações 161

Tabela 5.2 - Comparação das tensões de ruptura obtidas pelo modelo numérico para diferentes argamassamentos 
Tabela 5.3 - Comparação entre os resultados com e sem consideração de dano

Tabela 5.4 - Valores de tensão e deformação de pico de acordo com o ângulo de dilatância e comparação com o modelo validado.

Tabela 5.5 - Temperaturas obtidas ao longo da espessura da parede para diferentes refinamentos de malha de acordo com o tempo de incêndio

Tabela 5.6 - Temperaturas obtidas ao longo da espessura da parede para diferentes espessuras de blocos de acordo com os tempos de incêndio

Tabela 5.7 - Critério de isolamento térmico obtido numericamente para comparação quanto à variação da espessura, em minutos

Tabela 5.8 - Critério de isolamento térmico obtido numericamente para comparação quanto às propriedades térmicas, em minutos 180

Tabela 5.9 - Temperaturas obtidas ao longo da espessura da parede para diferentes configurações da face oposta ao fogo e diferentes tempos de incêndio

Tabela 5.10 - Critério de isolamento térmico obtido numericamente para comparação quanto à variação do confinamento dos gases na face oposta ao fogo, em minutos

Tabela 5.11 - Temperaturas obtidas ao longo da espessura da parede para diferentes configurações da face oposta ao fogo para tempo de incêndio de 120, 180 e 240 minutos .. 183 Tabela 5.12 - Deformações máximas e respectivos tempos quanto ao critério de resistência mecânica para as três condições de contorno.

Tabela 5.13 - Deformações máximas e respectivos tempos para as três condições de contorno considerando confinamento dos gases na face oposta ao fogo 203

Tabela 5.14 - Deformações máximas e respectivos tempos para os diferentes carregamentos para a condição de contorno CC1

Tabela 5.15 - Deformações máximas e respectivos tempos para os diferentes carregamentos para a condição de contorno CC2 208 


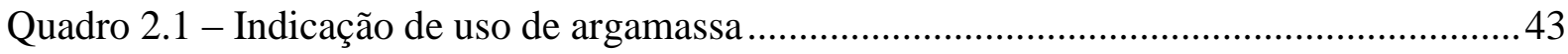

Quadro 3.1 - Dimensões médias dos blocos e meio blocos de concreto experimentais .......... 93

Quadro 3.2 - Dados de entrada referentes aos comportamentos à compressão e à tração..... 106

Quadro 3.3 - Propriedades plásticas utilizadas no modelo numérico .................................... 106

Quadro 3.4 - Nomenclatura das condições de contorno baseadas no trabalho experimental de Dupim (2019) 116

Quadro 3.5 - Nomenclatura das condições de contorno baseadas no trabalho experimental de

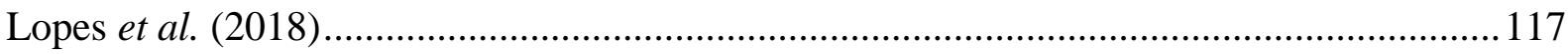

Quadro 4.1 - Resumo das referências de validação dos modelos numéricos ........................121

Quadro 5.1 - Resumo das informações para a análise numérica do item 5.1.1 .................... 160

Quadro 5.2 - Resumo das informações para a primeira análise numérica do item 5.1.2...... 162

Quadro 5.3 - Resumo das informações para a segunda análise numérica do item 5.1.2 ....... 164

Quadro 5.4 - Resumo das informações para a terceira análise numérica do item 5.1.2 ........ 165

Quadro 5.5 - Resumo das informações para a primeira análise numérica do item 5.1.3 ...... 168

Quadro 5.6 - Resumo das informações para a segunda análise numérica do item 5.1.3 ....... 168

Quadro 5.7 - Resumo das informações para a análise numérica do item 5.1.4 ....................170

Quadro 5.8 - Resumo das informações para a análise numérica do item 5.2.1 .................... 172

Quadro 5.9 - Resumo das informações para a análise numérica do item 5.2.2 .................... 174

Quadro 5.10 - Resumo das informações para a análise numérica do item 5.2.3 .................. 178

Quadro 5.11 - Resumo das informações para a análise numérica do item 5.2.4 ….............. 181

Quadro 5.12 - Resumo das informações para a análise numérica do item 5.2.5 …............... 184

Quadro 5.13 - Resumo das informações para a análise numérica do item 5.3.1 .................. 190

Quadro 5.14 - Resumo das informações para a análise numérica do item 5.3.2 …...............202

Quadro 5.15 - Resumo das informações para a análise numérica do item 5.3.3 ..................206 

1. INTRODUÇÃ

1.1. OBJETIVO

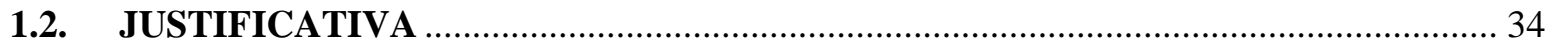

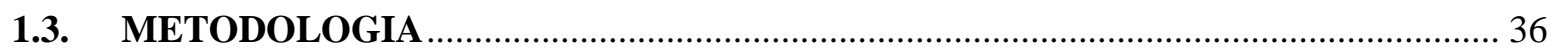

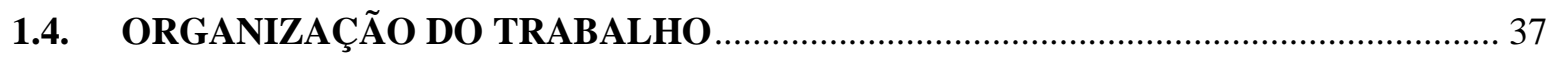

2. REVISÃO BIBLIOGRÁFICA .................................................................................39

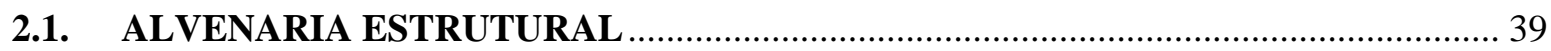

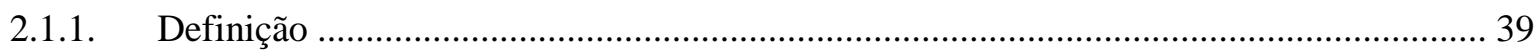

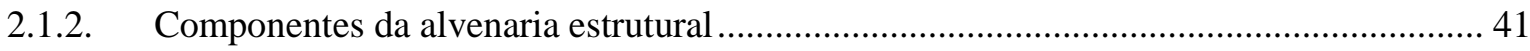

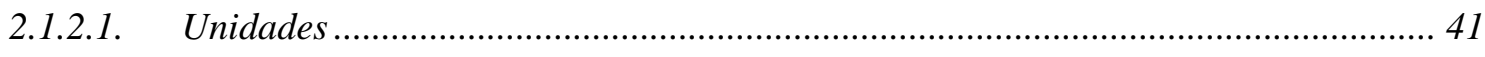

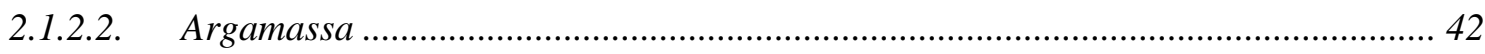

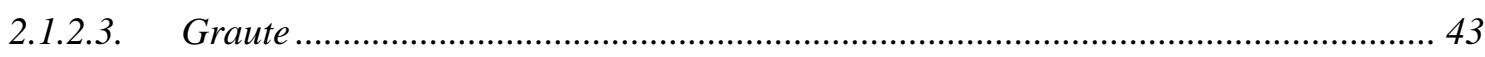

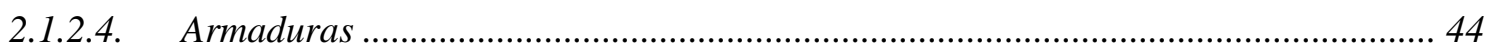

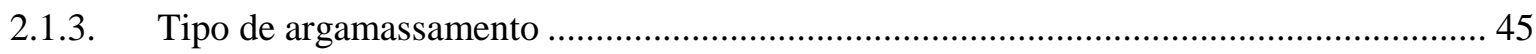

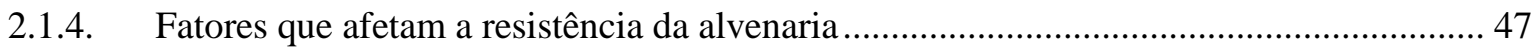

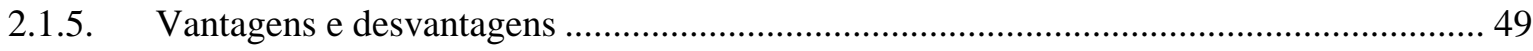

2.2. ALVENARIA ESTRUTURAL EM SITUAÇÃO DE INCÊNDIO................................. 49

2.2.1. Fatores que influenciam o desempenho da alvenaria em elevadas temperaturas ..............50

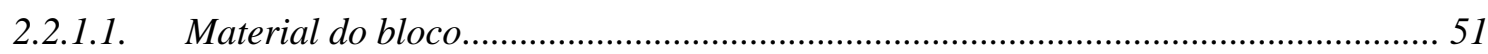

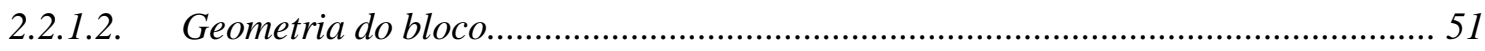

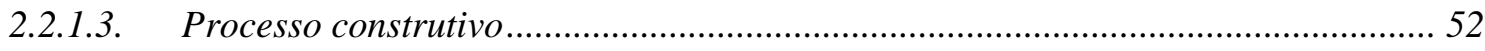

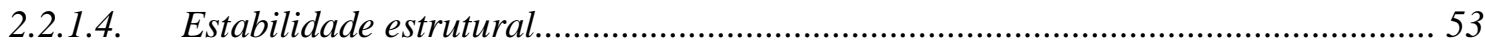

2.2.2. Breve revisão sobre trabalhos em alvenaria e incêndio ..................................................... 54

\section{ASPECTOS REFERENTES À ESTRATÉGIA DE MODELAGEM NUMÉRICA.87}

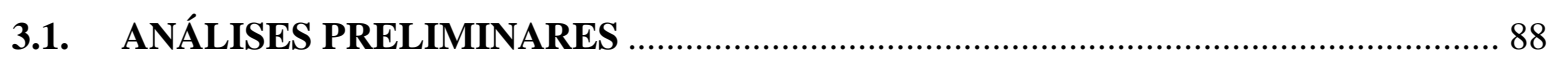

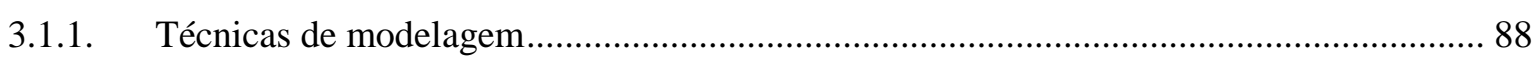

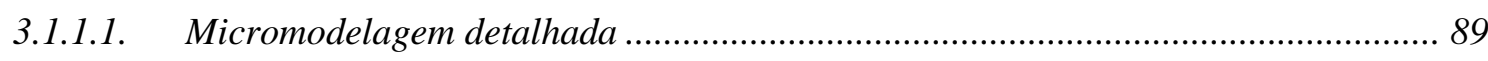

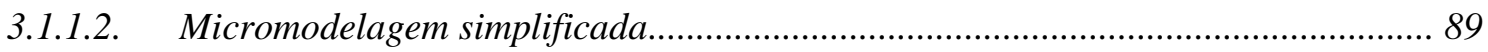

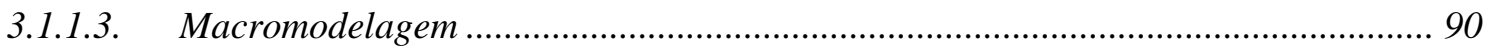

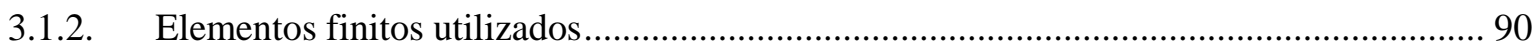

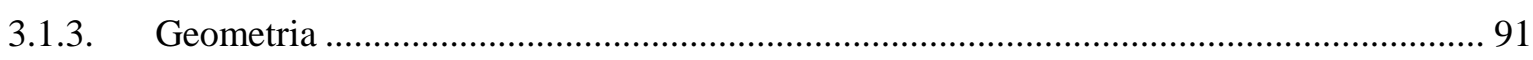

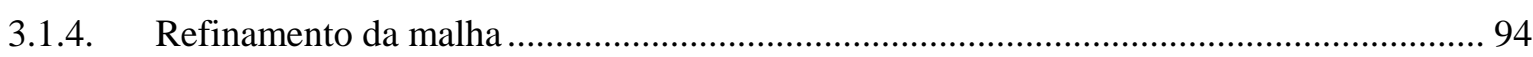

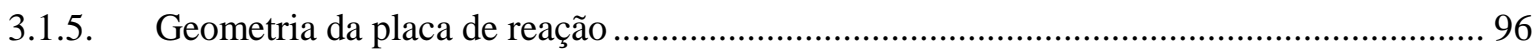

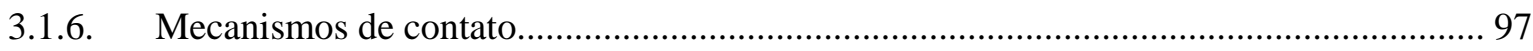

3.2. MODELO NUMÉRICO VOLTADO À ANÁLISE ESTRUTURAL .............................. 99 


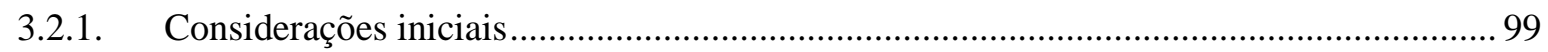

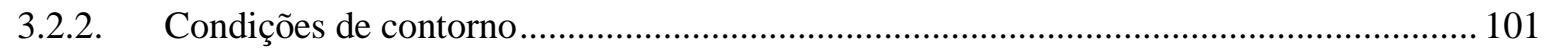

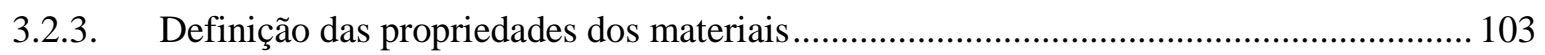

3.3. MODELO NUMÉRICO VOLTADO À ANÁLISE TÉRMICA …................................. 107

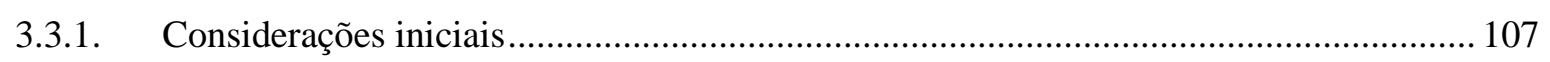

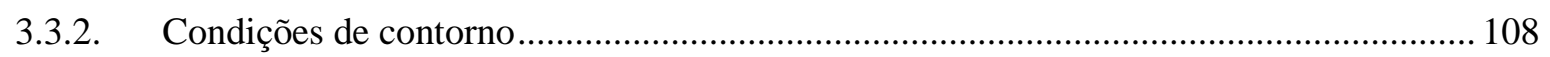

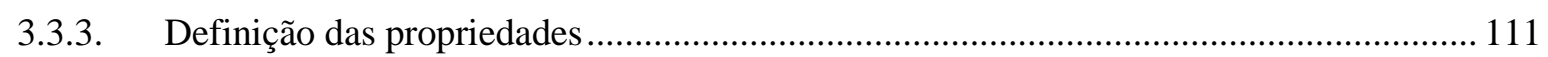

3.4. MODELO NUMÉRICO PARA ANÁLISE TERMOESTRUTURAL .......................... 114

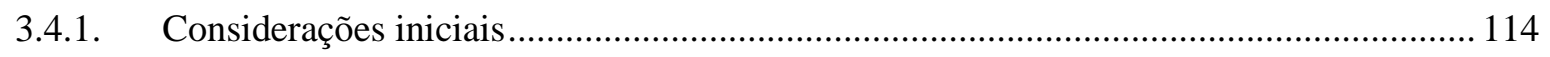

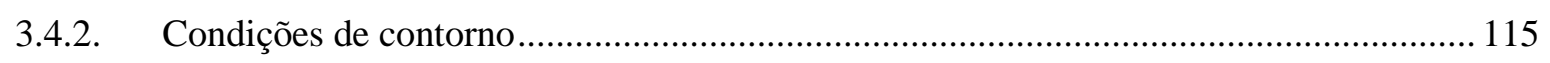

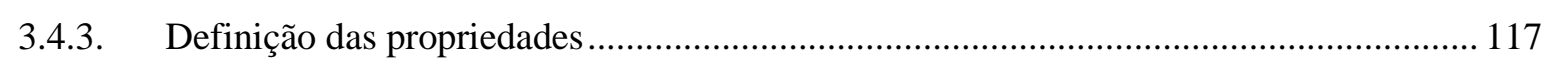

4. RESULTADOS E DISCUSSÃO: VALIDAÇÃO DOS MODELOS ........................... 121

4.1. PROCEDIMENTO DE VALIDAÇÃO DO MODELO ESTRUTURAL ....................... 122

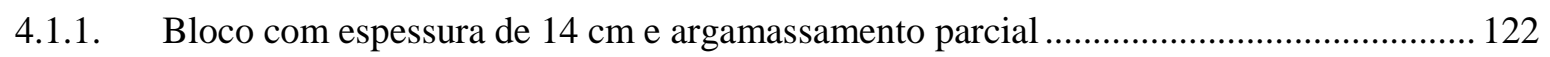

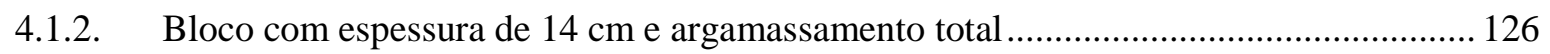

4.1.3. Bloco com espessura de $19 \mathrm{~cm}$ e argamassamento total ................................................ 131

4.2. PROCEDIMENTO DE VALIDAÇÃO DO MODELO TÉRMICO ............................... 136

4.2.1. Bloco com espessura de $14 \mathrm{~cm}$, argamassamento total e fogo em uma face ................... 136

4.2.2. Bloco com espessura de $14 \mathrm{~cm}$, argamassamento total e fogo em ambas as faces .......... 142

4.3. MODELO TERMOESTRUTURAL - ANÁLISE QUALITATIVA …......................... 144

4.3.1. Bloco com espessura de $14 \mathrm{~cm}$ e argamassamento total sem carregamento ..................... 145

4.3.2. Bloco com espessura de $14 \mathrm{~cm}$ e argamassamento total com carregamento .................... 153

5. ANÁliSES COMPLEMENTARES E PARAMÉTRICAS ASSOCIADAS AOS MODELOS NUMÉRICOS ........................................................................................ 159

5.1. ANÁLISES REFERENTES AO MODELO ESTRUTURAL ........................................ 160

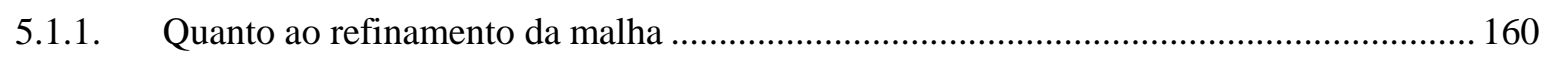

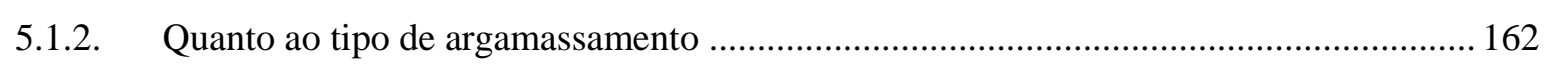

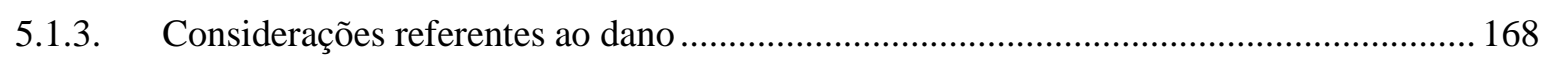

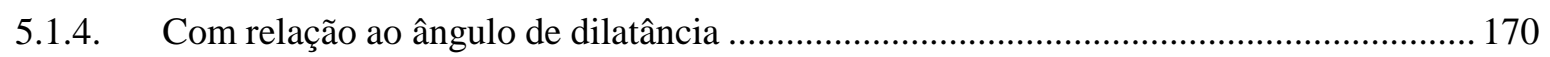

5.2. ANÁLISES REFERENTES AO MODELO TÉRMICO ............................................. 171

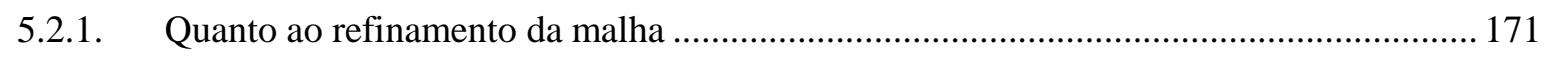

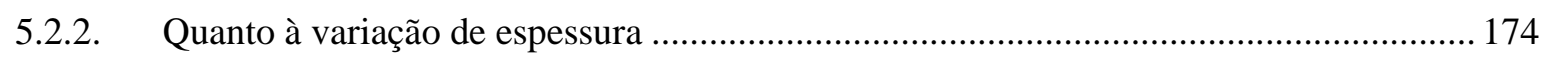

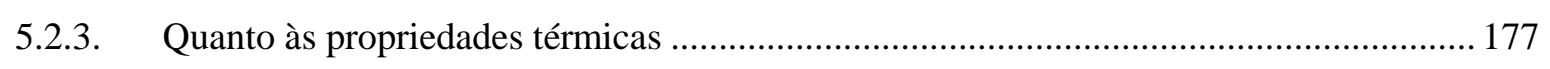

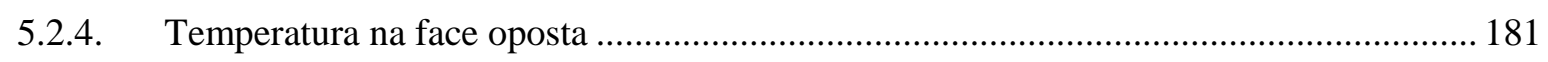

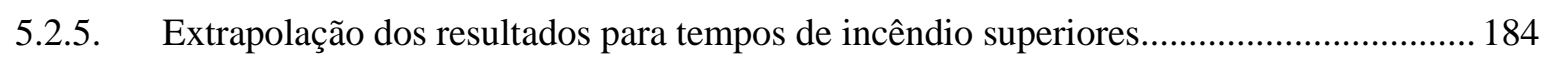

5.3. ANÁLISES REFERENTES AO MODELO TERMOESTRUTURAL ........................... 190

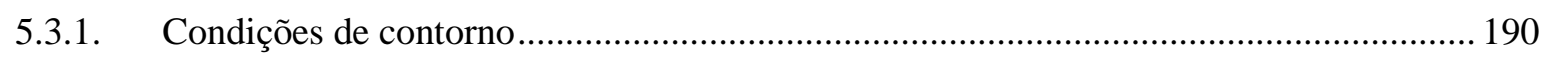


5.3.2. Temperatura na face oposta ao fogo.

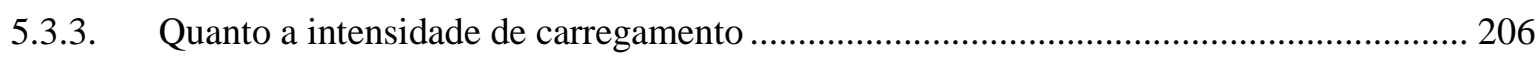

6. CONSIDERAÇÕES E CONCLUSÕES ..................................................................211

6.1. COM RELAÇÃO ÀS ANÁLISES EM CONTEXTO ESTRUTURAL …..................... 212

6.2. COM RELAÇÃO ÀS ANÁLISES EM CONTEXTO TÉRMICO ................................. 213

6.3. COM RELAÇÃO ÀS ANÁLISES EM CONTEXTO TERMOESTRUTURAL ......... 215

6.4. SUGESTÕES PARA TRABALHOS FUTUROS …..................................................... 217

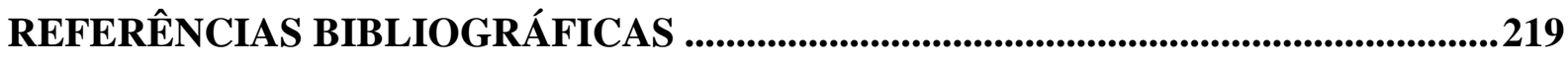

APÊNDICE A - NOÇÕES GERAIS SOBRE INCÊNDIO ...............................................235

APÊNDICE B - ASPECTOS REFERENTES ÀS PRECRIÇÕES NORMATIVAS

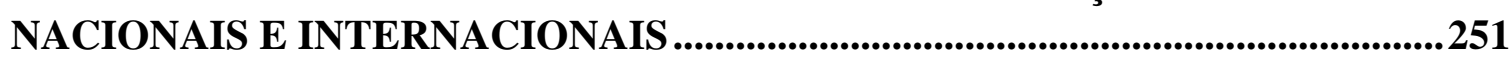

APÊNDICE C - CARACTERÍSTICAS DA ALVENARIA ESTRUTURAL ................265

APÊNDICE D - PROPRIEDADES DOS MATERIAIS DA ALVENARIA

ESTRUTURAL DE BLOCOS DE CONCRETO SOB ELEVADAS

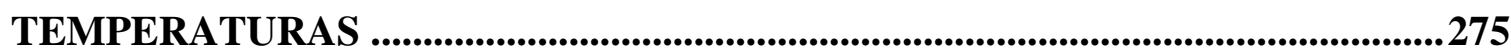

APÊNDICE E - CONSIDERAÇÕES ADICIONAIS SOBRE MODELAGEM

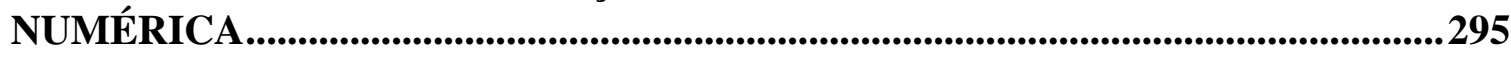

APÊNDICE F - EQUAÇÕES DO MODELO DE GUO (2014) PARA EXTRAPOLAÇÃO

DAS CURVAS DE COMPRESSÃO E DE TRAÇÃO DO CONCRETO................299

APÊNDICE G - INFORMAÇÕES COMPLEMENTARES DAS ANÁLISES

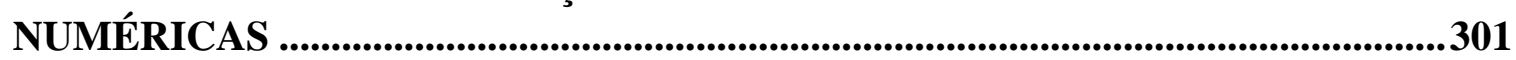

APÊNDICE H - HISTÓRICO DA ALVENARIA ESTRUTURAL E INCÊNDIO NAS

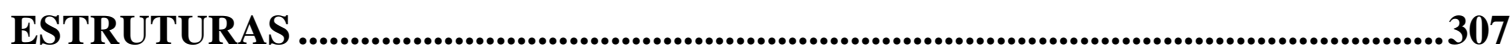





\section{INTRODUÇÃO}

A alvenaria estrutural consiste de um sistema construtivo cujo crescimento tem se mostrado contínuo em seu uso no Brasil ao longo das últimas décadas. Este tipo de sistema permite economia de tempo e de material, bem como reduz o volume de resíduos gerados na obra (RAMALHO; CORRÊA, 2003).

O sistema construtivo é formado por unidades (blocos ou tijolos), unidos por juntas de argamassa, além de graute e armaduras, cujas funções destes últimos elementos dependem da classificação do sistema (CAMACHO, 2006). As unidades usuais são normalmente blocos vazados de concreto ou cerâmicos. Entretanto existem também tijolos de solo-cimento, blocos de concreto celular auto clavado e blocos silico-calcários. A alvenaria estrutural exerce função de vedação e age também como elemento estrutural tendo em vista a elevada resistência à compressão que apresenta, quando comparada à resistência à tração.

O fator preponderante para a determinação da resistência à compressão da alvenaria refere-se principalmente à resistência das unidades. De forma secundária, de acordo com Camacho (2006), a resistência da argamassa também possui influência, porém, em menor intensidade e dependendo do nível de resistência da própria unidade. Outro fator relevante diz respeito à sua execução propriamente dita, referente à qualidade da mão-de-obra onde devem ser mantidos os devidos alinhamentos, espessuras de juntas e bom assentamento para evitar a redução da resistência da parede.

Aos materiais componentes da alvenaria estrutural, algumas características são buscadas nestes para que sejam incorporados junto ao sistema construtivo. Por exemplo, no caso das unidades, os materiais constituintes devem apresentar resistência à compressão adequada, bem como boa capacidade de aderência à argamassa e dimensões uniformes. Apesar do pouco conhecimento existente acerca deste sistema construtivo em situações de incêndio, outra característica relevante às unidades se refere à elevada resistência ao fogo (SOARES, 2010).

Em relação aos incêndios, os dados relativos à sua ocorrência em todo o mundo indicam milhares de mortes a cada ano. De acordo com um estudo feito pela Geneva Association e com o cruzamento de dados do Sistema Único de Saúde (SUS), o Brasil esteve em 2011 em terceiro lugar no ranking mundial de mortes por incêndio. O Sistema de Informações sobre Mortalidade do SUS registrou, no ano citado, 1.051 mortes por incêndio ou por exposição a fumaça, havendo apenas os Estados Unidos e o Japão com números superiores, de 3.192 e 1.750 mortes, respectivamente (World Fire Statistics). 
Outro dado acerca dos incêndios no Brasil se refere à média anual destas ocorrências. De acordo com a Secretaria Nacional de Segurança Pública (Senasp) do Ministério da Justiça ${ }^{1}$, o Brasil tem uma média de 267 mil incêndios anualmente (incluindo ocorrências florestais e residenciais). De acordo com a International Association of Fire and Rescue Service (CTIF, 2017), a qual possui base de dados de diversos grandes centros de 31 países, os incêndios em edificações foram responsáveis por $38 \%$ dos casos, como pode ser visto na Figura 1.1.

Figura 1.1 - Distribuição de incêndio em 31 países de acordo com a origem (2015)

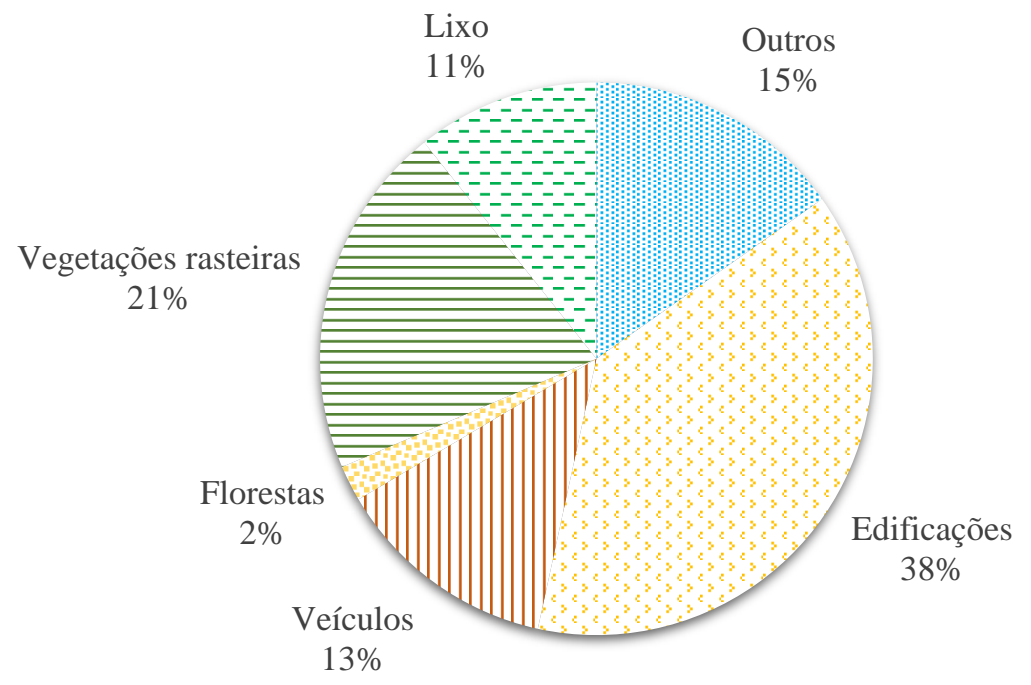

Fonte: Adaptado de CTIF (2017)

A existência de normas técnicas que incidam sobre as diferentes possibilidades de solicitações das estruturas, como deve ocorrer com qualquer tipo de sistema construtivo, é de suma relevância a fim de garantir segurança aos usuários. No Brasil, ainda não há norma técnica específica para situações de incêndio em alvenaria estrutural. Em virtude desta lacuna, o Corpo de Bombeiros do Estado de São Paulo, por exemplo, através da Instrução Técnica 08:2001, recomenda o uso do Eurocode 6:2005 ou de normas internacionais similares para o dimensionamento de alvenaria estrutural em situação de incêndio.

De acordo com o Instituto de Pesquisas Tecnológicas², a resistência ao fogo pode ser definida como a capacidade dos elementos construtivos de suportar a ação do incêndio, impedindo por determinado período sua propagação e preservando a estabilidade estrutural da

\footnotetext{
${ }^{1}$ Disponível em: http://www.sprinklerbrasil.org.br/imprensa/brasil-e-o-3o-pais-com-o-maior-numero-de-mortespor-incendio-newsletter-no-5/. Acesso em 20 nov. 2017.

${ }^{2}$ Disponível em: http://www.ipt.br/solucoes/325-resistencia_ao_fogo.htm. Acesso em 30 nov. 2017.
} 
edificação. Os edifícios devem ser concebidos de modo que, em caso de ocorrência de incêndio, os ocupantes possam abandoná-lo em segurança ou serem socorridos.

De acordo com o Eurocode 6 Part 1-2:2005, os procedimentos considerados para os elementos estruturais em situações de incêndio englobam a verificação da resistência mecânica (R), da estanqueidade (E), do isolamento térmico (I) e do impacto mecânico (M). Quanto à fuga nestas situações, a ABNT NBR 14432:2001 regulamenta tempos variáveis de acordo com o tipo de uso, profundidade do subsolo e altura da edificação. Além disso, faz considerações quanto à segurança das equipes de combate ao incêndio, bem como minimização de danos aos edifícios próximos.

De acordo com Leite, Moreno Júnior e Torres (2015), no Brasil, devido à inexistência de procedimentos normatizados de dimensionamento de alvenaria estrutural em incêndio, a verificação estrutural vem sendo omitida em relação às verificações quanto ao isolamento térmico e à estanqueidade, quando existentes.

Os códigos computacionais, simplificadamente, são ferramentas que permitem a resolução de diversos problemas de Engenharia, permitindo desde a mecânica dos sólidos até problemas de transferência de calor, incluindo a inter-relação entre os mesmos. A formulação destes códigos computacionais baseia-se, em sua maioria, no Método dos Elementos Finitos (MEF), no Método dos Elementos de Contorno (MEC) e no Método das Diferenças Finitas (MDF), sendo a escolha de acordo com o tipo de problema estudado.

Faz-se necessário destacar que os modelos numéricos podem apresentar algumas limitações para representação de situações reais de determinadas estruturas, uma vez que apresentam simplificações na construção de modelos mais complexos. Mesmo assim, estes códigos vêm sendo cada vez mais utilizados em pesquisas científicas e por profissionais de diversas áreas por apresentarem resultados satisfatórios nos diferentes regimes de elasticidade e linearidade.

Diante do exposto, o presente trabalho visou simular o comportamento estrutural de pequenas paredes de alvenaria estrutural constituídas de blocos de concreto, bem como seu comportamento térmico e termoestrutural quando em situação de incêndio. Para tanto, foram propostos modelos estrutural, térmico e termoestrutural, desenvolvidos com o auxílio do software ABAQUS versão 6.14, baseado no Método dos Elementos Finitos, os quais foram comparados com resultados experimentais e validados aqueles que possíveis.

Com a validação dos modelos estrutural e térmico, outras análises foram desenvolvidas com o intuito de analisar a influência de outros fatores quanto a resistência da parede e ao critério de isolamento térmico. Para o modelo termoestrutural, a variação das restrições e do 
nível de carregamento para análise quanto ao tempo de resistência ao fogo quanto ao critério de resistência mecânica.

\subsection{OBJETIVO}

O objetivo geral deste trabalho visa o desenvolvimento de modelos numéricos no pacote computacional ABAQUS versão 6.14 que simulem o comportamento estrutural, térmico e termoestrutural de pequenas paredes de alvenaria estrutural não armada, executada em blocos de concreto sem revestimento e em situação de incêndio. Especificamente, tem-se:

- Comparar e validar quantitativamente os resultados obtidos pelos modelos estrutural e térmico com os valores experimentais existentes na literatura;

- Comparar qualitativamente os resultados obtidos pelo modelo termoestrutural com os resultados experimentais existentes na literatura;

- Realizar análises complementares acerca das variáveis envolvidas para cada modelo;

- Desenvolver o ramo do conhecimento no qual este trabalho está inserido a fim de melhor avaliar o comportamento da alvenaria estrutural em situações de incêndio.

\subsection{JUSTIFICATIVA}

O uso de métodos numéricos para a solução de problemas relacionados à Engenharia é uma alternativa eficaz, versátil e com grande viabilidade quando comparada com análises experimentais e analíticas. Na solução por meio de métodos numéricos é desenvolvido um protótipo virtual do objeto de interesse, representado por um sistema de equações fundamentadas em uma teoria matemática, como o Método de Elementos Finitos (MEF).

Em relação ao primeiro caso, a análise numérica torna-se mais vantajosa em situações em que o custo é uma variável limitante, devido aos elevados valores por conta da construção do protótipo e também para a disponibilização da infraestrutura necessária para os ensaios. Além disso, demanda maior tempo para a obtenção dos resultados, uma vez que se deve seguir os procedimentos adequados ao longo dos ensaios. Outro ponto é que a sua aplicabilidade apresenta particularidade para cada situação ensaiada.

Em relação à análise analítica, a vantagem da modelagem numérica se refere à possibilidade de estudo de situações com maior complexidade. No caso analítico, as equações geralmente contemplam características físicas e de operação relativamente idealizadas, muito simplificadas se comparadas com o que se observa na realidade ou são restritas às condições específicas previstas no cálculo. Desta forma, os resultados obtidos por este método podem 
apresentar um desvio significativo em relação ao produto real, não proporcionando um entendimento detalhado do comportamento do objeto em estudo.

Para uma modelagem numérica consistente, é de extrema relevância a sua validação a partir de resultados experimentais. Com isto, faz-se possível a extrapolação de diversos parâmetros do objeto de estudo para o melhor entendimento de seu comportamento sem a necessidade de comprovação experimental para cada variação.

Quanto ao objeto de estudo desta pesquisa, a alvenaria estrutural de blocos de concreto tem obtido grande crescimento quanto ao seu uso em território nacional o que torna cada vez mais necessário o estudo de parâmetros de projeto específico para este sistema construtivo a fim de obter maior confiabilidade, segurança e eficiência. Como citado anteriormente, este sistema construtivo apresenta grandes vantagens em relação aos sistemas usuais no país, dentre as quais podem ser citadas a economia de tempo durante a construção, a redução de desperdício e de materiais e a queda dos resíduos gerados em obra.

A engenharia de segurança contra incêndio, definida por Purkiss ${ }^{3}$ (2007, apud NUNES, 2014 p.11) como a aplicação do conhecimento científico e dos princípios da engenharia aos efeitos do fogo, tem como maior objetivo a redução das perdas de vidas e de materiais através de medidas preventivas ou de proteção adequadas.

Em relação às normas nacionais de alvenaria estrutural, atualmente, não há contemplação para verificação quanto às situações de incêndio, havendo apenas a sugestão de uso de normas estrangeiras para tal dimensionamento.

Quanto às pesquisas na área de alvenaria e incêndio, poucas são as instituições no Brasil capazes de contribuir com este tipo de estudo (MORENO JR.; MOLINA, 2012), principalmente, devido à necessidade de fornos específicos e ao alto custo de ensaio.

Considerando o exposto, é possível notar a existência de uma lacuna na qual tanto a normatização brasileira quanto o mercado necessitam que seja preenchida, e assim, os projetos e execuções possam prover segurança aos usuários em aspectos possíveis de serem previstos. Esta pesquisa busca auxiliar no desenvolvimento da área de alvenaria estrutural e incêndio através da obtenção de modelos numéricos capazes de simular o comportamento de pequenas paredes de blocos de concreto em situação de incêndio. Para tanto, buscou-se validar o comportamento estrutural e térmico para uma sinalização mais adequada do comportamento termoestrutural, em virtude dos poucos de ensaios em paredes carregadas sob incêndio.

\footnotetext{
${ }^{3}$ PURKISS, J. A. (2007). Fire Safety Engineering - Design of Structures. Second Edition. ButterworthHeinemann: 1-13.
} 


\subsection{METODOLOGIA}

Os estudos aqui desenvolvidos se baseiam em modelos numéricos discretizados em elementos finitos e construídos por meio da utilização do software ABAQUS versão 6.14, sendo consideradas as não-linearidades geométrica e material nas análises.

No desenvolvimento do presente trabalho, buscou-se obter a validação numérica acerca do comportamento estrutural de pequenas paredes de blocos de concreto à temperatura ambiente, bem como a validação térmica sob situação de incêndio com elevação de temperatura baseada na curva ISO 834-1:1999. Por outro lado, vale destacar que o presente trabalho pode ser caracterizado como exploratório no tocante ao comportamento termoestrutural, devido às comparações qualitativas em relação aos ensaios disponíveis e aos poucos resultados de ensaios submetidos a altas temperaturas com carregamento da estrutura.

Inicialmente, foi realizada uma extensa revisão bibliográfica na área de modelagem numérica, alvenaria, incêndio, alteração das propriedades dos materiais sob elevadas temperaturas e verificação das normas existentes no mundo relativo à área de alvenaria e incêndio. As análises numéricas foram realizadas na seguinte ordem: análise preliminar do modelo, análise estrutural, análise térmica e análise termoestrutural das pequenas paredes de blocos de concreto.

$\mathrm{Na}$ análise preliminar, em virtude do menor tempo de processamento, foram modelados prismas de três blocos para calibração do modelo estrutural, baseando-se no estudo de Rodovalho (2018). Nesta etapa, foram realizadas as definições gerais do modelo numérico para posterior criação da pequena parede, sendo analisados os elementos finitos que melhor representariam o problema, a variação da geometria dos elementos constituintes do modelo, a variação do refinamento da malha e os mecanismos de contato.

Após a obtenção de resultados tidos como coerentes, foram modeladas as pequenas paredes à temperatura ambiente, cujas validações para o modelo estrutural basearam-se nos trabalhos experimentais de Oliveira (2014) e de Dupim (2019). Nesta etapa, buscou-se simular as condições de contorno do ensaio, permitindo apenas o deslocamento vertical na superfície superior da parede, considerando o aumento de carga na estrutura pelo incremento de deslocamento, bem como, foram calibrados alguns parâmetros do modelo, de acordo as propriedades dos materiais inicialmente estudados na revisão bibliográfica.

Para os modelos térmicos, foram desconsideradas as condições de contorno do modelo anterior, apenas com o intuito de avaliar o gradiente de temperatura ao longo da seção transversal da parede e compará-lo quantitativamente com os resultados obtidos por Dupim 
(2019). Nesta etapa, foram calibradas as propriedades térmicas dos materiais, baseando-se em normas nacionais e internacionais, em virtude da inexistência de resultados experimentais em relação às propriedades térmicas dos blocos estudados.

$\mathrm{Na}$ sequência, os modelos termoestruturais foram criados, unindo os modelos anteriormente estudados, utilizando as propriedades mecânicas e térmicas definidas e calibradas anteriormente. Nesta etapa, foram inseridos os coeficientes de minoração da resistência e do módulo de elasticidade em função da temperatura, bem como, a expansão térmica dos materiais, baseando-se nas normatizações existentes. A análise qualitativa deste modelo foi baseada nos resultados obtidos por Dupim (2019) e Lopes et al. (2018).

Após a definição de todos os modelos, validados de acordo com o material experimental disponível, foram realizadas algumas análises complementares, envolvendo variáveis entendidas como relevantes, tanto para verificação da coerência dos modelos criados, como para a extrapolação dos resultados e análises paramétricas.

\subsection{ORGANIZAÇÃO DO TRABALHO}

No Capítulo 1, é realizada a apresentação do tema abordado neste trabalho, estando, na sequência, os objetivos e a justificativa, bem como, a metodologia, com os aspectos gerais para a realização deste trabalho.

O Capítulo 2 trata dos temas principais em que este trabalho está envolvido, abordando aspectos relevantes da alvenaria estrutural em situação ambiente e sob elevadas temperaturas. Inclui-se neste capítulo a revisão bibliográfica sobre os principais trabalhos na área e em áreas correlatas desta pesquisa.

O Capítulo 3 apresenta as estratégias utilizadas para a modelagem numérica, incluindo a escolha dos elementos finitos, do tipo de geometria dos elementos envolvidos e dos mecanismos de contato. Além disso, estão descritas as condições de contorno para cada tipo de análise, estrutural, térmica e termoestrutural, além das definições das propriedades dos materiais analisados.

No Capítulo 4 são feitas as validações dos modelos estrutural e térmico, baseando-se em trabalhos experimentais, e, feitas análises qualitativas do modelo termoestrutural de acordo com os ensaios existentes.

No Capítulo 5 constam as análises complementares e paramétricas de cada modelo, considerando diversas variações tidas como pertinentes, a partir dos modelos validados e analisados anteriormente. 
No Capítulo 6 consta a conclusão deste trabalho, com os comentários acerca das validações realizadas e as possíveis generalizações e restrições para cada modelo numérico. Ainda, são apresentadas sugestões para trabalhos futuros, com o intuito de direcionar pesquisas para o desenvolvimento do tema e para geração de subsídios para a obtenção da primeira norma nacional de alvenaria em situação de incêndio.

Nos Apêndices constam alguns assuntos entendidos como pertinentes à pesquisa, porém, com importância secundária em relação aos capítulos citados. Dentre eles, estão noções gerais sobre incêndio, onde é comentado sobre a caracterização e os modelos de incêndio existentes, prescrições normativas nacionais e internacionais na área de alvenaria e incêndio, onde são comentadas, de forma simplificada, sobre as principais normas relativas ao tema deste trabalho, características da alvenaria estrutural, onde são abordadas algumas propriedades relevantes da alvenaria em situação ambiente, propriedades dos materiais sob elevadas temperaturas, baseando-se em normas e pesquisas anteriormente realizadas referentes aos materiais deste trabalho, algumas considerações adicionais referentes à modelagem numérica, além de um breve histórico da alvenaria estrutural e incêndio nas estruturas. 


\section{REVISÃO BIBLIOGRÁFICA}

Neste capítulo é apresentado uma breve revisão dos conceitos básicos do sistema construtivo denominado como alvenaria estrutural, foco deste trabalho, bem como, de trabalhos realizados nesta área considerando a elevação de temperatura.

Os conceitos relacionados ao incêndio, tais como sua definição, a caracterização quanto às suas fases, incluindo o conceito do flashover, os modelos de incêndio possíveis, como o modelo de incêndio-padrão, utilizado neste trabalho, e a explicação e exemplificação do Tempo Requerido de Resistência ao Fogo estão inclusos no Apêndice A. Estes itens foram selecionados como apêndice em virtude da elevada disseminação quanto a estes conceitos em trabalhos acadêmicos recentes.

Em relação à normatização brasileira, esta está presente na alvenaria estrutural de blocos de concreto no dimensionamento, execução e controle, bem como, em relação aos procedimentos de ensaio para pequenas paredes relativos aos esforços possíveis à temperatura ambiente. Não há, atualmente, normatização brasileira vigente para alvenaria estrutural em situação de incêndio, excetuando-se casos específicos, como da IT-08:2011, do Corpo de Bombeiros do Estado de São Paulo que estabelece algumas condições a serem atendidas e indica o uso do Eurocode quando não houver abordagem do tema por normatização nacional. Um breve resumo do tratamento de estruturas de alvenaria em situação de incêndio por normas internacionais é feito no Apêndice $\boldsymbol{B}$.

\subsection{ALVENARIA ESTRUTURAL}

\subsubsection{Definição}

De acordo com Franco (1992), a alvenaria estrutural é um processo construtivo que se caracteriza pelo emprego de paredes de alvenaria e lajes enrijecedoras como principal estrutura de suporte dos edifícios.

Utiliza peças industrializadas de dimensões e peso que as fazem manuseáveis, ligadas por argamassa, tornando o conjunto monolítico. Estas peças industrializadas podem ser moldadas em cerâmica, concreto ou sílico-calcáreo. Os componentes principais do sistema são os blocos, a argamassa, o graute e a armadura. 
Roman et al. (1999) entende que a maior vantagem da alvenaria estrutural é possibilitar a incorporação dos conceitos de racionalização, produtividade e qualidade produzindo construções com bom desempenho tecnológico aliado a baixos custos.

A principal característica do sistema é o bom comportamento quanto aos esforços de compressão, sendo os blocos os elementos com maior contribuição nessa resistência. Isto não exclui a relevância dos demais elementos constituintes da alvenaria estrutural, sendo primordial o conhecimento das funções e características de cada qual para obtenção do melhor desempenho estrutural do sistema construtivo.

Figura 2.1 - Exemplos de construção em alvenaria estrutural de blocos de concreto e de blocos cerâmicos
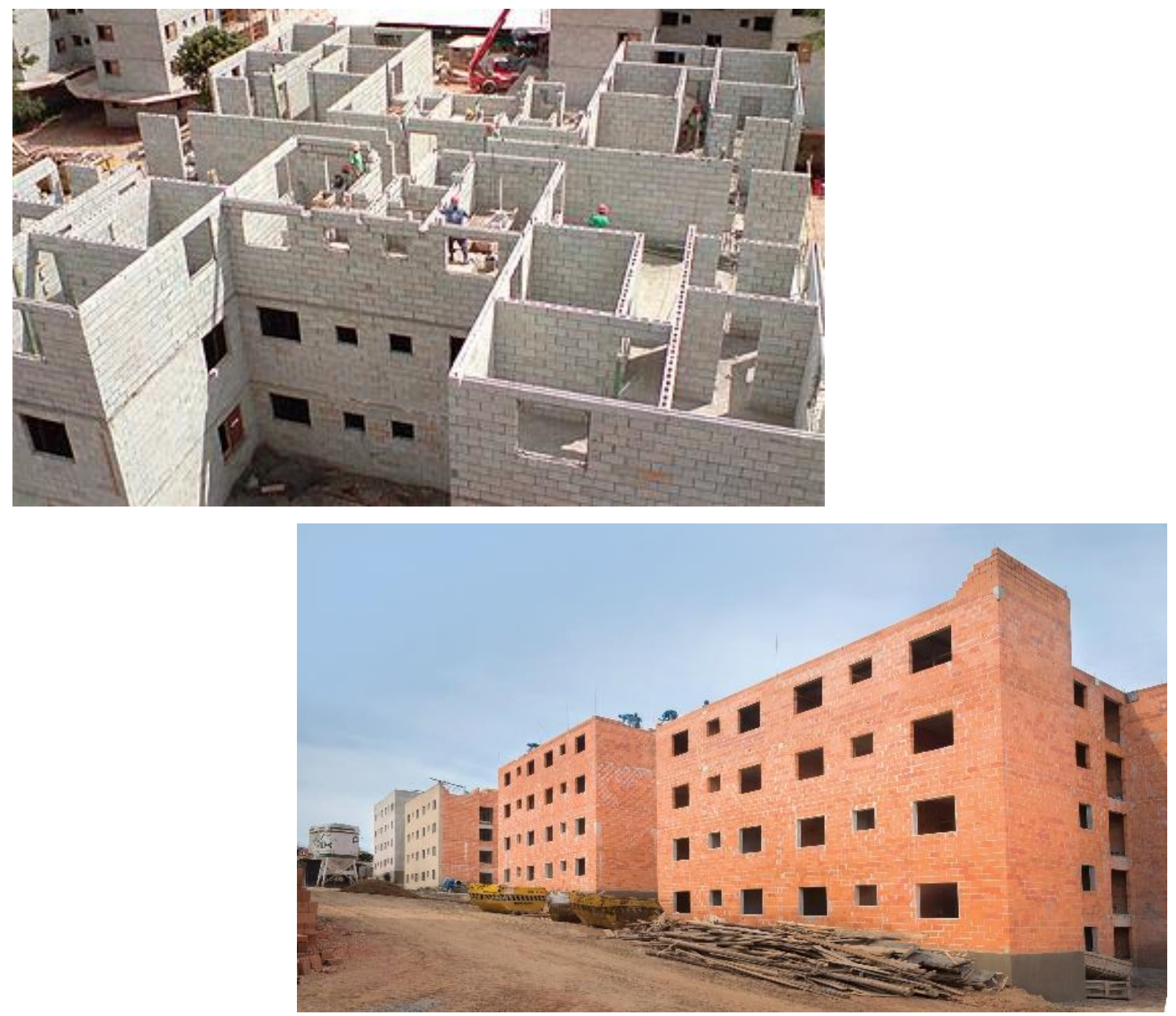

Fonte: Bloq (2018) e Cerâmica City (2018)

Um breve histórico da alvenaria estrutural é apresentado no Apêndice $\boldsymbol{H}$, incluindo, também, histórico de incêndios relevantes ao longo da história. 


\subsubsection{Componentes da alvenaria estrutural}

A alvenaria estrutural é constituída por componentes, os quais são considerados como unidades básicas do sistema. A união dos componentes forma os elementos, os quais, unidos, por sua vez, compõem a estrutura. Os componentes principais da alvenaria estrutural são as unidades (blocos ou tijolos), a argamassa, o graute e a armadura. A junção de dois ou mais destes componentes formam elementos tais como paredes, vergas e cintas.

\subsubsection{Unidades}

As unidades são os componentes mais importantes da alvenaria estrutural por, além de constituírem a maior parte da estrutura, serem as principais responsáveis pela definição das características de resistência da alvenaria. Podem ser classificadas de acordo com o material (concreto, cerâmico ou sílico-calcáreo), quanto à forma (maciço ou vazado) e quanto ao tipo (vedação ou estrutural).

Os blocos podem ser constituídos de diferentes materiais, sendo os mais utilizados os cerâmicos e os de concreto. De acordo com Soares (2010), para qualquer material utilizado para os blocos, as propriedades desejáveis são as seguintes:

- Resistência à compressão adequada;

- Capacidade de aderir à argamassa tornando homogênea a parede;

- Durabilidade frente aos agentes agressivos (umidade, variação de temperatura e ataque por agentes químicos);

- Dimensões uniformes;

- Resistência ao fogo.

Em relação aos blocos de concreto, objeto deste trabalho, podem ser classificados em maciços ou vazados. Blocos maciços são aqueles que possuem índice de vazios de até $25 \%$ da área total, caso contrário são classificados como vazados. Quanto à aplicação, classificam-se em blocos de vedação e blocos estruturais.

Os blocos de concreto são classificados pela ABNT NBR 6136:2016 de acordo com as suas dimensões, isto é, larguras de $190 \mathrm{~mm}$ e de $140 \mathrm{~mm}$. Em relação às propriedades mecânicas, a mesma norma faz a seguinte classificação:

- Classe A: aplica-se às alvenarias com função estrutural, para uso em elementos de alvenaria acima ou abaixo do nível do solo. O bloco deve possuir resistência característica à compressão maior do que $8 \mathrm{MPa}$; 
- Classe B: alvenarias com função estrutural, para uso em elementos apenas acima do nível do solo. A resistência característica do bloco deve variar entre 4 e $8 \mathrm{MPa}$;

- Classe C: com função estrutural, para uso em elementos de alvenaria acima do nível do solo até 5 pavimentos, com resistência característica do bloco entre 3 e $4 \mathrm{MPa}$.

Na sequência, na Figura 2.2 estão ilustradas duas famílias de blocos comuns nas edificações brasileiras.

Figura 2.2 - Famílias de blocos de concreto comuns

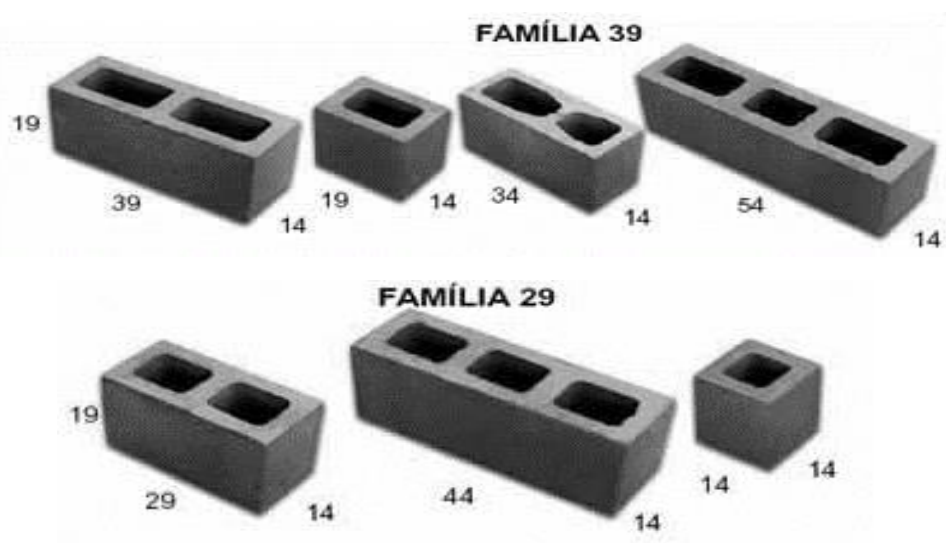

Fonte: Bastos (2013)

\subsubsection{Argamassa}

A argamassa de assentamento, de acordo com a ABNT NBR 13281:2005, é definida como elemento utilizado na ligação entre os blocos de concreto, a qual garante a distribuição uniforme de esforços, e é composta por cimento, agregado miúdo, água e cal ou outra adição destinada a conferir plasticidade e retenção de água de hidratação à mistura. $O$ principal componente que confere resistência mecânica à argamassa é o cimento devido às suas reações pozolânicas. A cal reage com o gás carbônico formando compostos que promovem o endurecimento mas possui resistência muito menor se comparado ao concreto.

Dentre as funções básicas da argamassa de assentamento, estão a de apoiar os blocos, transmitir e uniformizar as tensões entre as unidades de alvenaria, absorver pequenas deformações (devido a variações de temperatura, pequenos recalques, retração por secagem, etc.), desenvolver resistência adequada para não comprometer a alvenaria, compensar pequenas variações dimensionais das unidades e impedir a entrada de água, de vento e de agentes agressivos nas edificações. Para um bom desempenho do material, são necessárias condições como boas características de trabalhabilidade, resistência, plasticidade, durabilidade e capacidade de retenção de água (BASTOS, 2013). 
As argamassas de assentamento são compostas, em sua maioria, por cimento, cal, areia, e água podendo conter adições ou aditivos. No caso de possuírem como aglomerante a combinação entre cimento e cal, são denominadas argamassas mistas.

As argamassas possuem diversos tipos de classificação. Quanto aos tipos de argamassas utilizadas em alvenaria estrutural, podem ser citadas as mistas, semiprontas e industrializadas. As normas americanas subdividem as argamassas mistas, ainda, de acordo com o local de uso, havendo variação de sua resistência. As argamassas semiprontas são usinadas de cal e areia, sendo adicionado em obra, o cimento para a mistura. As argamassas industrializadas são classificadas em dois grupos: as prontas, entregues em baldes ou contêineres, e argamassas em que é necessário o acréscimo de água, entregues em sacos ou a granel.

O Quadro 2.1 mostra a divisão feita pela norma americana ASTM C 270:2014 para classificação de argamassas.

Quadro 2.1 - Indicação de uso de argamassa

\begin{tabular}{|c|c|}
\hline Argamassa & Indicação \\
\hline $\mathbf{M}$ & $\begin{array}{c}\text { Alvenaria sujeita a altas forças de compressão, ação severa do frio, altas forças } \\
\text { laterais de pressão do solo, vento, terremotos, estruturas de fundação, alicerce, } \\
\text { poço, muros de arrimo. }\end{array}$ \\
\hline $\mathbf{S}$ & $\begin{array}{c}\text { Estruturas que requerem alta resistência à flexão, e sujeitas a cargas laterais e } \\
\text { de compressão. }\end{array}$ \\
\hline $\mathbf{N}$ & Uso geral nas alvenarias acima. Base de residências, paredes internas. Porão. \\
\hline $\mathbf{O}$ & Paredes de vedação. \\
\hline
\end{tabular}

Fonte: ASTM C270:2014

\subsubsection{Graute}

Outro componente da alvenaria estrutural, o graute é uma mistura dos materiais utilizados para produzir concreto convencional, com as diferenças de que, os agregados são mais finos, com $100 \%$ passando na peneira $12,5 \mathrm{~mm}$ e cuja relação água/cimento é mais alta, conferindo fluidez ao material (abatimento de 20 a $28 \mathrm{~cm}$ ).

$\mathrm{O}$ graute possui dois principais objetivos na alvenaria estrutural. $\mathrm{O}$ primeiro se refere a proporcionar a integração da armadura com a alvenaria, no caso de alvenaria estrutural armada ou em armaduras apenas de caráter construtivo, enquanto o segundo se refere ao aumento da resistência da parede sem a necessidade de aumentar a resistência da unidade (SOARES, 2010). 
De acordo com Bastos (2013), o graute ainda aumenta a resistência da parede quanto às forças laterais, à propagação do som e ao fogo.

A ABNT NBR 15961-1:2011 informa que a resistência característica do graute para alvenaria de blocos de concreto armada deve apresentar valor mínimo de $15 \mathrm{MPa}$.

\subsubsection{Armaduras}

Finalmente, quanto às armaduras, estas são as mesmas utilizadas no concreto armado, ou seja, CA-25, CA-50 e CA-60. As funções das armaduras dentro do sistema se referem à absorção de esforções de tração e/ou compressão e às necessidades construtivas.

De acordo com a ABNT NBR 15812:2010, os elementos de alvenaria podem ser definidos conforme a função desempenhada pelas armaduras em:

- Não-armado: elemento no qual a armadura não é considerada para resistir aos esforços solicitantes. Caso haja armadura para esta classificação, esta tem finalidade construtiva ou de amarração de modo a prevenir problemas patológicos futuros como trincas por acomodação da estrutura e por efeito térmico, vento e concentração de tensões;

- Armado: elemento que possui armaduras passivas calculadas para resistir aos esforços solicitantes. Estas armaduras são dispostas nas cavidades dos blocos que são posteriormente preenchidas por graute;

- Protendido: elemento que possui armaduras ativas para resistir aos esforças solicitantes.

Figura 2.3 - Representação dos componentes da alvenaria estrutural

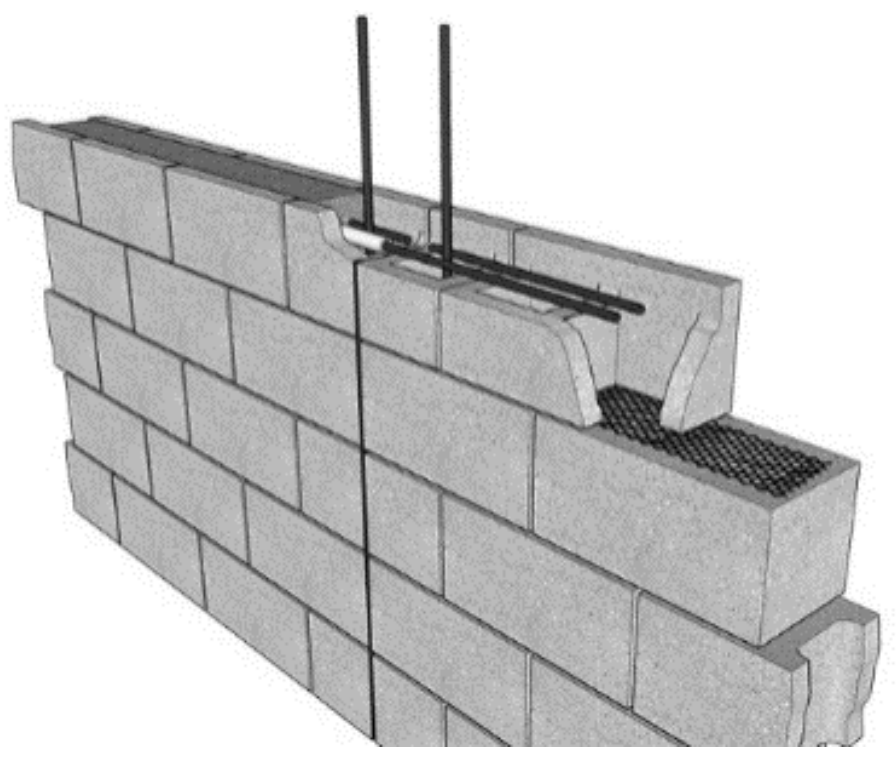

Fonte: Ecivil (2018) 


\subsubsection{Tipo de argamassamento}

O tipo de argamassamento, também chamado de tipo de assentamento da argamassa, consiste na forma em que é feito o preenchimento da superfície das paredes dos blocos pela argamassa. Em obra, este é um fator relevante, pois interfere diretamente na produção e no rendimento da etapa de serviço. Os tipos de argamassamento possíveis são:

- Argamassamento total: onde todos os septos dos blocos são preenchidos por argamassa;

- Argamassamento parcial: onde apenas as áreas relativas aos septos longitudinais dos blocos recebem o preenchimento.

A Figura 2.4 exemplifica os tipos de argamassamento.

Figura 2.4 - Argamassamento total (a) e argamassamento parcial (b)

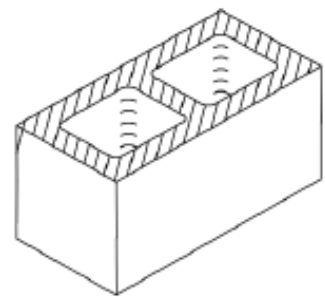

(a)

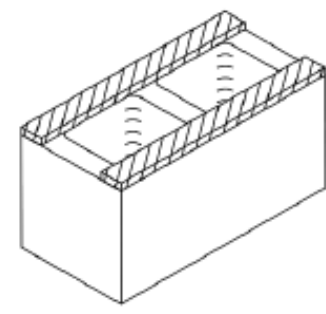

(b)

Fonte: Oliveira (2014)

O tipo de argamassamento influencia diretamente o comportamento estrutural da alvenaria, como no caso de sua resistência, da distribuição de tensões e de fissuras e da ruptura das paredes estruturais. A redução da resistência no caso do argamassamento parcial, em comparação ao argamassamento total, deve-se à maior concentração de tensões ocorrente na face lateral da alvenaria, justamente pela ausência da argamassa nos septos transversais dos blocos.

Este tipo de comportamento foi observado por Shrive (1982) ${ }^{4}$ apud Mohamad (2007) em ensaios de prismas de blocos de concreto moldados com argamassamento parcial. Nos ensaios ocorreu o desenvolvimento de tensões de tração na face lateral dos prismas causado pela rotação e esmagamento da argamassa, a qual trabalhava como apoio dos blocos, culminando, assim, na ruptura por flexão do material, conforme demonstrado na Figura 2.5.

\footnotetext{
${ }^{4}$ SHRIVE, N. G., The failure mechanism of face-shell bedded (ungrouted and unreinforced) masonry subjected to compressive loading. The International Journal of Masonry Construction. Vol. 2, $\mathrm{N}^{\circ}$ 3, p. 115-128, 1982.
} 
Figura 2.5 - Modo de ruptura de prismas de blocos de concreto com argamassamento parcial
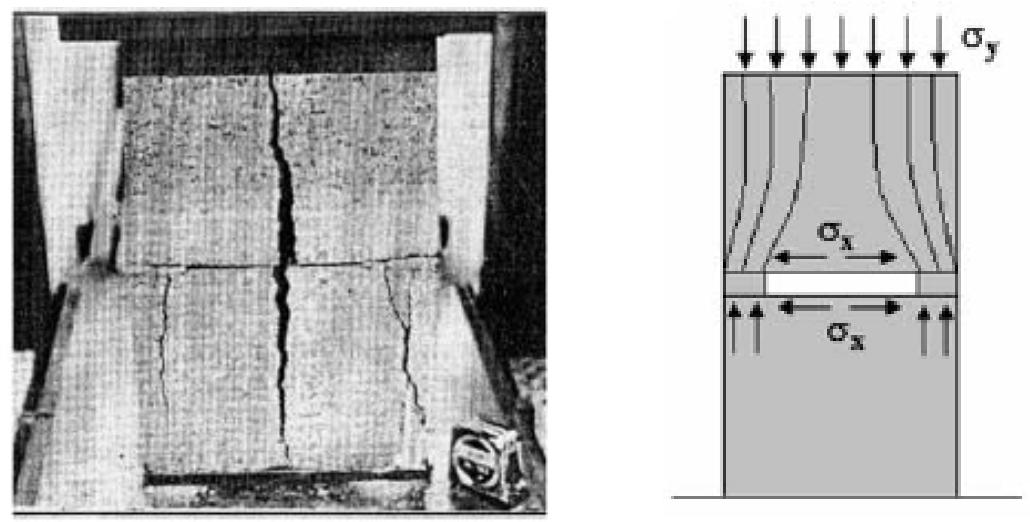

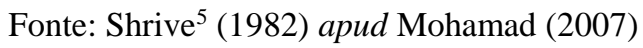

Parsekian (2002) indica como vantagem do argamassamento parcial, a maior estanqueidade em alvenarias aparentes, devido à falta de ligação entre os cordões de argamassa, diminuindo a transferência de umidades externa. Além disso, pode-se citar a maior economia e produtividade na obra.

Dentre os estudos realizados acerca da influência do tipo de argamassamento, podem ser citados os experimentos realizados por Colville e Wolde-Tinsae (1991), os quais concluíram que a resistência à compressão dos prismas vazados deve ser calculada de acordo com a área de assentamento, e que a resistência à compressão em prismas executados com argamassamento parcial é cerca de $8 \%$ inferior aos executados com argamassamento total. Assim, estes autores sugerem que os ensaios sejam realizados em corpos-de-prova com argamassamento total, sendo, caso necessário, extrapolado os valores para o assentamento parcial, de acordo com a relação anterior.

Ganesan e Ramamurthy (1992) e Mata (2006) verificaram numericamente o surgimento de concentração de tensão nas paredes transversais dos blocos para prismas executados com assentamento parcial. Em relação à primeira referência concluiu-se que, devido ao processo de fissuração nos septos centrais, ocorre a perda do enrijecimento causado pelos próprios septos, o que leva as faces a trabalhar de forma independente até a ruptura súbita. Na segunda referência, o autor comenta que as deformações obtidas nos modelos com assentamento parcial são maiores que na situação de argamassamento total, bem como, ocorrem fissuras prematuras no septo central e perda de integridade com menores intensidades de carregamento.

\footnotetext{
${ }^{5}$ SHRIVE, N. G., The failure mechanism of face-shell bedded (ungrouted and unreinforced) masonry subjected to compressive loading. The International Journal of Masonry Construction. Vol. 2, $\mathrm{N}^{\circ}$ 3, p. 115-128, 1982.
} 
Izquierdo (2011) realizou ensaios de compressão em prismas e pequenas paredes de alvenaria de blocos de concreto com ambos os argamassamentos. Obteve diferença média de resistência de $36 \%$ e $14 \%$ para prismas e pequenas paredes, respectivamente, feitas com argamassamento total e parcial. Quanto à ruptura, verificou a ocorrência de fissuras verticais ao longo dos septos transversais, sendo de forma mais acentuada para as situações com argamassamento parcial, semelhante ao apresentado por Shrive (1982).

Para situações em que forem realizados ensaios em prismas ou pequenas paredes para determinação da resistência da alvenaria, a ABNT NBR 15961-1:2011 recomenda o uso de argamassamento total e, para a determinação da resistência do elemento para argamassamento parcial, o uso de fator de correção de 0,80 .

\subsubsection{Fatores que afetam a resistência da alvenaria}

A alvenaria estrutural dispensa o uso de pilares e vigas, ficando a cargo, principalmente, dos blocos estruturais a função portante da estrutura. Quanto às lajes da edificação, estas podem ser executadas em concreto armado ou protendido e serem moldadas "in loco" ou préfabricadas.

Para a determinação da resistência de uma parede de alvenaria estrutural, segundo Camacho (2006) e Campos (2008), os principais fatores são:

- Resistência das unidades;

- Resistência da argamassa;

- Qualidade da mão-de-obra;

- Esbeltez do elemento.

O fator preponderante que determina a resistência da alvenaria é a resistência das unidades. Camacho (2006) comenta que alvenarias constituídas de blocos apresentam maior eficiência que aquelas constituídas por tijolos. Desta forma, os blocos necessitam de menores resistências que os tijolos para a obtenção de uma mesma resistência da alvenaria.

Camacho (2006) também comenta que para resistências das unidades mais baixas a influência da argamassa é menor em relação à resistência final da alvenaria. Porém, conforme aumenta-se a resistência das unidades, a variação do traço da argamassa exerce maior influência na resistência final do conjunto. 
Em Bastos (2013) se comenta que a resistência das argamassas na alvenaria passa a ser relevante quando atinge valores menores que 30 a $40 \%$ da resistência da unidade, onde assume maior influência na estrutura. A Figura 2.6 exemplifica tal situação.

Figura 2.6 - Influência da resistência da argamassa sobre a resistência da parede à compressão

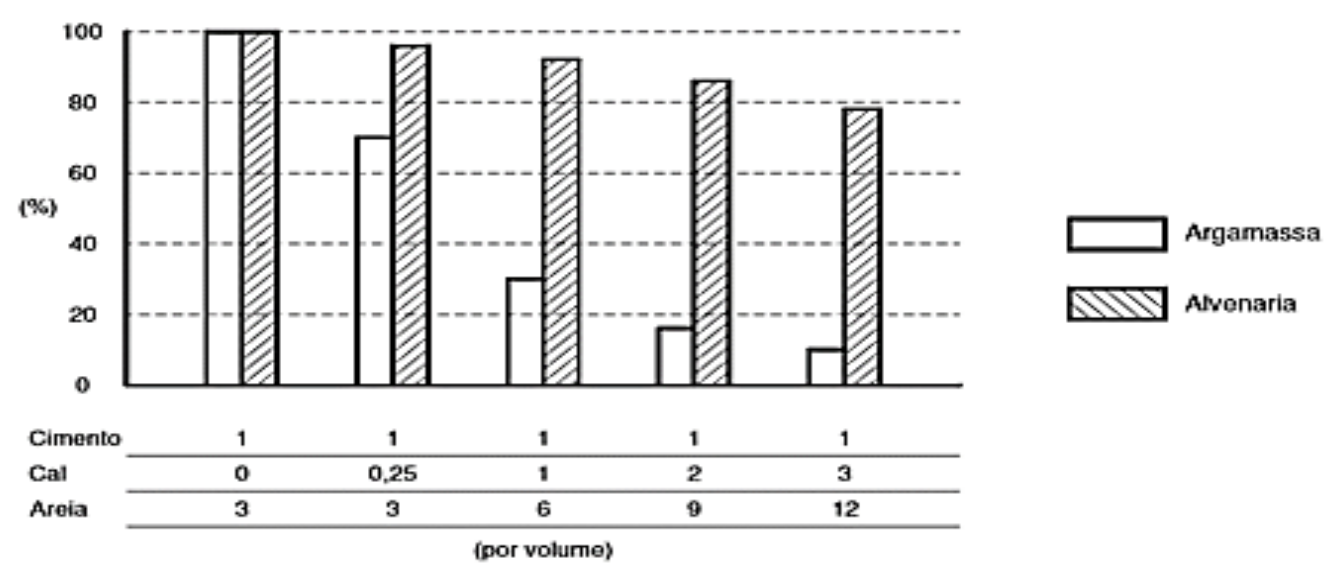

Fonte: Curtin $^{6}$ et al. (1982) apud Bastos (2013)

É importante ressaltar que a resistência à compressão do corpo-de-prova da argamassa não é a mesma desenvolvida na junta, devido às diferentes condições que o material fica submetido. Isto significa que as propriedades mecânicas obtidas nos ensaios padronizados variam em relação às propriedades efetivas da junta. Dentre as causas estão a influência do processo de absorção e ao efeito de confinamento exercido pelo bloco (TANGO, 1981).

De acordo com Camacho (2006), em relação à qualidade da mão-de-obra, os principais fatores que devem ser observados durante a execução da alvenaria são: controle do traço da argamassa, preenchimento das juntas e uniformidade de espessuras, controle e verificação de alinhamento e prumo e cuidados de assentamento, buscando evitar condições que possam perturbar a aderência entre as unidades e a argamassa. Individualmente, estes fatores podem representar uma redução de até $25 \%$ da resistência da alvenaria estrutural.

Bastos (2013) acrescenta que a resistência da parede tem decréscimo com o aumento da espessura das juntas, uma vez que há queda do confinamento da argamassa, tornando-a suscetível à ruptura. De acordo com o autor, a cada aumento de $3 \mathrm{~mm}$ na espessura da argamassa, pode ocorrer redução de até $15 \%$ da resistência da parede.

Conforme comentado, uma das principais características da alvenaria estrutural é a resistência à compressão. Além dela, pode ser também considerado o módulo de elasticidade

\footnotetext{
${ }^{6}$ CURTIN, W. G.; SHAW, G.; BECK, J. K.; BRAY, W. A. Structural masonry designers' manual. Granada Publishing Limited, London, 1982, 498p.
} 
como primordial para um bom desempenho do sistema construtivo. Algumas normatizações e autores propuseram a estimativa destes valores baseando-se, inicialmente, na resistência à compressão dos blocos ou de prismas. Além disso, as variáveis que alteram a aderência da estrutura e a resistência ao cisalhamento são outros parâmetros de interesse para este sistema construtivo. Estes assuntos estão discutidos com maiores detalhamentos no Apêndice $\boldsymbol{C}$.

\subsubsection{Vantagens e desvantagens}

Alguns pontos relevantes da alvenaria estrutural frente aos demais sistemas estruturais usuais devem ser citados, tais como: rapidez de execução, maior controle de qualidade, coordenação modular, diminuição de improvisações e desperdícios, redução da mão-de-obra (como no caso de armadores e carpinteiros), redução do uso de materiais (fôrmas de madeira, aço, concreto, revestimentos argamassados, etc.). Todos estes itens direcionam para maior racionalização do método construtivo, através de maior produtividade e redução de custos.

Em contrapartida, a alvenaria estrutural não apresenta flexibilidade quanto a adaptações no arranjo arquitetônico posteriores à execução, uma vez que as paredes são a própria estrutura. Além disso, há a necessidade de mão-de-obra mais qualificada para sua execução, o que torna indispensáveis treinamentos da equipe para uso adequado dos instrumentos de trabalho. Devido à modulação do sistema, também são necessárias as devidas compatibilizações dos diversos projetos envolvidos anteriores à execução.

De acordo com o exposto, para se obter um projeto eficiente e eficaz, a alvenaria estrutural não pode ser entendida simplesmente como um conjunto de paredes superpostas, as quais resistem ao seu peso próprio e a outras cargas adicionais, mas, compreendida como um processo construtivo racionalizado, projetado e planejado de acordo com uma coordenação entre os diversos projetos existentes, executado e calculado conforme sua modulação e em conformidade com as normas pertinentes, visando funcionalidade com segurança e economia.

\subsection{ALVENARIA ESTRUTURAL EM SITUAÇÃO DE INCÊNDIO}

O comportamento da alvenaria estrutural quanto à resistência ao fogo depende, logicamente, do comportamento resistente de cada componente, tanto de forma isolada quanto em conjunto. Para tanto é de grande relevância o conhecimento das propriedades dos materiais envolvidos no sistema construtivo sob a variação da temperatura. Além disso, faz-se relevante 
conhecer o comportamento do sistema com variações de carregamentos sob elevadas temperaturas.

Neste sentido, Leite (2018) comenta sobre a escassez de conhecimento, em âmbito nacional, das propriedades térmicas e mecânicas, sob elevadas temperaturas, dos materiais componentes da alvenaria estrutural. Comenta também sobre a insignificância numérica de resultados nacionais de paredes avaliadas sob carga em situação de incêndio.

Neste item são apresentados os principais fatores que influenciam o comportamento da alvenaria sob elevadas temperaturas e uma revisão sobre trabalhos numéricos e experimentais em alvenaria estrutural considerando a elevação de temperaturas. Ainda, no Apêndice $\boldsymbol{D}$ estão inseridas algumas equações para obtenção das propriedades térmicas e mecânicas do concreto sob elevadas temperaturas, além de comentários para blocos de concreto e argamassa.

\subsubsection{Fatores que influenciam o desempenho da alvenaria em elevadas temperaturas}

Adreini et al. (2014) comenta que diversos são os parâmetros que podem interferir no comportamento da alvenaria em situação de incêndio. Dentre eles, cita a forma, a geometria, a textura dos blocos, a espessura das juntas de argamassa, o teor de umidade dos componentes, as dimensões e restrições impostas e a forma de exposição ao fogo.

Bonitese (2007) comenta que além das propriedades térmicas e mecânicas, a composição química dos materiais também possui grande interferência no comportamento do elemento estrutural quando submetido às variações de temperatura. Isso porque grande parte dos materiais utilizados na construção civil têm suas propriedades físico-químicas alteradas durante o aquecimento do material.

Rosemann (2011) cita também as mudanças que ocorrem nos mecanismos de transferência de calor na ocasião de incêndio em apenas uma das faces do elemento estrutural. A mudança de umidade presente nos materiais faz com que ocorra o transporte de massa através do meio poroso, acarretando variação ao longo da espessura para a transferência de calor.

As mudanças citadas nas referências anteriores, considerando a exposição ao fogo, se referem à microestrutura do material e à alteração de suas propriedades, no caso, a condutividade térmica, o módulo de elasticidade e o calor específico. Para os elementos da alvenaria estrutural, propriamente ditos, existem poucas pesquisas realizadas em âmbito nacional considerando a variação de temperatura. Assim sendo, faz-se necessário o conhecimento do desempenho dos materiais constituintes da alvenaria mediante a ação do fogo para que seja possível prever o comportamento da alvenaria como um todo. 


\subsubsection{Material do bloco}

Os materiais utilizados na fabricação dos blocos apresentam grande influência para o comportamento do compósito frente à variação térmica, uma vez que estes materiais determinam propriedades termofísicas, tais como a densidade, a porosidade e a resistência mecânica (MEYER, 2006).

Paredes construídas a partir de materiais com menor condutividade térmica possuem maior isolamento térmico. Da mesma forma, aquelas que são construídas com materiais de maior calor específico, apresentam maior isolamento térmico devido à necessidade de maior absorção de calor para a transferência de calor ao longo da espessura. A junção destas duas características, denominadas conjuntamente de difusidade térmica, aumenta a eficiência da parede quanto ao critério de isolamento térmico.

Ensaios realizados por Thomaz e Helene (2000) e Chichierchio (1990) verificaram melhores resultados para paredes executadas com blocos cerâmicos em relação às executadas com blocos de concreto, levando em consideração o isolamento térmico e a estanqueidade. De forma análoga, para a resistência mecânica, ambos os autores verificaram tempos superiores para blocos cerâmicos que para os de concreto, em ensaios realizados para unidades com espessura de $14 \mathrm{~cm}$.

Ensaios realizados por Al-Hadhrami e Ahmad (2009) verificaram melhores desempenhos dos blocos cerâmicos quanto ao isolamento que de blocos de concreto, o que é coerente com os resultados citados. Al Nahhas et al. (2007) também comenta que a densidade e a porosidade são de alta relevância neste tipo de análise, principalmente devido ao fato de a umidade existente no interior dos poros consumir parte do calor que atravessa a espessura da parede, ocasionando a sua evaporação.

\subsubsection{Geometria do bloco}

Nguyen et al. (2009) indica que as características geométricas do bloco, tais como o tipo de bloco (vazado ou maciço), as dimensões externas, o percentual e o formato dos vazados apresentam alto grau de influência na resistência ao fogo. Blocos com maiores espessuras apresentam maiores resistências quanto ao isolamento térmico, uma vez que existe maior espaço a ser percorrido na transferência de calor por condução. Com a existência dos vazados dos blocos, ocorre alteração dos mecanismos de transferência de calor ocorrendo também a convecção e a radiação nos septos vazados. Esta circunstância resulta em redução da condutividade térmica efetiva e do calor absorvido pela parede. 
A variação do formato e da distribuição dos vazados internos também exercem influência no isolamento térmico. Em ensaios realizados por Al-Hadhrami e Ahmad (2008), estes verificaram que blocos com dois vazados apresentam aumento significativo do isolamento térmico em relação a blocos com um único vazado, considerando ambos os casos, com dimensões idênticas dos blocos.

Quanto às dimensões externas dos blocos, estas determinam a quantidade de juntas de argamassa de assentamento necessárias, o que influencia diretamente o isolamento térmico devido às diferentes propriedades termofísicas dos materiais (ROSEMANN, 2011).

\subsubsection{Processo construtivo}

Dentre as disposições construtivas que podem influenciar a resistência ao fogo, podem ser citadas: tipo de argamassa especificada para o assentamento dos blocos, tipo e espessura das juntas, existência de preenchimento nos vazados dos blocos e existência de revestimento das paredes (MEYER, 2006).

Em relação ao tipo de argamassa, conforme já abordado para a composição dos blocos, as propriedades da argamassa, bem como as adições que podem ser inseridas na mistura podem provocar alterações de suas propriedades no que se refere à transferência de calor. $\mathrm{O}$ uso de materiais isolantes junto à argamassa, por exemplo, aumenta o isolamento (AL-HADHRAMI e AHMAD, 2009). Quanto ao tipo das juntas, sejam parciais ou totais, ocorre também variação dos mecanismos de transferência de calor.

A existência de enchimentos nos vazios dos blocos exerce grande influência quanto ao isolamento. O grauteamento, por exemplo, utilizado para melhorar as características mecânicas e estruturais das paredes, aumenta o isolamento térmico, pois a quantidade de calor absorvido pela parede aumenta em uma proporção maior que ocorre o aumento da condutividade térmica (OLIVEIRA, 1998). A melhoria do isolamento térmico pode ser feita também, a partir do enchimento dos vazados com areia e materiais de baixa massa específica.

Outra forma de obter aumento do isolamento térmico é o uso de revestimentos das faces das paredes. Com a camada de revestimento, há um aumento da espessura da parede, o que aumenta o tempo para que haja o aumento da temperatura na face oposta. Oliveira (1998) alerta sobre a limitação do tempo em que o revestimento na face exposta ao fogo mantém-se solidário, uma vez que o ganho quanto ao isolamento fica limitado à sua integridade junto à parede. Chichierchio (1990) ensaiou variações de paredes com e sem revestimentos. No caso, obteve 
resistência quanto ao isolamento de 90 minutos, na situação sem revestimento, e de 120 minutos, considerando revestimento de cimento e areia com $1,5 \mathrm{~cm}$ em ambas as faces.

\subsubsection{Estabilidade estrutural}

Meyer (2006) lista alguns fatores ligados à estabilidade estrutural das paredes que podem afetar a resistência durante um incêndio, sendo eles: degradação dos materiais em altas temperaturas, encurvamento devido à dilatação térmica, restrições, geometria da parede e presença de excentricidades. Em relação à degradação dos materiais, sabe-se que com o aumento da temperatura ocorre a perda da resistência mecânica dos blocos, o que faz com que se iniciem as fissuras podendo levar à ruptura. Além disso, a argamassa também perde resistência e pode ocasionar situação semelhante.

Em situações em que o incêndio acontece em apenas uma das faces da alvenaria, ocorre um encurvamento da parede. Isto, porque com a existência de um gradiente térmico, a dilatação é maior nas partes mais aquecidas, criando, assim, um arqueamento da parede na direção do fogo. Nadjai (2006) comenta que esta situação faz com que as cargas aplicadas tenham as suas excentricidades aumentadas, gerando momentos de $2^{\mathrm{a}}$ ordem e aumentando as solicitações sobre as paredes, conforme Figura 2.7.

Figura 2.7 - Arqueamento da parede em situação de incêndio

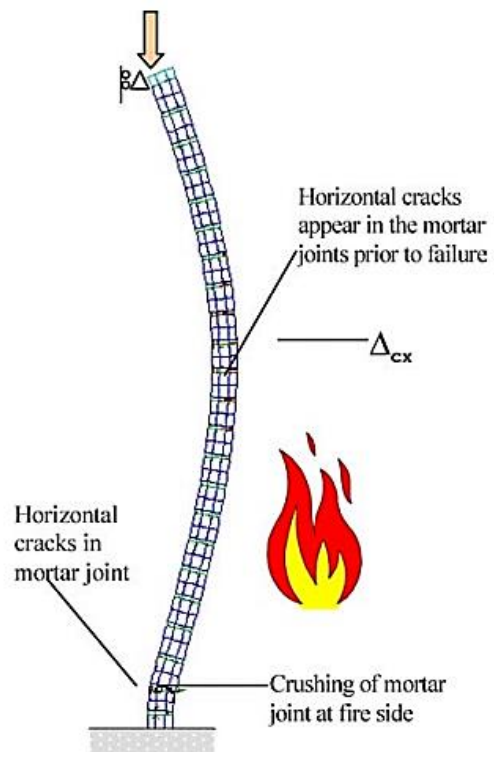

Fonte: Nadjai et al. (2006)

Para o encurvamento, as principais variáveis são o coeficiente de expansão térmica, a condutividade térmica do material e a existência de carregamentos verticais sobre o elemento estrutural. Em relação a esta última variável, sua ocorrência não inibe, mas reduz a deflexão. 
Desta forma o carregamento torna-se benéfico nos estágios iniciais, mas após um longo período de exposição ao fogo a parede tende a apresentar certa instabilidade lateralmente, gerando altas tensões em função do aparecimento de momentos induzidos pela deformação lateral. Quanto às vinculações e restrições, estas podem gerar esforços internos adicionais, uma vez que impedem deslocamentos ocorrentes devido à expansão do material com o aumento da temperatura.

A geometria da parede é importante para verificar a influência quanto à esbeltez da mesma. Rosemann (2011) comenta que uma medida que vem sendo adotada para aumentar a segurança contra o colapso em situação de incêndio se refere à redução da esbeltez da parede, pois há a redução dos efeitos de segunda ordem. Oliveira (1998) sugere que a esbeltez seja diminuída aumentando-se a espessura das paredes ou, também, prevendo-se suportes ou pilares ao longo dos bordos das paredes.

Nadjai et al. (2013) criou modelos para verificar a influência da variação da esbeltez da parede, do tipo de vinculação e da influência da excentricidade da carga aplicada. A constatação foi que com o aumento da esbeltez, menor era a temperatura de falha das paredes. Além disso, verificou que a consideração de carregamento excêntrico na face oposta ao incêndio gerou um aumento da deflexão e redução da temperatura de falha nas paredes do tipo A e B (Figura 2.8), enquanto que na parede de tipo $\mathrm{C}$ nenhuma modificação significativa sobre este parâmetro foi observada.

Figura 2.8 - Condição de contorno para vinculação de paredes

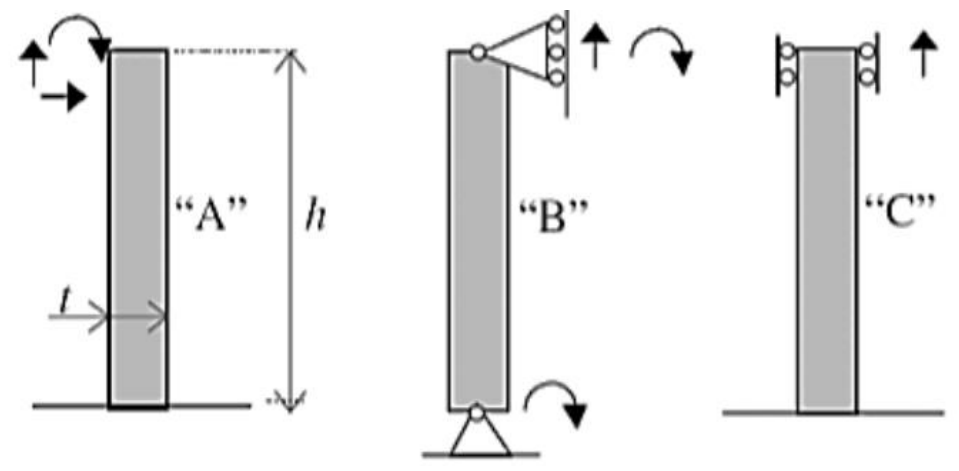

Fonte: Nadjai et al. (2003)

\subsubsection{Breve revisão sobre trabalhos em alvenaria e incêndio}

Nesta seção são apresentados trabalhos relevantes para a realização da presente pesquisa na área de alvenaria e de incêndio, tanto em contextos numéricos como experimentais. Além destes, trabalhos de relevância para a área de modelagem numérica de alvenaria em incêndio, 
não necessariamente sob as condições deste trabalho. Organizou-se a esta apresentação por trabalhos realizados à temperatura ambiente e posteriormente a elevadas temperaturas, em ordem cronológica.

Gomes (2001) estudou o comportamento elasto-plástico de paredes de alvenaria estrutural considerando a influência das interfaces no comportamento mecânico. Para tanto, baseou-se em resultados experimentas anteriormente obtidos por Mohamad ${ }^{7}$ (1998), Mendes ${ }^{8}$ (1998) e Romagna ${ }^{9}$ (2000) para criação de modelo numérico capaz de descrever o comportamento mecânico da parede, sendo o principal interesse, a zona de interface.

O autor utilizou o pacote computacional DIANA para a modelagem numérica. Para o elemento de interface, foi escolhido um elemento finito tridimensional com nove pontos de integração, enquanto para os blocos foi utilizado elemento finito tridimensional de 20 nós com formulação isoparamétrica. Quanto à formulação teórica, o modelo utilizado foi o DruckerPrager para os blocos de concreto visando a simulação da fissuração à tração e o comportamento à compressão, e para a interface foi usada a formulação teórica de Coulomb. Como resultados, o autor obteve boa proximidade com os valores experimentais, havendo maior discrepância a partir de determinado nível de deslocamentos, na zona plástica. Na Figura 2.9 são mostrados os gráficos comparativos para dois tipos de argamassas utilizadas nos blocos de concreto.

Figura 2.9 - Diagramas tensão-deformação comparativo para dois tipos de argamassa
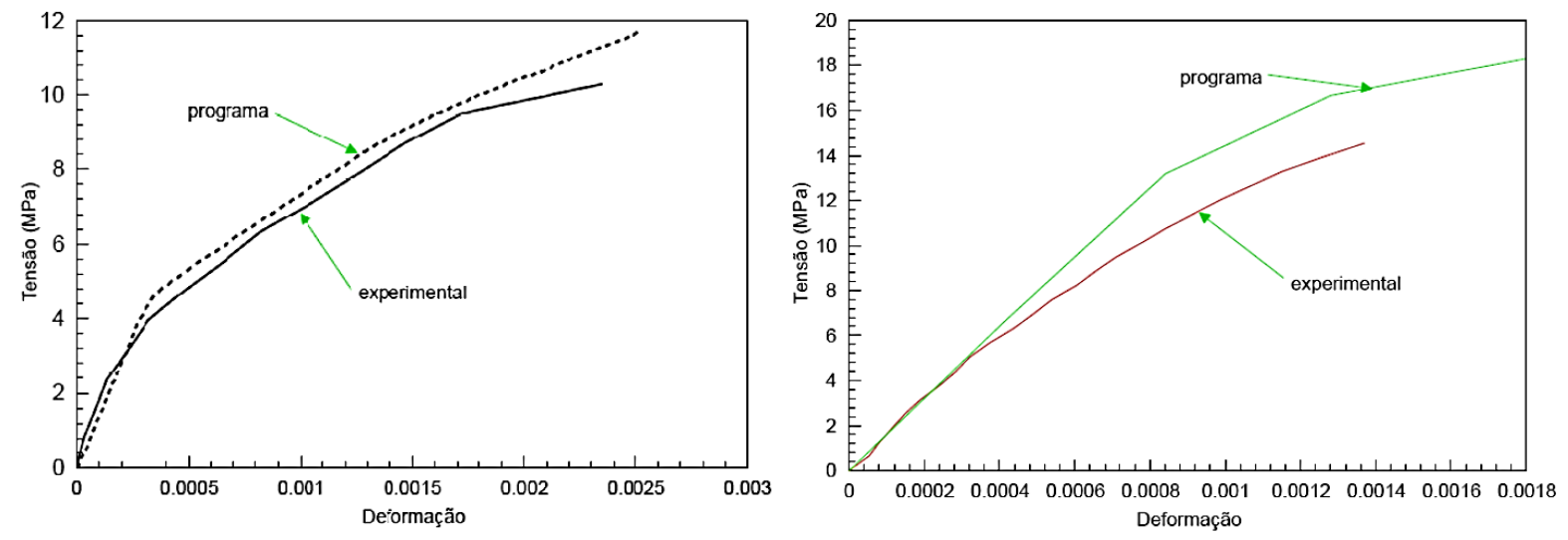

Fonte: Gomes (2001)

\footnotetext{
7 MOHAMAD, G. Comportamento na ruptura da alvenaria de blocos de concreto não-grauteado. Dissertação (Mestrado), Universidade Federal de Santa Catarina, Florianópolis, 1998.

${ }^{8}$ MENDES, R. J. K. Resistência à compressão de alvenarias de blocos cerâmicos estruturais. Dissertação (Mestrado), Universidade Federal de Santa Catarina, Florianópolis, 1998.

${ }^{9}$ ROMAGNA, R. H. Estudo da resistência de blocos de concreto. Dissertação (Mestrado), Universidade Federal de Santa Catarina, 2000.
} 
Oliveira (2014) e Izquierdo (2015) estudaram o comportamento entre as interfaces verticais da alvenaria estrutural à temperatura ambiente, sendo que, o primeiro trabalho teve ênfase no estudo de paredes interconectadas e o segundo, na interface entre bloco e graute. Em ambos os casos, foram realizados estudos experimentais e numéricos tanto para alvenaria com blocos de concreto quanto para blocos cerâmicos. Foram realizados ensaios mecânicos em blocos, prismas de dois e três blocos e pequenas paredes, com as mesmas dimensões abordadas na presente pesquisa.

Nestes estudos, diversos parâmetros relevantes para a modelagem inicial da presente pesquisa foram utilizados, os quais foram devidamente abordados e citados nos capítulos seguintes. Dentre as conclusões dos autores, verificou-se o aumento da resistência à compressão das pequenas paredes quando utilizado graute. Os resultados obtidos para as situações em que foram utilizados blocos de concreto tiveram resultados superiores de resistência em relação aos cerâmicos.

Figura 2.10 - Ensaio de resistência à compressão para prismas de três blocos e pequena parede, ambos com argamassamento parcial
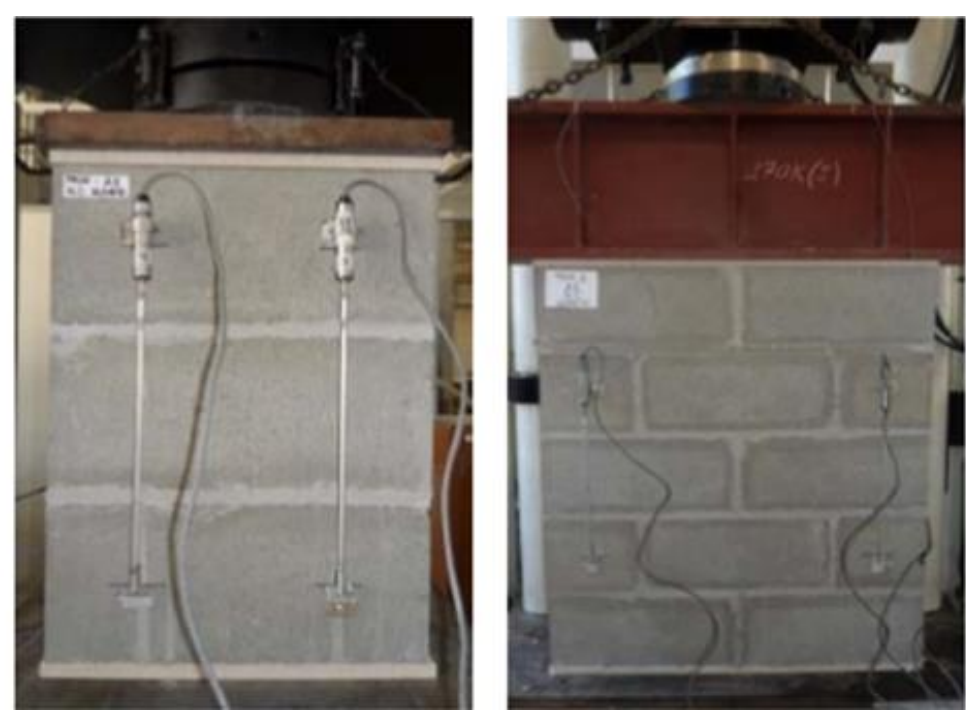

Fonte: Oliveira (2014)

Santos (2016) avaliou numericamente a interação entre paredes de alvenaria estrutural de blocos de concreto, sob ações verticais. Para tanto, realizou a modelagem numérica no ABAQUS a partir de resultados experimentais de Oliveira (2014) e Castro (2015). Utilizou como estratégia de modelagem para o prisma, a micromodelagem detalhada, onde cada material é representado por suas características mecânicas, enquanto para as paredes, utilizou da macromodelagem, associando as propriedades dos materiais. Como elementos de interface, 
considerou, no caso do prisma, normal e tangential entre bloco e argamassa, e cohesive e damage nas superfícies dos blocos onde ocorreriam as fissuras, de acordo com os resultados experimentais. Obteve resultados com divergência de 5\% para os prismas entre os resultados numéricos e experimentais, para os valores de resistência à compressão e módulo de deformação. Para as paredes, a maior diferença foi em torno de $10 \%$ em relação aos resultados experimentais, considerando os resultados de carga de ruptura, carga de fissuração e módulo de deformação.

Figura 2.11 - Tensões principais mínimas obtidas numericamente para o prisma e para a parede
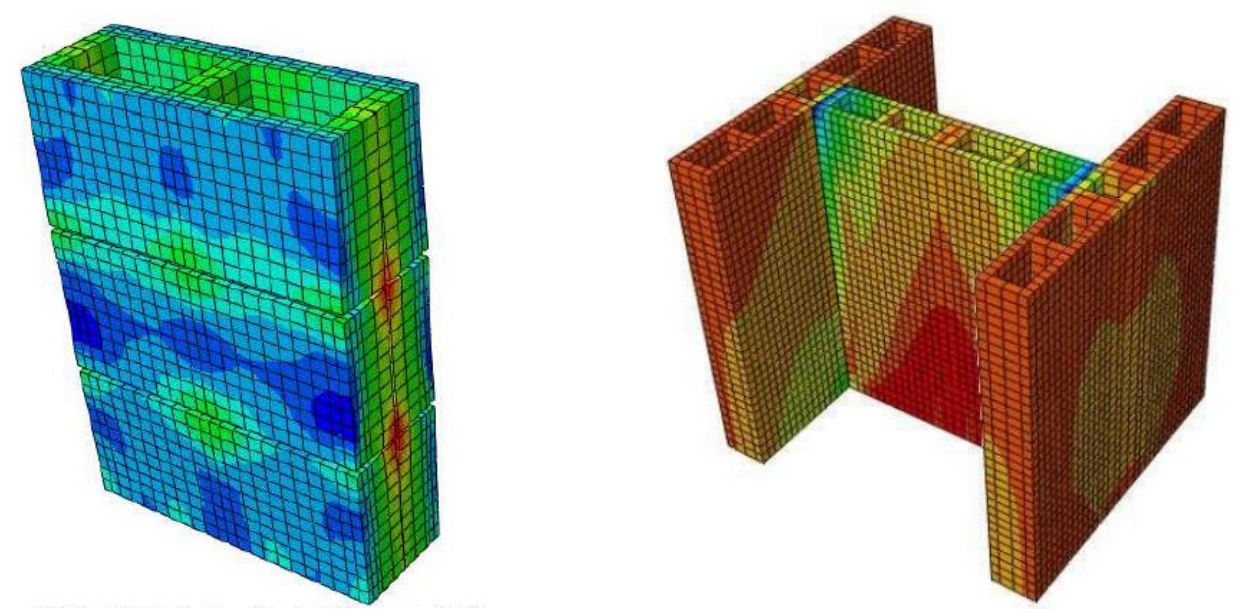

Fonte: Santos (2016)

Nadjai et al. (2003) analisaram numericamente o comportamento da alvenaria estrutural de blocos de concreto carregadas em situação de incêndio, comparando os resultados obtidos com os estudos experimentais realizados por outros autores. As dimensões das paredes em meia escala eram de $0,43 \times 1,33 \times 0,05 \mathrm{~m}$ (largura $\mathrm{x}$ altura $\mathrm{x}$ espessura). $\mathrm{O}$ software utilizado foi o MasSET (Masonry Subject to Elevated Temperatures) baseado no método dos elementos finitos.

$\mathrm{O}$ aquecimento das paredes foi realizado em uma única face, com taxa de aquecimento de acordo com a norma australiana. As condições de contorno consideradas foram com restrição rotacional e lateral nas extremidades e bordas verticais das paredes, livres. O fator de redução das tensões máximas em função da temperatura utilizado por Nadjai et al. (2003) é mostrado na Figura 2.12, baseado nos trabalhos de Abrams ${ }^{10}$ (1971) e Thelanderson ${ }^{11}$ (1972).

\footnotetext{
${ }^{10}$ ABRAMS, M.S. Compression Strength of Concrete at Temperatures to $1600 \mathrm{~F}$. Effect of Temperature on Concrete. Portland Cement Association Research and Development (SP 25-2). 1971; 33-58.

${ }^{11}$ THELANDERSSON, S. Effect of High Temperature on Tensile Strength of Concrete. Nordisk Betong, 1972.
} 
Figura 2.12 - Fator de redução das tensões de ruptura na compressão e na tração de acordo com a temperatura

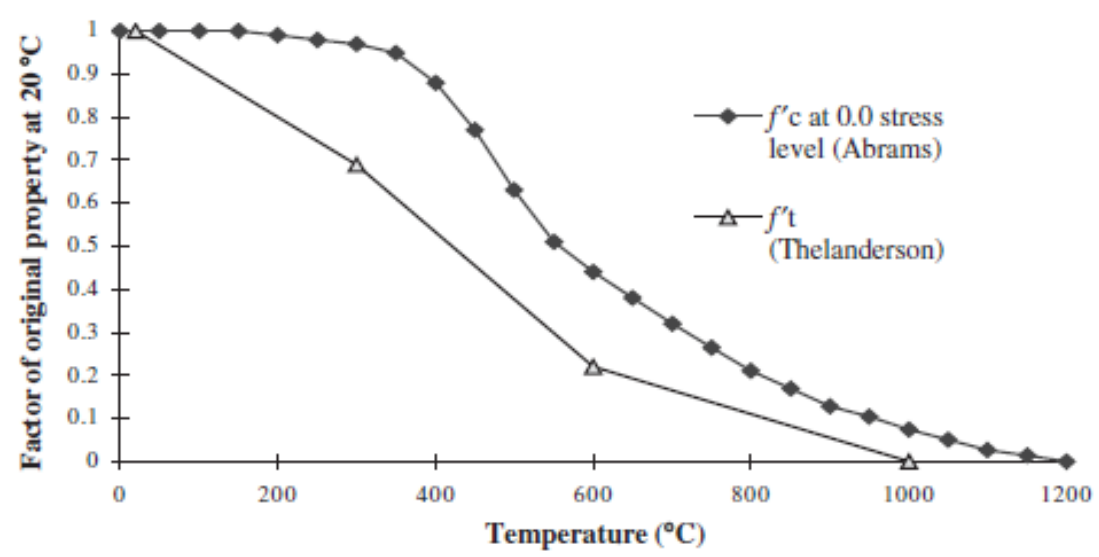

Fonte: Nadjai et al. (2003)

Dois testes foram realizados no programa experimental, sendo o primeiro para $50 \%$ e o segundo para $100 \%$ da carga última de projeto. Para o primeiro teste, o colapso estrutural ocorreu com 28 minutos, com curvatura da parede em direção ao fogo, conforme indicado na Figura 2.7 e mostrado novamente na Figura 2.13.

Figura 2.13 - Modo de falha para o primeiro teste experimental

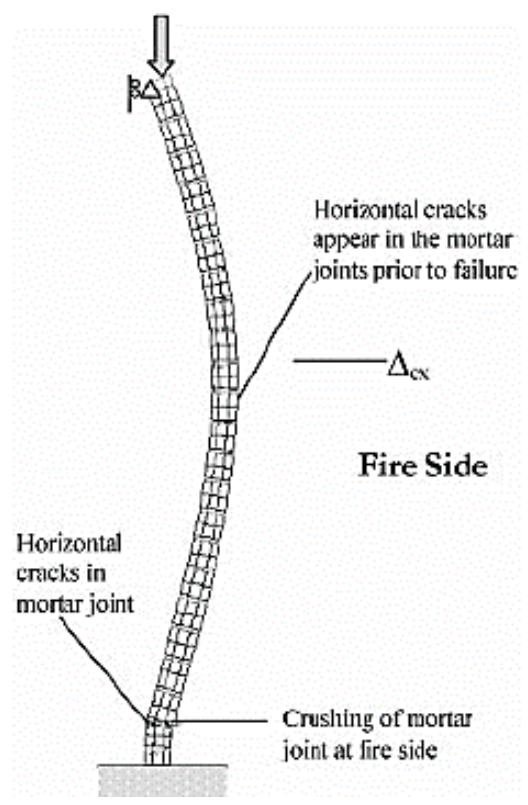

Fonte: Nadjai et al. (2003)

O modo de falha para o primeiro teste foi provocado, de acordo com os autores, devido à instabilidade. Neste caso, as deflexões criaram tensões de tração na face exposta a qual produziu fissuras horizontais nas juntas de argamassa, seguidas pelo colapso estrutural. Ainda, os autores comentam que foi observado ao longo da análise o esmagamento da argamassa 
próximo à base da parede, o que aliviou a consideração sobre a restrição rotacional inferior, possibilitando o início de grandes deslocamentos. Os resultados deste teste podem ser vistos na Figura 2.14 (a). Para o segundo teste, a parede teve seu colapso aos 60,5 minutos, porém, com curvatura contrária ao fogo neste instante. Neste comportamento, entretanto, o modelo numérico não foi capaz de realizar a simulação, conforme Figura 2.14 (b).

Figura 2.14 - Comparação entre os resultados experimentais e numéricos para a deflexão lateral em função da temperatura para os testes 1 (a) e 2 (b)

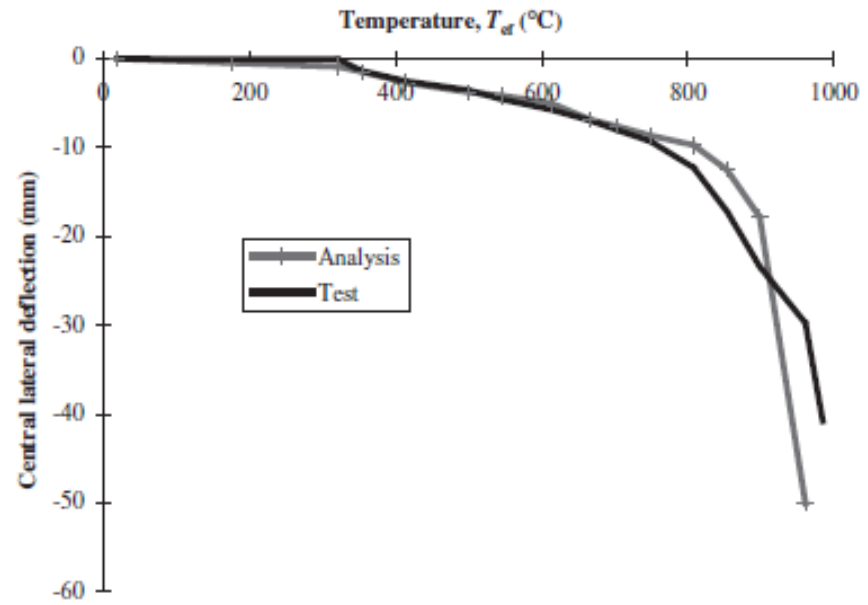

(a)

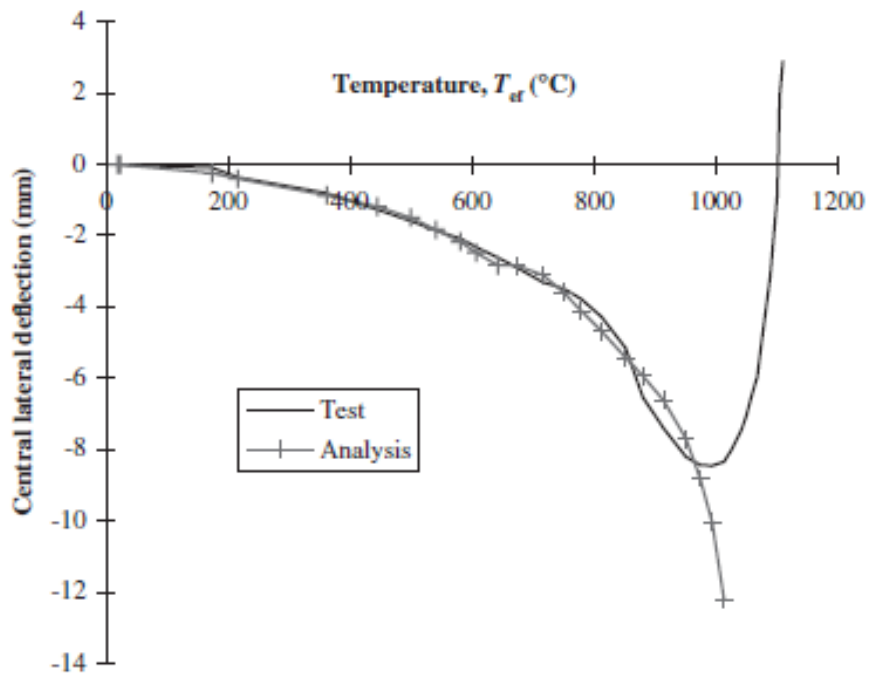

(b)

Fonte: Nadjai et al. (2003)

Inicialmente, como esperado, a curvatura ocorreu na direção do fogo, porém, aos 992 ${ }^{\circ} \mathrm{C}$, houve a inversão da mesma. Os autores comentam que este fenômeno ocorre quando a degradação térmica das propriedades do material passa a ser dominante, gerando, assim, uma carga efetivamente excêntrica para o lado do fogo onde o material está enfraquecido. Em relação ao primeiro teste, a magnitude da carga aplicada era significativamente mais alta, 
impossibilitando a ocorrência de grandes deformações térmicas o que promoveria a nãolinearidade geométrica.

Nadjai et al. (2006) estudaram o comportamento de paredes de compartimentação em situação de incêndio. A princípio, utilizando o software MasSET, buscaram validar um modelo numérico para posteriormente simular o comportamento de paredes de canto e centrais em edifícios com lajes de concreto armado com variação da incidência do incêndio em cada pavimento. O modelo considerou as não-linearidades geométrica e material, a fissuração e o esmagamento a partir do critério de falha tensão-deformação para alvenaria em elevadas temperaturas. A taxa de elevação de temperatura foi baseada na norma britânica BS 476:1997.

Quanto à incidência do incêndio, os autores consideraram a exposição em apenas um dos lados da parede, possibilitando, então, a curvatura devido à expansão térmica diferencial. Além disso, alguns outros fatores podem levar ao colapso estrutural da parede, tais quais: a degradação das propriedades dos materiais iniciada no lado exposto, as condições de vinculação, a magnitude da carga e a geometria da parede.

O modelo validado inicialmente baseou-se no ensaio de Gnanakrishnan ${ }^{12}$ (1989, apud Nadjai et al., 2006), o qual utilizou parede de alvenaria de blocos cerâmicos com dimensões 300 x 300 x 9 cm (largura x altura x espessura). As vinculações do ensaio eram de restrições de deslocamento e rotação no topo e na base, estando as laterais livres para os efeitos de expansão térmica. Os resultados numéricos obtidos para validação do modelo estão mostrados na Figura 2.15 .

Figura 2.15 - Deslocamento lateral em função da temperatura de acordo com os efeitos de restrição rotacional

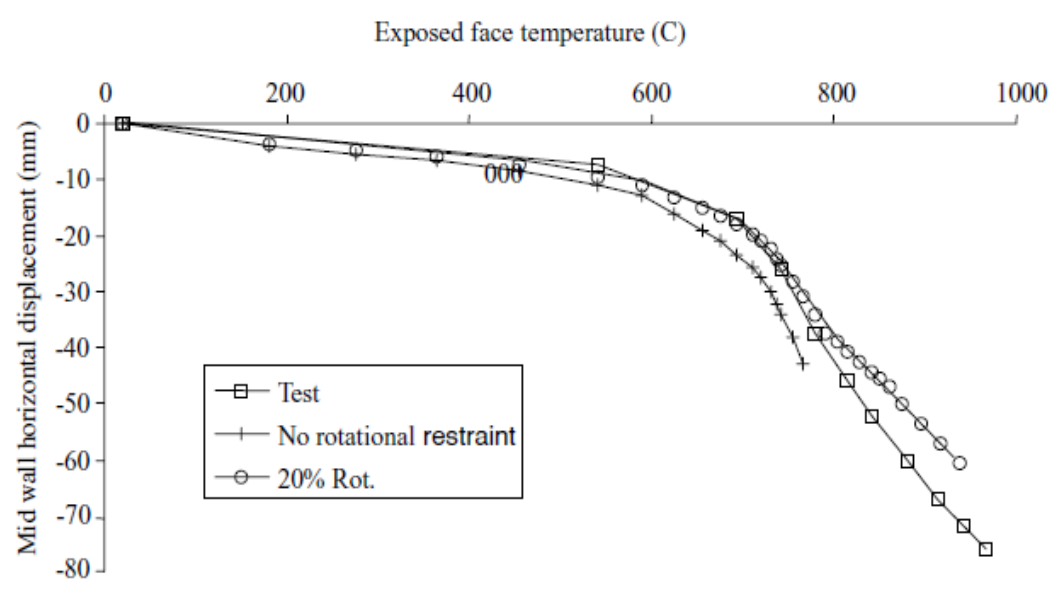

Fonte: Nadjai et al. (2006)

\footnotetext{
${ }^{12}$ GNANAKRISHNAN, N. The Effect of end Restraint on the Stability of Masonry Walls Exposed to Fire. National Building Technology Centre, Technical Records No. 531. 1989.
} 
Com o modelo validado, os autores realizaram simulações de incêndio em paredes de canto e centrais de um edifício, conforme visto na Figura 2.16 (a) e (b). Os autores consideraram que as superfícies das paredes estariam apenas encostadas, e não amarradas, e que os movimentos térmicos poderiam causar acomodação ou separação do contato nos apoios. Em ambos os casos, foram considerados os seguintes cenários: incêndio apenas no primeiro andar, incêndio apenas no segundo andar, e incêndio nos dois pavimentos.

Figura 2.16 - Subestruturas consideradas para a modelagem numérica com paredes centrais

(a) e de canto (b)

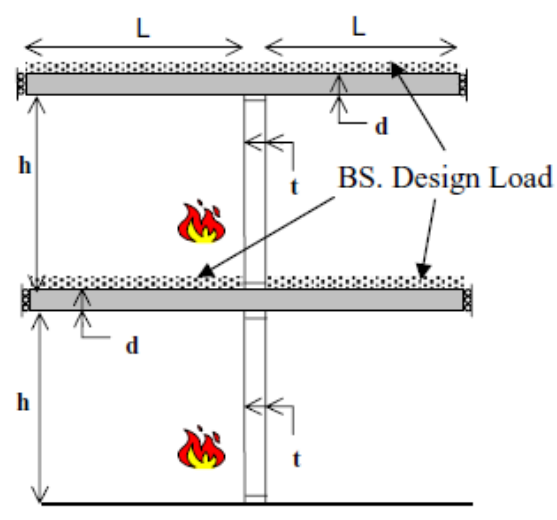

(a)

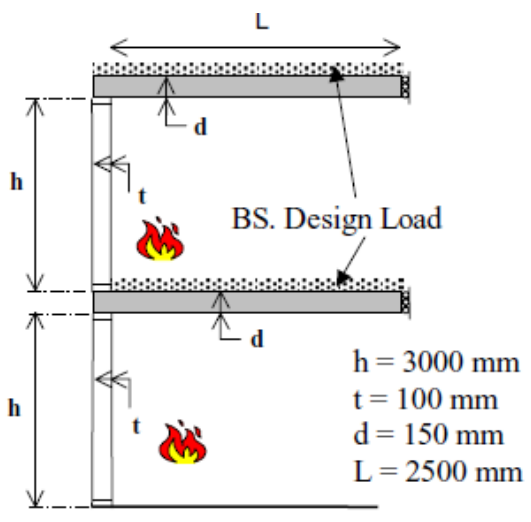

(b)

Fonte: Nadjai et al. (2006)

Como constatações do modelo, os autores verificaram que a curvatura devido ao gradiente térmico de uma parede não foi afetada pela ocorrência de incêndio em uma parede superior ou inferior. $\mathrm{O}$ deslocamento lateral em ambas as configurações foi maior para as paredes superiores do que para as paredes inferiores visto que o nível de tensão das paredes inferiores era maior (Figura 2.17 (a)). Para as situações em que o incêndio contemplava apenas um compartimento, os deslocamentos nas paredes de cômodo vizinho eram insignificantes (Figura 2.17 (b)).

Na subestrutura 1 (Figura 2.16 (a)), a situação mais crítica ocorreu quando simulado incêndio nos dois andares, sendo a falha deste sistema o esmagamento nos apoios da parede inferior. Por outro lado, a situação mais favorável ocorreu quando considerado incêndio apenas no pavimento superior, sendo a falha ocorrente devido aos efeitos de segunda ordem (instabilidade). Na subestrutura 2 (Figura 2.16 (b)), não ocorreu falha por esmagamento, uma vez que a carga aplicada era inferior ao caso anterior. Todas as falhas ocorreram por instabilidade após a curvatura causada pelo gradiente térmico. A situação mais favorável ocorreu para a situação considerando apenas fogo no pavimento inferior. 
Figura 2.17 - Deformação anterior à falha para configuração com fogo em dois pavimentos (a), e com fogo apenas no segundo pavimento (b)

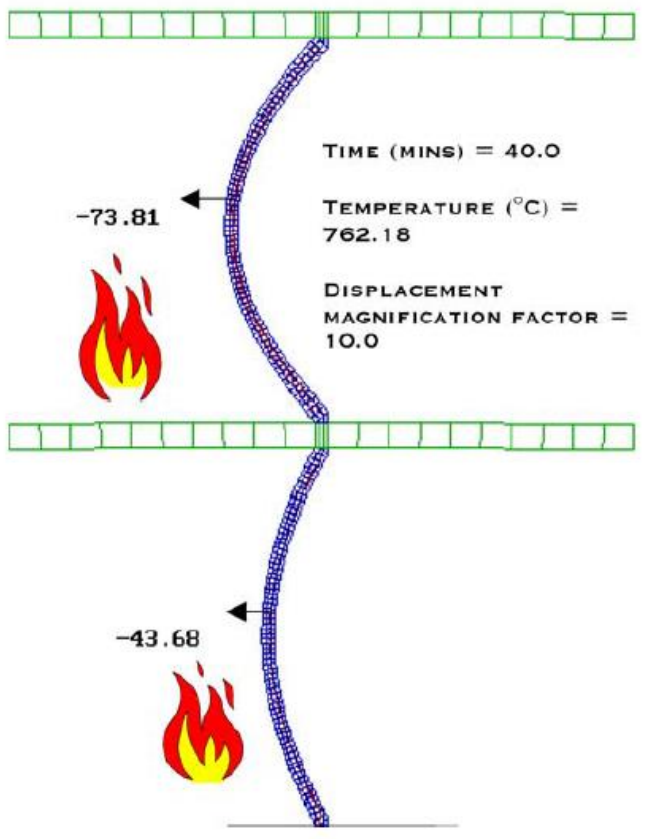

(a)

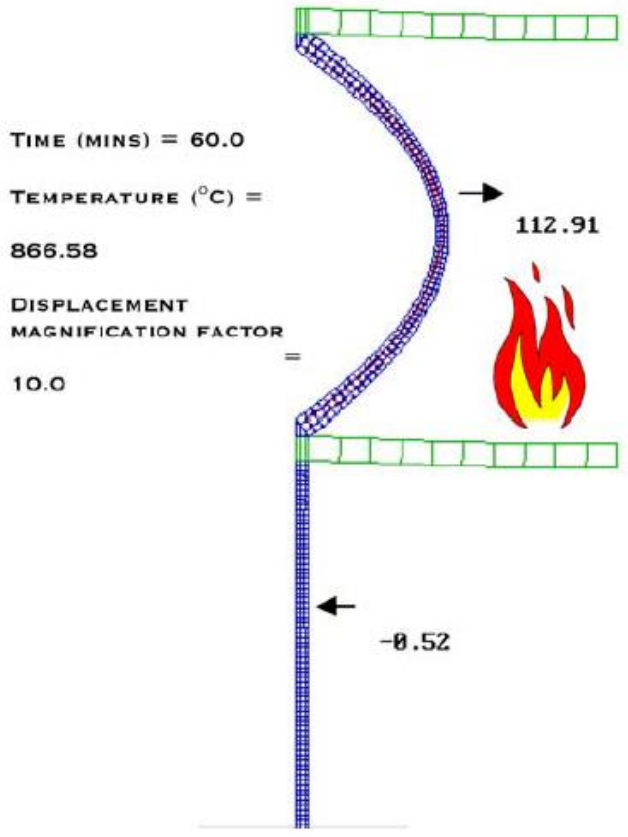

(b)

Fonte: Nadjai et al. (2006)

Os autores lembram que dificilmente são realizados ensaios em estruturas de dimensões maiores, principalmente devido às limitações físicas dos equipamentos existentes, no caso dos fornos, e também, aos altos custos envolvidos. Desta forma, citam a relevância das simulações numéricas para obtenção de solução para tais limitações

Al Nahhas et al. (2007) estudaram o comportamento de paredes de alvenaria estrutural com blocos de concreto celulares do ponto-de-vista teórico e experimental. Estas paredes foram submetidas à variação de temperatura e a carregamentos verticais aplicados durante o aquecimento, dentro do intervalo entre 20 e $1200{ }^{\circ} \mathrm{C}$, por um período de 6 horas, seguindo a curva-padrão proposta pela ISO 834-1:1999. Foram verificados e estudados os deslocamentos verticais e horizontais das paredes.

As dimensões das paredes executadas foram de 2,82 $\mathrm{m}$ de altura, 2,80 $\mathrm{m}$ de comprimento e 19,7 cm de espessura, tendo, as juntas de assentamento, a espessura de $12 \mathrm{~mm}$. A resistência nominal característica dos blocos foi de 4,0 $\mathrm{MPa}$. O carregamento da parede foi realizado através de equipamento servo-hidráulico, o qual fez a transferência do carregamento para uma viga para este fosse uniformemente dividido ao longo da parede, conforme visto na Figura 2.18 (a). A carga vertical aplicada foi de $357 \mathrm{kN}$. 
Figura 2.18 - Aparato utilizado para inserção do carregamento na parede (a) e locação dos termopares ao longo da seção transversal da parede (b)

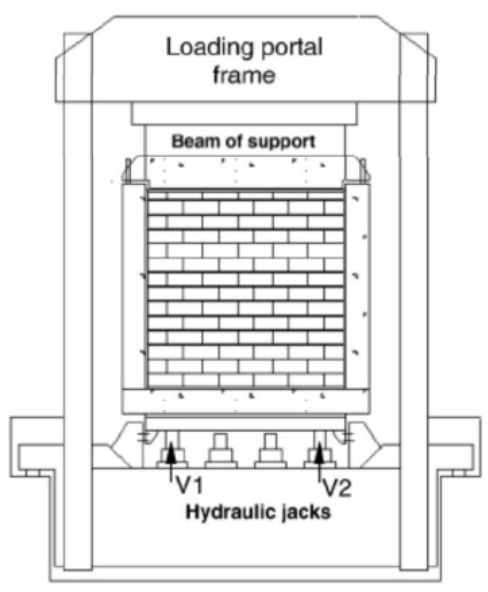

(a)
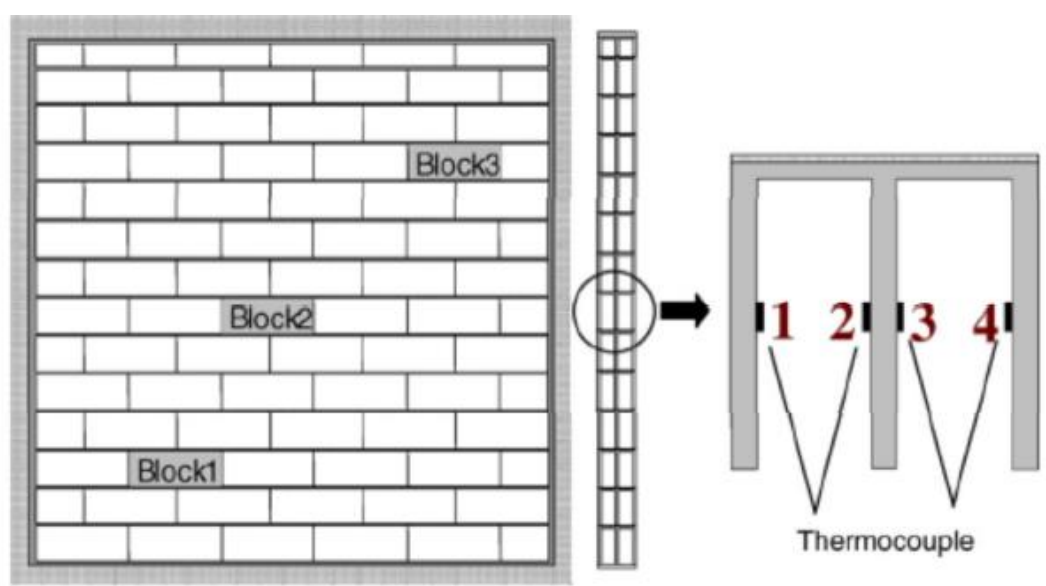

(b)

Fonte: Nahhas et al. (2007)

As medições de temperaturas foram realizadas em três diferentes blocos, sendo, em cada um, posicionados termopares nas quatro faces internas dos blocos celulares, sendo o ponto $1 \mathrm{o}$ mais próximo da face exposta ao fogo, os pontos 2 e 3 nas paredes do septo central e o ponto 4 o mais próximo da face não exposta conforme Figura 2.18 (b). Os resultados obtidos para a evolução de temperatura ao longo do tempo são mostrados na Figura 2.19.

Figura 2.19 - Evolução da temperatura dos pontos de medição do bloco em função o tempo

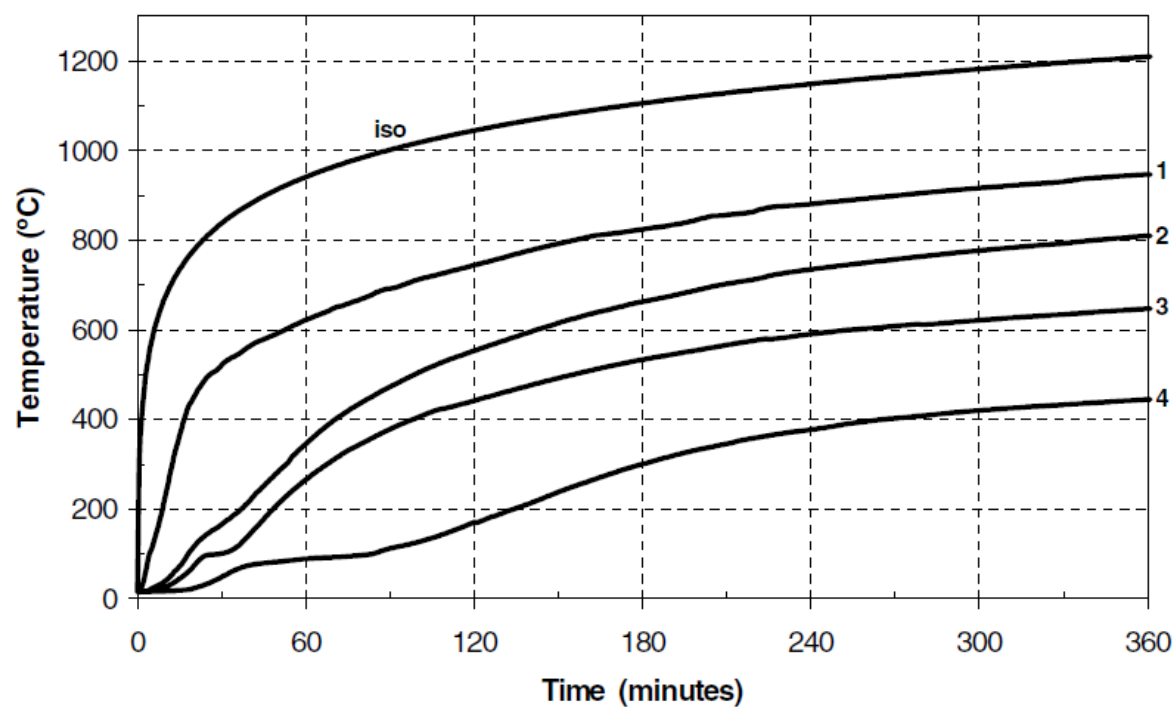

Fonte: Nahhas et al. (2007)

Observa-se que com temperaturas próximas a $100{ }^{\circ} \mathrm{C}$, as curvas de elevação de temperatura apresentam patamares para os pontos 2, 3 e 4 . Este tipo de situação foi explicado 
pelos autores pela ocorrência de mudança de fase da água livre nos poros do bloco, o que demanda a absorção de energia térmica para o processo de evaporação da mesma.

Os autores não desenvolveram um modelo termoestrutural, apenas térmico. Foi utilizado um modelo simplificado unidimensional, considerando os efeitos de convecção, radiação e condução. Também foi considerada a energia absorvida para evaporar a água intersticial no modelo, o qual foi baseado em diferenças finitas, sendo cada partição da parede dividida em três subpartições. Como conclusões, os valores máximos de deslocamentos horizontal e vertical obtidos foram de 45 e $25 \mathrm{~mm}$, respectivamente. Quanto aos modelos térmicos, estes tiveram boa concordância em relação aos resultados experimentais, em relação à distribuição de temperatura.

Poças (2008) realizou estudo experimental e numérico acerca do comportamento térmico e mecânico de paredes de alvenaria estrutural de bloco de concreto leve com 4 fiadas. A geometria do bloco, no entanto, não é a tradicional, apresentando diversos septos ao longo de sua seção transversal. O autor utilizou o pacote computacional ABAQUS, onde considerou o modelo elastoplástico com dano para os blocos para a modelagem numérica. $\mathrm{O}$ modelo térmico utilizado é validado pela EN 1745:2005. Neste trabalho, o autor verifica que a não consideração de movimento relativo entre a junta e o bloco não causa prejuízo quanto aos resultados obtidos, simplificando o modelo numérico.

Figura 2.20 - Distribuição das tensões principais e distribuição de temperatura
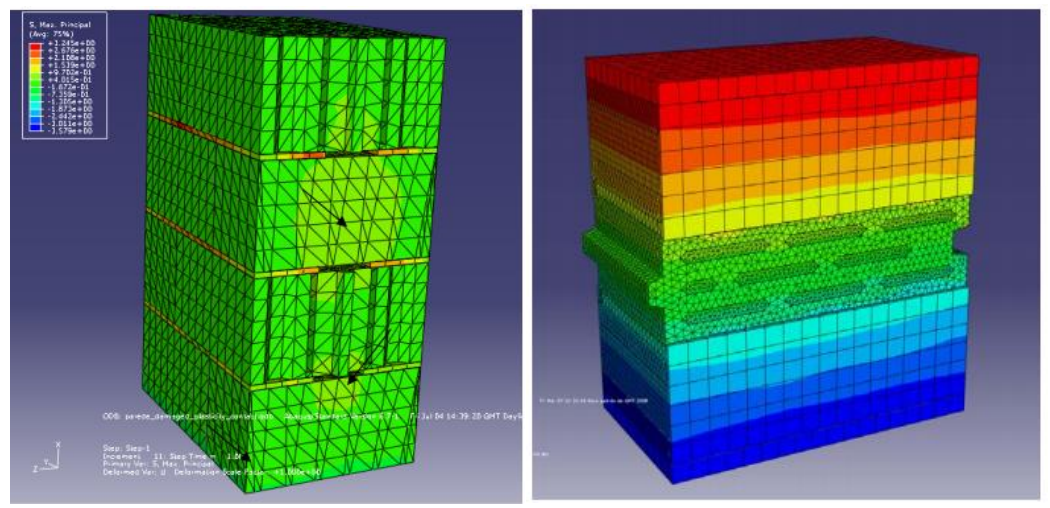

Fonte: Poças (2008)

Nguyen et al. (2009) estudaram através de experimentos e análises numéricas o comportamento termomecânico de paredes de blocos cerâmicos não carregadas. As dimensões das paredes eram de 3,0 × 3,0 x 0,1 m (largura x altura x espessura). Para as análises numéricas, utilizou-se o CAST3M, baseado no método dos elementos finitos. Inicialmente, realizaram análise térmica, onde consideraram transferências por condução, convecção e radiação, bem como, o consumo de energia pela água livre existente nos poros dos blocos. A validação do 
modelo numérico foi feita de acordo com os valores obtidos experimentalmente, considerando o incêndio em uma das faces da parede, de acordo com a ISO 834-1:1999. Os resultados obtidos para o comportamento térmico, experimental e numérico, são mostrados na Figura 2.21. Verifica-se, como já comentado em trabalhos anteriores, o patamar próximo aos $100{ }^{\circ} \mathrm{C}$, devido à evaporação da água livre.

Figura 2.21 - Locação dos termopares (a), distribuição de temperatura no bloco (b) e evolução da temperatura em função do tempo ao longo da espessura (c)
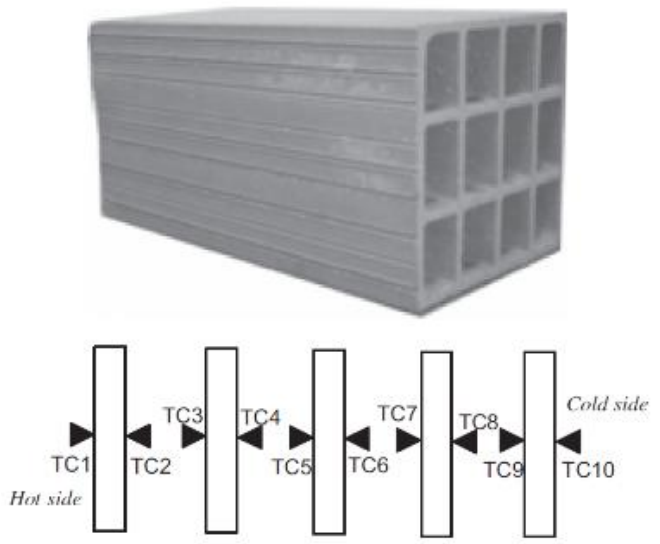

(a)

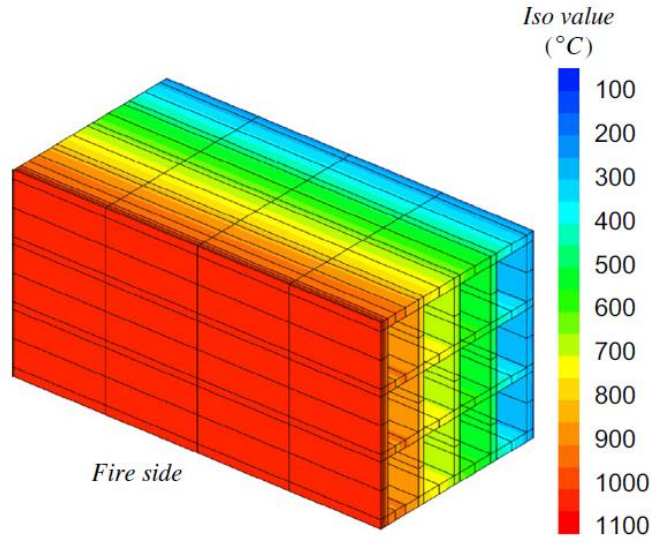

(b)

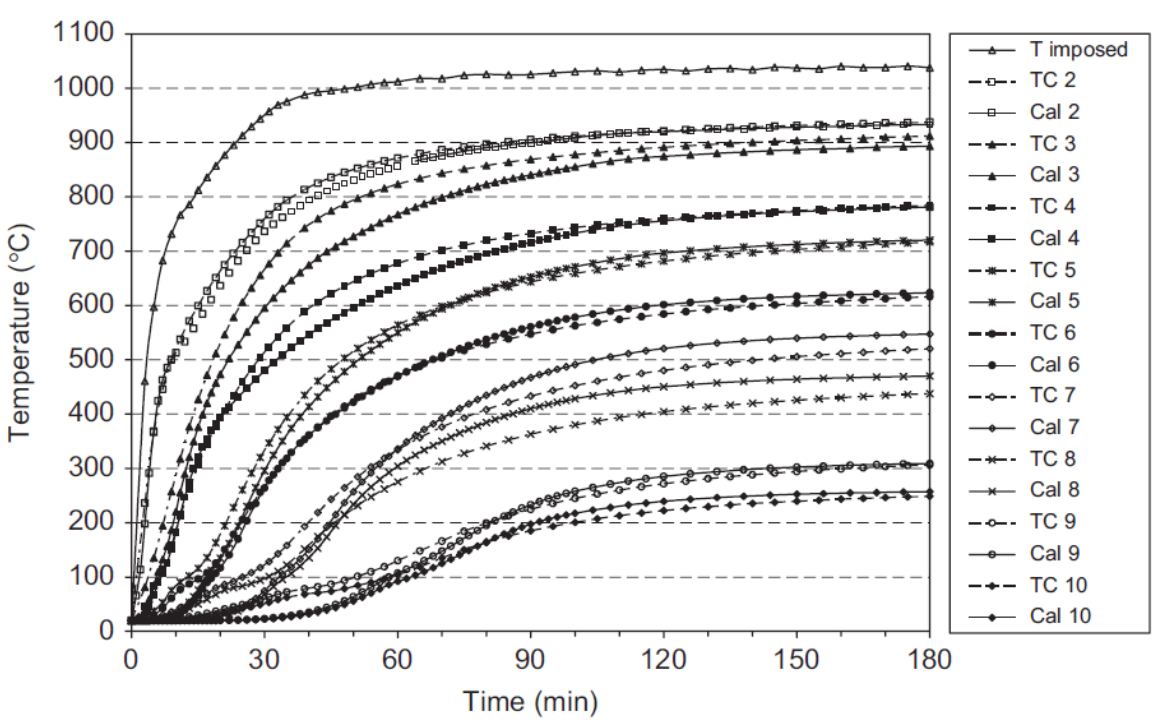

(c)

Fonte: Nguyen et al. (2009)

Para a modelagem termomecânica Nguyen et al. (2009) verificaram os resultados de deslocamentos laterais com os valores experimentais. Além disso, numericamente, fizeram algumas análises paramétricas com algumas variáveis, tais quais, o coeficiente de condutividade térmica, o módulo de elasticidade do bloco e o coeficiente de expansão térmica. 
Os autores concluíram que para uma boa representatividade desse tipo de parede em situação de incêndio a modelagem termoelástica apresentou-se suficiente e com resultados satisfatórios, pois seu comportamento é influenciado principalmente pelo decréscimo do módulo de elasticidade de acordo com a elevação de temperatura, se diferenciando do modo de ruptura de paredes carregadas.

Figura 2.22 - Deslocamento lateral em função do tempo com variação do coeficiente de expansão térmica (a) e do módulo de elasticidade do bloco (b)

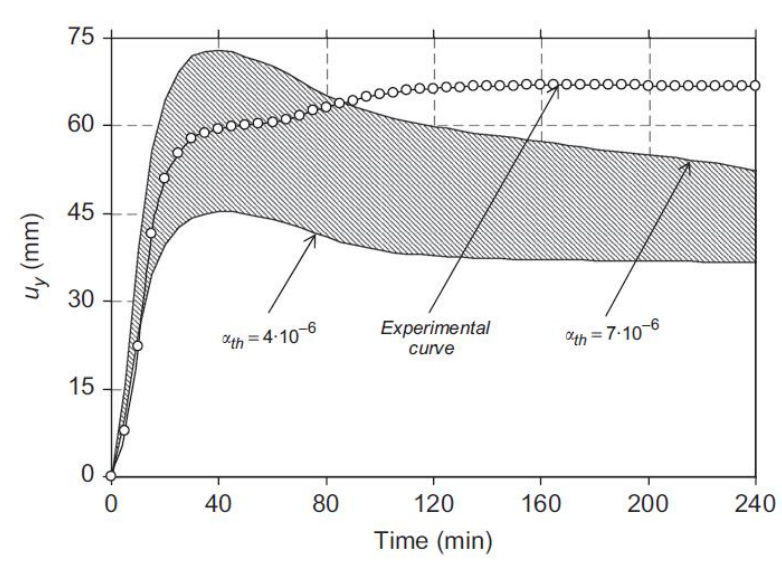

(a)

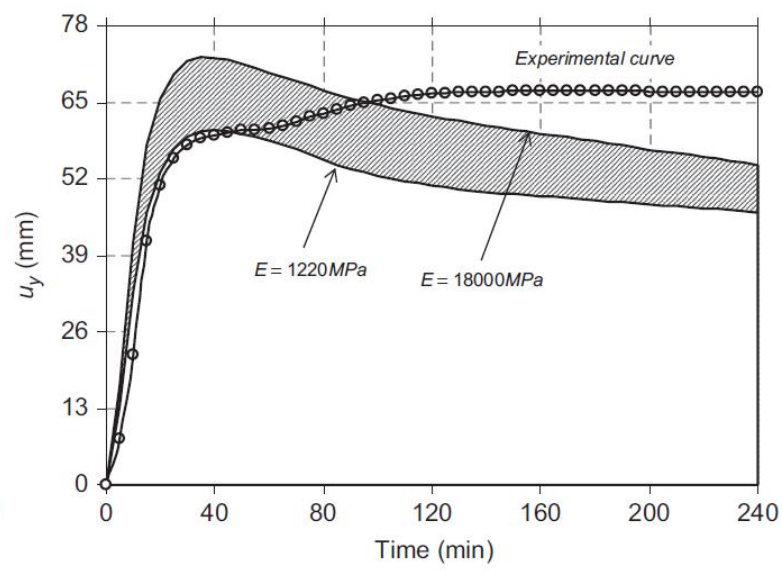

(b)

Fonte: Nguyen et al. (2009)

Ayala (2010) estudou o comportamento de tijolos de concreto, argamassa e pequenas paredes de tijolos de concreto leve em elevadas temperaturas, em contexto experimental e numérico. As dimensões das pequenas paredes ensaiadas eram de 68,5 x 67 x $10 \mathrm{~cm}$ (largura x altura $\mathrm{x}$ espessura).

Nos ensaios, as amostras foram aquecidas até as temperaturas de 200, 400, 600, 700 e $800^{\circ} \mathrm{C}$, com taxa de aquecimento de $10^{\circ} \mathrm{C} / \mathrm{min}$, sendo posteriormente submetidas à compressão após o equilíbrio térmico (quando os termopares registravam o mesmo valor), com incrementos de força de $10 \mathrm{kN} / \mathrm{min}$, até a ruptura.

O Eurocode 6:2005 descreve que a redução da resistência à compressão de concretos com agregados leves é menor nesta situação do que para agregados normais devido à combinação entre as propriedades térmicas destes agregados e da pasta de cimento.

Sobre o módulo de elasticidade, Ayala (2010) cita diversos estudos realizados para esta propriedade, como aqueles realizados por Schneider (1988). Este último autor ressalta a importância de diversos fatores para tal determinação, dentre os quais, cita: a proporção água/cimento, o tipo de agregado, o tipo de cimento, a proporção agregado/cimento, o nível de 
carregamento, a taxa de aquecimento, a taxa de evaporação, a idade do concreto, o tipo de cura e a selagem para se obter o módulo de elasticidade do concreto em elevadas temperaturas.

No modelo numérico, Ayala (2010) seguiu o programa experimental, através de micromodelagem simplificada, executado no ABAQUS. Utilizou elementos tridimensionais contínuos de 8 nós (C3D8) para os tijolos de concreto e, para a argamassa, utilizou molas, conectadas entre os nós dos blocos. O autor explica que esta estratégia foi usada para evitar problemas relacionados à interação entre os materiais.

Figura 2.23 - Modelo do tijolo (a) e elementos de mola utilizados para a argamassa (b)

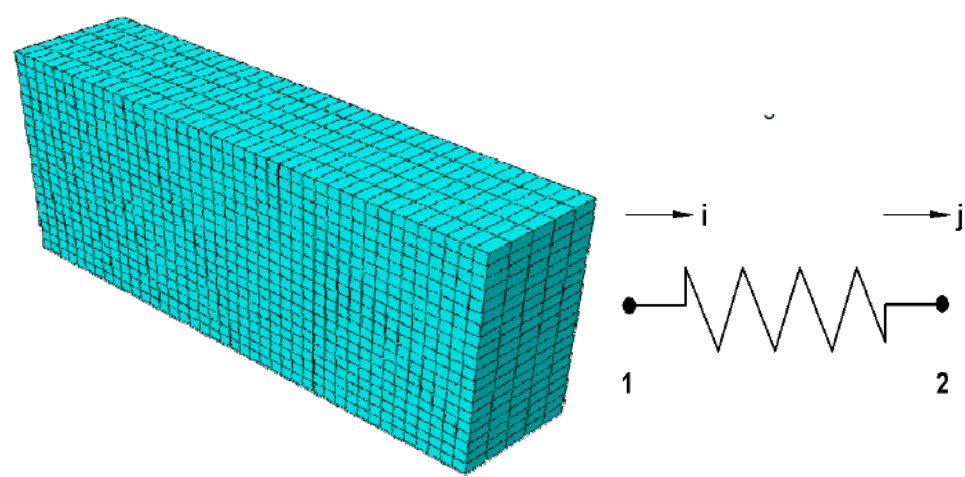

(a)

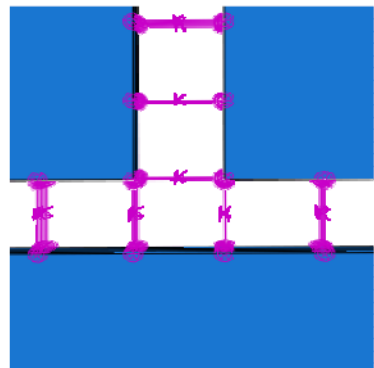

(b)

Fonte: Ayala (2010)

Quanto aos resultados obtidos, verificou redução das resistências à compressão das paredes com o aumento de temperatura conforme indicado na Tabela 2.1.

Tabela 2.1 - Redução da resistência à compressão das pequenas paredes em relação à temperatura ambiente em função da temperatura

\begin{tabular}{|c|c|c|}
\hline Temperatura $\left({ }^{\circ} \mathbf{C}\right)$ & $\begin{array}{c}\text { Redução da resistência à } \\
\text { compressão }(\boldsymbol{\%})\end{array}$ & $\begin{array}{c}\text { Redução do módulo de } \\
\text { elasticidade (\%) }\end{array}$ \\
\hline $\mathbf{4 0 0}$ & 9 & 40 \\
\hline $\mathbf{6 0 0}$ & 19 & 65 \\
\hline $\mathbf{7 0 0}$ & 60 & 89 \\
\hline $\mathbf{8 0 0}$ & 83 & 98 \\
\hline
\end{tabular}

Fonte: Adaptado de Ayala (2010)

Nos ensaios realizados nas paredes à temperatura ambiente, o colapso ocorreu por uma combinação de cisalhamento e fissuras horizontais largas. Para as temperaturas elevadas, a forma de colapso predominante foi com fissuras na diagonal. Foi observada a ocorrência de lascamento explosivo nas paredes aquecidas com temperaturas superiores a $400{ }^{\circ} \mathrm{C}$, sendo mais 
intenso com o aumento da temperatura. Quanto à expansão térmica, verificou-se um efeito mínimo nos espécimes ensaiados a $200{ }^{\circ} \mathrm{C}$ e com um efeito mais severo naqueles ensaiados a $700{ }^{\circ} \mathrm{C}$ e a $800{ }^{\circ} \mathrm{C}$.

Rosemann (2011) avaliou a resistência ao fogo de paredes de alvenaria estrutural de blocos cerâmicos por meio de métodos experimentais e numéricos quanto ao critério do isolamento térmico. Foram realizados ensaios em quatro diferentes configurações, sendo executado um exemplar para cada situação. As configurações baseavam-se no não preenchimento dos vazados dos blocos e no preenchimento com areia, sendo, para cada caso, executada parede com e sem revestimento (espessura de 1,5 cm). As paredes apresentaram dimensões de 2,70 × 2,60 × 0,14 m (largura x altura x espessura) e funcionavam no ensaio, como as próprias paredes do forno, conforme mostrado na Figura 2.24.

Figura 2.24 - Corpos-de-prova ensaiados sem preenchimento dos vazados (a), e com preenchimento dos vazados (b)

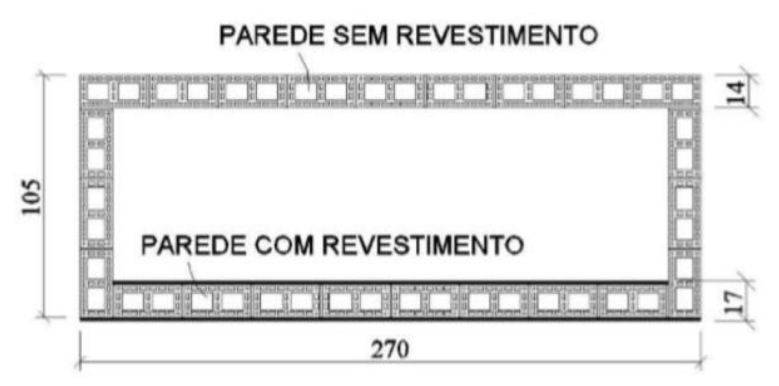

(a)

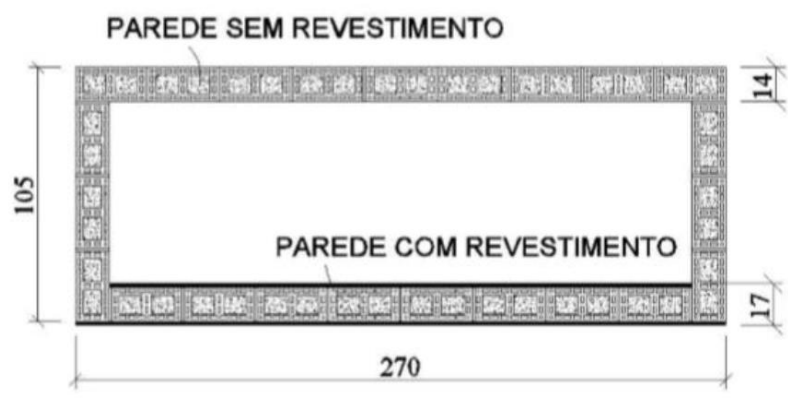

(b)

Fonte: Rosemann (2011)

O aumento de temperatura no forno seguiu a curva de incêndio-padrão da ISO 8341:1999. As paredes sem preenchimento apresentaram, no caso sem revestimento, resistência ao fogo durante 106 minutos, enquanto a parede com revestimentos suportou por 196 minutos. Já as amostras com preenchimento dos vazados com areia apresentaram, no caso sem revestimento resistência ao fogo por 243 minutos, enquanto a parede revestida suportou por 405 minutos. 
Em relação aos valores comparativos de resistência ao isolamento térmico, o uso do revestimento em ambos os lados da parede sem preenchimento nos vazados provocou um aumento de $85 \%$ em relação à parede sem revestimento. Esse comportamento foi semelhante para o caso com preenchimento dos vazados, apresentando aumento de $67 \%$ em relação à situação sem revestimento. Por outro lado, em ambos os casos, a parede com revestimento apresentou maiores fissuras e arqueamento devido às diferenças de dilatações térmicas nas faces.

Para a análise quanto ao preenchimento com areia nos vazios dos blocos, houve um acréscimo de $100 \%$ em relação às paredes não preenchidas, para ambas as situações quanto ao revestimento. Constatou-se, portanto, que o emprego de revestimentos nas faces e o preenchimento dos vazios com areia representam boas alternativas, a um custo relativamente baixo, para aumentar a resistência ao fogo de paredes de alvenaria cerâmica quanto ao critério de isolamento térmico.

Figura 2.25 - Parede com revestimento após o ensaio (destaque para localização da fissura)

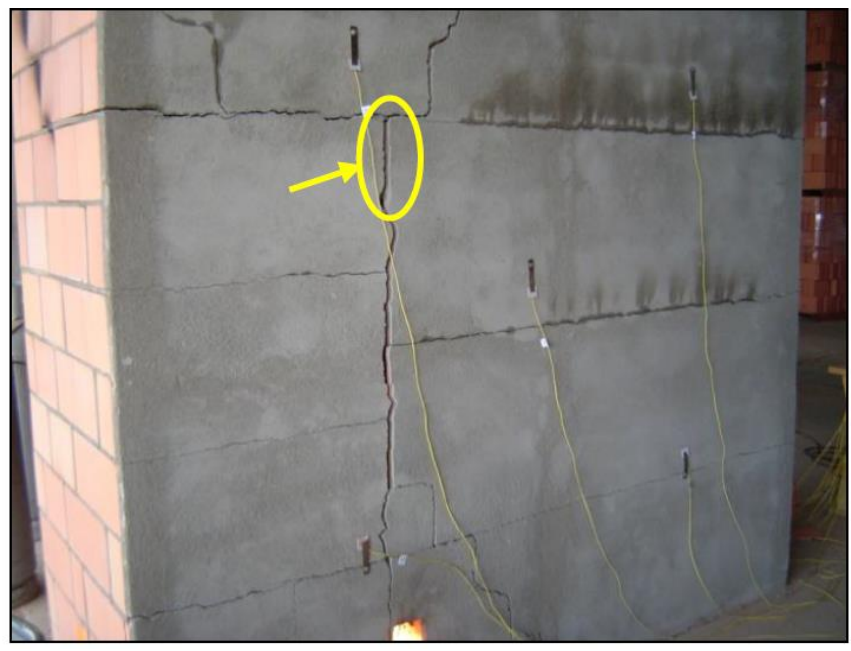

Fonte: Rosemann (2011)

Quanto às análises numéricas, foram utilizados dois métodos, um analítico e outro pelo método dos elementos finitos. Pelo analítico, utilizando o método de cálculo do Brick Industry Association (BIA), o qual baseia-se no cálculo de uma espessura equivalente para cada tipo de parede, foram obtidos valores, em média, $25 \%$ inferiores aos encontrados nos ensaios, cuja justificativa, segundo o autor, deve-se ao fato de os valores tabelados para os materiais possuírem características diferentes dos utilizados nos ensaios.

Pelo método dos elementos finitos, utilizando o programa computacional CAST3M, após calibração com os resultados experimentais, obteve-se erro máximo de 6,4\%. Os elementos escolhidos para a modelagem numérica foram bidimensionais. Para o aquecimento 
das paredes, foram considerados os mecanismos de radiação e convecção entre os gases do forno e as faces expostas das paredes e condução entre os materiais sólidos componentes da parede.

Na sequência, nas Figuras 2.26 e 2.27, são apresentadas as curvas comparativas entre resultados experimentais e numéricos via $\mathrm{MEF}$, obtidas para as configurações sem e com revestimento e preenchimento, sendo o valor constante a $140{ }^{\circ} \mathrm{C}$ representado o limite de isolamento térmico.

Figura 2.26 - Elevação de temperatura em função do tempo na face não exposta do bloco sem revestimento e sem preenchimento

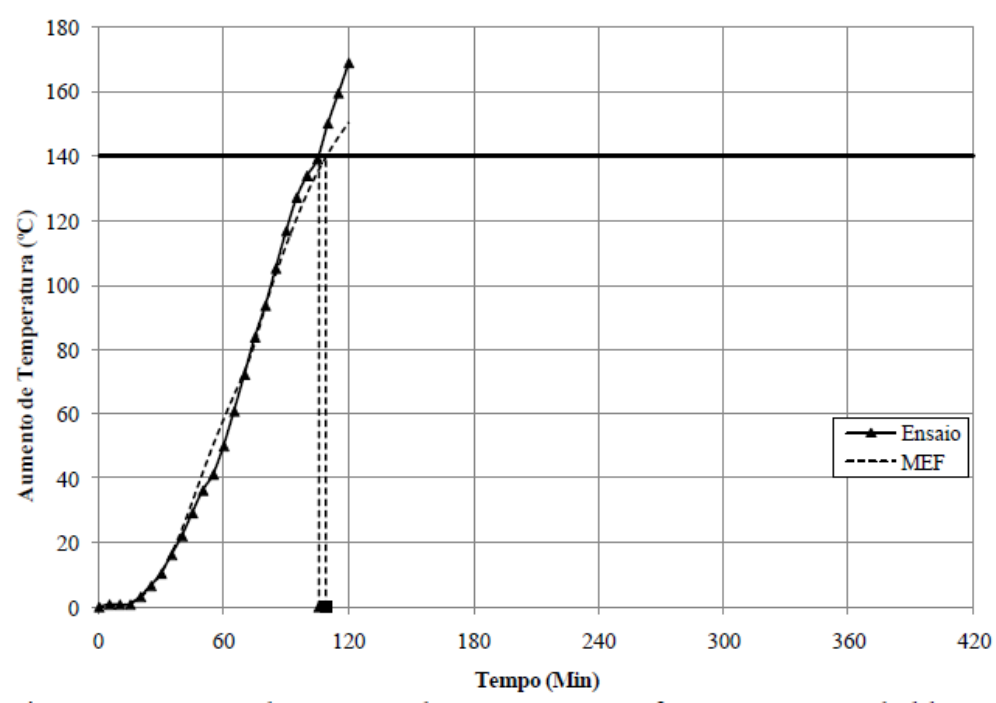

Fonte: Rosemann (2011)

Figura 2.27 - Elevação de temperatura em função do tempo na face não exposta do bloco com revestimento e com preenchimento

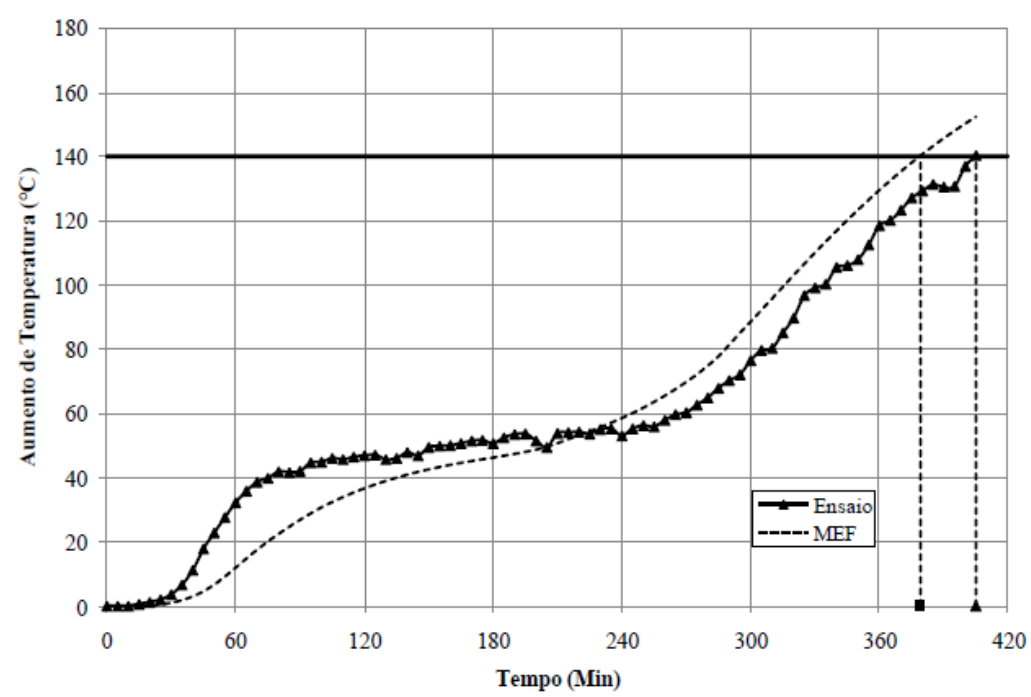

Fonte: Rosemann (2011) 
Através de análise paramétrica quanto à influência da espessura de revestimento, Rosemann (2011) concluiu que o aumento de $5 \mathrm{~mm}$ de espessura desta camada, resulta em relação quase linear, no aumento de 35 minutos de resistência quanto ao isolamento térmico.

Nguyen e Meftah (2012) estudaram experimentalmente paredes de alvenaria estrutural de blocos cerâmicos em situação de incêndio. As dimensões das paredes estudadas eram de 3,0 x 3,0 (largura x altura) com variações da espessura dos blocos entre 10 e $20 \mathrm{~cm}$. A taxa de aquecimento do ensaio, em uma das faces das paredes, seguiu a curva ISO 834-1:1999.

Foram estudados quatro tipos de configurações, variando entre paredes carregadas e não carregadas e as dimensões dos blocos. Os critérios avaliados foram o de isolamento térmico (I), estanqueidade (E) e resistência mecânica $(R)$. O controle dos ensaios foi por força e a aplicação do carregamento, distribuído através de uma viga. O resumo dos resultados obtidos consta na Tabela 2.2.

Tabela 2.2 - Resumo dos resultados obtidos por Nguyen e Meftah (2012)

\begin{tabular}{|c|c|c|c|c|c|}
\hline Parede & Configuração & $\begin{array}{c}\text { Isolamento } \\
\text { térmico } \\
\text { (min) }\end{array}$ & $\begin{array}{l}\text { Estanqueidade } \\
\qquad(\min )\end{array}$ & $\begin{array}{c}\text { Resistência } \\
\text { mecânica } \\
\text { (min) }\end{array}$ & $\begin{array}{c}\text { Máxima } \\
\text { deflexão } \\
(\mathbf{m m})\end{array}$ \\
\hline 1 & $\begin{array}{l}\text { Sem carregamento, } \\
\text { espessura de } 10 \mathrm{~cm}\end{array}$ & 43 & - & - & 67 \\
\hline 2 & $\begin{array}{l}\text { Sem carregamento, } \\
\text { espessura de } 20 \mathrm{~cm}\end{array}$ & 104 & - & - & 40 \\
\hline 3 & $\begin{array}{c}\text { Carregadas }(130 \mathrm{kN} / \mathrm{m}), \\
\text { espessura de } 20 \mathrm{~cm}\end{array}$ & - & - & 136 & 48 \\
\hline 4 & $\begin{array}{l}\text { Carregadas }(90 \mathrm{kN} / \mathrm{m}) \text {, } \\
\text { espessura de } 30 \mathrm{~cm}(20 \\
\text { do bloco, } 8 \text { de lã de } \\
\text { rocha e } 2 \mathrm{~cm} \text { de gesso - } \\
\quad 1 \mathrm{~cm} \text { por face })\end{array}$ & - & 60 & 60 & 6 \\
\hline
\end{tabular}

Fonte: Adaptado de Nguyen e Meftah (2012)

Para as paredes não carregadas, os autores verificaram que a resistência ao fogo foi controlada pelo isolamento térmico. A verificação do critério de resistência mecânica (R) foi monitorada pelos limites de deslocamento lateral. No caso da segunda parede, foi observada a ocorrência de lascamento explosivo, porém, o critério de isolamento permaneceu como o primeiro a falhar. Para as paredes carregadas, a perda de estabilidade, de acordo com os autores, 
foi devida ao lascamento explosivo localizado, o qual se espalhou através de suas espessuras, fazendo com que os efeitos de segunda ordem fossem agravados. Para estas paredes, o critério de resistência mecânica foi o primeiro a falhar. Na sequência, a Figura 2.28 mostra a situação das paredes após os ensaios.

Figura 2.28 - Face exposta ao fogo após o incêndio da parede 2 (a), face não exposta ao fogo da parede 3 (b) e face não exposta ao fogo da parede 4 (c)

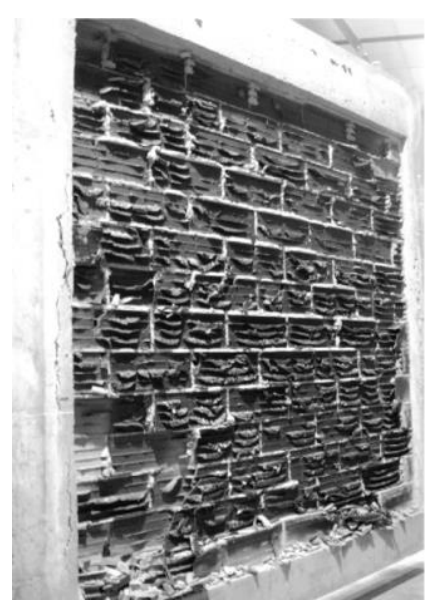

(a)

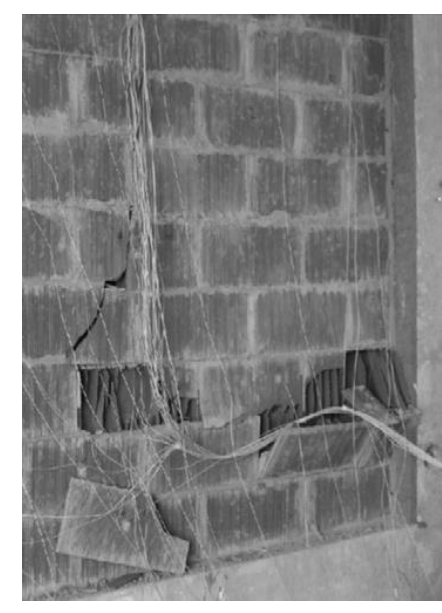

(b)

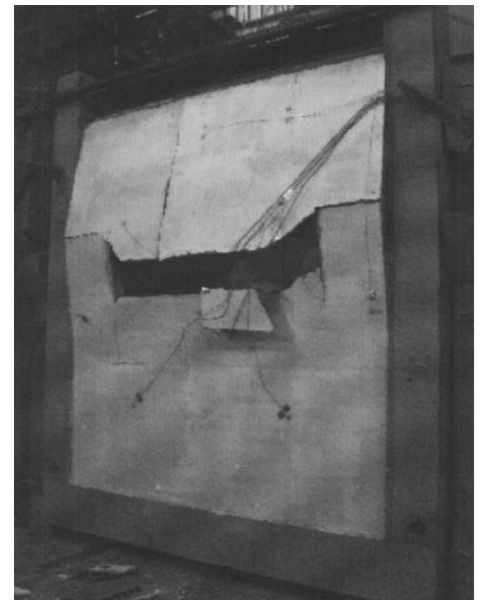

(c)

Fonte: Nguyen e Meftah (2012)

Os autores comentam também sobre a importância de se obter modelos numéricos sofisticados que sejam capazes de prever o comportamento da alvenaria sob elevadas temperaturas, o que possibilitaria considerações de cenários específicos de incêndio, como no caso de geometrias diferentes e processos complexos de degradação dos materiais, como no caso de lascamento explosivo. Ressaltam, porém, da necessidade de ensaios específicos e padronizados para obtenção das propriedades térmicas e mecânicas.

Rigão (2012) estudou o comportamento de prismas e pequenas paredes de alvenaria estrutural com blocos cerâmicos submetidas à compressão e temperaturas elevadas, bem como, analisou o comportamento de corpos-de-prova de argamassa nas mesmas circunstâncias. Os corpos-de-prova dos prismas e pequenas paredes foram ensaiados com restrição de deslocamento vertical. As dimensões dos prismas de dois blocos foram de 0,29 x 0,40 x 0,14 $\mathrm{m}$ (largura $\mathrm{x}$ altura $\mathrm{x}$ espessura) enquanto das pequenas paredes foram de $0,90 \times 1,00 \times 0,14 \mathrm{~m}$ sem a existência de revestimento em ambos os casos. Para os corpos-de-prova da argamassa, as dimensões eram de 4 x 4 x $16 \mathrm{~cm}$. Não foi possível realizar comparações com as curvas de incêndio-padrão uma vez que não houve controle do aumento de temperatura nos ensaios.

Para a argamassa, foram executados corpos-de-prova para ensaios em três etapas. A primeira etapa foi utilizada para a caracterização mecânica em temperatura ambiente, donde 
obteve-se resistência média à compressão de 4,10 MPa. Na segunda etapa, os corpos-de-prova foram submetidos ao aquecimento até a temperatura de $400{ }^{\circ} \mathrm{C}$ e comprimidos após resfriamento natural, obtendo-se resistência à compressão residual média de 2,32 MPa (57\%). Finalmente, na terceira etapa, os corpos-de-prova de argamassa foram submetidos ao aquecimento até $900{ }^{\circ} \mathrm{C}$ e não apresentou resistência significativa quando comprimidos.

Os prismas apresentaram resistência à temperatura ambiente de 5,30 MPa. Desta forma, apresentaram resistência residual média maior que as argamassas, sendo de $73 \%$ à temperatura de $400{ }^{\circ} \mathrm{C}(3,87 \mathrm{MPa})$ e de $49 \%$ a $900{ }^{\circ} \mathrm{C}(2,58 \mathrm{MPa})$. As pequenas paredes ensaiadas à temperatura ambiente apresentaram tensão de ruptura à compressão de 3,77 MPa, enquanto que no caso exposto a altas temperaturas (uma única face exposta) apresentou valor de 2,58 $\mathrm{MPa}$, isto é, resistência residual à compressão de $63 \%$.

Figura 2.29 - Esquema de ensaio das pequenas paredes em temperaturas elevadas (a) e, fissuras ocorrentes na face não exposta ao fogo (b)

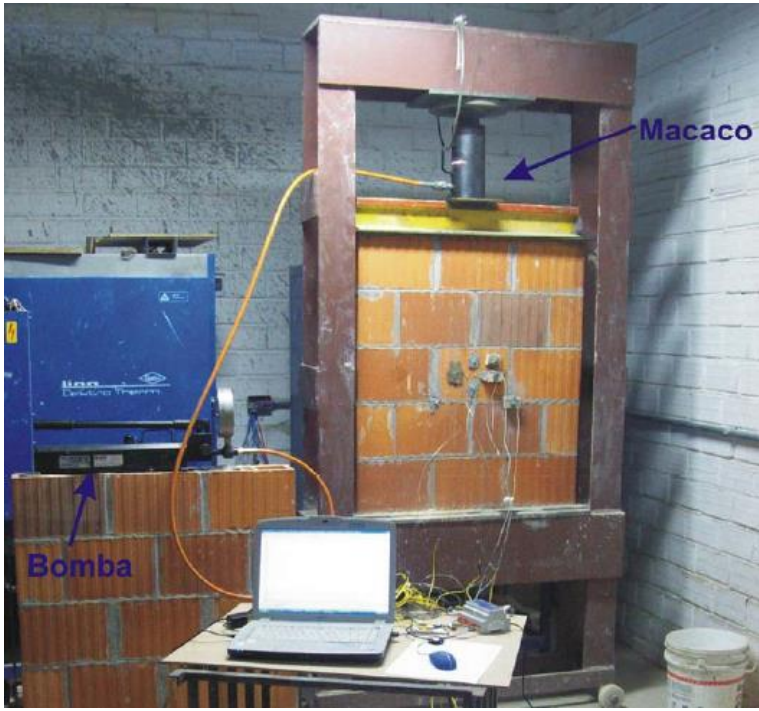

(a)

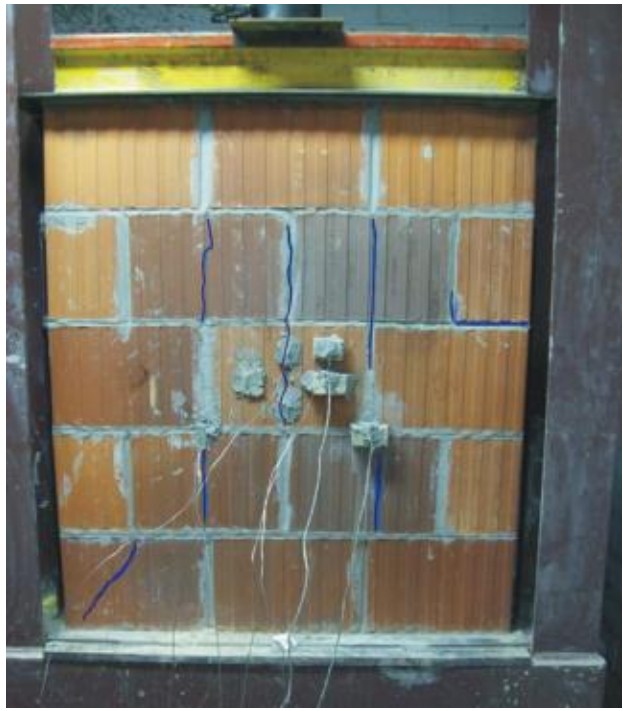

(b)

Fonte: Rigão (2012)

O autor constatou um aumento de carga considerável ao longo do ensaio, em virtude do gradiente térmico e da restrição de deslocamento vertical imposta. Também foi verificado um atraso para o início do incremento de carga, em todas as paredes, de aproximadamente 20 minutos. $\mathrm{O}$ autor justifica tal ocorrência devido à inércia térmica, em que a temperatura da face não aquecida e das paredes internas mantiveram-se praticamente inalteradas e, portanto, ainda não existiam tensões térmicas significativas.

Russo e Sciarretta (2014) fizeram uma análise numérica quanto à resistência residual de paredes de tijolos cerâmicos sujeita a situação de incêndio em uma das faces. A curva de 
aquecimento utilizada foi a ISO 834-1:1999. O software utilizado foi o DIANA, e a análise baseou-se em quatro configurações com diferentes espessuras da alvenaria, sendo elas 12, 25, 38 e $51 \mathrm{~cm}$, conforme visto na Figura 2.30.

Figura 2.30 - Configurações dos quatro modelos criados
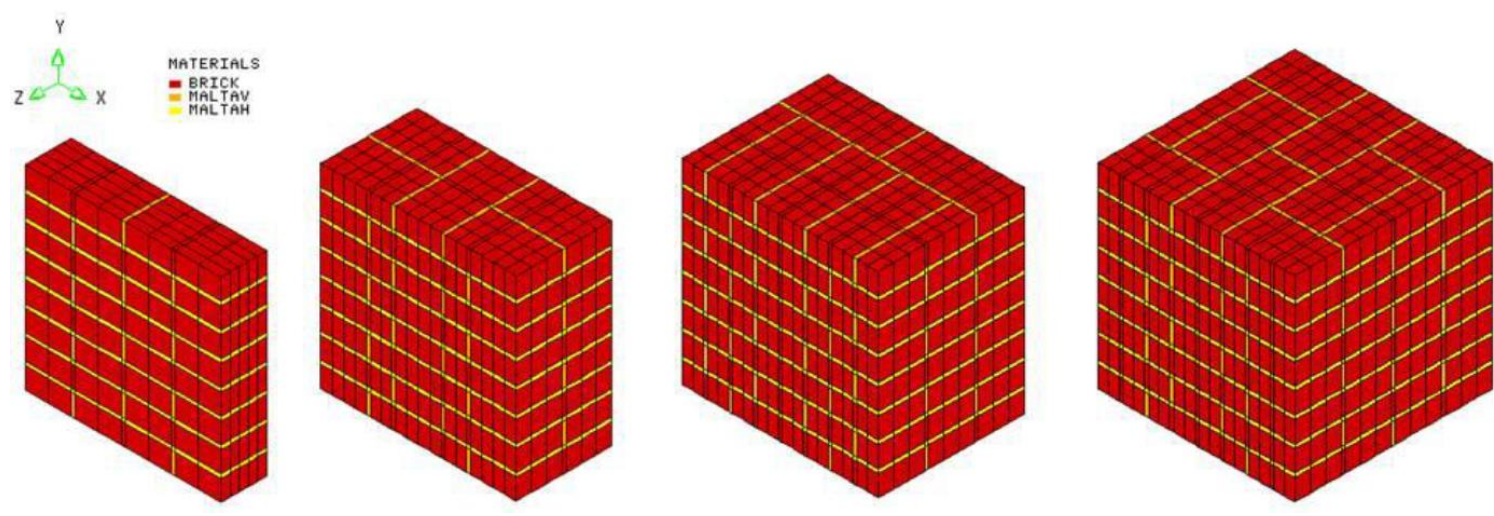

Fonte: Russo e Sciarretta (2014)

Os autores basearam-se em ensaios anteriormente realizados por Russo e Sciarretta ${ }^{13}$ (2012) para verificação e análise preliminar dos modelos numéricos. Inicialmente, aplicaram a curva de incêndio-padrão numa das faces e verificaram a variação de temperatura ao longo de cada espessura. O critério de parada utilizado pelos autores foi o de isolamento térmico, isto é, ao atingir os níveis de temperatura indicados pelo critério, a simulação era finalizada. Posteriormente, fizeram a modelagem do ensaio estrutural, considerando análise "fria", com o a aplicação do carregamento no modelo deformado após o resfriamento.

A seguir é mostrado na Tabela 2.3 os resultados numéricos obtidos e, na Figura 2.31, o nível de fissuração após cada análise.

Tabela 2.3 - Resumo dos resultados obtidos por Russo e Sciarretta (2014)

\begin{tabular}{cccc}
\hline $\begin{array}{c}\text { Espessura } \\
(\mathbf{m i n})\end{array}$ & $\begin{array}{c}\text { Exposição ao } \\
\text { fogo }(\mathbf{m i n})\end{array}$ & $\begin{array}{c}\text { Resistência à compressão } \\
\text { residual }(\%)\end{array}$ & $\begin{array}{c}\text { Módulo de elasticidade } \\
\text { residual }(\%)\end{array}$ \\
\hline $\mathbf{1 2}$ & 57 & 71 & 100 \\
\hline $\mathbf{2 5}$ & 178 & 51 & 97 \\
$\mathbf{3 8}$ & 240 & 53 & 94 \\
\hline $\mathbf{5 1}$ & 240 & 53 & 84 \\
\hline
\end{tabular}

Fonte: Adaptado de Russo e Sciarretta (2014)

13 RUSSO, S., SCIARRETTA, F. Experimental and theoretical investigation on masonry after high temperature exposure. Experimental Mechanics, 52, 341-359, 2012 
Figura 2.31 - Resultados da análise estrutural: padrão de fissuras após análise térmica (fase 1) e análise estrutural (fase 2)

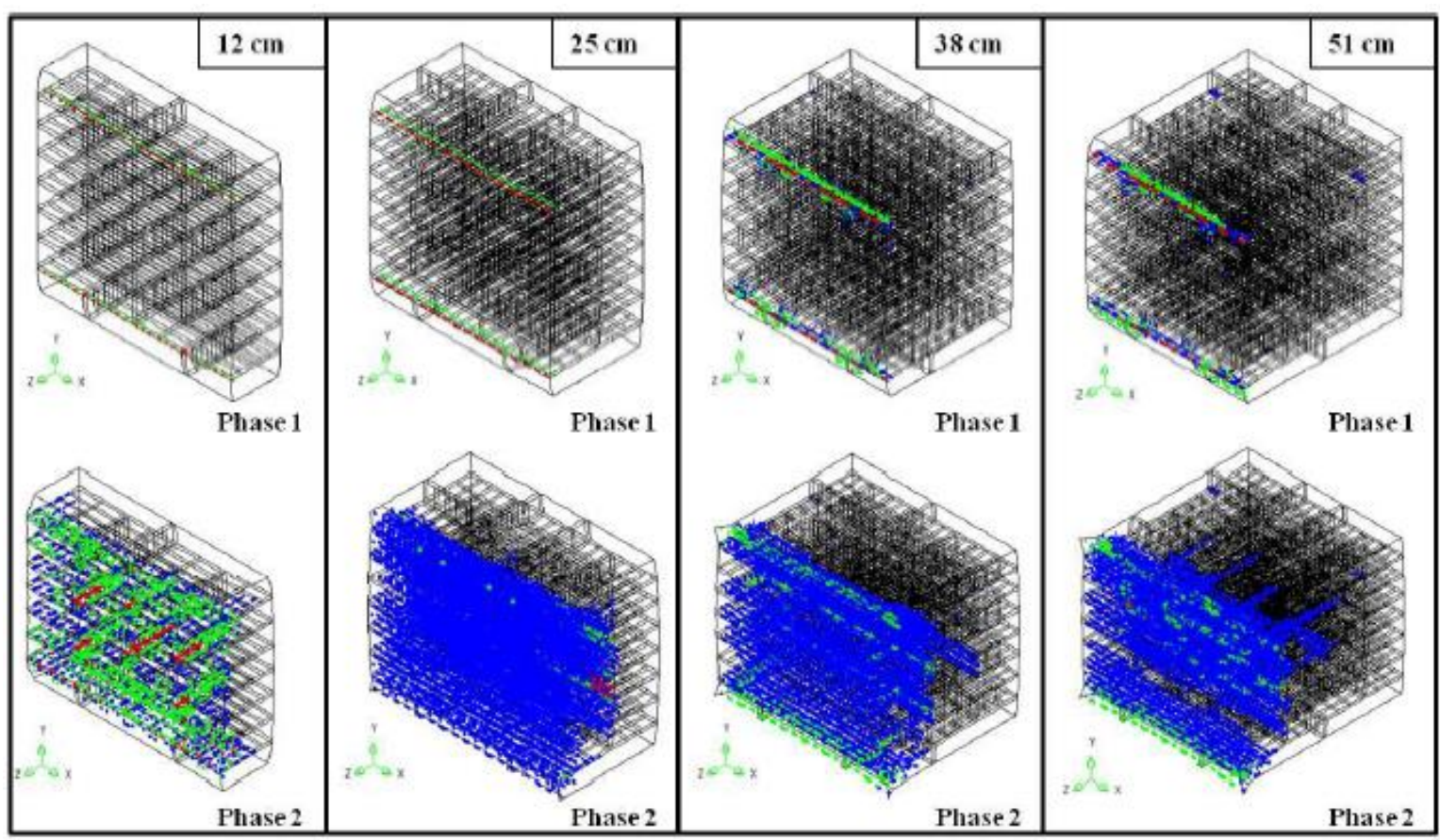

Fonte: Russo e Sciarretta (2014)

O Instituto de Pesquisas Tecnológicas (IPT) (2013, 2015 e 2016) realizou ensaios em paredes de alvenaria com blocos de concreto para análise do seu comportamento quanto aos critérios de isolamento e estanqueidade, baseados na ABNT NBR 5628:2001. A taxa de evolução de temperatura foi feita de acordo com a ISO 834-1:1999. Nos ensaios, ainda, houve a aplicação de choques mecânicos laterais nos corpos-de-prova, aos tempos de 3 minutos antes do término dos mesmos a fim de verificar sua estabilidade. Esta metodologia, porém, não está baseada em normatização nacional, uma vez que não existe critério para tal avaliação.

Os corpos-de-prova foram executados com blocos com comprimento de $39 \mathrm{~cm}$ e largura de $14 \mathrm{~cm}$, com variação da espessura. O revestimento do lado exposto ao fogo foi aplicado em todas as paredes, com espessura de $1,5 \mathrm{~cm}$. Houve grauteamento de todos os furos do corpode-prova 3. Os resultados quanto ao critério de estanqueidade pelo IPT estão compilados na Tabela 2.4

A Figura 2.32 mostra a situação da face exposta ao fogo após o ensaio para o corpo-deprova 2. Para o critério de estanqueidade, todos os ensaios apresentaram resultados satisfatórios. Mesma situação ocorrente para o critério de estabilidade, anteriormente comentado. 
Tabela 2.4 - Compilação dos resultados obtidos pelo IPT

\begin{tabular}{ccccc}
$\begin{array}{c}\text { Corpo-de-prova } \\
\text { (Ensaio) }\end{array}$ & $\begin{array}{c}\text { Espessura do } \\
\text { bloco }(\mathbf{c m})\end{array}$ & $\begin{array}{c}\text { Dimensões do } \\
\text { corpo-de-prova }-\mathbf{l} \\
\mathbf{x ~ h ~} \mathbf{x ~ e ~ ( m ) ~}\end{array}$ & $\begin{array}{c}\text { Tempo de } \\
\text { ensaio (min) }\end{array}$ & $\begin{array}{c}\text { Critério de } \\
\text { isolamento } \\
\text { térmico (min) }\end{array}$ \\
\hline $\mathbf{1}(\mathbf{1 0 5 0})$ & 19 & $2,70 \times 2,62 \times 0,22$ & 180 & 151 \\
\hline $\mathbf{2}(\mathbf{1 0 7 2})$ & 14 & $2,60 \times 2,60 \times 0,16$ & 120 & 106 \\
\hline $\mathbf{3}(\mathbf{1 0 8 1})$ & 19 & $2,60 \times 2,60 \times 0,205$ & 240 & - \\
\hline
\end{tabular}

Fonte: Adaptado de IPT (2013, 2015 e 2016)

Figura 2.32 - Face exposta ao fogo do ensaio 2 após o ensaio

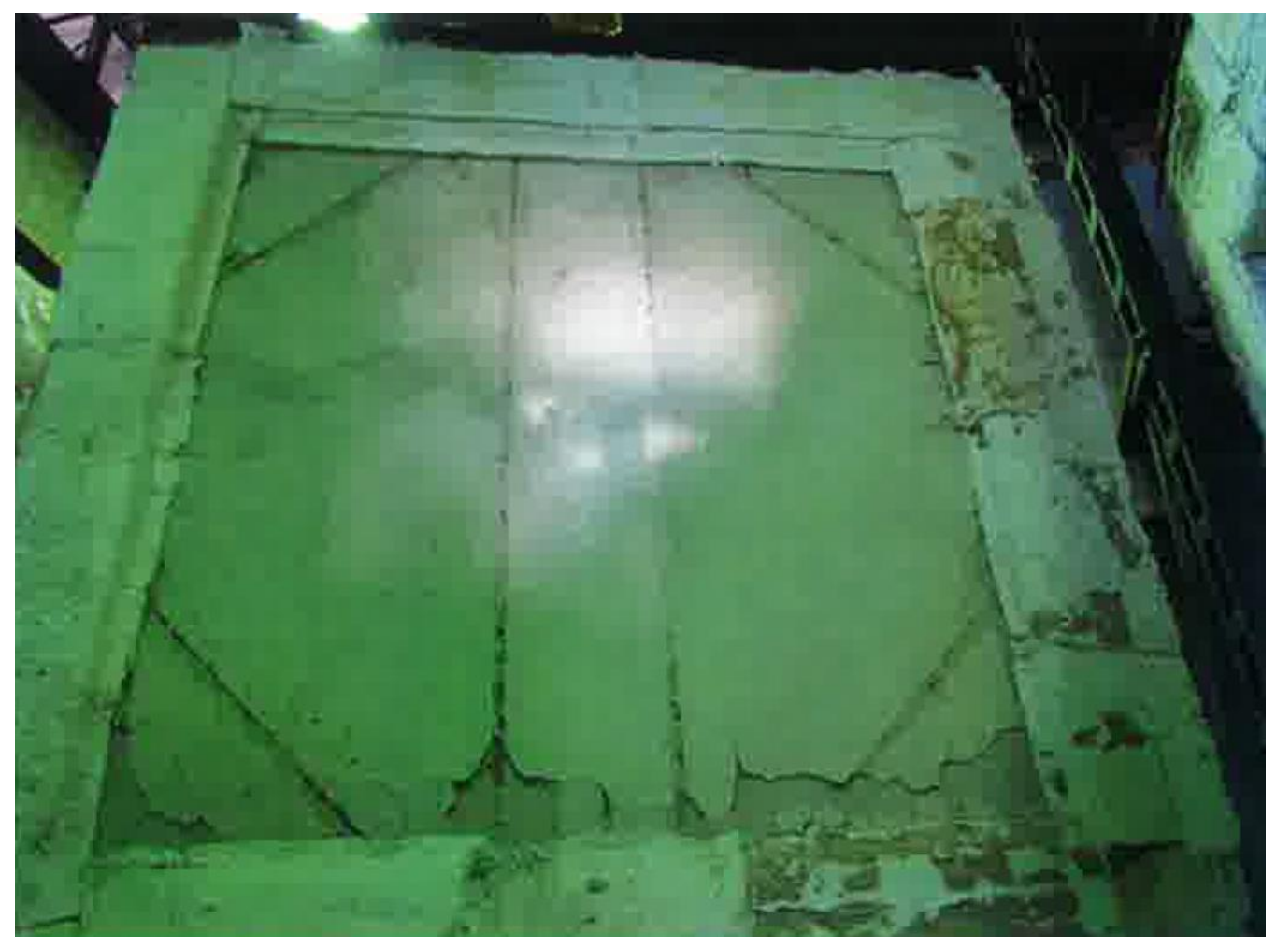

Fonte: IPT (2015)

Mohamad e Chen (2016) fizeram análises experimentais e numéricas acerca do comportamento da alvenaria sob tensões de compressão e esforços cortantes para concreto com isolantes térmicos e com graute. Para a modelagem numérica, utilizaram o software ABAQUS através dos modelos Concrete Damaged Plasticity (CDP) e Cohesive Surface-Based Element. $\mathrm{O}$ modelo tridimensional utilizado para análise foi o C3D8R. O uso destes modelos teve divergência máxima de $6 \%$ em relação aos valores experimentais obtidos, e, inferior a 10\% em relação aos deslocamentos horizontais. 
Figura 2.33 - Geometria da malha de elementos finitos utilizada para a pequena parede e o prisma: comportamento à compressão (a); e ao cisalhamento (b)

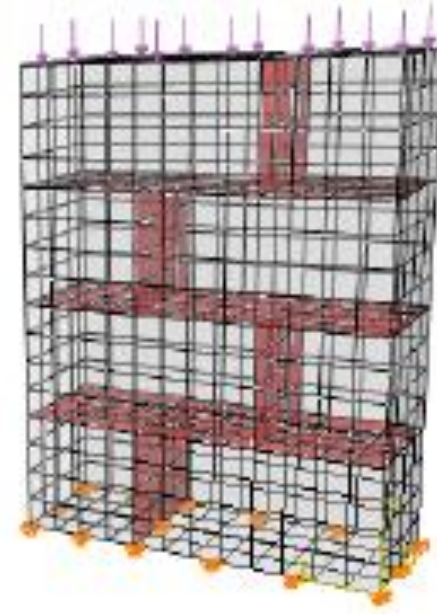

(a)

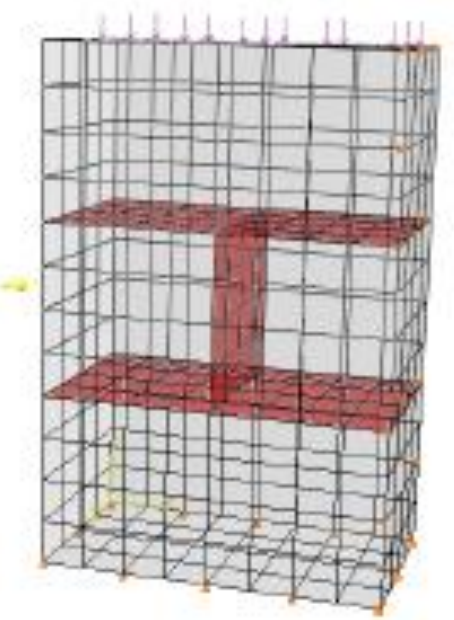

(b)

Fonte: Mohamad e Chen (2016)

Russo e Sciarretta (2016) fizeram um estudo numérico sobre as propriedades mecânicas da alvenaria estrutural durante e após a situação de incêndio. Foram simulados diversos tipos de blocos cerâmicos, os quais apresentaram variação de abertura, no pacote computacional DIANA. O modelo utilizado foi o mesmo para todos os blocos, por motivo de simplificação da análise numérica, sendo a diferenciação entre os mesmos, feita através da adaptação da condutividade térmica de acordo com o percentual de vazios. Como conclusão, os modelos criados conseguiram representar de forma satisfatória o comportamento das unidades. Além disso, concluíram que a resistência das unidades com maior percentual de vazios é menor que no caso de unidades sólidas.

Santos et al. (2017) fizeram uma análise numérica para o comportamento termoestrutural de alvenaria de blocos cerâmicos baseada nos estudos experimentais de Rosemann (2011) e Rigão (2012), a partir do software ABAQUS e da macromodelagem utilizando elementos do tipo C3D8R. Concluíram que o nível de carga afeta diretamente o comportamento termoestrutural da alvenaria e negativamente a resistência ao fogo. Neste trabalho, o carregamento não foi elevado até a ruptura. Quanto aos modelos, estes apresentaram com proximidade as curvas de temperatura em função do tempo.

Rodovalho (2018) estudou numericamente o comportamento termoestrutural de blocos e primas de concreto com e sem revestimento (espessura de 1,5 cm). A autora utilizou o pacote computacional ABAQUS e os modelo de plasticidade e dano para representar o comportamento 
não-linear dos blocos e das juntas de argamassa. No modelo idealizado, não houve consideração quanto a deslocamento relativo entre argamassa e bloco. A malha utilizada foi de $1 \mathrm{~cm}$.

Figura 2.34 - Modelo de pequena parede utilizado para as simulações numéricas
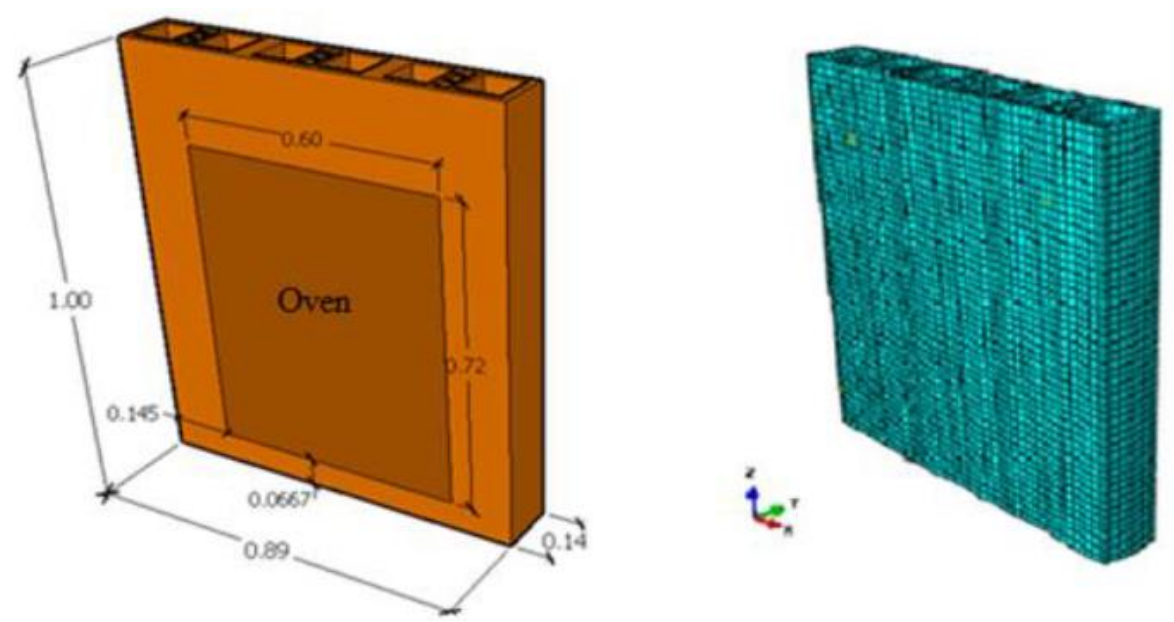

Fonte: Santos et al. (2017)

Nos modelos estruturais, utilizou elementos tridimensionais contínuos com integração reduzida (C3D8R). Inseriu o carregamento através de controle de deslocamentos com o objetivo de simular os ensaios realizados por Oliveira (2014) e verificar os resultados. A Figura 2.35 mostra a comparação dos resultados experimentais e numéricos obtidos, para prismas de 3 blocos com argamassamento parcial.

Figura 2.35 - Comparação dos diagramas tensão-deformação de prismas de três blocos e argamassamento parcial

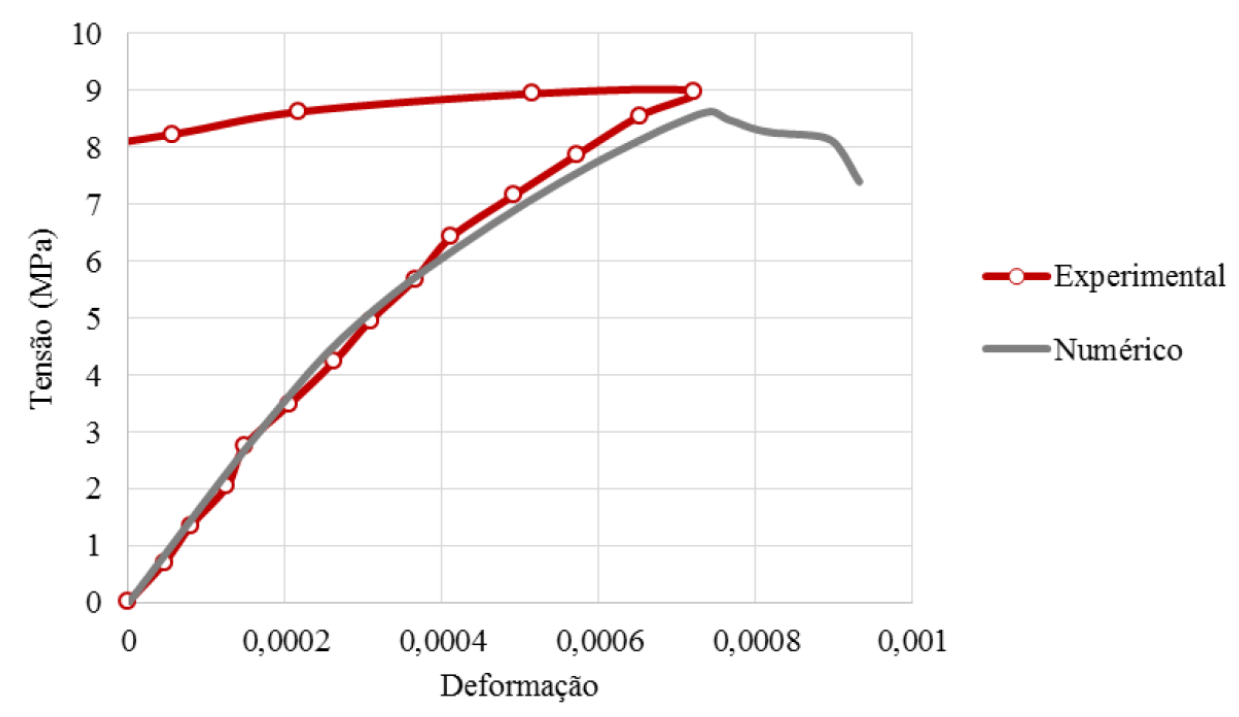

Fonte: Rodovalho (2018) 
A Figura 2.36 mostra os resultados obtidos pelo programa computacional ABAQUS para as tensões mínimas ocorrentes em prismas de dois blocos com argamassamento parcial.

Figura 2.36 - Distribuição de tensões máximas para prisma de dois blocos e argamassamento parcial $(\mathrm{Pa})$
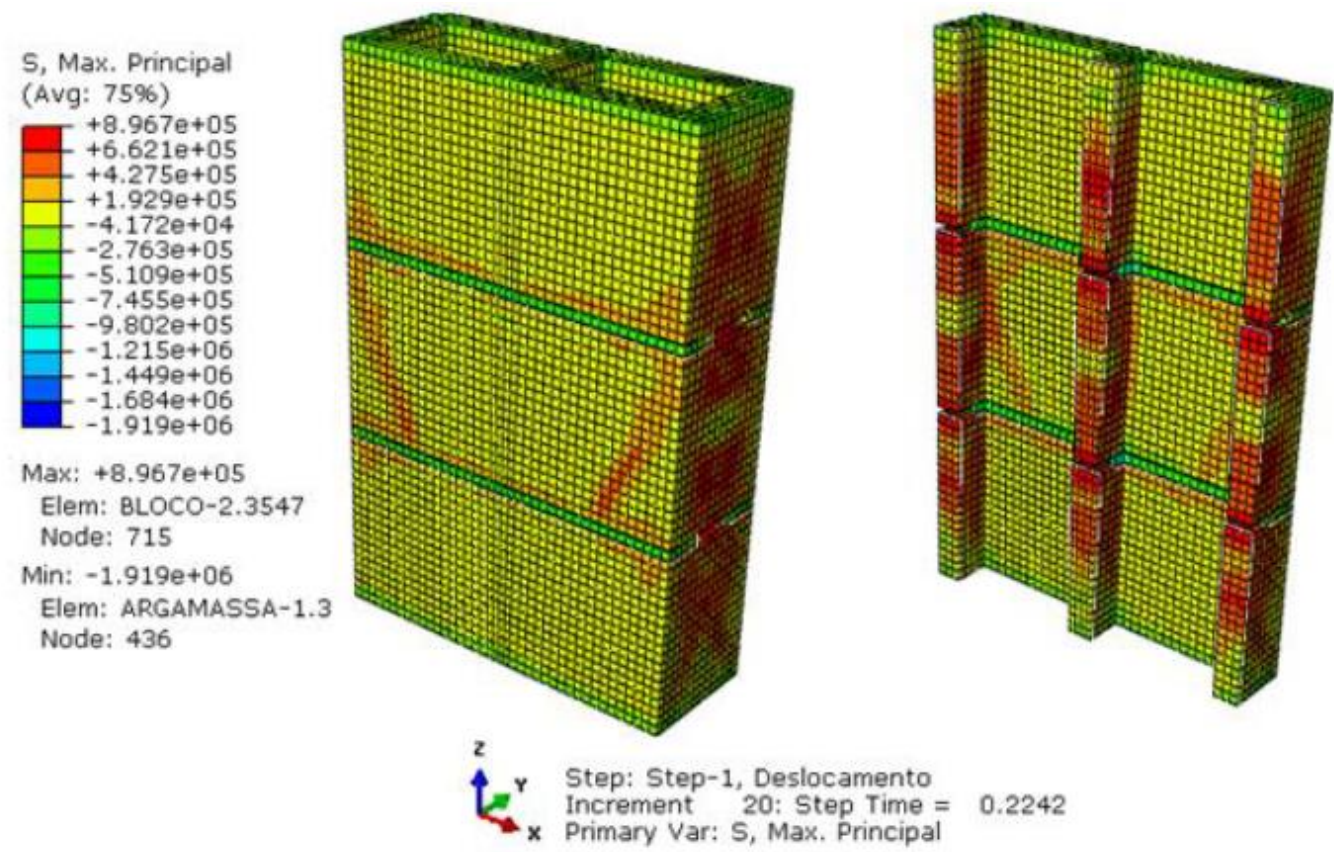

Fonte: Rodovalho (2018)

Através de análises paramétricas com argamassamentos total e parcial, verificou numericamente que prismas executados com argamassamento total apresentam rigidezes mais elevadas que no caso de argamassamento parcial. Para as modelagens de prismas de dois e três blocos, verificou numericamente que prismas de dois blocos apresentam resistências maiores que prismas de três blocos, conforme obtido experimentalmente por Oliveira (2014).

Para a modelagem de transferência de calor, a malha para os prismas de blocos de concreto foi a mesma utilizada para o modelo estrutural. Os elementos foram o DC3D8 relacionados à transferência de calor dos blocos e argamassa. Para a massa de ar interna, utilizou elementos do tipo FC3D8, através da interação fluido-estrutura onde a transferência de calor ocorre por meio da condução e convecção. A transferência de calor considerada para o meio sólido foi a condução e entre o ar e o material do bloco, a convecção e a radiação. O aquecimento adotado foi de acordo com a curva ISO 834-1:1999, em uma das faces. Para os prismas de blocos de concreto, obteve as resistências indicadas na Tabela 2.5, de acordo com o critério de isolamento térmico. 
Tabela 2.5 - Resultados obtidos para prismas de blocos de concreto de acordo com o critério de isolamento térmico

\begin{tabular}{cc} 
Configuração & Critério de isolamento térmico (min) \\
\hline Sem revestimento & 86 \\
\hline Com revestimento em uma das faces & 106 \\
\hline Com revestimento em ambas as faces & 137 \\
\hline
\end{tabular}

Fonte: Adaptado de Rodovalho (2018)

Rodovalho (2018) também realizou a modelagem de transferência de calor de blocos cerâmicos sujeitos ao fogo em uma das faces, para verificação com os resultados experimentais obtidos por Rosemann (2011). A malha utilizada é mostrada na Figura 2.37, em que é possível notar que os elementos são semelhantes aos utilizados para blocos de concreto.

Figura 2.37 - Malhas utilizadas nas modelagens com blocos cerâmicos
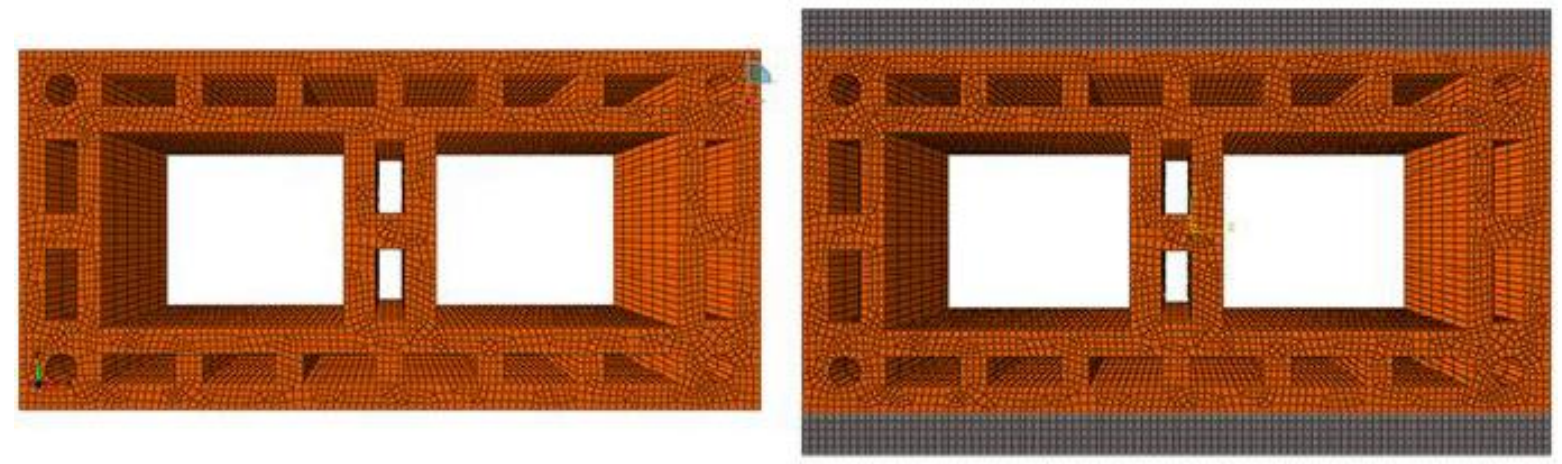

Fonte: Rodovalho (2018)

Os resultados obtidos para blocos cerâmicos estão mostrados na Figura 2.38, comparando com os resultados experimentais obtidos por Rosemann (2011). As simulações termomecânicas foram feitas para prismas de blocos de concreto sem revestimento. Foram consideradas dois tipos de carregamentos, com 20 e 35\% da resistência característica dos prismas.

Para cada carregamento, consideradas, ainda, variação das condições de contorno, sendo elas: casos sem restrição de deslocamento vertical (S.R.D.V.), com restrição de deslocamento vertical (C.R.D.V.), com restrição rotacional (C.R.R.) e sem restrição rotacional (S.R.R.). O resumo dos resultados obtidos para as simulações termomecânicas está mostrado na Figura 2.39, de acordo com o critério de resistência mecânica. 
Figura 2.38 - Elevação de temperatura em função do tempo na face não exposta ao fogo das paredes cerâmicas

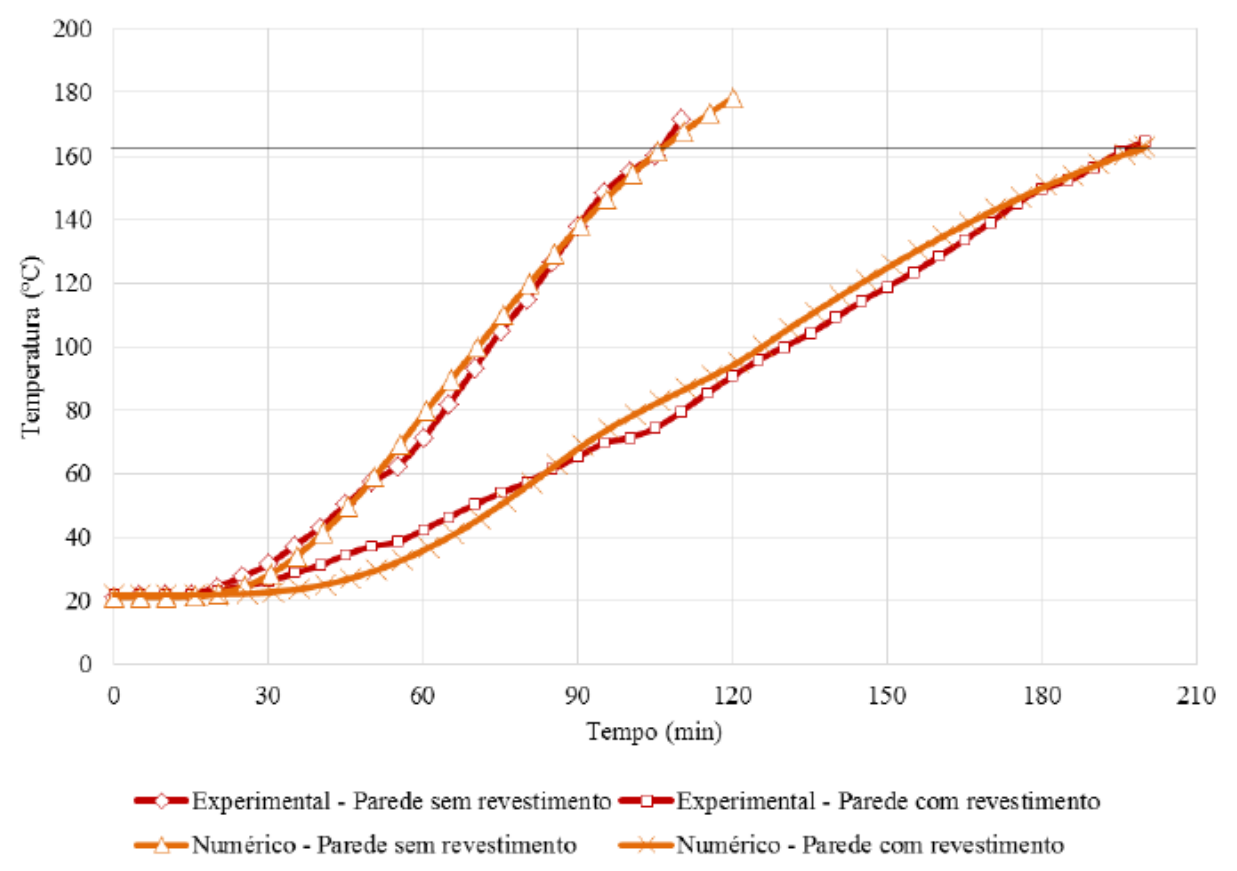

Fonte: Rodovalho (2018)

Figura 2.39 - Resumo das simulações numéricas pelo critério de resistência mecânica

\begin{tabular}{cccccc}
\hline Esquema da simulação & Carregamento & \multicolumn{2}{c}{ S.R.D.V. (min) } & \multicolumn{2}{c}{ C.R.D.V. (min) } \\
\hline & & C.R.R. & S.R.R. & C.R.R. & S.R.R. \\
& & & & & \\
\hline & & & & & \\
\hline \\
\hline
\end{tabular}

Fonte: Rodovalho (2018)

O impedimento de deslocamento vertical resultou em redução do tempo quanto ao critério de resistência mecânica, uma vez que as expansões térmicas estão impedidas. Quanto ao critério de estanqueidade, este não foi avaliado nas simulações.

Lopes et al. (2018) ensaiaram paredes de alvenaria estrutural de blocos de concreto de três células em situação de incêndio. As dimensões das paredes eram de 1,40 x 1,00 x 0,10 m (comprimento $\mathrm{x}$ altura $\mathrm{x}$ espessura). Devido às limitações de ensaio, as paredes foram confeccionadas na escala 1:2. O aquecimento foi realizado em uma das faces, respeitando o aumento de temperatura de acordo com a curva ISO 834-1:1999. Porém, de acordo com os autores, devido à inércia térmica do forno, às perdas de calor pela superfície dos elementos e 
pela capacitância térmica dos materiais, a temperatura interna dos gases não conseguiu acompanhar a curva-padrão com precisão.

Os corpos-de-prova ensaiados foram enumerados de 1 a 6 , sendo, as paredes 1 e 2 submetidas a uma carga de 30\% da carga de ruptura observada em Haach (2009), as paredes 3 e 4 submetidas a uma carga de $46 \%$ da mesma referência, e, as paredes 5 e 6 submetidas a 30\% da carga de ruptura por 90 minutos e com incremento constante do carregamento de $0,05 \mathrm{kN} / \mathrm{s}$ até o colapso. Os pontos de medição de temperatura variaram ao longo da seção transversal da parede e, para verificação do deslocamento lateral em função do tempo, foram utilizados transdutores de deslocamento (LVDT).

Como observado no trabalho de Al Nahhas et al. (2007), à temperatura de $100{ }^{\circ} \mathrm{C}$ é possível verificar a ocorrência de patamar, isso, devido à absorção de energia térmica para evaporação da água livre nos poros dos blocos. Os autores verificaram para os deslocamentos laterais das paredes de 1 a 4, um aumento gradativo até os 30 minutos, acentuando-se posteriormente. Para as paredes 5 e 6, ocorre uma redução do deslocamento lateral a partir dos 60 minutos até próximo a 90 minutos, onde ocorre o colapso.

A Tabela 2.6 resume os resultados obtidos pelos autores.

Tabela 2.6 - Resultado dos ensaios de Lopes et al. (2018)

\begin{tabular}{ccccccc} 
Parede & $\begin{array}{c}\text { Isolamento } \\
\text { térmico } \\
(\mathbf{m i n})\end{array}$ & $\begin{array}{c}\text { Estanqueidade } \\
(\mathbf{m i n})\end{array}$ & $\begin{array}{c}\text { Resistência } \\
\text { mecânica } \\
(\mathbf{m i n})\end{array}$ & $\begin{array}{c}\text { Carga } \\
\text { última }\end{array}$ & \multicolumn{2}{c}{ Deslocamento } \\
$(\mathbf{k N})$ & $\begin{array}{c}\text { meitura } \\
(\mathrm{mm})\end{array}$ & $\begin{array}{c}\text { Tempo } \\
(\mathrm{min})\end{array}$ \\
\hline $\mathbf{1}$ & 72 & - & - & - & 5,52 & 74 \\
\hline $\mathbf{2}$ & 67 & - & - & - & 5,80 & 79 \\
\hline $\mathbf{3}$ & - & - & 83 & - & 9,52 & 80 \\
\hline $\mathbf{4}$ & - & - & 40 & - & 10,74 & 40 \\
\hline $\mathbf{5}$ & - & - & - & 273 & 11,58 & 68 \\
\hline $\mathbf{6}$ & - & - & - & 421 & 11,14 & 66 \\
\hline
\end{tabular}

Fonte: Adaptado de Lopes et al. (2018)

Demais análises e gráficos relativos a este trabalho estão abordados nos próximos capítulos, fazendo as devidas comparações com os resultados numéricos obtidos nesta pesquisa.

Dupim (2019) ensaiou blocos, prismas e pequenas paredes de alvenaria estrutural de blocos de concreto em situação de incêndio, de acordo com a curva ISO 834-1:1999, com o intuito de avaliar a resistência residual destes elementos, em forno horizontal. Em seus ensaios, 
utilizou dois grupos de resistência de blocos, de 4,0 e 10,0 MPa com espessura de 14 cm. Em temperatura ambiente, ensaiou paredes com espessura de $19 \mathrm{~cm}$. Além disso, fez a análise da influência da utilização de revestimento de $5 \mathrm{~mm}$ de gesso.

Para a primeira fornada (realizada até o tempo de 70 minutos de incêndio) foram estudados os corpos-de-prova sem revestimento e com espessura de $14 \mathrm{~cm}$. Dupim (2019) utilizou a disposição mostrada na Figura 2.40 para o ensaio.

Figura 2.40 - Disposição dos corpos-de-prova da primeira fornada

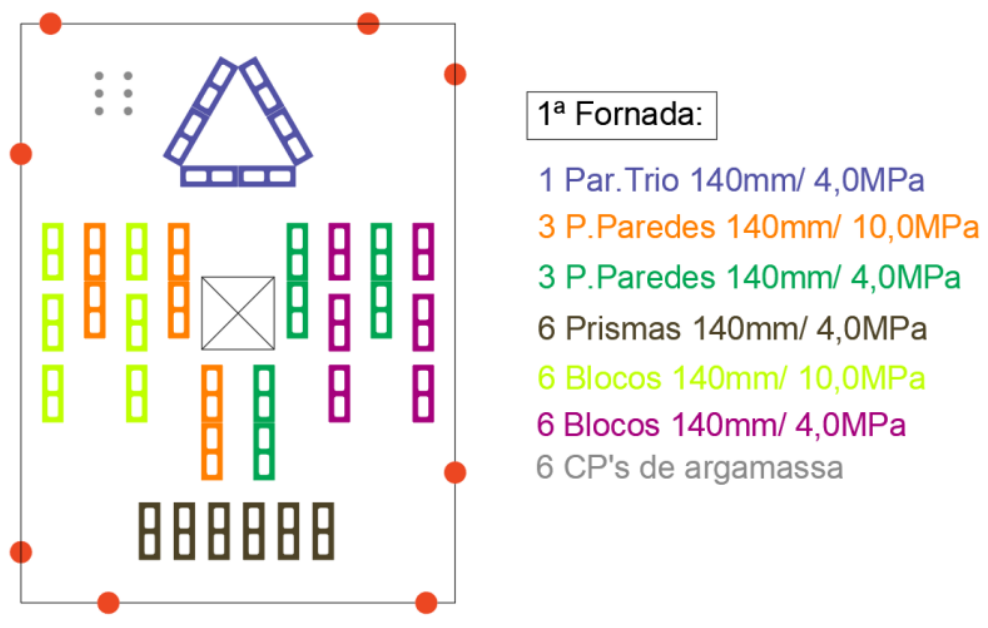

Fonte: Dupim (2019)

Dentre os ensaios realizados, Dupim (2019) simulou a ocorrência de incêndio em ambas as faces das pequenas paredes, bem como, considerando exposição direta em uma única face, como visto pelo trio de paredes da Figura 2.40. Para evitar a entrada de calor no trio, Dupim (2019) inseriu manta cerâmica nos encontros entre as paredes, lateralmente, bem como, cobriu com placa de gesso com manta cerâmica a superfície superior de todos os elementos, conforme visto na Figura 2.41.

Figura 2.41 - Isolamento dos elementos com manta cerâmica
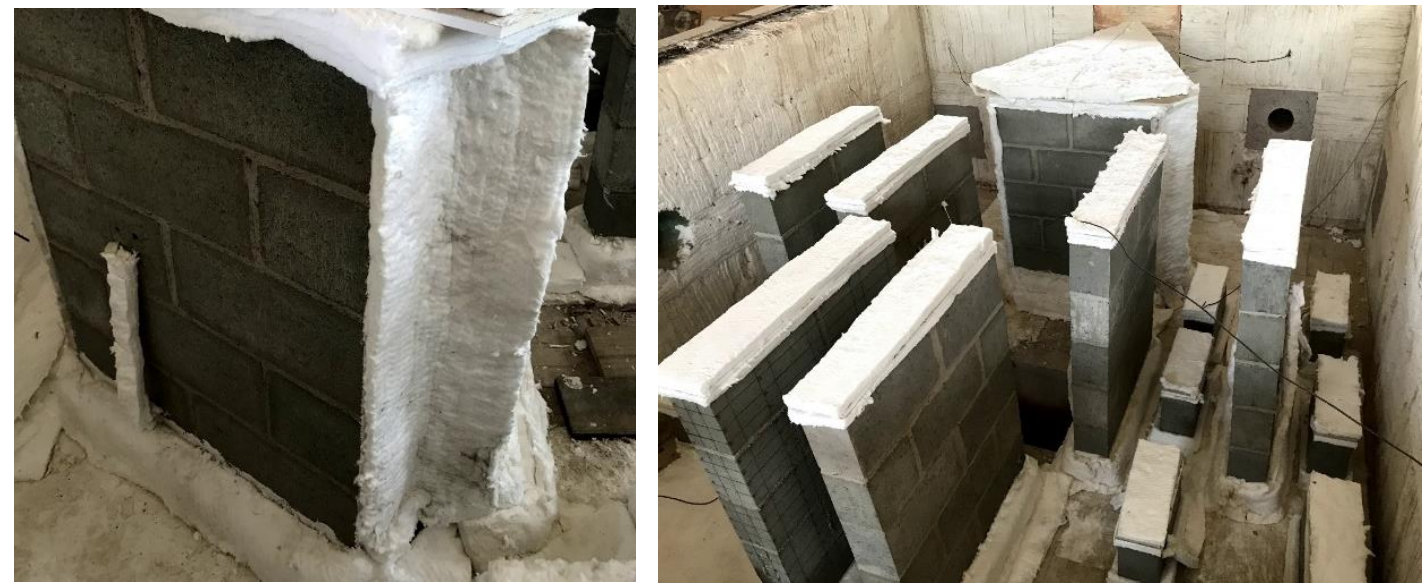

Fonte: Dupim (2019) 
Os pontos de instrumentação das pequenas paredes, para a obtenção da temperatura ao longo do tempo foram obtidos conforme mostrado na Figura 2.42.

Figura 2.42 - Instrumentação das pequenas paredes com as duas faces expostas ao fogo (a) e com uma face exposta ao fogo (b)
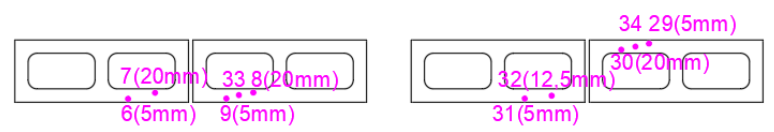

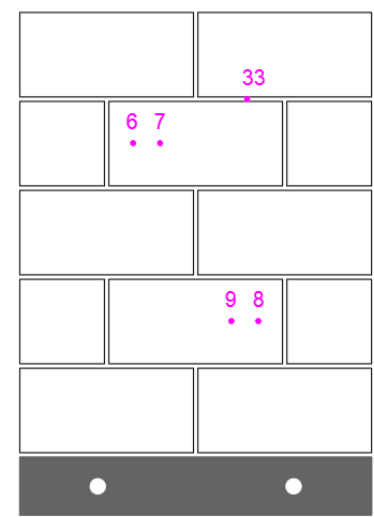

Par1-4,0(14)-N

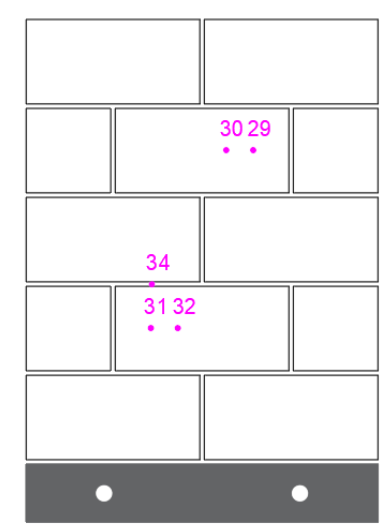

Par2-4,0(14)-N

(a)
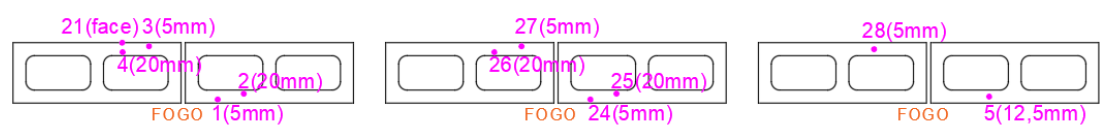

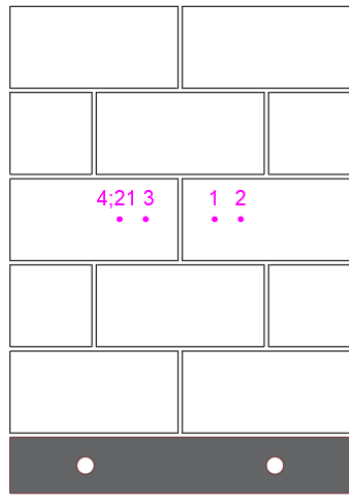

Par1-4,0(14)-C

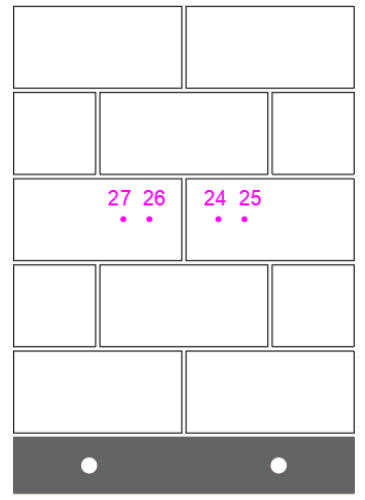

Par2-4,0(14)-C

(b)

Fonte: Dupim (2019)

Posteriormente ao ensaio, optou por resfriamento lento dos corpos-de-prova para o seu rompimento e obtenção da resistência residual. A Figura 2.43 mostra a evolução da temperatura obtida para os pontos de instrumentação para a situação com ambas as faces expostas e para uma única face exposta ao fogo. 
Figura 2.43 - Evolução da temperatura em função do tempo para ambas as faces expostas (a) e para uma única face exposta ao fogo (b)

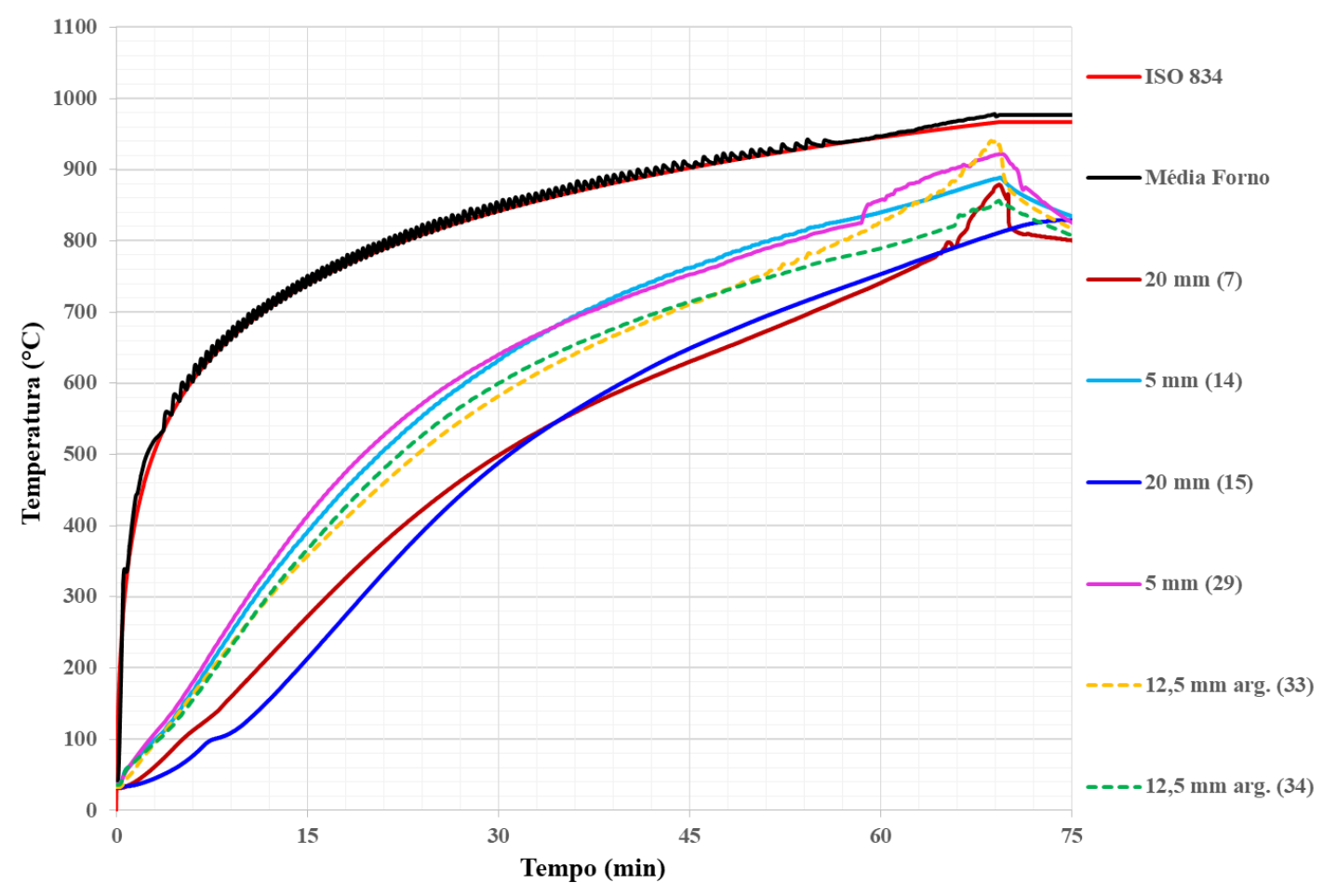

(a)

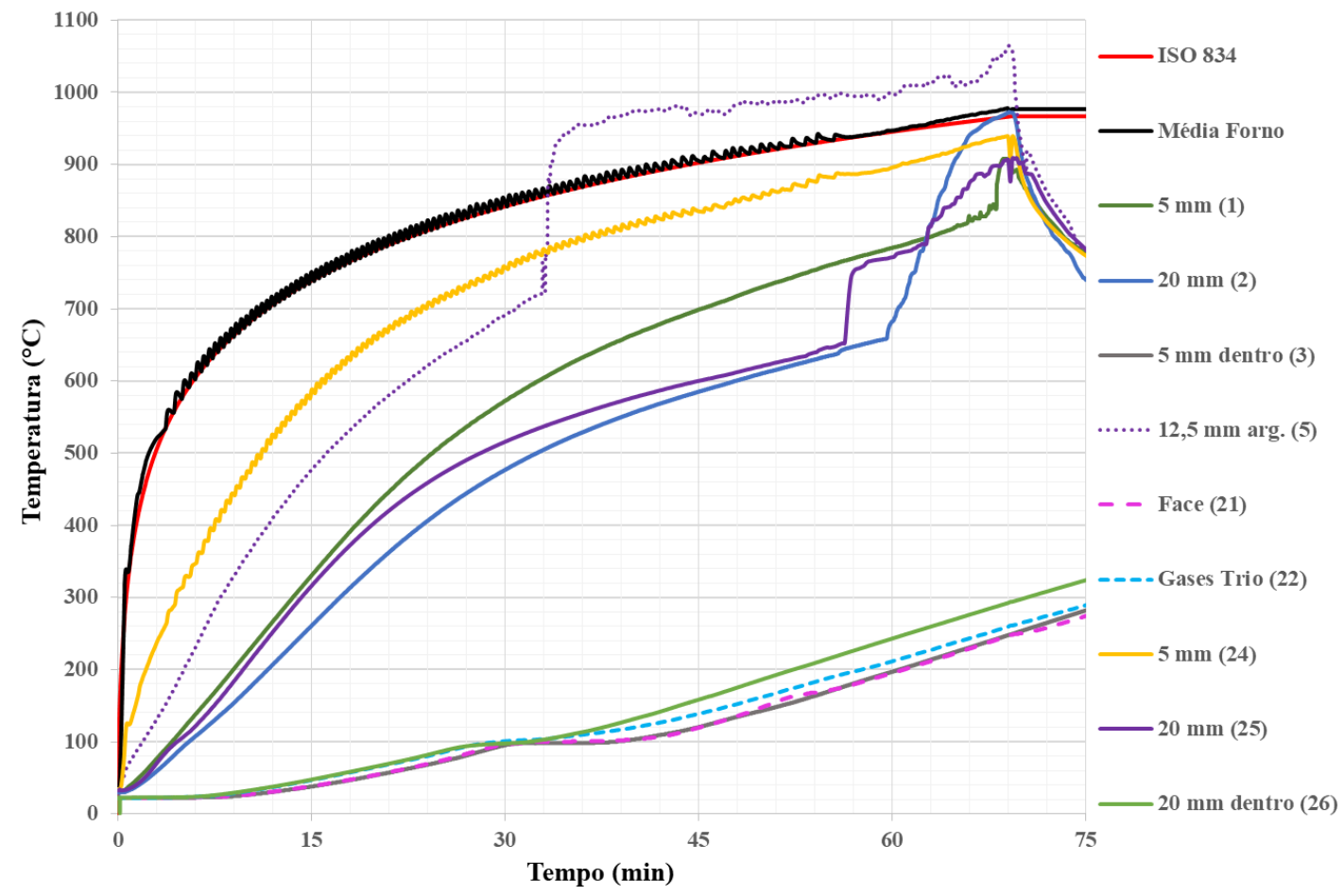

(b)

Fonte: Dupim (2019) 
Dupim (2019) comenta que foram selecionadas as curvas com resultados mais condizentes com o tipo de comportamento esperado para inserção nestes gráficos. As curvas da Figura 2.43 que apresentaram saltos acentuados a partir de determinados tempos de incêndio deixaram de retratar a realidade em virtude do possível contato da instrumentação com os gases quentes do forno. Dupim (2019) comenta que a evolução de temperatura ao longo da seção transversal para os blocos e pequenas paredes estiveram bastante próximas entre si.

Para o trio de paredes, em relação ao critério de isolamento térmico, este foi atingido com o tempo de 61 minutos. Lembrando que, na disposição realizada por Dupim (2019), apesar de não haver exposição ao fogo na face protegida, ocorre o confinamento de gases quentes no interior do trio de paredes em virtude da própria transferência de calor ao longo da seção transversal. Em virtude da impossibilidade da troca de calor diretamente com o ambiente, o que reduziria a temperatura nesta face, o autor considera a situação ensaiada mais crítica que aquelas ensaiadas em fornos verticais, como executado por Lopes et al. (2018).

Em relação à resistência residual das pequenas paredes sem revestimento e com resistência de 4,0 MPa, para a situação com exposição ao fogo em todas as faces, foi obtida relação de $14 \%$ entre a resistência pós-fogo e à temperatura ambiente, enquanto que, com exposição em uma única face, foi de 46\%. Para paredes com resistência de 10,0 MPa, o valor obtido considerando fogo em ambas as faces, foi de $13 \%$.

Para a segunda fornada, Dupim (2019) ensaiou paredes com revestimento em gesso, a partir dos mesmos procedimentos citados anteriormente. No entanto, estas fornadas ocorreram até o tempo de 120 minutos. Não houve, neste caso, a execução do trio de paredes verificado na primeira fornada.

As pequenas paredes com resistência menor apresentaram resistência residual de $11 \%$, enquanto as paredes com maior resistência, obtiveram resistência residual de $4 \%$.

Dentre os trabalhos citados nesta revisão, aqueles com maiores relevâncias quanto ao fornecimento de dados de entrada para os modelos numéricos e comparações com resultados experimentais foram os seguintes: Oliveira (2014), Izquierdo (2015), Rodovalho (2018), Lopes et al. (2018) e Dupim (2019). Maiores detalhes destes trabalhos, quando necessários, estão inseridos nos próximos capítulos. 


\section{ASPECTOS REFERENTES À ESTRATÉGIA DE MODELAGEM NUMÉRICA}

Freitas (2008) define modelos constitutivos como simplificações matemáticas que aproximam um comportamento físico complexo dentro de certas circunstâncias. Eles possuem grande relevância para a representação do comportamento físico dos materiais, uma vez que é impossível a reprodução exata de toda a informação presente na natureza. A escolha adequada do modelo constitutivo é de suma relevância para a obtenção de resultados próximos à realidade, os quais contemplem o comportamento do material, tais como os valores de ruptura, a relação tensão-deformação do material e a resposta pós-pico de carregamento da estrutura.

Além das propriedades dos materiais, os resultados também dependem, dentre outros fatores, da geometria e da malha de elementos finitos adotada. Para a formulação das relações não-lineares, as teorias usualmente utilizadas são a plasticidade e a mecânica do dano. Para o concreto e a alvenaria, estruturas onde ocorre fissuração, a qual é responsável de modo dominante pela não-linearidade, as formulações da mecânica do dano são bastante representativas.

A pequena parede de alvenaria estrutural de blocos de concreto estudada neste trabalho possui as dimensões mostradas na Figura 3.1, conforme especifica a ABNT NBR 16522:2016. Seu comprimento é equivalente ao comprimento de dois blocos de $39 \mathrm{~cm}$ juntamente com uma junta vertical de $1 \mathrm{~cm}$, totalizando $79 \mathrm{~cm}$, a altura aproximada equivale a cinco vezes a altura do bloco $(19 \mathrm{~cm})$ juntamente com as juntas horizontais $(1 \mathrm{~cm})$, totalizando $99 \mathrm{~cm}$.

Figura 3.1 - Esquematização das dimensões da pequena parede

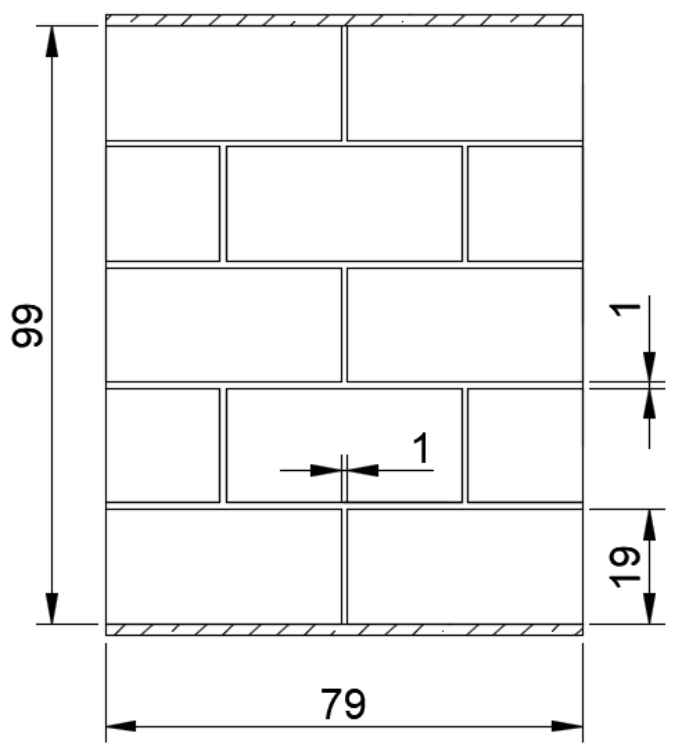


Quanto à espessura, nos modelos estruturais e térmicos foram estudadas aquelas com 14 e $19 \mathrm{~cm}$, enquanto no termoestrutural foi considerada apenas espessura igual a $14 \mathrm{~cm}$. Para o argamassamento, verificados tanto o total quanto o parcial para os modelos estruturais e o argamassamento total para os demais modelos.

Neste capítulo são apresentadas as estratégias e parâmetros utilizados para modelagem das pequenas paredes para as análises estrutural, térmica e termoestrutural, sendo, inicialmente, apresentados alguns estudos preliminares que definiram parâmetros gerais utilizados em todas as análises. No Apêndice $\boldsymbol{E}$, estão indicadas breves informações referentes à nomenclatura dos modelos e das propriedades de interface do ABAQUS.

\subsection{ANÁLISES PRELIMINARES}

Para a definição do modelo a ser utilizado nas pequenas paredes de blocos de concreto, foram realizadas algumas análises iniciais em prismas de 3 blocos de concreto, conforme Rodovalho (2018), uma vez que o esforço computacional resultou significativamente menor, o que possibilitou um grande número de análises. Desta forma, entende-se que as definições seguintes podem estender-se às pequenas paredes por não estarem diretamente ligadas ao comportamento da parede em si, mas à definição de parâmetros da modelagem numérica.

\subsubsection{Técnicas de modelagem}

As técnicas de modelagem a serem utilizadas em estruturas dependem do nível de precisão e da simplicidade em que se buscam obter os resultados. As estratégias possíveis existentes são a micromodelagem e a macromodelagem, ambas, de forma aproximada. $\mathrm{Na}$ micromodelagem, os componentes da alvenaria estrutural são discretizados individualmente, enquanto na macromodelagem, estes são considerados como compósito.

A Figura 3.2 exemplifica as três técnicas de modelagem, estando, na sequência do texto, a descrição detalhada de cada qual. 
Figura 3.2 - Técnicas de modelagem da alvenaria: (a) exemplar da alvenaria; (b) micromodelagem detalhada; (c) micromodelagem simplificada; (d) macromodelagem

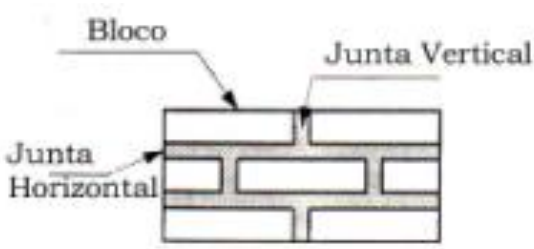

(a)

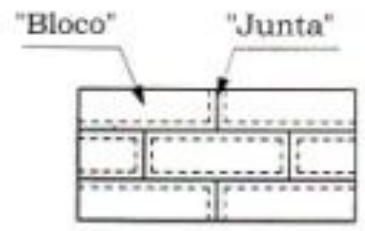

(c)

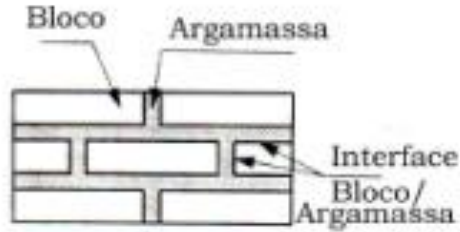

(b)

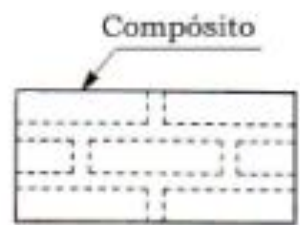

(d)

Fonte: Lourenço (1996)

\subsubsection{Micromodelagem detalhada}

Neste tipo de modelagem faz-se necessário considerar as características mecânicas das unidades e da argamassa, como no caso do módulo de elasticidade, do coeficiente de Poisson e, opcionalmente, das propriedades não-lineares (OLIVEIRA, 2014). Desta forma, tanto as unidades como a argamassa são representados como elementos contínuos.

A grande vantagem deste tipo de modelagem se refere ao nível de detalhamento dos resultados obtidos em relação à ação conjunta entre as unidades, a argamassa e a interface. Por outro lado, sua grande desvantagem diz respeito ao maior tempo de processamento em relação às demais técnicas, uma vez que necessita de malha com alto grau de refinamento e grande quantidade de parâmetros.

Esta foi a técnica escolhida para as análises realizadas no presente trabalho, e também adotada por Rodovalho (2018), considerando separadamente bloco e junta de argamassa, bem como as placas superior e inferior.

\subsubsection{Micromodelagem simplificada}

Neste tipo de modelagem, as unidades são representadas por elementos contínuos, sendo que as juntas de argamassa e a interface se tornam um único elemento descontínuo, de espessura nula (PELETEIRO, 2002). Neste caso, as dimensões das unidades sofrem uma expansão de suas medidas a fim de permanecer as características geométricas reais da estrutura. Os resultados apresentam boa precisão, porém inferiores a micromodelagem detalhada. $\mathrm{O}$ efeito de Poisson das argamassas é desprezado nesta técnica. 


\subsubsection{Macromodelagem}

A alvenaria é considerada como um meio contínuo, anisotrópico com propriedades homogêneas. Assim, as unidades, a argamassa e a interface ficam dispersas neste meio. Para esta abordagem, são necessárias técnicas de homogeneização para determinação da matriz de um material homogêneo fictício, equivalente à alvenaria com as propriedades inicialmente estudadas.

A macromodelagem é a técnica que proporciona maior praticidade dentre as demais técnicas citadas, apresentando tempo de processamento reduzido, economia da memória dos computadores e criação de malhas mais simples

\subsubsection{Elementos finitos utilizados}

Todos os componentes envolvidos nas análises deste trabalho foram criados a partir de elementos finitos do tipo C3D8R, disponibilizado na biblioteca interna do ABAQUS. Trata-se de elemento finito contínuo (sólidos), tridimensionais de 8 nós (elementos lineares) e com integração reduzida. Maiores detalhes a respeito desse elemento podem ser consultados no Apêndice $\boldsymbol{E}$ do presente trabalho.

O uso de elementos finitos tridimensionais fez-se necessário devido à complexidade do problema, uma vez que se busca análise com maior profundidade e detalhamento relativo aos estados de tensões e deformações para validação dos modelos. Os graus de liberdade incluídos nas análises se referem diretamente aos deslocamentos e forças no modelo estrutural, temperaturas ao longo da seção da parede na análise térmica, bem como rotações na análise termoestrutural.

Quanto ao uso de elementos finitos de oito nós, os quais utilizam interpolação linear em cada direção, vale destacar que a escolha se deu com base em Rodovalho (2018), Santos (2016), Mohamad e Chen (2016) e Ayala (2010), cujas referências obtiveram resultados significativos em suas abordagens numéricas. Além disso, o uso de interpolação de segunda ordem levaria a um maior esforço computacional, o que não necessariamente significa a obtenção de resultados melhores em relação aos de interpolação linear. Quanto à integração reduzida, esta diminui consideravelmente o tempo de processamento, sobretudo em problemas tridimensionais não comprometendo a precisão dos resultados. 


\subsubsection{Geometria}

Quanto à geometria dos elementos constituintes do modelo numérico foram realizadas duas simplificações, sendo elas:

- Utilização de geometria plana dos blocos de concreto, em detrimento da geometria tronco-cônica medidas experimentalmente, e;

- Utilização de dimensões modulares para os blocos de concreto, não utilizando o valor médio das dimensões obtidas experimentalmente.

O motivo das simplificações visa melhorar o desempenho computacional quando realizada a modelagem de paredes, principalmente no caso termoestrutural, uma vez que na inserção de meio blocos a necessidade de partição dos elementos é elevada para que haja coincidência dos nós, além dessa maior partição poder gerar distorções acima dos limites tolerados aos elementos finitos, em situações de refinamentos menores. Adicionalmente, a utilização de geometrias com menores particularidades passa a ser relevante para a obtenção de modelos com maior generalização das situações.

Para tanto, foram modelados prismas de três blocos para análises preliminares, baseando-se em Rodovalho (2018) e em Oliveira (2014). Para a primeira simplificação é possível visualizar através da Figura 3.3 a variação das dimensões dos elementos finitos ao longo da altura do bloco, principalmente ao longo dos septos, conforme destaque.

Figura 3.3 - Comparação da malha com geometria tronco-cônica (a) e plana (b) dos blocos de concreto

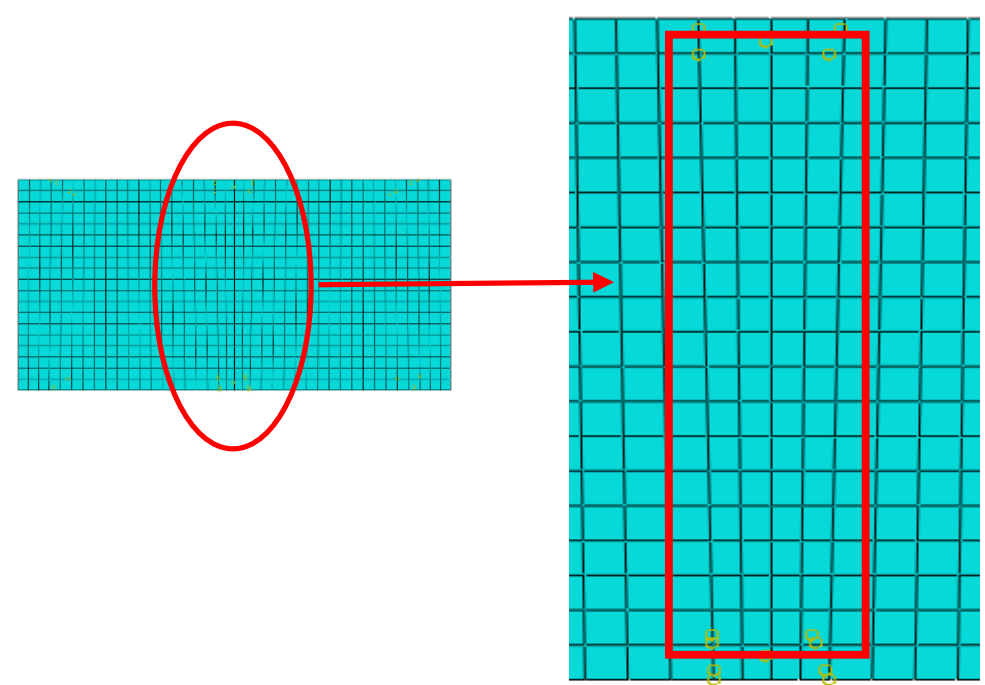

(a)

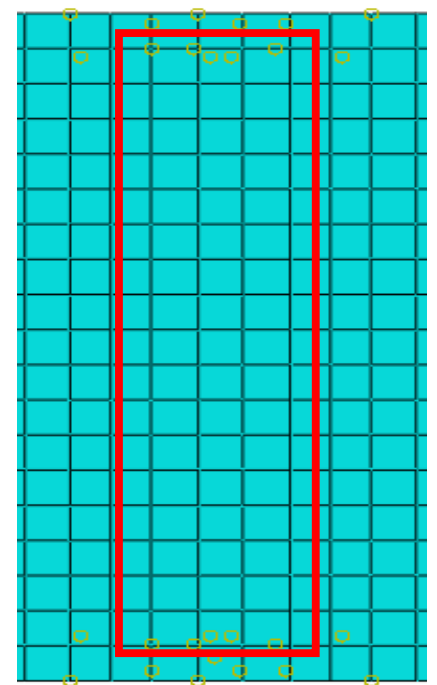

(b) 
Para a obtenção da geometria plana, foi calculada a média entre as dimensões das paredes longitudinais, transversais e septos dos blocos superiores e inferiores, cujos valores também eram a média dos blocos analisados experimentalmente, com o objetivo de permanecer com área líquida próxima aos valores experimentais. Buscando ainda maior simplificação, estes valores foram aproximados para valores inteiros, em centímetros, bem como dimensões modulares externas, obtendo-se resultados comparativos quanto ao diagrama tensãodeformação, conforme Figura 3.4, para as duas situações citadas.

Figura 3.4 - Comparação do diagrama tensão-deformação experimental de prismas de 3

blocos com os resultados numéricos

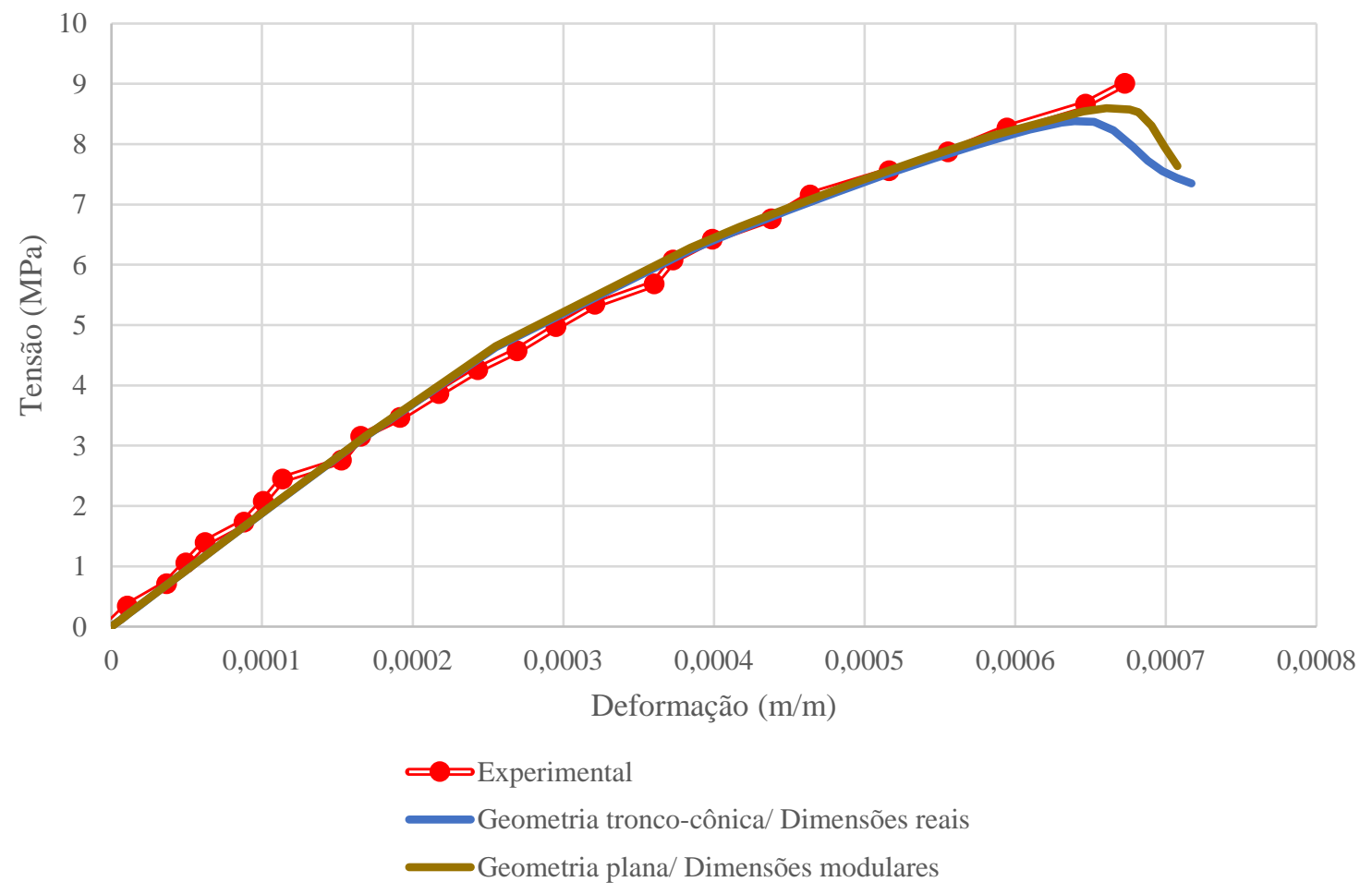

A diferença obtida em relação à tensão de ruptura entre os dois diagramas numéricos foi inferior a $3 \%$ e, em relação à deformação, inferior a 4\%. Em relação aos resultados experimentais, o uso de geometria plana com dimensões modulares divergiu em 5\% em relação à tensão, e em $2 \%$ em relação à deformação, enquanto que o modelo com geometria troncocônica e dimensões reais divergiu em 7 e $5 \%$, respectivamente.

Desta forma, entende-se que as simplificações não geraram grandes variações em relação aos resultados com geometrias com maior detalhamento, obtendo-se assim resultados bastante próximos aos valores experimentais, o que justifica tais simplificações. O Quadro 3.1 indica as medidas utilizadas para os modelos em análise. 
Quadro 3.1 - Dimensões médias dos blocos e meio blocos de concreto experimentais

\begin{tabular}{|ccccccc|}
\hline & \multicolumn{3}{c}{ Bloco } & \multicolumn{3}{c|}{ Meio bloco } \\
Referência & Largura & Altura & Comp. & Largura & Altura & Comp. \\
& $(\mathrm{cm})$ & $(\mathrm{cm})$ & $(\mathrm{cm})$ & $(\mathrm{cm})$ & $(\mathrm{cm})$ & $(\mathrm{cm})$ \\
\hline \multirow{2}{*}{ Oliveira (2014) } & 13,931 & 19,156 & 39,057 & 14,042 & 18,950 & 19,046 \\
\hline \multirow{2}{*}{ Dupim (2019) } & 13,925 & 18,980 & 39,022 & 13,820 & 18,800 & 19,058 \\
\cline { 2 - 7 } & 19,026 & 19,031 & 39,047 & 18,984 & 19,062 & 18,999 \\
\hline \multirow{2}{*}{ Modelo numérico } & 14,000 & 19,000 & 39,000 & 14,000 & 19,000 & 19,000 \\
\cline { 2 - 7 } & 19,000 & 19,000 & 39,000 & 19,000 & 19,000 & 19,000 \\
\hline
\end{tabular}

As dimensões das paredes longitudinais e transversais, bem como dos septos, resultou igual a 3,0 cm para os blocos de $14 \mathrm{~cm}$ de largura, e igual a 3,5 cm para os blocos de $19 \mathrm{~cm}$ de largura. Estes valores, conforme já comentado anteriormente esteve próximo aos valores de área líquida medidas experimentalmente, com desvio inferior a 5\%. As geometrias dos componentes das pequenas paredes e as partições necessárias de acordo com as definições anteriores estão mostradas na Figura 3.5.

Figura 3.5 - Elementos sólidos: bloco (a), meio bloco (b), argamassa (c) e placa de reação (d)

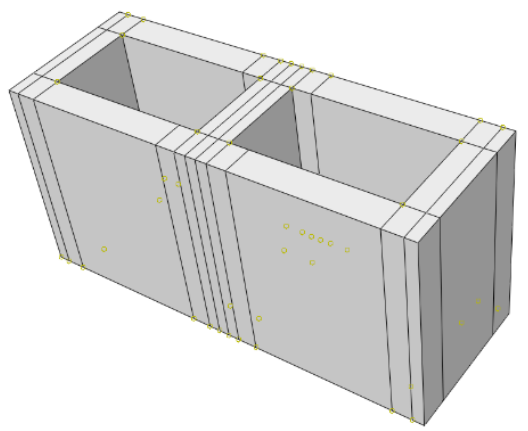

(a)

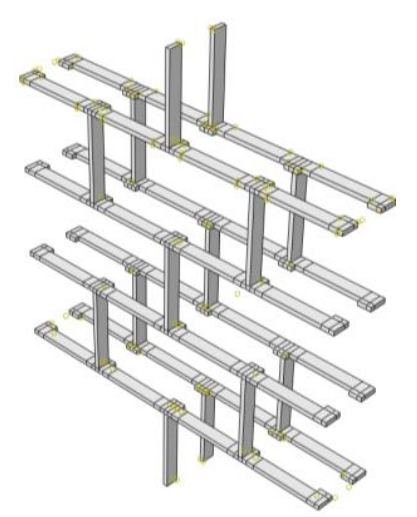

(c)

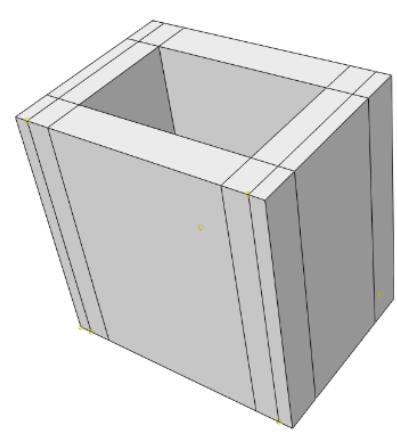

(b)

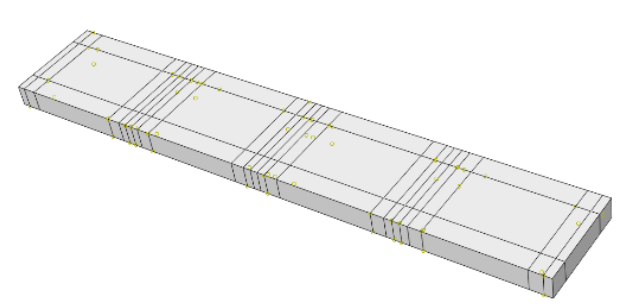

(d) 


\subsubsection{Refinamento da malha}

O refinamento da malha dos blocos e juntas de argamassa também foi previamente estudado em prismas de três blocos com o intuito de obter definições para as análises posteriores em paredes.

Uma vez que no presente trabalho se propõe obter modelagem numérica representativa quanto aos resultados e eficiente quanto aos custos computacionais, buscou-se a menor densidade possível, em elementos finitos, a qual resultasse em comportamentos próximos aos obtidos pelos resultados experimentais. A Figura 3.6 indica o refinamento da malha para os quatro casos estudados.

Figura 3.6 - Discretizações realizadas nos blocos de concreto com 0,5 cm (a), 1,0 cm (b), 1,5 $\mathrm{cm}(\mathrm{c})$ e $3,0 \mathrm{~cm}(\mathrm{~d})$

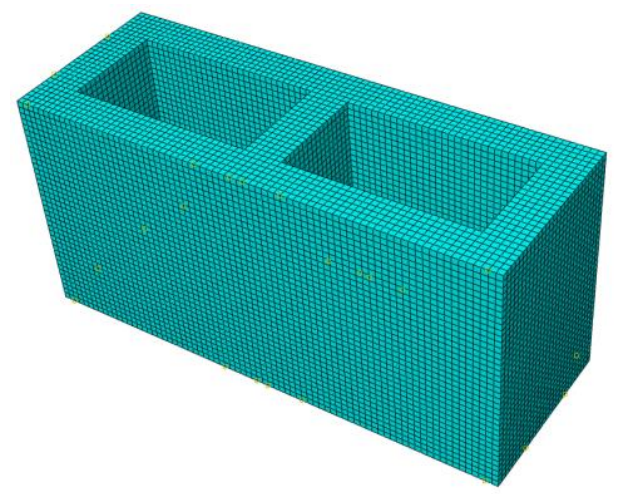

(a)

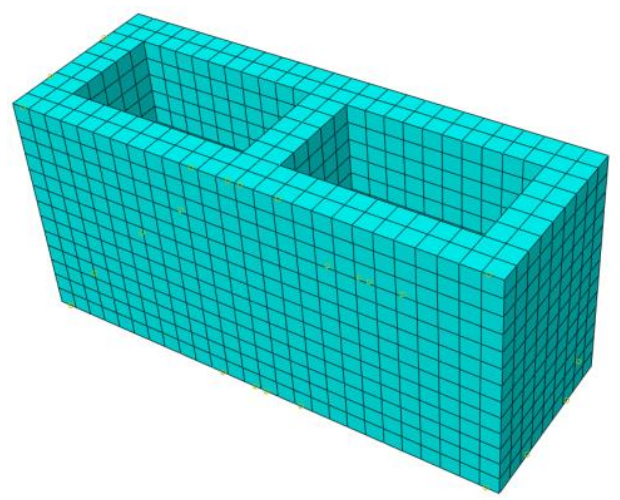

(c)

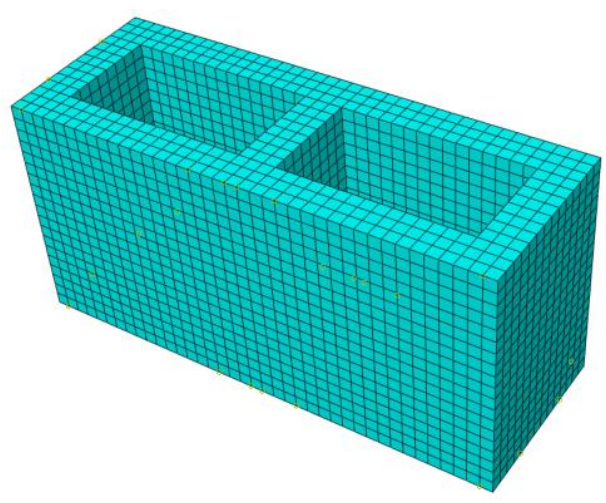

(b)

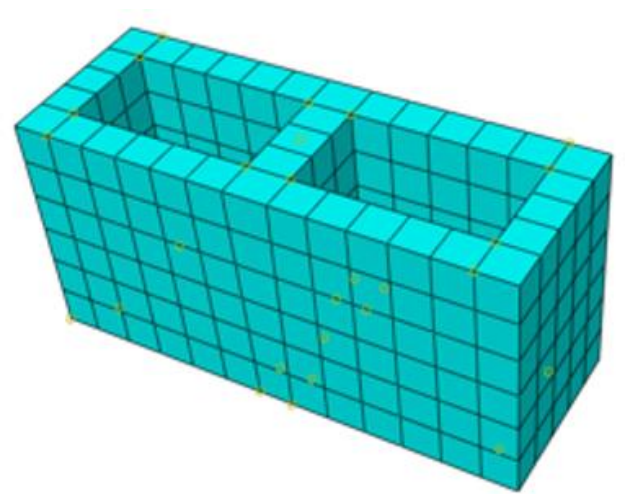

(d)

A Tabela 3.1 indica os valores comparativos obtidos para os quatro tamanhos de malha de elementos finitos testadas em relação à quantidade total de elementos e o tempo de processamento para prismas de três blocos. Em relação à curva tensão-deformação, os modelos com malha diferentes apresentaram os resultados conforme Figura 3.7. 
Tabela 3.1 - Comparação entre as discretizações realizadas nos prismas de 3 blocos

\begin{tabular}{ccc} 
Malha (cm) & Quantidade de elementos & Tempo de processamento $(\mathbf{m i n}) *$ \\
\hline $\mathbf{0 , 5}$ & 177.060 & 740 \\
\hline $\mathbf{1 , 0}$ & 22.832 & 60 \\
\hline $\mathbf{1 , 5}$ & 9.524 & 20 \\
\hline $\mathbf{3 , 0}$ & 904 & 5 \\
\hline
\end{tabular}

*Processador: Intel Core i7-7700 CPU 3.60Hz; Memória RAM 16,0 GB; Sistema Operacional de 64 bits

Figura 3.7 - Comparação do diagrama tensão-deformação experimental de prismas de 3 blocos com os resultados numéricos com diferentes malhas

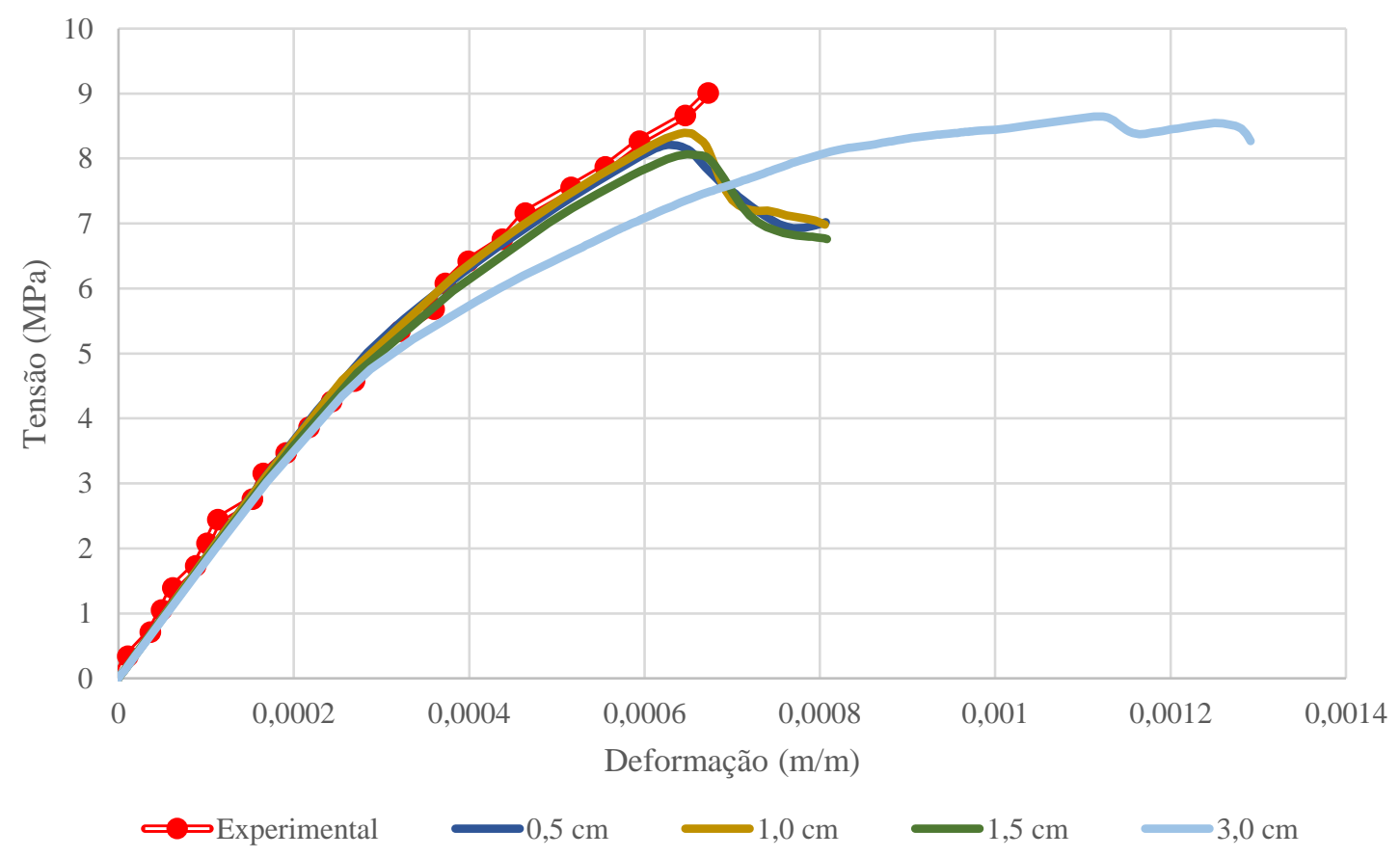

Em relação ao ponto de ruptura as variações percentuais que cada modelo apresentou em relação aos resultados experimentais estão expressos na Tabela 3.2.

Tabela 3.2 - Comparação dos resultados obtidos por cada malha em relação à tensão de ruptura e respectiva deformação

\begin{tabular}{ccc} 
Malha $(\mathbf{c m})$ & $\begin{array}{r}\text { Variação quanto à } \\
\text { tensão }(\boldsymbol{\%})\end{array}$ & $\begin{array}{c}\text { Variação quanto à } \\
\text { deformação }(\mathbf{\%})\end{array}$ \\
\hline $\mathbf{0 , 5}$ & $-8,8$ & $-6,8$ \\
\hline $\mathbf{1 , 0}$ & $-6,8$ & $-4,1$ \\
\hline $\mathbf{1 , 5}$ & $-10,4$ & $-3,6$ \\
\hline $\mathbf{3 , 0}$ & $-4,0$ & 66,5 \\
\hline
\end{tabular}


Considerando os resultados apresentados, é possível notar que os modelos com maiores refinamentos se apresentaram mais próximos aos resultados experimentais, o que era esperado. Optou-se neste trabalho em usar nos modelos estrutural e térmico, malhas com 1,0 cm, e, nos modelos termoestruturais, malhas com $1,5 \mathrm{~cm}$, em virtude do custo computacional.

Em relação ao uso de refinamentos variáveis para blocos e juntas de argamassa, estes testes também foram testados, porém, sem apresentar divergências significativas, optando-se, portanto, em utilizar malhas iguais para os elementos envolvidos.

Faz-se relevante comentar que o uso de malha com densidade muito baixa para o problema estudado pode ocasionar em grande perda de precisão quanto aos resultados esperados. Além disso, na ocasião do particionamento dos elementos, existe a possibilidade de ocorrência de distorções acima dos limites estabelecidos pelo programa computacional para os elementos finitos, levando a análises inconsistentes.

\subsubsection{Geometria da placa de reação}

No modelo numérico optou-se por criar placas de reação superior e inferior para buscar simular os equipamentos de ensaio. Da forma idealizada, isto possibilita possíveis deslizamentos entre as superfícies superiores e inferiores dos blocos e juntas de argamassa junto às respectivas placas, conforme ocorre esta possibilidade ao longo do ensaio.

Porém, para verificar possíveis concentrações de tensão na placa superior, o que poderia comprometer os resultados numéricos do prisma propriamente dito, foram testados modelos considerando placas com espessuras de $2 \mathrm{~cm}$ e de $20 \mathrm{~cm}$, em ambos os casos com propriedades mecânicas na ordem de 10 vezes o módulo de elasticidade dos blocos. A Figura 3.8 indica as duas geometrias citadas.

Figura 3.8 - Malha das placas com alturas de $2 \mathrm{~cm}$ (a) e de $20 \mathrm{~cm}$ (b)

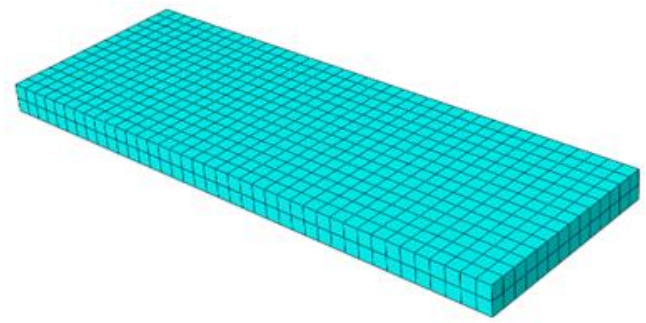

(a)

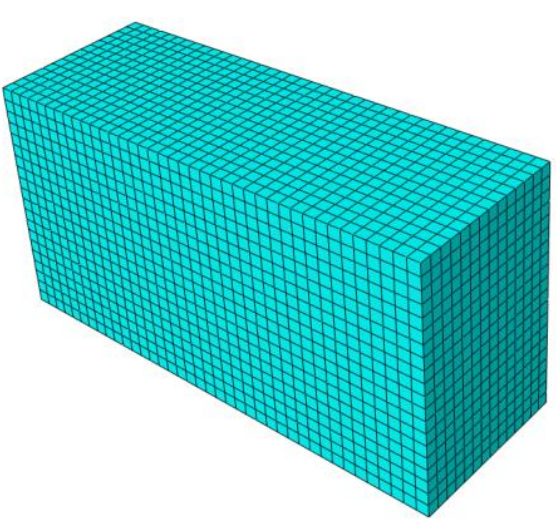

(b) 
A diferença percentual para o ponto de ruptura foi inferior a $0,2 \%$ para a tensão máxima e nula para a deformação respectiva. $\mathrm{O}$ uso de placas com espessura menor se justifica pela menor quantidade de elementos para análise do problema. Desta forma, o custo computacional resulta bastante reduzido.

\subsubsection{Mecanismos de contato}

O acoplamento entre as superfícies dos blocos e juntas pode ser feito de diversas formas dependendo das restrições e propriedades de interface impostas. No trabalho de Rodovalho (2018) utilizou-se como mecanismo de contato entre os blocos e as juntas horizontais a ferramenta tie, a qual não permite deslocamento diferencial entre as superfícies dos materiais distintos. Porém, para as paredes, devido principalmente à maior esbeltez para a análise estrutural e à expansão térmica na análise termoestrutural, optou-se por utilizar as ferramentas de interação de contato denominadas interaction, as quais possibilitam tais deslocamentos.

Quanto à interface entre a placa e o bloco, Rodovalho (2018) considerou a existência de interação de contato normal e tangencial, tendo este último, coeficiente de atrito de 0,6 . Neste trabalho também se fez tal consideração.

Figura 3.9 - Comparação do diagrama tensão-deformação experimental de prismas de 3

blocos com os resultados numéricos com diferentes mecanismos de contato

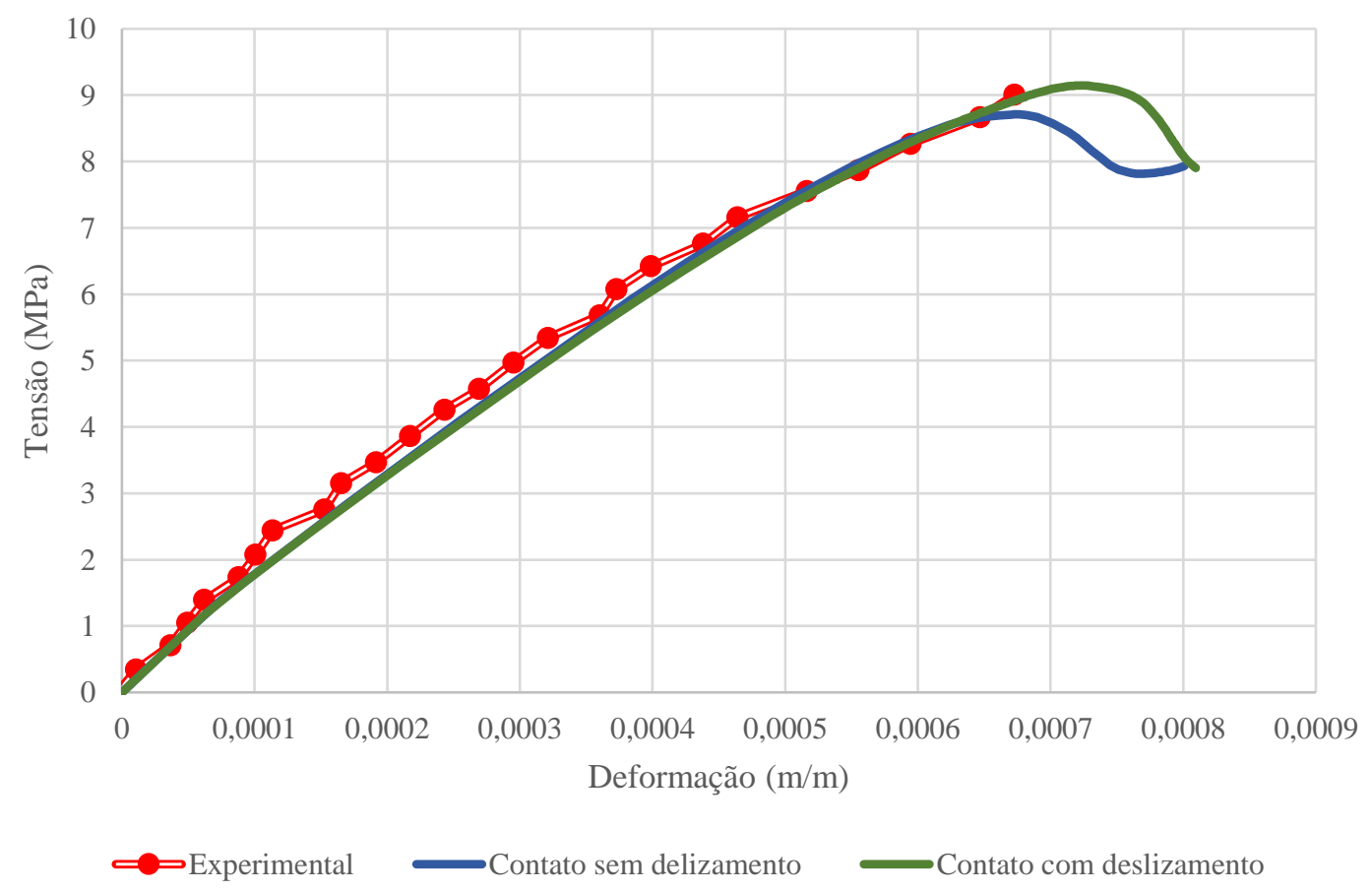

De forma análoga aos itens anteriores, foram analisadas situações com ambos os tipos de contato para prismas de 3 blocos de concreto, para comparação quanto aos resultados 
experimentais. A Figura 3.9 indica os diagramas tensão-deformação para modelos com e sem consideração de deslizamento entre os materiais, enquanto os desvios percentuais quanto ao ponto de ruptura do prisma estão indicados na Tabela 3.3.

Tabela 3.3 - Comparação dos resultados obtidos por cada mecanismo de contato em relação à tensão de ruptura e respectiva deformação

\begin{tabular}{rcc} 
Mecanismo de contato & $\begin{array}{c}\text { Variação quanto à } \\
\text { tensão }(\boldsymbol{\%})\end{array}$ & $\begin{array}{c}\text { Variação quanto à } \\
\text { deformação }(\%)\end{array}$ \\
\hline Sem deslizamento & 3,3 & 0,6 \\
\hline Com deslizamento & 1,6 & 7,6 \\
\hline
\end{tabular}

De forma condizente, o modelo que faz consideração de deslizamento obteve resultados com maiores deformações na ruptura do prisma em relação ao modelo utilizando a ferramenta tie. Quanto ao valor de tensão, obteve aproximação pouco melhor. Para a situação do prisma, a modelagem com tie apresentou resultados melhores, porém, como citado no início deste item, para o comportamento das pequenas paredes onde há a inclusão de juntas verticais, além das horizontais, optou-se por considerar deslizamento entre os diferentes materiais.

$\mathrm{O}$ coeficiente de atrito utilizado nas modelagens, considerando as juntas horizontais e verticais com os blocos e meio blocos, entre as placas e as respectivas superfícies de blocos, de meio blocos e da argamassa, foi igual a 0,6 , com base em calibrações do próprio modelo. Vale lembrar ainda que se utilizou a interação de contato normal do tipo hard contact, para não permitir que um material se adentre no outro.

Como exemplo dos dois mecanismos comentado, a Figura 3.10 exemplifica o deslizamento ocorrente entre bloco e argamassa para determinado carregamento.

Figura 3.10 - Comparação em escala aumentada da interface entre bloco e junta de argamassa utilizando a ferramenta tie (a) e interaction (b)

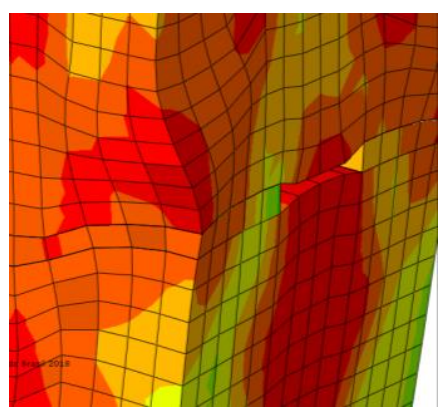

(a)

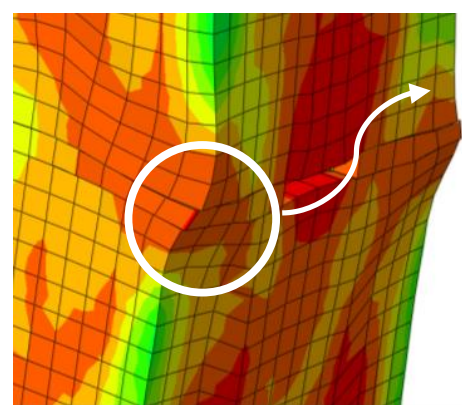

(b)

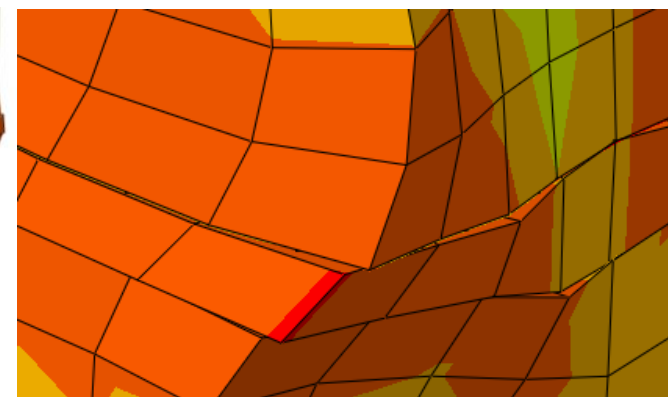




\subsection{MODELO NUMÉRICO VOLTADO À ANÁLISE ESTRUTURAL}

\subsubsection{Considerações iniciais}

Para o comportamento dos materiais foi admitida a não-linearidade do material, considerando o dano devido ao aumento do carregamento aos materiais, além da nãolinearidade geométrica. A aplicação do carregamento foi feita por incrementos de deslocamento visando simular da forma mais precisa possível a aplicação do carregamento no ensaio experimental.

Quanto aos modelos de plasticidade, o ABAQUS possui diversos tipos possíveis para a modelagem do comportamento das estruturas, de acordo com o comportamento de seus materiais. Para o concreto, existem dois modelos principais fornecidos pelo software, sendo eles, o Concrete Smeared Cracking (CSC) e o Concrete Damaged Plasticity (CDP). De acordo com o Manual do ABAQUS (2013), ambos os tipos de modelos podem ser usados para materiais quase-frágeis.

A diferença entre os modelos consiste principalmente no tipo de carregamento, onde o CSC permite como entrada carregamentos apenas monotônicos, enquanto o CDP permite carregamentos tanto monotônico quanto cíclico ou dinâmico em baixas pressões de confinamento. Além disso, o CDP tem capacidade para rastrear o progresso da fissuração ocorrente através de todo o histórico de carregamento, sendo que no caso do CSC isto não é possível. Neste trabalho foi feito uso do modelo CDP por ser mais abrangente e por este também ter sido utilizado nos trabalhos de Rodovalho (2018), Santos (2016), Mohamad e Chen (2016) e Ayala (2010).

O comportamento inelástico do concreto, no caso do CDP, é representado através de conceitos de elasticidade isotrópica com dano no material em combinação com tensões de compressão e de tração já no regime de plasticidade do material. Este modelo permite a simulação do comportamento não-linear da alvenaria de blocos de concreto. Os modos de falha referem-se às fissuras devidas às tensões de tração ou esmagamentos por compressão.

No presente trabalho, para validação dos modelos tensão-deformação e danos correspondentes, os parâmetros foram baseados em modelos primários anteriormente propostos por Lubliner et al. (1989), Lee e Fenves (1998) e Mohamad e Chen (2016), os quais se baseiam no CDP. Desta forma, a resposta uniaxial compressiva e de tração do concreto é descrito por plasticidade e dano como mostrado na Figura 3.11.

No caso de tensão uniaxial, a curva tensão-deformação segue uma relação elástica linear até atingir um determinado valor de tensão. Este ponto corresponde ao aparecimento de 
microfissuras no concreto. Após este trecho inicial, a resposta da curva tensão-deformação, já no regime plástico, é caracterizada pelo regime de hardening (trecho ascendente) até a tensão de ruptura e pelo trecho de softening (trecho descendente), logo após a tensão citada, conforme indicado na Figura 3.11.

Figura 3.11 - Comportamento do concreto para carregamento uniaxial para tração (a) e compressão (b)

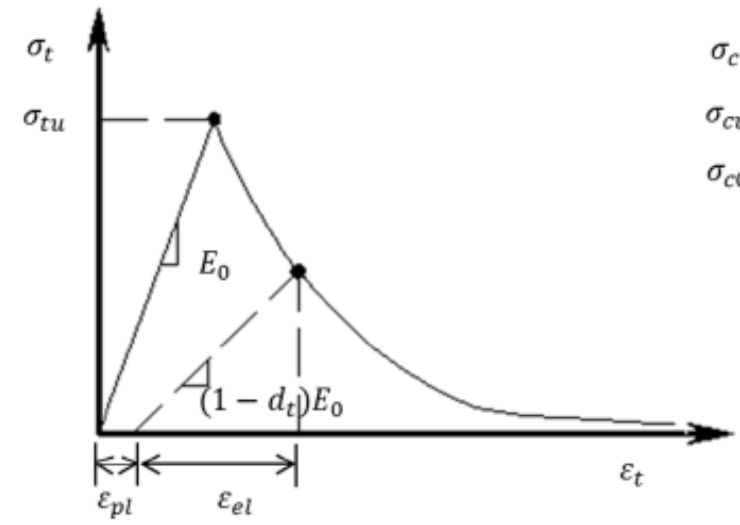

(a)

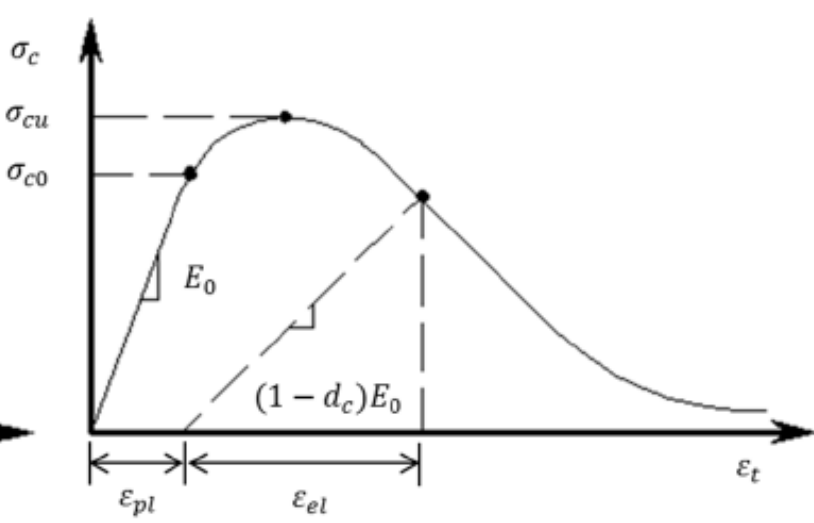

(b)

Fonte: ABAQUS (2013)

A representação deste modelo, apesar de simplificada, possibilita obter as principais características da resposta do concreto. O ABAQUS faz a conversão das curvas de tensãodeformação uniaxial em tensão-deformação plástica automaticamente, a partir dos dados de entrada relativos às deformações inelásticas, como visto na sequência:

$$
\begin{aligned}
& \sigma_{t}=\sigma_{t}\left(\varepsilon_{t}^{p l}, \dot{\varepsilon}_{t}^{p l}, \theta, f_{i}\right) \\
& \sigma_{c}=\sigma_{c}\left(\varepsilon_{c}^{p l}, \dot{\varepsilon}_{c}^{p l}, \theta, f_{i}\right)
\end{aligned}
$$

Onde:

$t$ e $c$ : índices relativos às tensões de tração e compressão, respectivamente;

$\varepsilon_{t}^{p l}$ e $\varepsilon_{c}^{p l}:$ deformações plásticas relativas à tração e à compressão, respetivamente;

$\dot{\varepsilon}_{t}^{p l}$ e $\dot{\varepsilon}_{c}^{p l}$ : taxas de deformações plásticas relativas à tração e à compressão, respetivamente;

$\theta$ : temperatura;

$f_{i},(i=1,2, \ldots)$ outras variáveis de campo pré-definidas. 
Este modelo considera a existência de duas variáveis de dano, conforme equações (3.3) e (3.4), com o intuito de ser feita a devida consideração para a resposta do descarregamento das curvas. Estas variáveis são assumidas como função das deformações plásticas, temperatura e demais variáveis envolvidas.

$$
\begin{aligned}
& d_{t}=\sigma_{t}\left(\varepsilon_{t}^{p l}, \theta, f_{i}\right) ; 0 \leq d_{t} \leq 1 \\
& d_{c}=\sigma_{c}\left(\varepsilon_{c}^{p l}, \theta, f_{i}\right) ; 0 \leq d_{c} \leq 1
\end{aligned}
$$

Considerando as duas últimas equações, vale ressaltar que o valor limite inferior representa o material não danificado, enquanto o limite superior representa a situação totalmente danificada. Desta forma, se considerada a rigidez inicial não-danificada do material como $E_{0}$, as relações tensão-deformação sob carregamentos uniaxiais de tração ou compressão podem ser escritas, respectivamente, pelas equações (3.5) e (3.6).

$$
\begin{aligned}
& \sigma_{t}=\left(1-d_{t}\right) \cdot E_{0} \cdot\left(\varepsilon_{t}-\varepsilon_{t}^{p l}\right) \\
& \sigma_{c}=\left(1-d_{c}\right) \cdot E_{0} \cdot\left(\varepsilon_{c}-\varepsilon_{c}^{p l}\right)
\end{aligned}
$$

Donde define-se como tensões "efetivas" de tração e de compressão como, respectivamente:

$$
\begin{aligned}
& \bar{\sigma}_{t}=\frac{\sigma_{t}}{\left(1-d_{t}\right)}=E_{0} \cdot\left(\varepsilon_{t}-\varepsilon_{t}^{p l}\right) \\
& \bar{\sigma}_{c}=\frac{\sigma_{c}}{\left(1-d_{c}\right)}=E_{0} \cdot\left(\varepsilon_{c}-\varepsilon_{c}^{p l}\right)
\end{aligned}
$$

Na condição tridimensional com carregamentos multiaxiais, a expressão (3.8) pode ser reescrita conforme equação (3.9), em que $D_{0}^{e l}$ é a matriz de elasticidade inicial (sem dano).

$$
\sigma_{t}=\left(1-d_{t}\right) \cdot D_{0}^{e l}:\left(\varepsilon_{t}-\varepsilon_{t}^{p l}\right)
$$

\subsubsection{Condições de contorno}

Para as condições de contorno, a fim de simular o ensaio realizado por Oliveira (2014), Izquierdo (2015) e Dupim (2019), foram criadas as seguintes condições de contorno: 
- Superior: foram impossibilitadas as translações nos planos perpendiculares a altura da parede em sua face superior;

- Inferior: foram travados quaisquer tipos de movimento na base.

Na Figura 3.12 estão esquematizadas as condições de contorno impostas para a pequena parede.

Figura 3.12 - Condições de contorno para a pequena parede

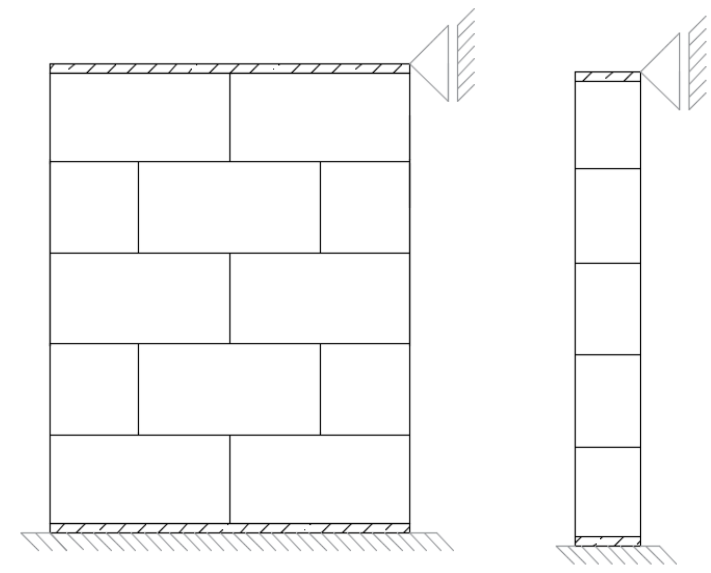

Baseando-se nos resultados obtidos por Oliveira (2014) e Dupim (2019), foram impostos, como carregamentos, deslocamentos superiores aos valores de ruptura da pequena parede, locados conforme visto na Figura 3.13, simulando o respectivo ensaio. A escolha por imposição de deslocamento ao invés de força deve-se às condições de ensaio, o que também, gerou menor custo computacional.

Figura 3.13 - Carregamento para a pequena parede
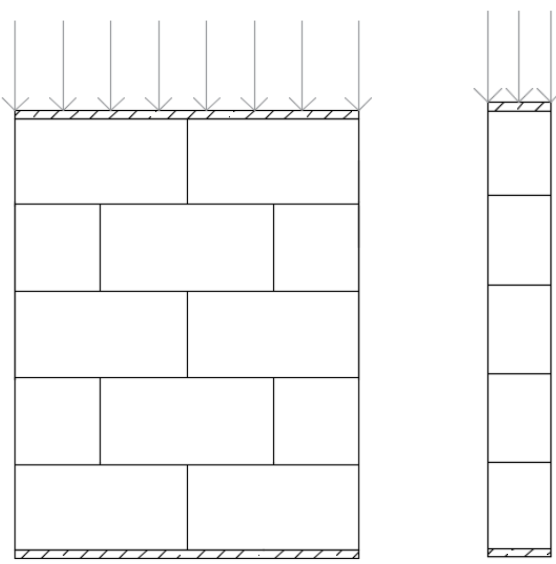

Os resultados obtidos a partir dos modelos citados neste capítulo estão inseridos no

\section{Capítulo 4.}




\subsubsection{Definição das propriedades dos materiais}

Os modelos iniciais foram baseados nos trabalhos experimentais de Oliveira (2014), Izquierdo (2015) e Dupim (2019). Os autores utilizaram como objeto de estudo estruturas de alvenaria estrutural de blocos de concreto, as quais foram utilizadas como base de validação da modelagem numérica deste trabalho. As propriedades mecânicas da argamassa, dos meio blocos e dos blocos de concreto foram retiradas dos ensaios experimentais de Oliveira (2014), Izquierdo (2015) e Dupim (2019). As curvas com os dados dos ensaios à compressão e à tração estão indicadas nas Figuras 3.14, 3.15, 3.16 e 3.17.

Figura 3.14 - Diagramas tensão-deformação experimentais relativas à compressão do bloco de concreto (a), do meio bloco (b) com espessuras de $14 \mathrm{~cm}$ e da argamassa (c) obtidos por Oliveira (2014)

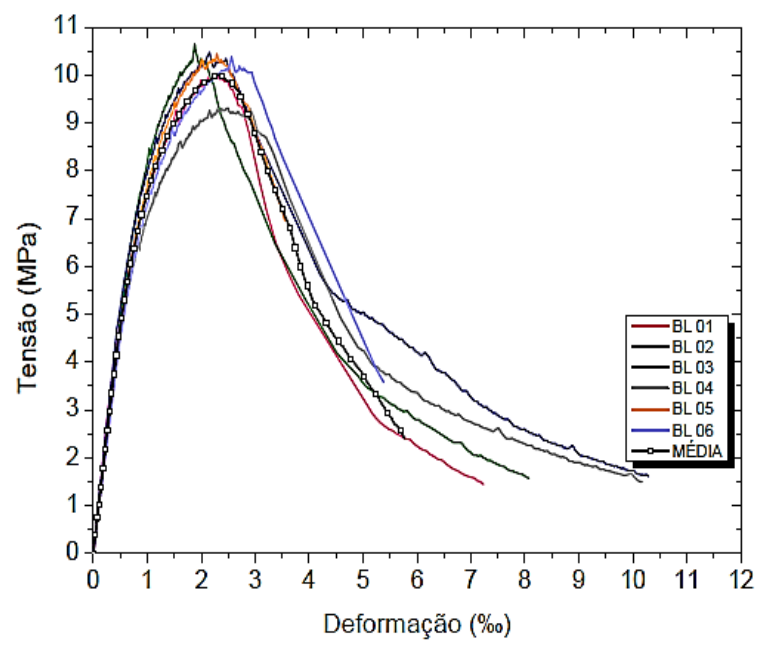

(a)

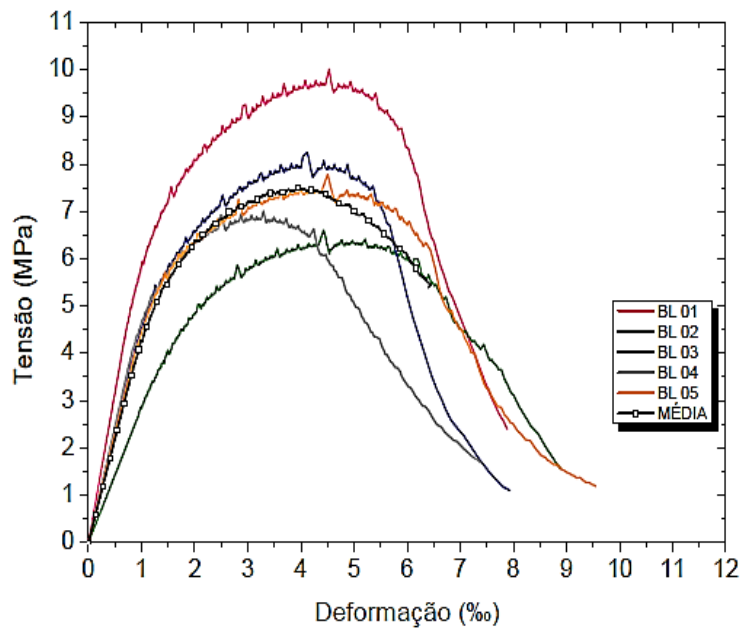

(b)

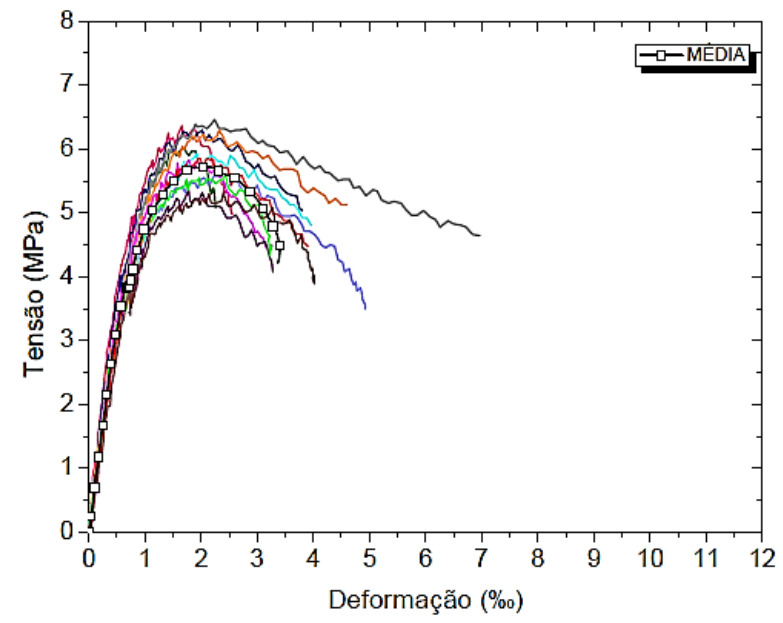

(c)

Fonte: Oliveira (2014) 
Figura 3.15 - Diagrama força-deslocamento experimentais relativas à tração do bloco de concreto obtido por Izquierdo (2015)

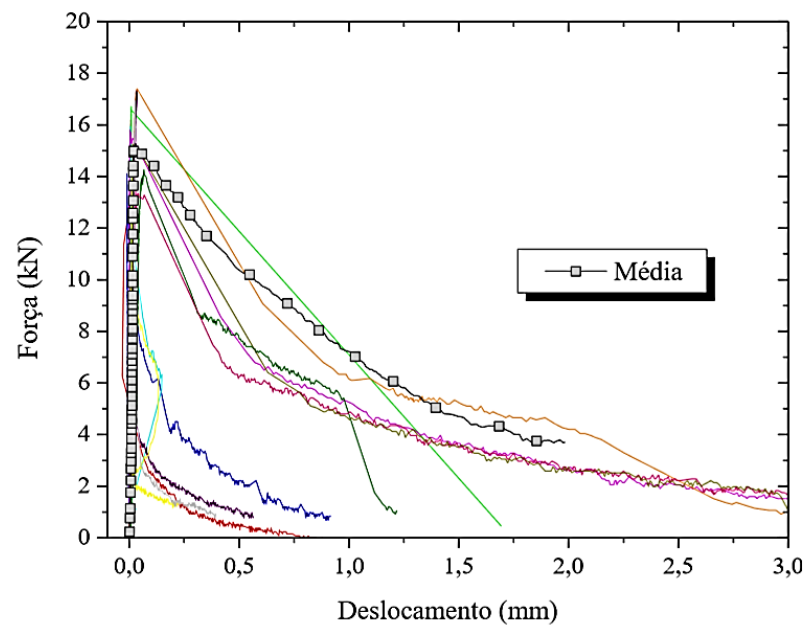

Fonte: Izquierdo (2015)

Dupim (2019) forneceu os dados obtidos nos ensaios de ruptura dos blocos com 14 e 19 cm de espessura. Com estes, foram obtidos os gráficos vistos na Figura 3.16 e 3.17, já considerando os valores médios de tensão de ruptura.

Figura 3.16 - Diagramas tensão-deformação experimentais relativas à compressão do bloco de concreto (a) e do meio bloco (b) com espessuras de $14 \mathrm{~cm}$ de acordo com dados de Dupim (2019)

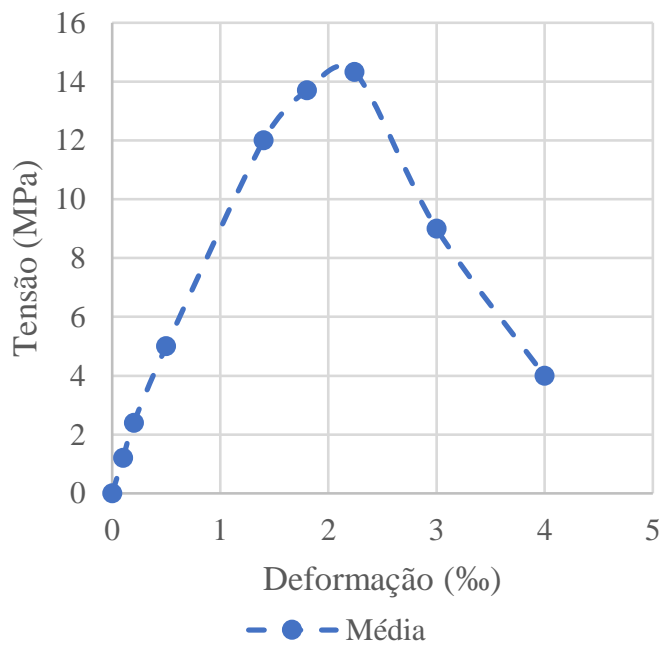

(a)

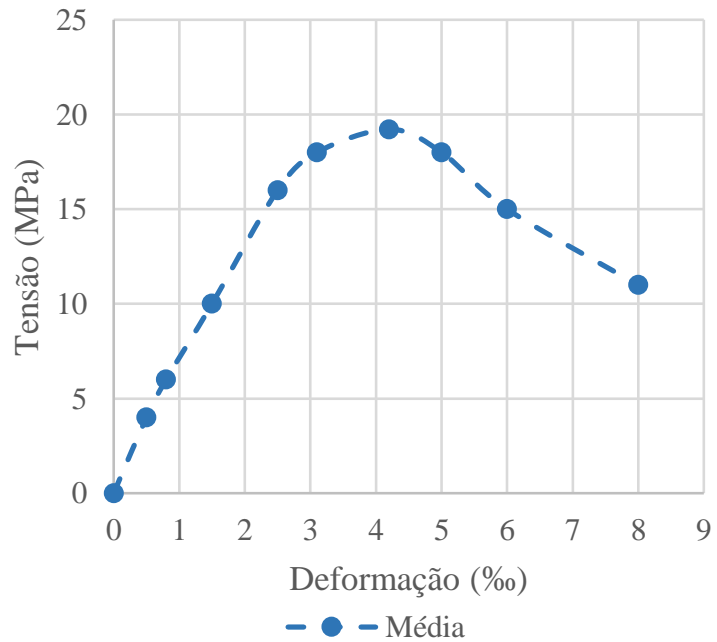

(b) 
Figura 3.17 - Diagramas tensão-deformação experimentais relativas à compressão do bloco de concreto (a) e do meio bloco (b) com espessuras de $19 \mathrm{~cm}$ de acordo com dados de Dupim

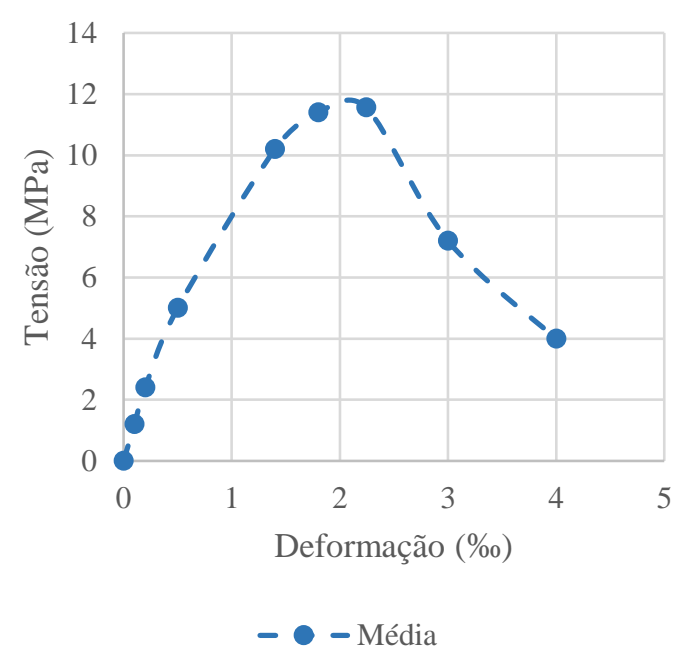

(a)

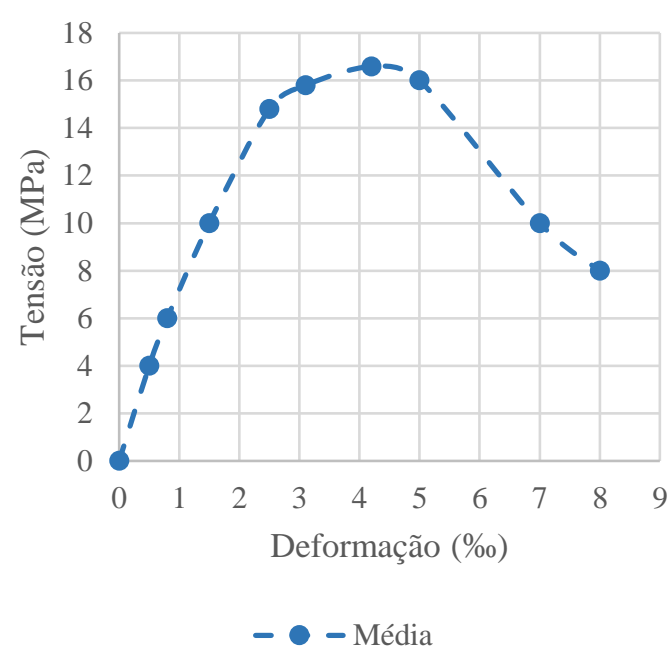

(b)

Os experimentos de Dupim (2019) utilizaram argamassas com os mesmos materiais e traços dos ensaios realizados por Oliveira (2014). Desta forma, na modelagem numérica, considerou-se os mesmos dados de entrada relativos à argamassa. Quanto à resistência à tração da argamassa, esta foi estimada através da equação (3.10), baseada no trabalho de Genikomsou e Polak (2015), a qual apresentou maior coerência em relação aos resultados obtidos.

$$
f_{b t m}=0,33 \cdot f_{b m}^{1 / 2}
$$

Para o comportamento à tração dos blocos, Oliveira (2014) utilizou os mesmos materiais de Izquierdo (2014), sendo assim, utilizados dos dados obtidos por Izquierdo (2014) para a modelagem numérica. Dupim (2019) não realizou ensaios de tração no bloco, assim, foi considerado a razão obtida por Izquierdo (2014) entre os valores de tensão de ruptura à compressão e à tração para o cálculo da tensão máxima à tração nos modelos numéricos baseados nos resultados de Dupim (2019).

Para inserção dos dados acerca dos comportamentos à compressão e à tração no ABAQUS, faz-se necessário o cálculo das deformações inelásticas para cada situação. Assim, fez-se uso das equações propostas por Guo (2014), também utilizadas por Santos (2016), as quais constam no Apêndice $\boldsymbol{F}$ do presente trabalho. 
As curvas utilizadas para tais extrapolações referem-se às curvas médias mostradas anteriormente. O Quadro 3.2 resume as referências acerca dos comportamentos à compressão e à tração dos materiais.

Quadro 3.2 - Dados de entrada referentes aos comportamentos à compressão e à tração

\begin{tabular}{|c|c|c|c|c|}
\hline Material & Comportamento & Dado & $\begin{array}{c}\text { Modelo baseado em } \\
\text { Oliveira (2014) }\end{array}$ & $\begin{array}{c}\text { Modelo baseado em } \\
\text { Dupim (2019) }\end{array}$ \\
\hline \multirow{4}{*}{ Argamassa } & \multirow{2}{*}{ Compressão } & Tensão-deformação & Ensaio & Oliveira (2014) \\
\hline & & Dano & Guo (2014) & Guo (2014) \\
\hline & \multirow{2}{*}{ Tração } & Tensão-deformação & Eq. (3.10) & Eq. (3.10) \\
\hline & & Dano & Guo (2014) & Guo (2014) \\
\hline \multirow{4}{*}{$\begin{array}{l}\text { Bloco de } \\
\text { concreto }\end{array}$} & \multirow{2}{*}{ Compressão } & Tensão-deformação & Ensaio & Ensaio \\
\hline & & Dano & Guo (2014) & Guo (2014) \\
\hline & \multirow[t]{2}{*}{ Tração } & Tensão-deformação & Izquierdo (2015) & $\begin{array}{c}\text { Razão Izquierdo } \\
\text { (2015) }\end{array}$ \\
\hline & & Dano & Guo (2014) & Guo (2014) \\
\hline \multirow{4}{*}{$\begin{array}{l}\text { Meio bloco de } \\
\text { concreto }\end{array}$} & \multirow{2}{*}{ Compressão } & Tensão-deformação & Ensaio & Ensaio \\
\hline & & Dano & Guo (2014) & Guo (2014) \\
\hline & \multirow{2}{*}{ Tração } & Tensão-deformação & Idem bloco & Idem bloco \\
\hline & & Dano & Guo (2014) & Guo (2014) \\
\hline
\end{tabular}

Quanto às propriedades plásticas do modelo numérico, o Quadro 3.3 indica os valores utilizados para todos os modelos realizados e as respectivas referências.

Quadro 3.3 - Propriedades plásticas utilizadas no modelo numérico

\begin{tabular}{|ccc|}
\hline Propriedades & Valor usado & Referência \\
\hline Argamassa & \\
\hline Angulo de dilatância & $35^{\circ}$ & Rodovalho (2018) \\
\hline Excentricidade & 0,1 & Rodovalho (2018) \\
\hline $\boldsymbol{\sigma}_{\boldsymbol{b} \mathbf{0}} / \boldsymbol{\sigma}_{\boldsymbol{c} \mathbf{0}}$ & 1,14 & Rodovalho (2018) \\
\hline $\boldsymbol{K}_{\boldsymbol{c}}$ & 0,666 & Rodovalho (2018) \\
\hline Viscosidade & 0,0001 & Rodovalho (2018) \\
\hline & Concreto & Malm (2009) \\
\hline Ângulo de dilatância & $40^{\circ}$ & Rodovalho (2018) \\
\hline Excentricidade & 0,1 & Rodovalho (2018) \\
\hline $\boldsymbol{\sigma}_{\boldsymbol{b} \mathbf{0}} / \boldsymbol{\sigma}_{\boldsymbol{c} \boldsymbol{0}}$ & 1,4 & Adotado \\
\hline $\boldsymbol{K}_{\boldsymbol{c}}$ & 0,666 & 0,0001 \\
\hline Viscosidade & & \\
\hline
\end{tabular}


Onde:

$\sigma_{b 0} / \sigma_{c 0}:$ razão entre a tensão de compressão biaxial inicial e a tensão de compressão uniaxial inicial;

$K_{c}$ : razão entre o segundo invariante de tensão no meridiano de tração para o meridiano de compressão.

O módulo de elasticidade foi calculado por meio da curva tensão-deformação a compressão citada no Quadro 3.2, através do traçado de linha de tendência no regime linear, entre 5 e $33 \%$ da tensão de ruptura.

O coeficiente de Poisson, utilizado em todas as modelagens realizadas, foi igual 0,2, conforme modelos realizados por Oliveira (2014).

\subsection{MODELO NUMÉRICO VOLTADO À ANÁLISE TÉRMICA}

\subsubsection{Considerações iniciais}

Os elementos finitos utilizados para o modelo numérico térmico são os mesmos utilizados quando da análise estrutural, conforme item 3.2, com vistas à compatibilização quando da análise termoestrutural. No entanto, o ABAQUS nomeia o elemento C3D8 como como DC3D8, isto é, elementos de difusão de calor com 8 nós (elementos lineares), o qual se aplica para fins de análise exclusivamente térmica.

O princípio de conservação de energia é considerado pelo ABAQUS para qualquer análise térmica. Neste trabalho, optou-se pelo tipo de análise transiente, isto é, aquela em que as propriedades térmicas dos materiais e a distribuição de temperatura variam com o tempo. Os mecanismos de transferência de calor considerados na análise térmica se referem à condução, à convecção e à radiação, os quais estão comentados no Apêndice A quanto à sua ação na estrutura.

Para a consideração da convecção e radiação, as grandezas inseridas no software se referem à inserção dos respectivos coeficientes. No caso da condução, esta é considerada quando inseridas as propriedades térmicas de cada material, no caso do presente trabalho, a massa específica, a condutividade térmica e o calor específico. Na face exposta da parede ao fogo foi considerada a curva de evolução de temperatura ISO 834-1:1999, enquanto nos septos internos dos blocos, consideradas curvas de evolução da temperatura dos gases internos, baseando-se em resultados experimentais, os quais serão melhores abordados posteriormente neste capítulo. 
Para a validação do modelo numérico térmico, fez-se necessário a inserção de curvas de evolução de temperatura na face oposta ao fogo, com o intuito de simular o aumento de temperatura dos gases do ambiente oposto ao fogo, conforme resultados experimentais de Dupim (2019). As nomenclaturas usadas na sequência deste trabalho referem-se à distância de determinados pontos, em centímetros, que estes se encontram da face exposta ao fogo, como, por exemplo, "D0", entende-se como a face exposta ao fogo, e "D14", como a face com distância de $14 \mathrm{~cm}$ da face exposta ao fogo, para paredes com $14 \mathrm{~cm}$ de espessura, seria a face oposta ao incêndio.

\subsubsection{Condições de contorno}

As condições de contorno do modelo numérico térmico foram inicialmente criadas de acordo com os experimentos realizados por Dupim (2019) para validação do modelo numérico. Posteriormente, realizadas variações destas condições de contorno, as quais constam no Capítulo 4. Para a primeira validação numérica, com uma das faces da parede exposta ao fogo, a curva da ISO 834-1:1999 é inserida numa das faces da parede, sendo, ainda, considerada a inserção de curvas de aquecimento dos gases internos aos septos dos blocos, e, curvas de aquecimento dos gases ambientes na face oposta ao incêndio, conforme mostrado na Figura 3.18 (a). Para a segunda validação, com fogo em ambas as faces da parede, a Figura 3.18 (b) indica as considerações realizadas.

Rodovalho (2018) fez a modelagem dos gases internos aos septos e atribuiu propriedades a estes gases utilizando da fluidodinâmica computacional (comentários no Apêndice A). Neste trabalho optou-se por inserir as curvas internas aos septos mostradas nas figuras anteriores, com o objetivo de otimizar o custo computacional do modelo numérico, em virtude do maior vulto das paredes em relação aos prismas estudados pela autora citada.

A possibilidade de uso de tais curvas, internas aos septos dos blocos, ocorreu devido ao trabalho experimental realizado por Dupim (2019), onde foi medido ao longo do tempo a evolução da temperatura destes gases em paredes de alvenaria estrutural de blocos de concreto sem revestimento. Desta forma, a estratégia utilizada neste trabalho foi utilizar estas curvas para considerar o efeito do aquecimento dos gases internos em virtude da transferência de calor ao longo da espessura dos blocos. 
Figura 3.18 - Condições de contorno para as situações com exposição ao fogo em uma única face (a) e nas duas faces (b)

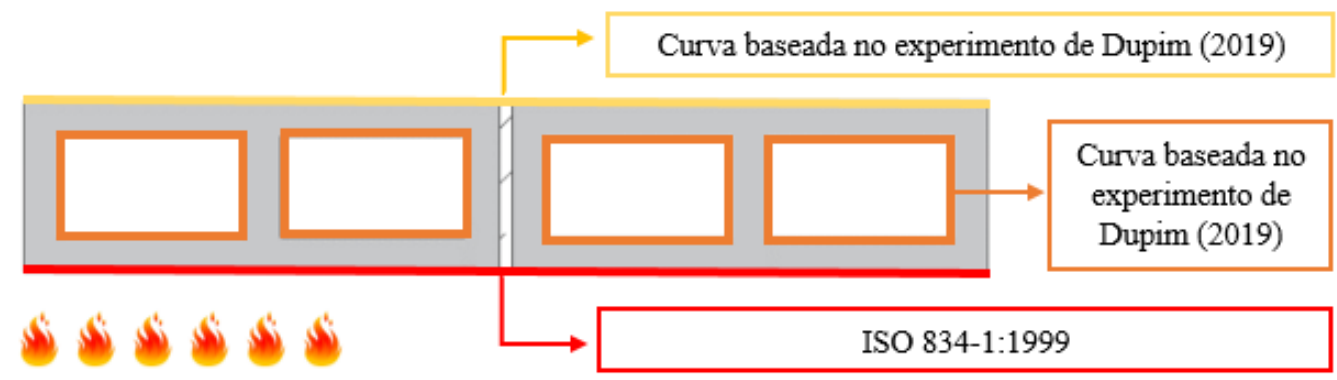

(a)

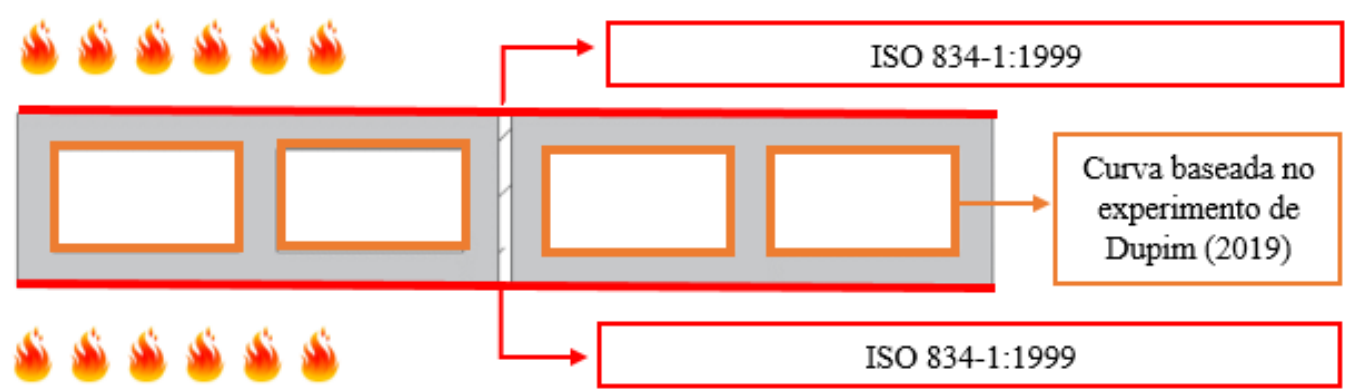

(b)

Além disso, para compatibilização da primeira validação em relação aos experimentos realizados por Dupim (2019), fez-se necessária a consideração de curvas de evolução de temperatura também na face não exposta ao fogo, uma vez que houve confinamento de gases aquecidos durante o experimento, conforme visto na Figura 3.19.

Figura 3.19 - Corpos-de-prova ensaiados com exposição ao fogo em apenas uma das faces e indicação do sentido da transferência de calor

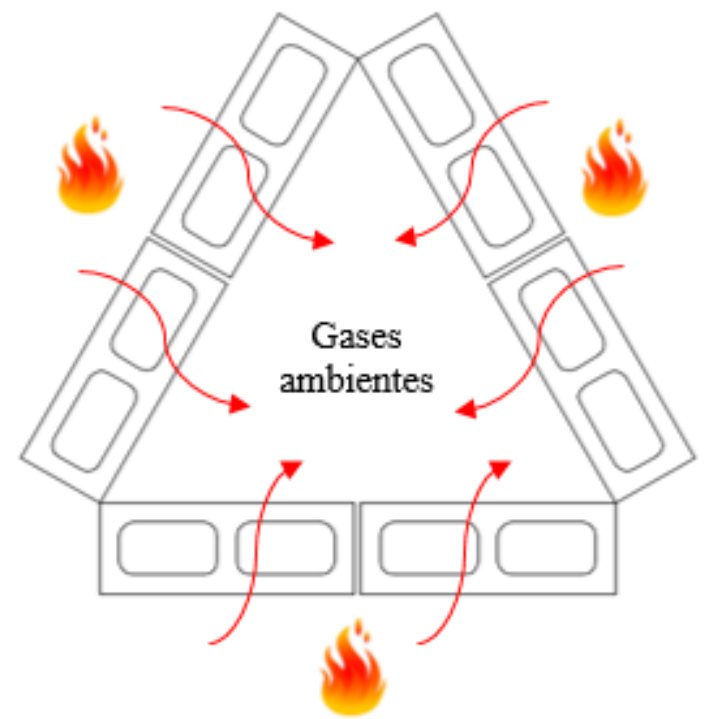


A consideração realizada para a face oposta ao fogo é vista na Figura 3.20. O motivo desta consideração se faz com vistas a realizar a modelagem numérica de forma mais simplificada, não necessitando a modelagem do trio de paredes, reduzindo, assim, o esforço computacional. Para tanto, mediu-se a temperatura no interior do trio de paredes e considerouse a contribuição proveniente de todas as transferências de calor para apenas uma única parede, uma vez que a temperatura no interior do trio seria teoricamente idêntica para qualquer superfície de parede individual.

Figura 3.20 - Consideração quanto à contribuição para o aumento de temperatura dos gases

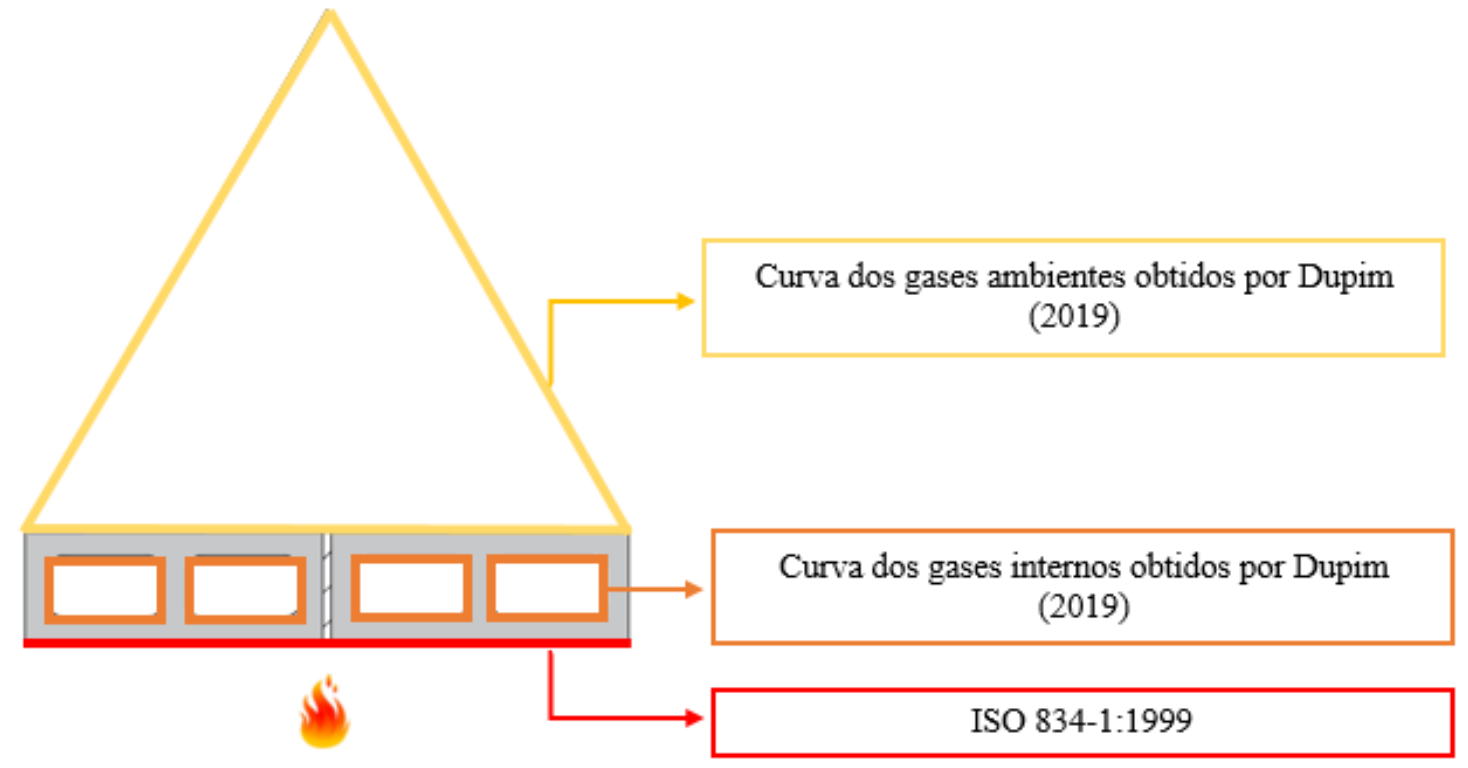

Quanto aos mecanismos de transferência de calor, nas faces exposta e não exposta ao fogo foram considerados por convecção e por radiação, bem como, nos septos internos. Ao longo dos blocos e das juntas, considerados transferência por condução. A indicação do mecanismo de transferência de calor nas respectivas faces, está mostrado na Figura 3.21.

Figura 3.21 - Consideração acerca da transferência de calor

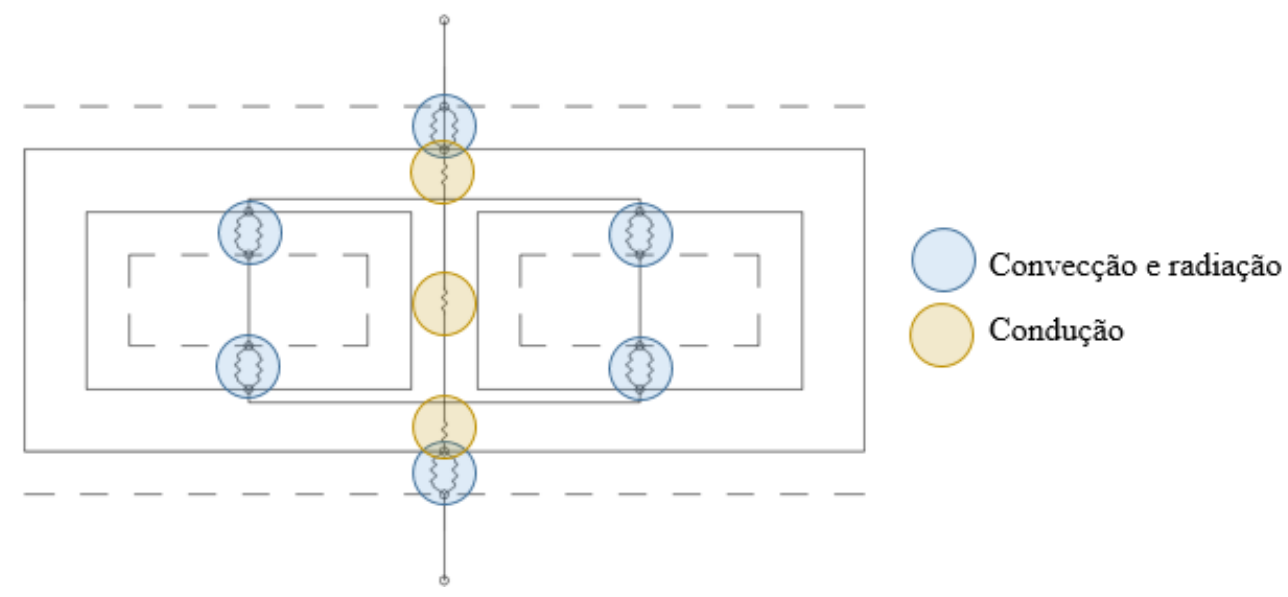


Os valores do coeficiente de convecção $(h)$ e da emissividade $(\varepsilon)$ tiveram por base os trabalhos de Santos et al. (2017) e Rodovalho (2018). A Figura 3.22 indica os valores utilizados para a primeira validação, em cada face e no septo. Para a segunda validação, utilizou-se os valores da face exposta ao fogo em ambas as faces, permanecendo com os valores internos.

Figura 3.22 - Indicação dos coeficientes de convecção e emissividades considerados

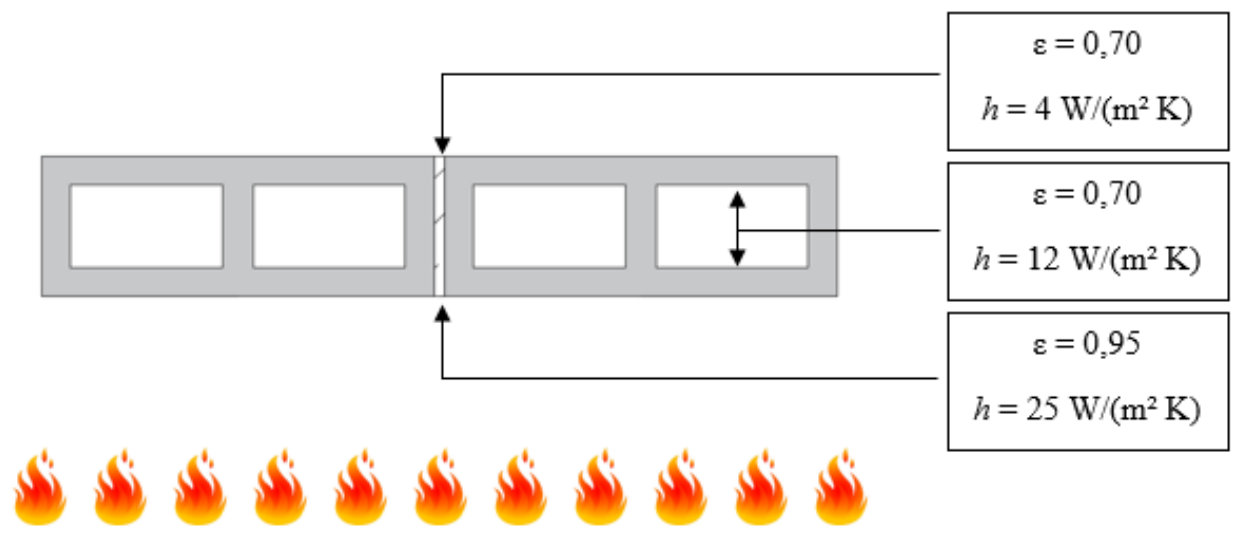

\subsubsection{Definição das propriedades}

Os dados de entrada neste modelo baseiam-se primordialmente em três propriedades, as quais variam de acordo com a temperatura, sendo elas: a massa específica, o calor específico e a condutividade térmica. Existe grande variação destes parâmetros de acordo com a temperatura, comparando-se as normas europeias de estruturas de concreto e de alvenaria estrutural em blocos de concreto, conforme pode ser melhor identificado no Apêndice D. A norma brasileira de concreto apresenta dados de calor específico e condutividade térmica semelhantes aos do Eurocode 2.

Como comentado anteriormente, não existe norma brasileira que padronize a variação de temperatura em alvenaria estrutural. Optou-se, desta forma, em calibrar a condutividade térmica e o calor específico dentro dos limites existentes da norma europeia para estruturas de concreto e de alvenaria estrutural. O não uso das curvas de forma integral da norma europeia de alvenaria estrutural, deve-se à variação construtiva dos blocos europeus em relação aos brasileiros. Além disso, a utilização desta estratégia deve-se à maior umidade dos blocos de concreto em relação às estruturas de concreto, propriamente ditas.

A umidade considerada no Eurocode 2 é de $3 \%$ para os valores máximos de suas curvas, enquanto que, os blocos, como verificado nos trabalhos de Oliveira (2014) e Dupim (2019), apresentaram umidade bastante superiores. As calibrações para a condutividade térmica e para 
o calor específico que obtiveram os melhores resultados para a validação do modelo térmico estão mostradas nas Figuras 3.23 e 3.24 .

Figura 3.23 - Calor específico calibrado para o material concreto

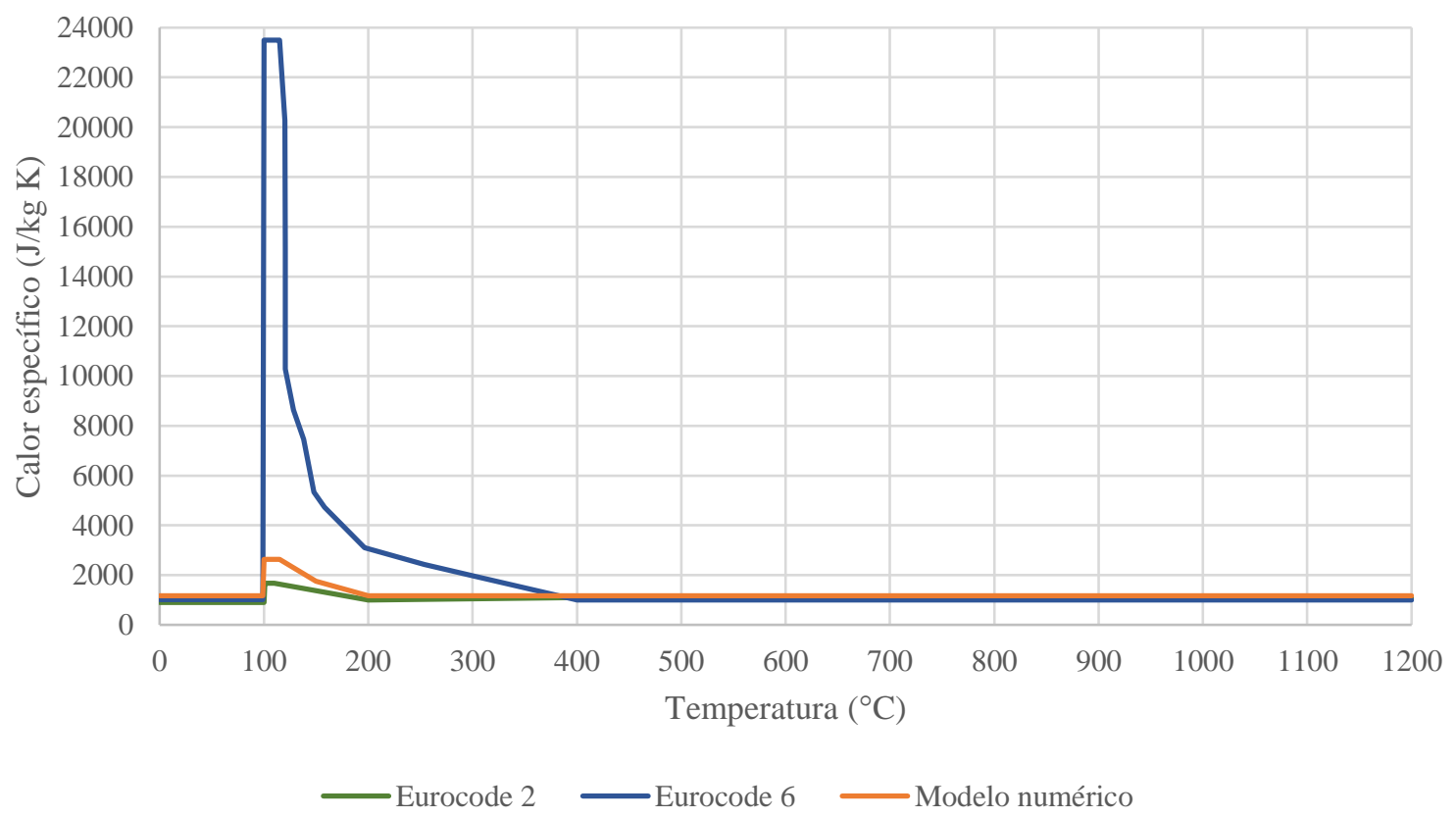

Como visualizado na última figura, a calibração do modelo resultou entre os limites impostos pelo Eurocode 2, de estruturas de concreto, e pelo Eurocode 6, de alvenaria estrutural. O pico do calor específico do modelo numérico corresponde a 12,5\% do pico do Eurocode 6 , e, é $57 \%$ maior que o valor do Eurocode 2.

Figura 3.24 - Condutividade térmica calibrada para o material concreto

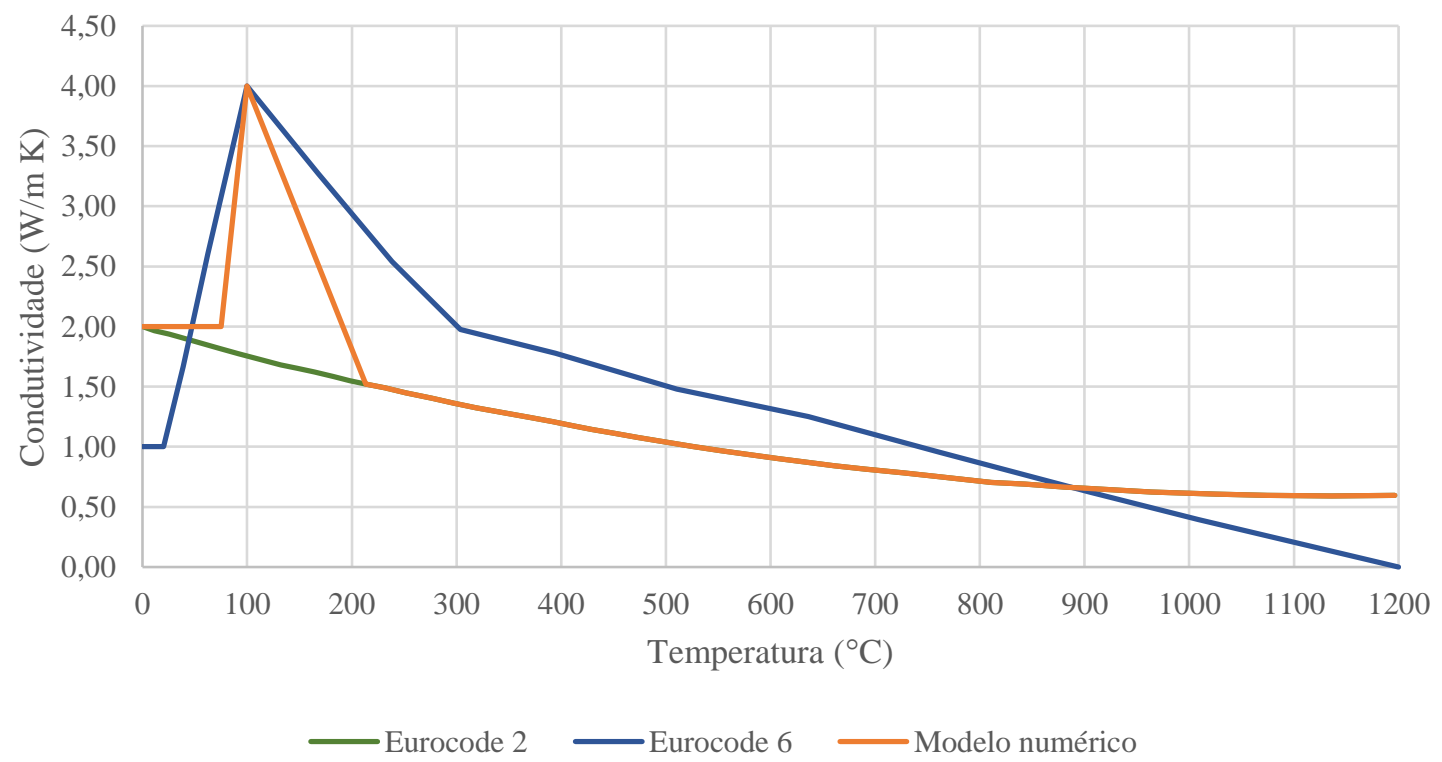


A calibração da condutividade térmica para o modelo numérico buscou seguir o Eurocode 6 em temperaturas até $100{ }^{\circ} \mathrm{C}$ e, posteriormente, seguiu a curva do Eurocode 2. Esta estratégia foi seguida devido aos motivos apresentados anteriormente referentes à umidade dos blocos, superiores aos valores estabelecidos no Eurocode 2. Para a argamassa, foram utilizados valores experimentais obtidos por Rosemann (2011) referentes às propriedades citadas anteriormente. O gráfico destas propriedades é mostrado na Figura 3.25.

Figura 3.25 - Calor específico e condutividade térmica da argamassa

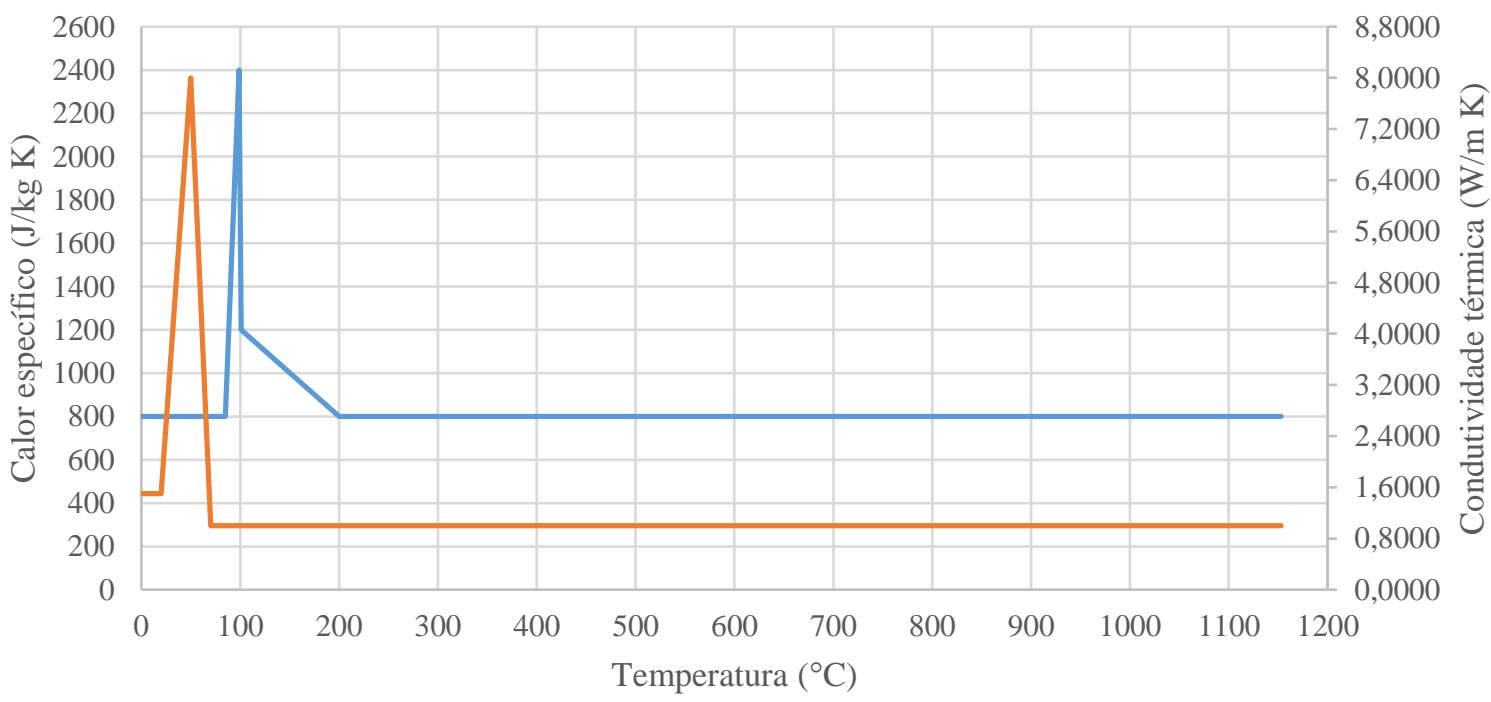

Fonte: Adaptado de Rosemann (2011)

Para a massa específica de ambos os materiais foram utilizadas as equações (3.10), (3.11), (3.12) e (3.13) que seguem, as quais estão presentes no Eurocode 2.

$$
\begin{gathered}
\rho(\theta)=\rho\left(20^{\circ} \mathrm{C}\right) 20^{\circ} \mathrm{C} \leq \theta \leq 115^{\circ} \mathrm{C} \\
\rho(\theta)=\rho\left(20^{\circ} \mathrm{C}\right) \cdot[1-0,02 \cdot(\theta-115) / 85] 115^{\circ} \mathrm{C}<\theta \leq 200^{\circ} \mathrm{C} \\
\rho(\theta)=\rho\left(20^{\circ} \mathrm{C}\right) \cdot[0,98-0,03 \cdot(\theta-200) / 200] 200^{\circ} \mathrm{C}<\theta \leq 400^{\circ} \mathrm{C} \\
\rho(\theta)=\rho\left(20^{\circ} \mathrm{C}\right) \cdot[0,95-0,07 \cdot(\theta-400) / 800] 400^{\circ} \mathrm{C}<\theta \leq 1200^{\circ} \mathrm{C}
\end{gathered}
$$

O Eurocode 6 recomenda o uso de valor constante para a massa específica em relação à temperatura para o tipo de bloco considerado nas curvas anteriores. Os valores de massa específica à temperatura ambiente foram obtidos nos trabalhos de Rosemann (2011), para a argamassa, e de Oliveira (2014) e de Dupim (2019), para o concreto, conforme indicado na Tabela 3.4. 
A Tabela 3.5 indica, de forma resumida, as referências nas quais as propriedades utilizadas nas modelagens numéricas foram baseadas.

Tabela 3.4 - Valores de massa específica utilizadas na modelagem numérica

\begin{tabular}{c|cc} 
Material & Massa específica $\left(\mathbf{k g} / \mathbf{m}^{\mathbf{3}}\right)$ & Referência \\
\hline Argamassa & 2100 & Rosemann (2011) \\
\hline Concreto & 2362 & Oliveira (2014) \\
\hline Concreto $(\mathbf{1 4} \mathbf{~ c m})$ & 2385 & Dupim (2019) \\
\hline Concreto $(\mathbf{1 9} \mathbf{~ c m )}$ & 2324 & Dupim (2019) \\
\hline
\end{tabular}

Tabela 3.5 - Resumo das referências acerca dos parâmetros utilizados na modelagem térmica

\begin{tabular}{cccc}
\hline Material & Calor específico & $\begin{array}{c}\text { Condutividade } \\
\text { térmica }\end{array}$ & Massa específica \\
Argamassa & Rosemann (2011) & Rosemann (2011) & $\begin{array}{c}\text { Rosemann (2011)/ } \\
\text { Eurocode 2 }\end{array}$ \\
\hline \multirow{2}{*}{ Concreto } & Eurocode 2 e & Eurocode 2 e & Oliveira (2014) e Dupim \\
& Eurocode 6 & Eurocode 6 & $(2019) /$ Eurocode 2 \\
\hline
\end{tabular}

\subsection{MODELO NUMÉRICO PARA ANÁLISE TERMOESTRUTURAL}

\subsubsection{Considerações iniciais}

O modelo termoestrutural basicamente consiste na consideração dos campos de temperaturas obtidos no modelo térmico (conforme item 3.3) inseridos no modelo estrutural. Neste trabalho optou-se por coincidir os nós de ambos os modelos, visando otimizar o custo computacional do problema.

Diferentemente do que foi considerado nos modelos estrutural e térmico, no modelo termoestrutural ocorreu a inclusão da propriedade da expansão térmica dos materiais e da variação das propriedades mecânicas em função da temperatura do material. Em relação às propriedades plásticas e de interface do modelo numérico, uma vez que não existe estudo específico experimental quanto à variação destes parâmetros de acordo com a temperatura, estas permaneceram constantes.

A redução da resistência das pequenas paredes foi baseada nas normas americana e europeia, as quais informam, para o concreto, coeficientes de minoração da resistência em função da temperatura. A norma americana traz informações que consideram tanto situações 
sem carregamento, como carregadas com $40 \%$ da carga de ruptura. Por sua vez, a norma europeia considera apenas a situação sem carregamento, além de indicar as deformações em que ocorrem estas tensões e os valores últimos de deformações.

Diferentemente dos modelos estrutural e térmico, os quais foram validados tanto qualitativamente quanto quantitativamente, os modelos termoestruturais não tiveram validação quantitativa em virtude da inexistência de ensaios com paredes de alvenaria estrutural carregadas e com materiais próximos aos utilizados no presente trabalho. Qualitativamente, os modelos foram comparados com o trabalho de Dupim (2019), na situação sem carregamento, e com o trabalho de Lopes et al. (2018) na situação carregada.

\subsubsection{Condições de contorno}

Neste tópico são apresentadas as condições de contorno que tiveram como base as comparações qualitativas com o trabalho de Dupim (2019) e Lopes et al. (2018). No Capítulo 5, estão apresentadas algumas variações para análises específicas.

Dupim (2019) estudou pequenas paredes de alvenaria estrutural com fogo em uma das faces, sem carregamento, conforme apresentado na modelagem térmica, para o sistema em trio de paredes. Para este sistema, foram comparadas duas condições de contorno efetuadas no modelo numérico: uma considerando a possibilidade de movimento na superfície superior da parede na direção do fogo e engastamento inferior, e, outra, considerando a impossibilidade de movimento na direção do fogo, e, permitindo o giro inferior em torno do eixo paralelo ao incêndio. Em ambos os casos, permitindo o movimento vertical na superfície superior. A Figura 3.26 indica o exposto.

Figura 3.26 - Condições de contorno para comparação com os ensaios de Dupim (2019) nomeadas como CD1 (a) e CD2 (b)
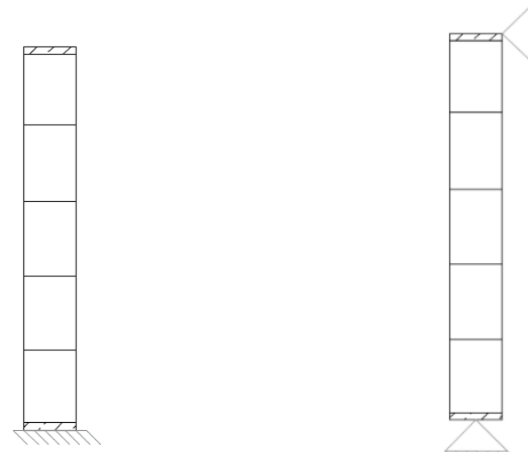

(a)

(b) 
O Quadro 3.4 descreve as condições de contorno abordadas na Figura 3.26.

Quadro 3.4 - Nomenclatura das condições de contorno baseadas no trabalho experimental de Dupim (2019)

\begin{tabular}{|ccc|}
\hline Nomenclatura & \multicolumn{2}{c|}{ Condição de contorno } \\
& Superior & Inferior \\
\hline \multirow{2}{*}{ CD1 } & $\begin{array}{c}\text { Liberado deslocamento vertical e } \\
\text { lateral na direção do fogo e giro } \\
\end{array}$ & Engastado \\
& perpendicular ao plano da parede & \\
\hline & Liberado deslocamento vertical e & Liberado giro perpendicular ao \\
& giro perpendicular ao plano da & plano da parede \\
& parede & \\
\hline
\end{tabular}

Entende-se que a condição que melhor se aproxima do ensaio realizado é intermediária às duas condições de contorno, porém, com maior proximidade à primeira mostrada na Figura 3.26. Apesar de as três paredes estarem interconectadas entre si para formar o trio exposto na Figura 3.19, entre estas paredes foram inseridas mantas cerâmicas com espessura de $2,5 \mathrm{~cm}$. Desta forma, é possível que ocorra o movimento destas paredes na direção do fogo devido à expansão térmica, sem que a manta impossibilite tal movimento em sua totalidade. Na segunda condição de contorno analisada, o movimento lateral superior na direção do fogo é impedido em sua totalidade.

Em virtude deste trabalho representar um estudo de caráter preliminar e com análises apenas qualitativas para a modelagem termoestrutural, não foram modeladas condições intermediárias aos dois casos acima, através do uso de molas, por exemplo.

Lopes et al. (2018) estudaram paredes de alvenaria estrutural de blocos de concreto com três septos e com dimensões mais esbeltas que as estudadas neste trabalho, carregadas com 30\% do valor de ruptura.

Para esta comparação qualitativa, a condição de contorno entendida como mais próxima ao ensaio é a condição de contorno CC2, indicada na Figura 3.27. No entanto, foram verificadas conjuntamente outras duas condições de contorno para análise comparativa quanto à tendência das curvas. Neste caso, a inserção de carregamento é de 30\% da carga de ruptura para o modelo estudado. 
Figura 3.27 - Condições de contorno para comparação com os ensaios de Lopes et al. (2018) nomeadas como CC1 (a), CC2 (b) e CC3 (c)

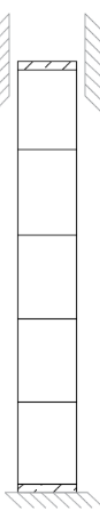

(a)

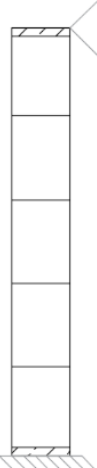

(b)

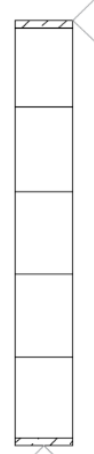

(c)

O Quadro 3.5 descreve as condições de contorno abordadas na Figura 3.27.

Quadro 3.5 - Nomenclatura das condições de contorno baseadas no trabalho experimental de Lopes et al. (2018)

\begin{tabular}{|c|c|c|}
\hline \multirow{2}{*}{ Nomenclatura } & \multicolumn{2}{|c|}{ Condição de contorno } \\
\hline & Superior & Inferior \\
\hline CC1 & Liberado deslocamento vertical & Engastado \\
\hline $\mathrm{CC2}$ & $\begin{array}{l}\text { Liberado deslocamento vertical e } \\
\text { giro perpendicular ao plano da } \\
\text { parede }\end{array}$ & Engastado \\
\hline $\mathrm{CC3}$ & $\begin{array}{l}\text { Liberado deslocamento vertical e } \\
\text { giro perpendicular ao plano da } \\
\text { parede }\end{array}$ & $\begin{array}{c}\text { Liberado giro perpendicular ao } \\
\text { plano da parede }\end{array}$ \\
\hline
\end{tabular}

Quanto aos passos de inserção do carregamento no ABAQUS, inicialmente impôs-se as condições de contorno incluindo o carregamento e, no seguinte, a variação de temperatura ao longo do tempo. Neste último passo, as propriedades mecânicas tiveram sua minoração de acordo com os dados comentados no item seguinte.

\subsubsection{Definição das propriedades}

O valor utilizado para a expansão térmica do concreto foi o fornecido pela ABNT NBR 15961-1:2011, de $9 \cdot 10^{-6}{ }^{\circ} \mathrm{C}^{-1}$. Para a argamassa foi adotado o mesmo valor em virtude da falta de testes experimentais e de valores normatizados. Quanto à variação do valor da expansão 
térmica em função da temperatura, este valor manteve-se constante conforme também realizado por Nadjai et al. (2003).

As propriedades mecânicas foram atualizadas com a temperatura de acordo com os coeficientes fornecidos pelas normas europeia e americana, bem como, o módulo de elasticidade, recalculado para cada temperatura. A Figura 3.28 ilustra a redução de temperatura para o concreto de acordo com as duas normas citadas, considerando agregado silicoso.

Figura 3.28 - Minoração da resistência à compressão do material concreto em função da temperatura

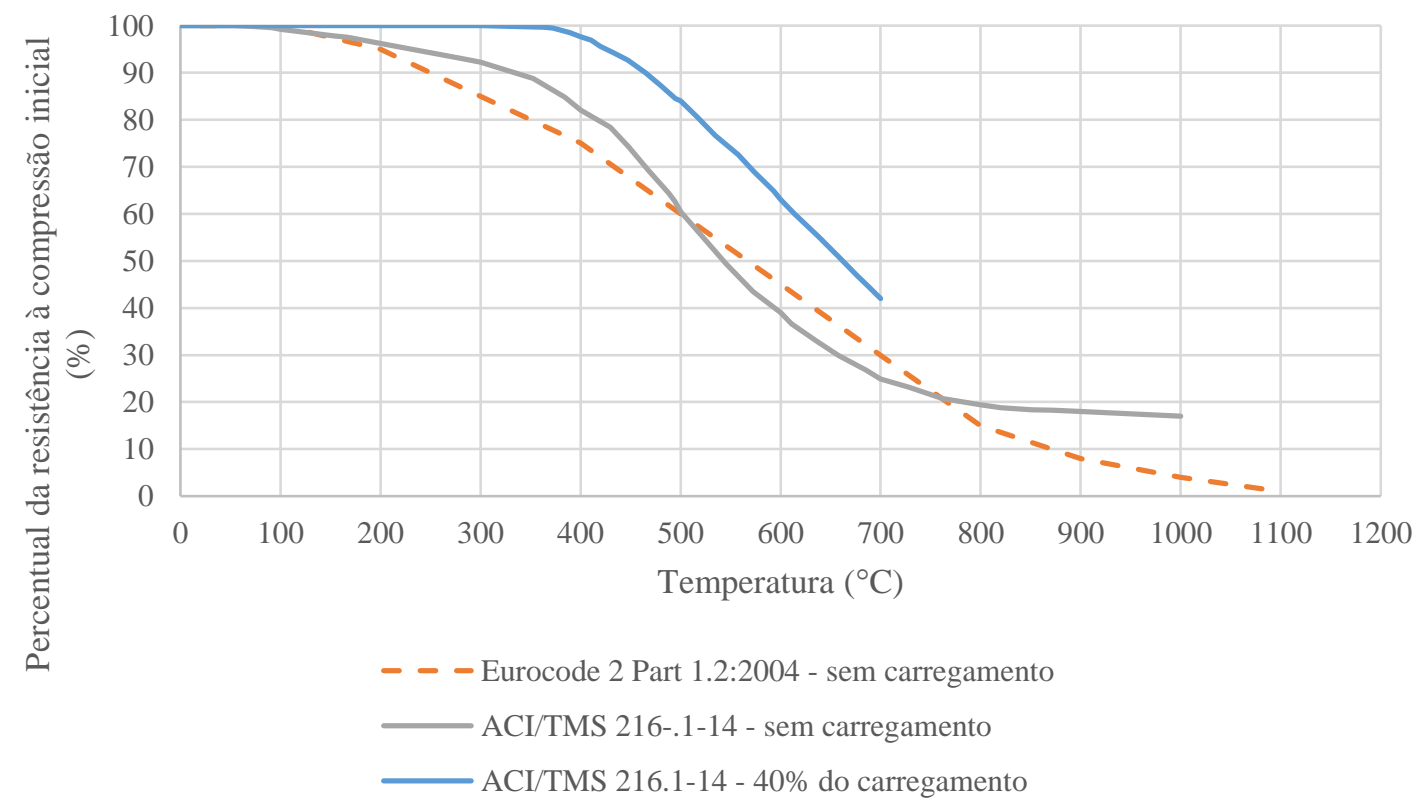

Para o ensaio comparativo com o experimento apresentado em Dupim (2019) foi usada a curva americana sem carregamento, enquanto que, para o experimento apresentado em Lopes et al. (2018) foi usada a curva com consideração de carregamento.

As propriedades mecânicas à temperatura ambiente para ambas as situações foram consideradas de acordo com os dados experimentais obtidos por Oliveira (2014) e utilizados no modelo estrutural. A Tabela 3.6 indica os valores das tensões máximas à compressão e à tração do bloco de concreto de acordo com a temperatura, utilizando os coeficientes da norma americana para as situações sem e com carregamento de $40 \%$ da carga de ruptura. As Figuras 3.29 e 3.30 exemplificam a relação tensão-deformação variável com a temperatura para o bloco de concreto sem e com carregamento, respectivamente. O mesmo procedimento foi realizado para o meio bloco e a argamassa.

As propriedades de plasticidade do modelo numérico mantiveram-se invariáveis em função da temperatura, em virtude dos escassos dados existentes na área. 
Tabela 3.6 - Tensões de compressão e de tração do concreto de acordo com a temperatura para as situações sem carregmento e com carregamento de $40 \%$ da carga máxima

\begin{tabular}{ccccc}
\hline \multirow{2}{*}{$\left({ }^{\circ} \mathbf{C}\right)$} & \multicolumn{2}{c}{ Sem carregamento } & \multicolumn{2}{c}{ Com carregamento } \\
& $\mathrm{f}_{\mathrm{c}, \mathrm{T}}(\mathrm{MPa})$ & $\mathrm{f}_{\mathrm{t}, \mathrm{T}}(\mathrm{MPa})$ & $\mathrm{f}_{\mathrm{c}, \mathrm{T}}(\mathrm{MPa})$ & $\mathrm{f}_{\mathrm{t}, \mathrm{T}}(\mathrm{MPa})$ \\
\hline $\mathbf{2 0}$ & 18,19 & 0,91 & 18,19 & 0,91 \\
\hline $\mathbf{1 0 0}$ & 18,05 & 0,90 & 18,19 & 0,91 \\
\hline $\mathbf{2 0 0}$ & 17,50 & 0,88 & 18,19 & 0,91 \\
\hline $\mathbf{3 0 0}$ & 16,77 & 0,84 & 18,19 & 0,91 \\
\hline $\mathbf{4 0 0}$ & 14,91 & 0,75 & 17,64 & 0,88 \\
\hline $\mathbf{5 0 0}$ & 11,00 & 0,55 & 15,28 & 0,76 \\
\hline $\mathbf{6 0 0}$ & 7,09 & 0,35 & 11,46 & 0,57 \\
\hline $\mathbf{7 0 0}$ & 4,53 & 0,23 & 7,64 & 0,38 \\
\hline $\mathbf{8 0 0}$ & 3,54 & 0,18 & 4,55 & 0,23 \\
\hline $\mathbf{9 0 0}$ & 3,27 & 0,16 & 2,18 & 0,11 \\
\hline $\mathbf{1 0 0 0}$ & 3,09 & 0,15 & 0,91 & 0,05 \\
\hline $\mathbf{1 1 0 0}$ & 2,91 & 0,15 & 0,36 & 0,02 \\
\hline
\end{tabular}

Figura 3.29 - Diagrama tensão-deformação do bloco de concreto para diferentes temperaturas sem carregamento

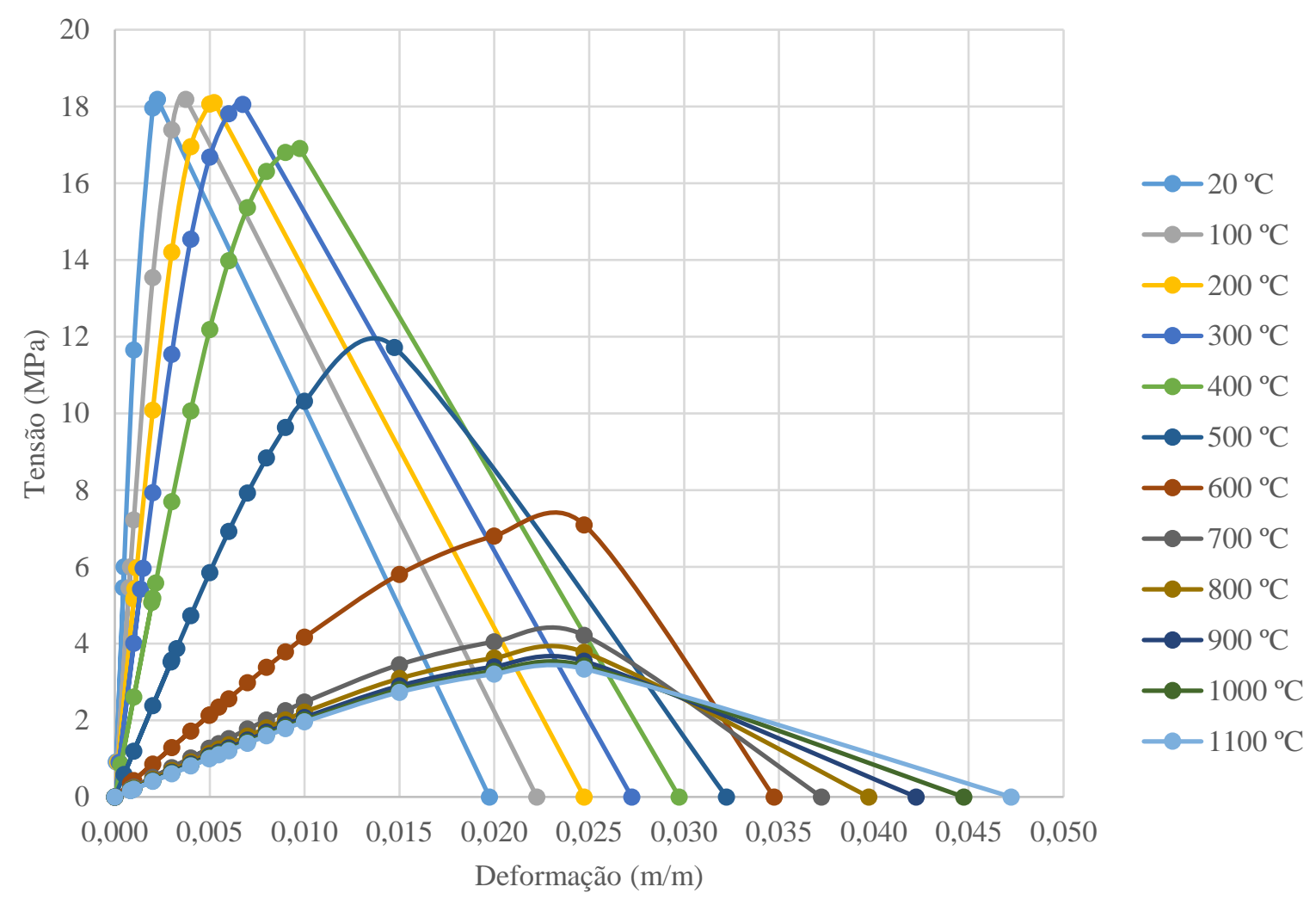


Figura 3.30 - Diagrama tensão-deformação do bloco de concreto para diferentes temperaturas considerando carregamento

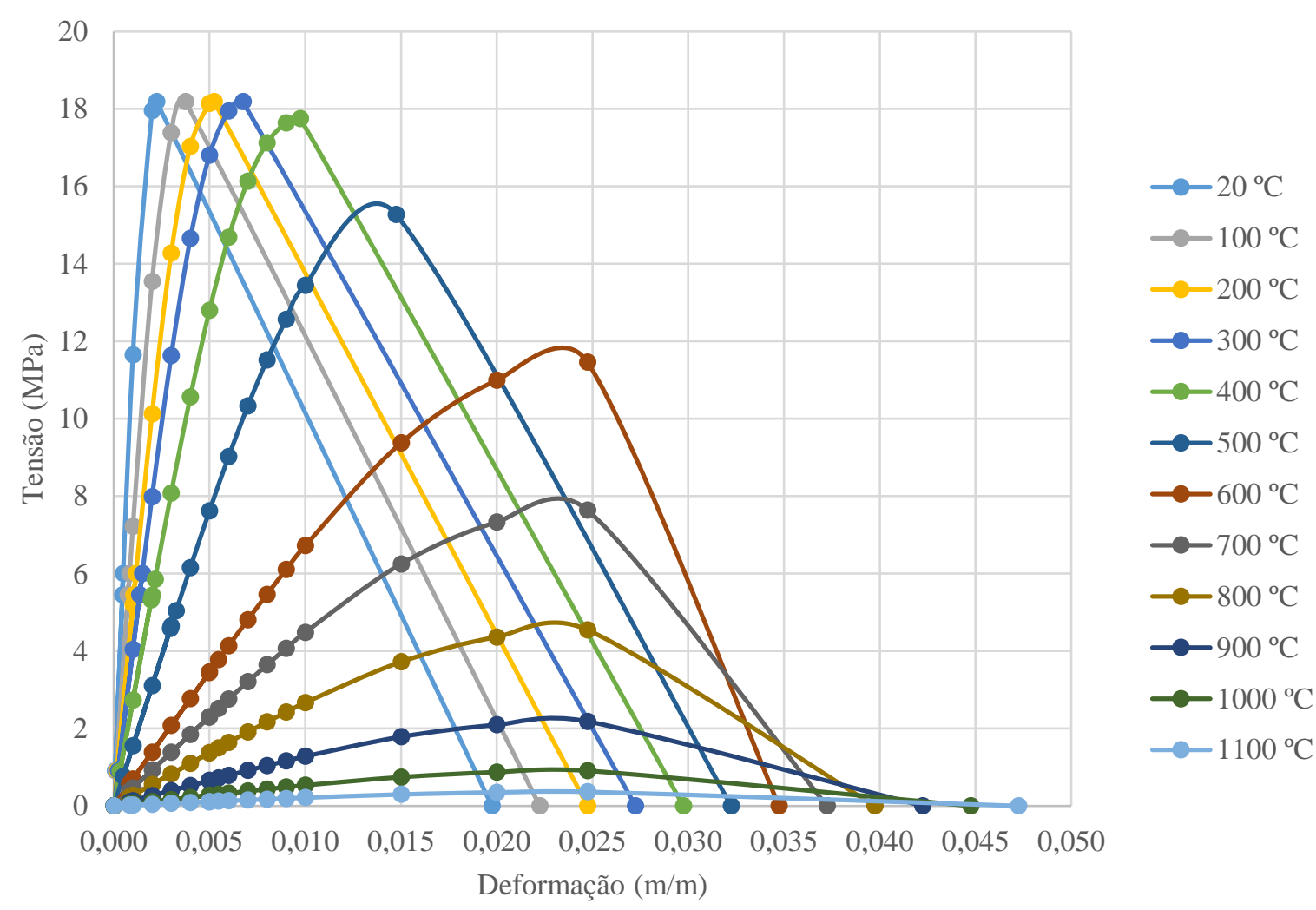




\section{RESULTADOS E DISCUSSÃO: VALIDAÇÃO DOS MODELOS}

No presente capítulo são realizadas as validações dos modelos numéricos propostos no Capitulo 3, com base em comparações destes com os resultados experimentais, quantitativa e qualitativamente para os modelos estrutural e térmico, bem como de forma apenas qualitativa para o modelo termoestrutural. O resumo destas validações consta no Quadro 4.1.

Quadro 4.1 - Resumo das referências de validação dos modelos numéricos

\begin{tabular}{|c|c|c|}
\hline Modelo & Especificação & $\begin{array}{c}\text { Referência } \\
\text { experimental }\end{array}$ \\
\hline \multirow{3}{*}{ Estrutural } & $\begin{array}{c}\text { Bloco com espessura de } 14 \mathrm{~cm} \text { e argamassamento } \\
\text { parcial }\end{array}$ & Oliveira (2014) \\
\hline & $\begin{array}{l}\text { Bloco com espessura de } 14 \mathrm{~cm} \text { e argamassamento } \\
\text { total }\end{array}$ & Dupim (2019) \\
\hline & $\begin{array}{l}\text { Bloco com espessura de } 19 \mathrm{~cm} \text { e argamassamento } \\
\text { total }\end{array}$ & Dupim (2019) \\
\hline \multirow{2}{*}{ Térmico } & $\begin{array}{l}\text { Bloco com espessura de } 14 \mathrm{~cm} \text {, argamassamento total } \\
\text { e fogo em uma face }\end{array}$ & Dupim (2019) \\
\hline & $\begin{array}{c}\text { Bloco com espessura de } 14 \mathrm{~cm} \text {, argamassamento total } \\
\text { e fogo em ambas as faces }\end{array}$ & Dupim (2019) \\
\hline \multirow{2}{*}{ Termoestrutural } & $\begin{array}{c}\text { Bloco com espessura de } 14 \mathrm{~cm} \text { e argamassamento } \\
\text { total sem carregamento }\end{array}$ & Dupim (2019) \\
\hline & $\begin{array}{l}\text { Bloco com espessura de } 14 \mathrm{~cm} \text { e argamassamento } \\
\text { total com carregamento }\end{array}$ & Lopes et al. (2018) \\
\hline
\end{tabular}

Vale destacar que nas imagens deste e dos próximos capítulos, referentes aos modelos numéricos, as unidades estão consideradas em Newton $(\mathrm{N})$ para força, em metro $(\mathrm{m})$ para comprimento, em Newton por metro quadrado $\left(\mathrm{N} / \mathrm{m}^{2}\right)$ para tensão e em Celsius $\left({ }^{\circ} \mathrm{C}\right)$ para temperatura. 


\subsection{PROCEDIMENTO DE VALIDAÇÃO DO MODELO ESTRUTURAL}

\subsubsection{Bloco com espessura de $14 \mathrm{~cm}$ e argamassamento parcial}

Neste tópico é avaliado o modelo numérico baseado no trabalho de Oliveira (2014), em que se considera blocos de concreto com espessura de $14 \mathrm{~cm}$ e argamassamento parcial. Inicialmente, são ilustrados os padrões de ruptura obtidos por Oliveira (2014), conforme Figura 4.1, os quais são comparados com tensões máximas e mínimas numéricas identificadas no instante da ruptura do modelo numérico, conforme Figuras 4.2 e 4.3

Figura 4.1 - Modo de ruptura da pequena parede
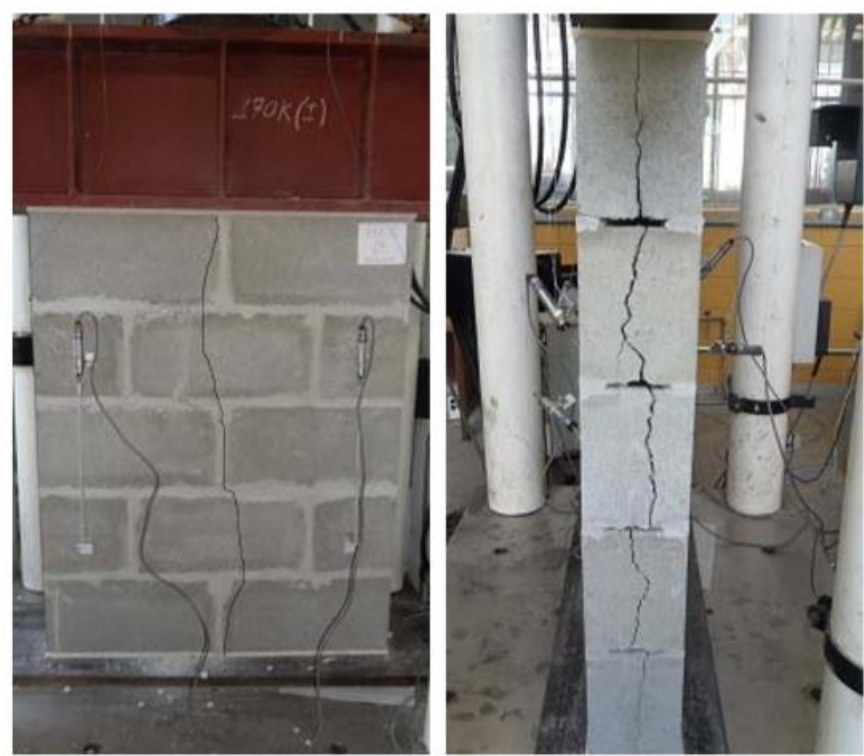

Fonte: Oliveira (2014)

Figura 4.2 - Tensões principais mínimas do modelo numérico no momento da ruptura

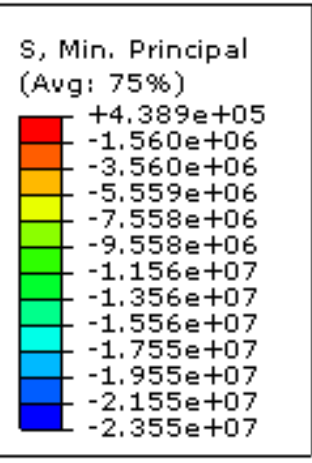

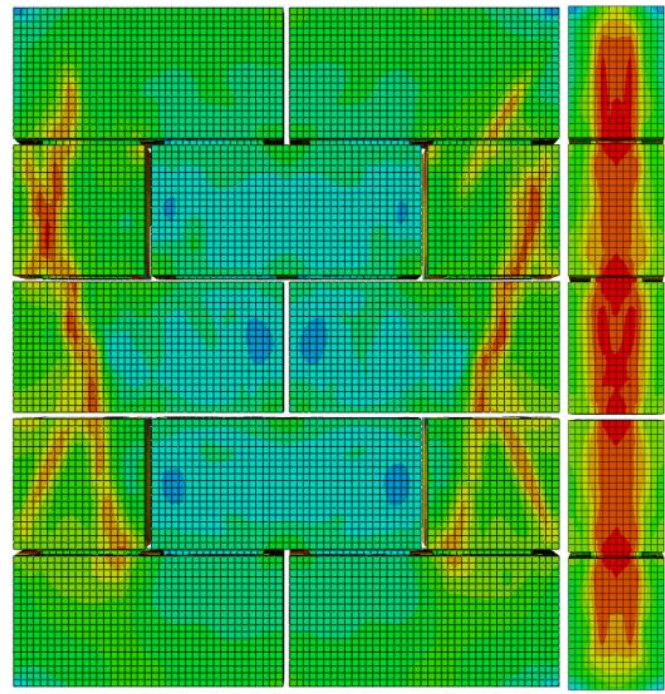


Figura 4.3 - Tensões principais máximas do modelo numérico no momento da ruptura

\begin{tabular}{|l|}
\hline S, Max. Principal \\
(Avg: $75 \%$ ) \\
$+8.875 \mathrm{e}+05$ \\
$+7.069 \mathrm{e}+05$ \\
$+5.262 \mathrm{e}+05$ \\
$+3.455 \mathrm{e}+05$ \\
$+1.649 \mathrm{e}+05$ \\
$-1.580 \mathrm{e}+04$ \\
$-1.965 \mathrm{e}+05$ \\
$-3.771 \mathrm{e}+05$ \\
$-5.578 \mathrm{e}+05$ \\
$-7.385 \mathrm{e}+05$ \\
$-9.191 \mathrm{e}+05$ \\
$-1.100 \mathrm{e}+06$ \\
$-1.280 \mathrm{e}+06$ \\
\hline
\end{tabular}
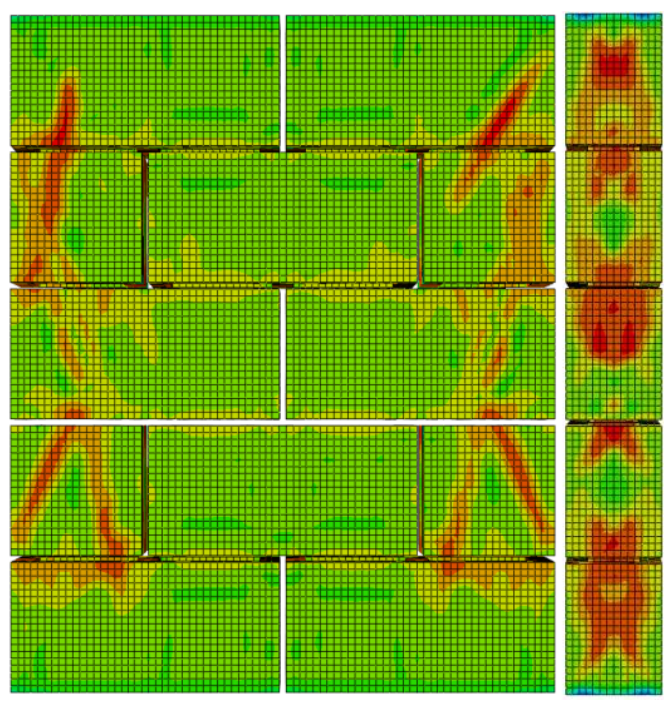

De acordo com Oliveira (2014), em todos os corpos-de-prova ensaiados ocorreram fissuras verticais bem acentuadas ao longo da face lateral das pequenas paredes, ocasionando uma divisão das unidades através dos septos, comportamento este típico de alvenaria com argamassamento parcial sujeita à compressão, conforme já comentado no Capítulo 2.

Nos modelos numéricos, no instante da ruptura da pequena parede, verifica-se o acúmulo de tensões de tração em sua lateral, com valores muito próximos aos de ruptura por tração do bloco, isto é, 0,91 MPa. Da mesma forma, verifica-se a mesma situação para as tensões mínimas, com valores próximos ao máximo experimental para o bloco, igual a 18,19 MPa na região central da parede. Desta forma, infere-se que nestas regiões ocorre o aparecimento de trincas, conforme modo de ruptura experimental. A Figura 4.4 indica as tensões principais pouco após a ruptura.

Figura 4.4 - Tensões principais absolutas do modelo numérico pouco após a ruptura

S, Max. Principal (Abs)
(Avg: 75\%)
\begin{tabular}{|l|l|}
$+9.865 e+05$ \\
\hline$-199 \mathrm{e}+05$ \\
$-2.626 \mathrm{e}+06$ \\
$-4.433 \mathrm{e}+06$ \\
$-6.239 \mathrm{e}+06$ \\
$-8.045 \mathrm{e}+06$ \\
$-9.852 \mathrm{e}+06$ \\
$-1.166 \mathrm{e}+07$ \\
$-1.346 \mathrm{e}+07$ \\
$-1.527 \mathrm{e}+07$ \\
$-1.708 \mathrm{e}+07$ \\
$-1.888 \mathrm{e}+07$ \\
$-2.069 \mathrm{e}+07$ \\
\hline
\end{tabular}
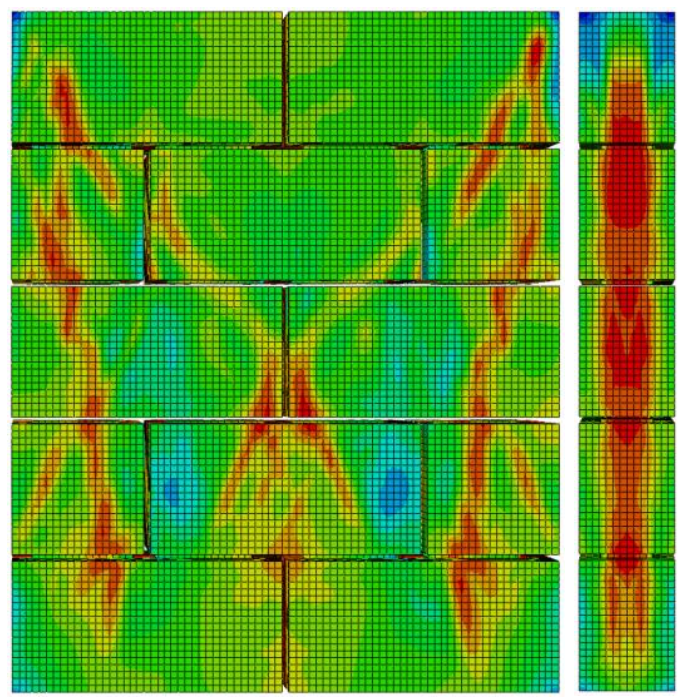
A Figura 4.5 (a) e (b) ilustram qualitativamente o comportamento da argamassa no instante da ruptura da pequena parede.

Figura 4.5 - Tensões principais mínimas (a) e máximas (b) na argamassa no instante da ruptura

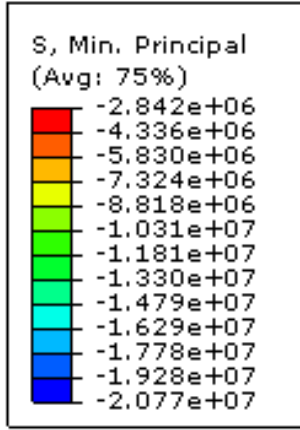

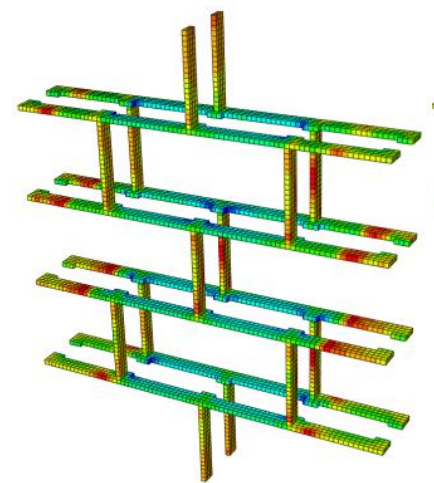

(a)
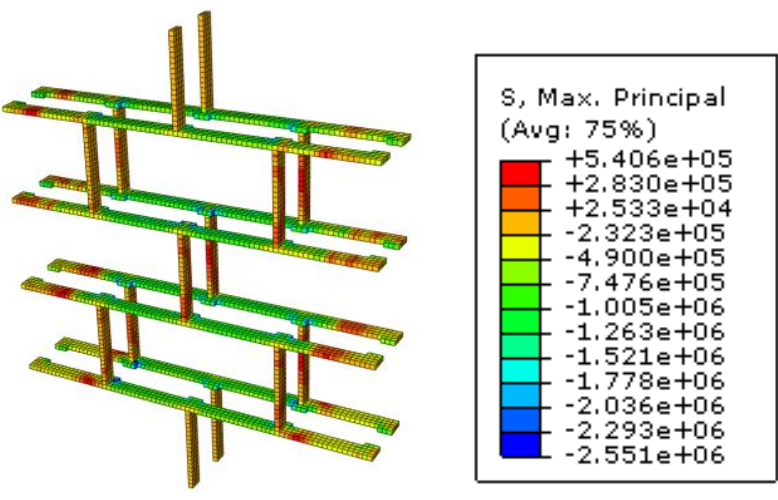

(b)

Conforme verificado para os blocos e meio blocos, a argamassa sofreu ruptura em alguns pontos, superando o valor máximo de 6,93 MPa para a compressão, bem como de 0,87 MPa para a tração. Porém, no caso da argamassa, em virtude do confinamento diferencial em relação às condições de ensaio, os valores de ruptura da argamassa tendem a ser superiores na situação em que se encontra, na estrutura.

Quanto às deformações, as Figuras 4.6 (a) e (b) indicam o comportamento da parede em relação às deformações elásticas e plásticas instantes após a ruptura, respectivamente. Algumas outras análises deste modelo, relativas ao deslocamento, podem ser vistas no Apêndice $\boldsymbol{G}$.

Figura 4.6 - Deformações elásticas (a) e plásticas (b) principais

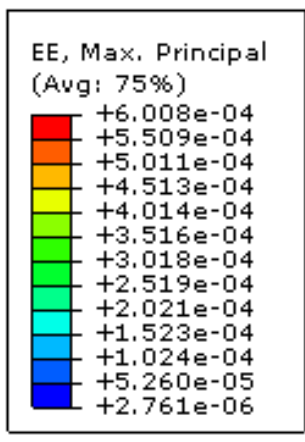

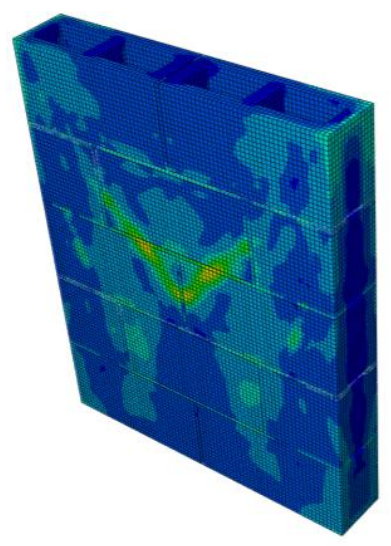

(a)
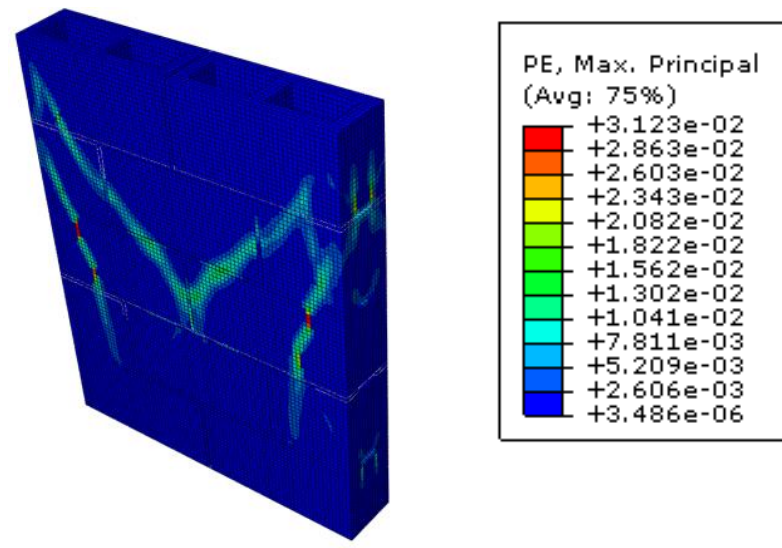

(b) 
Verificam-se as maiores deformações elásticas nas laterais das paredes, bem como deformações plásticas iniciadas tanto na lateral como na região central do modelo, conforme abordado anteriormente quanto à esta coerência. Para fins de análise quantitativa, é mostrada na Figura 4.7 a comparação dos limites obtidos experimentalmente, incluindo o seu valor médio, com o resultado do modelo numérico.

Figura 4.7 - Comparação da curva tesão-deformação entre os valores experimentais e numérico

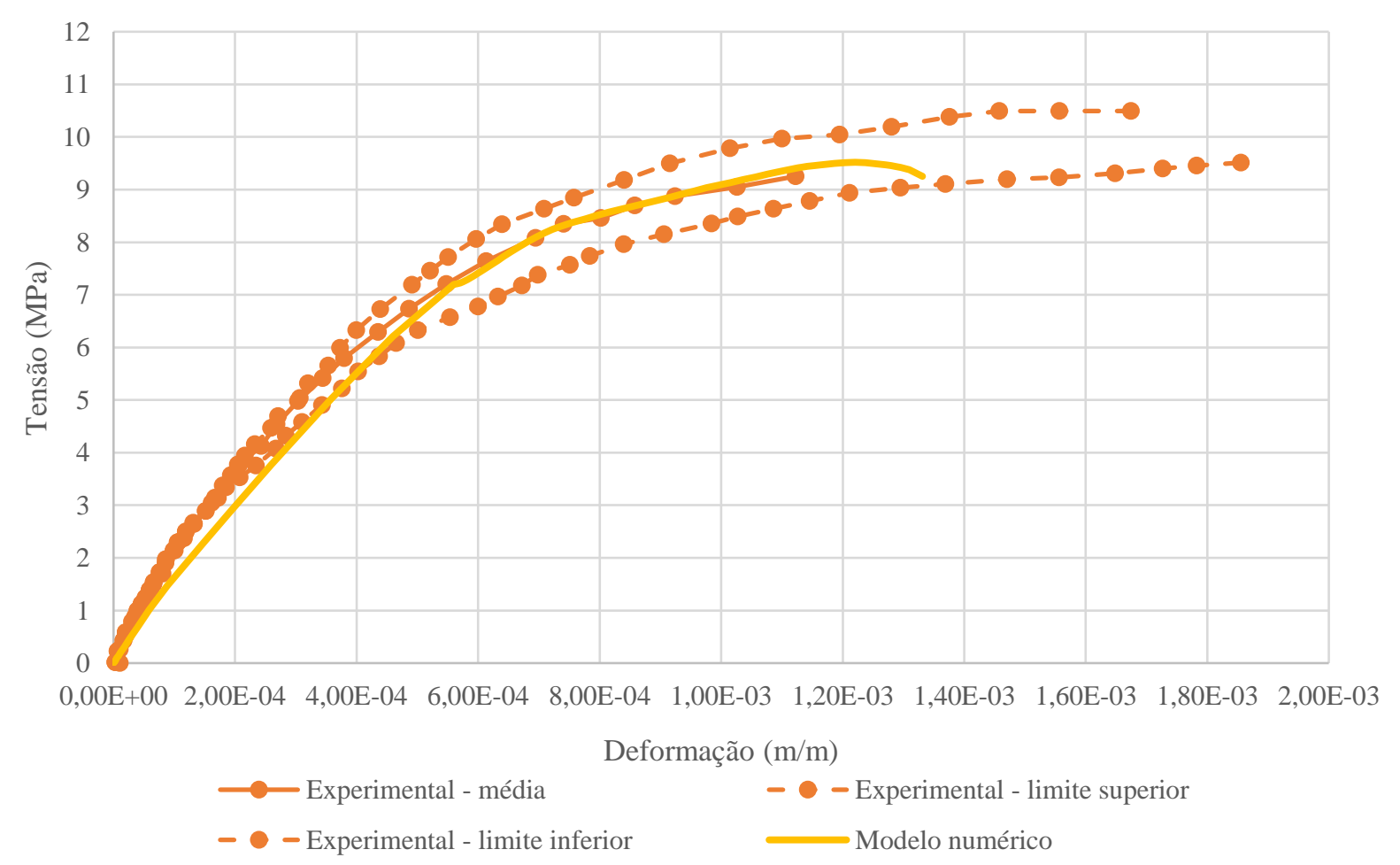

Na Tabela 4.1 é feita a comparação entre os valores experimental médio e referente ao modelo numérico no ponto de ruptura. Em relação ao valor médio obtido experimentalmente, o modelo apresenta, no pico, diferenças inferiores a $10 \%$, tanto quanto à tensão como quanto à deformação. No entanto, como verificado graficamente, o comportamento do modelo numérico encontra-se dentro dos limites máximo e mínimo obtidos experimentalmente, o que sugere um bom comportamento numérico.

Tabela 4.1 - Comparação dos valores médios obtidos por Oliveira (2014) com o numérico

\begin{tabular}{|c|c|c|c|c|}
\hline & $\begin{array}{l}\text { Tensão } \\
\text { (MPa) }\end{array}$ & Variação (\%) & $\begin{array}{l}\text { Deformação } \\
\qquad(\mathbf{m} / \mathbf{m})\end{array}$ & Variação (\%) \\
\hline Oliveira (2014) & 9,25 & \multirow{2}{*}{$-2,9$} & 0,00112 & \multirow{2}{*}{$-8,7$} \\
\hline Numérico & 9,52 & & 0,00122 & \\
\hline
\end{tabular}




\subsubsection{Bloco com espessura de $14 \mathrm{~cm}$ e argamassamento total}

Neste tópico é avaliado o modelo baseado no trabalho de Dupim (2019), com blocos de concreto com espessura de $14 \mathrm{~cm}$, de menor resistência e argamassamento total. Inicialmente são mostradas nas Figuras 4.8 e 4.9 os padrões de ruptura obtidos experimentalmente por Izquierdo (2015), cujo autor utilizou a mesma configuração de paredes, e por Dupim (2019), para comparação qualitativa com as tensões máximas e mínimas numéricas no instante da ruptura, vistas nas Figuras 4.10 e 4.11.

Figura 4.8 - Modo de ruptura da pequena parede obtido por Izquierdo (2015)
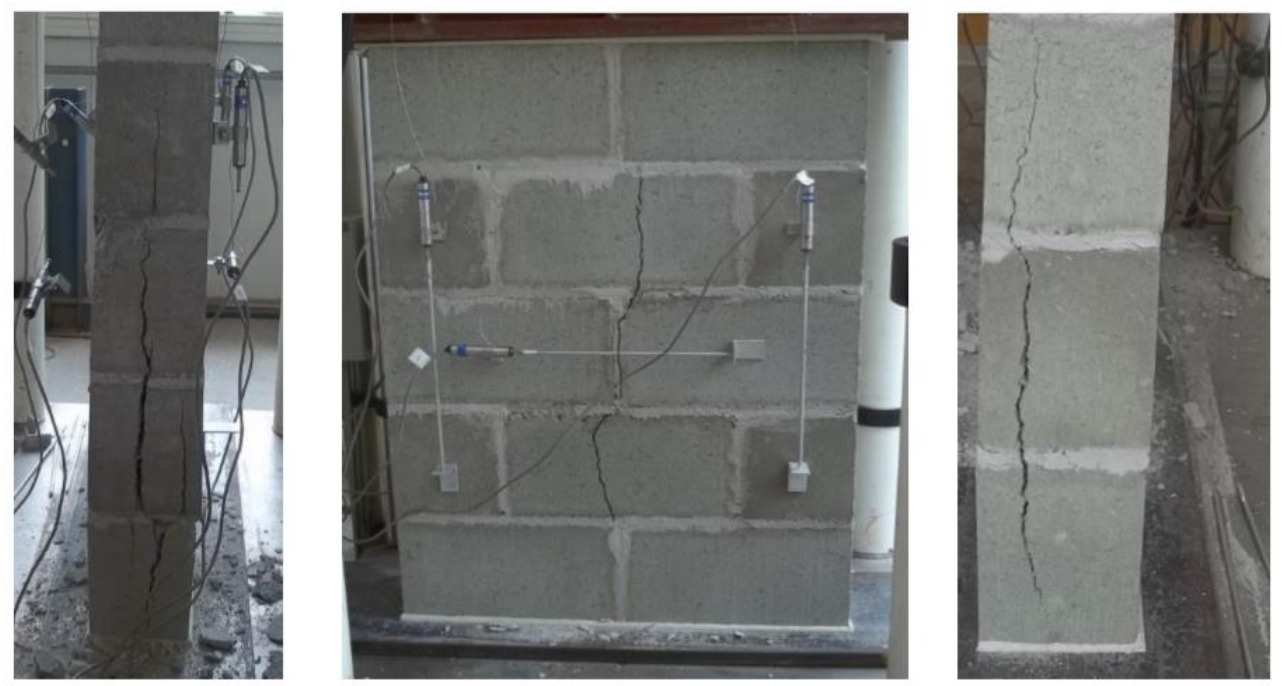

Fonte: Izquierdo (2015)

Figura 4.9-I - Modo de ruptura da pequena parede obtido por Dupim (2019)
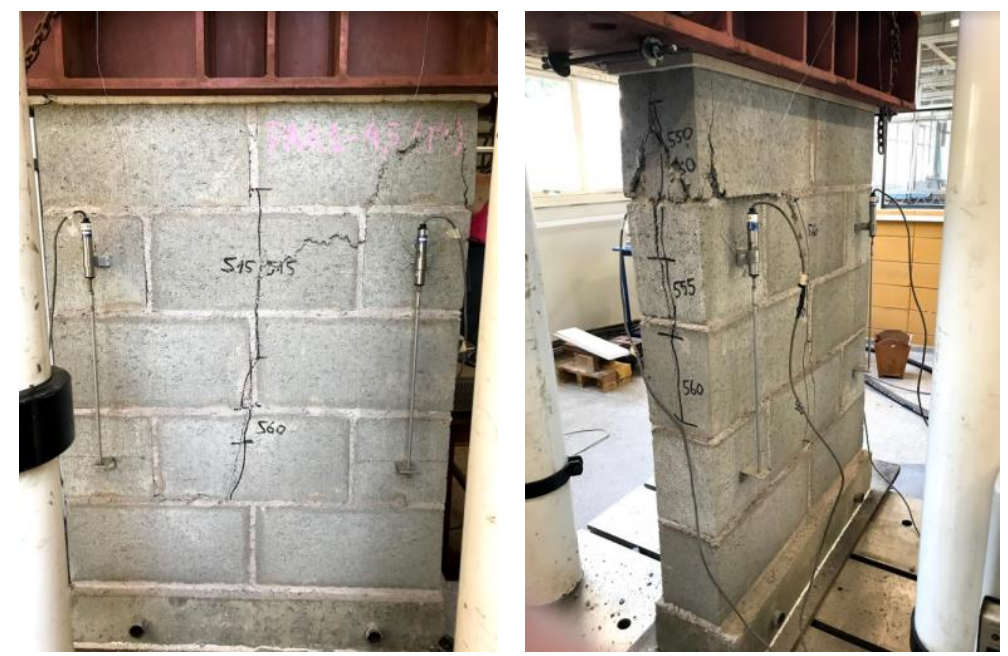

Fonte: Dupim (2019) 
Figura 4.9-II - Modo de ruptura da pequena parede obtido por Dupim (2019)
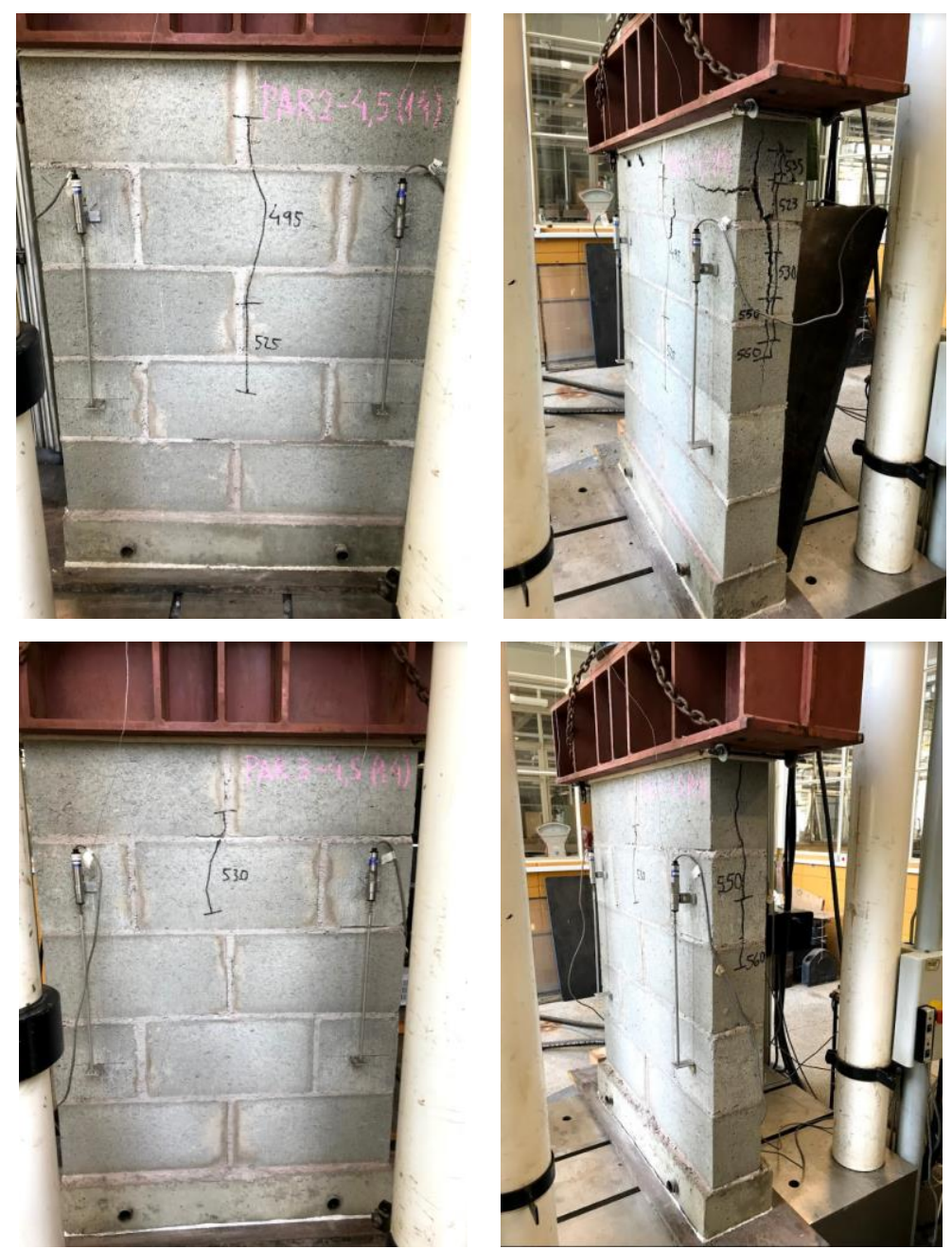

Fonte: Dupim (2019)

Figura 4.10 - Tensões principais mínimas do modelo numérico no momento da ruptura

S, Min. Principal
(Avg: $75 \%$ )
\begin{tabular}{|l}
$+3.076 \mathrm{e}+05$ \\
$-1.576 \mathrm{e}+06$ \\
$-3.460 \mathrm{e}+06$ \\
- \\
$-5.344 \mathrm{e}+06$ \\
$-7.228 \mathrm{e}+06$ \\
$-9.112 \mathrm{e}+06$ \\
$-1.100 \mathrm{e}+07$ \\
$-1.288 \mathrm{e}+07$ \\
$-1.476 \mathrm{e}+07$ \\
$-1.665 \mathrm{e}+07$ \\
$-1.853 \mathrm{e}+07$ \\
$-2.042 \mathrm{e}+07$ \\
$-2.230 \mathrm{e}+07$
\end{tabular}

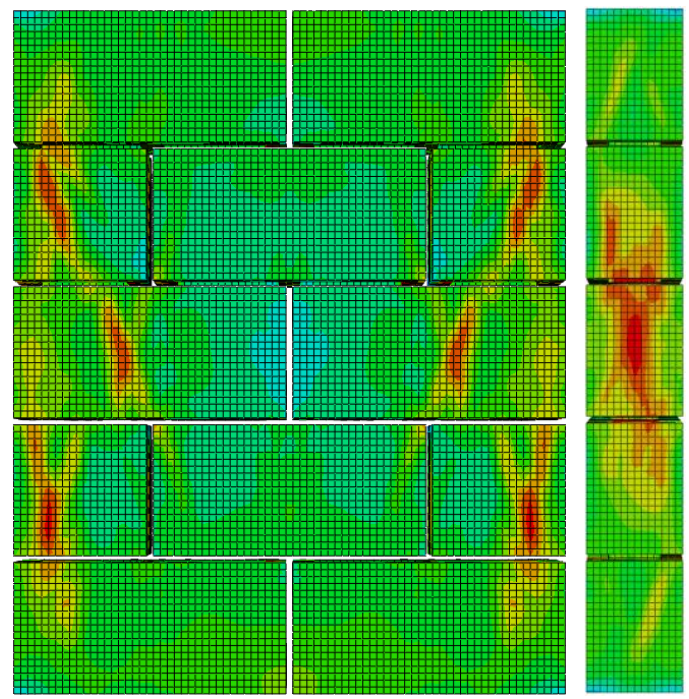


Figura 4.11 - Tensões principais máximas do modelo numérico no momento da ruptura
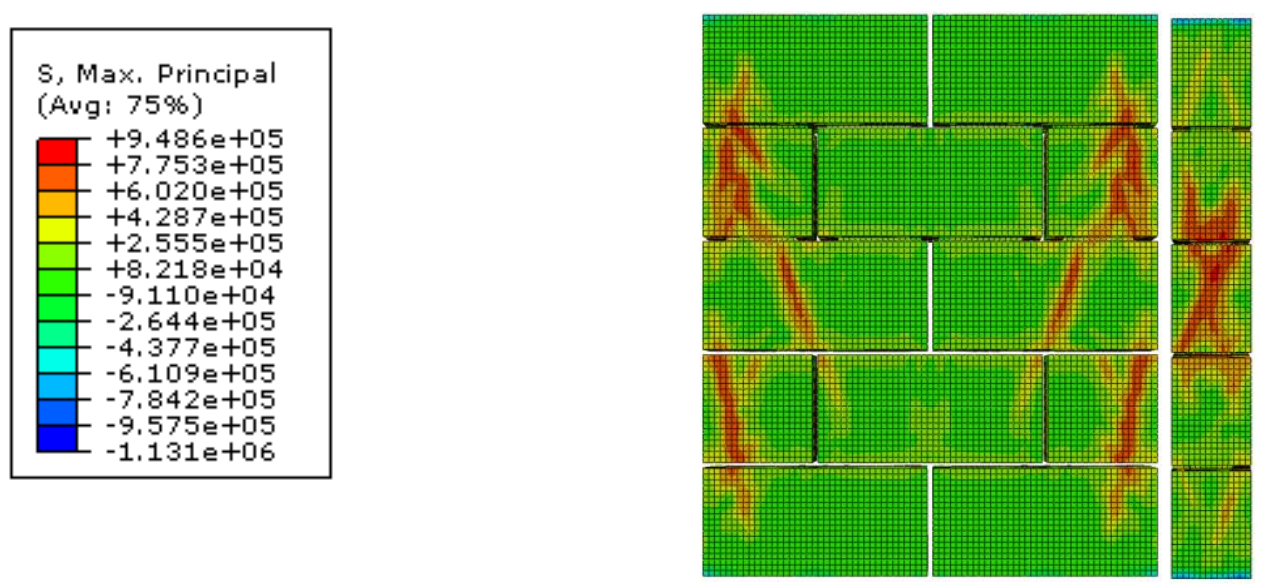

Dupim (2019) comenta que, independente do início das fissuras ter ocorrido na face lateral ou frontal, as fissuras que causaram a ruptura das paredes foram as laterais. Comenta também que a tendência dos ensaios foi o surgimento das fissuras laterais de cima para baixo aumentando conforme aumentava-se o carregamento.

Numericamente, no instante da ruptura da pequena parede, verifica-se acúmulo de tensões de tração em sua lateral, porém, com menor predominância em relação ao argamassamento parcial, como esperado e verificado nas imagens dos ensaios. Os resultados numéricos ultrapassam os resultados de ruptura por tração do bloco, na lateral da parede, no caso, 0,81 MPa. Da mesma forma, verifica-se para as tensões mínimas a obtenção do valor máximo experimental para os blocos de 14,32 MPa na região central da parede.

De forma análoga ao item anterior, é possível inferir que nas regiões de máximas tensões do modelo numérico, em que foram atingidos os valores experimentais máximos, ocorre o aparecimento de trincas, conforme modo de ruptura experimental. A Figura 4.12 indica as tensões principais pouco após o instante da ruptura.

Figura 4.12 - Tensões principais absolutas do modelo numérico pouco após a ruptura
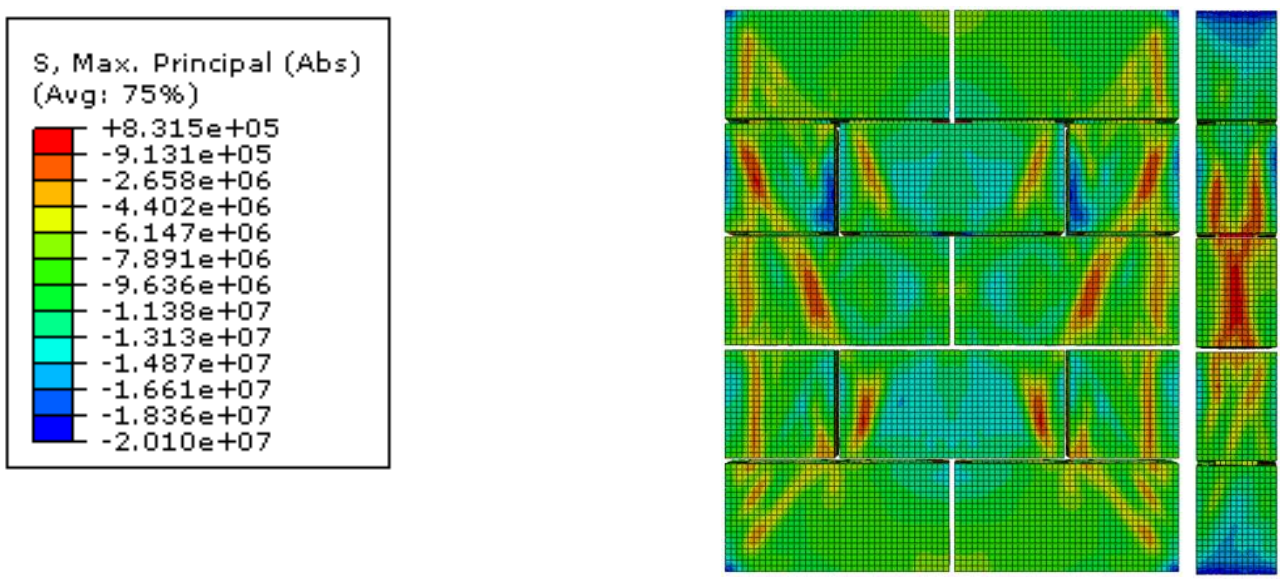
Também, conforme ocorrido com o argamassamento parcial, para as tensões absolutas, em instantes após a ruptura, ocorre inversão das tensões na região central da parede, onde as tensões de compressão tornam-se de tensões de tração devido ao seu rearranjo no compósito. Verifica-se também o aumento da área na qual as tensões laterais de tração ultrapassam os valores experimentais limites.

Analogamente ao item anterior, o comportamento do modelo pós-ruptura é justificado, uma vez que, após a ocorrência das primeiras fissuras se nota um rearranjo de tensões que implica em um aumento destas, justamente onde é visto um prolongamento das fissuras verificadas experimentalmente após a ruptura. As Figuras 4.13 (a) e (b) indicam o comportamento da argamassa no instante da ruptura da pequena parede.

Figura 4.13 - Tensões principais mínimas (a) e máximas (b) na argamassa no instante da ruptura

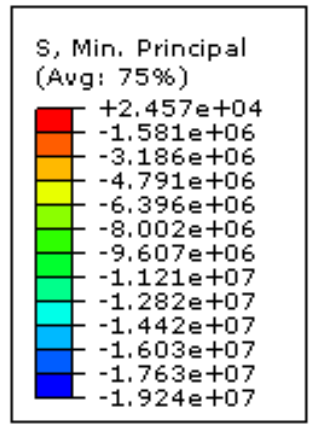

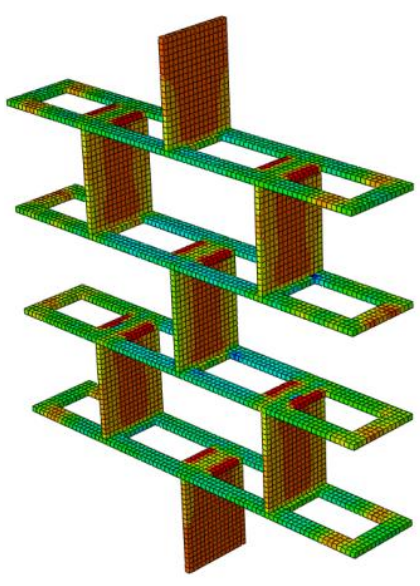

(a)

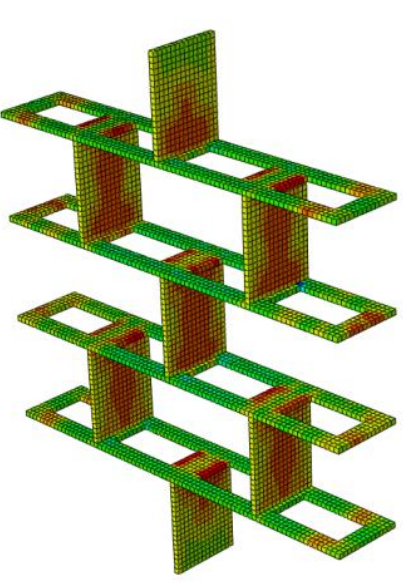

(b)

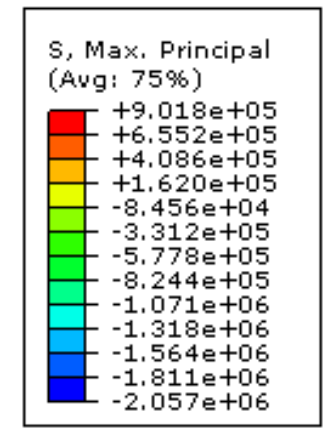

Conforme verificado para os blocos e meio blocos, a argamassa sofreu ruptura em alguns pontos, superando o valor máximo de 6,93 MPa para a compressão, bem como de 0,87 MPa para a tração. Neste caso, a mesma explicação do caso anterior é válida.

Para as deformações, as Figuras 4.14 (a) e (b) indicam, respectivamente, o comportamento da parede em relação às deformações elásticas e plásticas instantes após a ruptura. Outras análises do modelo, relativas ao deslocamento, encontram-se no Apêndice G.

Verifica-se as maiores deformações elásticas concentradas nas laterais das paredes e em algumas áreas da face frontal. As deformações plásticas apresentam valores superiores nas laterais, onde ocorrem as fissuras predominantes para a ruptura e em partes da face frontal, simulando o "efeito de arco". Para a análise quantitativa, é mostrada na Figura 4.15 a comparação dos valores médios obtidos experimentalmente com o resultado numérico. 
Figura 4.14 - Deformações elásticas (a) e plásticas (b) principais

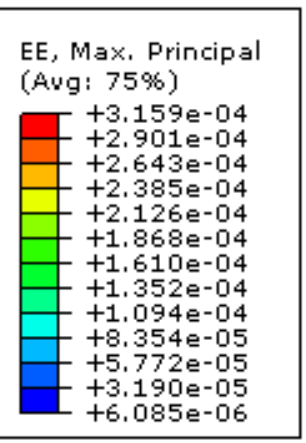

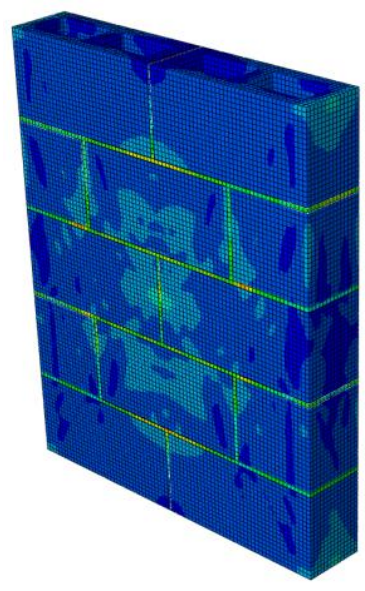

(a)
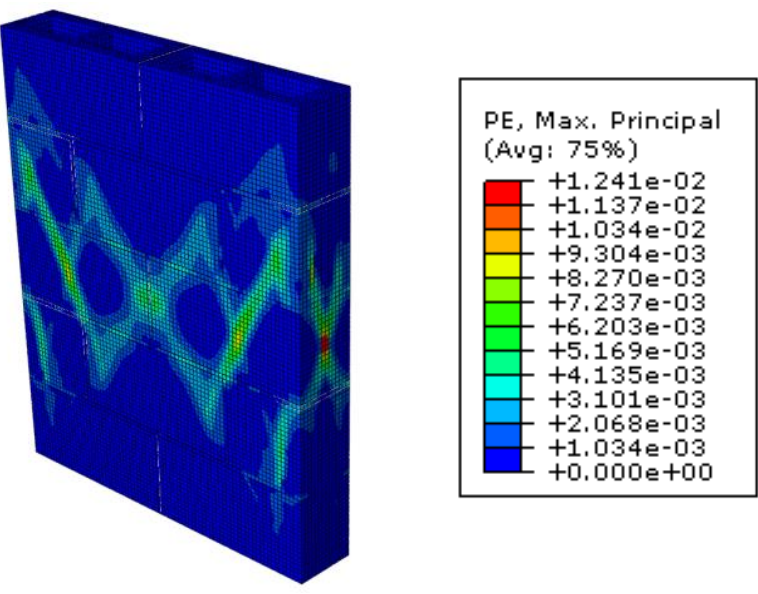

(b)

Figura 4.15 - Comparação da curva tesão-deformação entre os valores experimentais e numérico

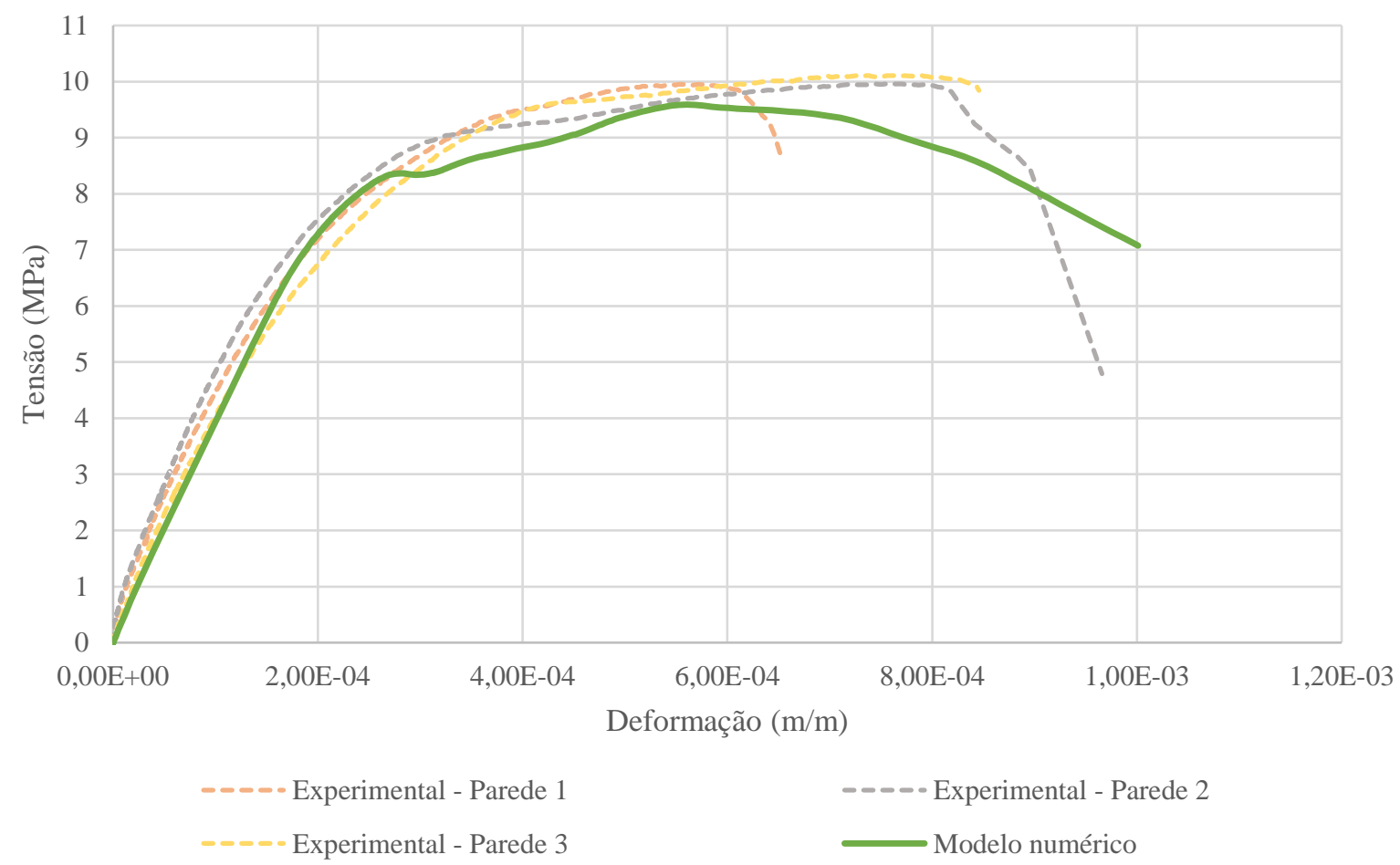

Na Tabela 4.2 é feita a comparação entre os valores experimental médio e do resultado numérico no ponto de ruptura. 
Tabela 4.2 - Comparação dos valores médios obtidos por Dupim (2019) com o numérico

\begin{tabular}{ccccc} 
& $\begin{array}{c}\text { Tensão } \\
(\mathbf{M P a})\end{array}$ & Variação $(\boldsymbol{\%})$ & $\begin{array}{c}\text { Deformação } \\
(\mathbf{m} / \mathbf{m})\end{array}$ & Variação $(\%)$ \\
\hline Parede 1 & 9,95 & $-3,6$ & 0,000555 & $-10,8$ \\
\hline Parede 2 & 9,97 & $-3,8$ & 0,000745 & 24,7 \\
\hline Parede 3 & 10,11 & $-5,1$ & 0,000790 & 28,9 \\
\hline Numérico & 9,59 & - & 0,000561 & - \\
\hline
\end{tabular}

Em relação ao valor médio obtido experimentalmente, o modelo apresenta, no pico, diferenças inferiores a 10\% quanto à tensão. Para a deformação, o modelo encontra-se de forma intermediária entre os três resultados experimentais obtidos. Graficamente, percebe-se que o modelo consegue seguir a tendência obtida experimentalmente até a ruptura, apresentando-se por quase a totalidade da deformação, dentro dos limites dos ensaios, o que sugere um bom comportamento numérico.

\subsubsection{Bloco com espessura de $19 \mathrm{~cm}$ e argamassamento total}

Neste tópico é avaliado o modelo baseado no trabalho de Dupim (2019), com blocos de concreto com espessura de $19 \mathrm{~cm}$, de menor resistência e argamassamento total. Conforme realizado nos itens anteriores, na sequência são apresentadas imagens com os padrões de ruptura obtidos experimentalmente (Figura 4.16), e, comparados com as tensões máximas e mínimas numéricas no instante da ruptura, para análise qualitativa, conforme indicado nas Figuras 4.17 e 4.18.

Figura 4.16-I - Modo de ruptura da pequena parede obtido por Dupim (2019)
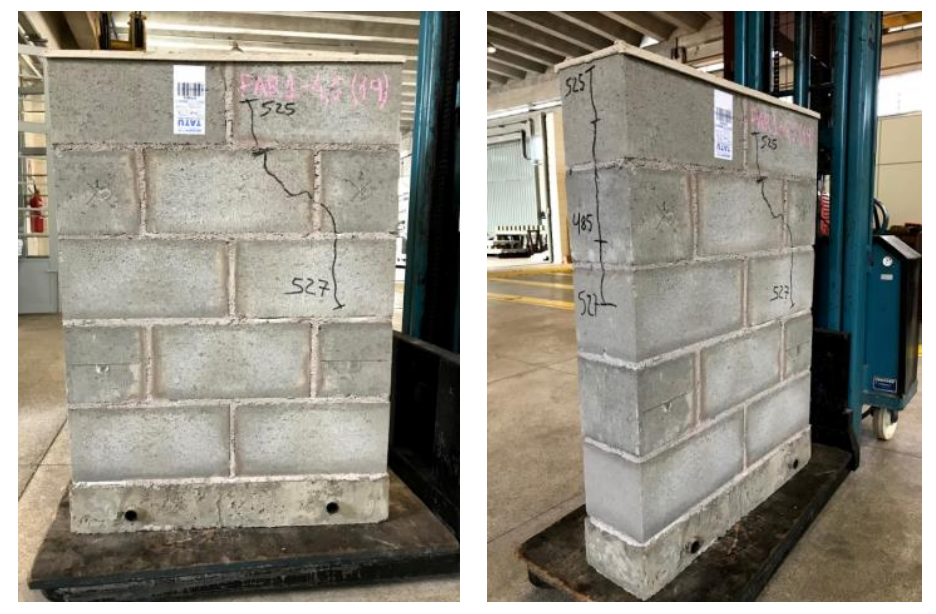

Fonte: Dupim (2019) 
Figura 4.16-II - Modo de ruptura obtido da pequena parede por Dupim (2019)
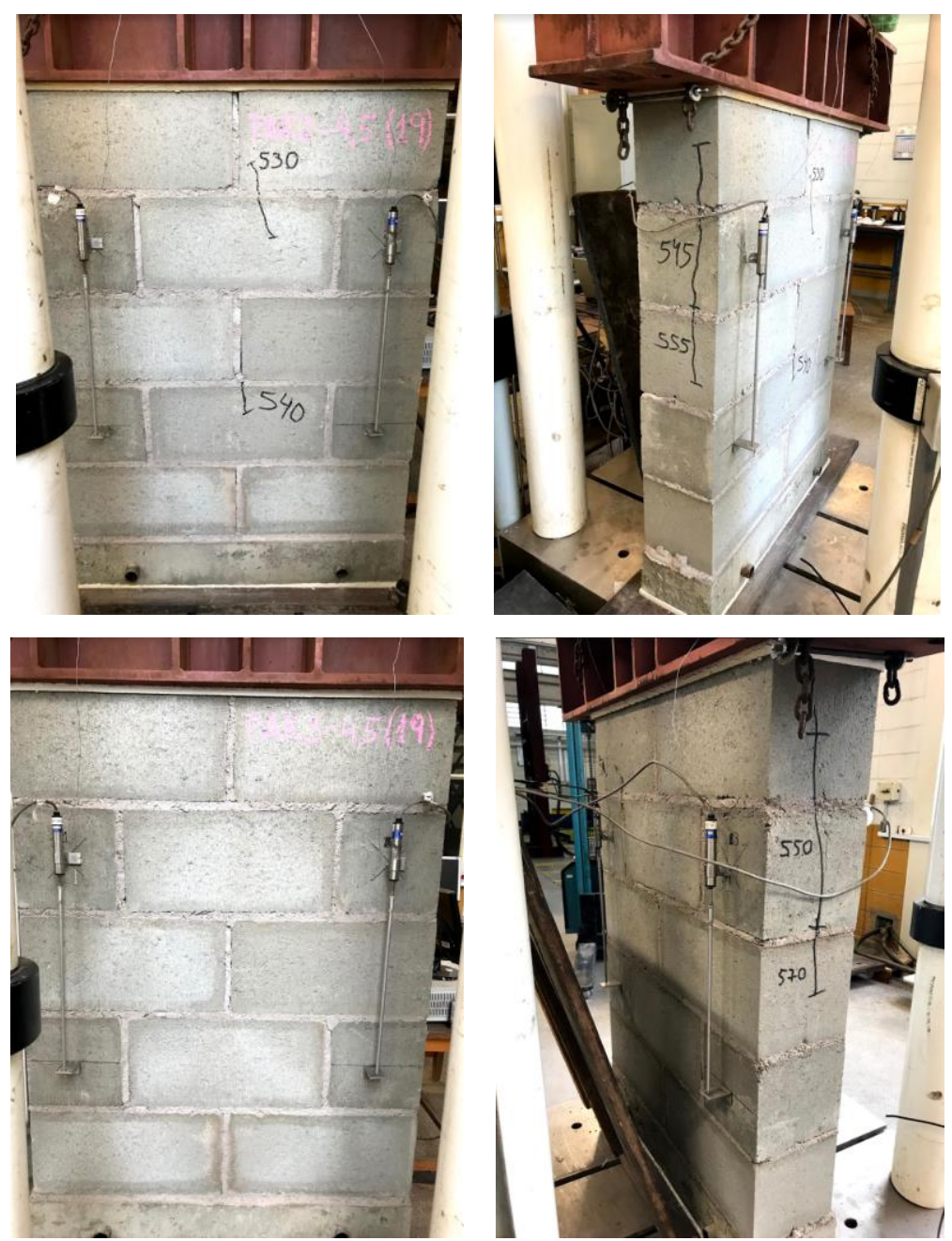

Fonte: Dupim (2019)

Figura 4.17 - Tensões principais mínimas do modelo numérico no momento da ruptura

$$
\begin{aligned}
& \text { S, Min. Principal } \\
& \text { (Avg: 75\%) } \\
& \begin{array}{|r|r|}
+2.166 \mathrm{e}+05 \\
-1.514 \mathrm{e}+06 \\
-3.245 \mathrm{e}+06 \\
-4.976 \mathrm{e}+06 \\
-6.707 \mathrm{e}+06 \\
-8.438 \mathrm{e}+06 \\
-1.017 \mathrm{e}+07 \\
-1.190 \mathrm{e}+07 \\
-1.363 \mathrm{e}+07 \\
-1.536 \mathrm{e}+07 \\
-1.709 \mathrm{e}+07 \\
-1.882 \mathrm{e}+07 \\
-2.055 \mathrm{e}+07
\end{array}
\end{aligned}
$$
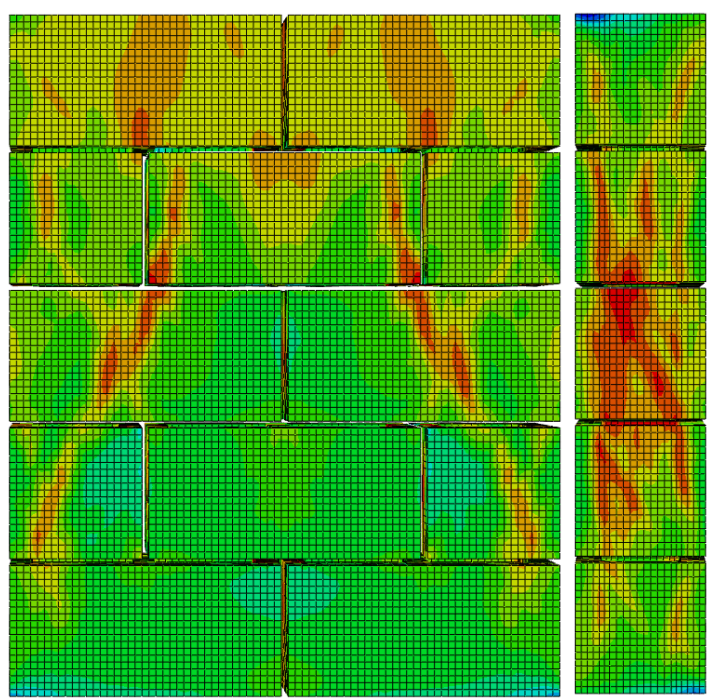
Figura 4.18 - Tensões principais máximas do modelo numérico no momento da ruptura

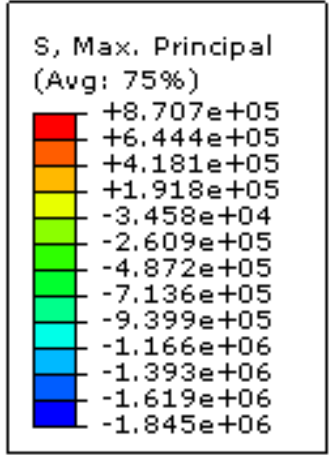

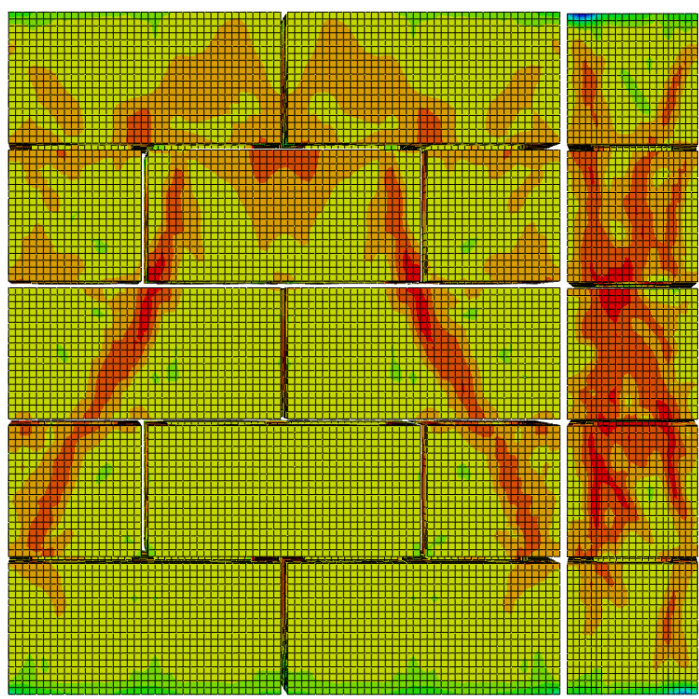

Como no caso das paredes com espessura de $14 \mathrm{~cm}$, Dupim (2019) reitera que, independentemente do local onde se iniciaram as fissuras, aquelas que causaram a ruptura das paredes foram as laterais. Neste caso, conforme visualizado na Figura 4.16, as fissuras frontais se manifestam com menor intensidade.

Numericamente, no instante da ruptura da pequena parede verifica-se maior acúmulo de tensões de tração nas faces laterais e na diagonal nas faces frontais. Os resultados numéricos ultrapassam os de ruptura por tração na lateral, no caso, 0,73 MPa. Além disso, em algumas regiões na face frontal onde ocorrem as fissuras (experimental) há proximidade com valores de ruptura indicados no modelo com tensões de tração elevadas. Para as tensões mínimas, a ruptura dos blocos ocorreria em 11,56 MPa, não chegando a este limite nas faces da parede. Na região central ocorre tensões de compressão, porém, inferiores aos limites.

De forma análoga aos demais itens, pode-se inferir que, nas regiões de máximas tensões do modelo numérico onde atingiram-se os valores experimentais máximos, ocorre o aparecimento de trincas, conforme modo de ruptura experimental. A Figura 4.19 indica as tensões principais pouco após o instante da ruptura.

Na região central da parede, pouco após a identificação de ruptura ocorre fenômeno parecido com os modelos anteriormente comentados, em que as tensões de compressão tornamse tensões de tração. Neste, porém, a intensidade desta variação é menor em relação aos demais. Verifica-se também rearranjo na área lateral onde estão concentradas as tensões de tração, predominantes para a ruptura da parede. Analogamente aos demais itens, o comportamento do modelo pós-ruptura justifica-se, uma vez que, após a ocorrência das primeiras fissuras, há um rearranjo de tensões coincidentes com a tendência de fissuração verificada experimentalmente. 
Figura 4.19 - Tensões principais absolutas do modelo numérico pouco após a ruptura

\begin{tabular}{|l|}
\hline S, Max. Principal (Abs) \\
(Avg: 75\%) \\
\begin{tabular}{|l}
$+7.530 e+05$ \\
$-1.043 e+06$ \\
$-2.840 e+06$ \\
$-4.636 e+06$ \\
$-6.433 e+06$ \\
$-8.229 e+06$ \\
$-1.003 e+07$ \\
$-1.182 \mathrm{e}+07$ \\
$-1.362 \mathrm{e}+07$ \\
$-1.542 \mathrm{e}+07$ \\
$-1.721 \mathrm{e}+07$ \\
$-1.901 \mathrm{e}+07$ \\
$-2.080 \mathrm{e}+07$
\end{tabular} \\
\hline
\end{tabular}
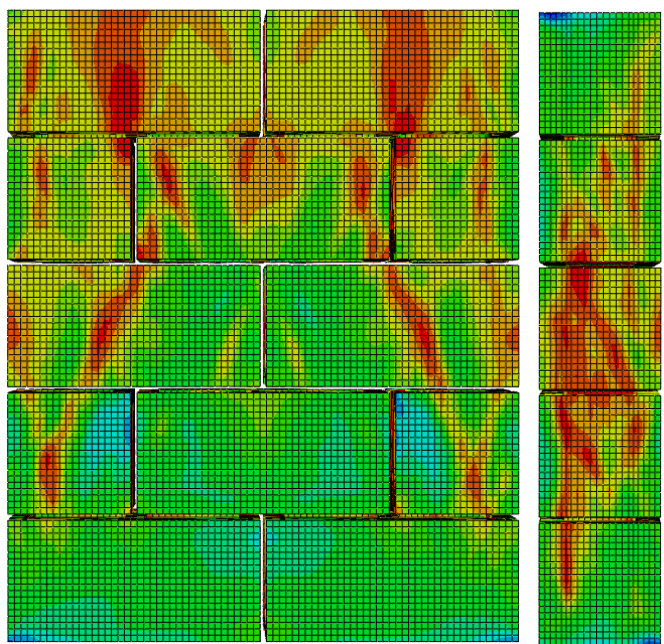

As Figuras 4.20 (a) e (b) indicam o comportamento da argamassa no instante da ruptura da pequena parede.

Figura 4.20 - Tensões principais mínimas (a) e máximas (b) na argamassa no instante da ruptura

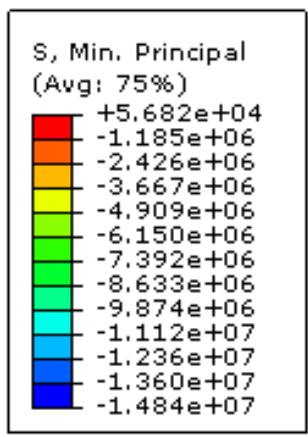

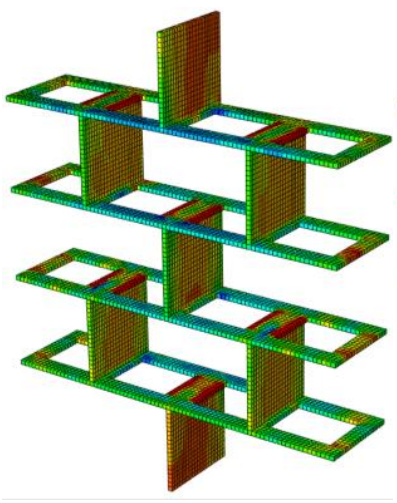

(a)

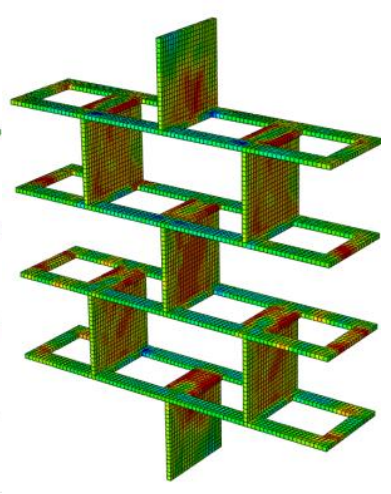

(b)

b)

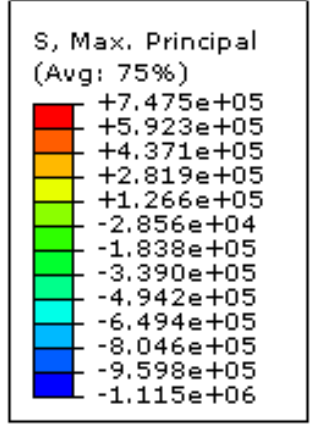

Conforme verificado para os blocos e meio blocos, a argamassa sofreu ruptura em alguns pontos, superando o valor máximo de 6,93 MPa para a compressão e de 0,87 MPa para a tração. A mesma explicação dos itens anteriores é válida para este caso.

Para as deformações, as Figuras 4.21 (a) e (b) indicam o comportamento da parede em relação às deformações elásticas e plásticas instantes após a ruptura. Outras análises do modelo, relativas ao deslocamento, podem ser vistas no Apêndice $\boldsymbol{G}$.

Verifica-se as maiores deformações elásticas concentradas nas laterais das paredes e em algumas áreas da face frontal, principalmente na argamassa. As deformações plásticas apresentam valores superiores nas laterais, onde ocorrem as fissuras predominantes para a ruptura e em partes da face frontal, simulando o "efeito de arco". Para a análise quantitativa, é 
mostrada na Figura 4.22, a comparação dos limites obtidos experimentalmente, bem como, seu valor médio, com os resultados numéricos.

Figura 4.21 - Deformações elásticas (a) e plásticas (b) principais
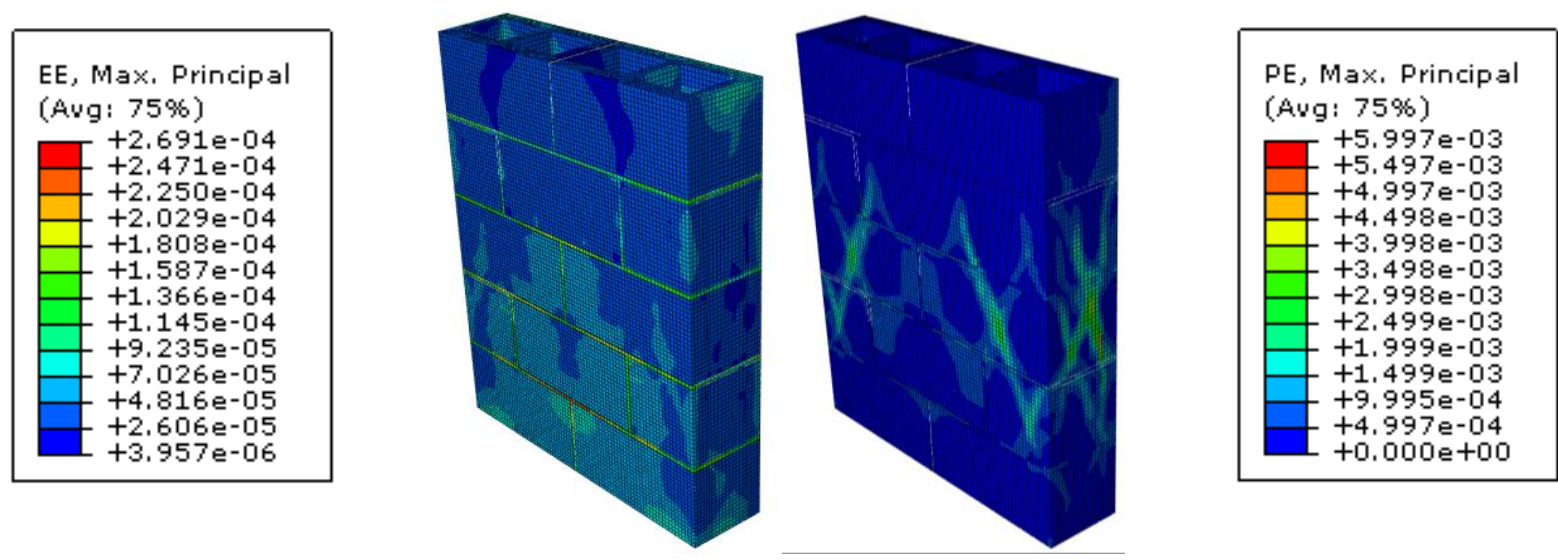

Figura 4.22 - Comparação da curva tesão-deformação entre os valores experimentais e numérico

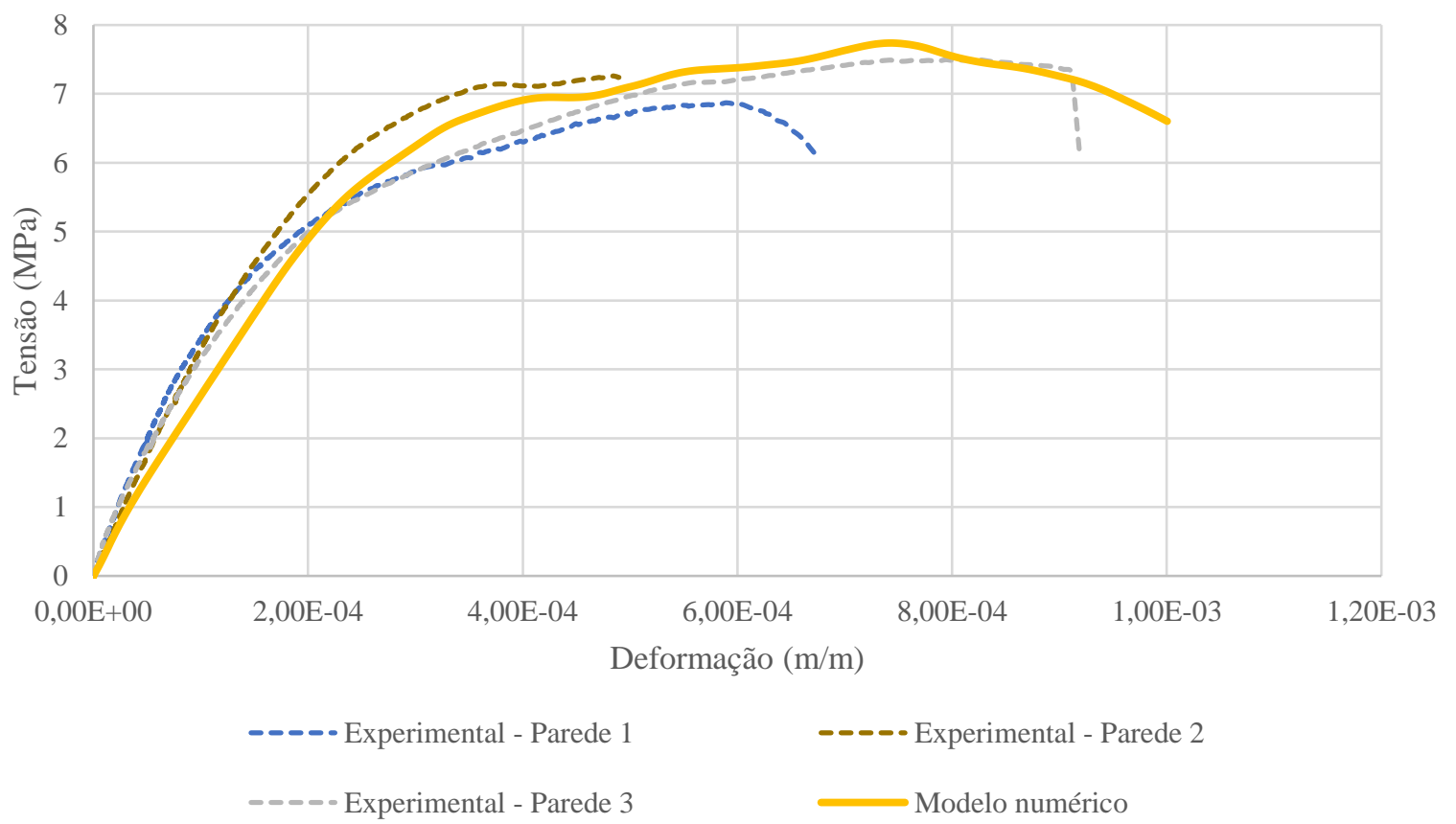

Na Tabela 4.3 é feita a comparação entre os valores experimentais médios e do resultado numérico no ponto de ruptura. 
Tabela 4.3 - Comparação dos valores médios obtidos por Dupim (2019) com o numérico

\begin{tabular}{ccccc} 
& $\begin{array}{c}\text { Tensão } \\
(\mathbf{M P a})\end{array}$ & Variação $(\mathbf{\%})$ & $\begin{array}{c}\text { Deformação } \\
(\mathbf{m} / \mathbf{m})\end{array}$ & Variação $(\%)$ \\
\hline Parede 1 & 6,87 & $-12,7$ & 0,000584 & $-26,7$ \\
\hline Parede 2 & 7,26 & $-6,6$ & 0,000479 & $-54,5$ \\
\hline Parede 3 & 7,49 & $-3,3$ & 0,000743 & 0,70 \\
\hline Numérico & 7,74 & - & 0,000740 & - \\
\hline
\end{tabular}

Como apresentado no item anterior o valor para o pico de tensão apresenta-se próximo aos valores experimentais. Para a deformação, o modelo encontra-se de forma intermediária entre os três resultados experimentais obtidos, aproximando-se da Parede 3. Graficamente, percebe-se que o modelo consegue seguir a tendência obtida experimentalmente até a ruptura, apresentando-se por quase a totalidade da deformação, dentro dos limites dos ensaios, o que sugere um bom comportamento numérico.

\subsection{PROCEDIMENTO DE VALIDAÇÃO DO MODELO TÉRMICO}

\subsubsection{Bloco com espessura de $14 \mathrm{~cm}$, argamassamento total e fogo em uma face}

Neste tópico é avaliado o modelo baseado no trabalho de Dupim (2019), com blocos de concreto com espessura de $14 \mathrm{~cm}$, de menor resistência, argamassamento total e fogo em uma face. Conforme apresentado no capítulo anterior, onde foram indicadas as condições de contorno no modelo experimental, na Figura 4.23 é mostrado o modelo antes e após a elevação de temperaturas.

Figura 4.23-I - Corpos-de-prova antes da elevação de temperatura (a)
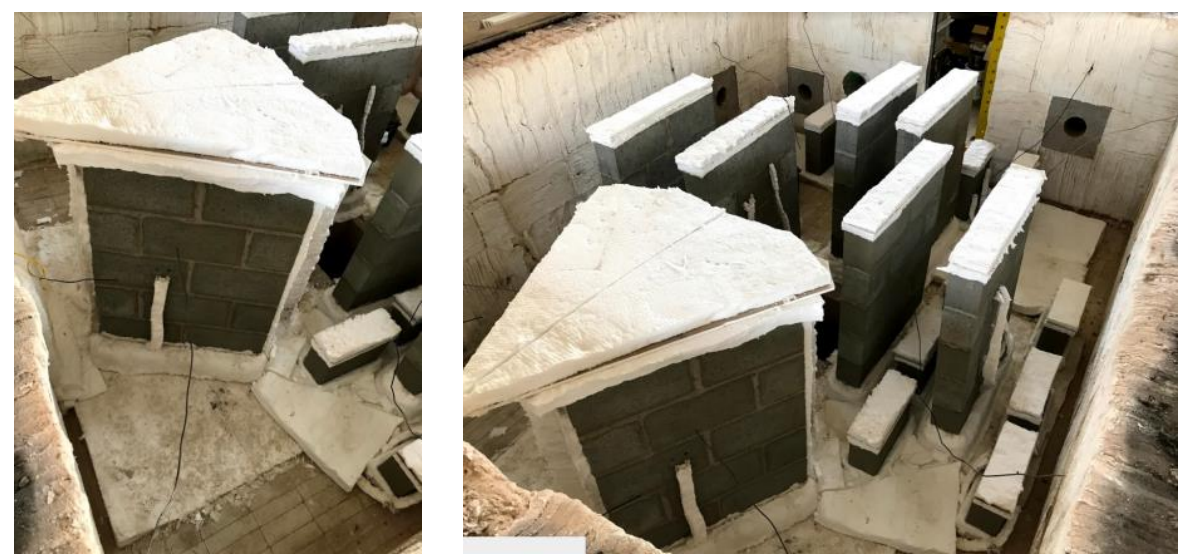

(a)

Fonte: Dupim (2019) 
Figura 4.23-II - Corpos-de-prova durante (b) e após a elevação de temperatura (c)
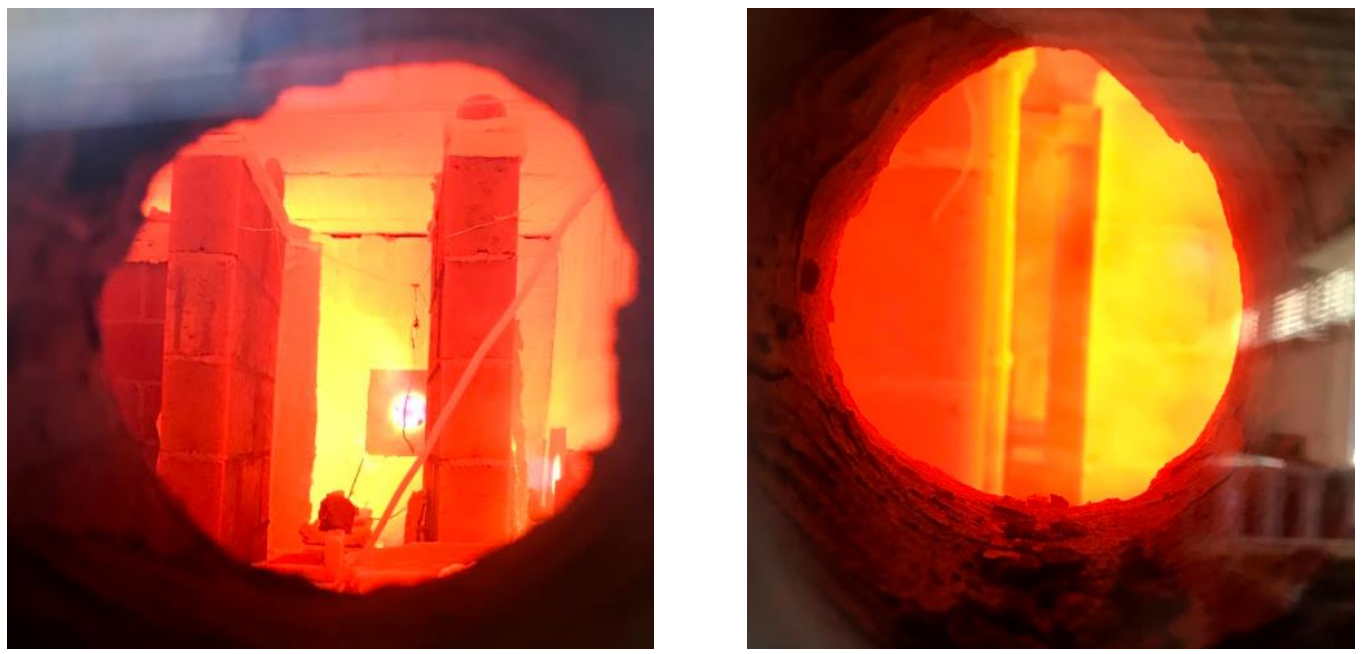

(b)
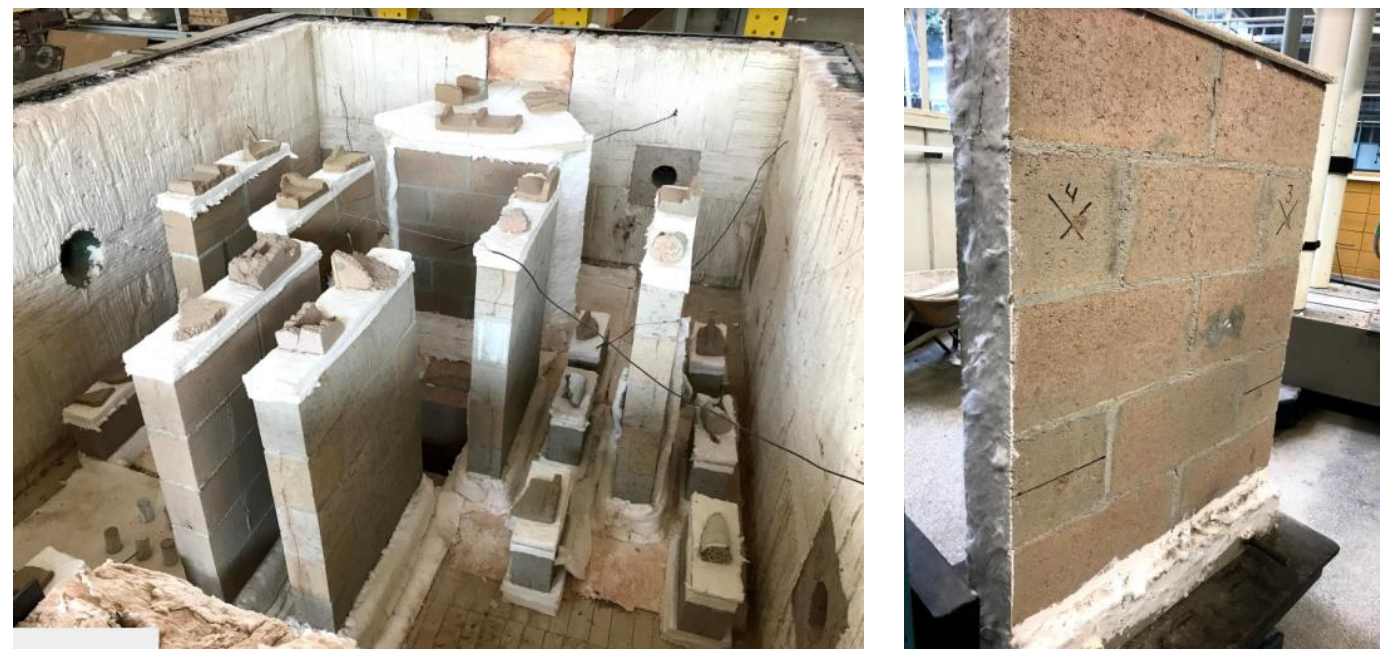

(c)

Fonte: Dupim (2019)

Dupim (2019) obteve, para o trio de paredes, dados que permitiram a criação de curvas de evolução de temperatura ao longo da espessura da parede para determinados tempos de incêndio, as quais foram comparadas com os resultados provenientes dos modelos numéricos conforme mostrado na Figura 4.24. As linhas tracejadas referem-se aos valores experimentais, enquanto as linhas cheias de referem aos valores numéricos para os respectivos tempos de incêndio indicados. Os pontos de medidas experimentais foram com distâncias de 5, 20, 120 e $135 \mathrm{~mm}$ da face exposta ao fogo. 
Figura 4.24 - Evolução da temperatura em função da espessura da parede de acordo com os tempos de incêndio indicados

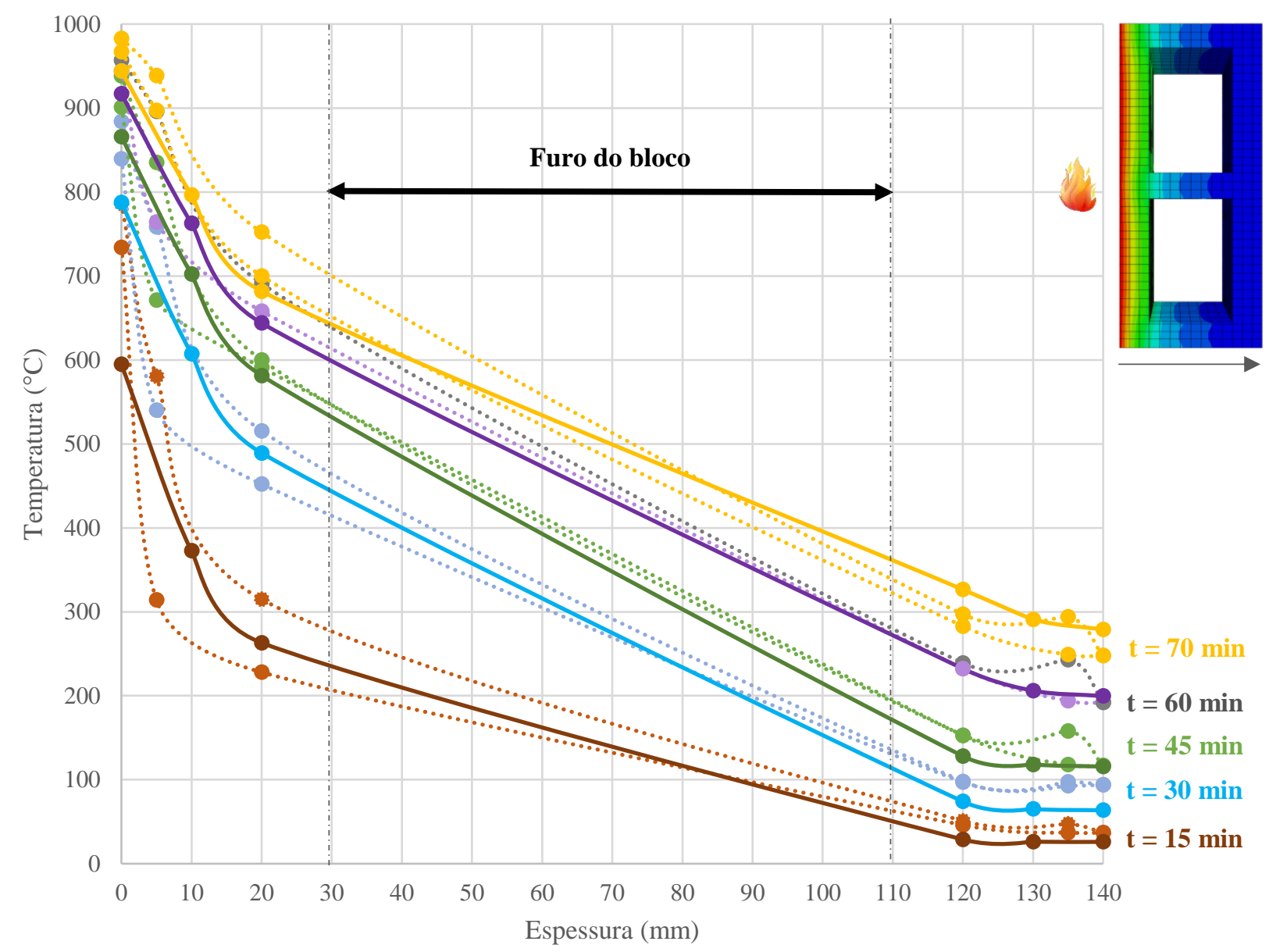

Para os pontos citados, a Tabela 4.4 indica as temperaturas mínima e máxima experimentais e as obtidas numericamente. Adicionalmente, indica a diferença de temperatura nos casos em que o modelo não obteve resultados dentro do intervalo experimental.

O modelo numérico apresenta um melhor comportamento quanto aos resultados experimentais nas espessuras iniciais, conforme visto na Tabela 4.4 e Figura 4.24. Dentre os possíveis motivos para a ocorrência dessa situação, podem ser citados:

- Ocorrência de fissuras no ensaio: o modelo não faz consideração acerca de abertura de fissuras. Logo, a possível entrada de ar mais quente pode fazer com que as paredes a partir do septo aumentem mais rapidamente sua temperatura;

- Incertezas de ensaio: devido à dificuldade de instalação dos termopares, as distâncias podem ter algumas variações em relação às informadas. Além disso, os termopares foram inseridos nos blocos utilizando de argamassa, o que, com a elevação de temperatura pode agilizar a ocorrência de desprendimentos; 
- Detalhamento do modelo numérico: a redução de maiores detalhamentos do modelo, como a não consideração de fissuração e o menor refinamento reduzem a precisão dos resultados;

- Inexistência de curvas para as propriedades dos materiais: conforme explicitado no Capítulo 3, as curvas para o calor específico e para a condutividade térmica foram obtidas através da combinação das curvas do Eurocode para estruturas de concreto e de alvenaria estrutural em blocos de concreto. A não existência de curvas específicas para o material em uso reduz a precisão dos resultados numéricos.

Tabela 4.4 - Temperaturas atingidas em função da distância em relação à face exposta e do tempo de incêndio

\begin{tabular}{|c|c|c|c|c|c|}
\hline $\begin{array}{l}\text { Distância } \\
\text { (mm) }\end{array}$ & $\begin{array}{c}\text { Tempo de } \\
\text { incêndio (min) }\end{array}$ & \multicolumn{2}{|c|}{ Limites experimentais } & Numérico & $\begin{array}{c}\text { Diferença } \\
\left({ }^{\circ} \mathrm{C}\right)\end{array}$ \\
\hline \multirow{5}{*}{5} & 15 & 314,0 & 580,3 & 483,6 & - \\
\hline & 30 & 540,0 & 758,5 & 697,3 & - \\
\hline & 45 & 671,0 & 835,3 & 783,9 & - \\
\hline & 60 & 764,0 & 895,9 & 839,8 & - \\
\hline & 70 & 825,0 & 938,7 & 870,2 & - \\
\hline \multirow{5}{*}{20} & 15 & 228,0 & 314,8 & 263,0 & - \\
\hline & 30 & 452,0 & 515,4 & 489,1 & - \\
\hline & 45 & 599,9 & 671,0 & 581,3 & $-18,6$ \\
\hline & 60 & 658,0 & 691,0 & 643,8 & $-14,2$ \\
\hline & 70 & 700,0 & 752,0 & 681,8 & $-18,2$ \\
\hline \multirow{5}{*}{120} & 15 & 46,0 & $\overline{51,1}$ & 28,8 & $-17,2$ \\
\hline & 30 & 97,1 & 98,0 & 74,0 & $-23,1$ \\
\hline & 45 & 152,6 & 153,0 & 128,1 & $-24,5$ \\
\hline & 60 & 232,5 & 239,0 & 232,3 & - \\
\hline & 70 & 282,9 & 297,0 & 326,5 & 29,5 \\
\hline \multirow{5}{*}{135} & 15 & 37,0 & 47,4 & 26,1 & $-10,9$ \\
\hline & 30 & 93,0 & 97,6 & 64,4 & $-28,6$ \\
\hline & 45 & 118,0 & 158,1 & 117,0 & $-1,0$ \\
\hline & 60 & 194,0 & 243,0 & 202,9 & - \\
\hline & 70 & 249,0 & 294,1 & 284,9 & - \\
\hline
\end{tabular}


Apesar do exposto anteriormente, as diferenças encontradas para as espessuras de 120 e $135 \mathrm{~mm}$ podem ser consideradas pequenas em resposta às temperaturas ocorrentes. As maiores diferenças obtidas entre os valores experimentais e numérico foram inferiores a $30^{\circ} \mathrm{C}$. Ademais, conforme as medidas experimentais se distanciaram da face exposta ao fogo, o intervalo entre os limites foi reduzido, impondo um maior nível de precisão aos resultados numéricos. Verifica-se, assim, de acordo com o objetivo deste trabalho, um bom comportamento do modelo numérico em relação aos resultados experimentais.

Outra comparação realizada do modelo numérico em relação aos resultados experimentais está exposta nas Figuras 4.25, 4.26, 4.27, 4.28 e 4.29, relativa à elevação de temperatura em função do tempo. As linhas tracejadas representam os resultados experimentais, enquanto as linhas cheias representam os resultados numéricos.

Figura 4.25 - Comparação da elevação da temperatura em função do tempo para a distância de $5 \mathrm{~mm}$ da face exposta

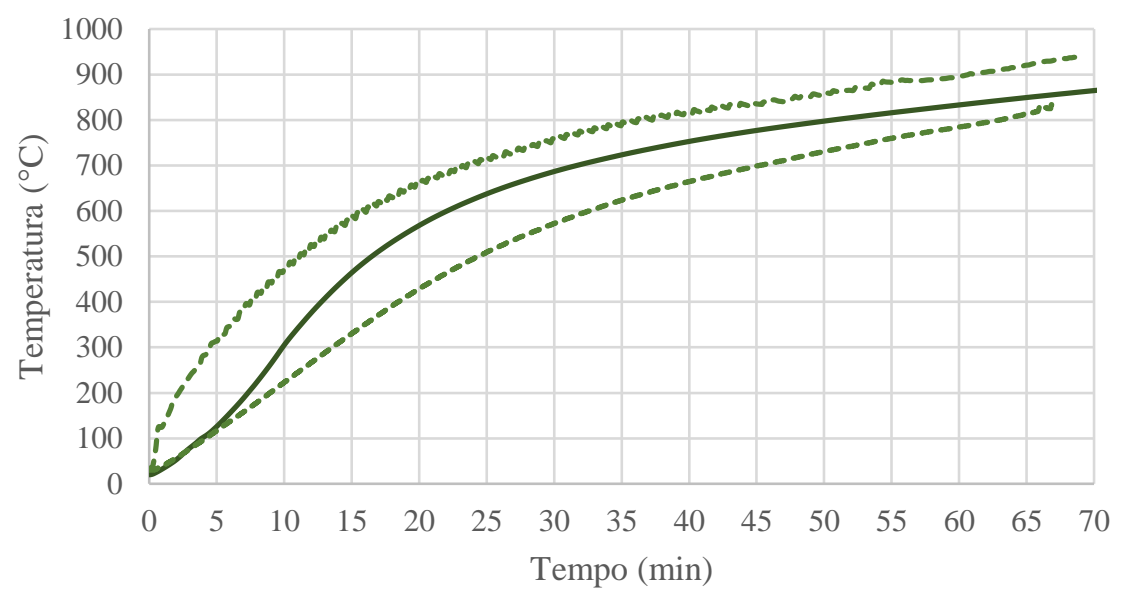

Figura 4.26 - Comparação da elevação da temperatura em função do tempo para a distância de $20 \mathrm{~mm}$ da face exposta

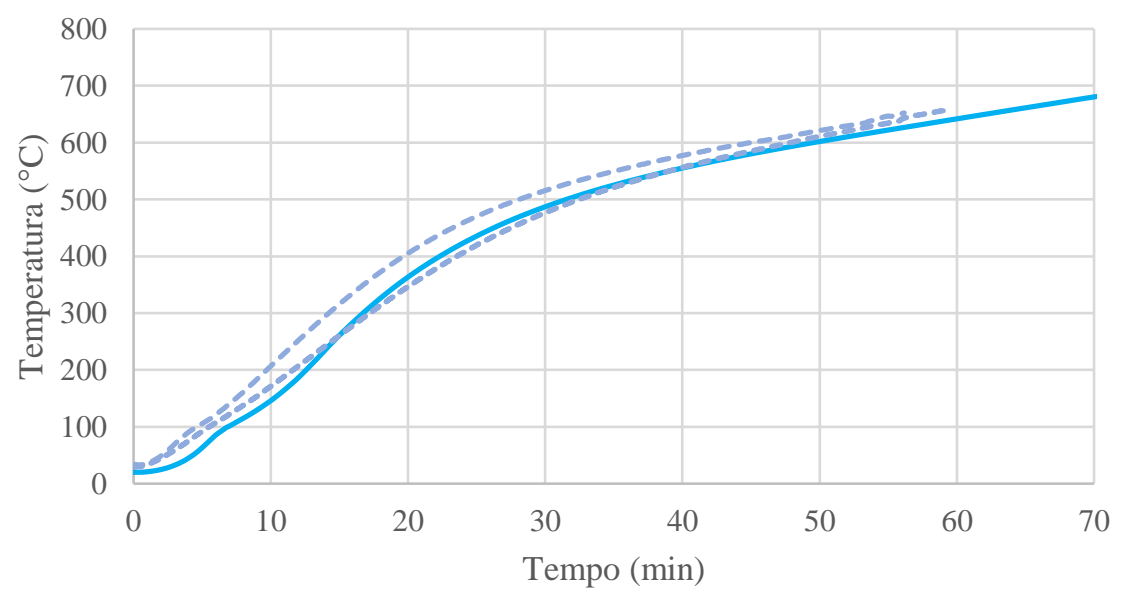


Figura 4.27 - Comparação da elevação da temperatura em função do tempo para a distância de $70 \mathrm{~mm}$ da face exposta

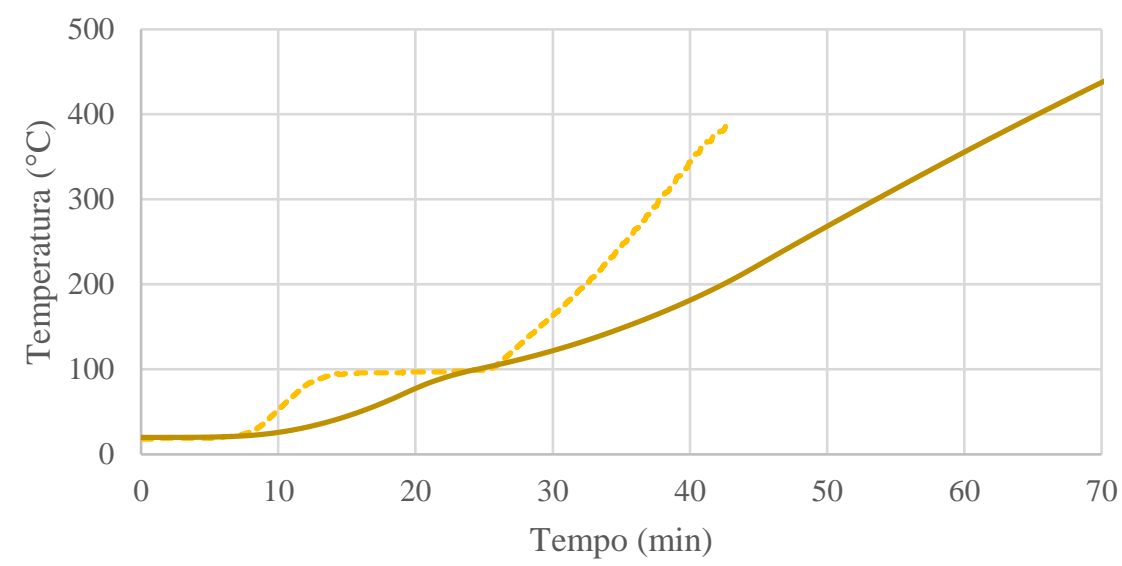

Figura 4.28 - Comparação da elevação da temperatura em função do tempo para a distância de $120 \mathrm{~mm}$ da face exposta

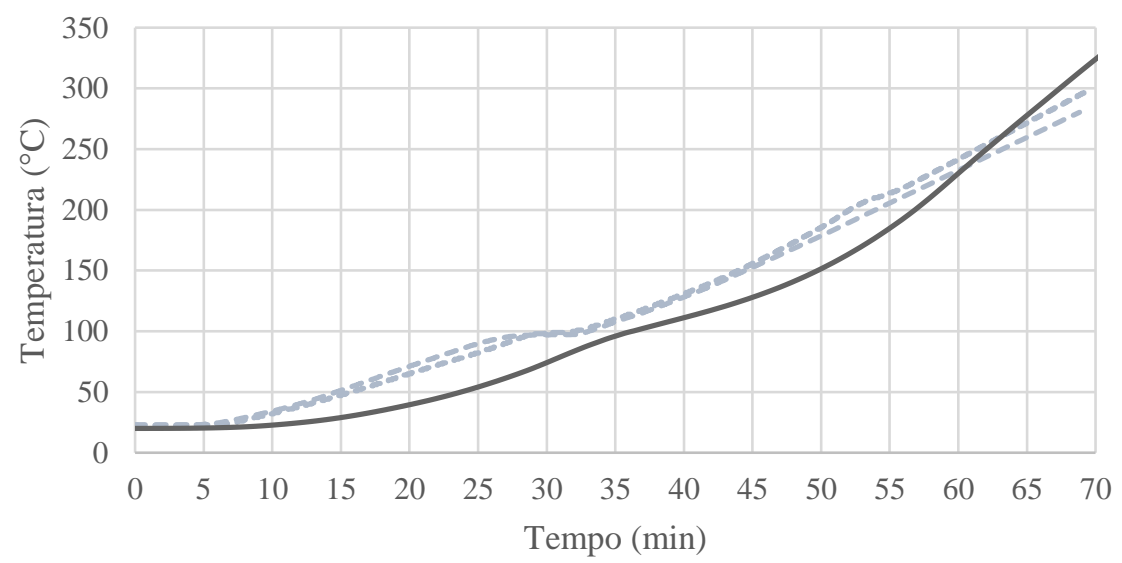

Figura 4.29 - Comparação da elevação da temperatura em função do tempo para a distância de $135 \mathrm{~mm}$ da face exposta

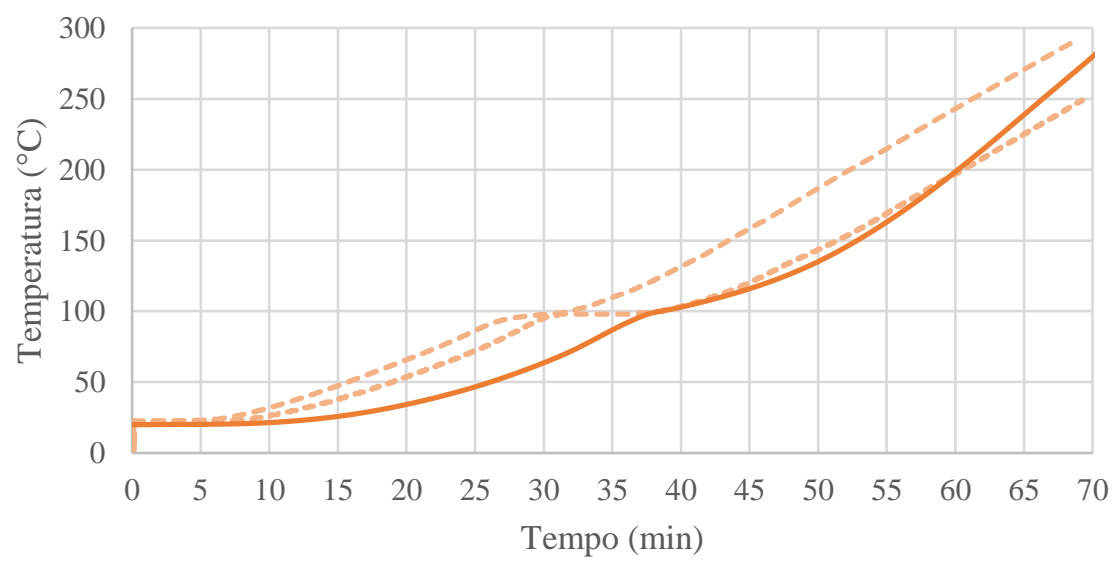


Verifica-se diferenças pequenas para as distâncias de 5, 20, 120 e $135 \mathrm{~mm}$ da face exposta, bem como, boa tendência das curvas numéricas em relação às experimentais. Porém, para a distância de $70 \mathrm{~mm}$ da face exposta, houve grande variação quanto ao valor obtido experimentalmente. Em virtude da proximidade dos demais valores, bem como da falta de maior quantidade de dados experimentais para o centro do bloco, considera-se as mesmas justificativas comentadas para a análise anterior, entendendo-se como principal justificativa a não consideração da abertura de fissuras para o modelo numérico.

Verificou-se também, para maiores distâncias em relação à face exposta, pequenos patamares, conforme resultados experimentais. Acredita-se que esta ocorrência, identificada aos $100{ }^{\circ} \mathrm{C}$, se deve ao pico de calor específico do concreto em que demanda-se maior quantidade de calor para a ocorrência de aumento de temperatura.

Em relação ao critério de isolamento térmico, a Tabela 4.5 indica os valores obtidos experimental e numericamente. Para os valores numéricos foram inseridos dois resultados, um deles referente ao aumento da temperatura no valor máximo de $180^{\circ} \mathrm{C}$, e, outro pela média das temperaturas na superfície da parede inferior a $140{ }^{\circ} \mathrm{C}$, em ambos os casos, verificados na superfície não exposta ao fogo.

Tabela 4.5 - Comparação entre os valores obtidos para o critério de isolamento térmico, em minutos

\begin{tabular}{cccc} 
& Experimental & \multicolumn{2}{c}{ Numérico } \\
& & Valor máximo & Valor médio \\
\hline Critério I & 61 & 60 & 52 \\
\hline
\end{tabular}

Verifica-se grande proximidade das temperaturas na face oposta ao fogo entre os valores experimental e numérico. Para o critério de isolamento térmico a variação foi de 1 minuto. Entende-se que, caso fosse possível a verificação experimental pela média das temperaturas na face oposta, este valor seria inferior a 61 minutos.

\subsubsection{Bloco com espessura de $14 \mathrm{~cm}$, argamassamento total e fogo em ambas as faces}

Neste tópico é avaliado o modelo baseado no trabalho de Dupim (2019), com blocos de concreto com espessura de $14 \mathrm{~cm}$, argamassamento total e fogo em ambas as faces. As imagens deste experimento foram indicadas na Figura 4.23 do tópico anterior.

As análises quanto à evolução de temperatura ao longo do tempo estão indicadas nas Figuras 4.30 e 4.31 para as distâncias de 5 e $20 \mathrm{~mm}$ da face exposta ao fogo, respectivamente. 
As linhas tracejadas representam os resultados experimentais, enquanto as linhas cheias representam os resultados numéricos.

Figura 4.30 - Comparação da elevação da temperatura em função do tempo para a distância de $5 \mathrm{~mm}$ da face exposta

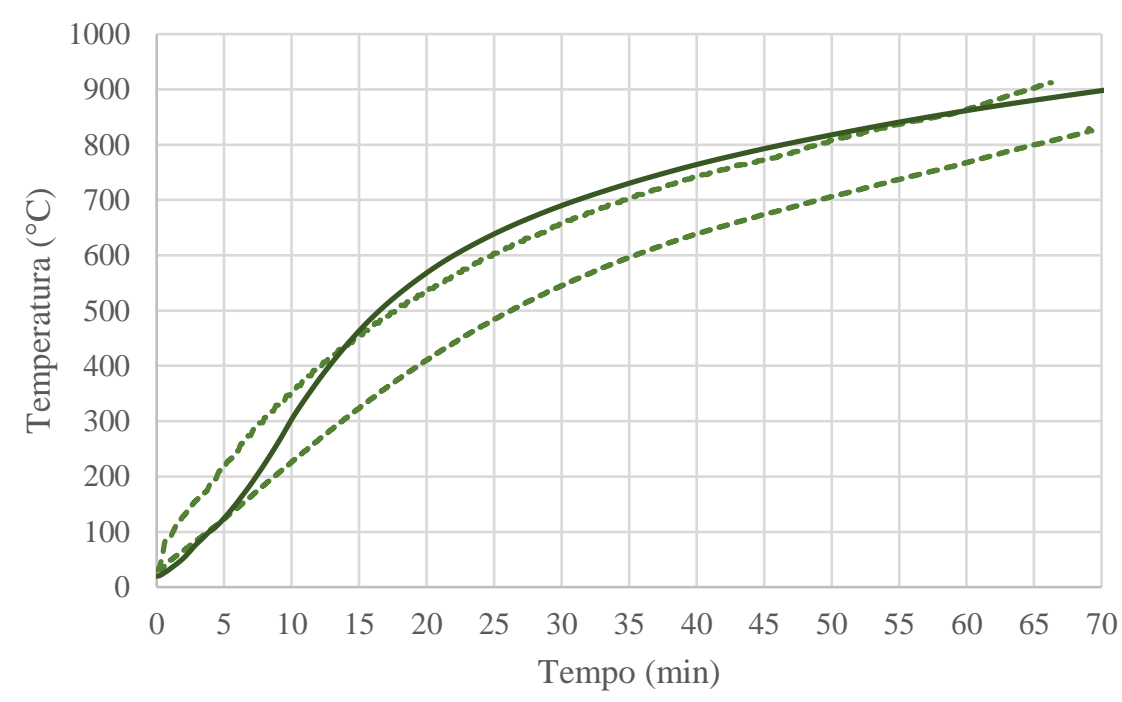

Figura 4.31 - Comparação da elevação da temperatura em função do tempo para a distância de $20 \mathrm{~mm}$ da face exposta

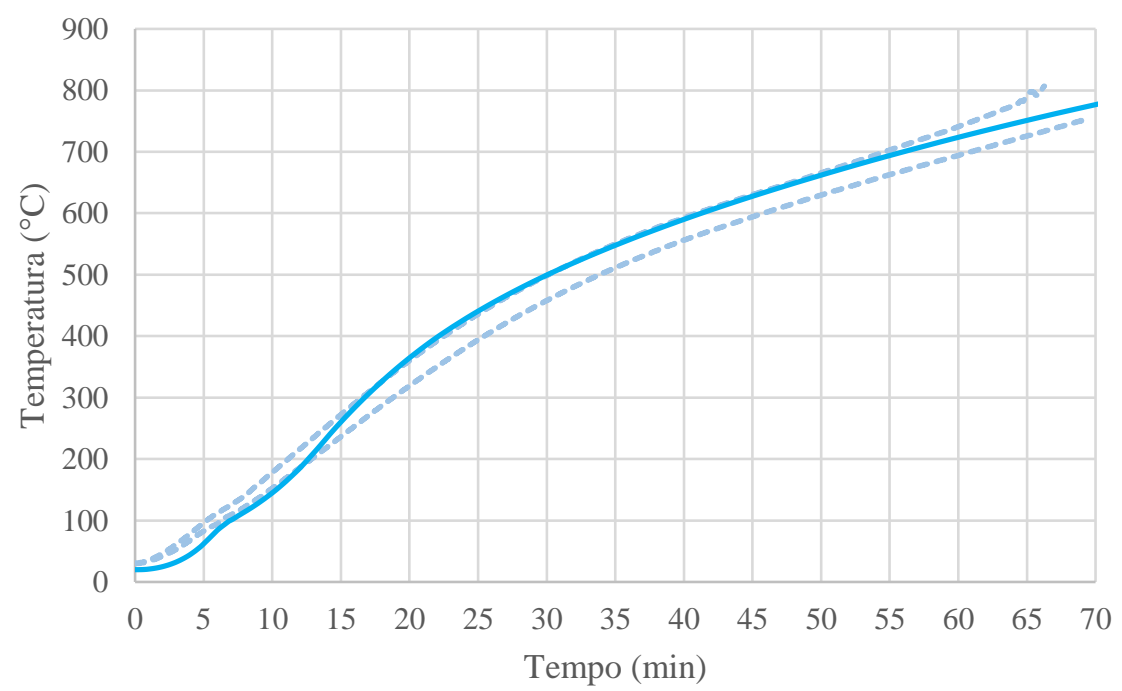

A Tabela 4.6 indica os valores de temperaturas experimental e numérico obtidos para intervalos de 15 minutos. 
Tabela 4.6 - Temperaturas atingidas em função da distância em relação à face exposta e do tempo de incêndio

\begin{tabular}{cc|cccc}
$\begin{array}{c}\text { Distância } \\
(\mathbf{m m})\end{array}$ & $\begin{array}{c}\text { Tempo de } \\
\text { incêndio (min) }\end{array}$ & \multicolumn{2}{|c}{ Limites experimentais } & Numérico & $\begin{array}{c}\text { Diferença } \\
\left({ }^{\circ} \mathbf{C}\right)\end{array}$ \\
& 15 & 322,0 & 453,0 & 464,6 & 11,6 \\
\hline \multirow{5}{*}{5} & 30 & 545,0 & 657,0 & 695,6 & 38,6 \\
& 45 & 674,4 & 772,0 & 790,8 & 18,8 \\
\hline \multirow{2}{*}{$\mathbf{2 0}$} & 70 & 767,0 & 863,0 & 860,2 & - \\
\hline & 70 & 811,0 & 918,0 & 896,5 & - \\
\hline & 15 & 235,0 & 271,0 & 261,4 & - \\
\hline & 30 & 458,0 & 498,0 & 506,1 & 8,1 \\
\hline & 45 & 594,0 & 630,0 & 625,2 & $-4,8$ \\
\hline & 60 & 694,0 & 741,0 & 721,6 & - \\
\hline
\end{tabular}

Conforme analisado para as paredes com fogo em uma face, verificam-se boas tendências de concordâncias do modelo numérico em relação aos resultados experimentais com variações inferiores a $40{ }^{\circ} \mathrm{C}$ dentro do intervalo estudado.

\subsection{MODELO TERMOESTRUTURAL - ANÁLISE QUALITATIVA}

Neste item, foram realizados dois tipos de análises qualitativas. A primeira relativa ao experimento realizado por Dupim (2019), analisando o comportamento das deformações do modelo numérico em relação ao experimental, não verificando, entretanto, os valores de deslocamentos em virtude da não medição experimental destes dados.

A segunda, relativa ao trabalho de Lopes et al. (2018), em que se considerou análise de tendência das curvas numéricas em relação às experimentais para a situação carregada. Para estas curvas, foram analisadas as deformações axiais e os deslocamentos laterais das paredes em função do tempo. O modelo fez uso das propriedades e geometrias dos materiais estudados em Oliveira (2014) com o carregamento imposto por Lopes et al. (2018). Não foram utilizadas as propriedades deste último autor para a modelagem numérica em virtude da não publicação dos dados de entrada necessários ao modelo numérico no respectivo artigo. 


\subsubsection{Bloco com espessura de $14 \mathrm{~cm}$ e argamassamento total sem carregamento}

Neste tópico é avaliado de forma qualitativa o modelo baseado no trabalho de Dupim (2019), com blocos de concreto com espessura de $14 \mathrm{~cm}$, de menor resistência, argamassamento total sem carregamento imposto. Algumas imagens das paredes ensaiadas foram mostradas no tópico anterior, nas Figuras 4.23 (a), (b) e (c). A Figura 4.32 indica outras imagens do mesmo ensaio, após a ocorrência de incêndio.

Figura 4.32 - Pequenas paredes após incêndio
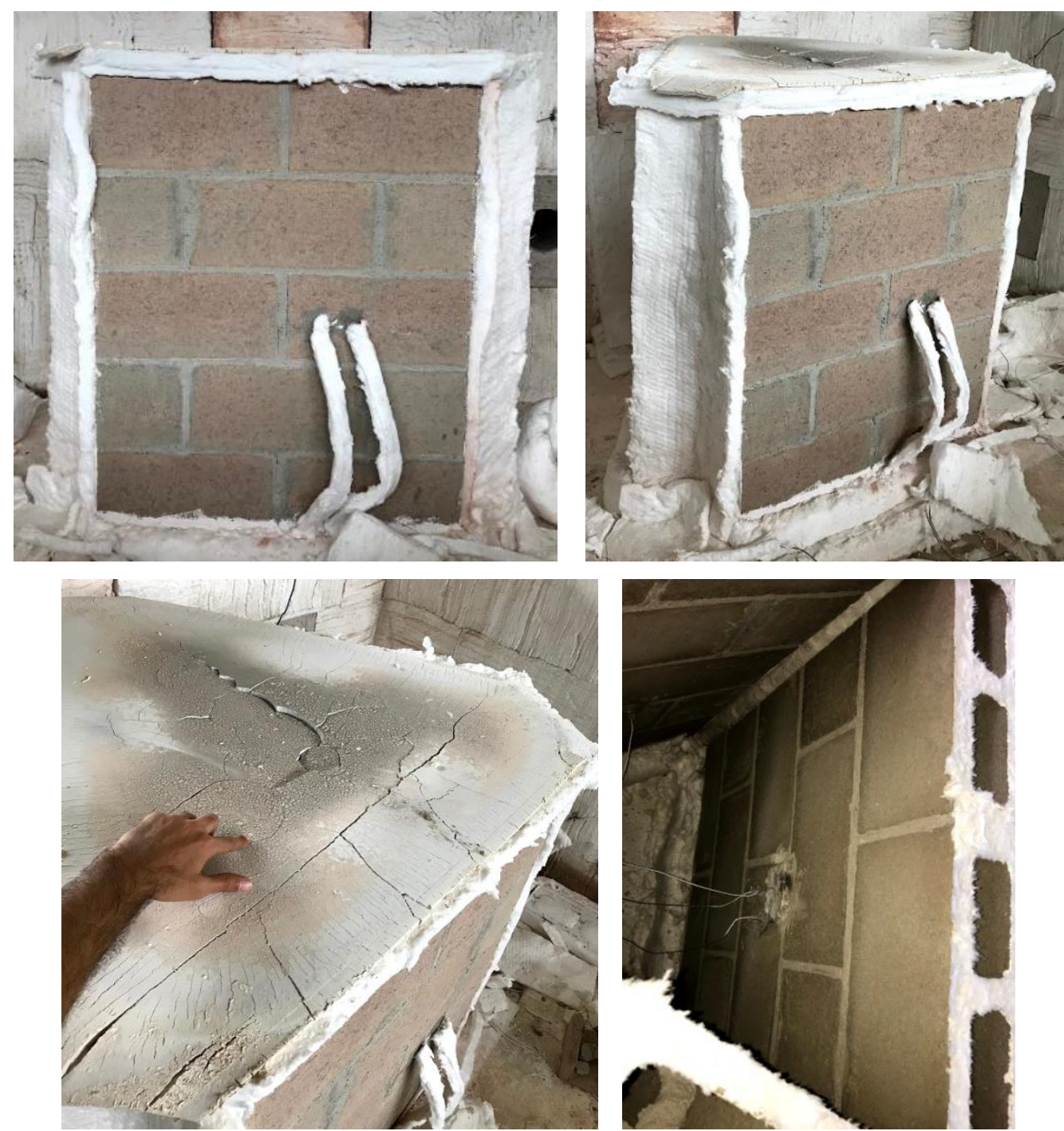

Fonte: Dupim (2019)

O tempo de ensaio deste trio de paredes resultou igual a 70 minutos. Em Dupim (2019) não se verificou a ocorrência de trincas com aberturas maiores ao longo das superfícies interna e externa das paredes. Foi verificada a curvatura das três paredes na direção do fogo, conforme visto na Figura 4.33. 
Figura 4.33 - Curvatura da parede após o ensaio

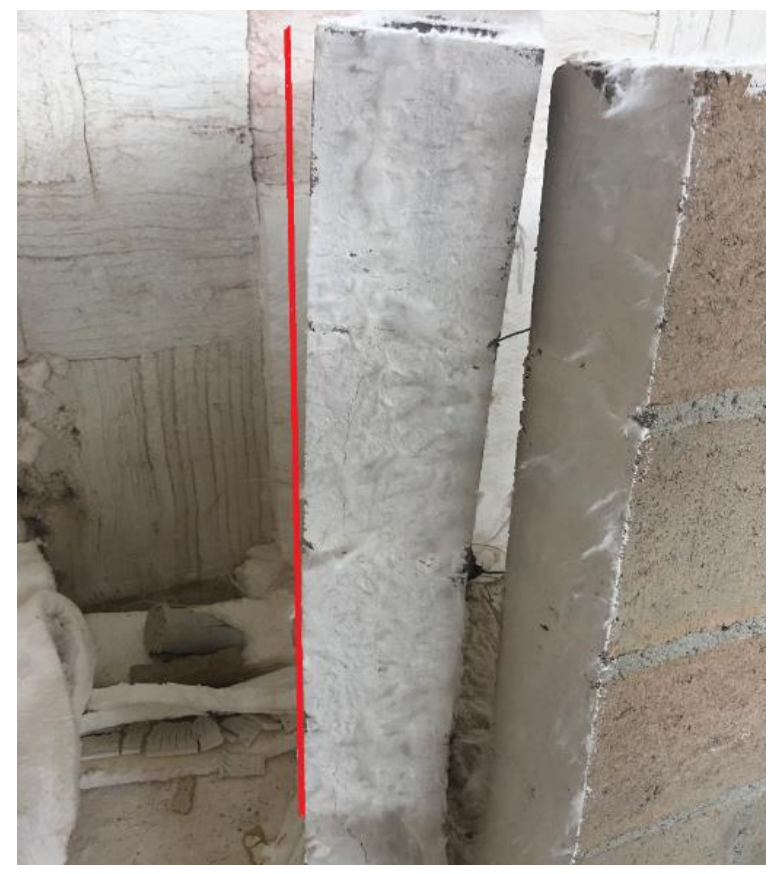

Fonte: Dupim (2019)

O modelo numérico sem carregamento não obteve tensões de compressão superiores aos valores de ruptura da parede. Quanto às tensões de tração, foi possível notar aproximação dos valores de ruptura em algumas faixas e pontos isolados. A Figura 4.34 indica o gradiente de temperatura ao longo da seção transversal do bloco aos 70 minutos de incêndio, tempo de parada do ensaio.

Figura 4.34 - Gradiente de temperatura em 70 minutos de incêndio

\begin{tabular}{|c|}
\hline $\begin{array}{l}\text { NT11 } \\
\begin{aligned} & +9.357 \mathrm{e}+02 \\
& +8.577 \mathrm{e}+02 \\
& +7.797 \mathrm{e}+02 \\
& +7.018 \mathrm{e}+02 \\
& +6.238 \mathrm{e}+02 \\
& +5.458 \mathrm{e}+02 \\
& +4.678 \mathrm{e}+02 \\
& +3.899 \mathrm{e}+02 \\
& +3.119 \mathrm{e}+02 \\
& +2.339 \mathrm{e}+02 \\
& +1.559 \mathrm{e}+02 \\
& +7.797 \mathrm{e}+01 \\
& +0.000 \mathrm{e}+00\end{aligned}\end{array}$ \\
\hline
\end{tabular}

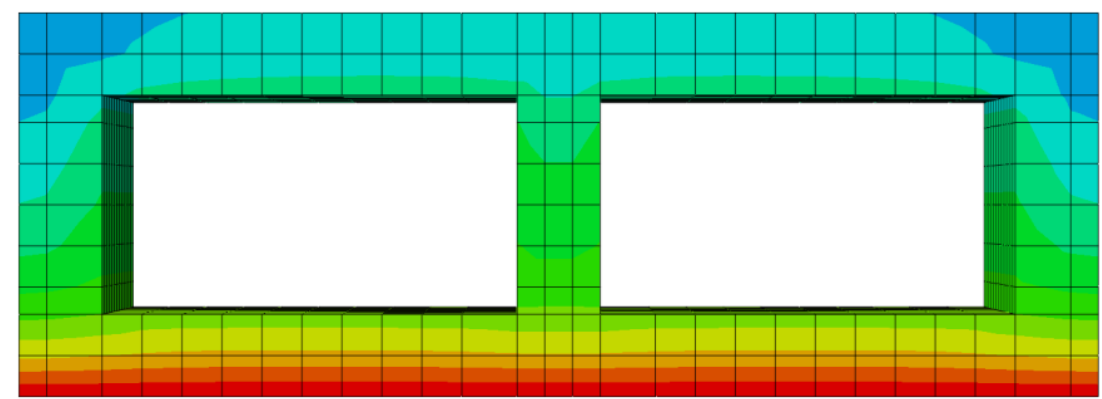

As análises realizadas neste tópico referem-se às condições de contorno definidas no Quadro 3.4. A Figura 4.35 indica as tensões mínimas obtidas em 70 minutos de incêndio. A indicação da face exposta ao fogo está mostrada na própria figura (lado esquerdo). 
Figura 4.35 - Tensões mínimas obtidas numericamente para as condições de contorno CD1

(1) e CD2 (2)

(1)

\begin{tabular}{|l|}
\hline S, Min. Principal \\
(Avg: 75\%) \\
\begin{tabular}{|l}
$+5.642 \mathrm{e}+05$ \\
$+2.871 \mathrm{e}+05$ \\
$+9.915 \mathrm{e}+03$ \\
$-2.672 \mathrm{e}+05$ \\
$-5.444 \mathrm{e}+05$ \\
$-8.215 \mathrm{e}+05$ \\
$-1.099 \mathrm{e}+06$ \\
$-1.376 \mathrm{e}+06$ \\
$-1.653 \mathrm{e}+06$ \\
$-1.930 \mathrm{e}+06$ \\
$-2.207 \mathrm{e}+06$ \\
$-2.484 \mathrm{e}+06$ \\
$-2.762 \mathrm{e}+06$
\end{tabular} \\
\hline
\end{tabular}

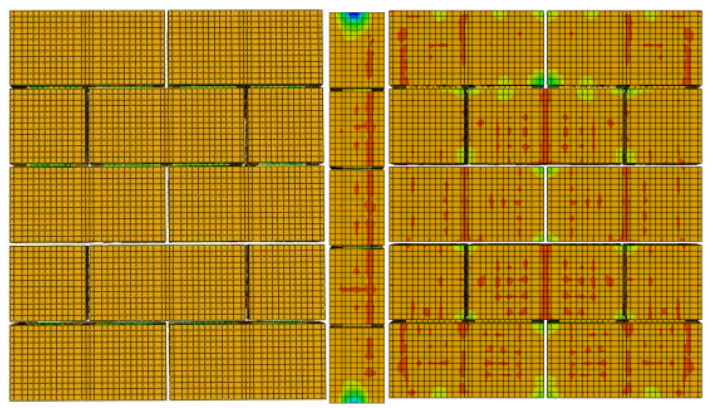

(2)
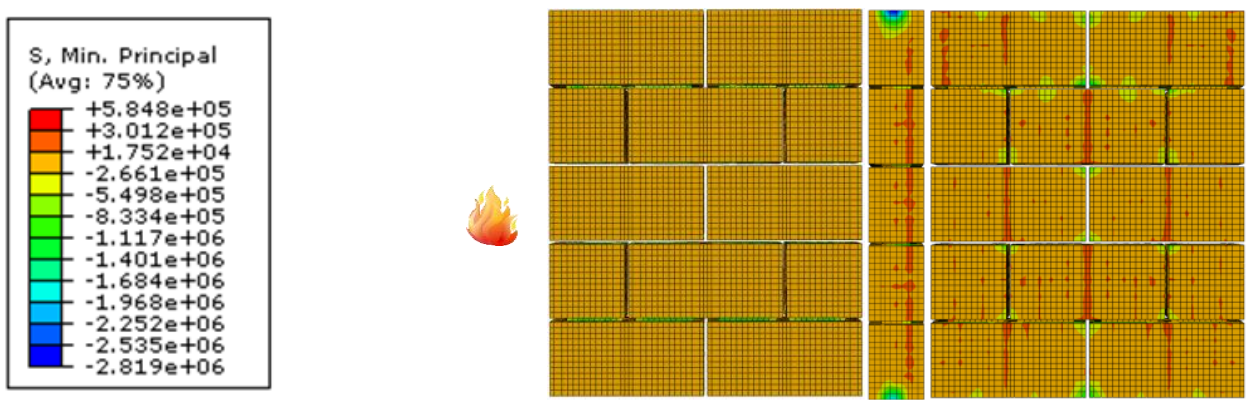

A Figura 4.36 indica as tensões máximas obtidas em 70 minutos de incêndio para as duas condições de contorno estudadas neste tópico.

Figura 4.36 - Tensões máximas obtidas numericamente para as condições de contorno CD1

(1) e CD2 (2)

\begin{tabular}{|c|}
\hline 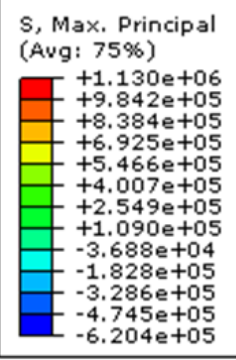 \\
\hline
\end{tabular}

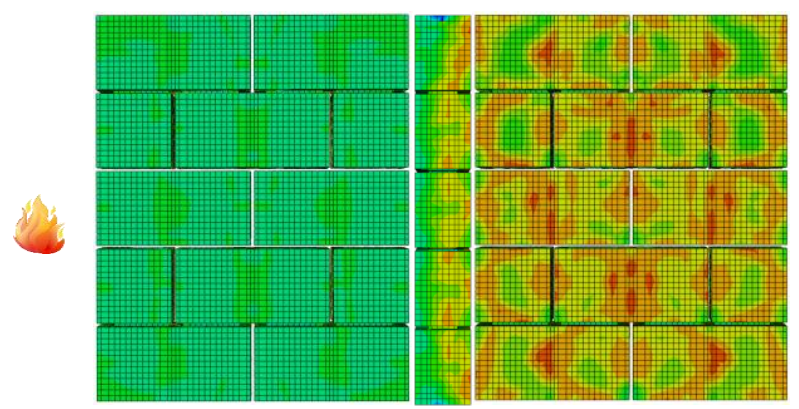

(2)
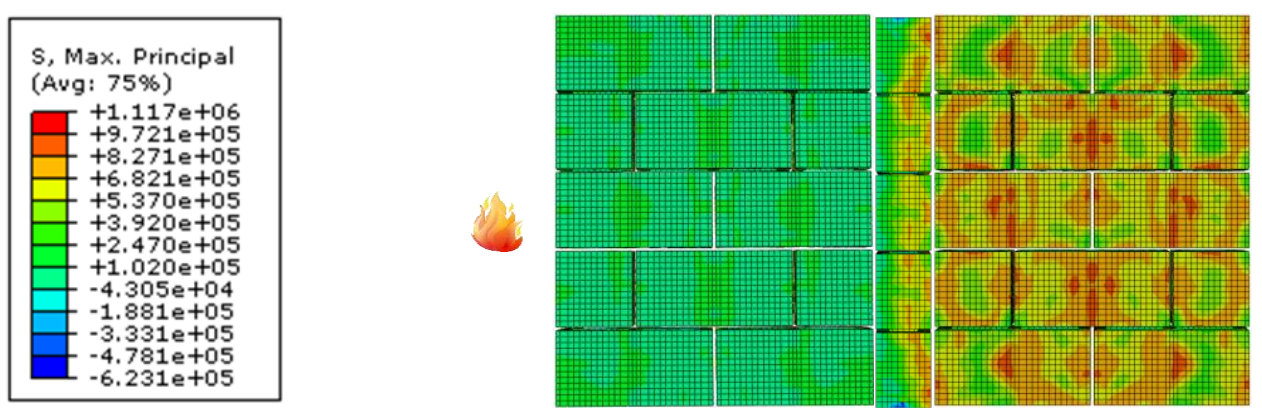

É possível verificar através da Figura 4.35, num primeiro momento, que a modificação da condição de contorno pouco modificou a distribuição das tensões mínimas para a situação 
sem carregamento, sendo visualizadas praticamente as mesmas faixas superficiais com maiores tensões de tração na face oposta ao fogo.

Analogamente, no caso da Figura 4.36, ocorrem distribuições muito próximas entre si, na comparação numérica entre as duas condições de contorno avaliadas.

Vale lembrar que os valores de ruptura do bloco de concreto de acordo com a temperatura estão indicados na Tabela 3.6. Neste caso, para ambos os lados vistos nas Figuras 4.35 e 4.36, observa-se que as tensões máximas se aproximam aos valores de ruptura do bloco, indicando uma provável ocorrência de fissuras em determinadas faixas.

Para a argamassa, as tensões mínimas e máximas são mostradas na Figura 4.37 para a condição de contorno CD1. O lado com exposição ao fogo é indicado na própria figura.

Figura 4.37 - Tensões principais mínimas (a) e máximas (b) na argamassa em 70 minutos de incêndio para a condição de contorno CD1

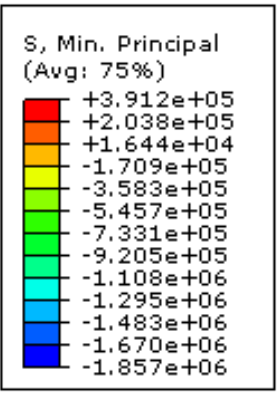

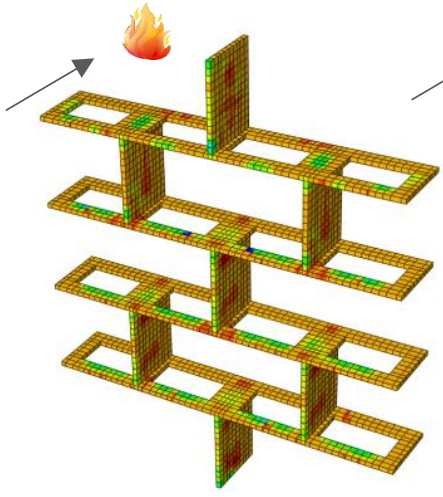

(a)

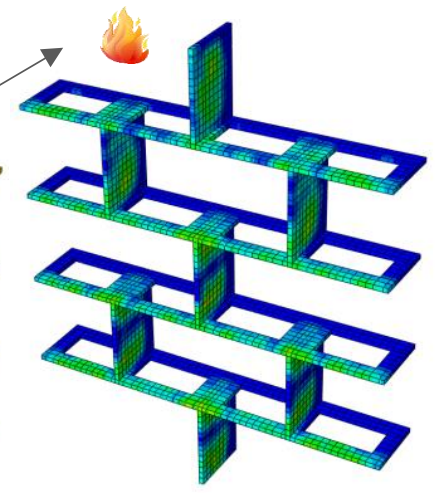

(b)

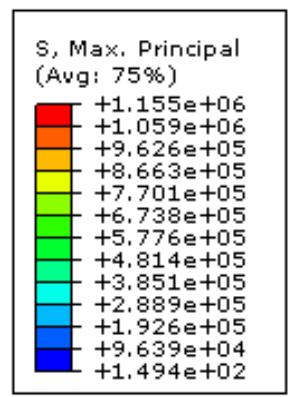

$+1.494 \mathrm{e}+02$

Não está indicado a distribuição para a condição de contorno CD2 em virtude da grande proximidade com a condições de contorno CD1.

As maiores tensões de compressão na argamassa ocorrem na face exposta ao fogo, como esperado, devido à curvatura da parede nesta direção em virtude dos efeitos da expansão térmica. A curvatura obtida numericamente está apresentada na Figura 4.38, para as duas condições de contorno sinalizadas.

Comparando as deformadas da Figura 4.38 com a Figura 4.33, onde está indicado a deformada obtida experimentalmente, é possível sinalizar maior concordância para a condição de contorno CD1. Assim, a suposição para a condição de contorno CD1, em que ocorre deslocamento lateral na superfície superior da parede, mesmo com a existência de manta cerâmica tem maior aproximação com a realidade que a consideração da impossibilidade de deslocamento (CD2). 
Figura 4.38 - Curvatura da parede no instante de 70 minutos em comparação com estado inicial para as condições de contorno CD1 (a) e CD2 (b)

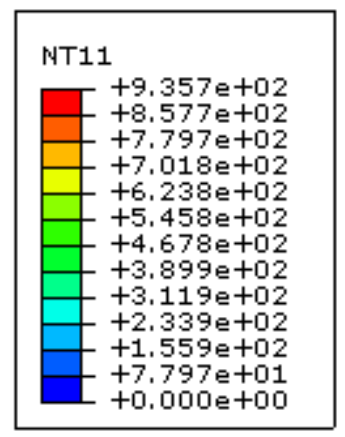

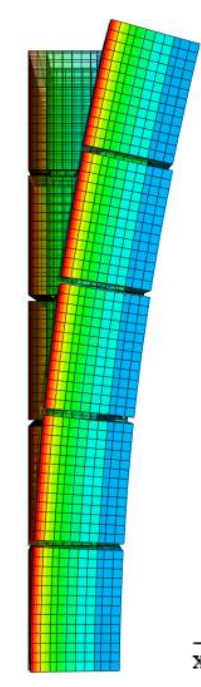

(a)

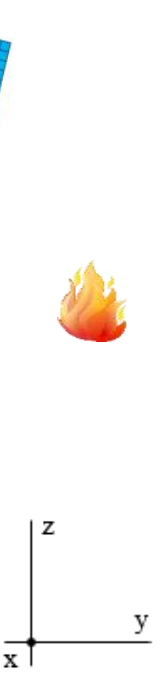

y

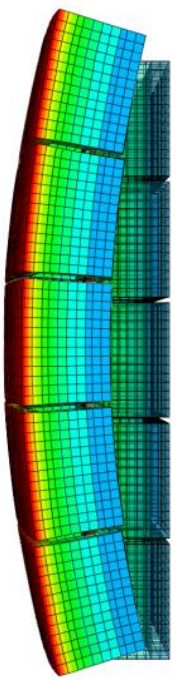

(b)

Obs.: Escala deformada aumentada em 12 vezes. Indicação de cores para temperatura.

Quanto aos deslocamentos, as Figuras 4.39, 4.40, 4.41 e 4.42 ilustram o comportamento do modelo nas três direções para ambas as condições de contorno. O sistema de referência encontra-se com a origem no canto inferior esquerdo do lado exposto ao fogo nas figuras mostradas.

Figura 4.39 - Magnitude dos deslocamentos ocorrentes no modelo numérico para as condições de contorno CD1 (1) e CD2 (2)

(1)
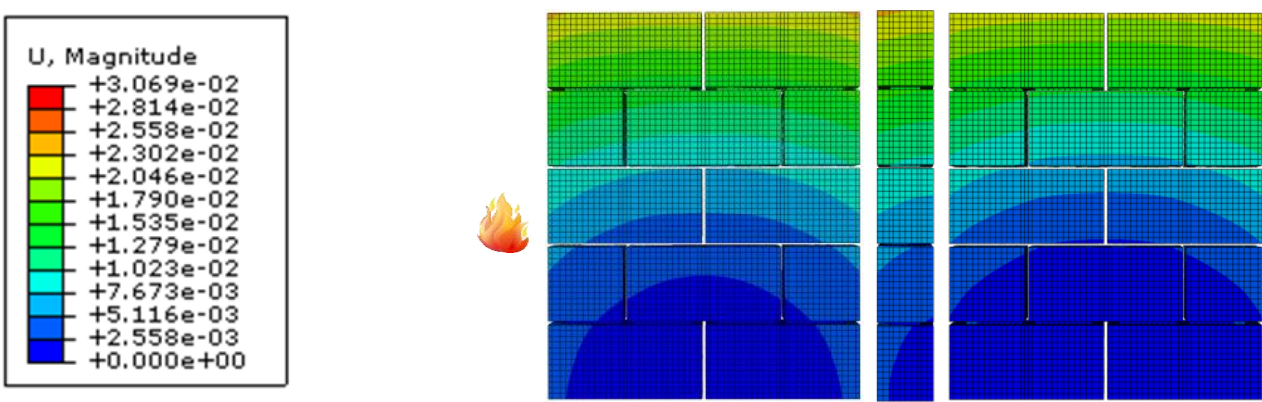

(2)
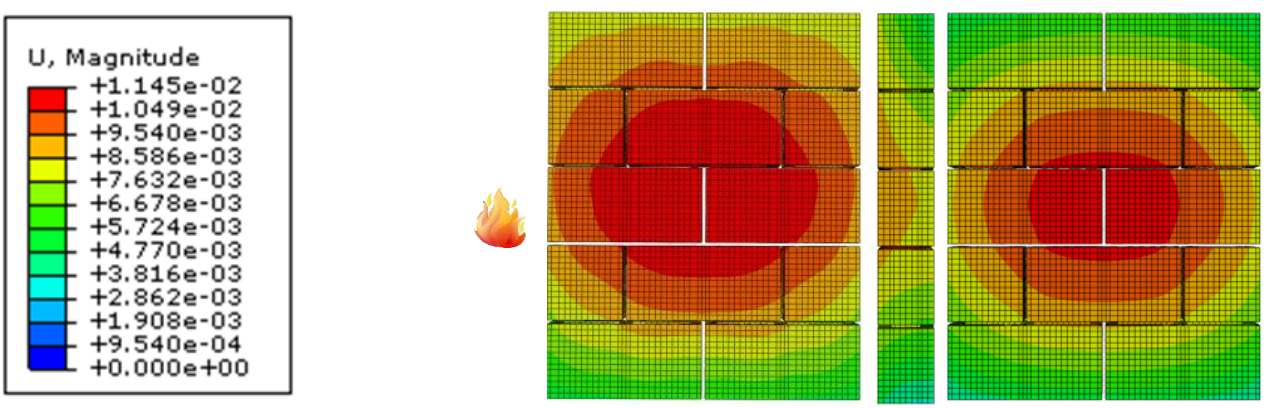
Figura 4.40 - Deslocamentos ocorrentes no modelo numérico na direção x para as condições de contorno CD1 (1) e CD2 (2)

(1)

\begin{tabular}{|c|}
\hline 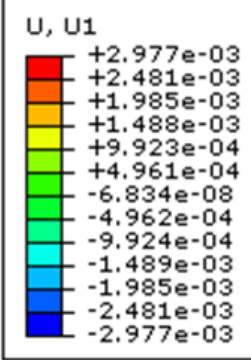 \\
\hline
\end{tabular}
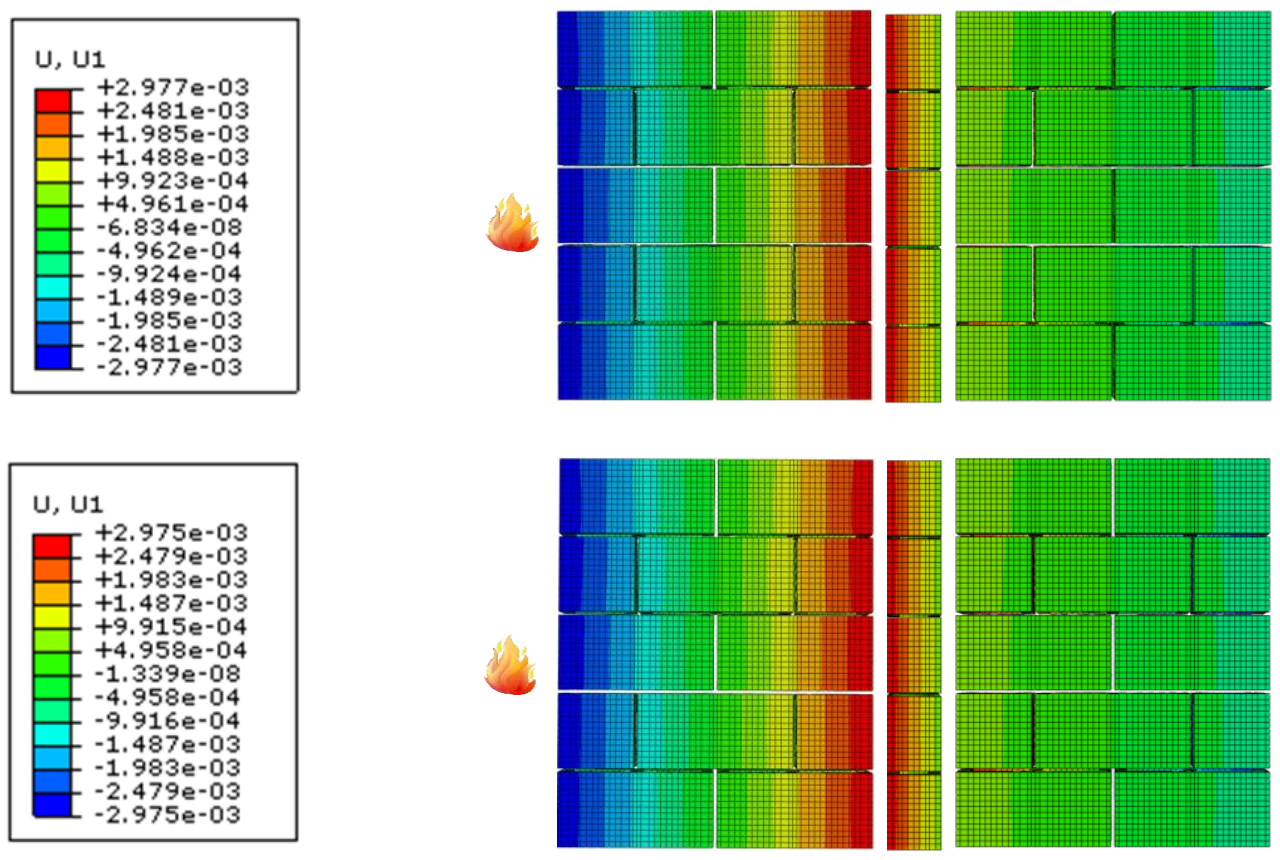

Figura 4.41 - Deslocamentos ocorrentes no modelo numérico na direção y para as condições de contorno CD1 (1) e CD2 (2)

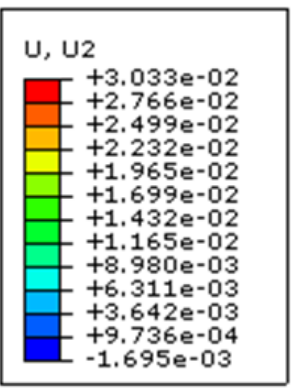
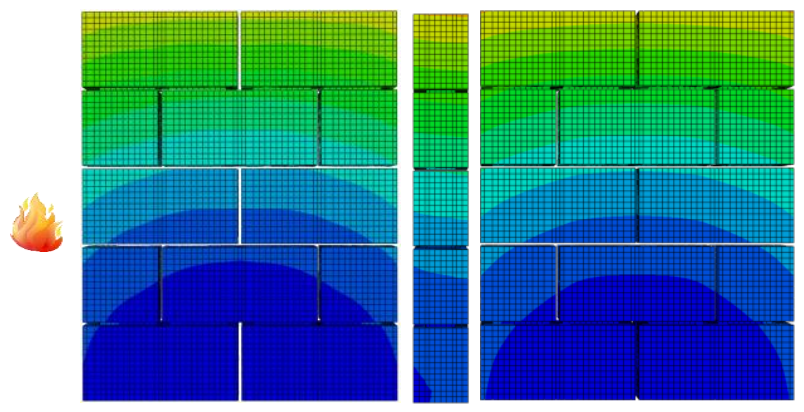

(1)
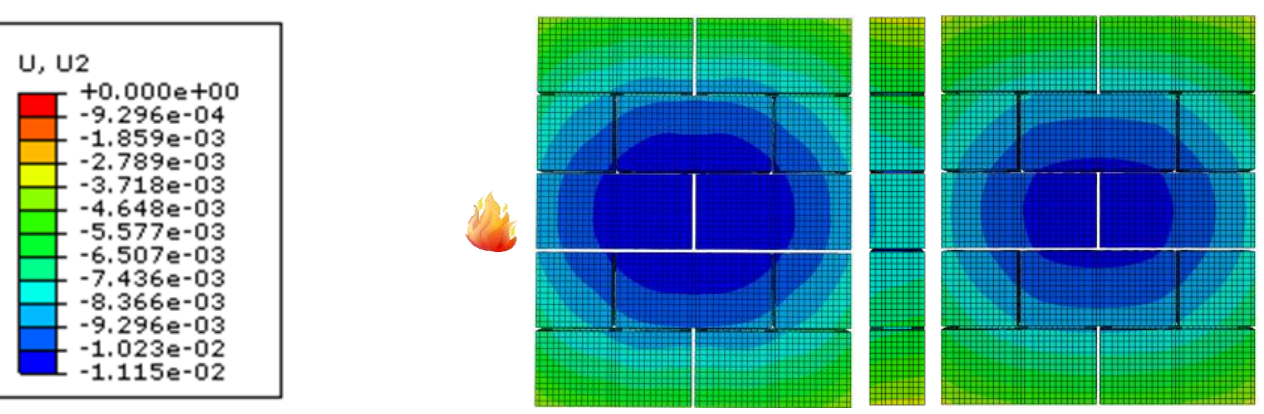
Figura 4.42 - Deslocamentos ocorrentes no modelo numérico na direção z para as condições de contorno CD1 (1) e CD2 (2)
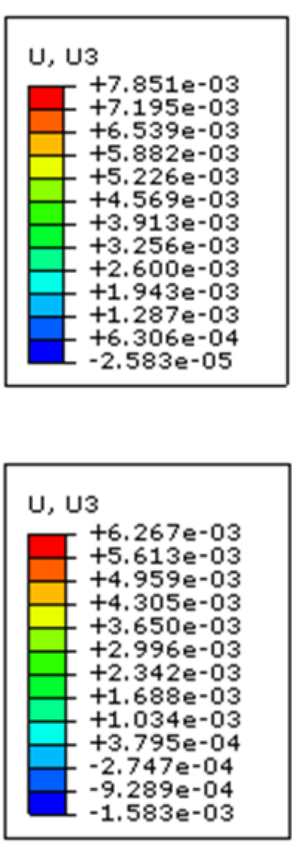
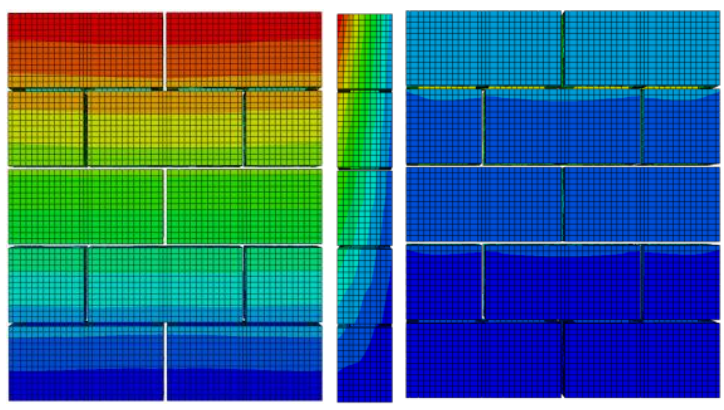

(2)
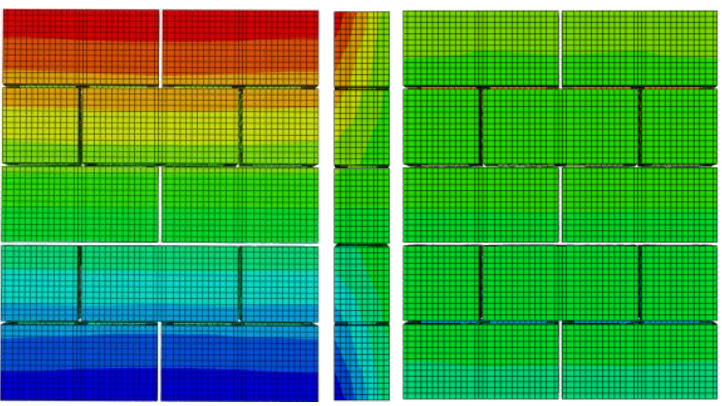

Diferentemente dos comportamentos identificados nos modelos numéricos voltados às análises puramente estruturais, no modelo termoestrutural não há simetria quanto aos deslocamentos. Provavelmente, tal aspecto pode se justificar pela variação de temperatura ao longo da seção transversal da parede, onde ocorre degradação diferencial dos materiais, além da consideração da expansão térmica, ocasionando a curvatura comentada anteriormente.

Não foi aferido experimentalmente o deslocamento na superfície superior da parede. Porém, a partir da Figura 4.33 sinaliza-se um deslocamento de aproximadamente $3,0 \mathrm{~cm}$, pouco acima do verificado numericamente pelas Figura 4.39 e 4.41, de aproximadamente 2,5 cm.

Qualitativamente verifica-se um acréscimo da altura da parede, conforme esperado, devido aos efeitos da expansão térmica e inexistência de restrições nesta direção.

Da mesma forma, quanto ao deslocamento lateral, ambos os lados da parede tendem a curvar-se para a direção do fogo até um determinado limite do material, tendo o lado exposto um deslocamento mais rápido que o lado oposto ao fogo, conforme verificado também por Rodovalho (2018).

As Figuras 4.43 e 4.44 mostram as deformações elásticas e plásticas do modelo termoestrutural. 
Figura 4.43 - Deformações elásticas principais para as condições de contorno CD1 (1) e CD2

(2)

(1)
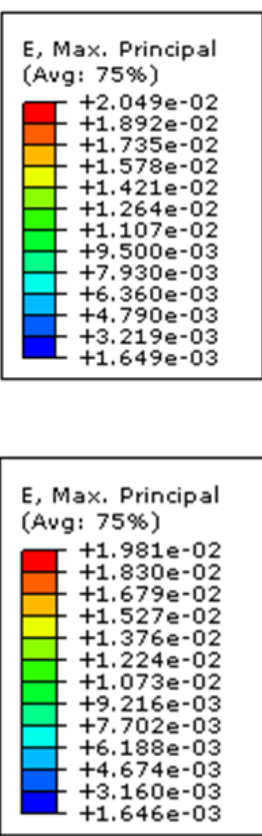
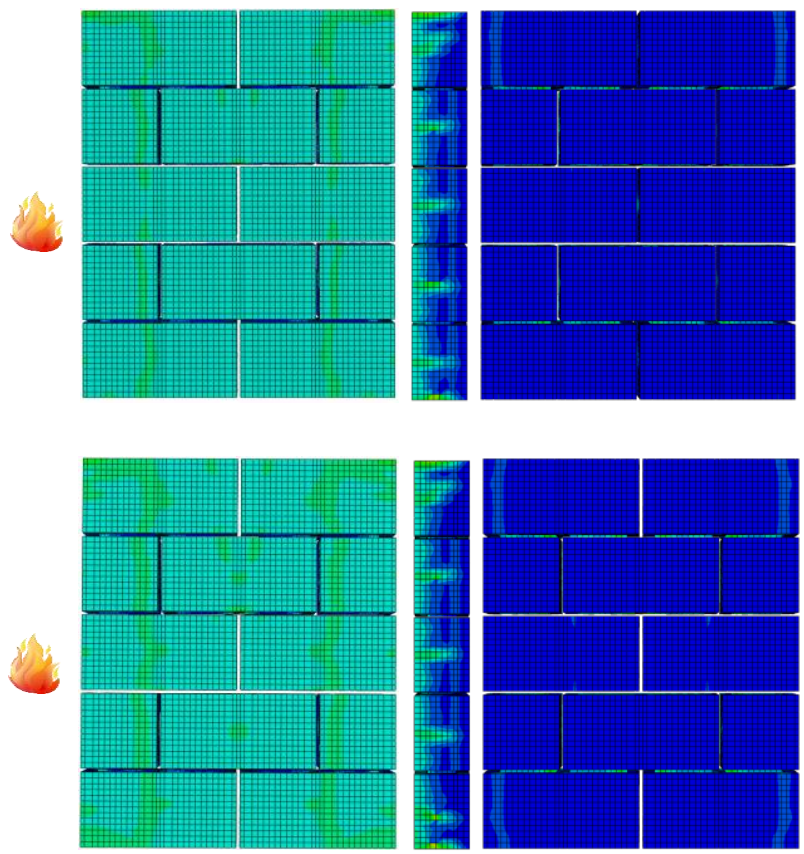

Figura 4.44 - Deformações plásticas principais para as condições de contorno CD1 (1) e CD2

(2)
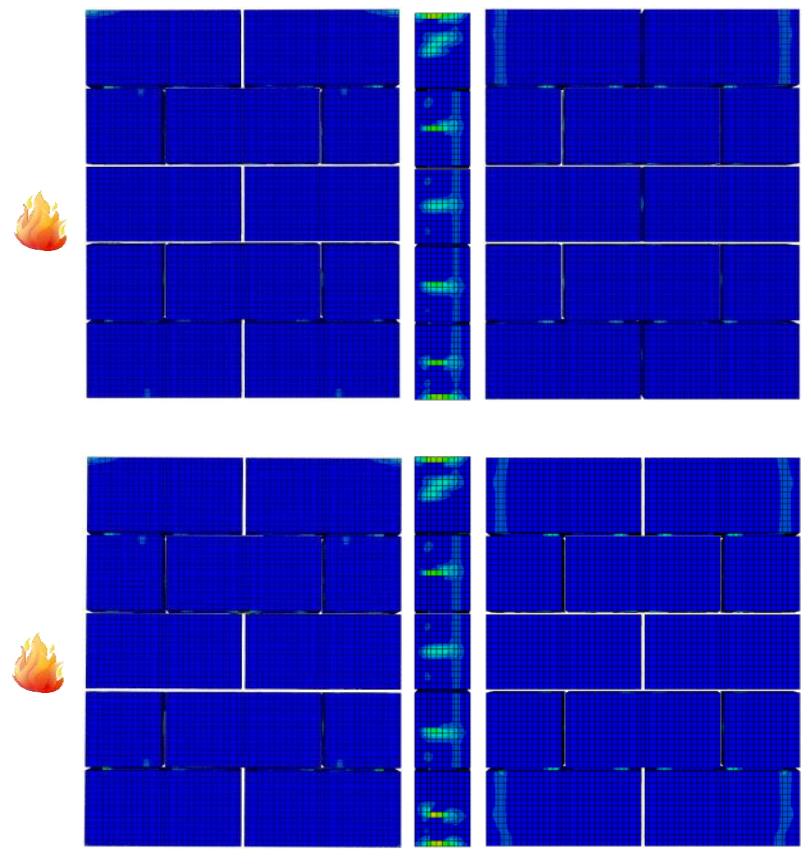

Neste caso, verifica-se o aumento das deformações elásticas na face exposta ao fogo, como já analisado devido à expansão térmica. Quanto às deformações plásticas, não foram 
identificados valores significativos até os 70 minutos de incêndio, aparecendo apenas em pequenas intensidades na lateral do modelo, no centro dos blocos e meio blocos.

\subsubsection{Bloco com espessura de $14 \mathrm{~cm}$ e argamassamento total com carregamento}

Neste item é realizada uma análise de tendência das curvas de deformação axial e deslocamento lateral em função do tempo, bem como comparação do comportamento do modelo numérico em relação ao experimental, pelos motivos especificados no início deste tópico. Como citado no Capítulo 3, a condição de contorno entendida como mais próxima à experimental é a denominada como $\mathrm{CC} 2$, sendo as outras duas, utilizadas de forma comparativa aos resultados.

Em Lopes et al. (2018) se estudou paredes com dimensões de 1,00 m de altura, 1,40 m de largura e $10 \mathrm{~cm}$ de espessura. Os blocos ensaiados são diferentes dos modelos deste trabalho, tanto em relação à geometria (ensaiados blocos de três células, com dimensões de 9,3 cm de altura, 20,1 cm de largura e $10 \mathrm{~cm}$ de espessura - Figura 4.45) quanto às propriedades. $\mathrm{O}$ argamassamento utilizado pelos autores é total. $\mathrm{O}$ aquecimento foi realizado em apenas uma das faces da parede conforme curva ISO 834-1:1999.

Figura 4.45 - Bloco e meio bloco utilizados no ensaio

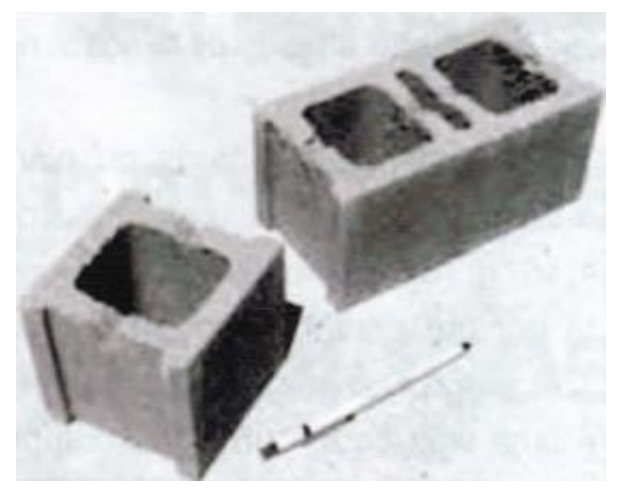

Fonte: Lopes et al. (2018)

Para o modelo numérico foi utilizada a geometria das paredes de blocos com $14 \mathrm{~cm}$ de espessura, com dois furos. O carregamento imposto foi de $30 \%$ da carga de ruptura, conforme experimento de Lopes et al. (2018), e, considerando as três condições de contorno comentadas no Capítulo 3, obteve-se o resultado indicado na Figura 4.46, referente a deformação axial em função do tempo. 
Figura 4.46 - Deformação axial em função do tempo para as diferentes condições de contorno consideradas em comparação com os resultados experimentais

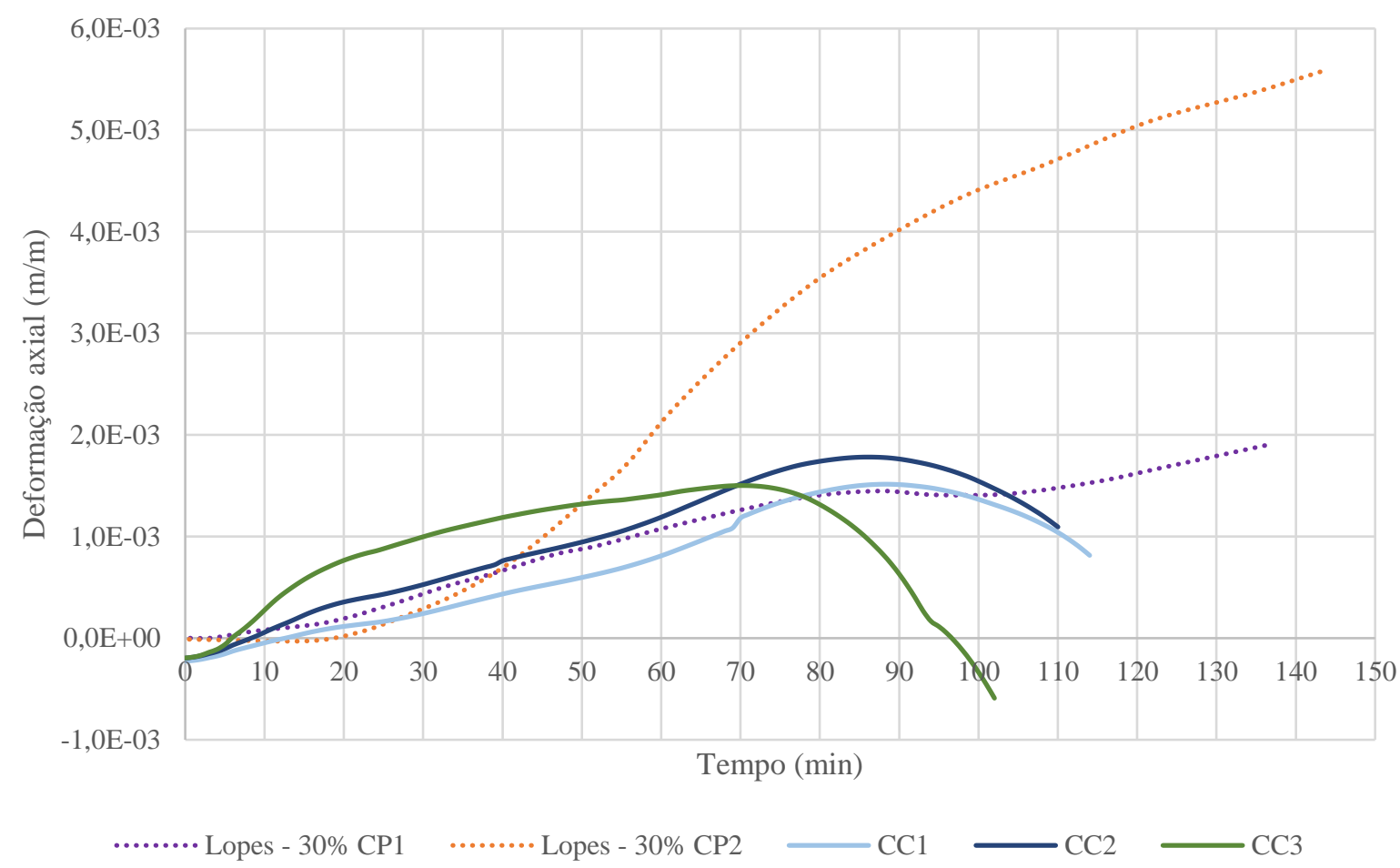

Vale lembrar que as condições de contorno estudadas numericamente referem-se à Figura 3.27, resumidas no Quadro 3.5.

As curvas CP1 e CP2 de Lopes et al. (2018) referem-se aos dois corpos-de-prova ensaiados sob as mesmas condições e com os mesmos materiais. Observa-se que, em relação à deformação axial, ocorre discrepância considerável entre os dois resultados. Os autores justificam esta questão pela heterogeneidade do material.

Quanto à comparação de tendência do modelo numérico em relação ao experimental, foco deste item, percebe-se um aumento das deformações axiais para as condições de contorno $\mathrm{CC} 1$ e CC2 próximas às visualizadas para o corpo-de-prova $\mathrm{CP} 1$ experimental. Desta forma, é possível aferir que a condição de contorno para a superfície superior experimental trabalhe com restrição ao giro, mas não necessariamente engastada. A condição de contorno CC3 apresenta tendência mais distante do visualizado experimentalmente. Além disso, quanto ao grau de grandeza das unidades, nenhum resultado numérico apresentou alta discrepância.

Em relação ao critério de resistência ao fogo, entende-se que devido aos dados numéricos não representarem as propriedades térmicas do material de Lopes et al. (2018), inclusive quanto à geometria (blocos com três núcleos internos), a variação é compreensível. Os deslocamentos laterais foram medidos na face oposta ao fogo e no centro da parede do modelo numérico, conforme indicado na Figura 4.47. 
Figura 4.47 - Deslocamento lateral em função do tempo para as diferentes condições de contorno consideradas em comparação com os resultados experimentais

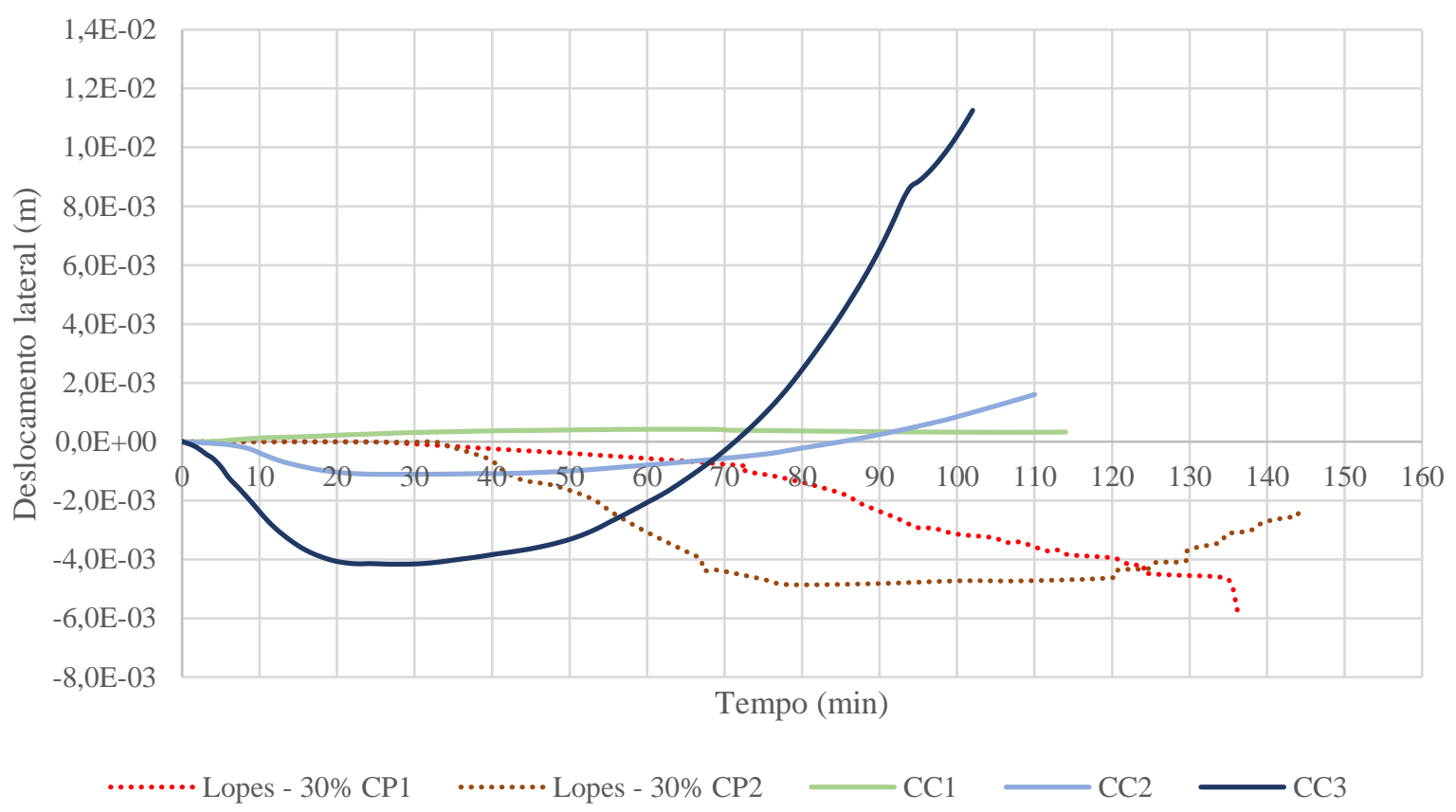

Analisando a Figura 4.47, em relação aos deslocamentos laterais verifica-se a maior discrepância para a condição de contorno $\mathrm{CC} 1$ em relação aos valores experimentais, bem como maior conformidade para as condições $\mathrm{CC} 2$ e CC3. No entanto, quanto à tendência da curva representativa da condição CC2, esta apresenta-se com tendência semelhante à vista para o corpo-de-prova $\mathrm{CP} 2$ experimental, embora o início do deslocamento lateral mais rápido e com menor intensidade no pico. Mais uma vez, considera-se que as restrições experimentais estejam intercaladas entre as condições numéricas apresentadas.

Algumas justificativas para a divergência quanto ao tempo de início dos deslocamentos laterais, bem como, à intensidade do pico de deslocamentos podem estar relacionadas à:

- Umidade: nos modelos numéricos foi adotada a umidade dos materiais baseada no trabalho de Dupim (2019). Este valor interfere diretamente nas propriedades térmicas de calor específico e condutividade térmica. Maior umidade, aumenta o nível de calor necessário para elevar a temperatura do material, o que pode retardar bastante o tempo para transferência de calor. Esta variação está apresentada nas análises complementares, no próximo capítulo;

- Agregados: o uso de escala reduzida no modelo experimental provavelmente fez necessária a utilização de agregados em escala reduzida. Qualquer variação quanto a sua geometria, e, principalmente, quanto ao tipo de agregado utilizado, alteram as propriedades térmicas do material; 
- Esbeltez do elemento: a parede ensaiada experimentalmente apresentou espessura inferior ao modelo numérico, possibilitando maiores amplitudes de deslocamento lateral no instante do pico;

- Propriedades mecânicas: o uso de propriedades mecânicas que não as do ensaio de Lopes et al. (2018) contribuem para maiores incertezas quanto aos resultados numéricos obtidos.

Conforme verificado por Dupim (2019), em Lopes et al. (2018) se comenta acerca da curvatura das paredes ensaiadas, as quais ocorreram na direção do fogo, o que também ocorreu com o modelo numérico. Foram verificadas grandes quantidades de fissuras ao longo do ensaio, sendo iniciadas por volta dos 30 minutos de incêndio, porém com aberturas que não culminaram na perda de estanqueidade dos corpos-de-prova.

A predominância destas fissuras deu-se nas células centrais dos blocos de concreto. Além destas, ocorreram fissuras horizontais nas juntas de argamassa e fissuras diagonais, iniciando-se nos cantos dos corpos-de-prova e propagando-se para o centro, de acordo com os autores, devido às condições de apoio. Nas laterais das paredes foram verificadas fissuras verticais. Finalmente, outras fissuras foram verificadas no meio da largura dos blocos, estas, devido ao processo de fabricação dos mesmos.

Na sequência, na Figura 4.48, estão indicadas as distribuições de tensão no instante da ruptura para cada condição de contorno comparando-as com as imagens obtidas neste mesmo instante por Lopes et al. (2018).

Para a face oposta ao fogo, a condição de contorno CC2 apresenta maior correspondência com a imagem apresentada por Lopes et al. (2018) devido à concentração de fissuras na região superior da parede, conforme maior concentração de tensões nesta mesma área no modelo. Para a face exposta, as três condições apresentam elevadas tensões de tração por toda a superfície, destacando-se na condição CC2 maiores concentrações na região inferior, o que também é possível verificar na imagem experimental.

Em suma, a análise deste item, teve como principal objetivo verificar tendências do modelo numérico em relação ao experimental, de forma qualitativa, em virtude dos argumentos mencionados anteriormente. Em relação às condições de contorno, entende-se que no experimento buscou-se restringir o giro na superfície de aplicação do carregamento, o que não ocorre de maneira perfeita, por isso a locação do experimento entre as condições de contorno estudadas numericamente. 
Figura 4.48 - Imagens no instante da ruptura da face oposta ao fogo (a), de sua da lateral (b) e da face exposta (c), e, distribuição de tensões para a condição de contorno CC1 (d), CC2 (e) e CC3 (f) para a face oposta (1) e exposta ao fogo (2)

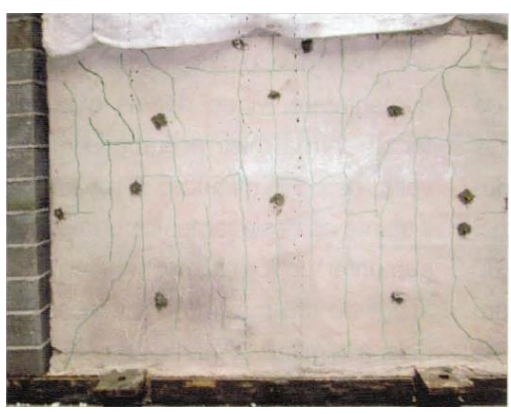

(a)

(1)

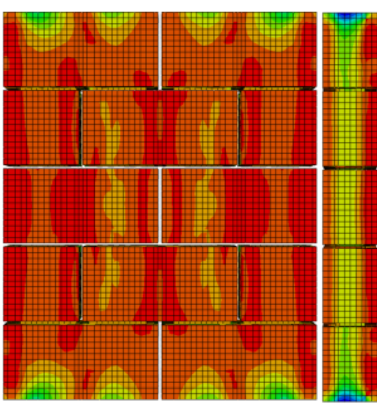

(2)

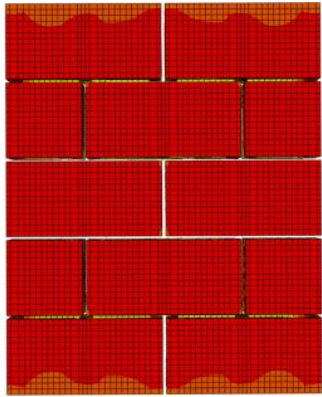

(d)

S, Max. Principal (Abs)
(Avg: $75 \%$ )
\begin{tabular}{|l}
$+8.778 e+05$ \\
\hline \\
$-9.422 \mathrm{e}+05$ \\
$-2.762 \mathrm{e}+06$ \\
$-4.582 \mathrm{e}+06$ \\
$-6.402 \mathrm{e}+06$ \\
$-8.222 \mathrm{e}+06$ \\
$-1.004 \mathrm{e}+07$ \\
$-1.186 \mathrm{e}+07$ \\
$-1.368 \mathrm{e}+07$ \\
$-1.550 \mathrm{e}+07$ \\
$-1.732 \mathrm{e}+07$ \\
$-1.914 \mathrm{e}+07$ \\
$-2.096 \mathrm{e}+07$
\end{tabular}

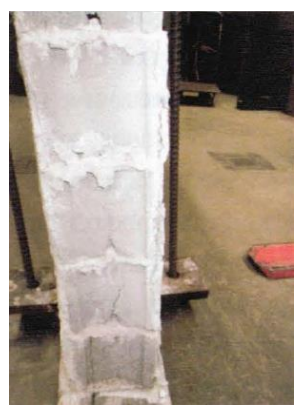

(b)
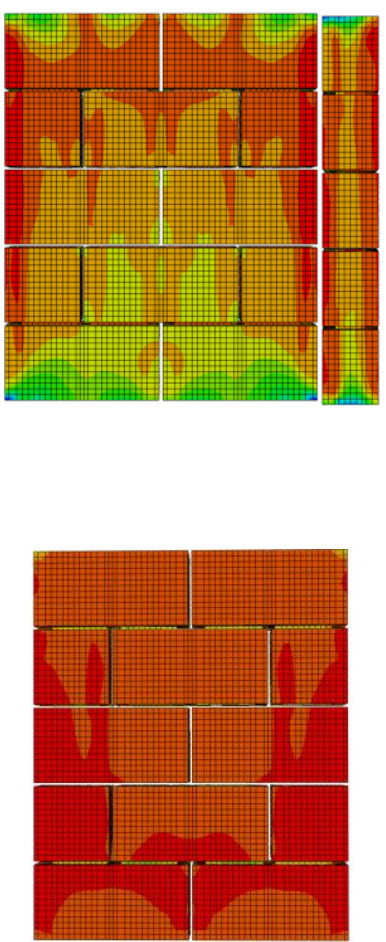

(e)

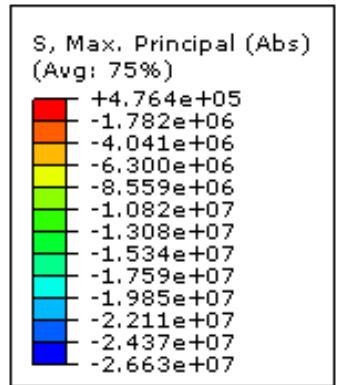

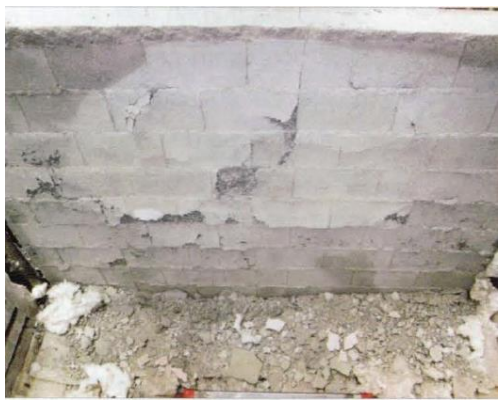

(c)
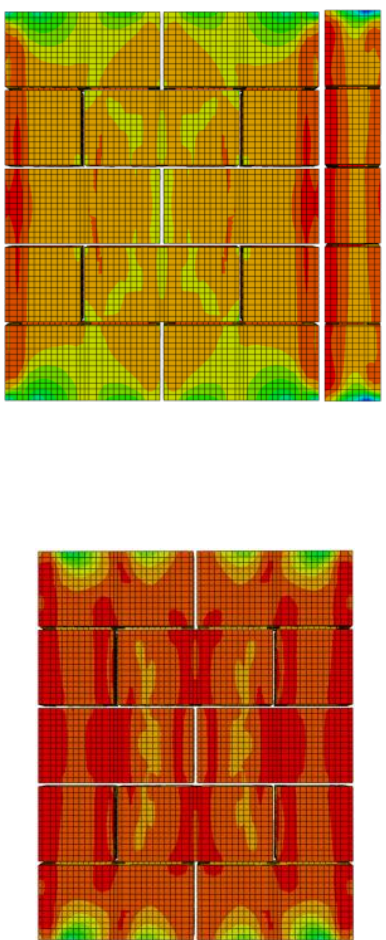

(f)

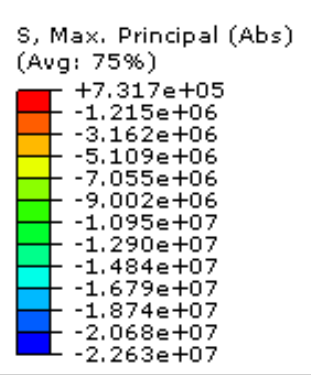




\section{ANÁLISES COMPLEMENTARES E PARAMÉTRICAS ASSOCIADAS AOS MODELOS NUMÉRICOS}

Neste capítulo são apresentadas as análises complementares e paramétricas relativas aos modelos estrutural, térmico e termoestrutural, os quais foram validados no Capítulo 4, em contextos quantitativo ou apenas qualitativo. O intuito destas análises refere-se também à busca por melhor entendimento do comportamento desses modelos em resposta à variação de determinados parâmetros.

Desta forma, quanto ao comportamento estrutural, foram estudados a variação do refinamento da malha, do tipo de argamassamento, do ângulo de dilatância e a consideração de dano nos materiais para o modelo numérico, o qual teve como base de validação os resultados experimentais de Oliveira (2014) e Dupim (2019).

Para o comportamento térmico, foram analisadas a variação quanto ao refinamento da malha, à espessura da parede, às propriedades térmicas, à temperatura na face oposta ao incêndio, bem como, extrapolados os resultados obtidos no capítulo anterior para tempos de incêndio superiores. As variações com relação à modelagem térmica baseiam-se no modelo validado no capítulo anterior a partir dos resultados experimentais de Dupim (2019).

Em relação ao comportamento termoestrutural, foram analisadas variações da condição de contorno para a situação com carregamento de $40 \%$ da carga última, da temperatura na face oposta ao fogo e quanto à variação da intensidade do carregamento. $\mathrm{O}$ modelo numérico utilizado para estas variações está associado àquele obtido no Capítulo 4, da maneira mais satisfatória possível a partir dos modelos estrutural e térmico, estes últimos, validados quantitativamente

Em cada tópico, consta um quadro com o resumo das informações utilizadas em cada análise, sendo identificado o modelo utilizado de acordo com a validação/análise qualitativa feita no Capítulo 4, a distinção dos parâmetros mecânicos e térmicos utilizados, seja de Oliveira (2014) ou de Dupim (2019), o dado originalmente avaliado e sua respectiva variação para a análise complementar ou paramétrica. 


\subsection{ANÁLISES REFERENTES AO MODELO ESTRUTURAL}

\subsubsection{Quanto ao refinamento da malha}

Neste tópico é estudada a variação da densidade da malha de elementos finitos referente ao modelo voltado à análise estrutural, sendo consideradas malhas com refinamentos de 1,5 e $3,0 \mathrm{~cm}$, bem como de $1,0 \mathrm{~cm}$, a qual passa a ser referencial para as comparações em virtude da validação demonstrada no item 4.1.1. O Quadro 5.1 indica o resumo das informações deste tópico.

Quadro 5.1 - Resumo das informações para a análise numérica do item 5.1.1

\begin{tabular}{|rl|}
\hline Modelo validado utilizado: & Estrutural (Item 4.1.1) \\
\hline Baseado nos resultados experimentais de: & Oliveira (2014) \\
\hline No modelo validado: & Refinamento da malha com $1,0 \mathrm{~cm}$ \\
\hline Nesta análise: & Refinamento de 1,5 e $3,0 \mathrm{~cm}$ \\
\hline
\end{tabular}

A Figura 5.1 indica o diagrama tensão-deformação na forma de comparação entre os refinamentos citados.

Figura 5.1 - Diagrama tensão-deformação para diferentes discretizações

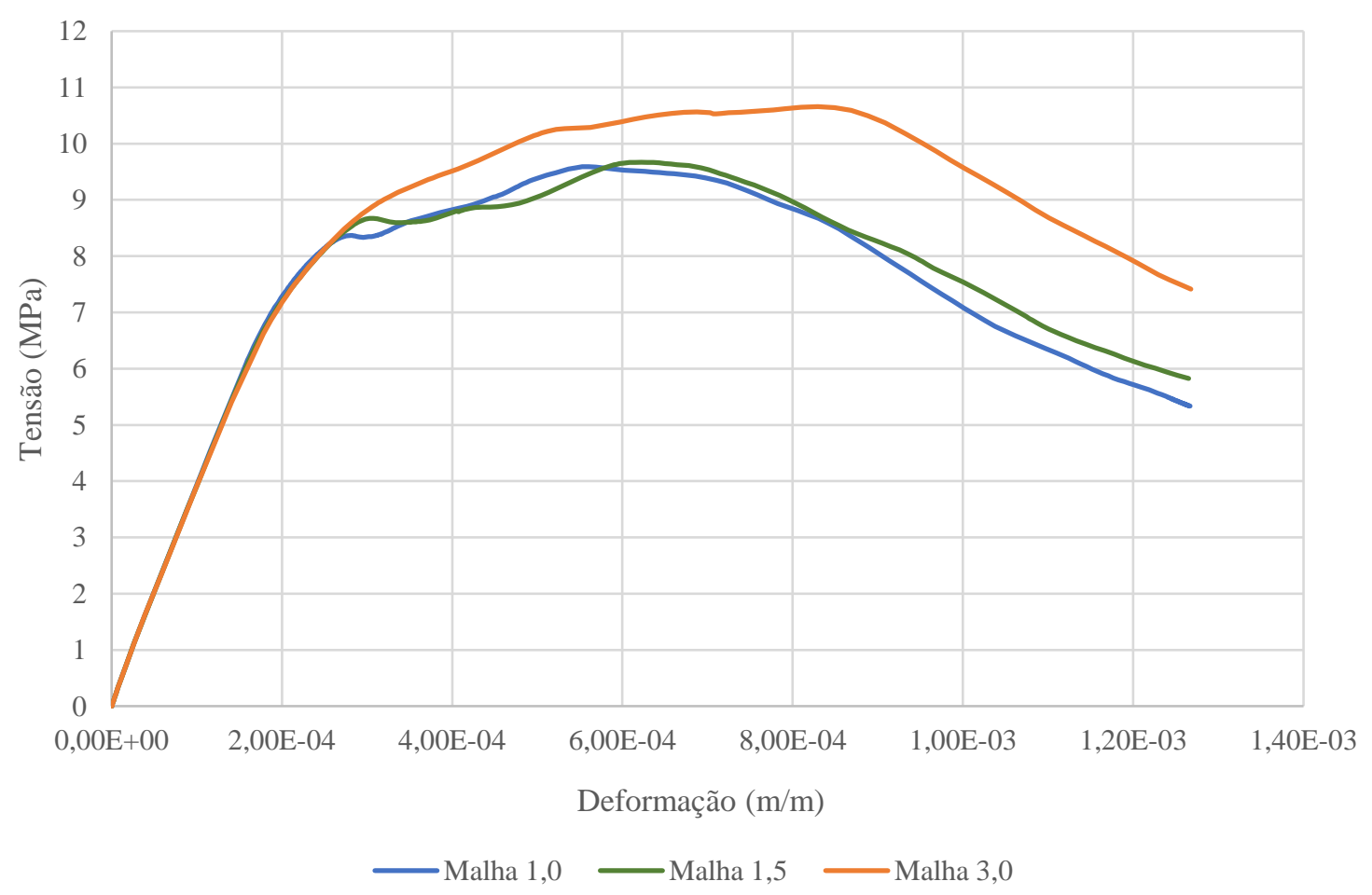


Conforme visto na Figura 5.1, na Tabela 5.1 estão indicados os valores de pico para a tensão e a deformação para os três casos estudados, além de indicar a variação percentual em relação à malha de referência.

Tabela 5.1 - Comparação dos valores de tensão e deformação entre as diferentes discretizações

\begin{tabular}{cccccc}
$\begin{array}{c}\text { Malha } \\
(\mathbf{c m})\end{array}$ & $\begin{array}{c}\text { Qtde. } \\
\text { elementos }\end{array}$ & $\begin{array}{c}\text { Tensão } \\
(\mathbf{M P a})\end{array}$ & $\begin{array}{c}\text { Comparação } \\
\text { com malha de } \\
\mathbf{1 , 0} \mathbf{~ c m}\end{array}$ & $\begin{array}{c}\text { Deformação } \\
(\mathbf{m} / \mathbf{m})\end{array}$ & $\begin{array}{c}\text { Comparação com } \\
\text { malha de } \mathbf{1 , 0} \mathbf{~ c m}\end{array}$ \\
\hline $\mathbf{1 , 0}$ & 67.678 & 9,59 & - & 0,000561 & - \\
\hline $\mathbf{1 , 5}$ & 22.826 & 9,67 & $3,9 \%$ & 0,000622 & $10,9 \%$ \\
\hline $\mathbf{3 , 0}$ & 4.952 & 10,66 & $11,2 \%$ & 0,000830 & $48,0 \%$ \\
\hline
\end{tabular}

A Figura 5.2, por sua vez, traz esquematizações de distribuição de tensões principais absolutas referentes às discretizações estudadas.

Figura 5.2 - Comparação das tensões máximas absolutas entre as discretizações com 1,0 (a),

$$
1,5 \text { (b) e } 3,0 \mathrm{~cm} \text { (c) }
$$
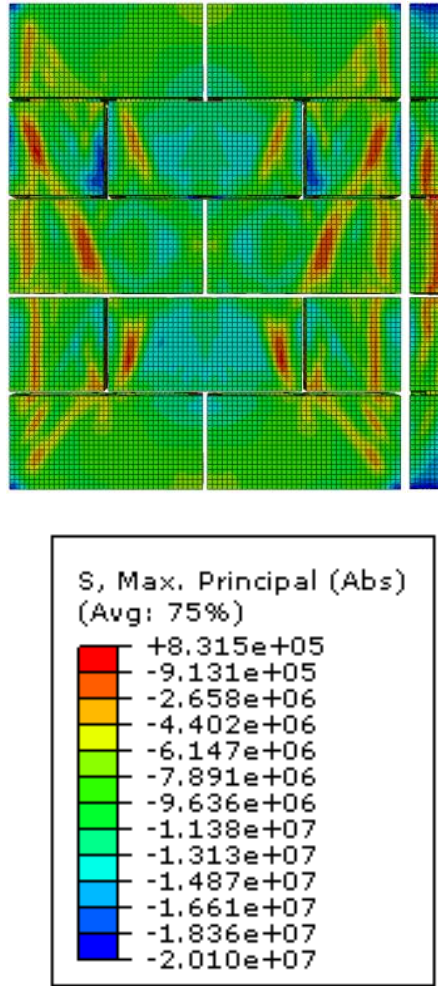

(a)
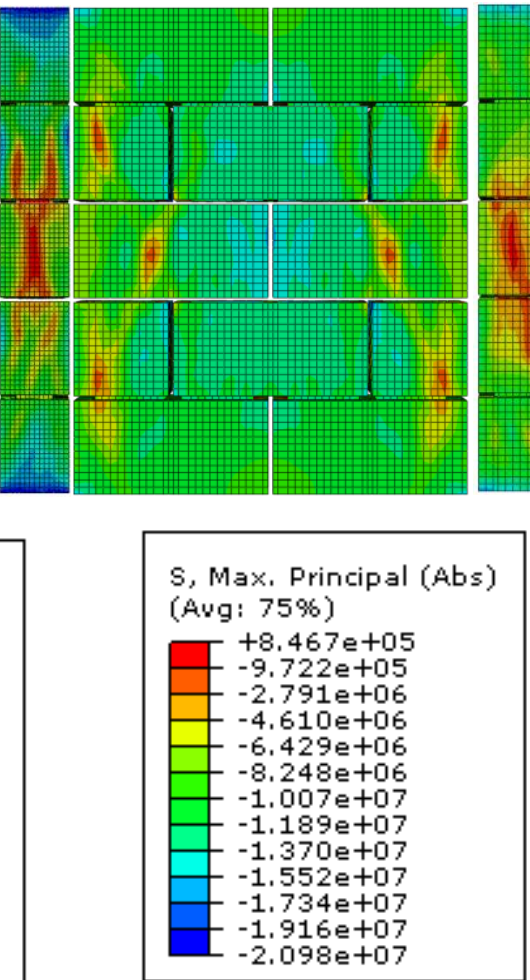

(b)
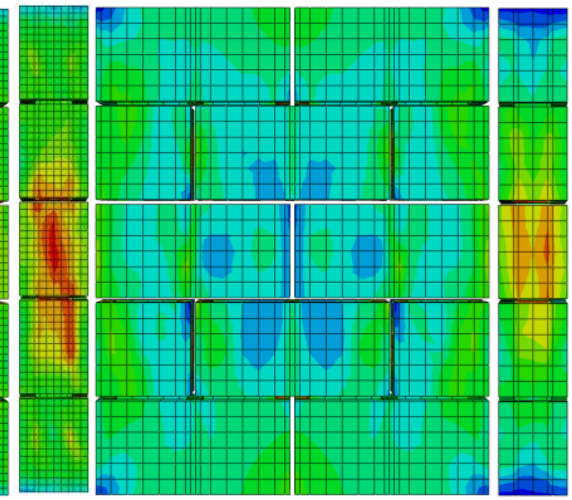

S, Max. Principal (A.bs)
(Avg: 75\%)
\begin{tabular}{|l}
\hline$+7.745 e+05$ \\
$-8.878 \mathrm{e}+05$ \\
$-2.550 \mathrm{e}+06$ \\
$-4.212 \mathrm{e}+06$ \\
$-5.875 \mathrm{e}+06$ \\
\hline$-7.537 \mathrm{e}+06$ \\
$-9.199 \mathrm{e}+06$ \\
$-1.086 \mathrm{e}+07$ \\
$-1.252 \mathrm{e}+07$ \\
$-1.419 \mathrm{e}+07$ \\
$-1.585 \mathrm{e}+07$ \\
$-1.751 \mathrm{e}+07$ \\
$-1.917 \mathrm{e}+07$
\end{tabular}

(c) 
Como comentado no Capítulo 3, o uso de refinamento muito grosseiro interfere no comportamento do material, não sendo fiel aos resultados experimentais, neste caso, tomando como base de comparação, o trabalho de Oliveira (2014). A malha com refinamento de $3,0 \mathrm{~cm}$ não apresentou tensões de tração na face frontal da parede no instante da ruptura, além de apresentar deformações muito elevadas em relação aos resultados experimentais, aparentemente inconsistente com o esperado.

O refinamento com 1,5 cm apresenta resultados próximos aos de 1,0 cm, com variação pequena em relação à tensão. Devido ao processamento robusto do modelo termoestrutural, bem como às pequenas diferenças consideradas entre estas situações, nas análises termoestruturais fez-se uso de refinamentos de $1,5 \mathrm{~cm}$ para este caso.

$\mathrm{O}$ uso de malha com refinamento inferior a $1,0 \mathrm{~cm}$ não foi apresentado para pequenas paredes devido ao elevado esforço computacional, inviabilizando assim as análises do presente trabalho. A análise para a densidade de $0,5 \mathrm{~cm}$ foi feita para prismas conforme apresentada na Capítulo 3, permitindo então concluir que o refinamento com $1,0 \mathrm{~cm}$ apresentaria boa qualidade quanto aos resultados e custo computacional adequado.

\subsubsection{Quanto ao tipo de argamassamento}

O modelo estrutural validado no Capítulo 4, com propriedades baseadas tanto no trabalho de Oliveira (2014) com argamassamento parcial quanto no de Dupim (2019) com argamassamento total, tiveram seus respectivos argamassamentos alterados e comparados com os resultados experimentais obtidos por Izquierdo (2015), em que se obteve relação de resistência entre estas situações. O Quadro 5.2 indica o resumo das informações para a primeira análise deste tópico.

Quadro 5.2 - Resumo das informações para a primeira análise numérica do item 5.1.2

\begin{tabular}{|rl|}
\hline Modelo validado utilizado: & Estrutural (Item 4.1.1) \\
\hline Baseado nos resultados experimentais de: & Oliveira (2014) \\
\hline No modelo validado: & Argamassamento parcial \\
\hline Nesta análise: & Argamassamento total \\
\hline
\end{tabular}

Para o modelo obtido a partir de Oliveira (2014), a Figura 5.3 indica a comparação do diagrama tensão-deformação para modelos com argamassamentos total e parcial. 
Figura 5.3 - Diagrama tensão-deformação com variação do argamassamento para os parâmetros de Oliveira (2014)

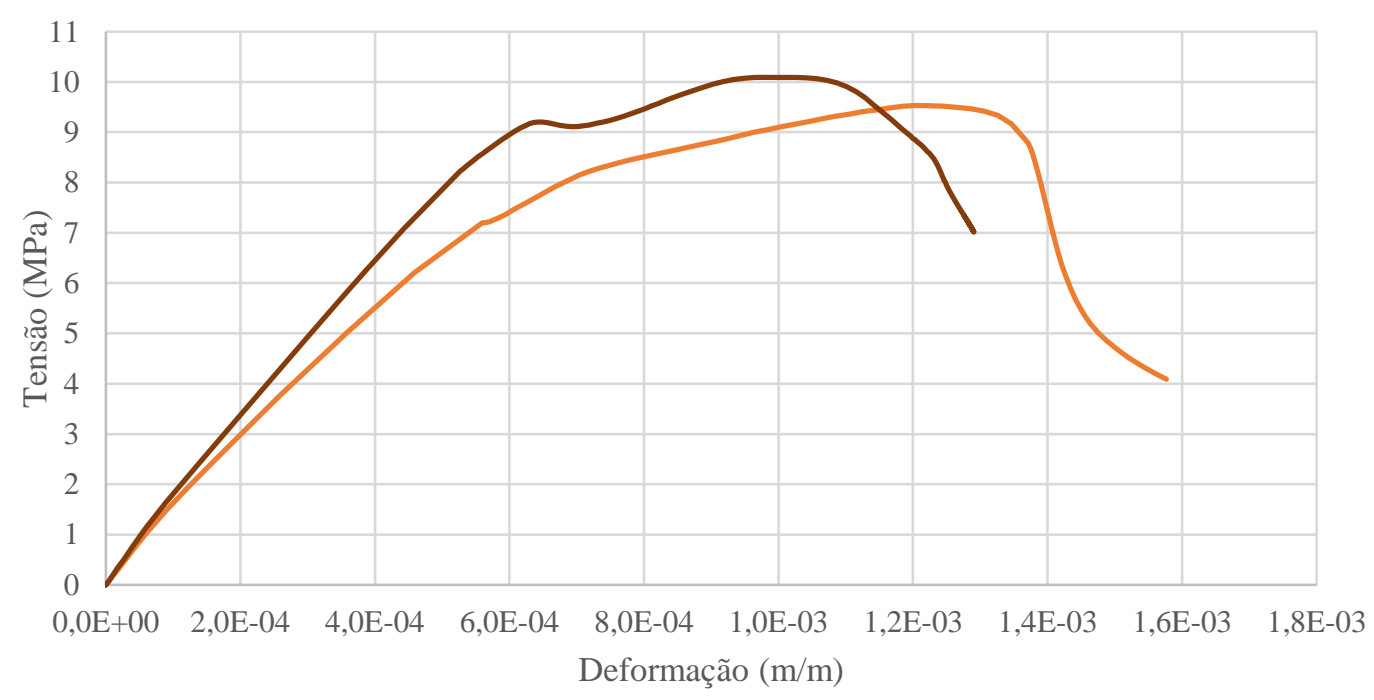

Argamassamento parcial — Argamassamento total

Nas Figuras 5.4 e 5.5, estão indicados de forma comparativa as distribuições de tensões principais mínimas e máximas, respectivamente, no instante da ruptura para modelos com argamassamentos total e parcial.

Figura 5.4 - Comparação das tensões mínimas entre as paredes com argamassamento total (esquerda) e argamassamento parcial (direita)
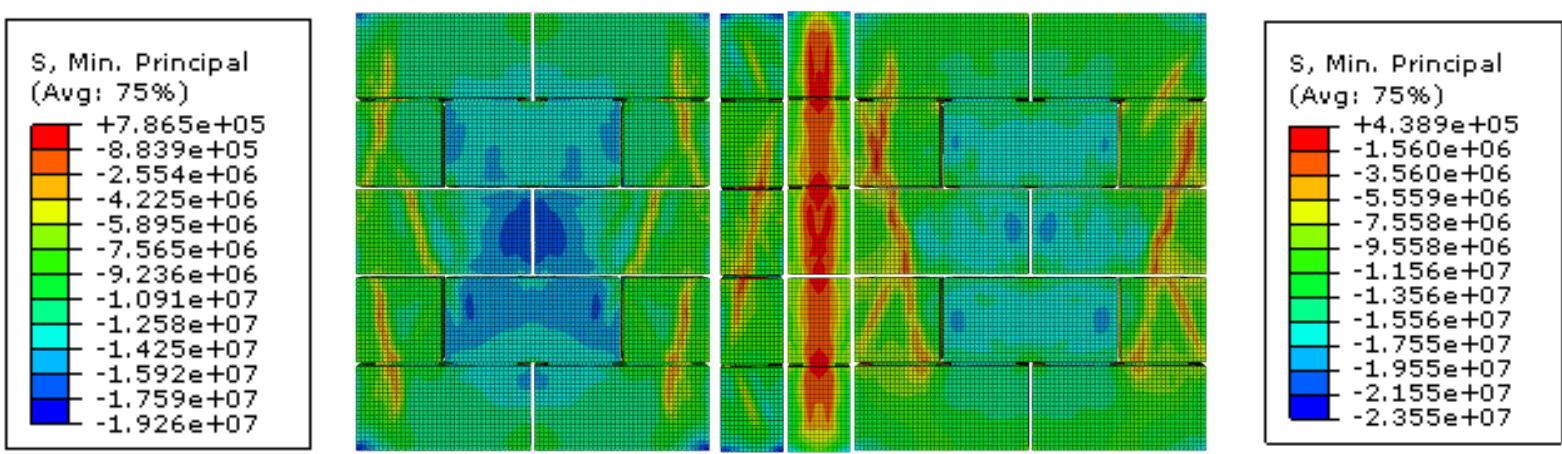

Figura 5.5 - Comparação das tensões máximas entre as paredes com argamassamento total (esquerda) e argamassamento parcial (direita)
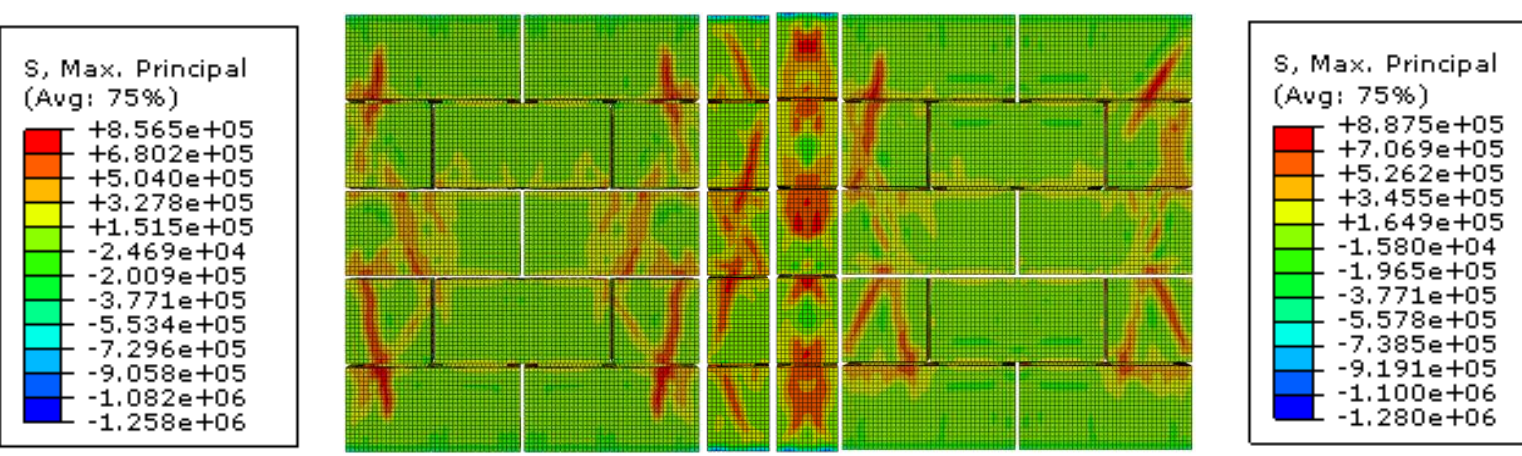
O Quadro 5.3 indica o resumo das informações para a segunda análise deste tópico.

Quadro 5.3 - Resumo das informações para a segunda análise numérica do item 5.1.2

\begin{tabular}{|rl|}
\hline Modelo validado utilizado: & Estrutural (Item 4.1.2) \\
\hline Baseado nos resultados experimentais de: & Dupim (2019) \\
\hline No modelo validado: & Argamassamento total \\
\hline Nesta análise: & Argamassamento parcial \\
\hline
\end{tabular}

Para os resultados obtidos a partir de Dupim (2019), a Figura 5.6 indica a comparação do diagrama tensão-deformação para modelos com argamassamentos total e parcial para paredes com espessura de $14 \mathrm{~cm}$.

Figura 5.6 - Diagrama tensão-deformação com variação do argamassamento para os parâmetros de Dupim (2019) para parede com espessura de $14 \mathrm{~cm}$

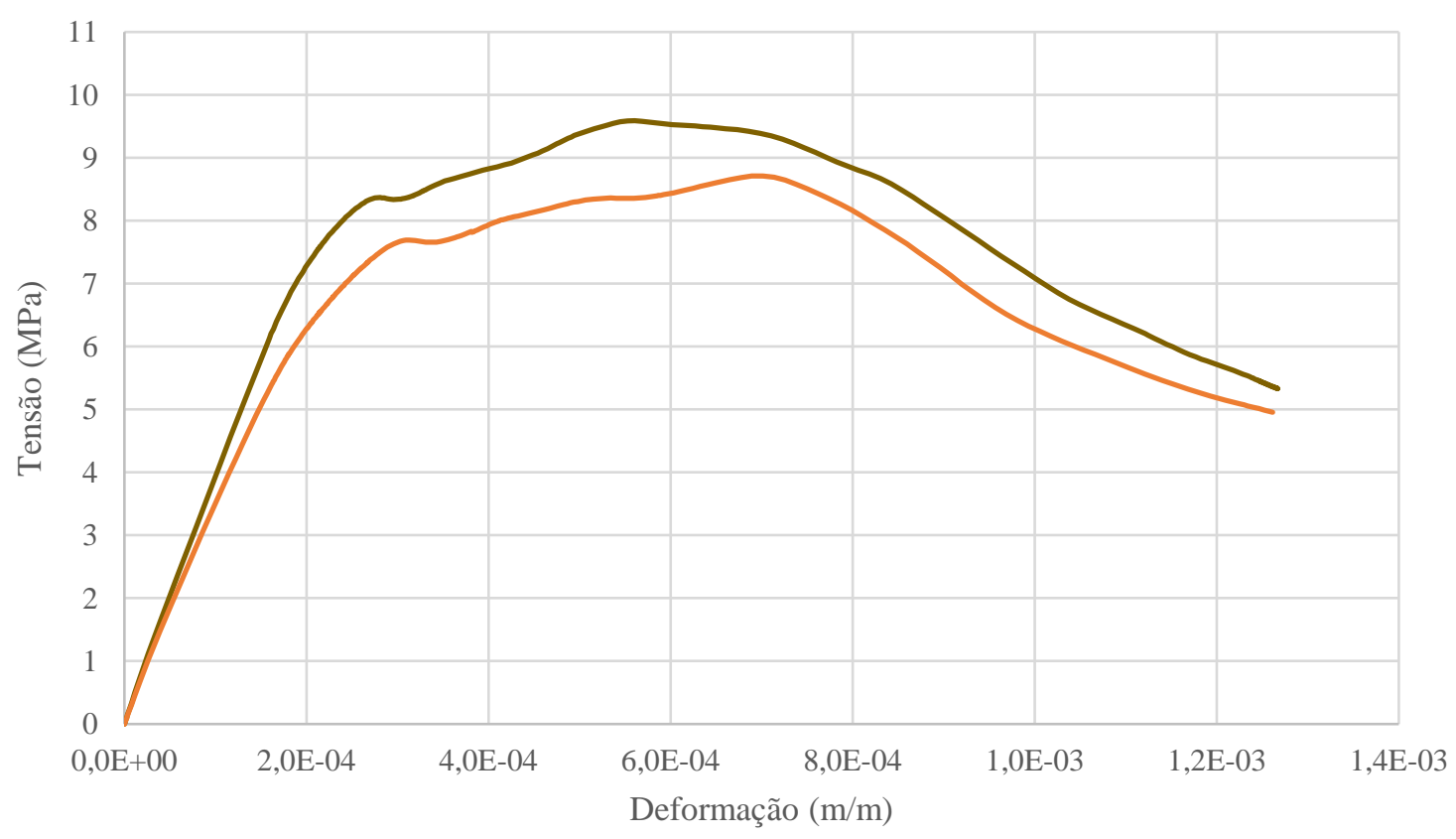

- Argamassamento total _ Argamassamento parcial

Conforme comparação anterior, as Figuras 5.7 e 5.8 indicam de forma comparativa as distribuições de tensões principais mínimas e máximas, respectivamente, no instante da ruptura para modelos com argamassamentos total e parcial. 
Figura 5.7 - Comparação das tensões mínimas entre as paredes de $14 \mathrm{~cm}$ de espessura com argamassamento total (esquerda) e argamassamento parcial (direita)
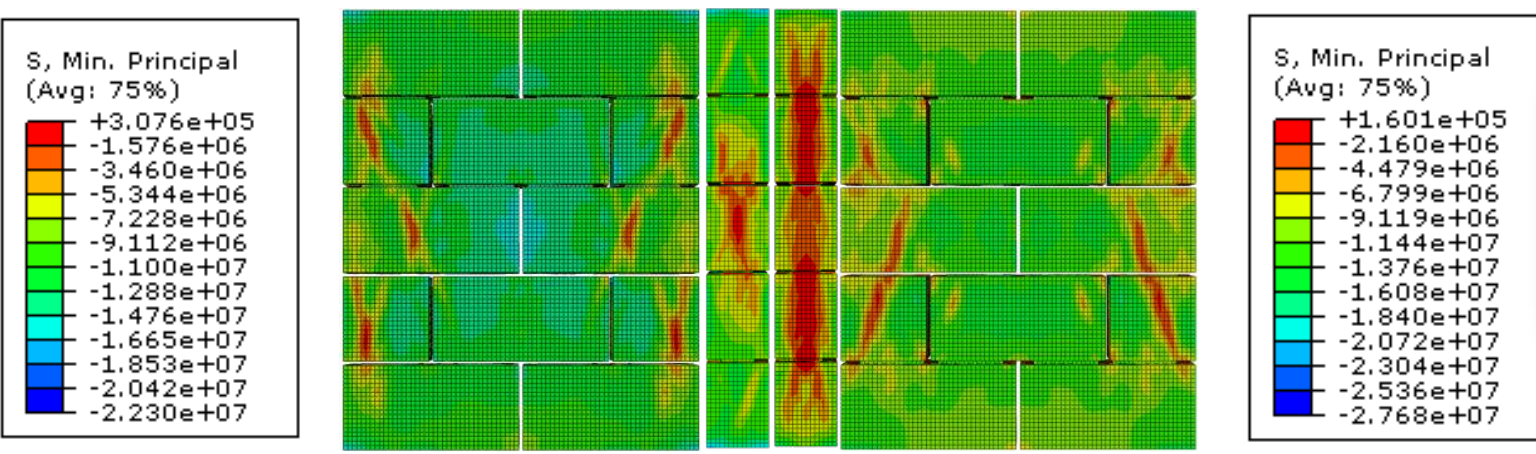

Figura 5.8 - Comparação das tensões máximas entre as paredes de $14 \mathrm{~cm}$ de espessura com argamassamento total (esquerda) e argamassamento parcial (direita)
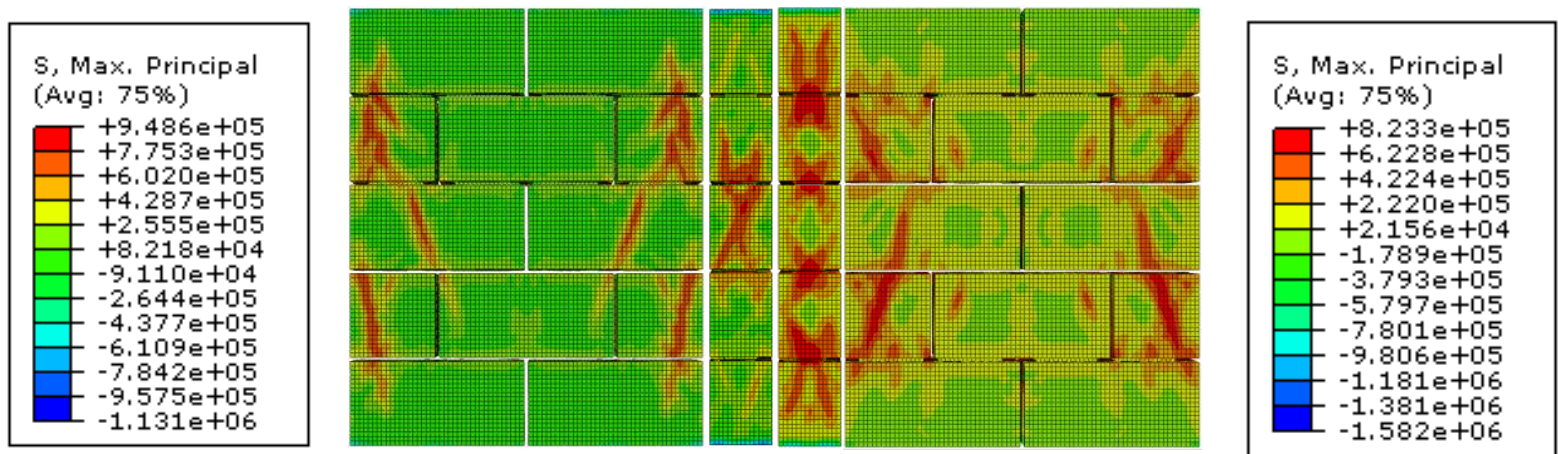

O Quadro 5.4 indica o resumo das informações para a terceira análise deste tópico.

Quadro 5.4 - Resumo das informações para a terceira análise numérica do item 5.1.2

\begin{tabular}{|rl|}
\hline Modelo validado utilizado: & Estrutural (Item 4.1.3) \\
\hline Baseado nos resultados experimentais de: & Dupim (2019) \\
\hline No modelo validado: & Argamassamento total \\
\hline Nesta análise: & Argamassamento parcial \\
\hline
\end{tabular}

Para o modelo com espessura de $19 \mathrm{~cm}$, apresentado em Dupim (2019), também foi analisada a variação do argamassamento total para parcial. A Figura 5.9 indica o diagrama tensão-deformação comparativo entre as duas situações. Nas Figuras 5.10 e 5.11 estão indicados, de forma comparativa, as tensões principais mínimas e máximas no instante da ruptura para modelos considerando argamassamentos total e parcial. 
Figura 5.9 - Diagrama tensão-deformação com variação do argamassamento para os parâmetros de Dupim (2019) para parede com espessura de $19 \mathrm{~cm}$

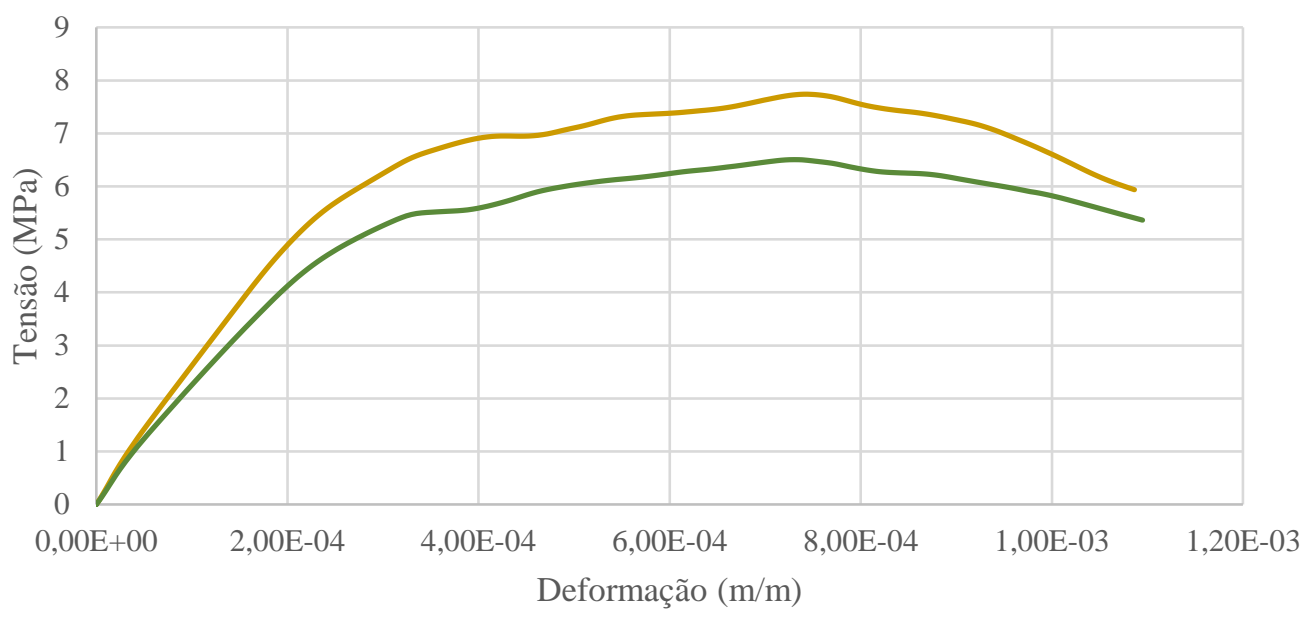

— Argamassamento total — Argamassamaneto parcial

Figura 5.10 - Comparação das tensões mínimas entre as paredes de $19 \mathrm{~cm}$ de espessura com argamassamento total (esquerda) e argamassamento parcial (direita)

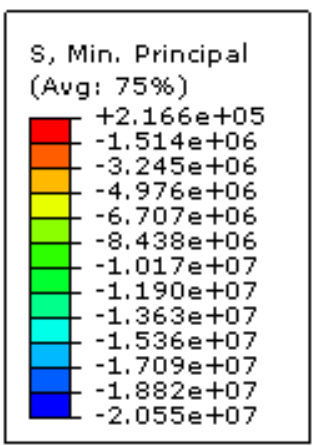
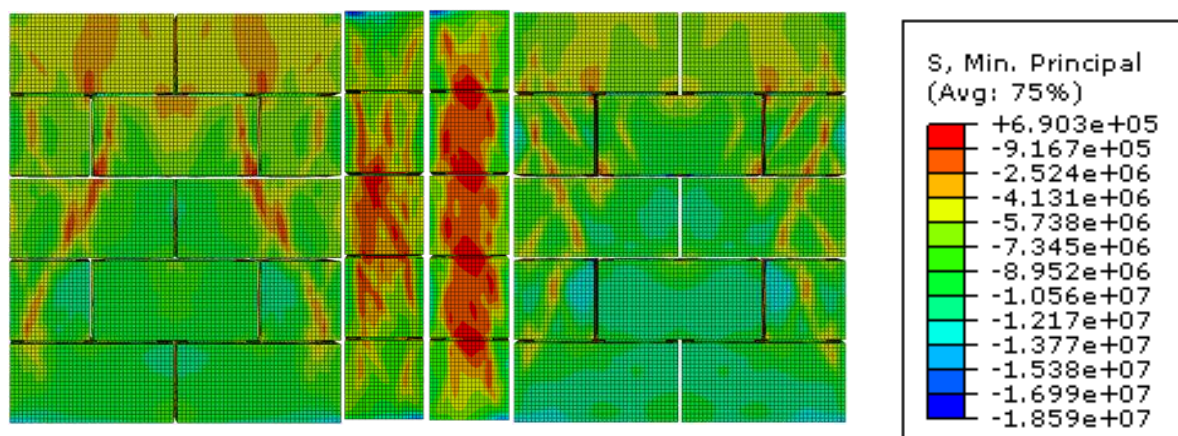

Figura 5.11 - Comparação das tensões máximas entre as paredes de $19 \mathrm{~cm}$ de espessura com argamassamento total (esquerda) e argamassamento parcial (direita)
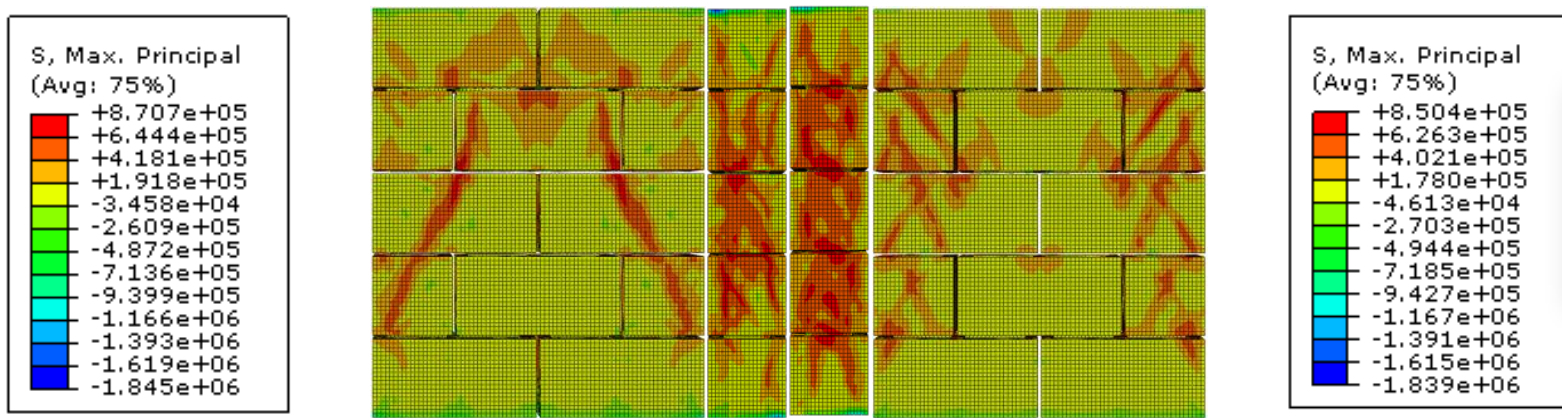

Em Izquierdo (2015) foram realizados ensaios em paredes de alvenaria estrutural de blocos de concreto de $14 \mathrm{~cm}$ de espessura com ambos os tipos de argamassamentos, verificando redução de $9,1 \%$ da resistência das paredes com argamassamento parcial em relação às com 
argamassamento total. Quanto ao modo de ruptura, comenta-se na mesma referência que as fissuras verticais nas laterais das paredes com argamassamento parcial apresentaram-se de forma muito mais acentuada, conforme verificado pelos modelos numéricos. Ainda, se menciona que o aumento da área de contato das paredes com argamassamento total não foi proporcional ao aumento da resistência, não sendo este o único fator que influenciou no comportamento à compressão, porém, o considerou como o mais importante.

Nos resultados numéricos obtidos nos gráficos das Figuras 5.3, 5.6 e 5.9, verifica-se que os modelos utilizando argamassamento parcial obtiveram rupturas com tensões menores e com deformações próximas às obtidas com argamassamento total. A Tabela 5.2 indica os valores das tensões e deformações no instante da ruptura, bem como, a redução percentual de resistência para cada caso.

Tabela 5.2 - Comparação das tensões de ruptura obtidas pelo modelo numérico para diferentes argamassamentos

\begin{tabular}{|c|c|c|c|c|}
\hline Argamassamento & $\begin{array}{c}\text { Propriedades dos } \\
\text { materiais/ Espessura }\end{array}$ & $\begin{array}{l}\text { Tensão } \\
\text { máxima } \\
\text { (MPa) }\end{array}$ & $\begin{array}{c}\text { Deformação } \\
\text { de ruptura } \\
(\mathrm{m} / \mathrm{m})\end{array}$ & $\begin{array}{c}\text { Redução da } \\
\text { resistência } \\
(\%)\end{array}$ \\
\hline Total & \multirow{2}{*}{ Oliveira $(2014) / 14 \mathrm{~cm}$} & 10,21 & 0,000980 & \multirow{2}{*}{6,8} \\
\hline Parcial* & & 9,52 & 0,001220 & \\
\hline Total* & \multirow{2}{*}{ Dupim (2019)/ $14 \mathrm{~cm}$} & 9,59 & 0,000561 & \multirow{2}{*}{9,2} \\
\hline Parcial & & 8,71 & 0,000702 & \\
\hline Total* & \multirow{2}{*}{ Dupim (2019)/ $19 \mathrm{~cm}$} & 7,74 & 0,000740 & \multirow{2}{*}{16,0} \\
\hline Parcial & & 6,50 & 0,000734 & \\
\hline
\end{tabular}

* Modelo validado

Para os resultados numérico apresentados na Tabela 5.2, observa-se redução bastante próxima à verificada por Izquierdo (2015) para o modelo representativo do trabalho de Dupim (2019). Em relação ao modelo representativo de Oliveira (2014), tem-se redução de resistência próxima a $7 \%$ e, para a situação com blocos de $19 \mathrm{~cm}$, redução de $16 \%$. Para a maior espessura, a justificativa para a diferença provavelmente esteja associada diretamente à variação da espessura da parede.

Na Figura 5.12 são mostradas algumas imagens extraídas do trabalho de Izquierdo (2015) para verificação qualitativa do modo de ruptura visto nas imagens anteriores deste tópico. 
Figura 5.12 - Modo de ruptura de pequenas paredes com argamassamento parcial (a) e total

(b)

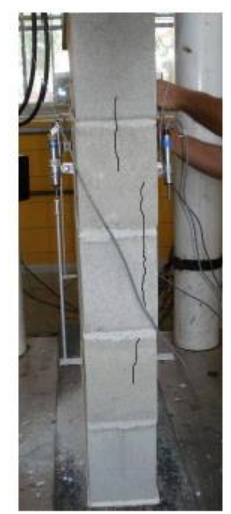

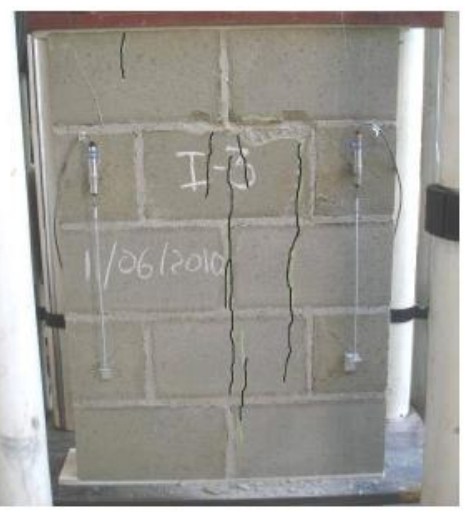

(a)
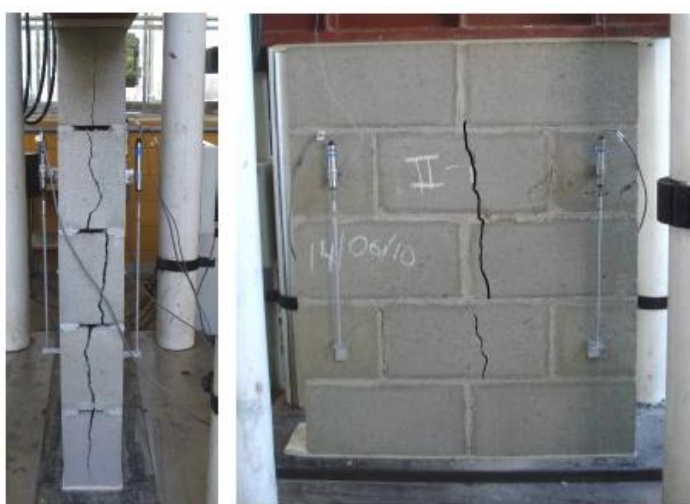

(b)

Donde, verifica-se tendência da ocorrência das fissuras, conforme resultados numéricos baseados nos experimentos de Oliveira (2014) e Dupim (2019).

\subsubsection{Considerações referentes ao dano}

Outra variação realizada no modelo estrutural se volta à desconsideração dos efeitos de dano no material, a qual interfere diretamente no tempo de processamento do modelo numérico, reduzindo, em média, em $30 \%$ do tempo de processamento se considerado dano. Os Quadros 5.5 e 5.6 indicam o resumo das informações para a primeira e segunda análises deste tópico.

Quadro 5.5 - Resumo das informações para a primeira análise numérica do item 5.1.3

\begin{tabular}{|rl|}
\hline Modelo validado utilizado: & Estrutural (Item 4.1.2) \\
\hline Baseado nos resultados experimentais de: & Dupim (2019) \\
\hline No modelo validado: & Consideração dos efeitos de dano \\
\hline Nesta análise: & Desconsideração dos efeitos de dano \\
\hline
\end{tabular}

Quadro 5.6 - Resumo das informações para a segunda análise numérica do item 5.1.3

\begin{tabular}{|rl|}
\hline Modelo validado utilizado: & Estrutural (Item 4.1.3) \\
\hline Baseado nos resultados experimentais de: & Dupim (2019) \\
\hline No modelo validado: & Consideração dos efeitos de dano \\
\hline Nesta análise: & Desconsideração dos efeitos de dano \\
\hline
\end{tabular}

Na Figura 5.13 estão indicados os diagramas tensão-deformação do modelo validado no Capítulo 4 e deste mesmo modelo com a retirada do dano ao material para a parede com 
espessura de $14 \mathrm{~cm}$ (primeira análise). A Figura 5.14 faz traz as mesmas indicações para o modelo validado com espessura de $19 \mathrm{~cm}$ (segunda análise).

Figura 5.13 - Comparação entre os diagramas tensão-deformação para paredes com espessura de $14 \mathrm{~cm}$ com e sem consideração de dano

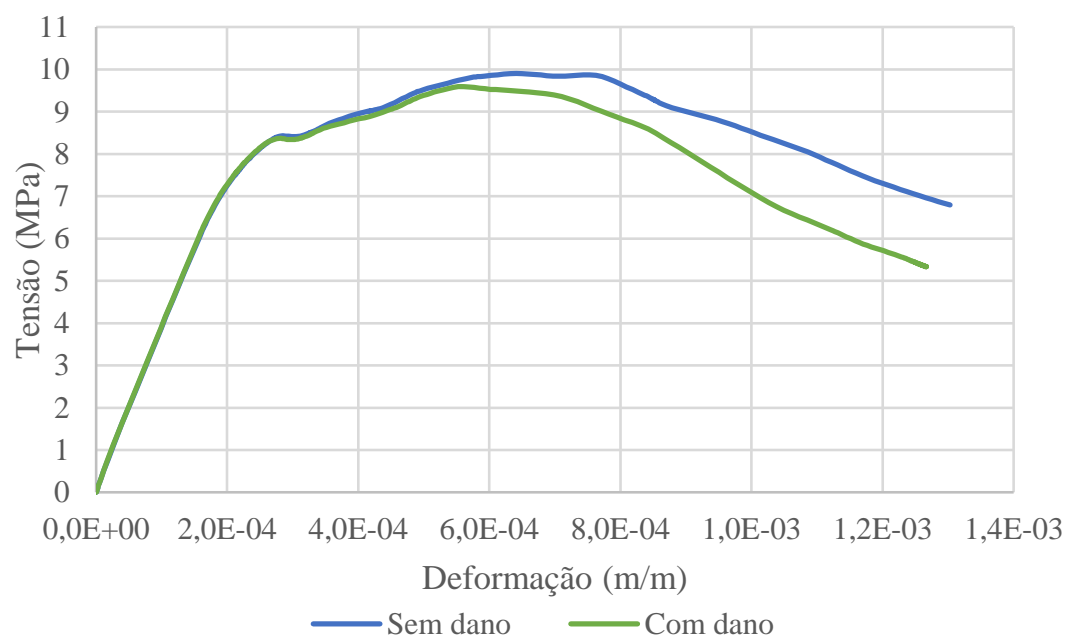

Figura 5.14 - Comparação entre os diagramas tensão-deformação para paredes com espessura de $19 \mathrm{~cm}$ com e sem consideração de dano

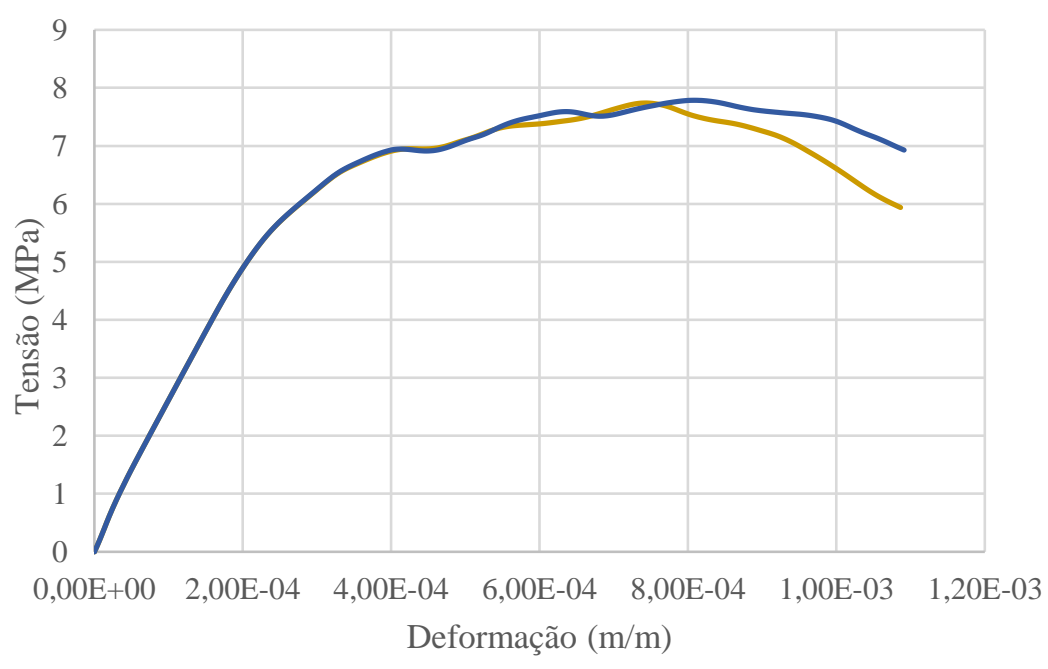

Com dano $\longrightarrow$ Sem dano

Verifica-se maior discrepância entre as curvas no trecho pós-pico tanto para a espessura de $14 \mathrm{~cm}$ quanto para de $19 \mathrm{~cm}$. Como no presente trabalho a comparação com os modelos experimentais se aplica somente até o pico de tensões, não é possível concluir acerca do comportamento real da estrutura em sua fase pós-pico e, portanto, não se consegue verificar quais modelos apresentam melhor comportamento. 
A Tabela 5.3 traz informações referentes aos resultados no instante da ruptura e a comparação com os resultados experimentais.

Tabela 5.3 - Comparação entre os resultados com e sem consideração de dano

\begin{tabular}{cccc}
\multirow{2}{*}{ Espessura } & $\begin{array}{c}\text { Consideração de } \\
\text { dano }\end{array}$ & $\begin{array}{c}\text { Tensão máxima } \\
(\mathbf{M P a})\end{array}$ & $\begin{array}{c}\text { Variação em relação à } \\
\text { média experimental }\end{array}$ \\
\cline { 2 - 5 } \multirow{2}{*}{14} & Com & 9,59 & $-4,2$ \\
& Sem & 9,90 & $-1,1$ \\
\hline \multirow{2}{*}{$\mathbf{1 9}$} & Com & 7,74 & $-7,4$ \\
& Sem & 7,79 & $-8,1$ \\
\hline
\end{tabular}

Verifica-se, após análise, que até a ruptura do modelo ocorre divergência pequena em relação a este tipo de consideração. Desta forma, nos modelos termoestruturais não se fez a consideração de dano tendo em vista os resultados aqui apresentados.

\subsubsection{Com relação ao ângulo de dilatância}

Para o modelo com espessura de $19 \mathrm{~cm}$ baseado na validação realizada no Capítulo 4, foi alterado o ângulo de dilatância do material concreto para análise quanto à variação do comportamento da curva tensão-deformação. Desta forma, foram utilizados ângulos de dilatância iguais a $34^{\circ}, 36^{\circ}$ e $40^{\circ}$, cujos valores foram baseados nos estudos de Malm (2009), e posteriormente comparados com o valor igual a $32^{\circ}$ utilizado quando da validação.

O Quadro 5.7 indica o resumo das informações deste tópico, enquanto a Figura 5.15 indica a curva obtida para cada ângulo analisado. A Tabela 5.4, por sua vez, indica os valores de pico para a tensão e a deformação, bem como, a comparação com o ângulo utilizado como referência de validação.

Quadro 5.7 - Resumo das informações para a análise numérica do item 5.1.4

\begin{tabular}{|rl|}
\hline Modelo validado utilizado: & Estrutural (Item 4.1.3) \\
\hline Baseado nos resultados experimentais de: & Dupim (2019) \\
\hline No modelo validado: & Ângulo de dilatância de $32^{\circ}$ \\
\hline Nesta análise: & Ângulos de dilatância de 34,36 e $40^{\circ}$ \\
\hline
\end{tabular}

Numericamente, para o modelo estudado, sinaliza-se pequena divergência tanto em relação à tensão de ruptura quanto à respectiva deformação, razão pela qual é possível 
considerar que, com o aumento do ângulo de dilatância, há tendência a um incremento no valor da tensão de ruptura, assim como na respectiva deformação.

Figura 5.15 - Curvas tensão-deformação para modelos com variação do ângulo de dilatância do concreto

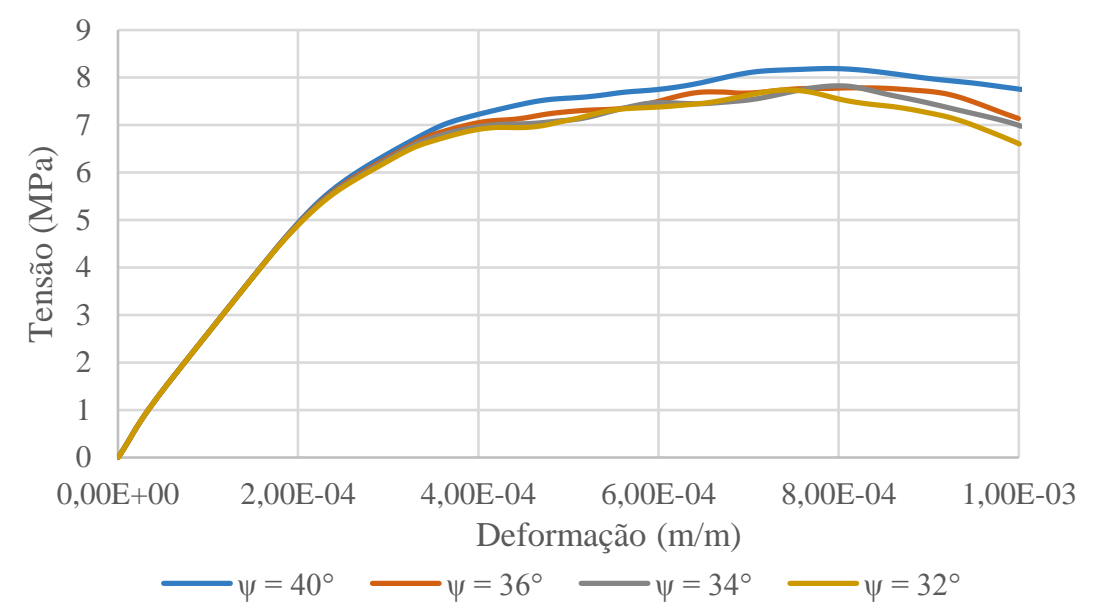

Tabela 5.4 - Valores de tensão e deformação de pico de acordo com o ângulo de dilatância e comparação com o modelo validado

\begin{tabular}{ccccc|}
\hline $\begin{array}{c}\text { Ângulo de } \\
\text { dilatância }\end{array}$ & $\begin{array}{c}\text { Tensão } \\
(\mathbf{M P a})\end{array}$ & Variação $(\boldsymbol{\%})$ & $\begin{array}{c}\text { Deformação } \\
(\mathbf{m} / \mathbf{m})\end{array}$ & Variação (\%) \\
\hline $\mathbf{3 2}^{\circ}$ & 7,74 & - & 0,000740 & - \\
\hline $\mathbf{3 4}^{\circ}$ & 7,83 & 1,2 & 0,000802 & 8,4 \\
\hline $\mathbf{3 6}^{\circ}$ & 7,78 & 0,5 & 0,000822 & 11,1 \\
\hline $\mathbf{4 0}^{\circ}$ & 8,19 & 5,8 & 0,000791 & 6,9 \\
\hline
\end{tabular}

\subsection{ANÁLISES REFERENTES AO MODELO TÉRMICO}

\subsubsection{Quanto ao refinamento da malha}

Neste tópico, o modelo térmico validado no Capítulo 4 baseado nos resultados experimentais de Dupim (2019) teve seu refinamento de malha alterado para verificação quanto à variação dos resultados. Esta análise foi realizada para paredes com espessura de $14 \mathrm{~cm}$, argamassamento total e fogo em uma face, com aumento de temperatura na face oposta conforme a mesma validação.

No que segue, o Quadro 5.8 traz valores considerando um resumo das informações deste tópico, enquanto a Tabela 5.5 indica os valores de temperaturas obtidos a partir da face da parede exposta ao fogo. 
Quadro 5.8 - Resumo das informações para a análise numérica do item 5.2.1

\begin{tabular}{|rl|}
\hline Modelo validado utilizado: & Térmico (Item 4.2.1) \\
\hline Baseado nos resultados experimentais de: & Dupim (2019) \\
\hline Elevação da temperatura na face oposta: & Com confinamento, conforme Dupim (2019) \\
\hline No modelo validado: & Refinamento da malha com $1,0 \mathrm{~cm}$ \\
\hline Nesta análise: & Refinamento da malha com 0,5 e $1,5 \mathrm{~cm}$ \\
\hline
\end{tabular}

Tabela 5.5 - Temperaturas obtidas ao longo da espessura da parede para diferentes refinamentos de malha de acordo com o tempo de incêndio

\begin{tabular}{|c|c|c|c|c|c|c|}
\hline \multirow{2}{*}{$\begin{array}{l}\text { Tempo de } \\
\text { incêndio } \\
\text { (min) }\end{array}$} & \multirow{2}{*}{$\begin{array}{c}\text { Malha } \\
\text { (cm) }\end{array}$} & \multicolumn{5}{|c|}{ Local } \\
\hline & & $\begin{array}{c}\text { Face } \\
\text { exposta }\end{array}$ & $\begin{array}{c}\text { Septo interno } \\
\text { exposto }\end{array}$ & Meio* & $\begin{array}{c}\text { Septo interno } \\
\text { oposto }\end{array}$ & $\begin{array}{c}\text { Face } \\
\text { oposta }\end{array}$ \\
\hline \multirow{3}{*}{15} & 0,5 & 594,5 & 218,8 & 45,0 & 34,8 & 26,0 \\
\hline & 1,0 & 594,6 & 221,9 & 46,3 & 34,5 & 26,0 \\
\hline & 1,5 & 597,5 & 228,7 & 42,5 & 34,5 & 26,1 \\
\hline \multirow{3}{*}{30} & 0,5 & 787,4 & 411,4 & 122,5 & 88,5 & 64,2 \\
\hline & 1,0 & 787,4 & 412,5 & 123,6 & 87,8 & 63,6 \\
\hline & 1,5 & 788,0 & 414,5 & 116,3 & 87,4 & 68,7 \\
\hline \multirow{3}{*}{45} & 0,5 & 865,3 & 490,8 & 223,0 & 147,7 & 115,6 \\
\hline & 1,0 & 865,9 & 491,8 & 226,6 & 147,8 & 115,7 \\
\hline & 1,5 & 866,1 & 492,6 & 211,6 & 147,4 & 115,7 \\
\hline \multirow{3}{*}{60} & 0,5 & 917,0 & 553,4 & 358,8 & 287,2 & 200,2 \\
\hline & 1,0 & 917,0 & 553,7 & 361,5 & 285,7 & 199,7 \\
\hline & 1,5 & 916,6 & 552,8 & 344,8 & 281,6 & 198,4 \\
\hline
\end{tabular}

*Medida próxima ao meio do bloco para o refinamento de $1,5 \mathrm{~cm}(\mathrm{D} 6,0)$

As Figuras 5.16 (a), (b), (c) e (d), por sua vez, ilustram o gradiente de temperaturas para os modelos com 15, 30, 45 e 60 minutos de tempos de incêndio, respectivamente. Ao analisar os resultados apresentados, é possível verificar pouca variação entre as malhas mais e menos densas para a análise térmica, com variação na ordem de $15^{\circ} \mathrm{C}$ para a distância de $7 \mathrm{~cm}$ da face exposta, bem como inferior a $3{ }^{\circ} \mathrm{C}$ nas demais medições.

A Figura 5.17 mostra a evolução de temperatura das três situações de refinamento da malha ao longo do tempo, por meio da qual é possível identificar certa sobreposição entre as curvas, sendo M0,5, M1,0 e M1,5 os refinamentos de malha de 0,5, 1,0 e 1,5 cm, respectivamente. 
Figura 5.16 - Esquematização do gradiente de temperatura com diferentes discretizações para 15 (a), 30 (b), 45 (c) e 60 (d) minutos de incêndio
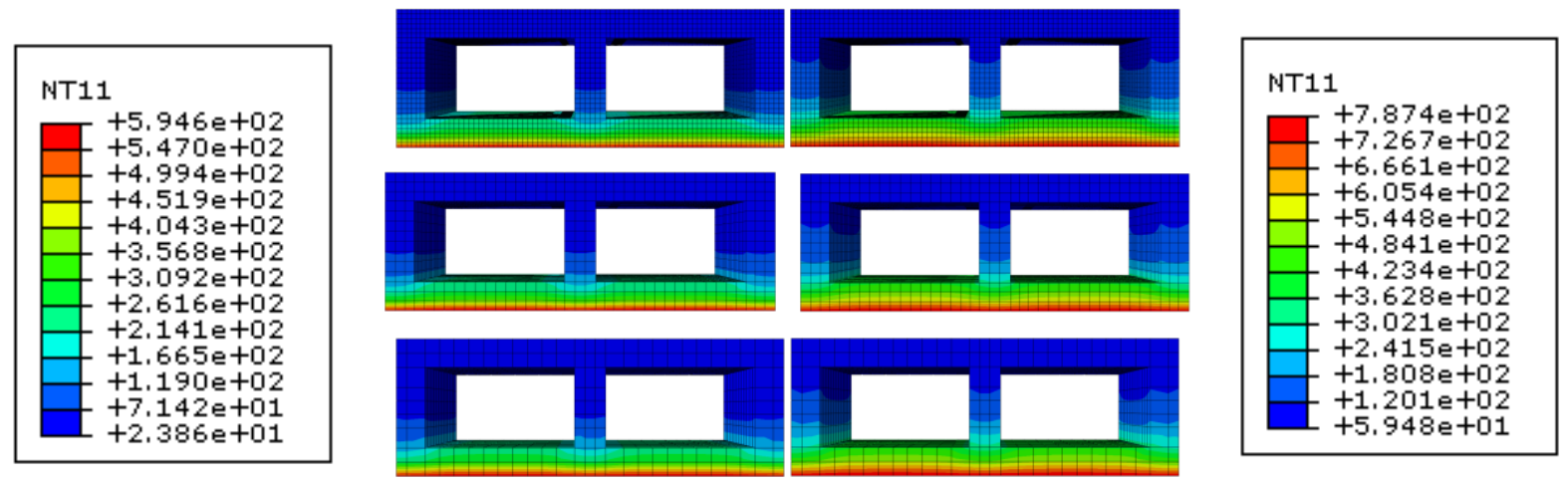

(a)

(b)
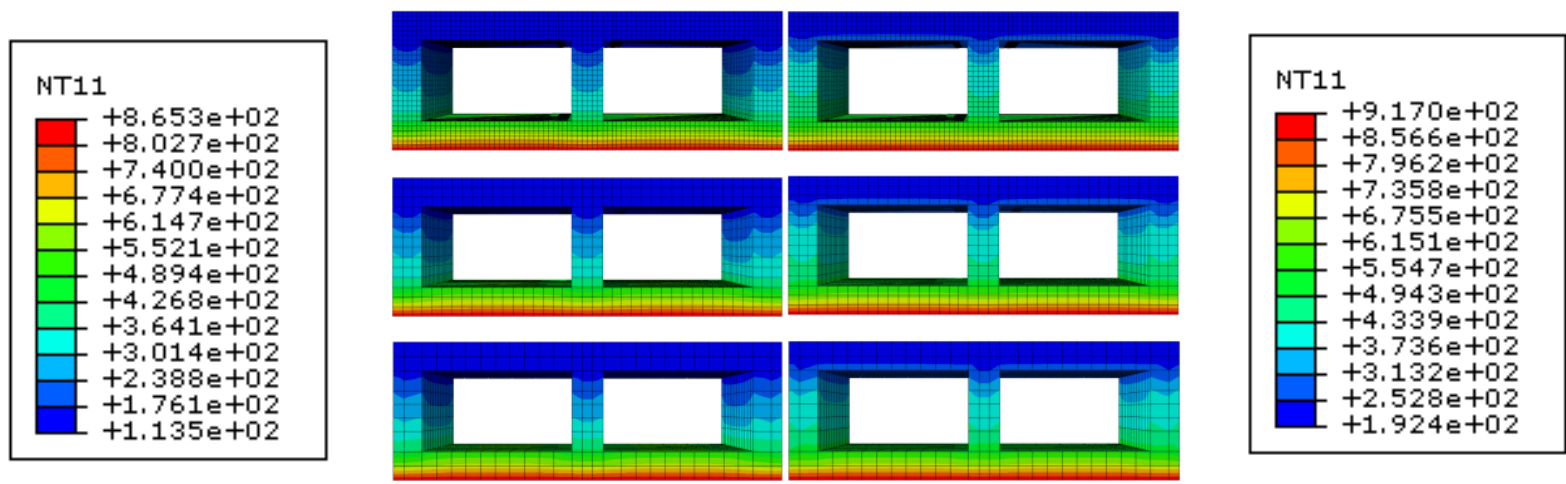

(c)

(d)

Figura 5.17 - Elevação da temperatura em função do tempo para os refinamentos estudados
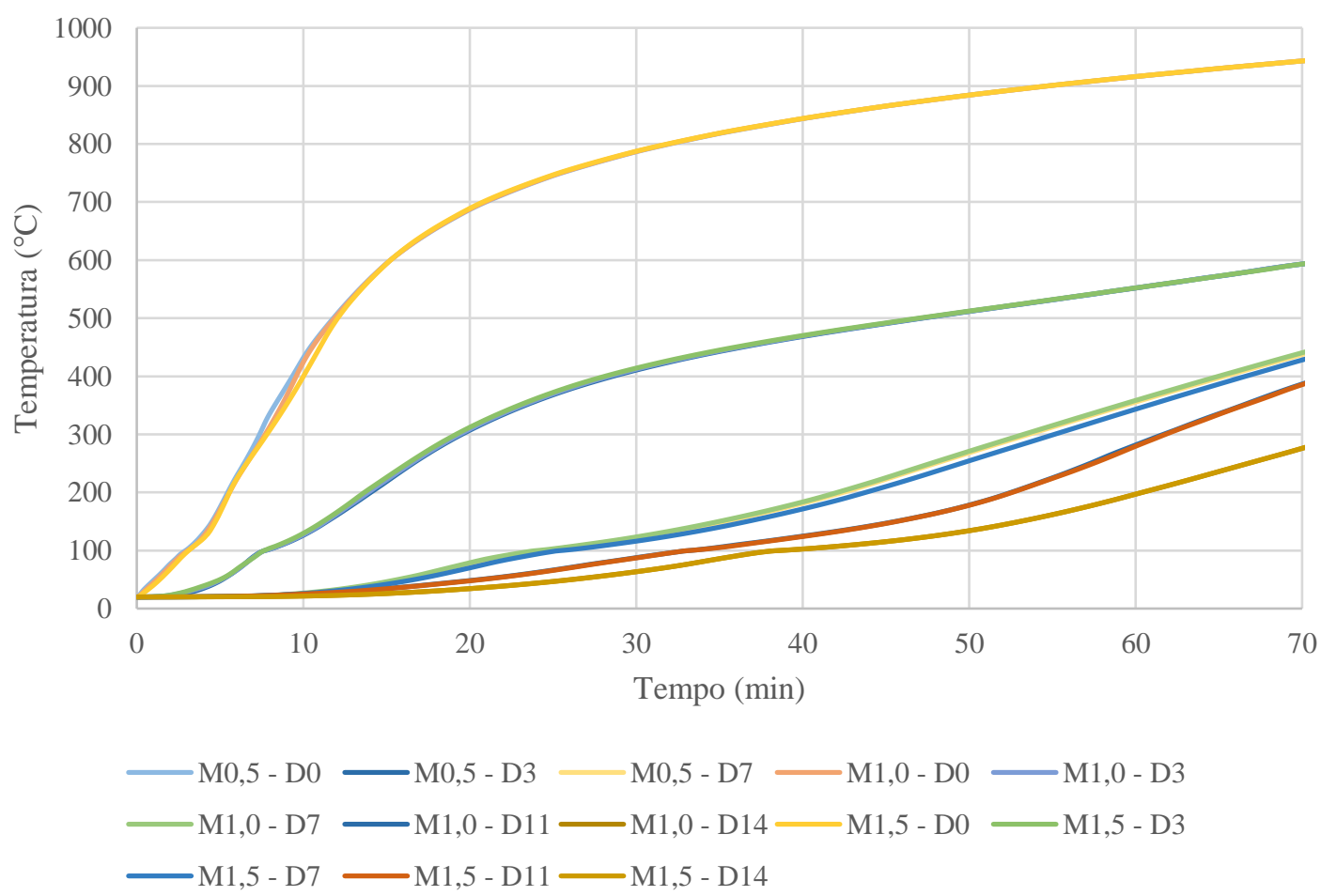


\subsubsection{Quanto à variação de espessura}

Neste tópico foi utilizado o modelo validado no Capítulo 4 através dos resultados experimentais de Dupim (2019) com espessura de $14 \mathrm{~cm}$, alterando a evolução da temperatura na face oposta ao fogo através da desconsideração de confinamento de gases. O modelo inicial teve sua espessura alterada para $19 \mathrm{~cm}$ para a comparação.

As curvas internas de evolução de temperatura (furos) das paredes com blocos de $19 \mathrm{~cm}$ foram obtidas da mesma forma comentada no Capítulo 3, para paredes formadas com blocos de $14 \mathrm{~cm}$ de espessura, a partir de resultados experimentais obtidos por Dupim (2019). As propriedades dos materiais utilizadas foram as mesmas para ambas as espessuras, bem como, o coeficiente de convecção e a emissividade. O Quadro 5.9 indica o resumo das informações deste tópico.

Quadro 5.9 - Resumo das informações para a análise numérica do item 5.2.2

\begin{tabular}{|rl|}
\hline Modelo validado utilizado: & Térmico (Item 4.2.1) \\
\hline Baseado nos resultados experimentais de: & Dupim (2019) \\
\hline Elevação da temperatura na face oposta: & Sem confinamento dos gases \\
\hline No modelo validado: & Espessura de $14 \mathrm{~cm}$ \\
\hline Nesta análise: & Espessura de $19 \mathrm{~cm}$ \\
\hline
\end{tabular}

A Tabela 5.6 indica as temperaturas obtidas para os diferentes pontos de medição, de acordo com o tempo de incêndio. Verifica-se que o tempo de aquecimento da face oposta ao fogo, em 90 minutos, retarda-se em cerca de $120^{\circ} \mathrm{C}$ na comparação entre as espessuras de $14 \mathrm{e}$ $19 \mathrm{~cm}$. Além disso, percebe-se maior retardamento do aumento de temperatura ao longo da espessura, aspecto que se dá em resposta ao aumento da espessura dos septos longitudinais dos blocos, o qual interfere tanto na transferência de calor por condução, que possui maior distância a ser percorrida, quanto na curva interna dos gases no interior dos septos.

Quanto ao critério de isolamento térmico, a Tabela 5.7 resume os dados obtidos numericamente, em que é possível notar que o critério de isolamento térmico é atingido aos 59 minutos para parede com espessura de $14 \mathrm{~cm}$, bem como aos 80 minutos para espessura de 19 $\mathrm{cm}$. Ocorre um ganho de 21 minutos neste critério, considerando o aumento da espessura da parede, de acordo com as considerações numéricas realizadas no Capítulo 3. 
Tabela 5.6 - Temperaturas obtidas ao longo da espessura da parede para diferentes espessuras de blocos de acordo com os tempos de incêndio

$\begin{array}{ccccccc}\begin{array}{c}\text { Tempo de } \\ \text { incêndio } \\ \text { (min) }\end{array} & \begin{array}{c}\text { Espessura } \\ (\mathbf{c m})\end{array} & \begin{array}{c}\text { Face } \\ \text { exposta }\end{array} & \begin{array}{c}\text { Septo interno } \\ \text { exposto }\end{array} & \text { Meio } & \begin{array}{c}\text { Septo interno } \\ \text { oposto }\end{array} & \text { Face } \\ \text { oposta }\end{array}$

Tabela 5.7 - Critério de isolamento térmico obtido numericamente para comparação quanto à variação da espessura, em minutos

\begin{tabular}{|ccccc|} 
& \multicolumn{2}{c}{ Valor médio } & \multicolumn{2}{c|}{ Valor máximo } \\
& $\mathrm{e}=14 \mathrm{~cm}$ & $\mathrm{e}=19 \mathrm{~cm}$ & $\mathrm{e}=14 \mathrm{~cm}$ & $\mathrm{e}=19 \mathrm{~cm}$ \\
\hline Critério I & 59 & 80 & 68 & 91
\end{tabular}

A ABNT NBR 14432:2001 indica que edificações residenciais com altura superior a 30 metros devem apresentar tempo requerido de resistência ao fogo (TRRF) superior a 120 minutos. Para edificações residenciais com altura entre 12 e 23 metros, a mesma norma apresenta o tempo mínimo de 60 minutos. O modelo numérico sinaliza uma proximidade de atendimento para a espessura de $14 \mathrm{~cm}$ e possibilidade de valor superior para a espessura de 19 cm, em relação ao critério de isolamento térmico. No Apêndice $\boldsymbol{A}$ estão indicados alguns valores de TRRF de acordo com a ocupação da edificação. 
A Figura 5.18 indica, de forma comparativa, a evolução de temperatura ao longo do tempo nas distâncias indicadas para as paredes com blocos de $14 \mathrm{~cm}$ de espessura (B14) e para as paredes com blocos de $19 \mathrm{~cm}$ (B19), para as faces externas e internas das paredes. A Figura 5.19 , por sua vez, esquematizam o gradiente de temperatura ao longo da espessura do bloco de $19 \mathrm{~cm}$ de espessura para os tempos de incêndio anteriormente indicados.

Figura 5.18 - Evolução de temperatura em função do tempo para paredes com blocos de 14 e

$19 \mathrm{~cm}$ de espessura
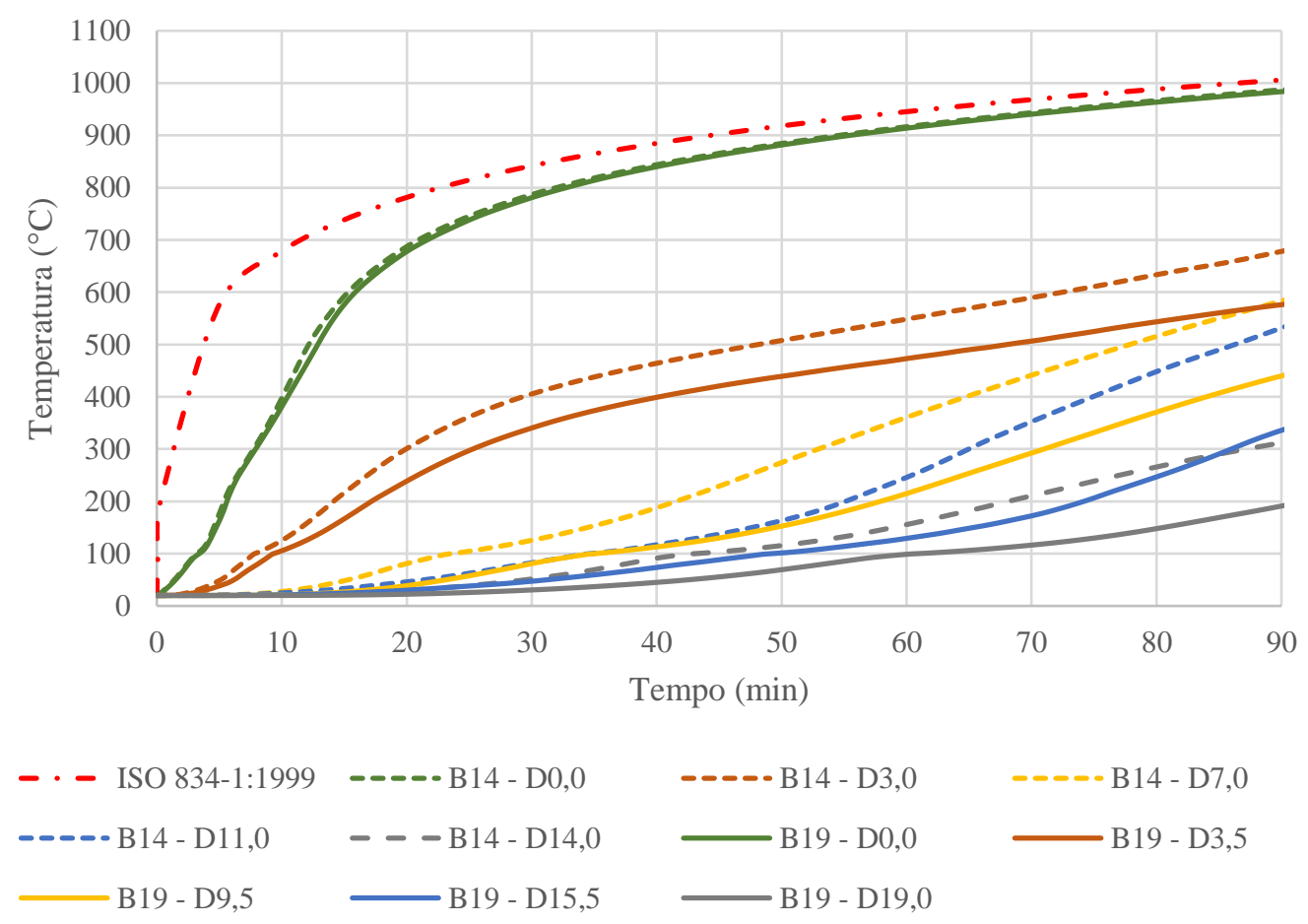

Figura 5.19-I - Temperatura ao longo da espessura para o tempo de 15 minutos (a) para parede com blocos de $19 \mathrm{~cm}$ e uma face exposta ao fogo

(a)

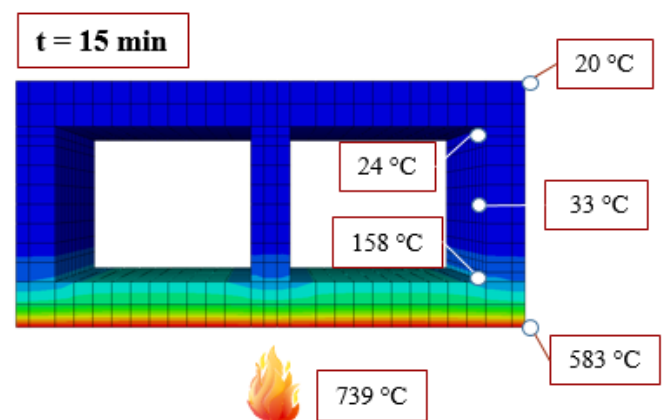


Figura 5.19-II - Temperatura ao longo da espessura para os tempos de 30 (b), 45 (c), 60 (d) e 90 minutos (e) para parede com blocos de $19 \mathrm{~cm}$ de espessura

(b)
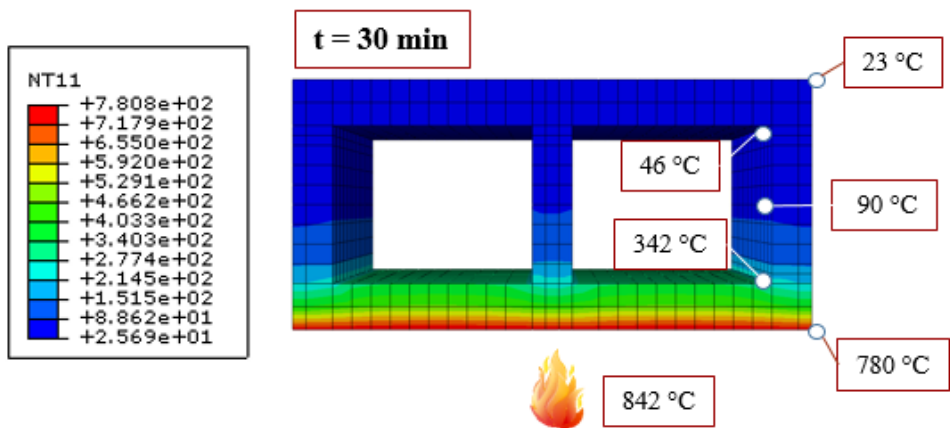

(c)
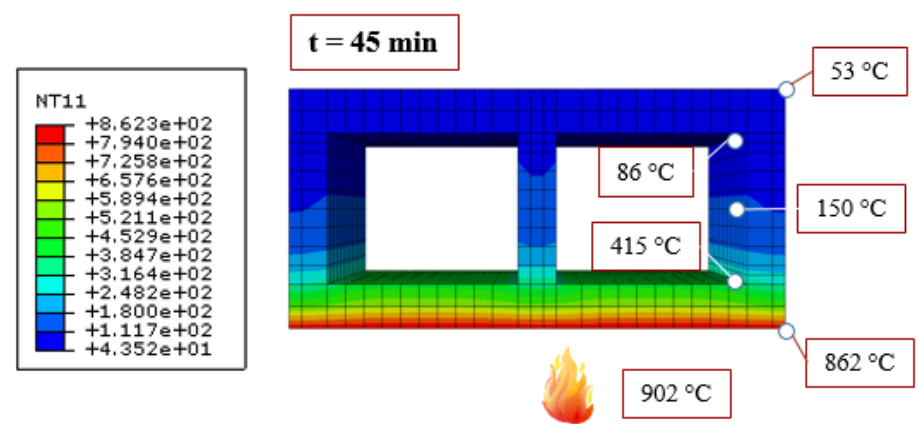

(d)
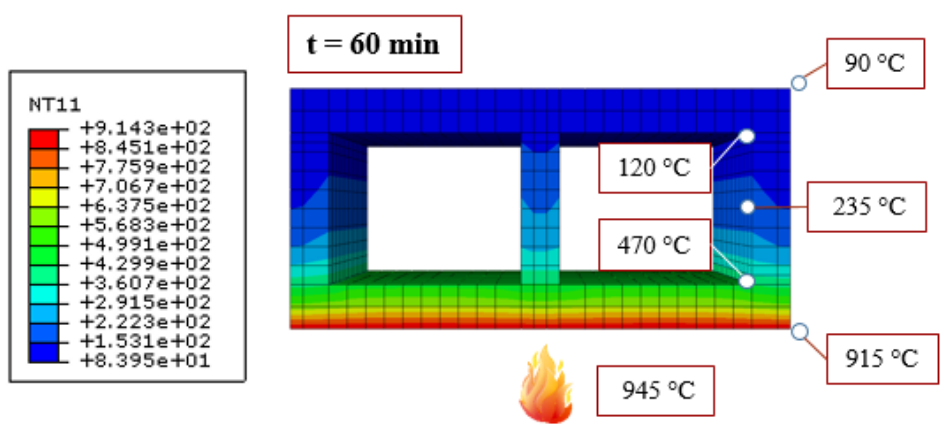

(e)
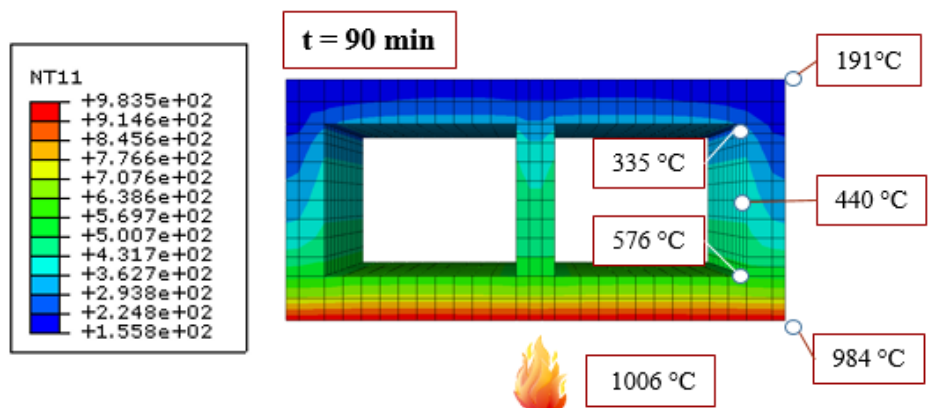

\subsubsection{Quanto às propriedades térmicas}

Neste tópico, para fins de comparação, são utilizados dos parâmetros térmicos existentes no Eurocode 2 e no Eurocode 6, com os parâmetros calibrados neste trabalho e utilizados na validação do Capítulo 4. Para esta análise, foi desconsiderado o confinamento de gases na face 
oposta ao fogo. As curvas e equações do calor específico, condutividade térmica e massa específica estão indicadas no Apêndice D. O Quadro 5.10 indica o resumo das informações deste tópico.

Quadro 5.10 - Resumo das informações para a análise numérica do item 5.2.3

\begin{tabular}{|rl|}
\hline Modelo validado utilizado: & Térmico (Item 4.2.1) \\
\hline Baseado nos resultados experimentais de: & Dupim (2019) \\
\hline Elevação da temperatura na face oposta: & Sem confinamento dos gases \\
\hline No modelo validado: & Curvas calibradas conforme 3.3 .3 \\
\hline Nesta análise: & Curvas do Eurocode 2 e Eurocode 6 \\
\hline
\end{tabular}

A Figura 5.20 indica o comportamento da evolução de temperaturas ao longo da parede com espessura de $14 \mathrm{~cm}$ utilizando os dados fornecidos por cada norma comentada anteriormente. As linhas cheias referem-se ao modelo calibrado, as pontilhadas se referem às curvas do Eurocode 2, enquanto as tracejadas se referem às curvas do Eurocode 6.

Figura 5.20 - Evolução da temperatura em função da espessura da parede de acordo com os tempos de incêndio indicados

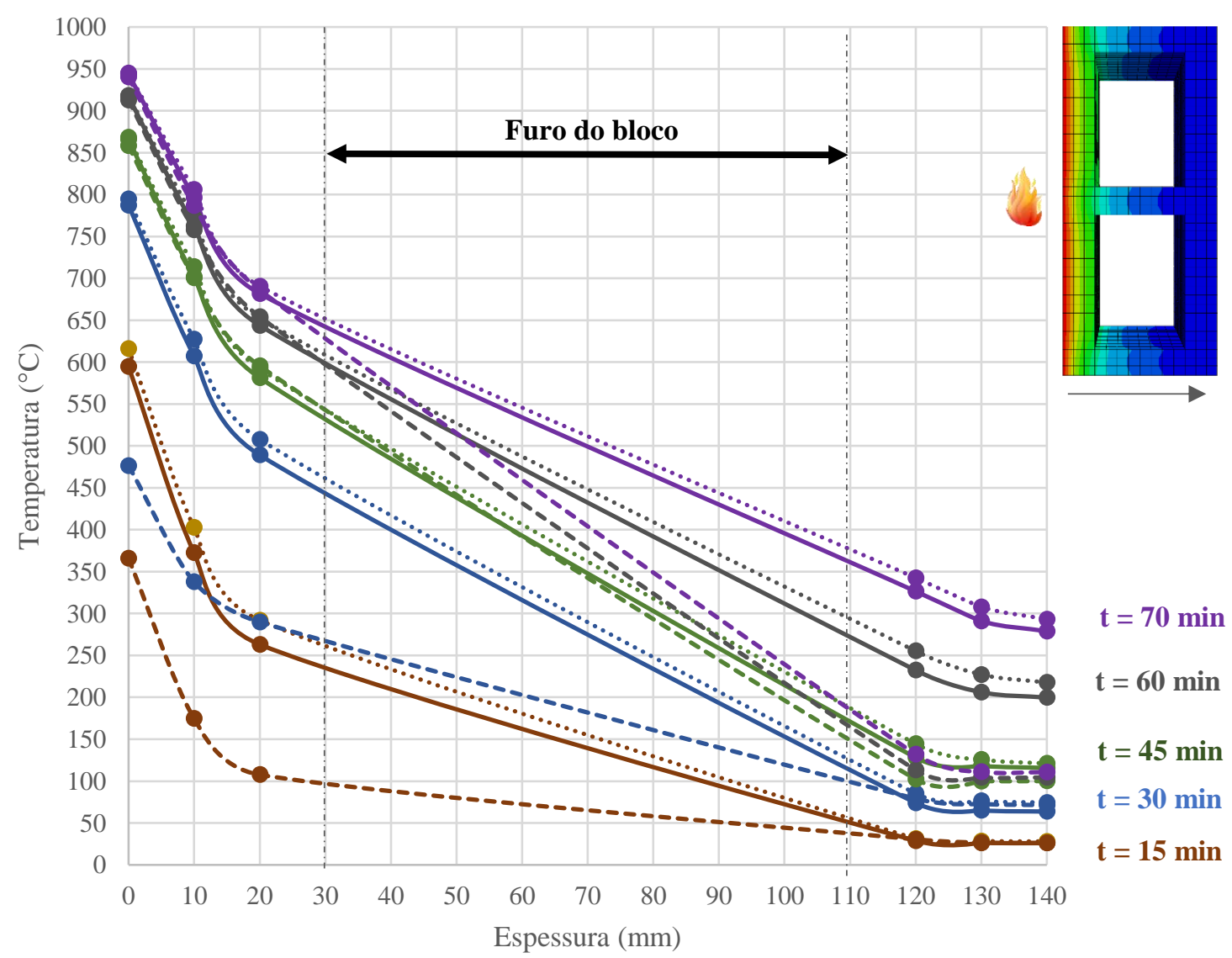


As Figuras 5.21 e 5.22 indicam a evolução da temperatura ao longo do tempo para as espessuras indicadas, em relação ao Eurocode 2 e Eurocode 6, respectivamente.

Figura 5.21 - Evolução da temperatura em função do tempo utilizando o Eurocode 2 e a calibração para os parâmetros térmicos

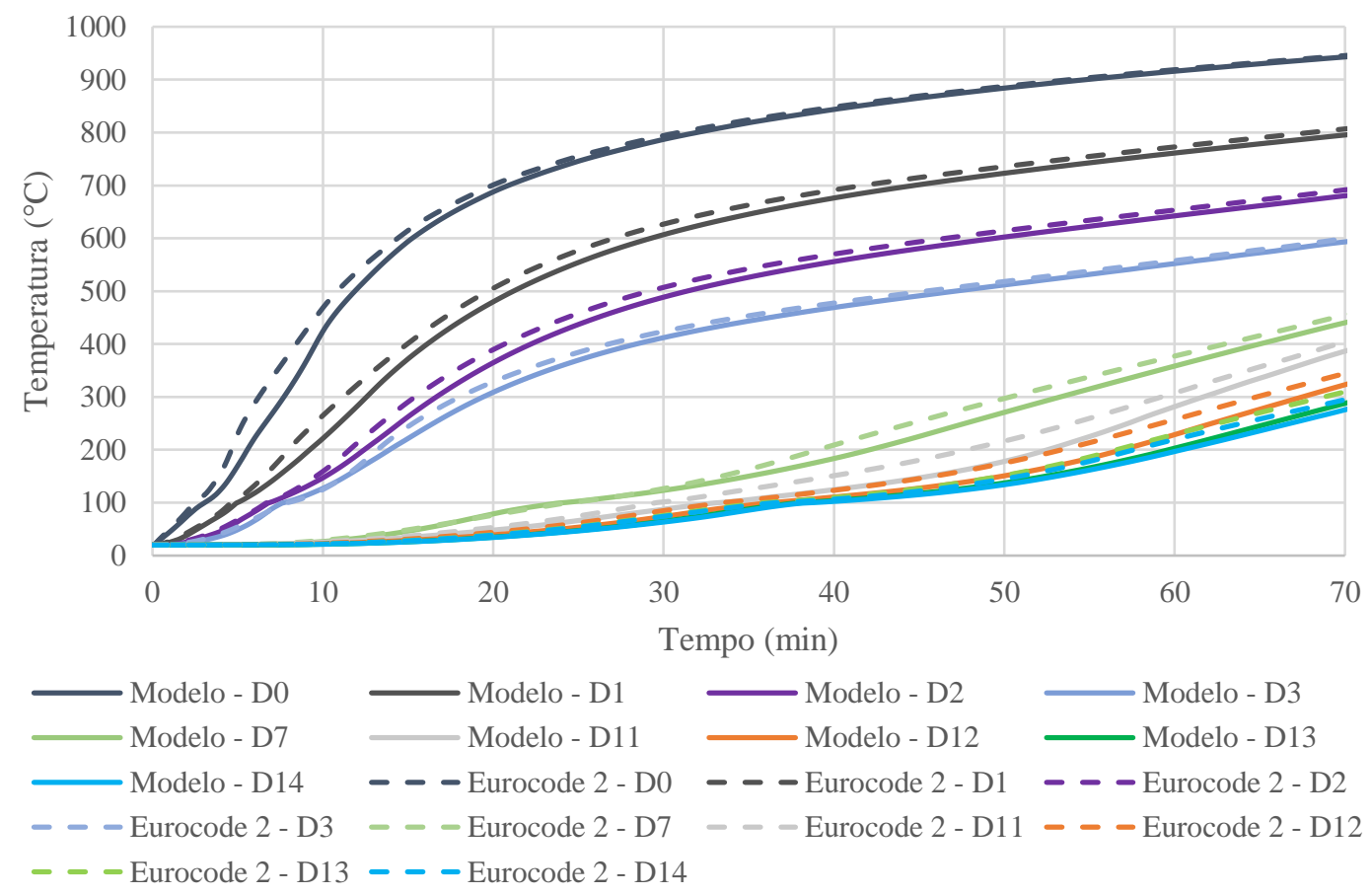

Figura 5.22 - Evolução de temperatura em função do tempo utilizando o Eurocode 6 e a calibração para os parâmetros térmicos

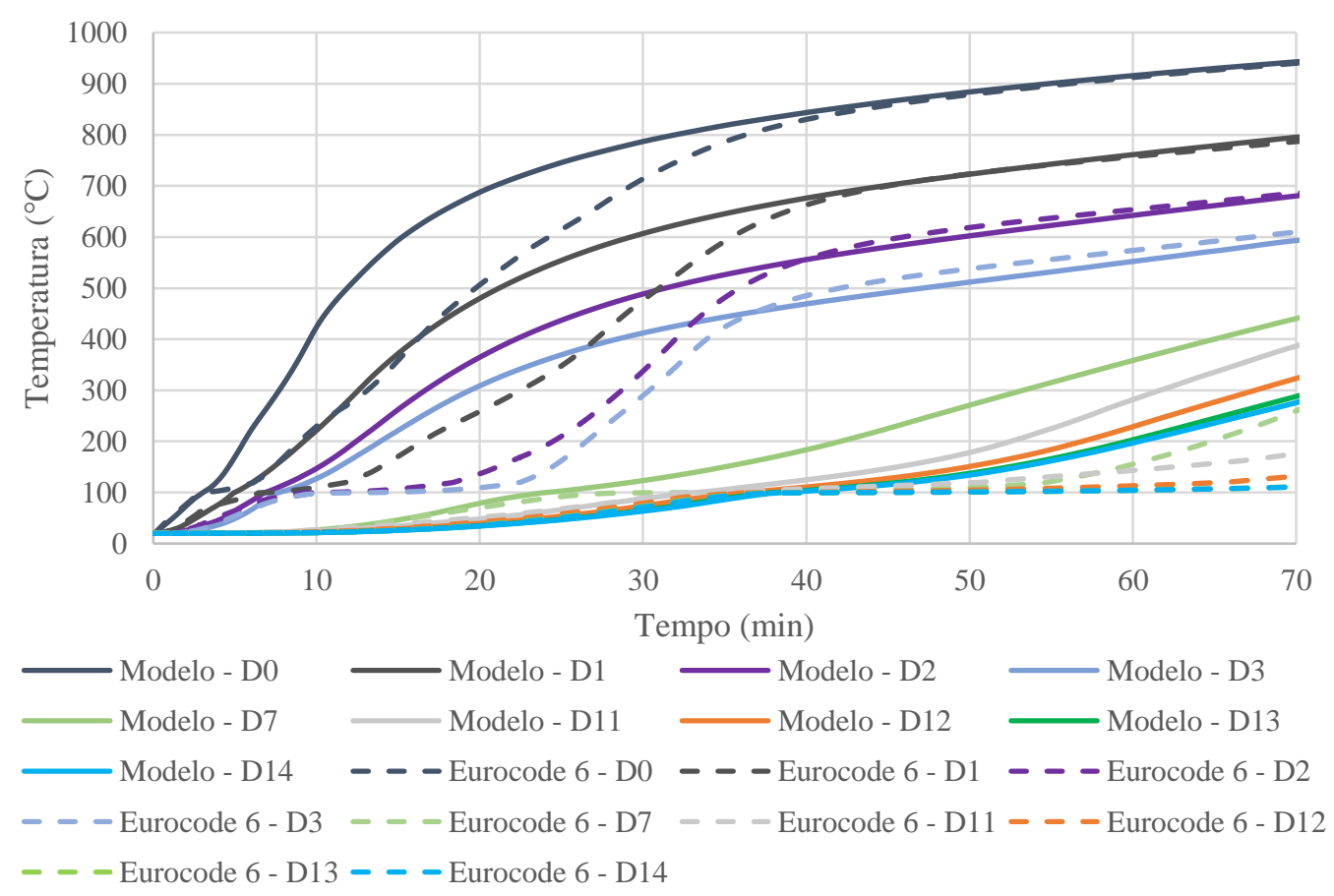


Em relação às curvas do Eurocode 2, a Figura 5.21 mostra que as calibrações se aproximam do seu comportamento. Por outro lado, na Figura 5.22, verifica-se a ocorrência de patamares nas curvas do Eurocode 6, conforme aumenta-se a distância em relação à face exposta ao fogo, aspecto este verificado no trabalho de Dupim (2019) em menor intensidade.

Verifica-se nas curvas provenientes dos parâmetros do Eurocode 6, um elevado atraso para a evolução das temperaturas em função do tempo, aspecto atrelado principalmente ao elevado calor específico a temperatura de $100^{\circ} \mathrm{C}$, a qual é cerca de 11 vezes maior que o valor máximo fornecido pelo Eurocode 2. Este comportamento difere-se rigorosamente do verificado experimentalmente no trabalho de Dupim (2019).

A calibração realizada buscou inserir aumento do pico de calor específico do material aos $100{ }^{\circ} \mathrm{C}$, para que haja consideração do alto valor de umidade dos blocos de concreto, cuja evaporação ocorre nesta temperatura. O Eurocode 2, que trata de elementos de concreto armado considera valores de umidade muito abaixo dos ocorrentes nos blocos de concreto. Em contrapartida, os valores de pico de calor específico do Eurocode 6 são utilizados para materiais que se diferem bastante dos utilizados no Brasil, o que se verifica pela grande divergência com os valores obtidos por Dupim (2019).

Quanto à condutividade térmica, a calibração buscou, de forma semelhante à anterior, basear-se no intervalo próximo a $100{ }^{\circ} \mathrm{C}$ no Eurocode 6 e, posteriormente, no Eurocode 2. Para a massa específica, o uso de valor constante ou com variação de acordo com a temperatura, pouco alterou o comportamento dos materiais, não havendo necessidade de estudo específico. Em relação ao critério de isolamento térmico, a Tabela 5.8 indica os valores obtidos numericamente.

Tabela 5.8 - Critério de isolamento térmico obtido numericamente para comparação quanto às propriedades térmicas, em minutos

\begin{tabular}{ccc} 
& Valor médio & Valor máximo \\
\hline Eurocode 2 & 50 & 58 \\
Eurocode 6 & 84 & 89 \\
\hline Modelo & 52 & 60 \\
\hline
\end{tabular}

Verifica-se mais uma vez que os valores médios são os limitantes para as variações realizadas neste tópico. Conforme esperado, de acordo com os resultados anteriormente analisados, o modelo validado apresenta resultados próximos aos do Eurocode 2 e com maior 
distância para o Eurocode 6, em decorrência do pico elevado de calor específico nas curvas do Eurocode 6, o que retarda a transferência de calor ao longo da seção transversal da parede.

\subsubsection{Temperatura na face oposta}

Neste tópico é estudada a variação da condição de contorno na face oposta ao incêndio, fazendo a comparação do modelo validado no Capítulo 4 , onde foram inseridas curvas de evolução de temperatura para considerar o efeito dos gases confinados no trio de paredes, bem como, a retirada desta consideração.

Neste último caso, a elevação de temperatura na face oposta ao fogo dá-se pela condução de calor ao longo da seção transversal, não havendo influência do meio externo. O Quadro 5.11 indica o resumo das informações deste tópico. A Tabela 5.9, por sua vez, indica a comparação entre as duas situações para os tempos de 15, 30, 45 e 60 minutos, respectivamente.

Quadro 5.11 - Resumo das informações para a análise numérica do item 5.2.4

\begin{tabular}{|rl|}
\hline Modelo validado utilizado: & Térmico (Item 4.2.1) \\
\hline Baseado nos resultados experimentais de: & Dupim (2019) \\
\hline No modelo validado: & $\begin{array}{l}\text { Consideração de confinamento de gases na } \\
\text { face oposta ao fogo }\end{array}$ \\
\hline Nesta análise: & $\begin{array}{l}\text { Desconsideração de confinamento de gases na } \\
\text { face oposta ao fogo }\end{array}$ \\
\hline
\end{tabular}

Verifica-se nos primeiros 60 minutos de incêndio que o septo longitudinal exposto ao fogo não apresenta variação quanto ao aumento de temperaturas devido à mudança da condição de contorno da face oposta. De forma coerente, isto significa que nos trechos iniciais de espessura da parede, a predominância acerca da transferência de calor baseia-se nas temperaturas da face exposta e nas propriedades dos materiais, bem como, os coeficientes de transferência de calor envolvidos. Por outro lado, no septo longitudinal oposto ao fogo, a variação de temperatura passa a ser mais significativa com o aumento do tempo de incêndio.

$\mathrm{Na}$ Tabela 5.10 estão indicados os tempos relativos ao critério de isolamento térmico para as duas situações de elevação de temperatura na face oposta ao incêndio. 
Tabela 5.9 - Temperaturas obtidas ao longo da espessura da parede para diferentes configurações da face oposta ao fogo e diferentes tempos de incêndio

\begin{tabular}{ccccccc}
$\begin{array}{c}\text { Tempo de } \\
\text { incêndio } \\
(\mathbf{m i n})\end{array}$ & Gases - face oposta & 0 & 3 & 7 & 11 & 14 \\
\multirow{3}{*}{$\mathbf{1 5}$} & Com confinamento & 597,5 & 228,7 & 42,5 & 34,5 & 26,1 \\
\cline { 2 - 7 } & Sem confinamento & 597,5 & 228,7 & 42,5 & 34,0 & 25,6 \\
\cline { 2 - 7 } & Diferença & 0,0 & 0,0 & 0,0 & 0,5 & 0,5 \\
\hline \multirow{3}{*}{$\mathbf{3 0}$} & Com confinamento & 788,0 & 414,5 & 116,3 & 87,4 & 68,7 \\
& Sem confinamento & 788,0 & 414,5 & 116,3 & 84,3 & 59,4 \\
\cline { 2 - 7 } & Diferença & 0,0 & 0,0 & 0,0 & 3,1 & 9,3 \\
\hline \multirow{3}{*}{$\mathbf{4 5}$} & Com confinamento & 866,1 & 492,6 & 211,6 & 147,4 & 115,7 \\
\cline { 2 - 7 } & Sem confinamento & 866,1 & 492,6 & 209,8 & 140,0 & 106,2 \\
\cline { 2 - 7 } & Diferença & 0,0 & 0,0 & 1,8 & 7,4 & 9,5 \\
\hline \multirow{2}{*}{$\mathbf{6 0}$} & Com confinamento & 916,6 & 552,8 & 344,8 & 281,6 & 198,4 \\
\cline { 2 - 7 } & Sem confinamento & 916,6 & 552,8 & 342,6 & 256,2 & 165,2 \\
\cline { 2 - 7 } & Diferença & 0,0 & 0,0 & 2,2 & 25,4 & 33,2 \\
\hline
\end{tabular}

Tabela 5.10 - Critério de isolamento térmico obtido numericamente para comparação quanto à variação do confinamento dos gases na face oposta ao fogo, em minutos

\begin{tabular}{ccccc} 
& \multicolumn{2}{c}{ Valor médio } & \multicolumn{2}{c}{ Valor máximo } \\
& Com & Sem & Com & Sem \\
& confinamento & confinamento & confinamento & confinamento \\
\hline Critério I & 52 & 59 & 60 & 68
\end{tabular}

Verifica-se ganho de 7 minutos da consideração sem confinamento na face oposta em relação à condição de contorno considerada no ensaio de Dupim (2019). Este resultado é coerente, uma vez que no ensaio, ocorreu o confinamento de gases no espaço entre o trio de paredes o que eleva a temperatura mais rapidamente na face oposta ao fogo.

É possível considerar que a existência de algum tipo de revestimento interno ou externo possibilite ganho em relação ao critério de isolamento térmico, uma vez que existiria outro material a ser percorrido pelo calor, bem como, resistência térmica de contato entre os materiais, o que retardaria a transferência até a face oposta. Extrapolando para tempos de incêndio maiores, obteve-se a Tabela 5.11 para tempos de incêndio de 120, 180 e 240 minutos. 
Tabela 5.11 - Temperaturas obtidas ao longo da espessura da parede para diferentes configurações da face oposta ao fogo para tempo de incêndio de 120, 180 e 240 minutos

\begin{tabular}{ccccccc}
$\begin{array}{c}\text { Tempo de } \\
\text { incêndio } \\
(\mathbf{m i n})\end{array}$ & $\begin{array}{c}\text { Temperatura inicial } \\
- \text { face oposta }\end{array}$ & 0 & 3 & 7 & 11 & 14 \\
\hline \multirow{2}{*}{$\mathbf{1 2 0}$} & Com confinamento & 1037,9 & 810,7 & 759,3 & 749,9 & 527,7 \\
\cline { 2 - 7 } & Sem confinamento & 1037,5 & 809,1 & 755,6 & 724,7 & 396,0 \\
\cline { 2 - 7 } & Diferença & 0,4 & 0,4 & 3,7 & 25,2 & 131,7 \\
\hline \multirow{2}{*}{$\mathbf{1 8 0}$} & Com confinamento & 1104,7 & 972,6 & 952,5 & 941,1 & 658,8 \\
\cline { 2 - 7 } & Sem confinamento & 1104,3 & 971,9 & 950,5 & 919,4 & 455,2 \\
\cline { 2 - 7 } & Diferença & 0,4 & 0,7 & 2,0 & 21,7 & 203,6 \\
\hline \multirow{2}{*}{$\mathbf{2 4 0}$} & Com confinamento & 1148,8 & 1041,8 & 1025,8 & 1016,3 & 709,4 \\
\cline { 2 - 7 } & Sem confinamento & 1148,8 & 1041,8 & 1024,5 & 996,0 & 472,5 \\
\cline { 2 - 7 } & Diferença & 0,0 & 0,0 & 1,3 & 20,3 & 236,9 \\
\hline
\end{tabular}

A Figura 5.23 indica a evolução de temperatura para as duas situações discutidas neste tópico.

Figura 5.23 - Evolução de temperatura em função do tempo para a variação da condição de contorno na face oposta ao incêndio

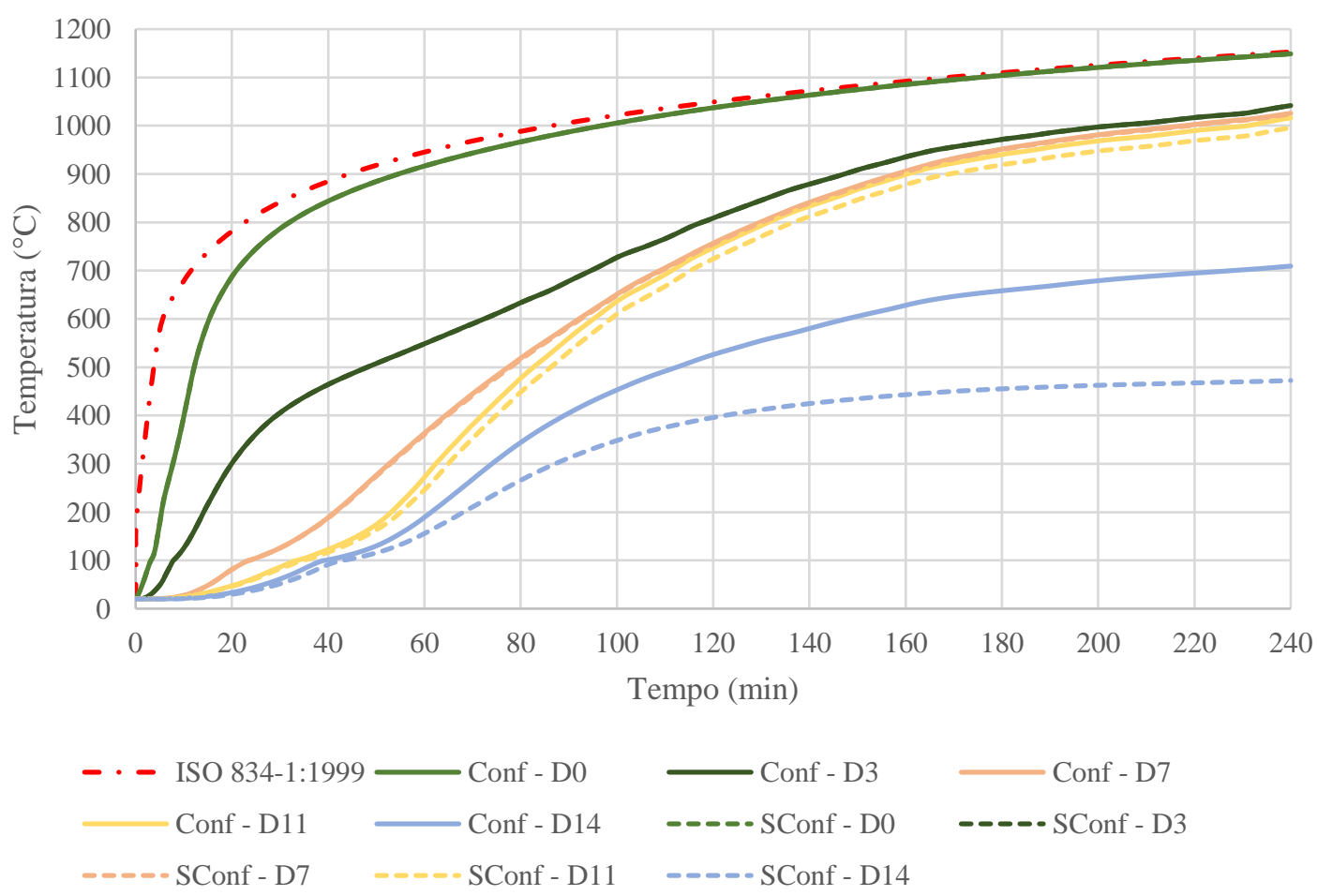


A sigla "Conf" indica a condição de contorno validada no capítulo anterior, conforme Dupim (2019), e a sigla "SConf” indica o não confinamento dos gases na face oposta ao fogo. As referências de distância são as mesmas citada nos demais gráficos.

Conforme verificado anteriormente, a mudança da condição de contorno do lado oposto ao fogo apresenta maior interferência nos resultados nesta mesma face e nos pontos mais próximos a ela. A diferença tende a aumentar conforme aumenta-se o tempo de incêndio, em virtude da condição de confinamento dos gases no caso da curva obtida experimentalmente, onde as temperaturas são maiores. Assim, conforme ocorre o aumento mais rápido da temperatura ambiente junto à face oposta ao fogo, menor é o tempo verificado pelo critério de isolamento térmico.

\subsubsection{Extrapolação dos resultados para tempos de incêndio superiores}

Os resultados obtidos numericamente para o modelo térmico validado no Capítulo 4 foram extrapolados até o tempo de 200 minutos de incêndio, para estudo da tendência das curvas ao longo de tempos de incêndio superiores. O Quadro 5.12 indica o resumo das informações deste tópico.

Quadro 5.12 - Resumo das informações para a análise numérica do item 5.2.5

\begin{tabular}{|rl|}
\hline Modelo validado utilizado: & Térmico (Item 4.2.1 e 4.2.2) \\
\hline Baseado nos resultados experimentais de: & Dupim (2019) \\
\hline Elevação da temperatura na face oposta: & Com confinamento, conforme Dupim (2019) \\
\hline No modelo validado: & Até 70 minutos de incêndio \\
\hline Nesta análise: & Extrapolação até 200 minutos de incêndio \\
\hline
\end{tabular}

A Figura 5.24 indica a evolução de temperatura ao longo do tempo para as paredes validadas conforme item 4.2.1. Da mesma forma, foram extrapolados os resultados obtidos para as paredes com as duas faces expostas ao fogo, de acordo com validação realizada no item 4.2.2, conforme indicado na Figura 5.25.

As linhas tracejadas indicam a extrapolação além do valor experimental. Os valores mostrados nas figuras indicam a respectiva distância em relação à face exposta ao fogo. 
Figura 5.24 - Evolução de temperatura em função do tempo da parede com uma face exposta ao fogo

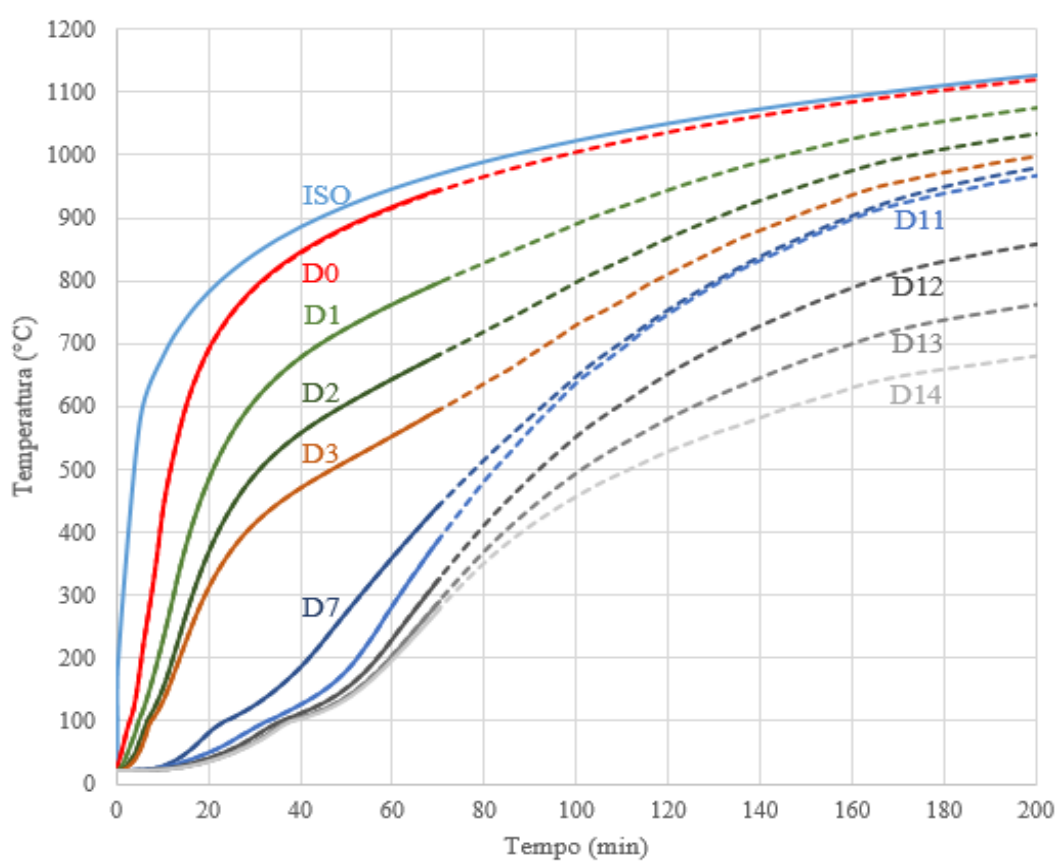

Figura 5.25 - Evolução de temperatura em função do tempo da parede com as duas faces expostas ao fogo

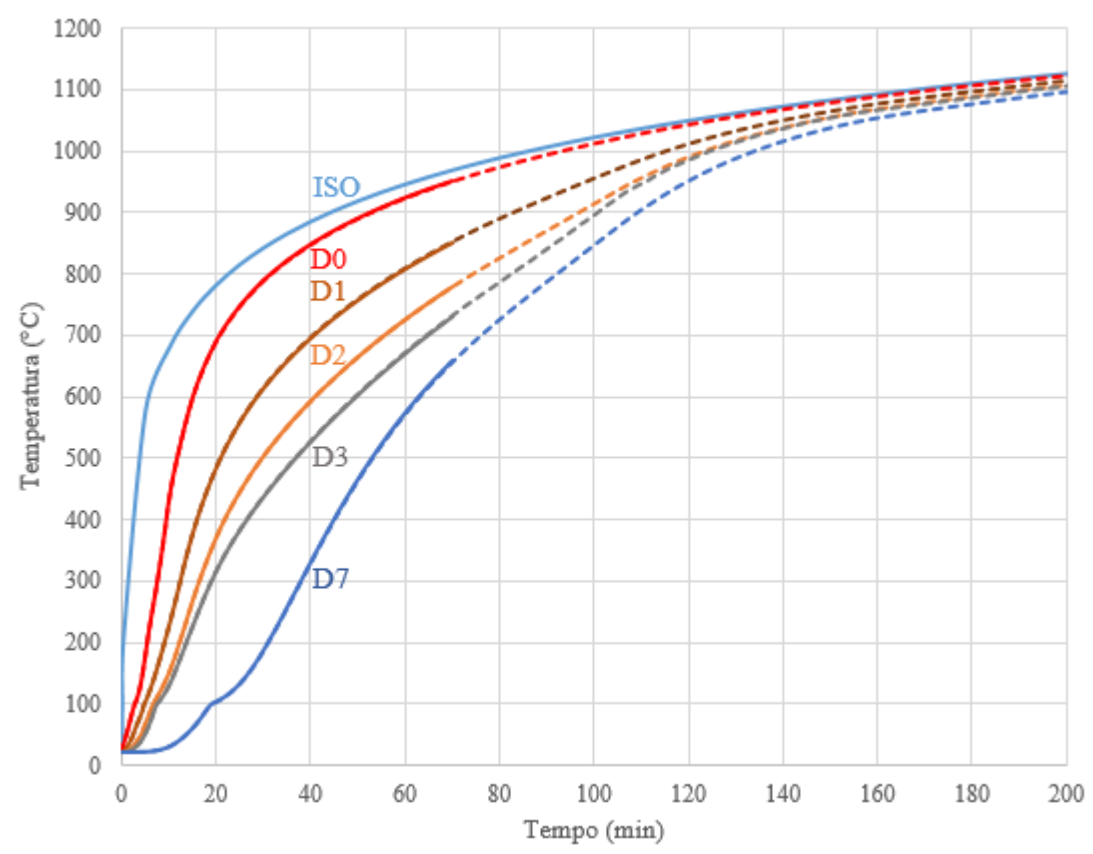

Na Figura 5.26, é mostrada a evolução de temperaturas a cada $0,5 \mathrm{~cm}$ ao longo da espessura da parede com uma face exposta ao fogo, conforme modelo validado no item 4.2.1 baseado nos resultados experimentais de Dupim (2019). 
Figura 5.26 - Evolução de temperatura em função do tempo ao longo da espessura da parede

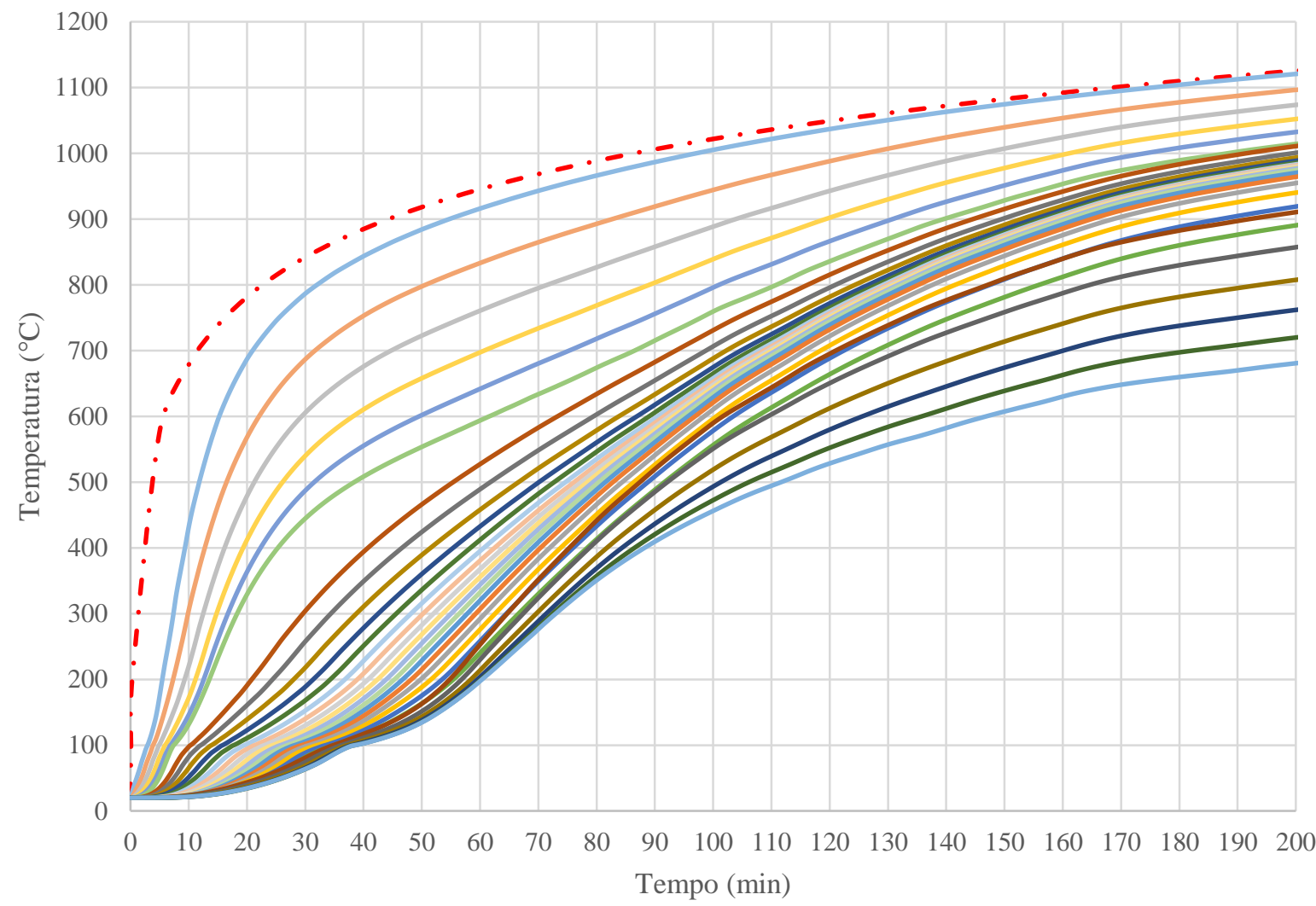

\begin{tabular}{|c|c|c|}
\hline - - ISO 834-1:1999 & D0,0 & $\longrightarrow$ D0,5 \\
\hline D1,5 & D2,0 & $\longrightarrow$ D2,5 \\
\hline - D3,5 & D4,0 & D4,5 \\
\hline D5,5 & $\longrightarrow$ D6,0 & $\longrightarrow$ D6,5 \\
\hline $\mathrm{D} 7,5$ & $\longrightarrow$ D 8,0 & D8,5 \\
\hline —D9,5 & $\longrightarrow$ D 10,0 & D 10,5 \\
\hline -D11,5 & $\longrightarrow \mathrm{D} 12,0$ & $\longrightarrow$ D12,5 \\
\hline 135 & - D14,0 & \\
\hline
\end{tabular}

Observa-se, aos $100{ }^{\circ} \mathrm{C}$, a ocorrência de formação de pequenos patamares, como comentado anteriormente, devido ao pico do calor específico nesta temperatura. Conforme ocorre o aumento da distância em relação à face exposta, aumenta-se a intensidade do patamar aos $100{ }^{\circ} \mathrm{C}$ devido à soma dos efeitos do atraso da elevação de temperatura em virtude do maior calor específico. Após os $200{ }^{\circ} \mathrm{C}$, o calor específico mantém-se constante e a condutividade térmica vai-se reduzindo.

Estas propriedades ficam visíveis a partir dos 90 minutos de incêndio, quando ocorre aquecimento mais lento conforme aumenta-se a distância da face exposta. A Figura 5.27 apresenta os gradientes de temperaturas para a situação com uma face exposta ao fogo até o tempo de incêndio de 240 minutos, conforme modelo validado a partir dos resultados experimentais de Dupim (2019). 
Figura 5.27-I - Temperatura ao longo da espessura para os tempos de exposição iguais a 15 (a), 30 (b), 60 (c) e 120 minutos (d) para parede com uma face exposta ao fogo

(a)
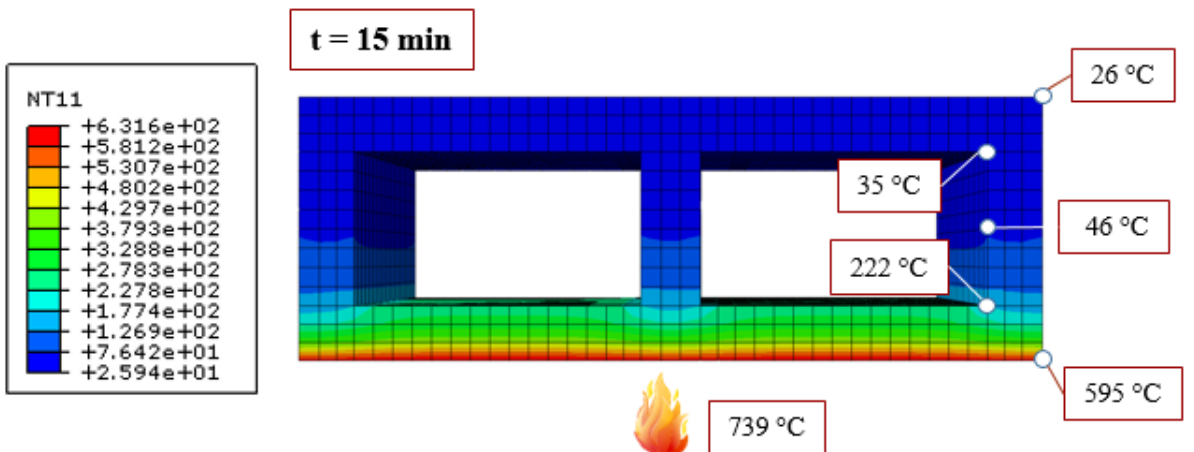

(b)
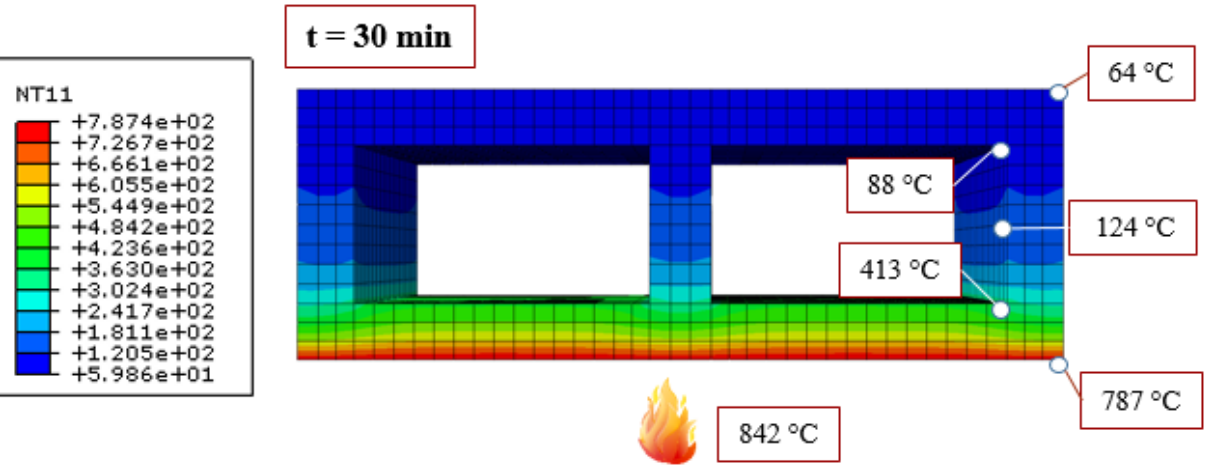

(c)

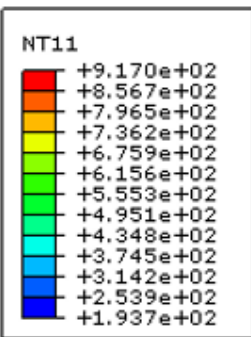

$$
t=60 \mathrm{~min}
$$

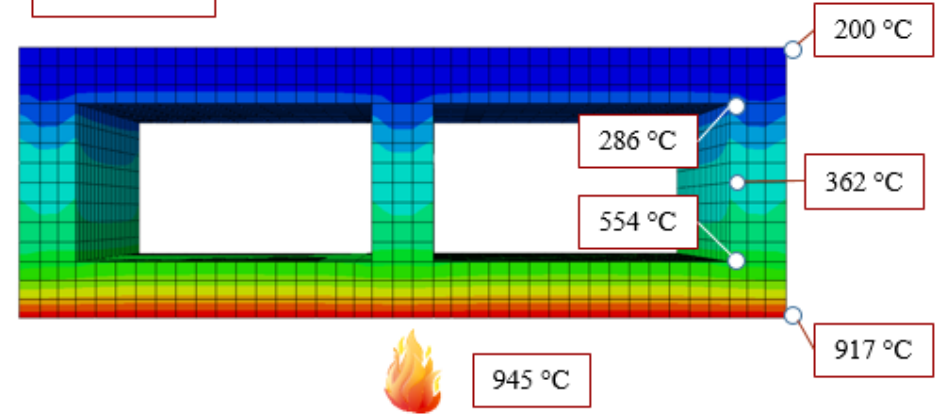

(d)

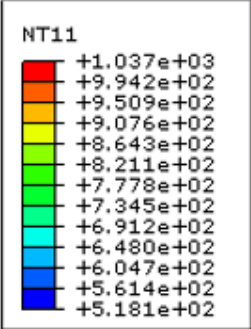

$$
\mathbf{t}=120 \mathrm{~min}
$$

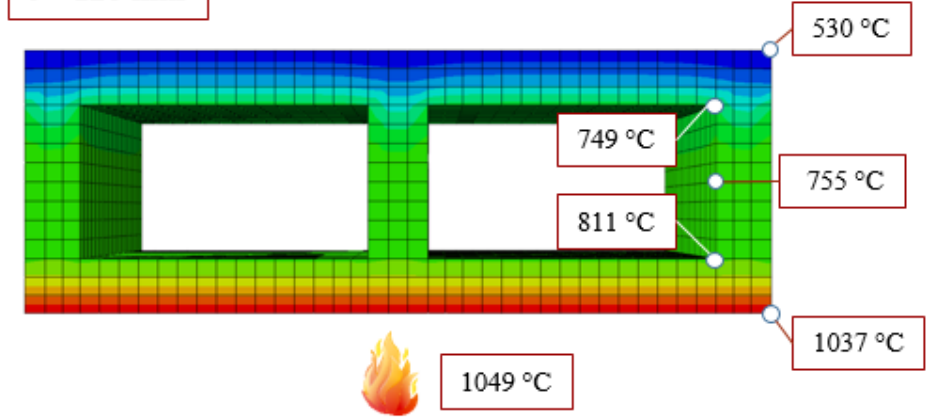


Figura 5.27-II - Temperatura ao longo da espessura para os tempos de 180 (e) e 240 minutos (f) para parede com uma face exposta ao fogo

(e)
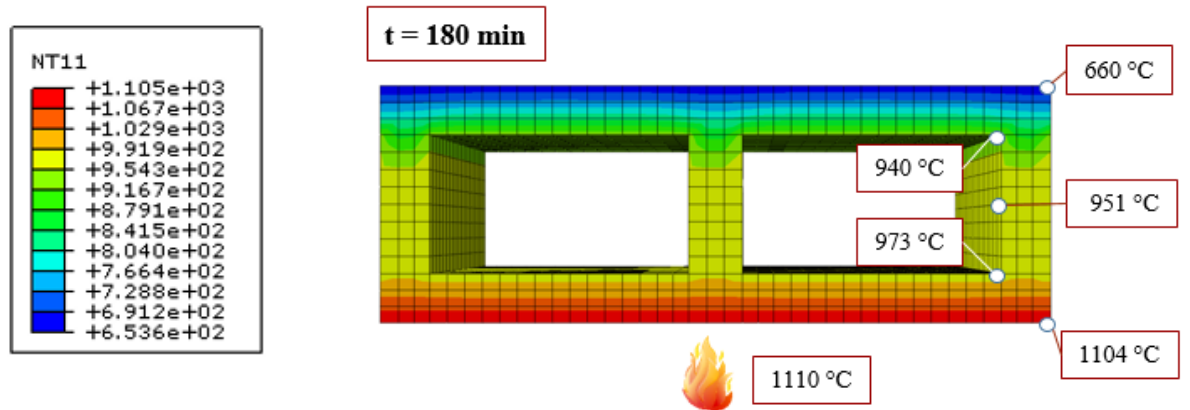

(f)
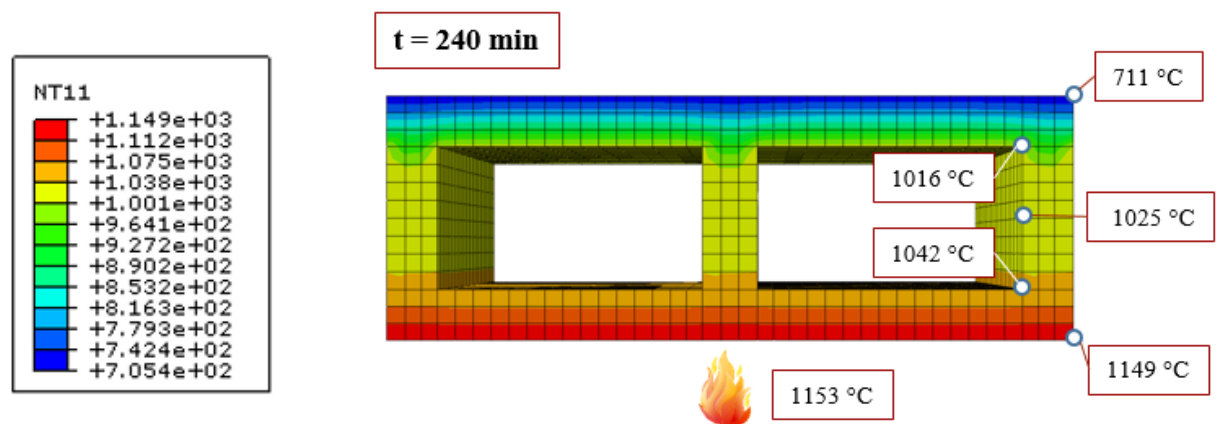

A Figura 5.28 indica a evolução de temperaturas a cada $1,0 \mathrm{~cm}$ para a parede com as duas faces expostas ao fogo, conforme modelo validado no item 4.2.2. É possível verificar a ocorrência de pequenos patamares conforme ocorre o aumento da distância dos pontos da face exposta ao fogo, porém, em menor intensidade que no caso anterior, devido à ocorrência de fogo nas duas faces.

Figura 5.28 - Evolução de temperatura em função do tempo ao longo da espessura da parede

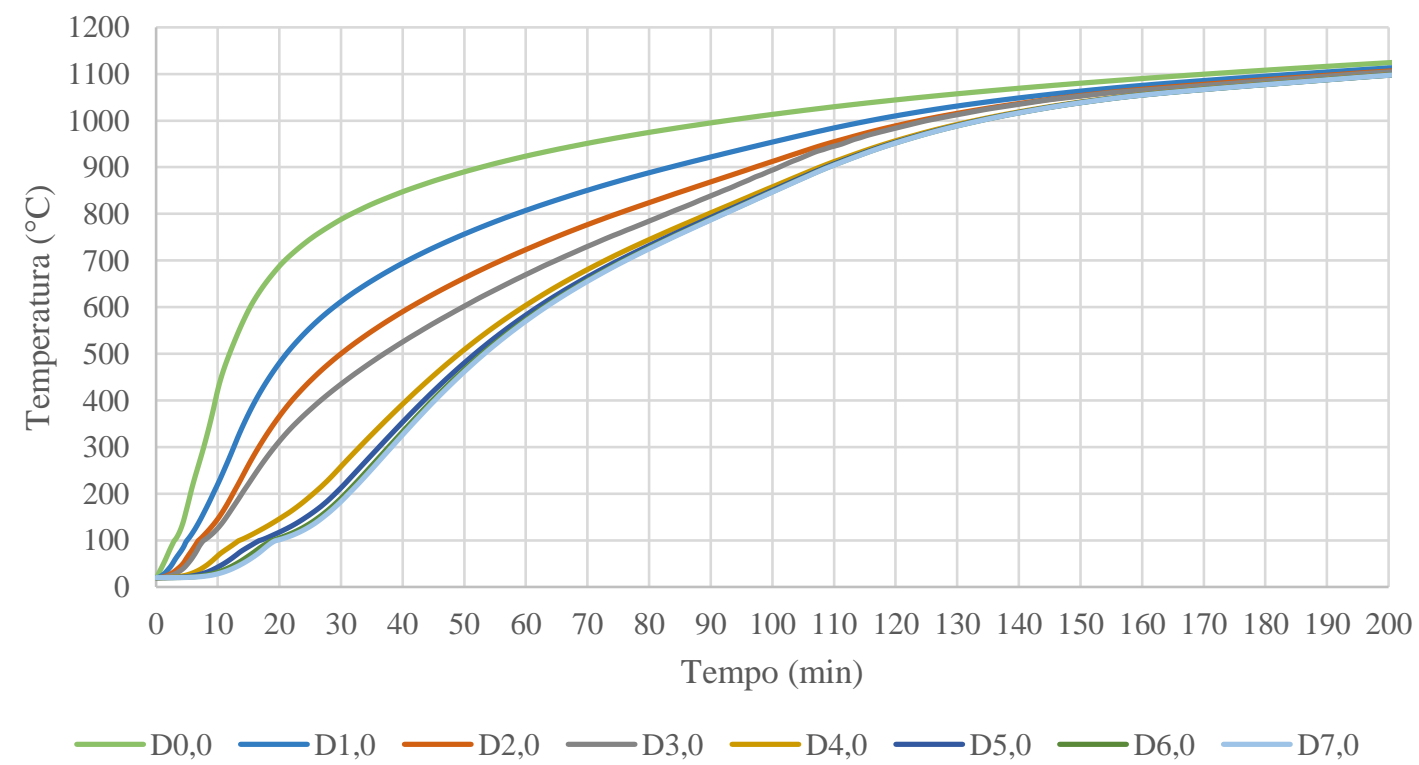


A Figura 5.29 indica o gradiente de temperaturas para a situação com as duas faces expostas ao fogo até o tempo de incêndio de 240 minutos.

Figura 5.29-I - Temperatura ao longo da espessura para os tempos de 15 (a), 30 (b), 60 (c) e 120 (d) minutos para parede com duas faces expostas ao fogo

(a)

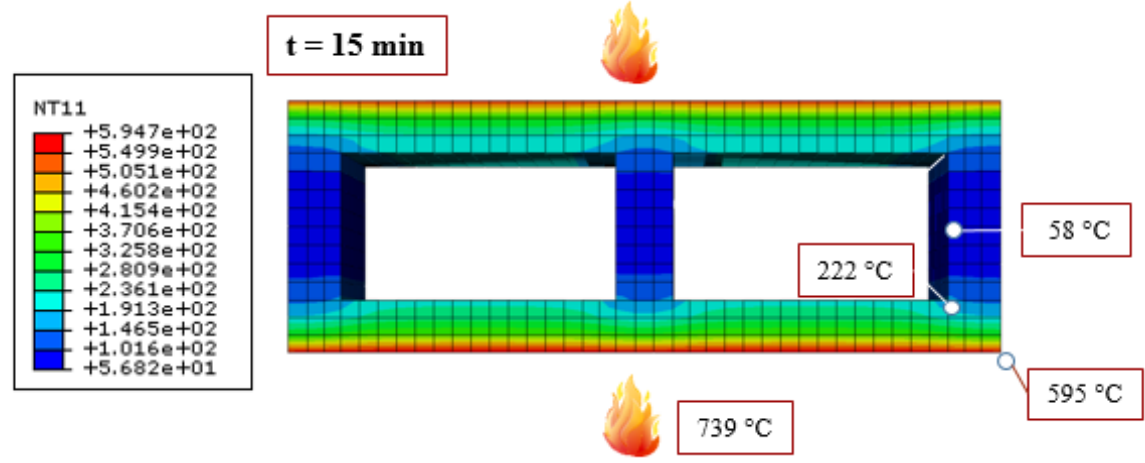

(b)

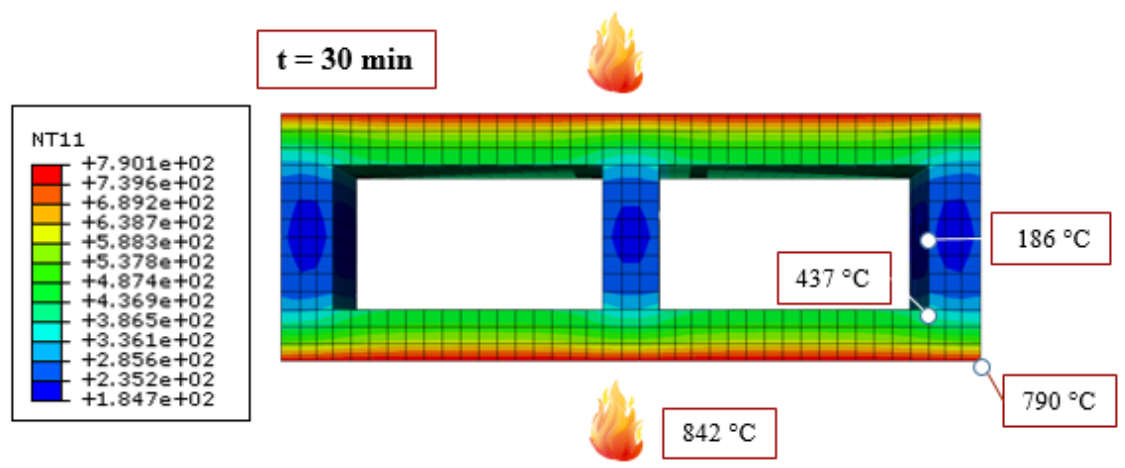

(c)

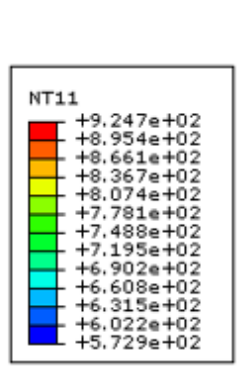

$$
t=60 \mathrm{~min}
$$

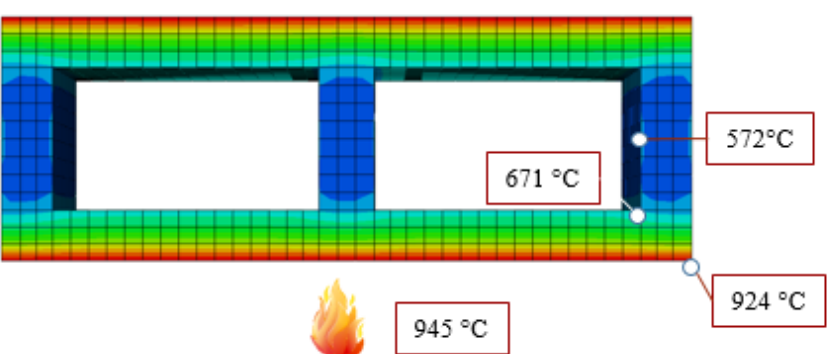

$945^{\circ} \mathrm{C}$

$$
t=120 \mathrm{~min}
$$

(d)

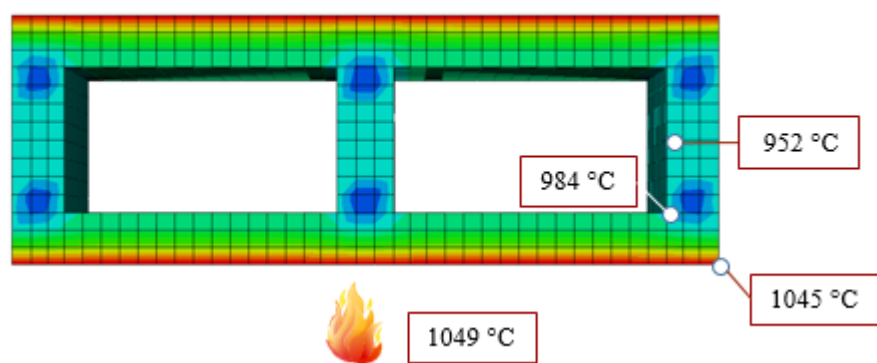


Figura 5.29-II - Temperatura ao longo da espessura para os tempos de 180 (e) e 240 (f) minutos para parede com duas faces expostas ao fogo

(e)

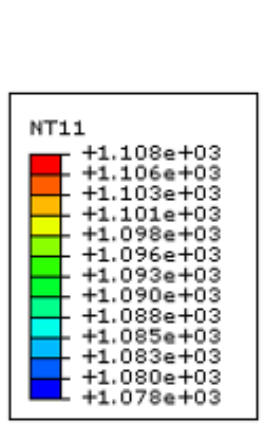

$$
\mathrm{t}=180 \mathrm{~min}
$$

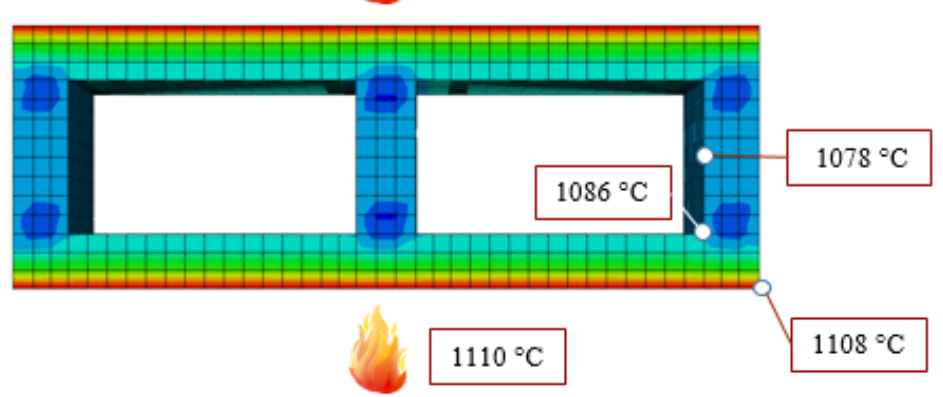

(f)

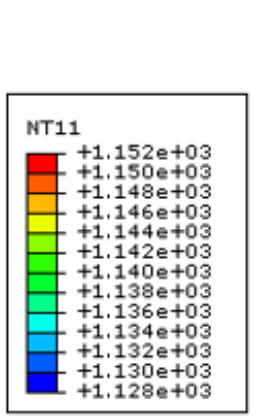

$$
\mathrm{t}=240 \mathrm{~min}
$$

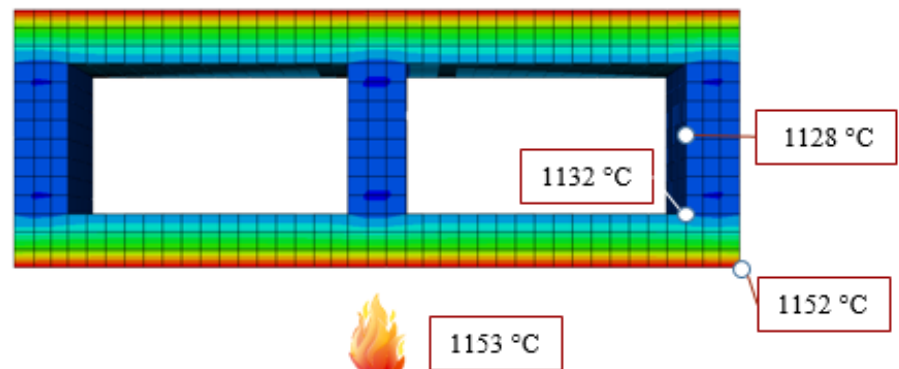

\subsection{ANÁLISES REFERENTES AO MODELO TERMOESTRUTURAL}

\subsubsection{Condições de contorno}

Para análise quanto às condições de contorno, foram utilizadas das restrições superior e inferior indicadas no Capítulo 3, as quais são as mesmas analisadas para o modelo experimental de Lopes et al. (2018), mostrados na Figura 3.27 e Quadro 3.5, não sendo considerado o confinamento de gases na face não exposta. O Quadro 5.13 indica o resumo das informações deste tópico.

Quadro 5.13 - Resumo das informações para a análise numérica do item 5.3.1

\begin{tabular}{|rl|}
\hline Modelo analisado: & Termoestrutural (Item 4.3) \\
\hline Elevação da temperatura na face oposta: & Sem confinamento dos gases \\
& Comparação das condições de contorno CC1, \\
Nesta análise: & CC2 e CC3 para carregamento de $40 \%$ da \\
& carga última \\
\hline
\end{tabular}


Pelo motivo comentado anteriormente sobre as informações existentes das propriedades dos materiais em elevadas temperaturas, as comparações deste item se referem ao carregamento de $40 \%$ do carregamento máximo obtido no modelo estrutural, no qual a ACI/TMS 216.1-14 indica os coeficientes de redução da resistência.

O tempo de resistência ao fogo quanto ao critério de resistência mecânica, neste trabalho, foi considerado até o ponto de maior deformação axial, uma vez que não existe normatização vigente referente ao tema. Até este ponto, a estrutura deforma-se contrariamente à força imposta devido aos efeitos da expansão térmica, em virtude da elevação da temperatura do material. Ao igualar-se os efeitos térmicos e devido ao carregamento imposto, ocorre a inversão da deformação na estrutura, passando a ser preponderante os efeitos do carregamento.

Entende-se que é possível que a estrutura possua integridade suficiente para suportar o carregamento por maior tempo, considerando a existência de resistência residual, mesmo no trecho descendente da deformação. Porém, de forma conservadora e em virtude da inexistência de experimentos neste tema, opta-se neste trabalho por definir o ponto de pico das deformações axiais como o tempo respectivo de resistência ao fogo.

A Figura 5.30 indica a deformação ocorrente nos modelos para as três condições de contorno. Todas as deformações axiais indicadas nos gráficos deste item foram obtidas a partir do ponto central da superfície superior do bloco locado na interface com a placa superior.

Figura 5.30 - Deformação axial em função do tempo de incêndio para as condições de contorno avaliadas

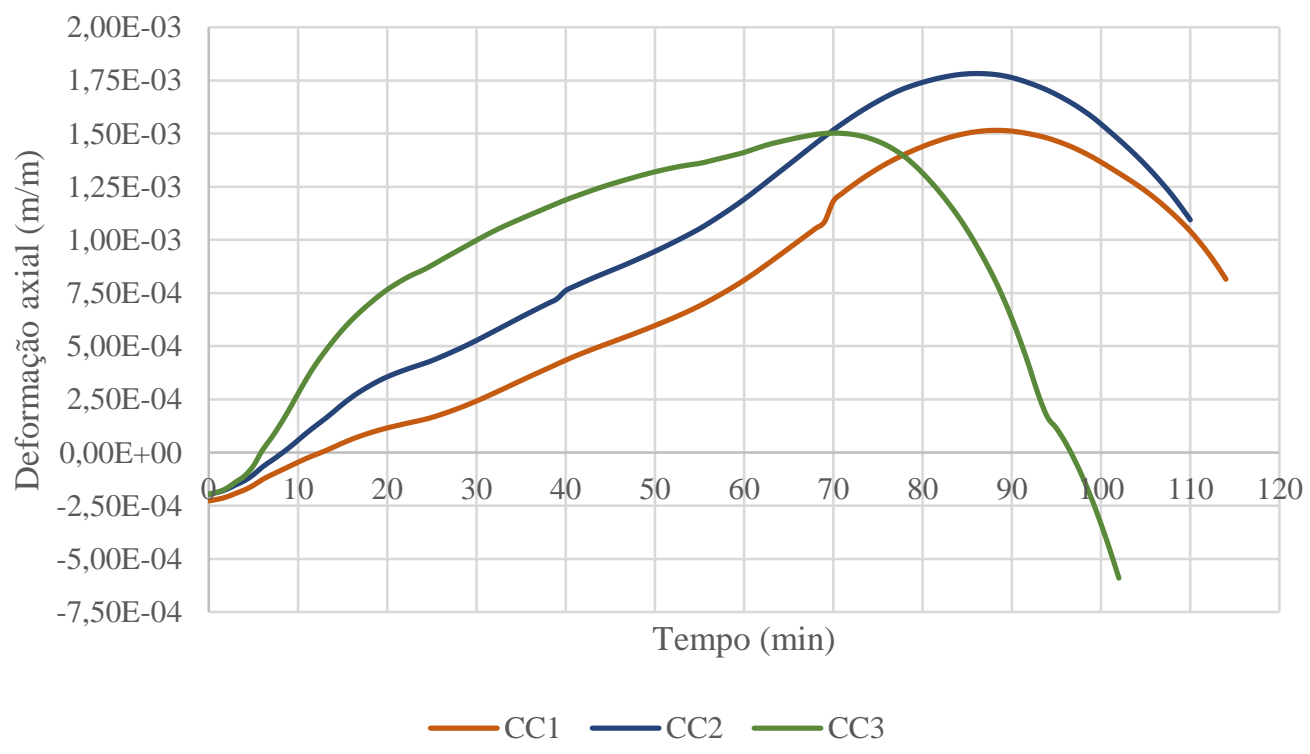

A Tabela 5.12 indica os valores máximos de deformação verificados numericamente, bem como seu respectivo tempo de incêndio. 
Tabela 5.12 - Deformações máximas e respectivos tempos quanto ao critério de resistência mecânica para as três condições de contorno

\begin{tabular}{ccc} 
Condição de contorno & Deformação máxima $(\mathbf{m} / \mathbf{m})$ & $\begin{array}{c}\text { Critério de resistência } \\
\text { mecânica (min) }\end{array}$ \\
\hline CC1 & 0,001515 & 88 \\
\hline CC2 & 0,001782 & 86 \\
\hline CC3 & 0,001502 & 70 \\
\hline
\end{tabular}

Verifica-se maior tempo quanto ao critério de resistência mecânica para a condição de contorno CC1. De fato, a maior quantidade de restrições quanto aos graus de liberdade provoca uma redução do deslocamento lateral em virtude do travamento dos giros superior e inferior, reduzindo a curvatura da parede. Possivelmente, ocorre também a redução das tensões de tração nos blocos, aumentando, assim, o tempo de resistência ao fogo até a inversão das deformações.

Sem restrição ao giro, primeiramente na superfície superior $(\mathrm{CC} 2)$ e, posteriormente, também na superfície inferior (CC3), há redução do tempo de incêndio até o pico de deformações, devido à maior curvatura ocorrente na estrutura o que gera maiores tensões de tração na parede, e, possivelmente, acelera a deterioração dos materiais.

Vale lembrar que pelo critério de isolamento térmico o tempo obtido foi de 59 minutos. Logo, sinaliza-se como valor limitante para o tempo de resistência ao fogo, este valor.

A Figura 5.31 indica o gradiente de temperaturas para os respectivos tempos de incêndio analisados para as situações deste tópico.

Figura 5.31 - Distribuição de temperatura aos 25 (a), 50 (b), 75 (c) e 100 minutos (d)
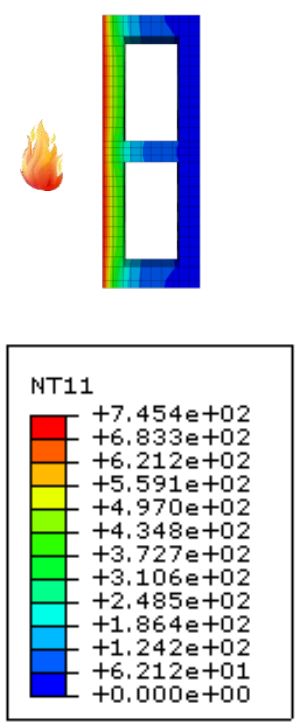

(a)
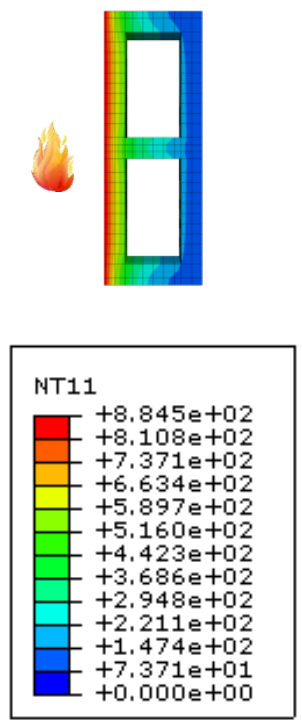
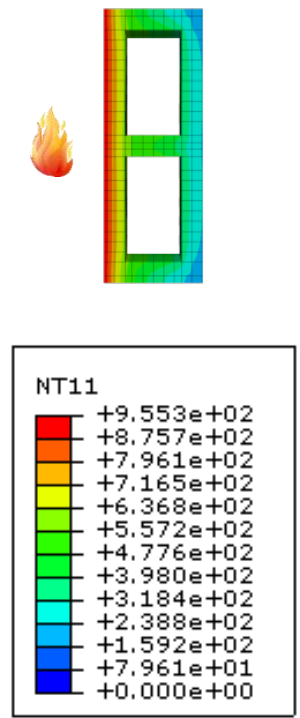

(c)
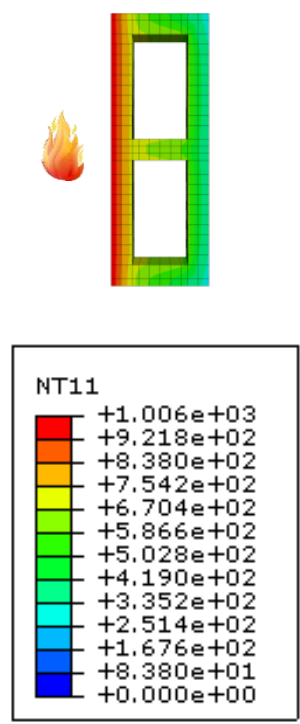

(b)

(b) (d) 
A Figura 5.32 indica a deformada dos modelos para cada condição de contorno estudada, estando a distribuição de temperatura de acordo com a Figura 5.31.

Figura 5.32 - Deformada para as condições de contorno CC1 (1), CC2 (2) e CC3 (3) para os tempos de 25 (a), 50 (b), 75 (c) e 100 minutos (d) de incêndio

(1)
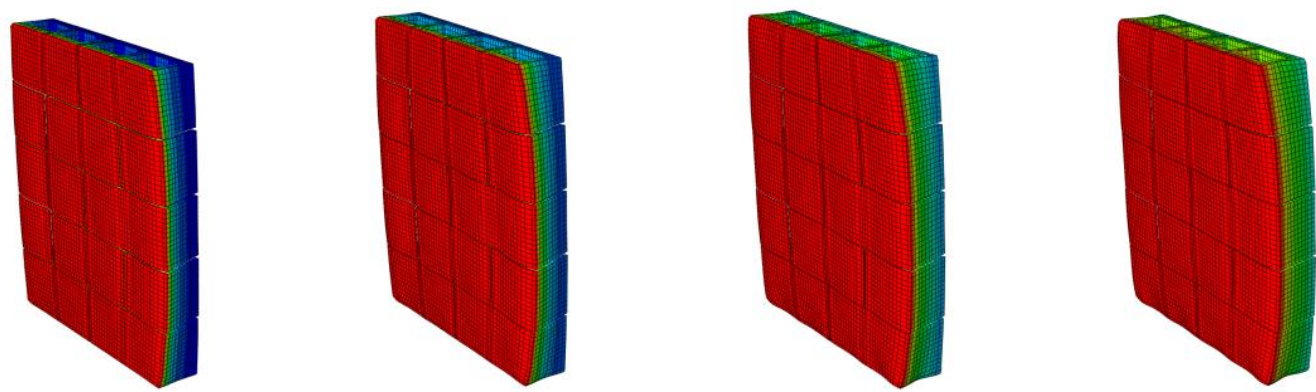

(2)
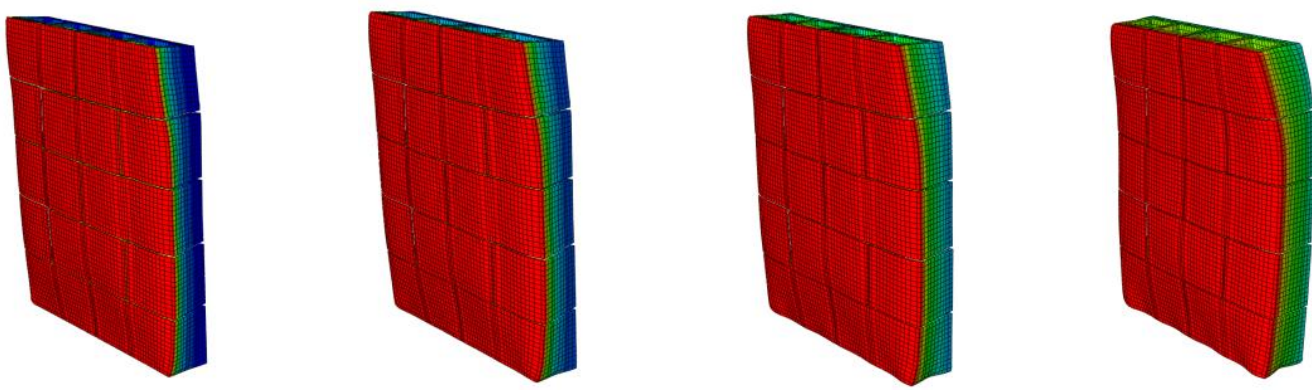

(3)

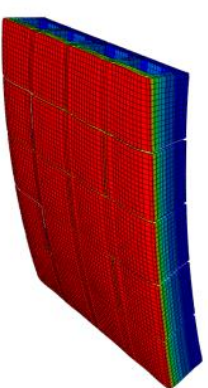

(a)

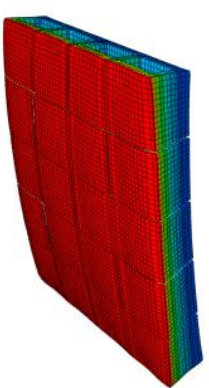

(b)

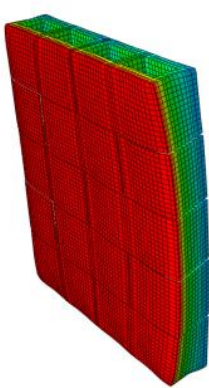

(c)

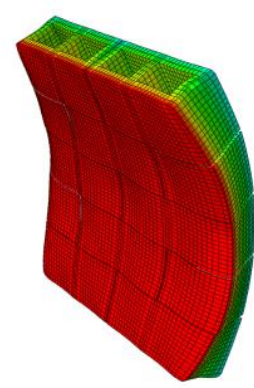

(d)

Obs.: Cores relativas à temperatura; deformadas majoradas.

Verifica-se nas condições de contorno CC2 e CC3 a inversão da curvatura da parede após determinado tempo de incêndio, conforme verificado por Nadjai et al. (2003). Inicialmente, a parede curva-se para a direção do incêndio e, conforme ocorre a perda das propriedades dos materiais, ocorre a inversão desta curvatura.

Em relação à seção transversal da parede, a Figura 5.33 indica a variação da deformação axial ao longo do tempo em relação às três condições de contorno estudadas. 
Figura 5.33 - Deformação axial em função do tempo para as condições de contorno CC1 (a), CC2 (b) e CC3 (c) de acordo com a distância em relação à face exposta ao fogo

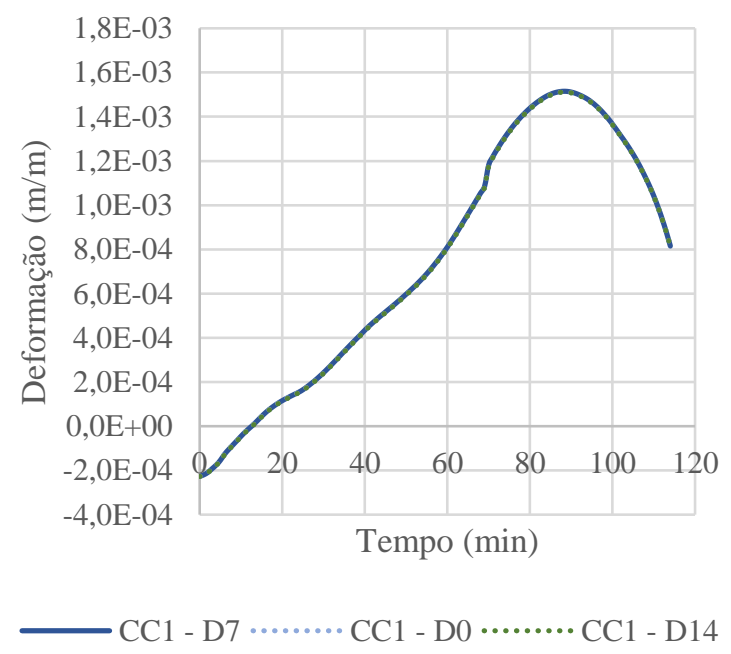

(a)

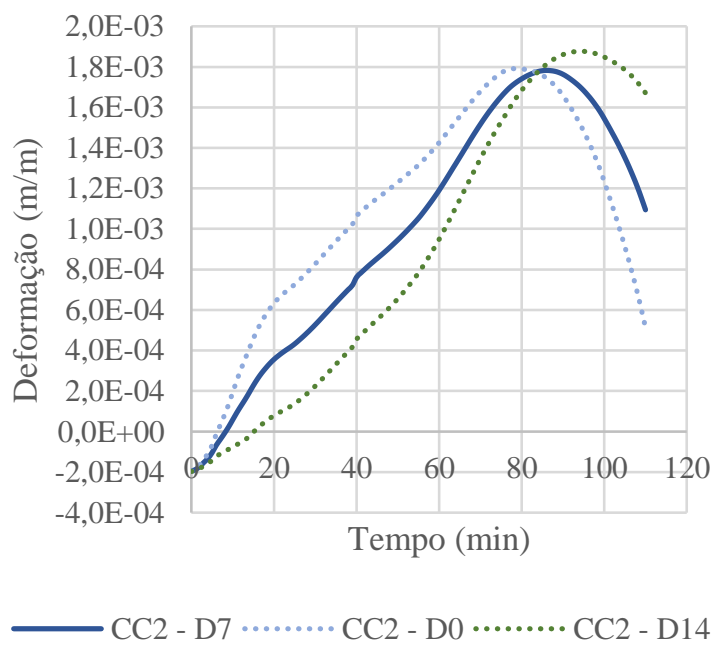

(b)

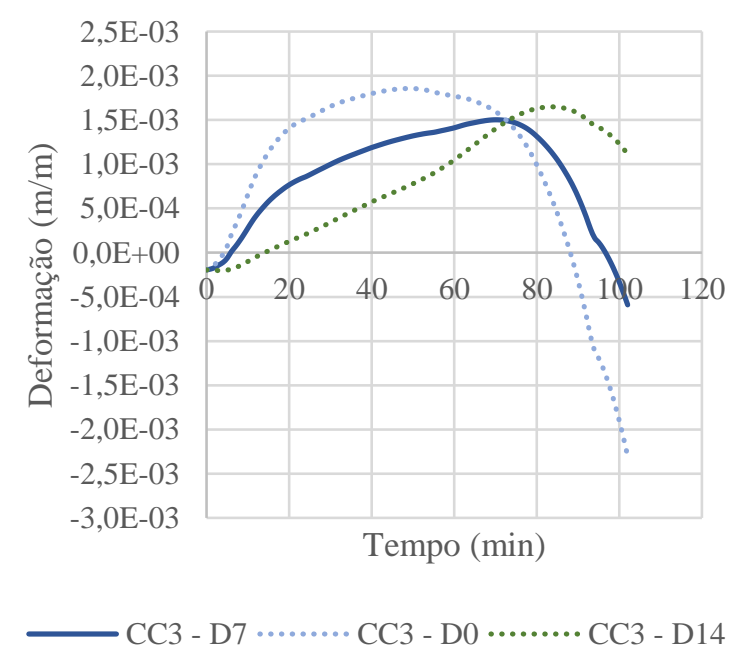

(c)

No caso da Figura 5.33 (a), em virtude do travamento do giro, não há variação quanto à deformação, seja na face exposta ou oposta ao fogo. Nas Figuras 5.33 (b) e (c), verifica-se a inversão dos pontos medidos nas faces extremas da parede, bem como, a inversão da curvatura no instante em que as curvas tracejadas se interceptam.

Quanto ao deslocamento lateral, as medições foram realizadas no centro das faces exposta e oposta ao incêndio e plotadas no gráfico das Figura 5.34 de acordo com o tempo de incêndio. 
Figura 5.34 - Deslocamento lateral em função do tempo para as condições de contono CC1, $\mathrm{CC} 2$ e $\mathrm{CC} 3$

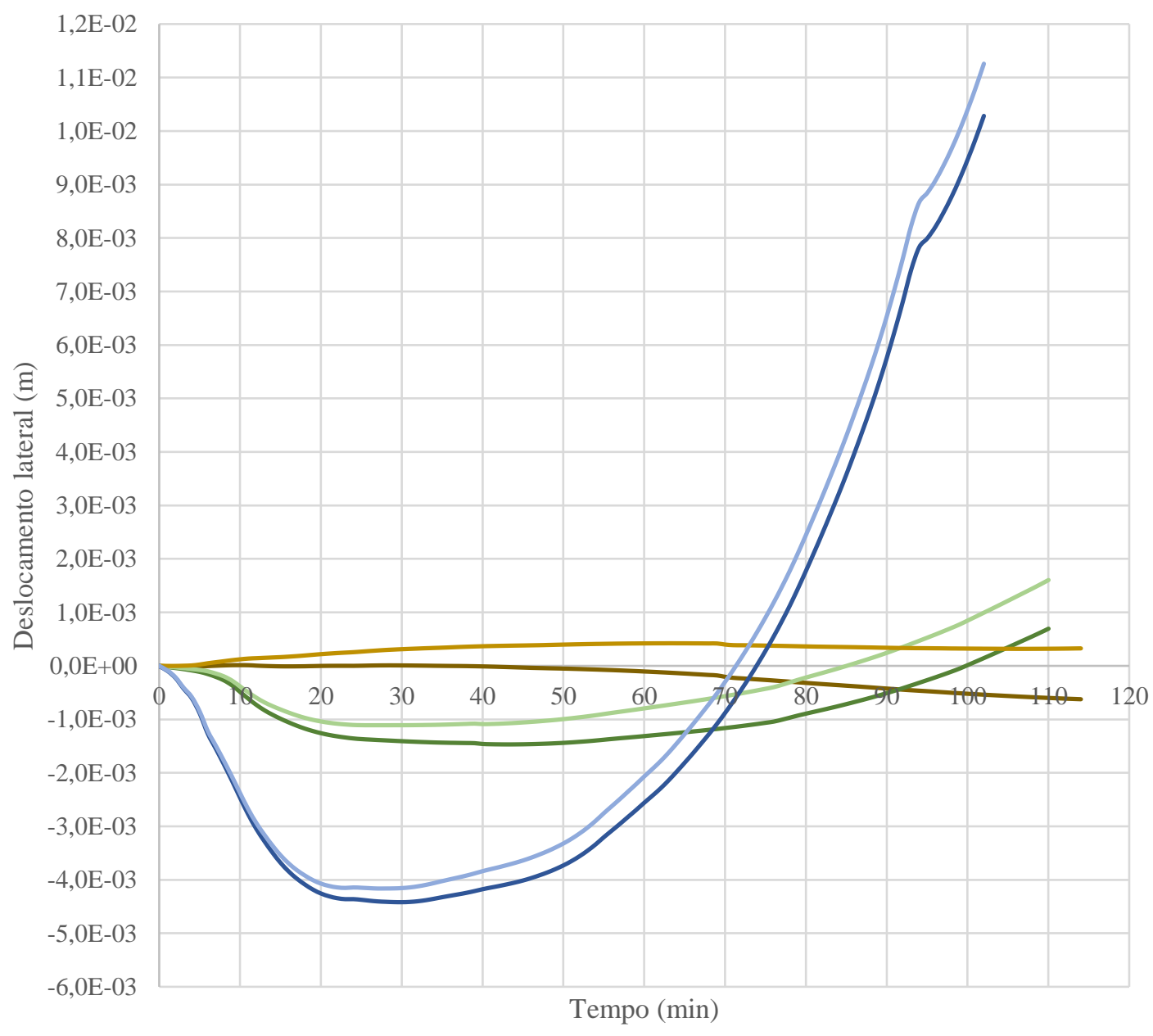

$-\mathrm{CC} 1-\mathrm{D} 0-\mathrm{CC} 2-\mathrm{D} 0-\mathrm{CC} 2-\mathrm{D} 14-\mathrm{CC} 1-\mathrm{D} 14-\mathrm{CC} 3-\mathrm{D} 0-\mathrm{CC} 3-\mathrm{D} 14$

Conforme comentado anteriormente, verifica-se pouca variação de deslocamento lateral na condição de contorno CC1, bem como curvatura para o lado do incêndio nas condições CC2 e CC3, com inversão para o lado oposto após a possível deterioração da estrutura, sendo mais intenso para a condição com permissão de giro superior e inferior.

A Figuras 5.35 indica o comportamento do modelo com condição de contorno CC1 em relação à distribuição de tensões, considerando os quatro tempos de incêndio conforme gradiente de temperaturas indicadas na Figura 5.31. Para a comparação dos valores de tensões de compressão e de tração do concreto, é indicado o uso da Tabela 3.6. 
Figura 5.35 - Distribuição de tensões absolutas na face exposta (1) e oposta (2) para os tempos de 25 (a), 50 (b), 75 (c) e 100 minutos (d) para a condição de contorno CC1

(1)
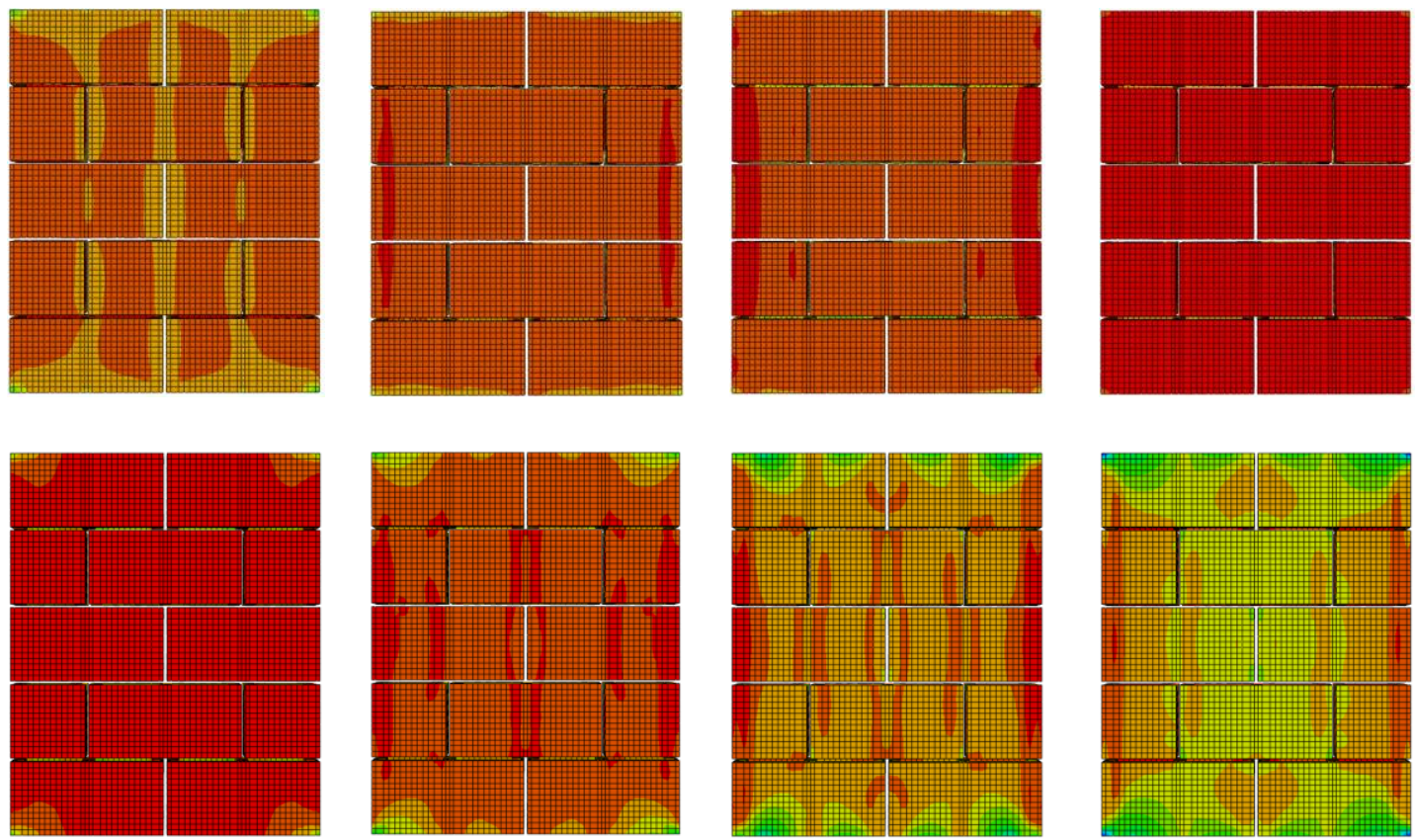

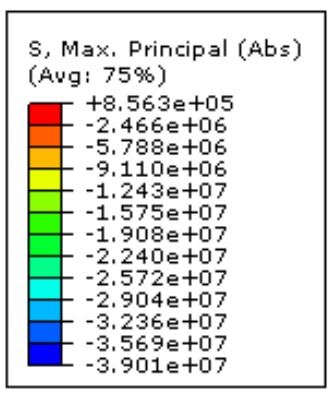

(a)

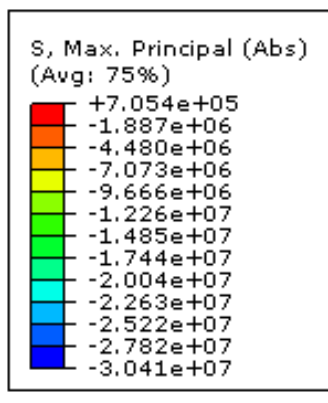

(b)

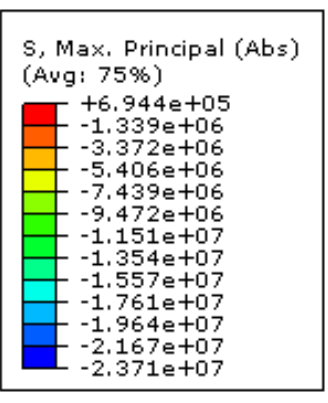

(c)

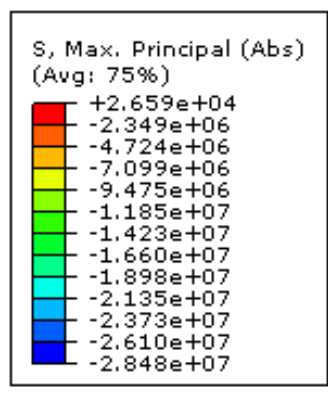

(d)

Observa-se que os valores máximos das tensões de compressão na face exposta ficam próximos aos de ruptura com 25 minutos de incêndio, o que não impede a estrutura de continuar a deformar-se por expansão térmica e não perder sua estabilidade. Após os 75 minutos, aparecem tensões de tração superiores aos valores de ruptura e, aos 100 minutos, percebe-se que toda a superfície exposta ultrapassou o valor de máxima ruptura para a temperatura ocorrente.

A Figuras 5.36 indica o comportamento do modelo com condição de contorno $\mathrm{CC} 1 \mathrm{em}$ relação à distribuição deformações para os quatro tempos de incêndio conforme gradiente de temperaturas indicadas na Figura 5.31. 
Figura 5.36 - Distribuição de deformações na face exposta (1) e oposta (2) para os tempos de 25 (a), 50 (b), 75 (c) e 100 minutos (d) para a condição de contorno CC1

(1)
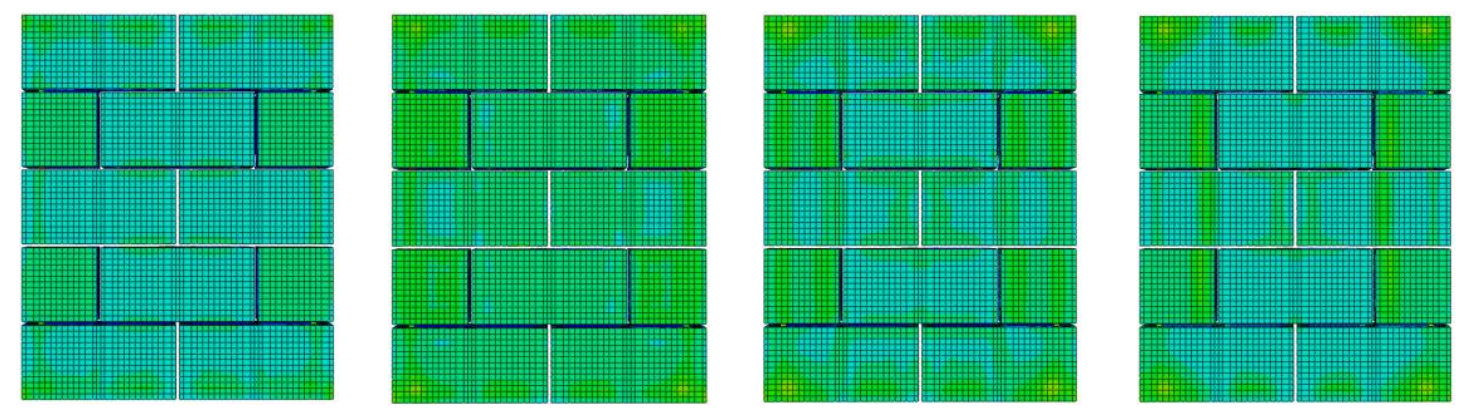

(2)
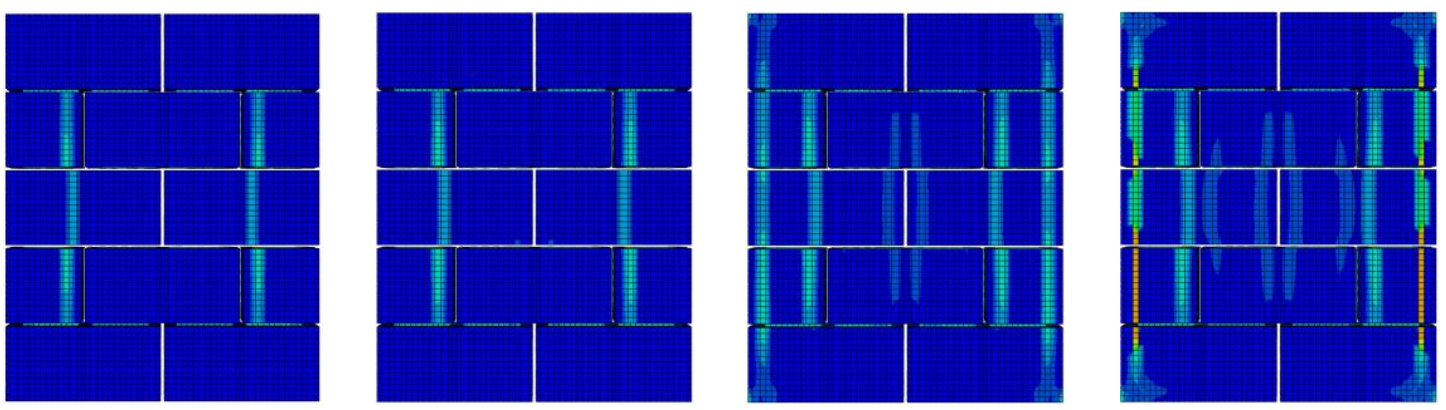

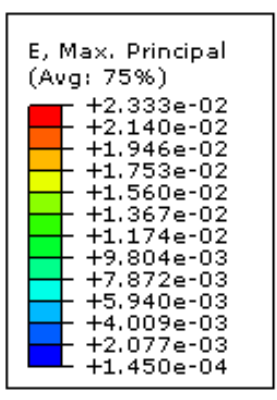

(a)

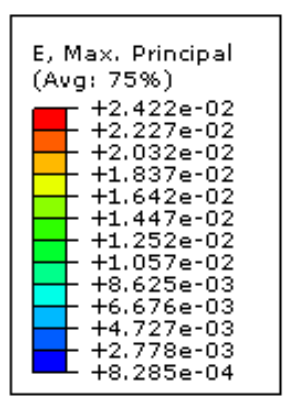

(b)

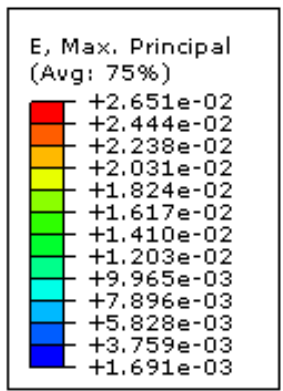

(c)

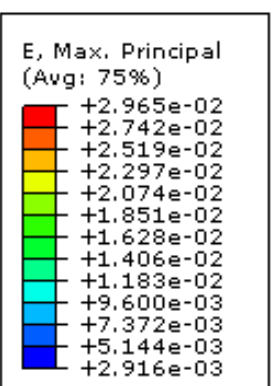

(d)

Pela análise das deformações, verifica-se na face exposta maior uniformidade após os 75 minutos. Quanto à face oposta, aos 75 minutos, verifica-se os elevados valores de tensões de tração comentados na Figura 5.35 a partir dos altos índices de deformação, as quais se tornam plásticas. A análise quanto aos deslocamentos encontra-se no Apêndice $\boldsymbol{G}$.

A Figuras 5.37 e indica o comportamento do modelo com condição de contorno CC2 em relação à distribuição de tensões. 
Figura 5.37 - Distribuição de tensões absolutas na face exposta (1) e oposta (2) para os tempos de 25 (a), 50 (b), 75 (c) e 100 minutos (d) para a condição de contorno CC2

(1)
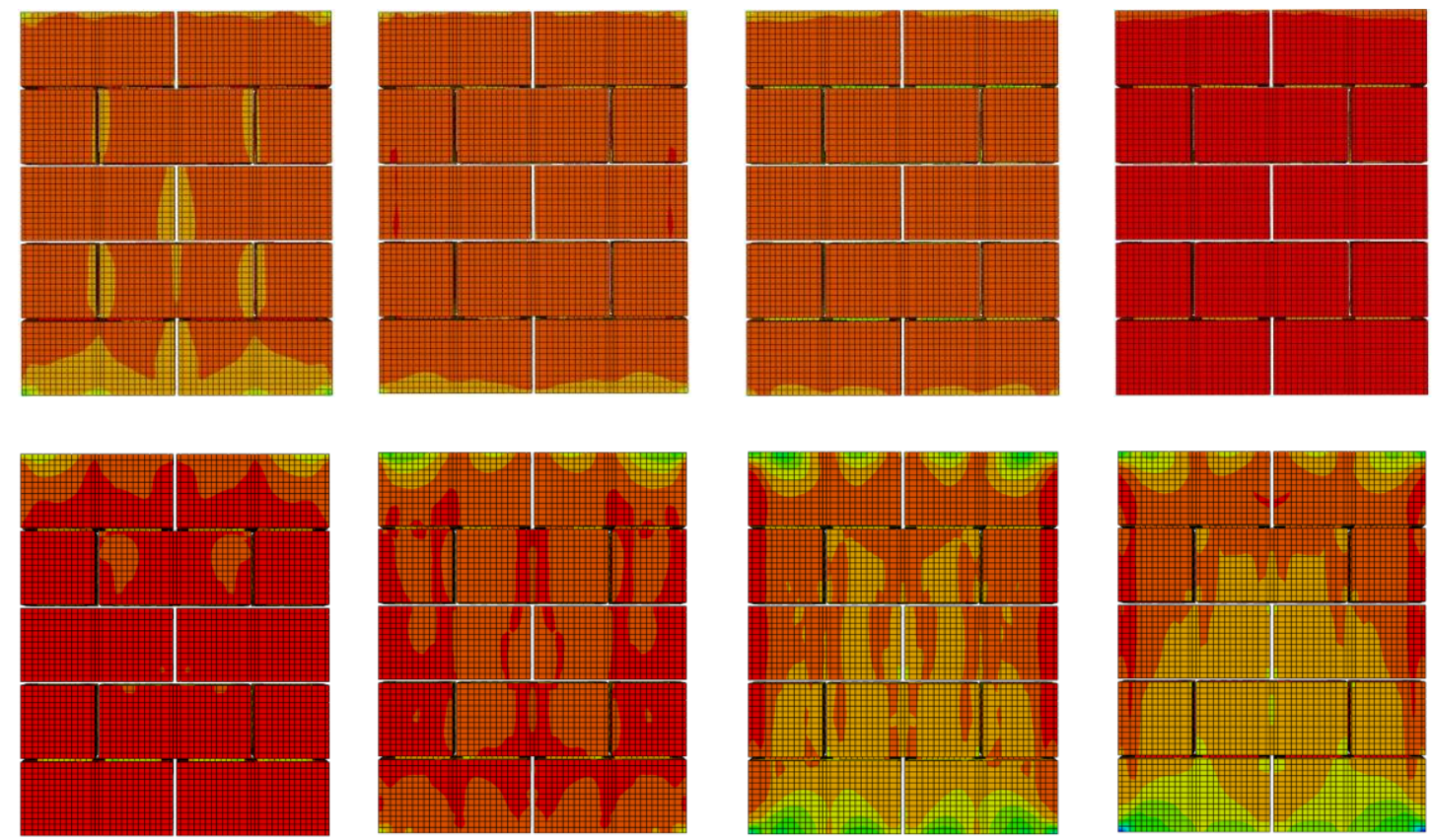

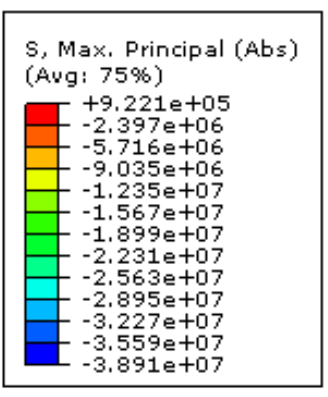

(a)

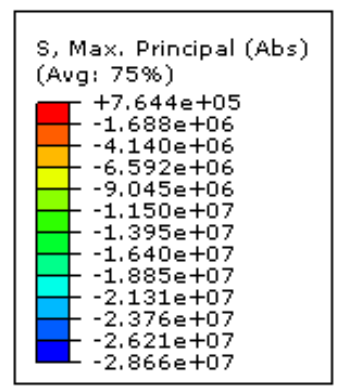

(b)

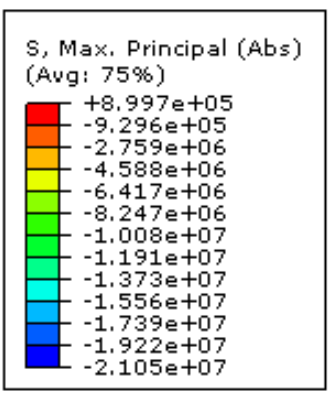

(c)

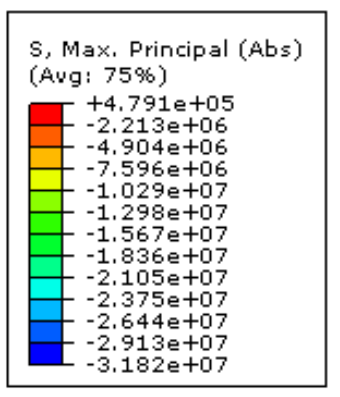

(d)

Para a condição CC2, analogamente ao caso anterior, as tensões de compressão na face exposta ao fogo aproximam-se aos de ruptura a partir dos 25 minutos. Isto ocorre pela combinação entre os esforços provenientes da expansão térmica e do carregamento imposto, criando maiores tensões de compressão na face. Aos 100 minutos, praticamente toda a face está sob tensões de tração superiores aos de ruptura.

Para a face oposta, as tensões de compressão começam a se aproximar aos valores de ruptura, em algumas regiões, a partir dos 75 minutos.

A Figura 5.38 indica o comportamento do modelo com condição de contorno CC2 em relação à distribuição de deformações. 
Figura 5.38 - Distribuição de deformações na face exposta (1) e oposta (2) para os tempos de 25 (a), 50 (b), 75 (c) e 100 minutos (d) para a condição de contorno CC2

(1)
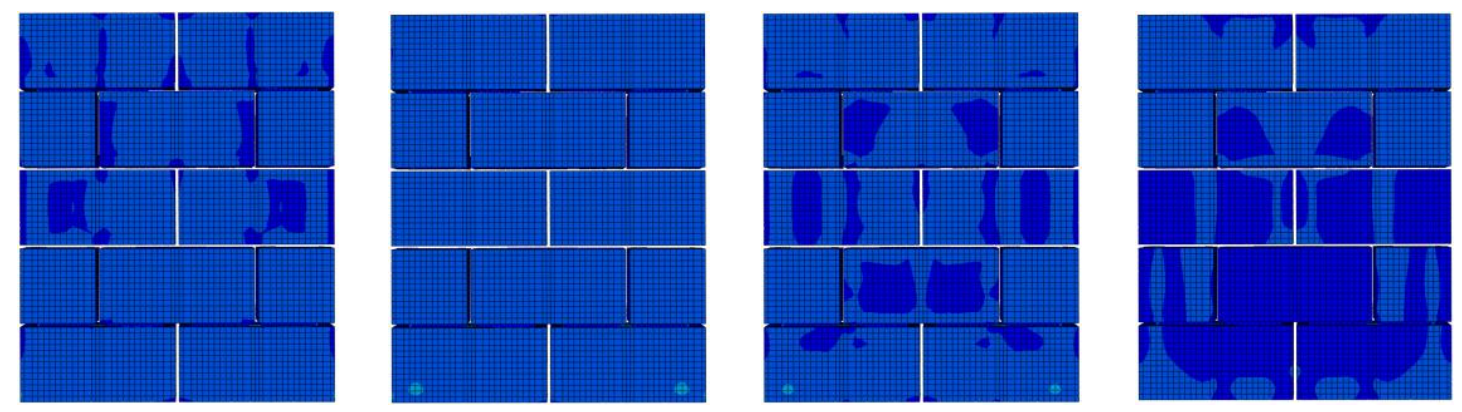

(2)
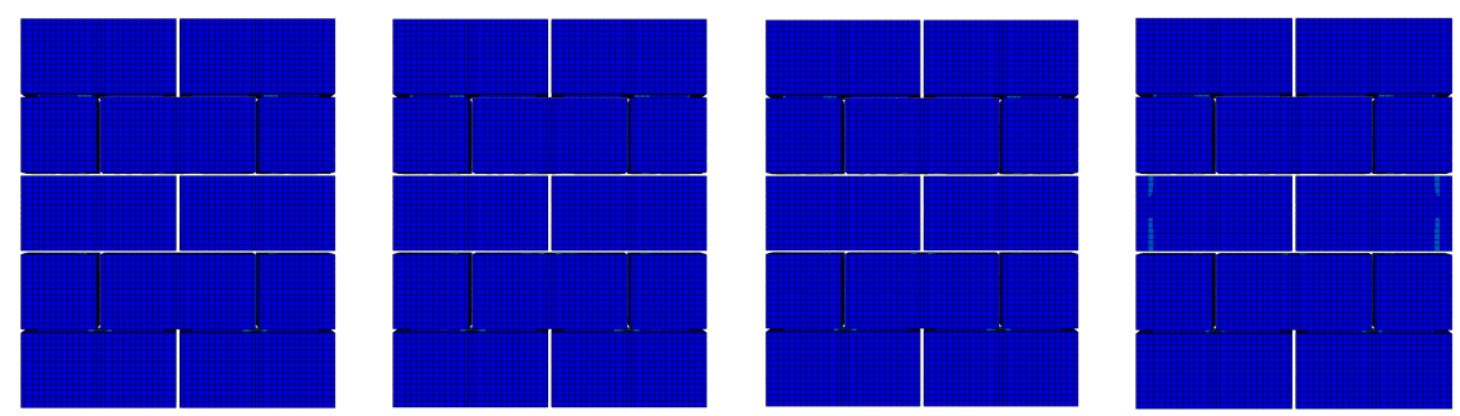

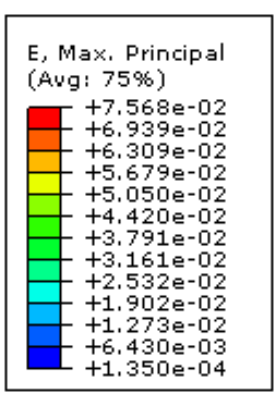

(a)

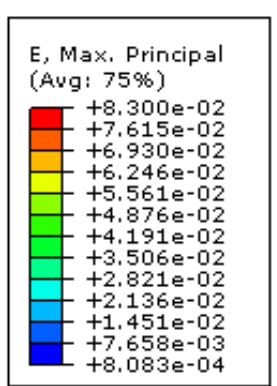

(b)

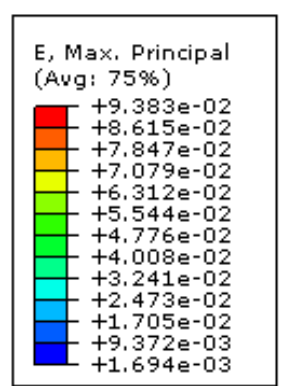

(c)

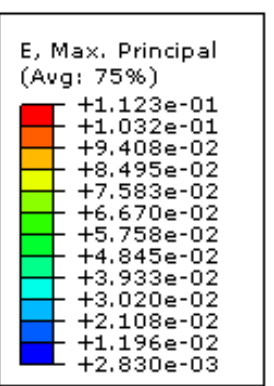

(d)

Verifica-se após os 75 minutos maior tendência à deformação na região mais baixa da parede, em virtude da condição de contorno superior, a qual permite que ocorra o giro. Aos 100 minutos é possível verificar algumas faixas com maiores deformações em relação ao restante da superfície. Análises relativas aos deslocamentos podem ser encontradas no Apêndice $\boldsymbol{G}$.

A Figuras 5.39 indica o comportamento do modelo com condição de contorno CC3 em relação à distribuição de tensões. 
Figura 5.39 - Distribuição de tensões absolutas na face exposta (1) e oposta (2) para os tempos de 25 (a), 50 (b), 75 (c) e 100 minutos (d) para a condição de contorno CC3

(1)
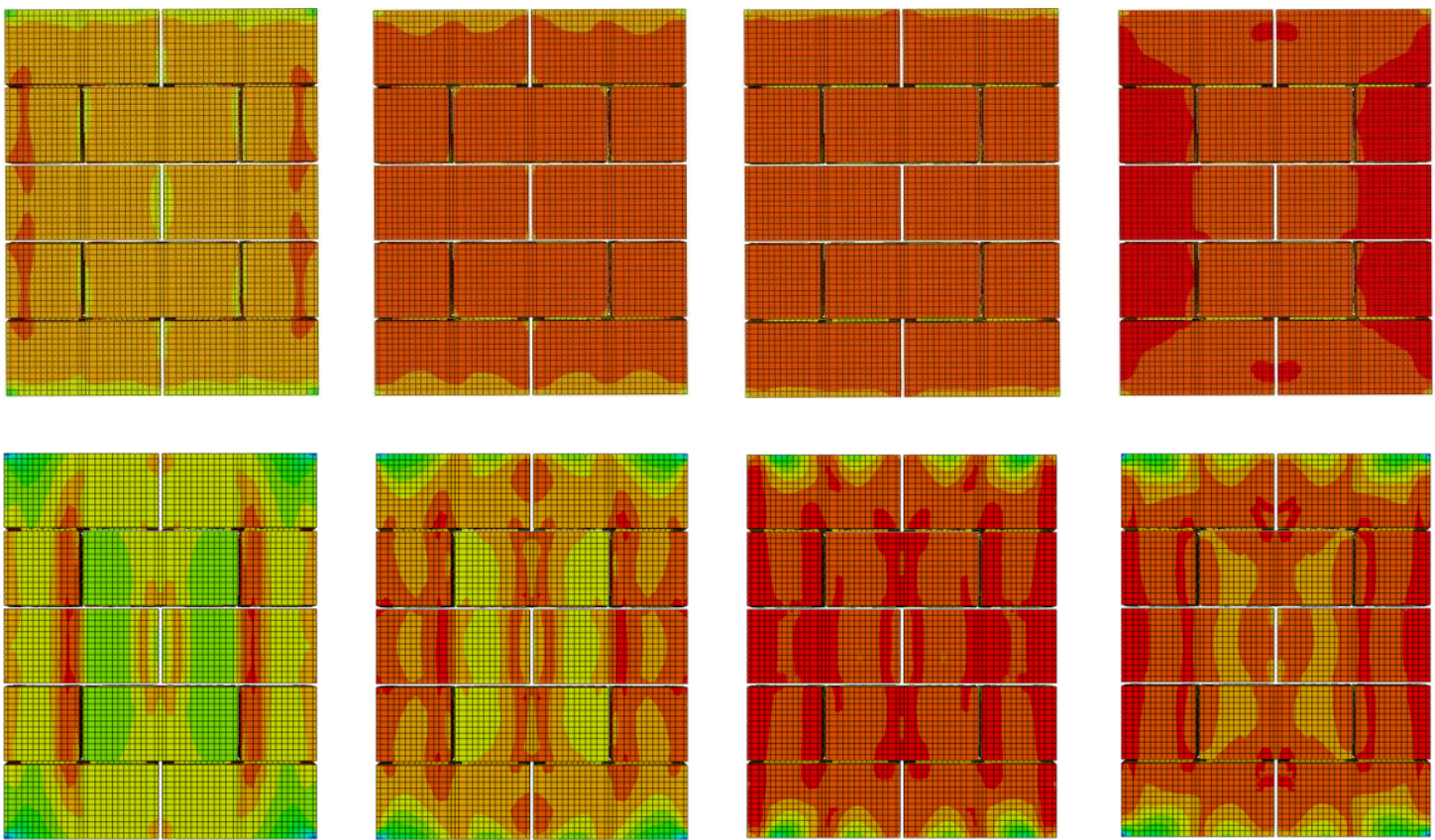

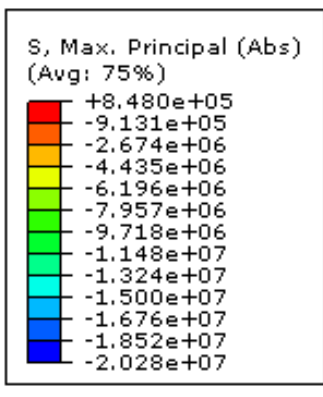

(a)

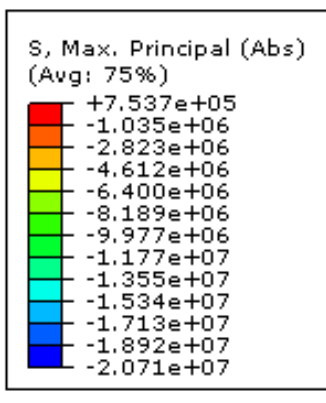

(b)

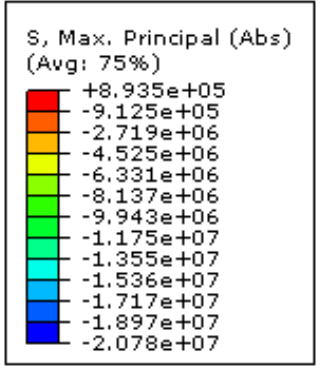

(c)

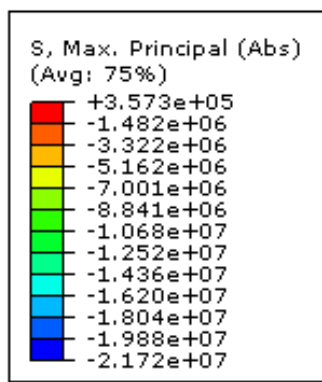

(d)

Para a condição de contorno CC3, na superfície exposta ao fogo, as tensões máximas de tração aproximaram-se das tensões de ruptura após os 50 minutos de incêndio, apresentando, após os 75 minutos, a maior parte da área da parede sob tensões superiores às de ruptura. Aos 100 minutos, grande parte da área apresentou-se com tensões de tração superiores às de ruptura.

Em relação à face oposta, após os 75 minutos, algumas áreas aproximaram-se dos valores de ruptura à tração.

A Figura 5.40 indica o comportamento do modelo com condição de contorno CC3 em relação à distribuição de deformações. 
Figura 5.40 - Distribuição de deformações na face exposta (1) e oposta (2) para os tempos de 25 (a), 50 (b), 75 (c) e 100 minutos (d) para a condição de contorno CC3

(1)
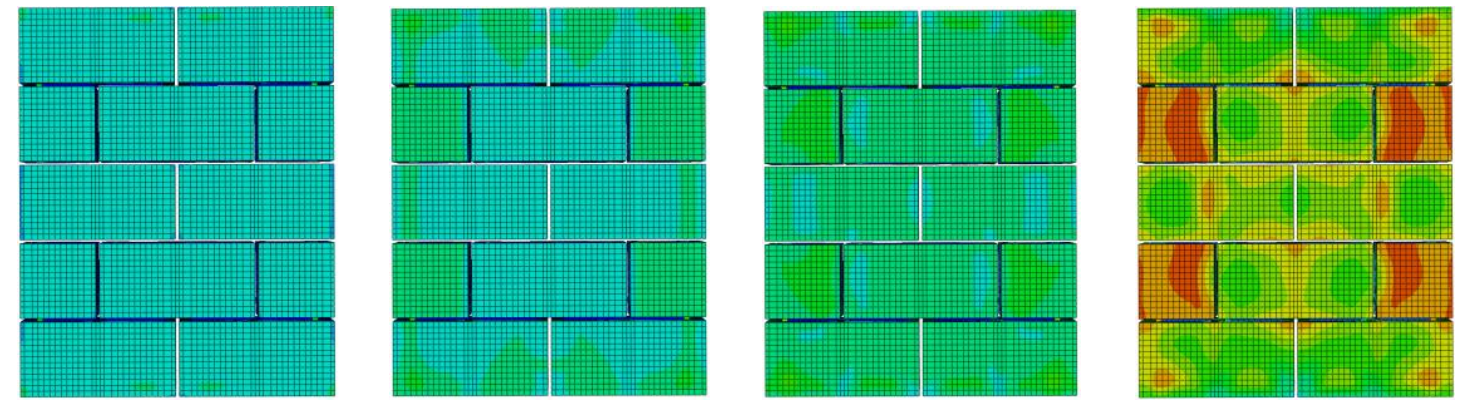

(2)
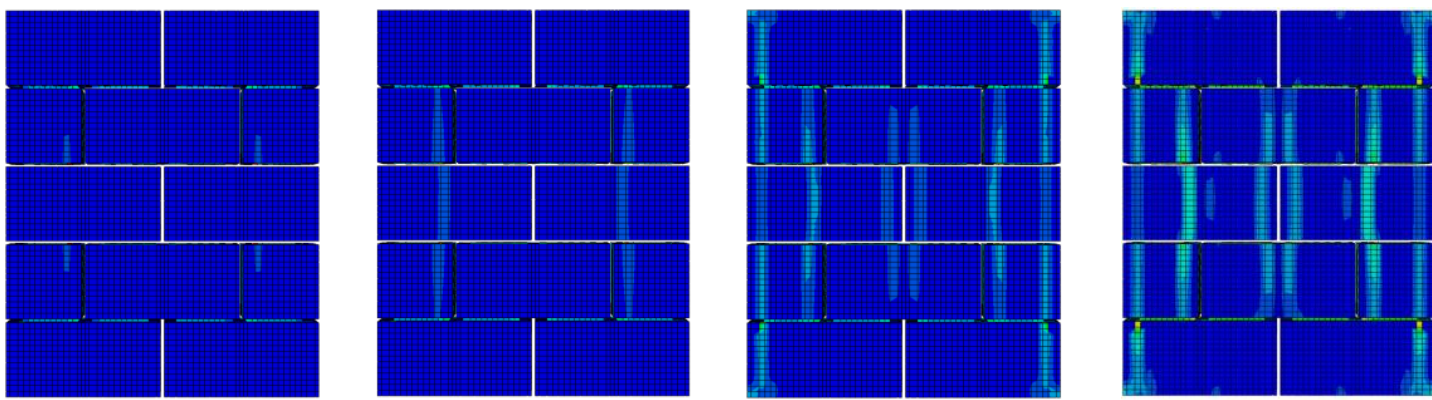

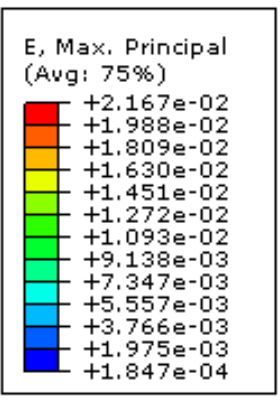

(a)

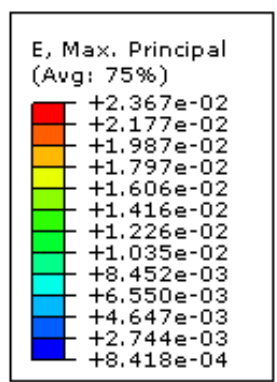

(b)

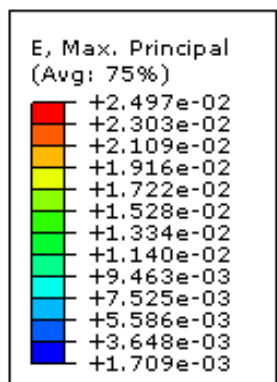

(c)

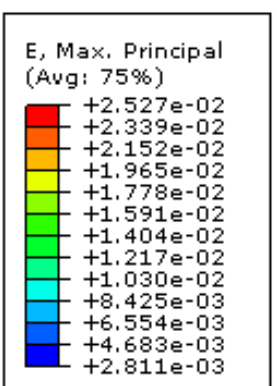

(d)

Conforme verificado para as tensões, aos 100 minutos ocorrem deformações muito elevadas, que podem ser verificadas na Figura 5.40 (d), devido às altas tensões de tração. Para a face oposta, após os 75 minutos, é possível verificar a ocorrência de deformações plásticas em algumas faixas da parede. Detalhes sobre os diagramas de deslocamentos podem ser vistos no Apêndice $\boldsymbol{G}$.

\subsubsection{Temperatura na face oposta ao fogo}

Neste item, foi realizada análise comparativa acerca da alteração da condição da temperatura na face oposta ao fogo, considerando o aumento de temperatura utilizado no Capítulo 4 para validação do modelo térmico, de acordo com os resultados experimentais de Dupim (2019). 
Esta variação teve o objetivo de analisar o comportamento da parede com diferentes condições de contorno sob diferentes temperaturas na face oposta ao incêndio. O Quadro 5.14 indica o resumo das informações deste tópico.

Quadro 5.14 - Resumo das informações para a análise numérica do item 5.3.2

\begin{tabular}{|rl|}
\hline Modelo analisado: & Termoestrutural (Item 4.3) \\
\hline Carregamento: & $40 \%$ da carga de ruptura da parede \\
& Comparação da elevação de temperatura na \\
& face oposta considerando e desconsiderando o \\
Nesta análise: & confinamento dos gases conforme Dupim \\
& $(2019)$ \\
\hline
\end{tabular}

A Figura 5.41 indica a variação entre a consideração do item 5.3.1, sem confinamento dos gases na face oposta ao fogo (“SConf”), e o uso das curvas de elevação de temperatura, considerando o confinamento dos gases, fornecidas por Dupim (2019) (“Conf”). A comparação, para fins de controle consistente, é feita considerando um mesmo nó superficial da parede.

Figura 5.41 - Evolução da temperatura em função do tempo para as duas situações de confinamento dos gases para a face oposta ao fogo

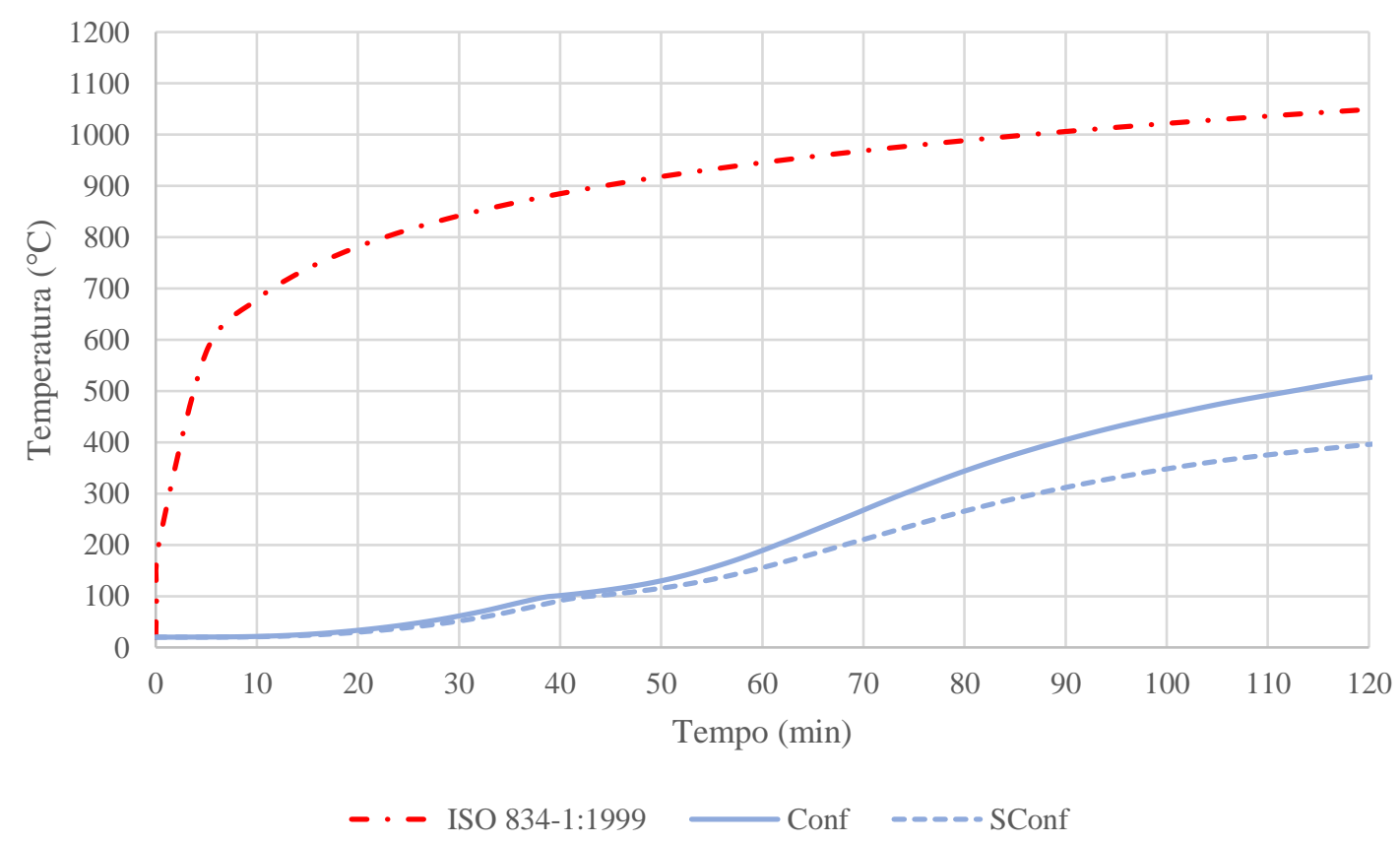

A Figura 5.42 indica o aumento das deformações axiais em função do tempo para a consideração de temperatura na face oposta, com confinamento dos gases baseado em Dupim (2019). 
Figura 5.42 - Deformação axial em função do tempo para as três condições de contorno estudadas considerando o confinamento dos gases

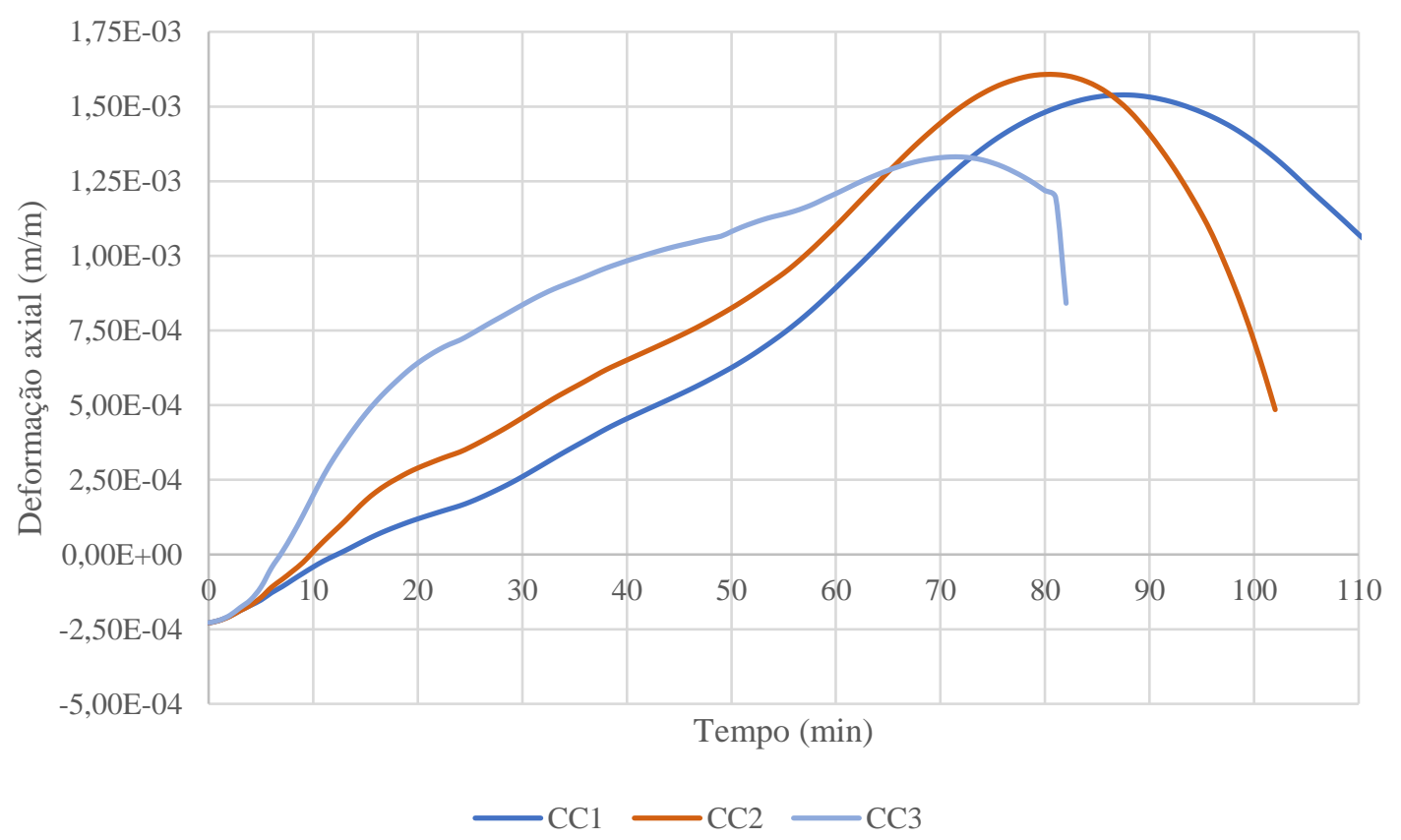

A Tabela 5.13 indica os valores máximos de deformação verificados numericamente e seu respectivo tempo de resistência ao fogo, conforme considerado no item anterior.

Tabela 5.13 - Deformações máximas e respectivos tempos para as três condições de contorno considerando confinamento dos gases na face oposta ao fogo

\begin{tabular}{ccc} 
Condição de contorno & $\begin{array}{c}\text { Deformação máxima } \\
(\mathbf{m} / \mathbf{m})\end{array}$ & $\begin{array}{c}\text { Critério de resistência } \\
\text { mecânica (min) }\end{array}$ \\
\hline CC1 & 0,001539 & 87 \\
\hline CC2 & 0,001607 & 80 \\
\hline CC3 & 0,001331 & 71 \\
\hline
\end{tabular}

Verifica-se, inicialmente, alteração pequena em relação ao critério de resistência mecânica, variando em menos de 8 minutos para cada condição de contorno em relação ao item 5.3.1. Para o critério de isolamento térmico, a diferença foi de 7 minutos. Mais uma vez, o valor limitante entre os critérios analisados ocorre com o critério de isolamento. Comparando os resultados do item anterior com o atual, foram obtidos os seguintes gráficos para cada condição de contorno. 
Figura 5.43 - Comparação da deformação axial em função do tempo para diferentes condições de confinamento dos gases para as condições de contorno CC1 (a), CC2 (b) e CC3

(c)

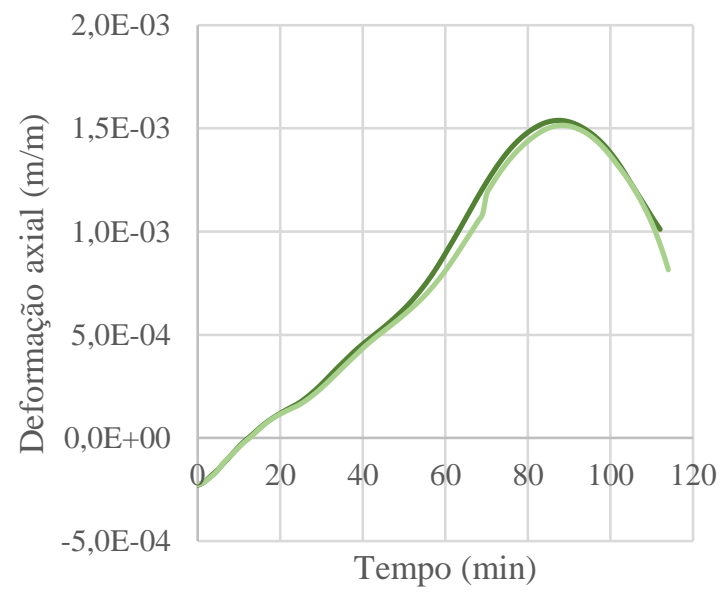

$\longrightarrow \mathrm{CC} 1, \mathrm{Conf} \longrightarrow \mathrm{CC} 1, \mathrm{SConf}$

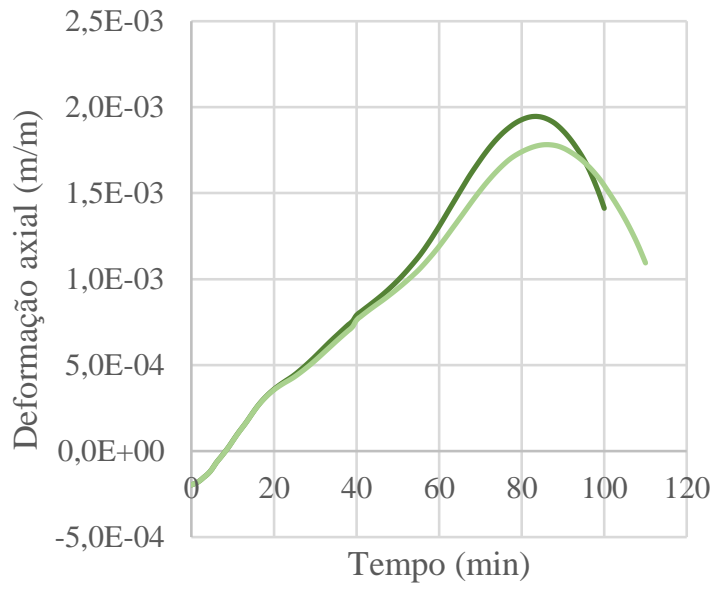

$\longrightarrow \mathrm{CC} 2, \mathrm{Conf} \longrightarrow \mathrm{CC} 2, \mathrm{SConf}$

(a)

(b)

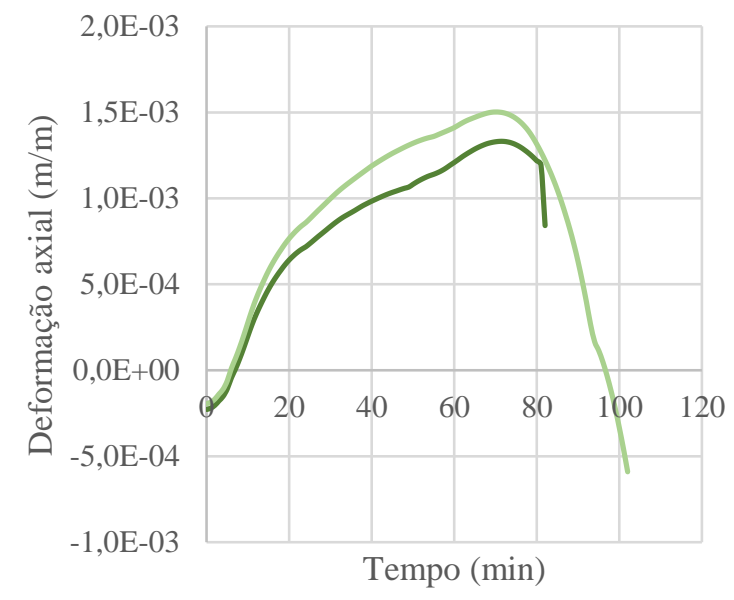

$-\mathrm{CC} 3, \mathrm{Conf} \longrightarrow \mathrm{CC} 3, \mathrm{SConf}$

(c)

Sinaliza-se, desta forma, variações pouco significativas na comparação entre as situações com e sem confinamento das curvas de elevação de temperatura dos gases fornecidos por Dupim (2019), principalmente para as condições de contorno CC1 e CC2. A condição de contorno CC3 apresenta pico de deformação inferior para a situação com confinamento.

Quanto ao deslocamento lateral, a Figura 5.44 mostra os resultados obtidos considerando o confinamento dos gases na face oposta.. 
Figura 5.44 - Deslocamento lateral em função do tempo para as condições de contono CC1, CC2 e CC3 com confinamento dos gases na face oposta

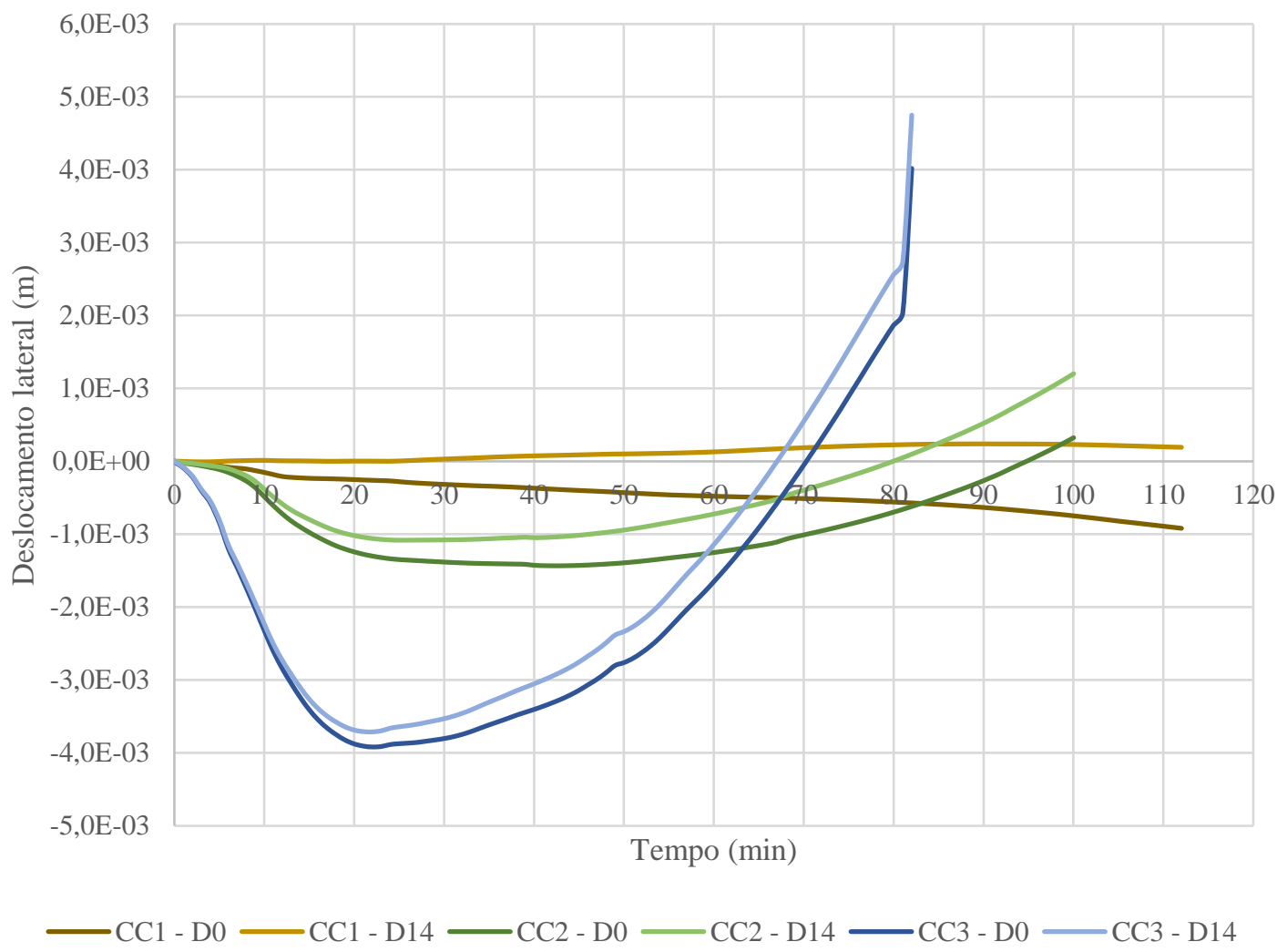

Os gráficos da Figura 5.45 indicam de forma comparativa os deslocamentos laterais ocorrentes para as duas condições de temperatura na face oposta ao incêndio.

Figura 5.45-I - Comparação entre os deslocamentos laterais em função do tempo para diferentes condições de confinamento dos gases para as condições de contorno CC1 (a) e CC2 (b)
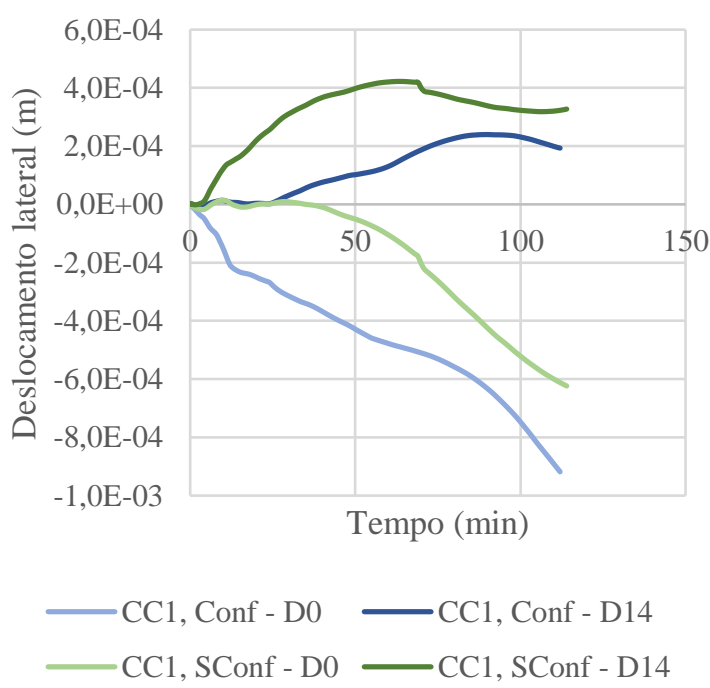

(a)

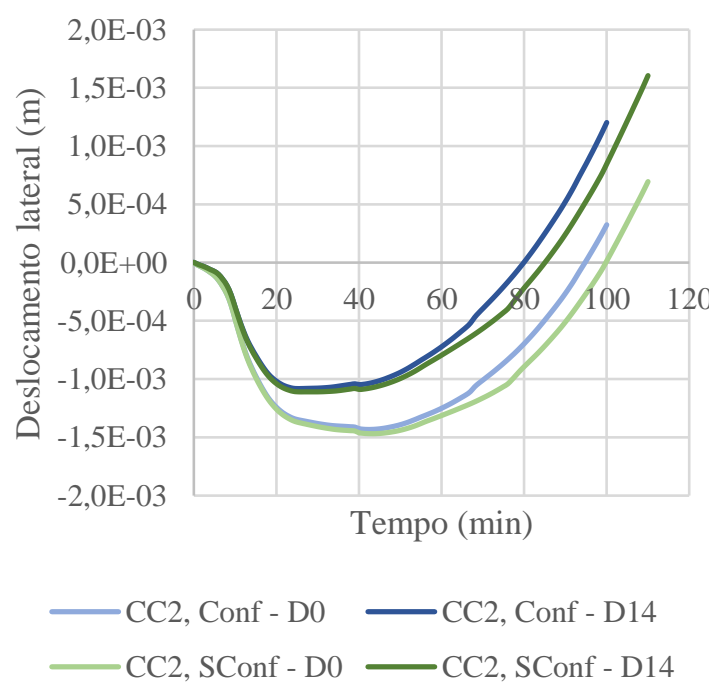

(b) 
Figura 5.45-II - Comparação entre os deslocamentos laterais em função do tempo para diferentes condições de confinamento dos gases para a condição de contorno CC3 (c)

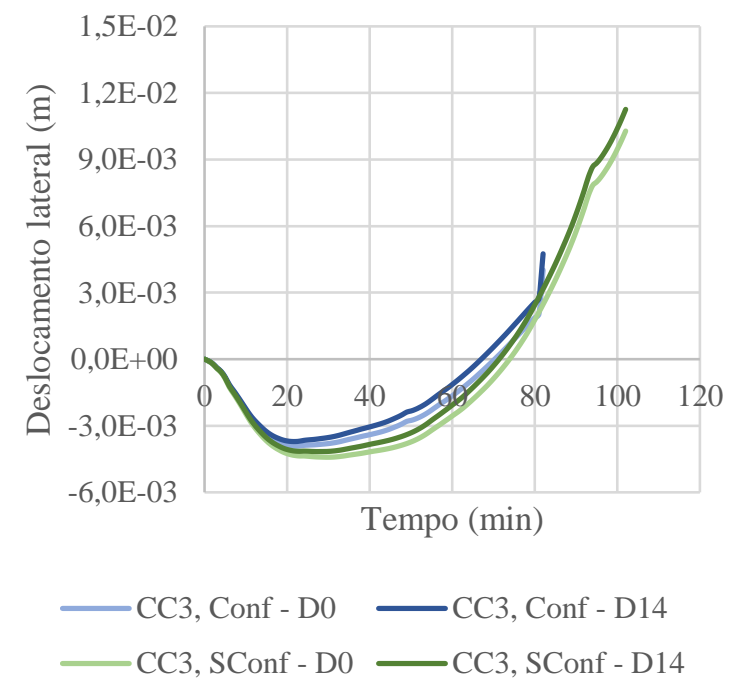

(c)

Verifica-se proximidade entre os resultados obtidos pelas condições de contorno CC2 e CC3, apresentando maior variação para a condição CC1.

\subsubsection{Quanto a intensidade de carregamento}

A análise deste item refere-se à variação do carregamento imposto utilizando os mesmos parâmetros para a análise com carregamento de $40 \%$ da carga de ruptura.

Estas análises foram realizadas apenas para as condições de contorno CC1 e CC2, definidas anteriormente, considerando temperatura da face oposta de acordo com Dupim (2019). Vale lembrar novamente que o intuito das análises termoestruturais deste trabalho é abordar de forma qualitativa o comportamento das paredes, principalmente, em virtude da falta de informações e parâmetros dos materiais em temperaturas elevadas, bem como, de ensaios com carregamento.

O Quadro 5.15 indica o resumo das informações deste tópico.

Quadro 5.15 - Resumo das informações para a análise numérica do item 5.3.3

\begin{tabular}{|rl|}
\hline Modelo analisado: & Termoestrutural (Item 4.3) \\
\hline Elevação da temperatura na face oposta: & Com confinamento, conforme Dupim (2019) \\
\hline Nesta análise: & Variação dos percentuais de carregamento \\
\hline
\end{tabular}


A Figura 5.46 indica a deformação axial em função do tempo para paredes com carregamentos de 20, 40 e $80 \%$ da carga de ruptura obtida por Oliveira (2014), bem como, a situação descarregada para a condição de contorno CC1.

Figura 5.46 - Deformação axial em função do tempo para a condição de contorno CC1 para diferentes carregamentos

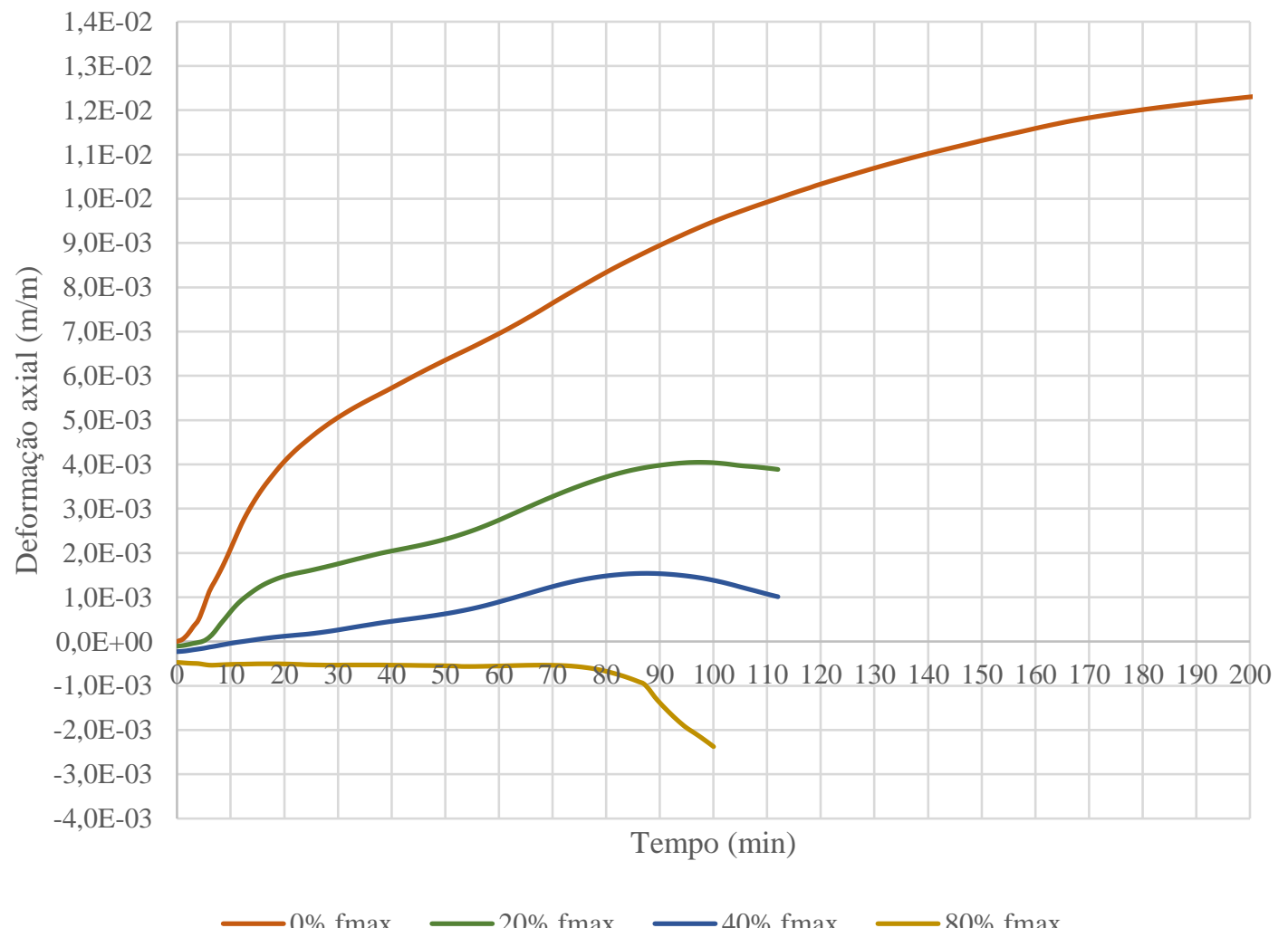

As deformações máximas e os tempos de resistência ao fogo, conforme definido anteriormente estão indicados na Tabela 5.14.

Tabela 5.14 - Deformações máximas e respectivos tempos para os diferentes carregamentos para a condição de contorno CC1

\begin{tabular}{ccc} 
Carregamento & $\begin{array}{c}\text { Deformação máxima } \\
(\mathbf{m} / \mathbf{m})\end{array}$ & $\begin{array}{c}\text { Critério de resistência } \\
\text { mecânica (min) }\end{array}$ \\
\hline Descarregado & - & - \\
\hline $\mathbf{2 0 \%} \mathbf{f}_{\text {máx }}$ & 0,004048 & 97 \\
\hline $\mathbf{4 0 \%}$ f $_{\text {máx }}$ & 0,001539 & 87 \\
\hline $\mathbf{8 0 \%} \mathbf{f}_{\text {máx }}$ & $-0,000534$ & 68 \\
\hline
\end{tabular}


Obteve-se, desta forma, redução do tempo quanto ao critério de resistência mecânica de acordo com o aumento da carga sobre a estrutura, aspecto que se mostra consistente em resposta à estratégia adotada para obtenção deste tempo, uma vez que o maior carregamento tende a fazer com que a inversão da deformação axial ocorra de forma mais rápida.

A Figura 5.47 indica o comportamento da parede sob condição de contorno CC2 para diferentes carregamentos.

Figura 5.47 - Deformação axial em função do tempo para a condição de contorno CC2 para diferentes carregamentos

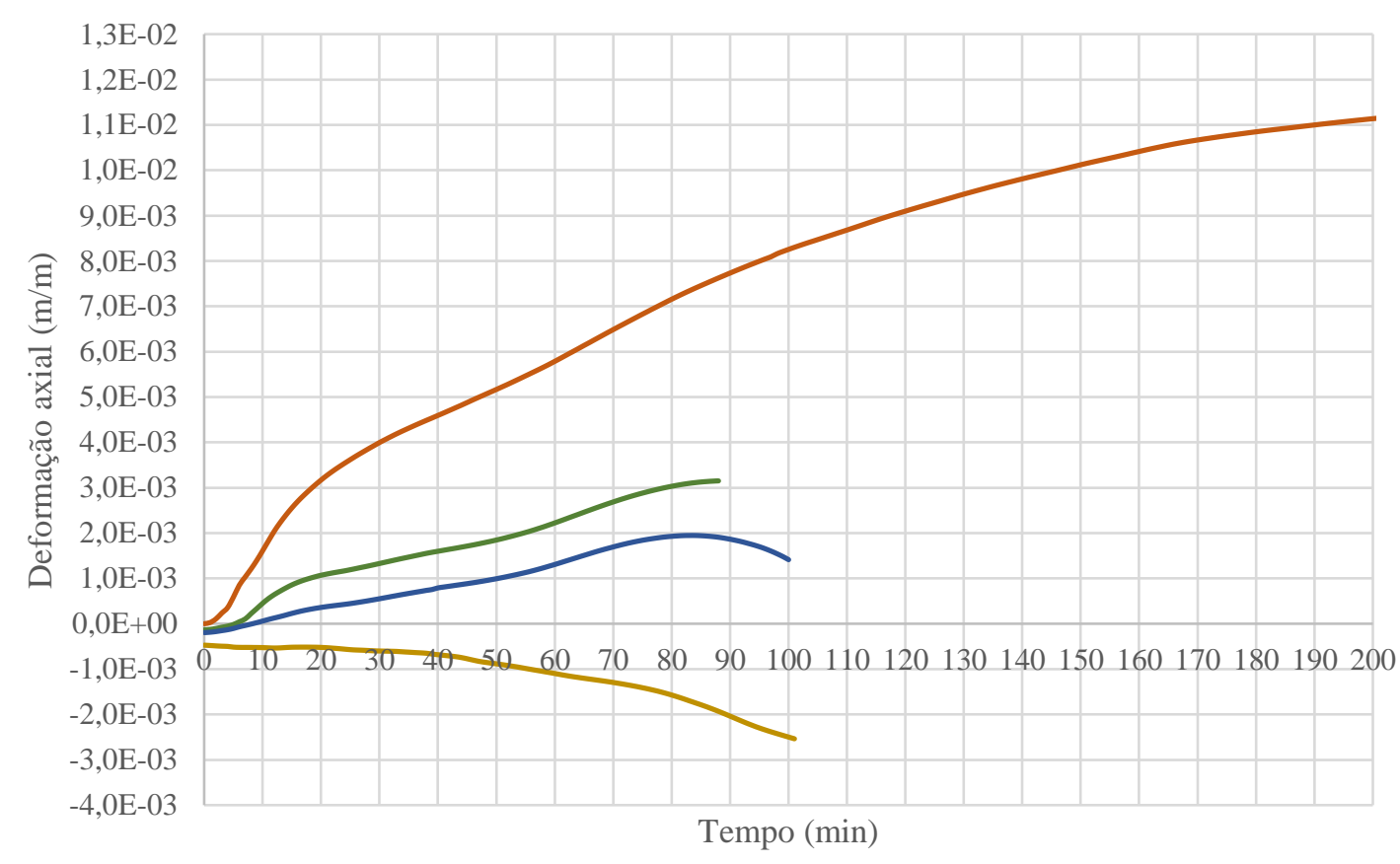

$-0 \% \mathrm{fmax}-20 \% \mathrm{fmax}-40 \% \mathrm{fmax}-80 \% \mathrm{fmax}$

Os tempos de resistência ao fogo, conforme definido anteriormente, bem como, as deformações máximas estão indicadas na Tabela 5.15 para cada carregamento.

Tabela 5.15 - Deformações máximas e respectivos tempos para os diferentes carregamentos para a condição de contorno CC2

\begin{tabular}{ccc|}
\hline Carregamento & $\begin{array}{c}\text { Deformação máxima } \\
(\mathbf{m} / \mathbf{m})\end{array}$ & $\begin{array}{c}\text { Critério de resistência } \\
\text { mecânica (min) }\end{array}$ \\
\hline Descarregado & - & - \\
\hline $\mathbf{2 0 \%} \mathbf{f}_{\text {máx }}$ & 0,003144 & 87 \\
\hline $\mathbf{4 0 \%} \mathbf{f}_{\text {máx }}$ & 0,001946 & 83 \\
\hline $\mathbf{8 0 \%} \mathbf{f}_{\text {máx }}$ & $-0,000515$ & 17 \\
\hline
\end{tabular}


Verifica-se redução dos tempos quanto ao critério estabelecido neste tópico da condição de contorno CC2 para a condição CC1. A restrição do giro na superfície superior, no caso de CC1, possibilitou maior deslocamento axial que no caso sem restrição.

Conforme comentado no item 5.3.1, o pico das deformações não necessariamente refere-se à perda de estabilidade estrutural, uma vez que é possível que a parede apresente resistência residual após a inversão da deformação axial por determinado período de tempo, não considerado no critério adotado, que é conservador.

Na Figura 5.48 estão indicados os deslocamentos laterais mensurados no centro do modelo numérico, na face oposta ao fogo.

Figura 5.48 - Deslocamento lateral em função do tempo para a condição de contorno CC1 para diferentes carregamentos

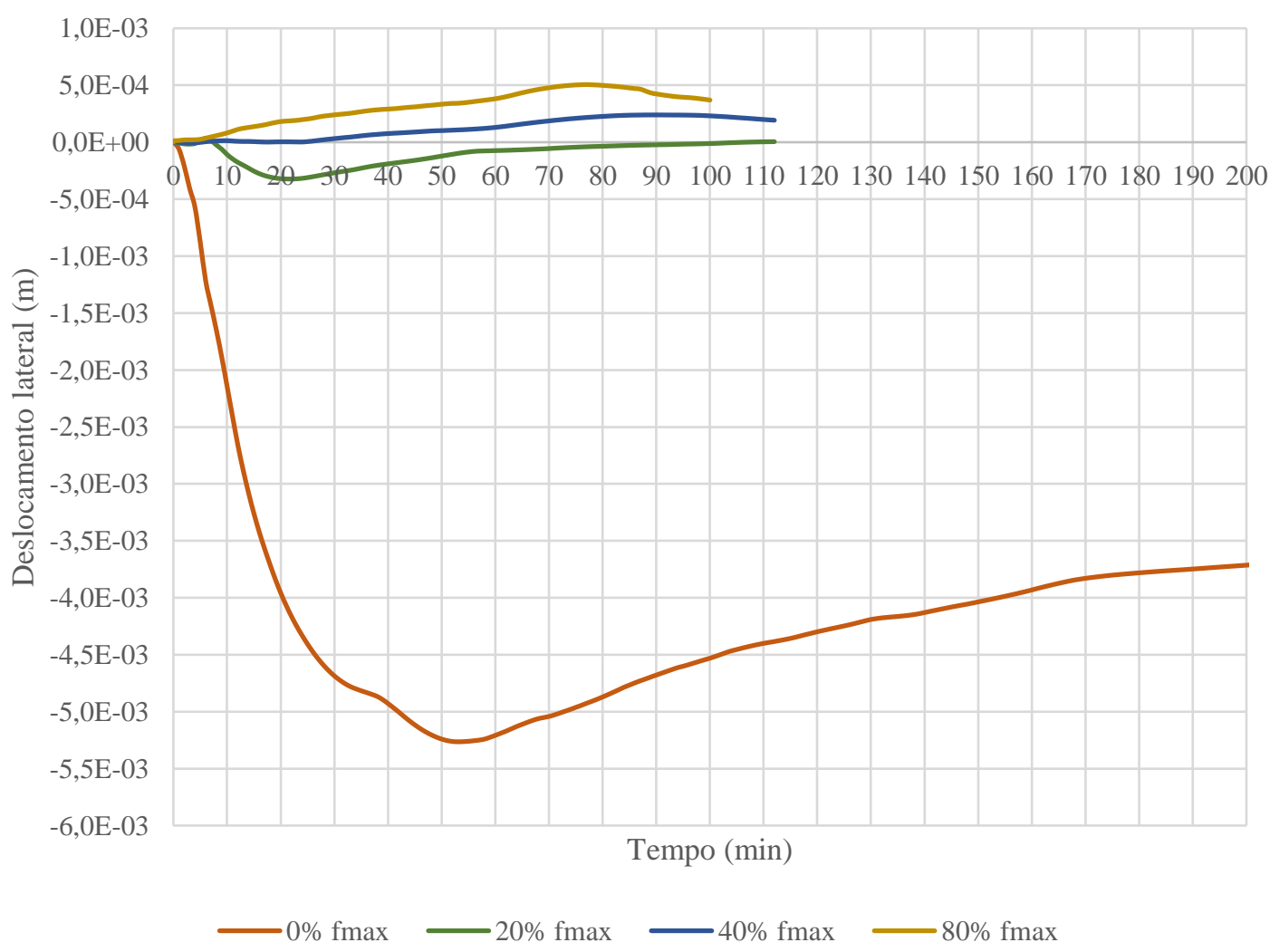

Observa-se deslocamento maior da situação sem carregamento em relação aos demais casos. A redução do carregamento, para a condição de contorno $\mathrm{CC} 1$, reduz a amplitude do deslocamento lateral na direção da face exposta ao fogo. Para o carregamento de $80 \%$ da carga de ruptura não ocorre curvatura para o lado exposto.

A Figura 5.49 indica os deslocamentos laterais para a condição CC2 para as diferentes taxas de carregamento. 
Figura 5.49 - Deslocamento lateral em função do tempo para a condição de contorno CC2 para diferentes carregamentos

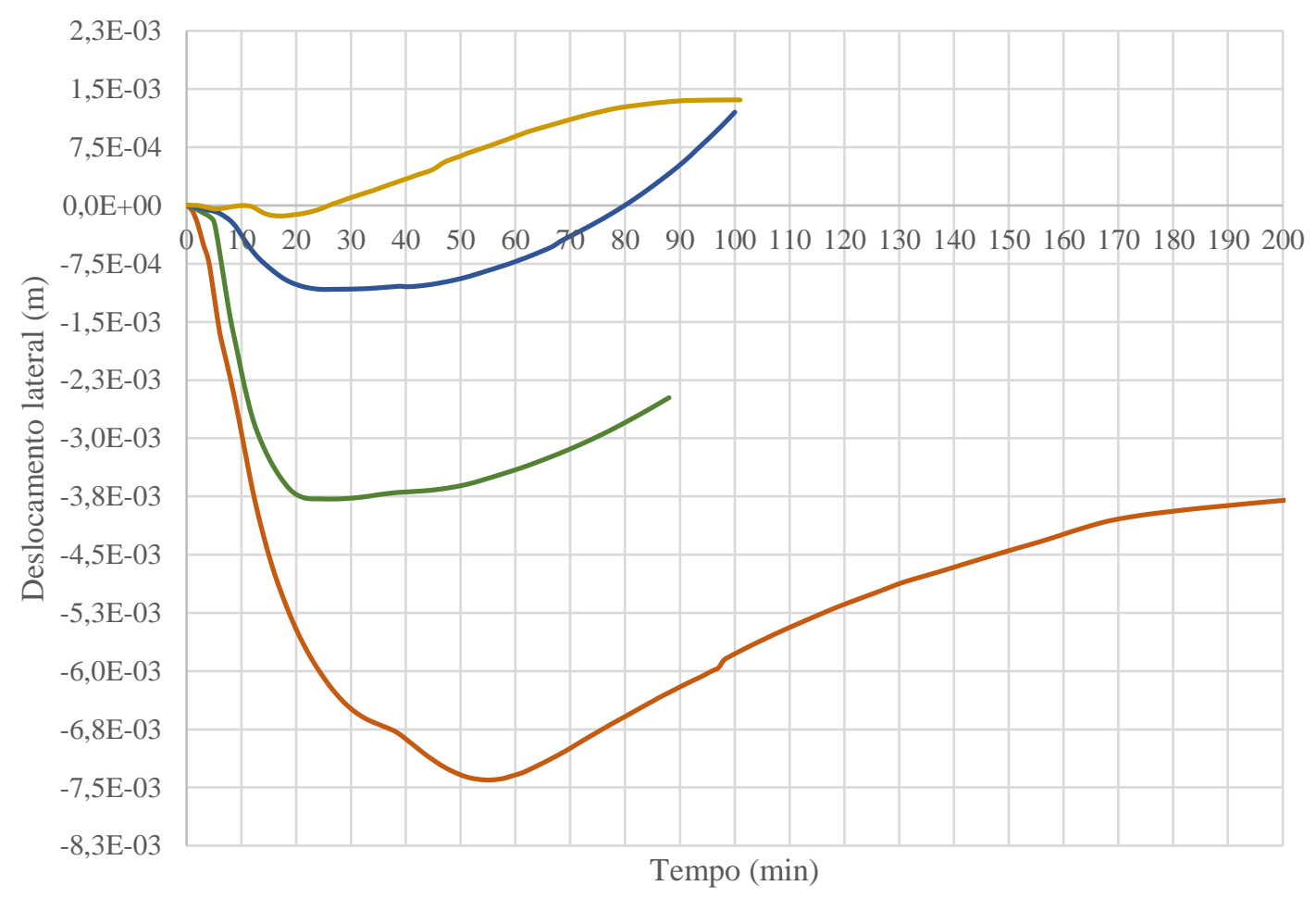

$-0 \% \mathrm{fmax}-20 \% \mathrm{fmax}-40 \% \mathrm{fmax} \quad-80 \% \mathrm{fmax}$

Em virtude do giro permitido para a condição de contorno CC2 na superfície superior, em todas as situações de carregamento, ocorre curvatura para a superfície exposta ao fogo. $\mathrm{O}$ nível de deslocamento para todas as situações apresenta-se com maior intensidade. A tendência das situações carregadas é a inversão da curvatura ao longo do tempo, como visto para 40 e $80 \%$ da carga de ruptura.

Tanto para a condição de contorno CC1 quanto para a CC2, na situação sem carregamento, a tendência da curvatura da parede é sua estabilização para o lado exposto ao fogo sem que haja inversão para o lado oposto.

Lembrando mais uma vez que, quanto ao critério de isolamento térmico, o tempo limite seria de 52 minutos, inferior a qualquer situação anteriormente comentada. 


\section{CONSIDERAÇÕES E CONCLUSÕES}

No sentido de contextualização, faz-se relevante comentar que o presente trabalho contou com um conjunto de análises numéricas realizadas através do software ABAQUS versão 6.14, com o objetivo principal de obter modelos numéricos capazes de simular os comportamentos estrutural e térmico, bem como sinalizar o comportamento termoestrutural de pequenas paredes de alvenaria estrutural constituídas de blocos de concreto.

Este tema tem especial relevância para a engenharia estrutural por tratar de um sistema construtivo ainda pouco estudado em condições de temperaturas elevadas, bem como por não possuir normatização nacional vigente para tal situação. $\mathrm{O}$ comportamento estrutural da alvenaria encontra-se bem definido e difundido quanto ao seu conhecimento, porém, no caso dos comportamentos térmico e termoestrutural, principalmente para os materiais utilizados no Brasil, ainda existe deficiência considerável a respeito.

Desta forma, em vista da forte necessidade da melhor compreensão da alvenaria estrutural composta por materiais nacionais, o presente estudo baseou-se em resultados experimentais obtidos por Oliveira (2014) e por Dupim (2019) para calibração de parâmetros térmicos e mecânicos com vistas à realização de análises quantitativas, em contextos térmico e estrutural, bem como qualitativas em contexto termoestrutural.

A escolha das estratégias de modelagem numérica deste trabalho teve grande embasamento no trabalho desenvolvido por Rodovalho (2018), o qual se voltou a prismas de dois e três blocos. Desta forma, as estratégias foram ampliadas, fazendo, por exemplo, considerações de mecanismos de interação de contato entre os materiais para as análises estruturais e inserção de curvas de evolução de temperatura para as análises térmicas. Ainda, buscou-se maior simplificação do modelo, como no caso da geometria dos blocos de concreto, com o intuito de otimizar as análises numéricas sem que houvesse grandes perdas de precisão dos resultados além de propiciar maior generalização para estudos futuros baseados neste trabalho.

Tendo em vista o exposto, no que segue, estão descritas as principais conclusões referentes aos resultados e análises complementares, divididas de acordo com os modelos estudados e validados. Ao final do presente capítulo, estão inseridas as sugestões para trabalhos futuros, consideradas fortemente relevantes para continuidade do tema tratado neste trabalho. 


\subsection{COM RELAÇÃO ÀS ANÁLISES EM CONTEXTO ESTRUTURAL}

Em relação ao modelo baseado no trabalho experimental de Oliveira (2014), de pequena parede de alvenaria estrutural com argamassamento parcial e espessura de $14 \mathrm{~cm}$, vale destacar que:

- A distribuição de tensões obtida numericamente apresentou concordância com os resultados experimentais em relação às laterais fissuradas, onde foram obtidas tensões de tração superiores aos valores limites do bloco de concreto;

- A distribuição de tensões central do modelo não apresentou caminhamento acentuado de fissuração ao longo da altura da parede, porém, indicou que, após a ruptura verificada pelo modelo numérico, as tensões no meio da parede ultrapassaram as tensões limites do bloco de concreto;

- A busca pela validação numérica foi realizada até o pico de tensões, em virtude dos resultados experimentais. Após a ruptura, normalmente os ensaios são interrompidos para preservação dos equipamentos. No caso da análise numérica, esta análise é possível, porém não esteve no foco deste trabalho;

- A curva tensão-deformação numérica esteve por quase todo o tempo dentro do intervalo entre os valores máximo e mínimo obtidos experimentalmente, com variação de $2,9 \%$ superior ao valor médio de tensão de ruptura experimental.

Em relação ao modelo baseado no trabalho experimental de Dupim (2019), o qual se voltou à pequena parede de alvenaria estrutural com argamassamento total e espessuras de 14 e de $19 \mathrm{~cm}$, vale destacar que:

- A distribuição de tensões obtida numericamente apresentou concordância com os resultados experimentais em relação às laterais fissuradas, porém, não necessariamente em relação à face frontal, verificando-se nos experimentos fissuras próximas à superfície superior, enquanto na modelagem numérica foram identificadas tensões maiores próximas ao meio da altura;

- Na região central, para a parede com espessura de $14 \mathrm{~cm}$, a distribuição de tensões do modelo não apresentou caminhamento acentuado de fissuração ao longo da altura da parede. Para a espessura de $19 \mathrm{~cm}$, apresentou distribuição de tensões mais próximas às verificadas pelas fissuras experimentalmente;

- A curva tensão-deformação identificada na modelagem numérica esteve por quase todo o tempo dentro do intervalo entre os três valores experimentais estudados, obtendo, para a espessura de $14 \mathrm{~cm}$, desvio inferior a $6 \%$ para as três situações em relação à tensão de 
ruptura, e, para espessura de $19 \mathrm{~cm}$, desvio médio inferior à $8 \%$ em relação à tensão máxima.

Em relação às análises complementares vale destacar:

- Verificação de bons resultados da curva tensão-deformação até o refinamento de $1,5 \mathrm{~cm}$ da malha dos elementos;

- O estudo da variação do argamassamento para os modelos com validação apresentouse coerente com os resultados obtidos por Izquierdo (2015), experimentalmente, para as paredes com espessura de $14 \mathrm{~cm}$, com valores na ordem de 9 e $7 \%$ de redução de resistência de paredes com argamassamento parcial em relação ao total. Para as paredes com bloco de $19 \mathrm{~cm}$ a redução resultou da ordem de $16 \%$;

- O uso de variáveis de dano nas análises numéricas apresentou pouca interferência quanto aos valores máximos de tensão, verificando-se maiores divergências no pós-pico das curvas, aspecto este não pertencente ao objetivo deste trabalho;

- A variação do ângulo de dilatância estudado para paredes com espessura de $19 \mathrm{~cm}$ apresentou algumas divergências para o modelo estudado, sendo, para uma variação de $8^{\circ}$, diferenças quanto à tensão inferiores a $6 \%$, e, quanto à deformação, de até $12 \%$. O aumento do ângulo de dilatância tende a aumentar a tensão máxima do material, como verificado por Malm (2009).

\subsection{COM RELAÇÃO ÀS ANÁLISES EM CONTEXTO TÉRMICO}

Em relação ao modelo baseado nos resultados experimentais de Dupim (2019), de pequena parede de alvenaria estrutural com argamassamento total, espessura de $14 \mathrm{~cm}$ e fogo em uma face, vale destacar que:

- Fez-se necessária a calibração dos parâmetros de calor específico e condutividade térmica para os blocos estudados, em virtude da inexistência de curvas e equações para os materiais nacionais. Esta calibração foi baseada no Eurocode 2 e no Eurocode 6;

- Ao longo da seção transversal, verificou-se boa concordância dos resultados numéricos em relação aos experimentais para os tempos de incêndio estudados, principalmente na primeira parede longitudinal dos blocos de concreto, onde foram obtidos desvios inferiores a $20{ }^{\circ} \mathrm{C}$, equivalente a $3,1 \%$. Nas paredes longitudinais opostas ao fogo, os desvios ocorrentes foram inferiores a $30{ }^{\circ} \mathrm{C}$ equivalente a desvio de 9,9\%. Em relação à ordem de grandeza das variações, estas podem ser consideradas com baixo desvio; 
- Para a análise da elevação de temperatura ao longo do tempo, as mesmas situações foram verificadas, com curvas com boa concordância na primeira parede longitudinal, com queda da precisão para a parede longitudinal oposta. No centro da parede, o modelo não conseguiu obter o mesmo padrão, enquanto patamar, verificado experimentalmente;

- A ocorrência dos desvios citados anteriormente, principalmente após a primeira parede longitudinal dos blocos, pode estar relacionada às fissuras dos blocos ao longo do ensaio, situação não abordada na modelagem numérica, bem como às incertezas do próprio ensaio em virtude de desprendimentos dos mecanismos de colagem dos termopares, por exemplo;

- Em relação ao isolamento térmico, o modelo atingiu este critério aos 52 minutos. Em comparação com o resultado experimental, neste caso, em relação ao valor máximo, a diferença foi de 1 minuto.

Em relação ao modelo baseado nos resultados experimentais de Dupim (2019), em que se considera pequena parede de alvenaria estrutural com argamassamento total, com espessura de $14 \mathrm{~cm}$ e fogo em ambas as faces, vale destacar que:

- As curvas de evolução de temperatura ao longo do tempo, referente às análises numéricas, mostram tendências semelhantes aos resultados experimentais, apresentando diferenças inferiores a $40{ }^{\circ} \mathrm{C}$ ao longo do tempo em relação aos limites experimentais. Tais diferenças resultam inferiores a $6 \%$.

Em relação às análises complementares, vale destacar que:

- O refinamento da malha não gerou variações significativas neste caso. Desta forma, o uso de malha menos densa otimiza o processamento dos modelos, reduzindo o esforço computacional das análises realizadas;

- Paredes com espessura de $19 \mathrm{~cm}$ apresentam maior tempo para aquecimento na face oposta. Após 90 minutos de incêndio, a diferença em relação à parede de $14 \mathrm{~cm}$ chega a cerca de $120^{\circ} \mathrm{C}$;

- Quanto ao critério de isolamento térmico, o uso de bloco de $19 \mathrm{~cm}$ pode ser sinalizado com aumento de cerca de $35 \%$ do tempo em relação aos blocos de $14 \mathrm{~cm}$;

- O estudo das propriedades térmicas do Eurocode 2 levaram a resultados próximos à calibração realizada, exceto em relação à obtenção de maiores patamares próximos à temperatura de $100{ }^{\circ} \mathrm{C}$. Pelo Eurocode 6, ocorre grande distanciamento dos resultados obtidos experimentalmente, principalmente em relação ao atraso da evolução de 
temperatura ao longo da seção da parede. Isto se justifica pelo elevado calor específico especificado por esta norma aos $100{ }^{\circ} \mathrm{C}$;

- Quanto ao critério de isolamento térmico, utilizando as curvas propostas pelo Eurocode 6, obteve-se tempo de 84 minutos, enquanto, pelo Eurocode 2, obteve-se 50 minutos. O atraso da elevação de temperatura ao longo da seção transversal da parede levou a esse resultado;

- O modelo com uso das curvas obtidas por Dupim (2019) em relação aos gases confinados no interior do trio de paredes obteve aquecimento mais rápido da face oposta ao fogo que no caso desconsiderando o confinamento. Pelo critério de isolamento térmico, a diferença entre as duas situações é de 7 minutos;

- Com a extrapolação dos resultados inicialmente validados, acredita-se que, para a modelagem baseada nos dados de Dupim (2019), as temperaturas aos 120, 180 e 240 minutos, seriam 1037,1104 e $1153{ }^{\circ} \mathrm{C}$, respectivamente, na face oposta ao fogo.

\subsection{COM RELAÇÃO ÀS ANÁLISES EM CONTEXTO TERMOESTRUTURAL}

Em relação ao modelo baseado nos resultados experimentais de Dupim (2019), de pequena parede de alvenaria estrutural com argamassamento total, espessura de $14 \mathrm{~cm}$ e sem carregamento, cuja análise foi realizada de forma qualitativa, tem-se:

- A condição de contorno que melhor se aproxima da situação experimental foi aquela denominada CD1, a qual desconsiderou restrição ao giro no plano paralelo ao fogo, e ao deslocamento, tanto na direção da altura da parede como na direção ao fogo, na superfície superior;

- A distribuição de tensões e de deformações pouco foi alterada em relação à mudança entre as condições de contorno CD1 e CD2, sendo esta última com consideração de restrição ao deslocamento na direção do fogo na superfície superior;

- Maior variação foi apresentada entre as condições quanto aos deslocamentos, principalmente em relação às direções y e z, isto é, para a altura e para a direção do fogo, verificando o comportamento diferente entre as diferentes condições de contorno;

- Em ambas as condições, no modelo numérico, ocorre a curvatura para o lado do fogo, conforme verificado experimentalmente e por Nadjai et al. (2003).

Em relação ao modelo baseado nos resultados experimentais de Lopes et al. (2018), de pequena parede de alvenaria estrutural com argamassamento total, espessura de $14 \mathrm{~cm}$ e com carregamento, cuja análise foi em relação à tendência das curvas obtidas, tem-se: 
- As curvas deformação-tempo dos dois corpos-de-prova experimentais apresentam tendências semelhantes às vistas para a condição de contorno CC2. Em relação às demais, ocorre divergências maiores, porém, estas, foram utilizadas apenas de forma comparativa;

- Para o deslocamento do centro da parede, a tendência da curva relativa à condição de contorno CC2 aproximou-se ao experimental, porém, com grande divergência quanto à ordem de grandeza;

- Dentre as possíveis justificativas para a situação anterior, lembrando novamente que esta foi uma análise de tendências, uma vez que não foram utilizadas as propriedades, geometrias e dados de ensaio, estão a umidade que pode ser bastante distinta à considerada na modelagem, a esbeltez do elemento ensaiado, o qual é maior que o modelo numérico e, as propriedades mecânicas, propriamente ditas.

Em relação às análises complementares, vale destacar que:

- Dentre as condições de contorno estudadas, a que apresentou menor tempo em relação ao critério de resistência mecânica, definida neste trabalho, foi a CC3, a qual possibilita o giro na base e no topo da parede. As condições CC1 e CC2 sinalizam tempos próximos entre si;

- Para as condições de contorno CC2 e CC3, as quais permitem o giro na superfície superior, ocorre a inversão da curvatura após determinado tempo de incêndio, conforme indicado por Nadjai et al. (2013);

- Os deslocamentos laterais apresentam maiores intensidades na seguinte ordem decrescente: $\mathrm{CC} 3, \mathrm{CC} 2$ e CC1. Isto é esperado em virtude do aumento das restrições rotacionais de $\mathrm{CC} 3$ para $\mathrm{CC} 1$;

- Em relação às considerações com e sem confinamento dos gases na face oposta ao fogo, no primeiro caso, ocorre redução inferior a 8 minutos em relação ao critério de resistência mecânica;

- O aumento do carregamento nas paredes sinaliza a redução do tempo relativo ao critério de resistência mecânica, para ambas as condições de contorno analisadas;

- Em relação ao deslocamento lateral, o aumento da carga sinaliza a redução do deslocamento na região central da parede;

- Em todas as situações analisadas, o critério de isolamento térmico é limitante para a resistência ao fogo da parede. 
Lembrando, mais uma vez, que as análises termoestruturais tiveram apenas caráter qualitativo. Estas conclusões indicam alguma coerência em vista de algumas observações, porém, a necessidade de ensaios para validação futura desta modelagem faz-se necessária.

\subsection{SUGESTÕES PARA TRABALHOS FUTUROS}

Tendo em vista a complexidade das análises realizadas, bem como a falta de informações sobre o comportamento dos materiais sob elevadas temperaturas, são indicadas na sequência algumas lacunas que necessitam ser sanadas para um melhor entendimento da engenharia de estruturas em incêndio em contexto de alvenaria estrutural, no caso:

- Estudos comparativos entre as propriedades mecânicas dos materiais, propriamente ditas, e dos elementos formados por estes materiais, para verificação da melhor escolha para uso como dado de entrada em modelos numéricos;

- Ensaios para mapeamento das propriedades térmicas dos blocos de concreto usuais no Brasil, e determinação de curvas específicas para o calor específico e condutividade térmica em função da variação da temperatura;

- Ensaios focados na obtenção de propriedades específicas dos materiais submetidos a elevadas temperaturas, como uma possível variação do ângulo de dilatância e dos coeficientes relacionados à interface entre os materiais;

- Estudo da interferência da variável de dano no comportamento termoestrutural da parede, combinando a ação devida à elevação de temperatura e ao carregamento imposto;

- Ensaios para determinação dos coeficientes de redução da resistência e do módulo de elasticidade do material em função da variação de temperatura para diferentes percentuais de carregamentos;

- Desenvolvimento de pesquisas experimentais e numéricas inserindo diversos tipos de revestimentos às pequenas paredes para verificação quanto ao comportamento térmico e termoestrutural;

- Evolução desta pesquisa para elementos estruturais com maiores dimensões, principalmente relacionado à análise termoestrutural;

- Verificação da interferência do tipo de resfriamento para o comportamento termoestrutural da estrutura; 
- Estudo da resistência residual pós-resfriamento de estruturas de alvenaria estrutural, em contexto experimental e numérico;

- Uso de macromodelagem para estudo de paredes de alvenaria estrutural como técnica de modelagem com menor custo computacional.

Com o aprofundamento dos estudos apresentados ao longo do presente trabalho, acredita-se que contribuições poderão ser direcionadas à futura norma nacional de alvenaria estrutural em situação de incêndio, de modo que a mesma venha a apresentar subsídios suficientes para o dimensionamento desse mesmo sistema em contexto de segurança das estruturas em situação de incêndio e, consequentemente, permitir a concepção de projetos que permitam introduzir a segurança considerando elevadas temperaturas. 


\section{REFERÊNCIAS BIBLIOGRÁFICAS}

AL-HADHRAMI, L. M.; AHMAD, A. Assessment of thermal performance of different types of masonry bricks used in Saudi Arabia. Applied Thermal Engineering, v. 29, p. 11231130, 2009.

AL NAHHAS, F. et al. Resistance to fire of walls constituted by hollow blocks: Experiments and thermal modeling. Applied Thermal Engineering, v. 27, n. 1, p. 258-267, 2007.

ALMEIDA, J. C. C. Caracterização da alvenaria submetida a esforços de tração. Dissertação - Escola de Engenharia da Universidade do Minho, 2002.

ALMEIDA, J. A. P. P., Mechanical characterization of traditional adobe masonry elements. Dissertação (Mestrado) - Escola de Engenharia da Universidade do Minho, 2012.

AMERICAN CONCRETE INSTITUTE. ACI-530: Building Code Requirements and Specification for Masonry Structures, Detroit, Michigan, 2013.

AMERICAN SOCIETY FOR TESTING AND MATERIALS. ASTM C270: Standard Specification for Mortar for Unit Masonry, West Conshohocken, Pensilvania, 2014.

ASTM C1072: Standard Test Methods for Measurement of Masonry Flexural Bond Strength. Pennsylvania, 2013.

AMRHEIN, J. E. Reinforced masonry engineering handbook. 5a. edição atualizada. Boca Raton, New York. CRC Press, 1998.

ASSOCIAÇÃO BRASILEIRA DE NORMAS TÉCNICAS. NBR 5628: Componentes construtivos estruturais - Determinação da resistência ao fogo. Rio de Janeiro, 2001.

NBR 6118: Projeto de estruturas de concreto - Procedimento. Rio de Janeiro, 2014.

NBR 6136: Bloco vazado de concreto simples para alvenaria estrutural. Rio de Janeiro, 2016. 
. NBR 10636: Paredes divisórias sem função estrutural - Determinação da resistência ao fogo. Rio de Janeiro, 1989.

. NBR 12118: Blocos vazados de concreto simples para alvenaria - Métodos de ensaio. Rio de Janeiro, 2007.

- NBR 13281: Argamassa para assentamento e revestimento de paredes e tetos Requisitos. Rio de Janeiro, 2005.

- NBR 13860: Glossário de termos relacionados com a segurança contra incêndio. Rio de Janeiro, 1997.

. NBR 14323: Projeto de estruturas de aço e de estruturas mistas de aço e concreto em situação de incêndio. Rio de Janeiro, 2013.

- NBR 14432: Exigências de Resistência ao Fogo de Elementos Construtivos de Edificações - Procedimento. Rio de Janeiro, 2001.

. NBR 15200: Projeto em estruturas de concreto em situação de incêndio. Rio de Janeiro, 2012.

- NBR 15220: Desempenho térmico de edificações, Parte 2: Métodos de cálculo da transmitância térmica, da capacidade térmica, do atraso térmico e do fator solar de elementos e componentes de edificações. Rio de Janeiro, 2005.

, NBR 15812-1: Alvenaria estrutural - Blocos cerâmicos. Parte 1: Projetos, Rio de Janeiro, 2010.

. NBR 15961-1: Alvenaria Estrutural - Blocos de Concreto, Parte 1: Projeto. Rio de Janeiro, 2011.

. NBR 15961-2: Alvenaria Estrutural - Blocos de Concreto, Parte 1: Execução e Controle de Obras. Rio de Janeiro, 2011.

- NBR 16522: Alvenaria de Blocos de Concreto - Método de Ensaio. Rio de Janeiro, 2016. 
AUSTRALIAN STANDARD. AS 3700. Masonry structures. Austrália, 2018.

AYALA, F. R. R. Mechanical properties and structural behaviour of masonry at elevated temperatures. Thesis - The University of Manchester. School of Mechanical, Aerospace and Civil Engineering. 294 p. 2010.

BARBOSA, C. S. Resistência e deformabilidade de blocos vazados de concreto e suas correlações com as propriedades mecânicas do material constituinte. 2004. 152p. Dissertação (Mestrado) - Escola de Engenharia de São Carlos, Universidade de São Paulo, São Carlos, 2004.

BASTOS, P. S. S. Alvenaria Estrutural. Bauru: Universidade Estadual Paulista, 2013.

BLOQ BLOCOS DE CONCRETO. Alvenaria Estrutural. Disponível em: <http://drfaztudo.com.br/blog/2016/03/16/alvenaria-estrutural/> .Acesso em 09/04/2018

BRITEZ, C. A. Avaliação de pilares de concreto armado colorido de alta resistência submetidos a elevadas temperaturas. 2011. 252p. Tese (Doutorado) - Escola Politécnica da Universidade de São. Departamento de Engenharia de Construção Civil. São Paulo, 2011.

BRITISH STANDARDS INSTITUTION. BS 5628: Code of practice for structural use of masonry. Part 1. Unreinforced masonry. Londres, Inglaterra. 2005.

BUCHANAN, A. H. Structural design for fire safety. Canterbury: John Wiley \& Sons, 2002. $421 \mathrm{p}$.

CALLISTER JÚNIOR, W. D. Ciência e engenharia de materiais: uma introdução. Tradução: Sérgio Murilo Stamile Soares. $5^{a}$ ed. Rio de Janeiro: LTC, 2002. xvii, 589 p.

CAMPOS, J.C. Alvenaria Estrutural - Especialização em Engenharia de Estruturas. Lins: Centro Universitário de Lins, 2008.

CAMACHO, J. S. Projeto de Edifícios de Alvenaria Estrutural. Ilha Solteira: Universidade Estadual Paulista, 2006.

CÁNOVAS, F. M. Ação do fogo sobre as estruturas. In: CÁNOVAS, F. M. Patologia e terapia do concreto armado. São Paulo: Pini, 1988. Cap. 8, p. 173-201. 
CARASEK, H. Aderência de argamassa à base de cimento Portland a substratos porosos - avaliação dos fatores intervenientes e contribuição ao estudo do mecanismo da ligação. Tese (Doutorado), Universidade de São Paulo. São Paulo, 1996.

CARREIRA, D. J.; CHU, K. H. Stress-Strain Relationship for Plain Concrete in Compression. ACI Journal, Indianapolis, Title n. 82-72, nov./dez. 1985.

CARVALHO, J. D. N. A contribuição de enrijecedores laterais para o efeito arco na alvenaria estrutural. 2007. 282 p. Tese (Doutorado) - Universidade Federal de Santa Catarina, Florianópolis, 2007.

CASTRO, D. V. Experimental and numerical analysis of blockwork structures under cyclic loading. Tese. Universidade do Minho. 2003.

CASTRO, L. O. Avaliação experimental da interação de paredes de blocos de concreto de alta resistência sob ações verticais. 2015. 163 p. Dissertação (Mestrado) - Universidade Federal de Viçosa, Viçosa, 2015.

CERÂMICA CITY. Alvenaria estrutural. Disponível em: $<$ https://www.ceramicacity.com.br/bloco_ceramico/bloco-ceramico-estrutural/> Acesso em $09 / 04 / 2018$.

CHICHIERCHIO, L. C. Conforto ambiental: Desempenho térmico e acústico e proteção contra o fogo. In: ASSOCIAÇÃO BRASILEIRA DA CONSTRUÇÃO INDUSTRIALIZADA - ABCI. Manual técnico de alvenaria. São Paulo: ABCI, 1990. p. 119-141.

CHUDYBA, K.; MATYSEK, P. Methods for Determining Masonry Walls Fire Resistance. Technical Transactions, Civil Engineering Issue, 1-B (6), 3-14, 2013.

COLOMBO, A. B. Aplicação do modelo de campo distorcido de tensões na análise de peças de concreto armado via Método dos Elementos Finitos. 2011. 81 p. Dissertação (mestrado) - Escola Politécnica, Universidade de São Paulo, São Paulo. 2011.

COlVille, J.; MiltenberGer, M. A.; WOlde-TinsAe, A. M., Hollow concrete masonry modulus of elasticity. The sixth North American Masonry Conference, Philadelphia, Pennsylvania, 1993. 
COLVILlE, J.; WOLDE-TINSAE, A. M. Compressive strength of hollow concrete masonry. The Masonry Society Journal, 1991.

COSTA, C. N.; SILVA, V. P. Revisão Histórica das Curvas Padronizadas de Incêndio. Núcleo de Pesquisa em Tecnologia da Arquitetura e Urbanismo da Universidade de São Paulo - NUTAU. Universidade de São Paulo, 2006.

COSTA, C. N. Dimensionamento de elementos de concreto armado em situação de incêndio. 2008. 767 p. Tese (Doutorado) - Escola Politécnica da Universidade de São Paulo, 2008 .

CTIF, Centre of Fire Statistics (International Association of Fire and Rescue Services). World fire statistics. Report n. 21, 2016. Disponível em:

<http://www.ctif.org/sites/default/files/ctif_report22_world_fire_statistics_2017.pdf>. Acesso em: 14 set. 2017.

CÜLFIK, M. S.; ÖZTURAN, T. Effect of elevated temperatures on the residual mechanical properties of high-performance mortar. Cement and Concrete Research 32. p. 809-816, 2012.

DORR, J. B. Modelos numéricos de pilares de aço em situação de incêndio considerando a influência da restrição axial. 2010. 210p. Dissertação (mestrado) - Escola de Engenharia de São Carlos, Universidade de São Paulo, São Carlos, São Paulo. 2010.

DRYSDALE, R. G.; HAMID, A. A.; BAKER, L. R. Masonry Structures: Behavior and Design. Englewood Cliffs: Prentice-Hall, New Jersey, 1994. 784 p.

DUPIM, R. H. Resistência residual de compressão de blocos, prismas e pequenas paredes de alvenaria estrutural de blocos de concreto submetidos à situação de incêndio. Dissertação (Mestrado). Escola de Engenharia de São Carlos, Universidade de São Paulo, São Carlos, Brasil, 2019.

ECIVIL. Alvenaria Estrutural. Disponível em: <http://www.ecivilnet.com/dicionario/o-quee-alvenaria-estrutural.html>. Acesso em 09/04/2018.

EUROPEAN COMMITTEE FOR STANDARDIZATION. Eurocode 1: Actions on structures - Part 1.1: General actions - Actions on structures exposed to fire. Bruxelas, Bélgica 2002. 
- Eurocode 2: Design of concrete structures - Part 1.1: General rules and rrules for buildings. Bruxelas, Bélgica 2004.

- Eurocode 2: Design of concrete structures - Part 1.2: General rules - Structural fire design. Bruxelas, Bélgica 2004.

. Eurocode 6: Design of masonry structures - Part 1.1: General rules for reinforced and unreinforced masonry structures. Bruxelas, Bélgica 2005.

- Eurocode 6: Design of masonry structures - Part 1.2: General rules - Structural fire design. Bruxelas, Bélgica 2005.

. Eurocode 6: Design of masonry structures - Part 2: Design considerations, selection and executionof masonry. Bruxelas, Bélgica 2006.

EUROPEAN STANDARD. EN 1052-2, Methods of test for masonry: Part 2: Determination of flexural masonry, 1999.

FÉDÉRATION INTERNATIONALE DU BÉTON - FIB. Fire design of concrete structures - Structural behavior and assessment. State-of-art report, bulletin 46, 216 p., 2008.

FRANCO, L.S. Aplicação de diretrizes de racionalização construtiva para a evolução tecnológica dos processos construtivos em alvenaria estrutural não armada. 1992. 319p. Tese (Doutorado) - Escola Politécnica da Universidade de São Paulo, São Paulo, 1992.

FREITAS, A. A (2008). Análise numérica e experimental do comportamento de prismas e miniparedes submetidos à compressão. 2008. 289p. Tese (Doutorado) - Escola de Engenharia de São Carlos, Universidade de São Paulo, São Carlos, 2008.

GANESAN, T. P.; RAMAMURTHY K., Behavior of concrete hollow-block masonry prisms under axial compression. Journal of Strucutural Engineering-ASCE. Jul. Vol. 118 (n. 7), 1751-1769. 1992.

GENIKOMSOU, A. S.; POLAK, M. A. Finite element analysis of punching shear of concrete slabs using damaged plasticity model in Abaqus. Journal of Structural Engineering, p. 38-48. Canada, 2015. 
GOMES, I. R. Simulação numérica do ensaio de compressão de prismas de alvenaria pelo método dos elementos finitos com comportamento de interface. 2001. Tese (Doutorado) Universidade Federal de Santa Catarina, Florianópolis. 2001

GUO, Zhenhai. Principles of Reinforced Concrete. 1 edition. Elsevier: Oxford, 2014.

HAACH, V. G. Developrnent of a design method for reinforced masonry subJected to inplane loading based on experimental and numerical analysis. $\mathrm{PhD}$ Thesis. University oi Minho, Portugal. 2009.

HENDRY, A. W.; SINHA, B. P.; DAVIES, S. R., Design of masonry structures. London, UK, E \& FN Spon, 1997.

HENDRY, E. A. W. Masonry walls: materials and construction. Construction and Building Materials, vol 15, $\mathrm{n}^{\circ}$ 8, 2001. P. 323-330.

INGHAM, J. Forensic engineering of fire-damaged structures. Proceedings of ICE, v. 162, $12-17,2012$.

INTERNATIONAL ORGANIZATION FOR STANDARDIZATION. ISO 834: Fire resistance tests - elements of building construction: Part 1. General requirements. Gèneve, 1999.

ISO 8421-1: Fire protection - Vocabulary: Part 1. General terms and phenomena of fire, 1987.

INSTITUTO DE PESQUISAS TECNOLÓGICAS (IPT). Relatório de ensaio número 1050 328-203, Determinação da resistência ao fogo em parede sem função estrutural. São Paulo, 2013. 12 p.

INSTITUTO DE PESQUISAS TECNOLÓGICAS (IPT). Relatório de ensaio número 1072 608-203, Determinação da resistência ao fogo em parede sem função estrutural. São Paulo, 2015. 12 p.

INSTITUTO DE PESQUISAS TECNOLÓGICAS (IPT). Relatório de ensaio número 1081 659-203, Determinação da resistência ao fogo em parede sem função estrutural. São Paulo, 2016. 13 p. 
IZQUIERDO, O. S. Influência do tipo de argamassamento e da utilização de peças de ajuste dimensional na resistência à compressão da alvenaria de blocos de concreto. 2011. 155p. Dissertação (Mestrado) - Escola de Engenharia de São Carlos, Universidade de São Paulo. São Carlos, 2011.

IZQUIERDO, O. S. Estudo da interface bloco/graute em elementos de alvenaria estrutural. 2015, 290p. Tese (Doutorado) - Escola de Engenharia de São Carlos, Universidade de São Paulo, São Carlos, 2015.

JANKOWIAK, T., LODYGOWSKI, T. Identification of parameters of concrete damage plasticity constitutive model. Foundations of Civil and Environmental Engineering, No. 6, 53-69, 2005.

JANUZZI, R. V. Modelagem do comportamento mecânico de blocos e prismas produzidos com escória de aciaria elétrica para alvenaria estrutural. 2014. 122p. Dissertação (Mestrado) - Escola de Minas da Universidade de Ouro Preto, Universidade de Ouro Preto, Ouro Preto, 2014.

JUKES, P.; RIDDINGTON, J. R. A review of masonry joint shear strength test methods. University of Sussex. Masonry international Journal, vol, 11, № 2, 1997.

JUSTE, A. E. Estudo da resistência e da deformabilidade da alvenaria de blocos de concreto submetida a esforços de compressão. 2001. 229p. Dissertação (Mestrado) - Escola de Engenharia de São Carlos, Universidade de São Paulo. São Carlos, 2011.

KARAHAN, O. Residual compressive strength of fire-damaged mortar after post-fire-aircuring. Fire and Material, vol 35, Issue 8, Dec. 2011. P. 561-567.

KIMURA, E. F. A. Análise termoestrutural de pilares de aço em situação de incêndio. 2009. 212p. Dissertação (Mestrado) - Escola de Engenharia de São Carlos, Universidade de São Paulo, São Carlos, São Paulo. 2009.

KLEEMAN, P. W.; PAGE, A. W. (1990). The in-situ properties of packing materials used in compression tests. Masonry International, London, v.4, n.2. 
LANDI, F. R. Ação do incêndio sobre as estruturas de concreto armado. Boletim técnico 01/86, Escola Politécnica da Universidade de São Paulo, Departamento de Engenharia de Construção Civil, São Paulo, 1986. 22 p.

LEE, J.; FENVES, G.L. Plastic-damage model for cyclic loading of concrete structures. J. Eng. Mech. 1998, 124, 892-900.

LEITE, H. A. L.; MORENO JÚNIOR, A. L.; TORRES, D. L. Dimensionamento da alvenaria estrutural em situação de incêndio: contribuição à futura normatização nacional. Ambiente Construído, Porto Alegre, v. 16, n. 2, p. 89-107, abr./jun. 2016.

LEITE, H. A. L. Alvenaria estrutural em situação de incêndio - Proposta de avaliação com vistas à normatização. 2018. 152 p. Dissertação (Mestrado) - Faculdade de Engenharia Civil, Arquitetura e Urbanismo, Universidade Estadual de Campinas. Campinas ,2018.

LIMA, R. C. A. Investigação do comportamento de concretos em temperaturas elevadas. 2005. Tese (Doutorado em Construção), Universidade Federal do Rio Grande do Sul -UFRGS, Porto Alegre, 2005.

LOPES, R. F. R.; RODRIGUES, J. P. C.; PEREIRA, J. M.; LOURENÇO, P. B. Análise experimental de uma parede de alvenaria estrutural de blocos de concreto de três células em situação de incêndio. Concreto e Construções, ed. 90. Abr. - Jun. 2018. p. 86 - 94.

LOURENÇO, P. B., Computational strategies for masonry structures. Delft University Press: The Netherlands., 1996.

LUBLINER, J.; OLIVER, J.; OLLER, S.; ONATE, E. A plastic-damage model for concrete. Inter. J. Solids Struct. 1989, 25, 299-326.

MALM, R. Predicting shear type crack initiation and growth in concrete with non-linear finite element method, 2009. Bulletin 97.

MALM, R. et al. Shear cracks in concrete structures subjected to in-plane stresses. Licentiate Thesis 2006. Bulletin 88. 
MARCATTI, J.; COELHO FILHO, H. S.; BERQUÓ FILHO, J. E. Compartimentação e afastamento entre edificações. In: SEITO, A. I. et al (Coord.). A segurança contra incêndio no Brasil. São Paulo: Projeto Editora, 2008. p. 169-179.

MATA, R. C., Influência do padrão de argamassamento na resistência à compressão de prismas e mini-paredes de alvenaria estrutural de blocos de concreto. Dissertação. Florianópolis. Universidade Federal de Santa Catarina. 2006.

MEDEIROS, J. S.; SABBATINI, F. H. Alvenaria estrutural não armada de blocos de concreto: Produção de componentes e parâmetros de projeto. Boletim Técnico da Escola Politécnica, Universidade de São Paulo, 1993.

MEHTA, P. K.; MONTEIRO, P. J. M. Concreto: estrutura, propriedades e materiais. São Paulo, PINI, 1997. 573 p.

MEYER, U. Extended Application Rules for the fire performance of masonry walls. In 7th International Masonry Conference, Londres, 2006. 4 p. Disponível em < http://www.masonry.org.uk/ >. Acesso em: 15 set. 2018.

MEYER, U. Fire Resistance Assessment of Masonry Structures. In: WORKSHOP 'STRUCTURAL FIRE DESIGN OF BUILDINGS ACCORDING TO THE EUROCODE', 2012, Brussels. Anais eletrônicos. Disponível em: http://eurocodes.jrc.ec.europa.eu/doc/2012 _11_WS_fire/presentations/07-MEYER-EC-FireDesign-WS.pdf>. Acesso em: 27 jun. 2018.

MOHAMAD, A. A. E; CHEN, Z. Experimental and Numerical Analysis of the Compressive and Shear Behavior for a New Type of Self-Insulating Concrete Masonry System. Applied Sciences Journal, Beijing, China, 2016.

MOHAMAD, G., Mecanismo de ruptura da alvenaria de blocos à compressão.Tese, Universidade do Minho, Guimarães, Portugal, 2007.

MORAlES, G.; CAMPOS, A.; FAGANELlO, A. M. P. A ação do fogo sobre os componentes do concreto. Ciência Exatas e Tecnológicas, Londrina, v. 32, n.1, p. 47-55, Jan/Mar. 2011 
MORENO JÚNIOR, A. L.; MOLINA, J. C. Considerações de interesse sobre a avaliação em laboratório de elementos estruturais em situação de incêndio: contribuições à revisão da NBR 5628/2001. Ambiente Construído, Porto Alegre, v. 12, n. 4, out./dez. 2012.

NADJAI, A.; O'GARRA, M.; ALI, F. Finite element modeling of compartment masonry walls in fire. Journal of Computer \& Structures, Vol 81, n 18-19, p. 1923-1930. 2003.

NADJAI, A.; O’GARRA, M.; ALI, F, LAVERTY, D. Finite element modeling of compartment masonry walls in fire. Fire and Materials p. 163-182. 2003.

NADJAI, A.; O'GARRA, M.; ALI, F.; JURGEN, R. Compartment Masonry Walls in Fire Situations. Fire Technology, v. 42, 211-231, 2006.

NGUYEN, T. et al. The behavior of masonry walls subjected to fire: Modelling and parametrical studies in the case of hollow bunrt-clay bricks. Fire Safety Journal, v 44, no 4 , 2009. p. 629-641.

NGUYEN, T. D.; MEFTAH, F.; CHAMMAS, R.; MEBARKI, A. The behaviour of masonry walls subjected to fire: Modelling and parametrical studies in the case of hollow burntclay bricks. Fire Safety Journal 44 p. 629-641, 2009.

NGUYEN, T. D.; MEFTAH, F. Behavior of clay hollow-brick masonry walls during fire. Part 1: Experimental analysis. Fire Safety Journal 52 p. 55-64, 2012.

NORTHWEST CONCRETE MASONRY ASSOCIATION - NWCMA. Concrete Masonry Fire Resistance. TEK Note. Lynwood, WA, 2005. 4 p.

NUnES, N. E. M. Código Computacional para Análise Térmica Tridimensional de Estruturas em Situação de Incêndio. 2014. Dissertação (Mestrado) - Escola de Engenharia de São Carlos, Universidade de São Paulo, São Carlos, 2014.

O'CONNOR, D. J.; SILCOCK, G. W. H.; MORRIS, B. An investigation of scale modeling of the thermo-structural performance of compartment walls in standard fire tests. In: 4 th International Mansonry Conference, 1995, Londres. p. 402-406. 
OLIVEIRA, L. A. P. de. Estimativa da resistência ao fogo de paredes de alvenaria pelo critério de isolamento térmico. Boletim Técnico da Faculdade de Tecnologia de São Paulo, $\mathrm{n}^{\circ}$ 05, dezembro 1998. p. Disponível em: <http://bt.fatecsp.br/system/articles/26/original02luiz antonio.pdf>. Acesso em: 15 set. 2018.

OLIVEIRA, L. M. F. Estudo teórico e experimental do comportamento das interfaces verticais de paredes interconectadas de alvenaria estrutural. 2014. Tese (Doutorado) Escola de Engenharia de São Carlos, Universidade de São Paulo, São Carlos, 2014.

PARSEKIAN, G. A. Tecnologia de produção de alvenaria estrutural protendida. Tese (Doutorado) - Escola Politécnica, Universidade de São Paulo. 2002.

PARSEKIAN, G. A.; HAMID, A. A.; DRYSDALE R, R. G. Comportamento e dimensionamento de alvenaria estrutural. São Carlos: Edufscar. 2012

PELETEIRO, S. C. Contribuições à modelagem numérica de alvenaria estrutural. 2002. Tese (Doutorado) - Escola de Engenharia de São Carlos, Universidade de São Paulo, São Carlos, 2002.

POÇAS. J. P. M. Estudo do comportamento térmico e mecânico em paredes de alvenaria. 2008. Dissertação (Mestrado) - Faculdade de Engenharia da Universidade do Porto, Universidade do Porto, Porto, 2008.

POLÍCIA MILITAR DO ESTADO DE SÃO PAULO. Instrução Técnica n. 03: Terminologia de Segurança contra Incêndio. São Paulo, 2011.

. Instrução Técnica n. 08: Resistência ao Fogo dos Elementos de Construção. São Paulo, 2011.

. Instrução Técnica n. 09: Compartimentação horizontal e compartimentação vertical. São Paulo, 2011.

PURKISS, J. A. Fire safety engineering design of structures. Oxford: Butterworth Heinemann, 1996.

RAMALHO, M.A.; CORRÊA, M.R.S. Projeto de edifícios de alvenaria estrutural. 1.ed. São Paulo: Editora Pini, 1a edição, 174p. 2003. 
RAZENTE, J. A. Aplicação de recursos computacionais em projetos de edifícios em alvenaria. 2004. 188p. Dissertação (Mestrado) - Escola de Engenharia de São Carlos, Universidade de São Paulo, São Carlos, 2004.

RIGÃO, A. O. Comportamento de pequenas paredes de alvenaria estrutural frente a altas temperaturas. 2012. 142p. Dissertação (Mestrado) - Escola de Engenharia, Universidade Federal de Santa Maria, Santa Maria, 2012.

RIGOBELLO, R. Desenvolvimento e aplicação de código computacional para análise de estruturas de aço aporticadas em situação de incêndio. 2011. 272p. Tese (Doutorado) Escola de Engenharia de São Carlos, Universidade de São Paulo, São Carlos, 2011.

RIO GRANDE DO SUL. Decreto $\mathbf{n}^{0}$ 38.273, de 09 de Março de 1998. Altera as Normas Técnicas de Prevenção de Incêndios, aprovadas pelo Decreto nº 37.380 de 29 de Abril de 1997.

RIVA, P. Structural behaviour under fire conditions: draft version (Feb. 2006). In: FIB Guidelines on fire design. [S.1.: s.n], 2006. Chapt. 3.

ROCHA, F. M. Modelos numéricos de vigas mistas de aço e concreto pertencentes a sistemas de pisos mistos de pequena altura em situação de incêndio. 2012. 267p. Dissertação (Mestrado) - Escola de Engenharia de São Carlos, Universidade de São Paulo, São Carlos, 2012.

ROCHA, F. M. Pilares de aço e mistos de aço e concreto inseridos em paredes em situação de incêndio. 2016. 262p. Tese (Doutorado) - Escola de Engenharia de São Carlos, Universidade de São Paulo, São Carlos, Brasil. Universidade de Coimbra, Portugal, 2016.

RODOVALHO, F. S. Simulação numérica de blocos e prismas de alvenaria em situação de incêndio. 2018. 158 p. Dissertação (Mestrado). Escola de Engenharia de São Carlos, Universidade de São Paulo, São Carlos, 2018.

ROMAN, H.; MUTTI, C.N.; ARAÚJO, H.N. Construindo em alvenaria estrutural. Florianópolis, UFSC, 1999.

ROSEMANN, F. Resistência ao fogo de paredes de alvenaria estrutural de blocos cerâmicos pelo critério de isolamento térmico. 2011. 160p. Dissertação (Mestrado) Universidade Federal de Santa Catarina, Florianópolis, 2011. 
RUSSO, S.; SCIARRETTA, F. Masonry exposed to high temperatures: Mechanical behaviour and properties - An overview. Fire Safety Journal, v. 55, 69 - 86, 2013.

RUSSO, S.; SCIARRETTA, F. Numerical study on the residual mechanical performance of traditional brickwork after standard fire exposure. International Conference on Structural Analysis of Historical Constructions. Mexico City, Mexico, 12 p. 2014.

SABBATINI, F. H. Argamassas de assentamento para paredes de alvenaria resistente. Boletim técnico 02/86, Escola Politécnica de São Paulo, Departamento de Engenharia de Construção Civil, USP, São Paulo, 1986. 26 p .

SANTOS, D. B. R. Modelagem numérica de lajes mistas de aço e concreto em situação de incêndio. 2014. 243p. Dissertação (mestrado) - Escola de Engenharia de São Carlos, Universidade de São Paulo, São Carlos, 2014.

SANTOS, C. F. R. Avaliação numérica da interação de paredes de alvenaria estrutural submetidas às ações verticais. 2016. 213 p. Dissertação (Mestrado) - Universidade Federal de Viçosa, Viçosa, 2016.

SANTOS, C. F. R; SIMÕES, Y. S.; RODOVALHO, F. S.; NALON, G. H. Thermo-structural modeling of clay units masonry walls under fire conditions. Cilamce, Florianópolis, 2017.

SCHNEIDER, U. Concrete at high temperatures - A general review. Fire Safety Journal 13. 1988; p. 55-68.

SEITO, A. I. et al. A segurança contra incêndios no Brasil. São Paulo: Projeto Editora, 2008. $484 \mathrm{p}$.

SILVA, V. P. Estruturas de aço em situação de incêndio. 1997. 170p. Tese (Doutorado) Escola Politécnica da Universidade de São Paulo. Departamento de Engenharia de Estruturas e Fundações, São Paulo, 1997.

SILVA, V. P. Estruturas de Aço em Situação de Incêndio. São Paulo: Zigurate, 2001.

SILVA, V. P.; VARGAS, M.R. Resistência ao Fogo das Estruturas de Aço. Instituto Brasileiro de Siderurgia - CBCA, Rio de Janeiro, 2003. 
SILVA, V. P. Sobre o coeficiente $\gamma s$ do método do tempo equivalente para a determinação do tempo requerido de resistência ao fogo das estruturas. Revista Minerva, Vol $5, \mathrm{n}^{\circ} 3$, 2008. P. 315-321.

SILVA, V. P.; PANNONI, F.D.; PINTO, E.M.; SILVA, A.A. da. Segurança das Estruturas em Situação de Incêndio. In: SEITO, A.I. et al. A segurança contra incêndio no Brasil. 496p. Projeto Editora. São Paulo. p. 135-167, 2008.

SIMULIA. Abaqus analysis user's manual 6.13. Dassault Systems Providence: Waltham, MA, USA, 2013.

SOARES, S. M. B. Alvenaria Estrutural. Porto Alegre: Pontifícia Universidade Católica do Rio Grande do Sul, 2010.

STANCATO, A. C. Determinação da condutividade térmica e da resistência mecânica em argamassa leve. Dissertação (Mestrado). Universidade Estadual de Campinas - Faculdade de Engenharia Civil. Campinas -SP, 184 p. 2000.

TANGO, C. E. S. (1981). Ensaios de controle de alvenaria estrutural de blocos de concreto. Seminário sobre Inspeção de Concreto. Publicação I.11. Instituto Brasileiro de Concreto.

THOMAZ, E.; HELENE, P. Qualidade no projeto e na execução de alvenaria estrutural e de alvenarias de vedação em edifícios. Boletim Técnico da Escola Politécnica da USP, BT/PCC/252. São Paulo: EPUSP, 2000. 31 p.

Van der PLUIJM, R. Out-of-Plane bending of masonry, behavior and strength. Tese, Eindhoven University of Technology, 1999.

WANG, Y. C. Steel and Composite Structures. Behavior and design for fire safety. London, Spon Press, 2002, New York. 332 p. 


\section{APÊNDICE A - NOÇÕES GERAIS SOBRE INCÊNDIO}

\section{A.1. DEFINIÇÃO}

O fogo, elemento essencial para a existência de incêndio é definido pela ISO 84211:1987, como o processo de combustão caracterizado pela emissão de calor acompanhado de fumaça, chama ou ambos. Esta definição é semelhante à da ABNT NBR 13860:1997, a qual estabelece como o processo de combustão caracterizado pela emissão de calor e luz.

Para a existência do fogo, faz-se necessária a coexistência de quatro elementos: combustível, comburente, calor e reação em cadeia, comumente representado através do tetraedro do fogo, visto na Figura A.1.

Figura A.1 - Tetraedro do fogo

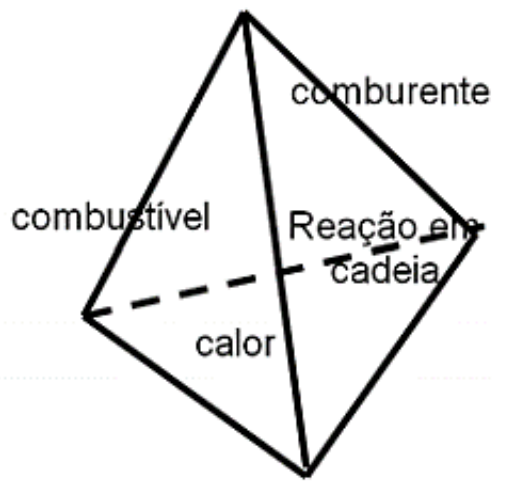

Fonte: Seito et al. (2008)

O combustível se refere ao material que será oxidado, enquanto o comburente, ao material que será reduzido (oxigênio). $\mathrm{O}$ calor se refere à fonte de ignição para início do processo de combustão, como no caso de um atrito, chama ou outra reação química que produza calor para dar início ao processo. Finalmente, a reação em cadeira, existente após o começo da combustão, consiste no uso de parte do calor liberado como ignição possibilitando a continuidade do processo de combustão.

Ainda de acordo com a ISO 8421-1:1987, o incêndio é definido como a combustão rápida disseminando-se de forma descontrolada no tempo e no espaço. A ABNT NBR 13860:1997, estabelece a definição de incêndio como fogo fora do controle. Para Seito et al. (2008), é impossível medir o incêndio através do tamanho do fogo. 


\section{A.2. MECANISMOS DE TRANSFERÊNCIA DE CALOR}

A capacidade resistente e os esforços de uma estrutura possuem dependência, seja de forma direta ou indireta, da temperatura dos materiais constituintes. Além disso, é de grande relevância o conhecimento acerca da temperatura dos gases no ambiente em chamas, além das formas de transferência de calor, para que seja possível a escolha da melhor técnica de combate ao incêndio.

Wang (2002) define a transferência de calor como a interação que ocorre entre um determinado sistema e o meio, ou, mesmo, entre dois sistemas, os quais apresentem temperaturas diferentes e estejam em contato, sendo os possíveis mecanismos de transferência, a condução, a convecção e a radiação.

O conhecimento dos mecanismos de transferência de calor torna-se relevante no dimensionamento de estruturas em situação de incêndio, uma vez que tanto as curvas de incêndio padrão quanto as de incêndio natural referem-se à temperatura dos gases do ambiente em chamas e, para que sejam feitas as considerações adequadas, necessita-se conhecer as temperaturas superficiais e a forma que se propagam ao longo do elemento.

$\mathrm{O}$ intuito da análise térmica em elementos estruturais se refere à determinação da variação de temperatura ou da variação do campo de temperaturas no elemento de interesse, de acordo com as condições de contorno decorrentes do modelo de incêndio adotado. A análise pode ser dividida em duas partes, no caso de estruturas em situação de incêndio, sendo elas, a determinação do calor transferido por convecção e radiação, e, por condução. No primeiro caso, a determinação é feita através do contorno do elemento, enquanto no segundo, no interior do mesmo.

A condução é a transferência de energia térmica entre átomos e/ou moléculas vizinhas em uma substância devido a um gradiente de temperatura, sendo que esta transferência de calor ocorre de regiões com maior energia cinética molecular para regiões de menor energia através de colisões moleculares, sem que haja movimento macroscópico da matéria. A lei física que governa esse fenômeno é a de Fourier (1822), conforme visto na equação (A.1):

$$
\dot{Q}=-\lambda \frac{d T}{d x}
$$

Onde:

$\lambda$ : condutividade térmica do material em $\mathrm{W} / \mathrm{m}^{\circ} \mathrm{C}$;

$\frac{d T}{d x}$ : diferença de temperatura ao longo da espessura infinitesimal. 
Este mecanismo é válido tanto para situações em resposta a um fluxo de calor gerado na superfície do elemento (por radiação ou convecção) quanto para situações em que existem elementos estruturais em contato entre si com variação de temperatura.

A convecção é a transferência de calor entre um sólido e um fluido em movimento nas adjacências desse sólido, desde que exista uma diferença de temperatura entre eles. De modo geral, o fluxo de calor por convecção é proporcional à diferença de temperatura dos gases aquecidos e a temperatura na superfície do elemento, confome visto na equação (A.2):

$$
\dot{Q}=\alpha_{c} \cdot\left(T_{g}-T_{m}\right)
$$

Onde:

$\alpha_{c}$ : coeficiente de transferência de calor por convecção em $\mathrm{W} / \mathrm{m}^{2}{ }^{\circ} \mathrm{C}$;

$T_{g}$ : temperatura dos gases aquecidos em ${ }^{\circ} \mathrm{C}$;

$T_{m}$ : temperatura na superfície do elemento em ${ }^{\circ} \mathrm{C}$.

Na situação de incêndio, os gases quentes, os quais são menos densos, tendem a ocupar a atmosfera superior, enquanto os gases frios, de densidade maior, tendem a se movimentar para a atmosfera inferior do ambiente, gerando a transferência de calor para a estrutura através do contato entre os gases quentes e a estrutura (DORR, 2010).

A radiação é a transferência de energia por meio de ondas eletromagnéticas sem a necessidade de um meio material para se propagar. É o principal mecanismo nos processos de transferência de calor que ocorrem em elevadas temperaturas, inclusive para situações em que se tenha a ocorrência de vácuo. A partir da lei de Kirchhoff, é possível demonstrar que o fluxo de calor por radiação é dado pela equação (A.3):

$$
\dot{Q}=\varepsilon_{r} \cdot \sigma \cdot\left(T_{1}^{4}-T_{2}^{4}\right)
$$

Onde:

$\varepsilon_{r}:$ emissividade resultante entre os gases aquecidos e a superfície considerada;

$\sigma$ : constante de Stefan-Boltzmann (igual a $5,67.10^{-8} \mathrm{~W} / \mathrm{m}^{2} \mathrm{~K}^{4}$ );

$T_{1}$ e $T_{2}$ : temperatura das superfícies 1 e 2 , respectivamente.

Em alvenaria estrutural, uma vez que as unidades não são maciças, a transferência de calor ocorre de maneira distinta ao longo da parede. Nas regiões maciças, a transferência ocorre 
por condução, enquanto que nos vazios, a transferência é feita por convecção e radiação (ALHADHRAMI e AHMAD, 2009), conforme visto na Figura A.2.

Figura A.2 - Transferência de calor em bloco submetido a incêndio compartimentado

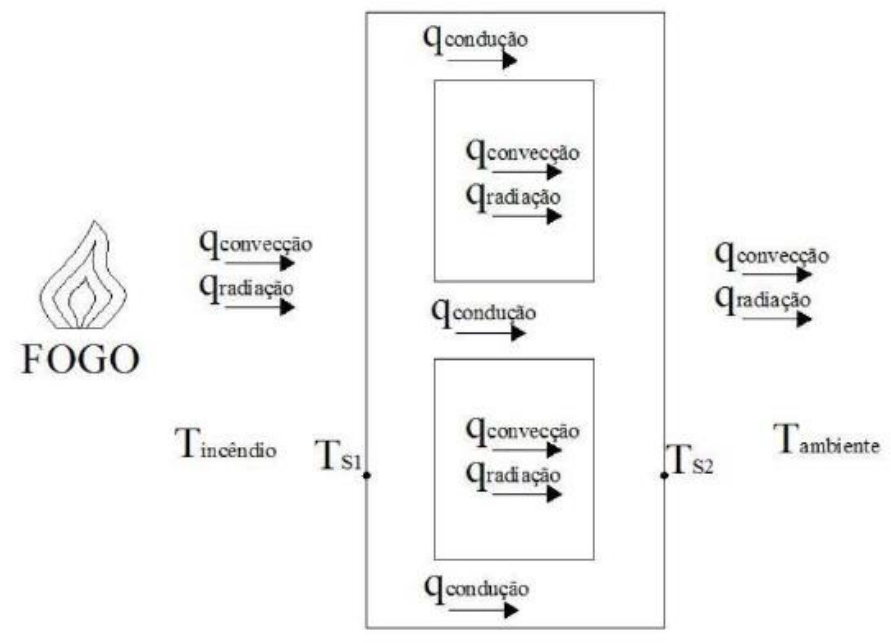

Fonte: Rosemann (2011)

Em situações em que é realizado o preenchimento do interior dos blocos por materiais sólidos, como no caso de graute, areia ou materiais de baixa massa específica, a transferência de calor ocorre por condução nos septos dos blocos. Para casos em que exista revestimentos, a transferência de calor nestas camadas ocorre também por condução.

Em relação ao perfil de distribuição de temperatura ao longo da espessura da parede, este ocorre em regime transiente e de forma não linear, o que foi verificado por O'Connor; Silcock; Morris (1995); Nadjai et al. (2006) e Nguyen et al. (2009) em ensaios de resistência ao fogo de paredes de alvenaria. Nadjai et al. (2006) comenta que o aumento de fatores como a espessura e a taxa de aquecimento leva ao aumento da concavidade da curva de temperatura ao longo da espessura. A Figura A.3 indica tal situação.

Figura A.3 - Distribuição de temperatura ao longo da espessura da parede

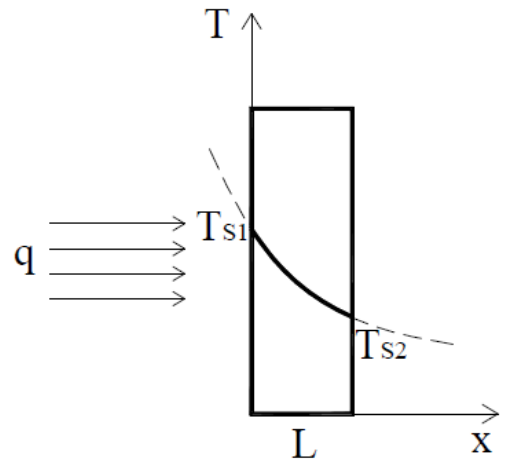

Fonte: Rosemann (2011) 


\section{A.3. CARACTERIZAÇÃO DE UM INCÊNDIO}

O incêndio é modelado e caracterizado através de curvas que associam a variação de temperatura com o tempo, isto é, curvas que combinam a elevação de temperatura em função do tempo de duração do incêndio, permitindo, assim, estimar os valores máximos de temperatura dos gases no ambiente em chamas.

Silva e Vargas (2003) afirmam que a principal característica de um incêndio é a curva que fornece a temperatura dos gases em função do tempo. De acordo com Seito et al. (2008), todo o incêndio possui uma curva natural de evolução com três fases distintas, sendo elas:

- Ignição (fase inicial): é o incêndio incipiente, com crescimento lento da temperatura, cuja duração varia entre 5 e 20 minutos. Nesta fase, não há grande influência das características do compartimento, tais como aberturas ou o tipo de material existente, e, não há risco de colapso estrutural. De acordo com Purkiss (1996), esta fase também é chamada de pré-flashover, sendo finalizada no instante do flashover (inflamação generalizada). Caso as medidas de proteção sejam eficientes, o fogo será extinto rapidamente, não havendo necessidade de verificação estrutural (COSTA; SILVA, 2006).

- Aquecimento (fase intermediária): inicia-se com a ignição, momento no qual as chamas começam a aumentar e ocorre mudança súbita de crescimento da temperatura. Nesta fase, todo o ambiente é tomado por gases e vapores combustíveis. A temperatura dos gases quentes ultrapassa os $300^{\circ} \mathrm{C}$ e atinge o pico da curva (temperatura máxima do incêndio). De acordo com Purkiss (1996), em incêndio compartimentado, a temperatura máxima dos gases pode superar os $1000{ }^{\circ} \mathrm{C}$.

- Resfriamento (fase final): ocorre a diminuição da temperatura do ambiente e das chamas, com o esgotamento do material combustível. Purkiss (1996) descreve a possibilidade de ocorrência de um pequeno "atraso" para o início desta fase, em virtude da inércia térmica, isto é, ao aumento da temperatura no elemento estrutural por alguns minutos durante o período de resfriamento.

De acordo com Walton \& Thomas $^{14}$ (1995, apud COSTA; SILVA, 2006 p.02), a temperatura associada ao flashover varia entre $300{ }^{\circ} \mathrm{C}$ e $650{ }^{\circ} \mathrm{C}$, embora o intervalo compreendido entre $300{ }^{\circ} \mathrm{C}$ e $600{ }^{\circ} \mathrm{C}$ seja o mais usado.

\footnotetext{
${ }^{14}$ WALTON, W. D; THOMAS, P. H. Section3/Chapter 6: Estimating temperatures in compartment fires. In: DiNenno, P. J.; Beyler, C. L.; Custer, R. L. P.; Walton, W. D., (Eds.). Handbook of Fire Protection Engineering. 2nd Edition. Quincy: NFPA, 1995.
} 
Dentre as fases citadas, existem estágios para delimitar de forma mais detalhada a evolução do incêndio. Dentre os estágios, tem-se: pré-ignição, crescimento do fogo, incêndio desenvolvido e extinção, conforme indicado pela Figura A.4.

Figura A.4 - Curva de evolução de incêndio

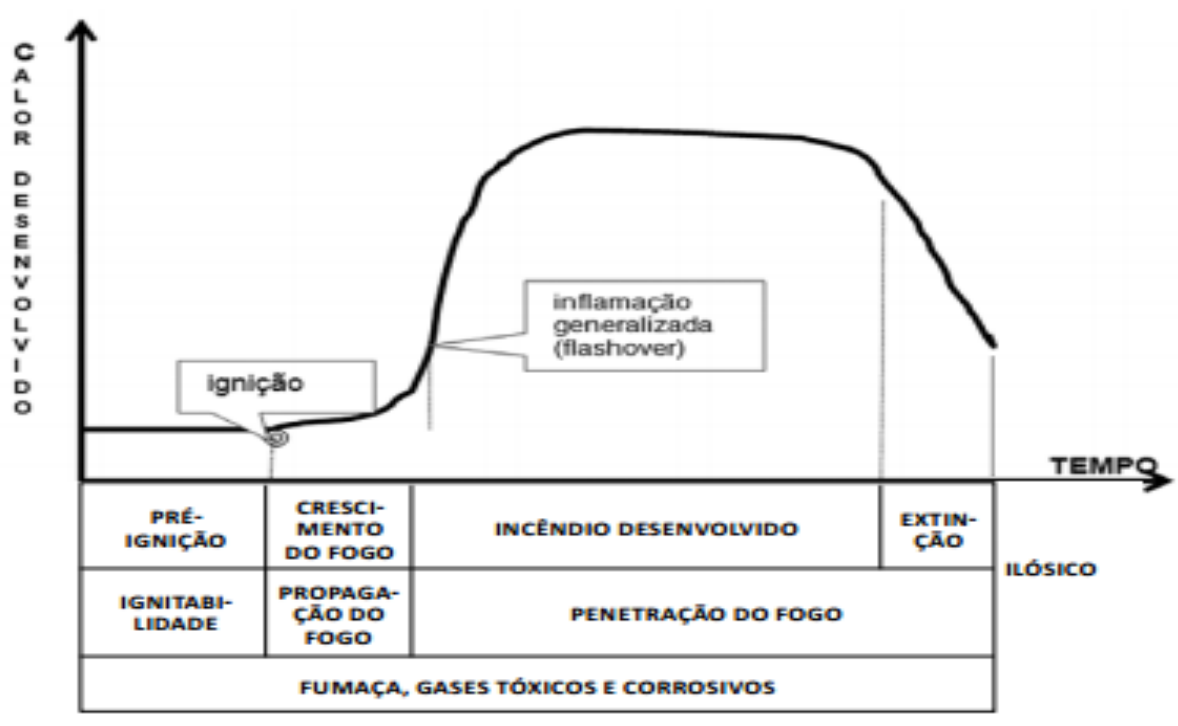

Fonte: ISO/TS $3814^{15}$ apud Seito et al. (2008)

O primeiro estágio possui um aumento lento de temperatura e pode ser dividido, ainda, em duas fases: abrasamento e chamamento. No primeiro caso, não há chamas e o calor é produzido lentamente, porém, com possibilidade de preenchimento do compartimento com gases combustíveis e fumaça. O chamamento é a forma de combustão com chama e fumaça. No segundo estágio ocorre a propagação do fogo para outros objetos e para os materiais da cobertura ou teto. Neste estágio é atingido o flashover. Denomina-se incêndio desenvolvido, o estágio em que o fogo já se espalhou por todo ou quase todo material combustível disponível e as temperaturas atingem seu pico causando danos em elementos estruturais, sendo o oxigênio consumido rapidamente. A extinção é o estágio semelhante ao citado anteriormente nas fases do incêndio.

Quanto ao nível de propagação do incêndio, diversos são os fatores a serem considerados. Geralmente, citam-se a carga de incêndio, o grau de ventilação e as características dos materiais da compartimentação (COSTA; SILVA, 2006).

\footnotetext{
15 INTERNATIONAL ORGANIZATION FOR STANDARDIZATION. ISO/TS 3814 (E): Tests to measuring reaction to fire of buildings materials - Their development and application, 2014.
} 
A carga de incêndio se refere aos materiais combustíveis existentes no ambiente. Para um mesmo compartimento e grau de ventilação constante, à medida que a carga de incêndio aumenta, maior é a duração e a temperatura máxima do incêndio. Este parâmetro pode ser calculado pela equação (A.4):

$$
q_{f i}=\frac{\sum_{r} \mu_{r} \cdot m_{r} \cdot H_{r}}{A_{p}}
$$

Onde:

$q_{f i}$ : carga de incêndio por unidade de área, em $M J / m^{2}$;

$\mu_{r}$ : coeficiente adimensional indicativo do grau de combustão real de cada tipo do material combustível (varia entre 0 e 1 );

$m_{r}$ : massa total de cada componente do material combustível, em $\mathrm{kg}$;

$H_{r}$ : poder colorífico de cada componente do material combustível, em $M J / k g$;

$A_{p}$ : área de piso do compartimento, em $m^{2}$.

O grau de ventilação se refere à quantidade de comburente no local, ou seja, a quantidade de oxigênio do ar que reage com a carga de incêndio, produzindo a combustão. Quanto maior o grau de ventilação, maior é a temperatura máxima de um incêndio e menor é a sua duração. O grau de ventilação (fator de abertura) pode ser calculado pela equação (A.5):

$$
v=\frac{A_{v} \cdot \sqrt{\frac{\sum\left(h_{i} \cdot A_{i}\right)}{A_{v}}}}{A_{t}}
$$

Onde:

U: fator de abertura, em $m^{2}$;

$A_{v}:$ área total das aberturas externas do edifício (portas e janelas), em $\mathrm{m}^{2}$;

$h_{i}:$ altura da abertura “i”, em $m$;

$A_{i}$ : área da abertura externa "i" ${ }^{2}$, $m^{2}$

$A_{t}$ : área total incluindo vedações (parede, piso e teto) e aberturas, em $m^{2}$. 
Quanto às características dos materiais da compartimentação, estas se referem às resistências destes materiais à ação do fogo o que influencia a temperatura e a duração das chamas por compartimento. Quanto maior a resistência da compartimentação à ação do fogo, impedindo-o que se propague, maior a temperatura máxima do incêndio. A propagação do fogo induz uma duração menor das chamas e a diminuição da temperatura máxima do incêndio no compartimento inicial (COSTA; SILVA, 2006). Seu cálculo pode ser feito pela equação (A.6):

$$
b=\sqrt{\rho \cdot c \cdot \lambda}
$$

Onde:

$b$ : fator característico de isolamento térmico do material de vedação, em $\mathrm{J}^{\circ} \mathrm{C} / \mathrm{m}^{2} s^{1 / 2}$;

$\rho$ : massa específica do material do elemento de vedação, em $\mathrm{kg} / \mathrm{m}^{3}$;

$c$ : calor específico do material do elemento de vedação, em $J{ }^{\circ} \mathrm{C} / \mathrm{kg}$;

$\lambda$ : condutividade térmica do material do elemento de vedação, em $W^{\circ} \mathrm{C} / \mathrm{m}$.

De acordo com Moreno Júnior e Molina (2012), na fase de extinção do incêndio pode ocorrer a recuperação de rigidez e resistência mecânica de alguns materiais utilizados em elementos estruturais, retardando a ruína da estrutura em caso de incêndio, cuja fase não é representada nos modelos de curva-padrão de incêndio. Em contrapartida, Cánovas (1988) destaca que o efeito da água utilizada para extinção das chamas pode ser tão nocivo quanto o fogo em virtude do resfriamento repentino o qual pode causar contrações bruscas na estrutura.

\section{A.4. MODELOS DE INCÊNDIO}

Devido à infinidade de combinações entre os fatores que caracterizam um incêndio e com o intuito de obter dados possíveis de serem comparados em qualquer pesquisa ao redor do mundo, seja em contexto experimental ou numérico, tornou-se necessária a padronização dos procedimentos para a simulação dos efeitos da ação térmica de um incêndio. Desta forma, o aquecimento é caracterizado por modelos matemáticos que associam a elevação da temperatura em função do tempo, donde criaram-se os modelos padronizados de incêndio. 
Franssen ${ }^{16}$ (2009) e Bailey ${ }^{17}$ (2011) apud Rigobello (2011, p.12) citam as várias opções de modelos disponíveis para situações dinâmicas de incêndio, sendo elas: incêndio natural ou paramétrico, incêndio padrão ou incêndio nominal, incêndio localizado, modelos de zona e fluidodinâmica computacional (CFD). Os três primeiros casos são classificados como modelos simples, enquanto que os demais são classificados como modelos avançados.

A diferença entre estas classificações refere-se, principalmente, ao nível de detalhamento das informações de entrada no respectivo modelo. Os modelos simples requerem menor quantidade de informações na entrada de dados e são empregados para a fase de pósflashover. Estes modelos consideram uniforme a temperatura dos gases no compartimento em estudo. Já os modelos avançados necessitam de informações mais detalhadas na entrada de dados, pois simulam os processos de transferência de calor e massa num compartimento em situação de incêndio. Diferentemente do modelo simplificado, os modelos avançados permitem obter resultados com detalhamento do compartimento em incêndio, além de ser possível considerar o movimento da fumaça e mapear o espalhamento do incêndio.

\section{A.4.1. Incêndio natural}

O modelo de incêndio natural ou paramétrico busca simular situações mais próximas às ocorrências reais de incêndios em compartimentos de edificações, porém, de forma mais simplificada. Segundo Silva (2001), este modelo baseia-se em ensaios ou modelos matemáticos criados através de experimentos. São variáveis necessárias para utilização deste modelo, a carga de incêndio e o grau de ventilação do compartimento, dentre outros aspectos.

As curvas temperatura-tempo deste modelo possuem a inflamação generalizada, o ramo ascendente (fase de aquecimento), e o ramo descendente (fase de resfriamento) o qual, simplificadamente, pode ser representado por meio de uma reta. A Figura A.5 exemplifica o gráfico para este modelo. A fase de ignição é desconsiderada por entender-se que não há alteração da capacidade estrutural da edificação.

\footnotetext{
${ }^{16}$ FRANSSEN, J. -M.; KODUR, V.; ZAHARIA, R. (2009). Designing steel structures for fire safety. CRC Press.

${ }^{17}$ BAILEY, C. G. (2011). One Stop Shop in Structural Fire Engineering by Manchester University. Disponível em: http://www.mace.manchester.ac.uk/project/research/structures/strucfire/. Acesso em 24/05/2011.
} 
Figura A.5 - Esquematização de modelo de incêndio paramétrico

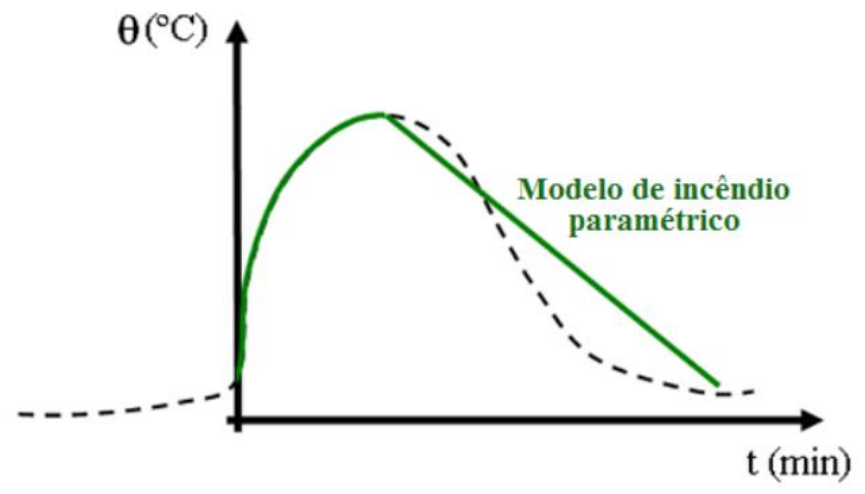

Fonte: Rigobello (2011)

\section{A.4.2. Incêndio padrão}

O modelo de incêndio padrão ou nominal foi desenvolvido, a princípio, para análise experimental de estruturas e de materiais de proteção contra o fogo em fornos de institutos de pesquisa (SILVA ${ }^{18}, 2001$, apud RIGOBELLO, 2011, p.13), admitindo-se que a temperatura dos gases quentes no compartimento em chamas obedeça às curvas padronizadas.

As curvas padrão possuem apenas o ramo ascendente, com a temperatura crescendo em relação ao tempo, independente da influência da carga de incêndio, do grau de ventilação do compartimento e das propriedades térmicas dos materiais da compartimentação (SILVA, 1997). Segundo Silva et al. (2008), a curva de incêndio padrão é empregada para incêndio em ambientes com material combustível formado, predominantemente, de materiais celulósicos (papéis e madeira).

Dorr (2010) ressalta a importância da análise cuidadosa a partir do uso da curva de incêndio padrão, pois, apesar da sua fácil aplicação, as conclusões devem considerar as divergências destas com as reais condições de um incêndio real.

Como exemplos destes modelos, podem ser citadas as curvas internacionalmente padronizadas ISO 834-1:1999, ASTM E119:2000, SBN 67, BS 476 e as curvas nominais do CEN EN 1992-1-2:2002.

No Brasil, a ABNT NBR 5628:2001 estabelece os métodos de ensaio aplicados para elementos estruturais, incluindo paredes estruturais, para a determinação de resistência ao fogo. Esta norma recomenda a curva-padrão da ISO 834-1:1999, através de equação (A.7):

\footnotetext{
${ }^{18}$ SILVA, V. P. Estruturas de Aço em Situação de Incêndio. São Paulo: Zigurate, 2001.
} 


$$
\theta_{g}=20+345 \cdot \log (8 \cdot t+1)
$$

Onde:

$\theta_{g}:$ temperatura dos gases em ${ }^{\circ} \mathrm{C}$;

$t$ : tempo decorrido em minutos.

As curvas propostas pelo Eurocode 1 Part 1-2:2002 para incêndio-padrão são as seguintes:

- Curva temperatura-tempo padrão: utilizada para ambientes cuja carga combustível é formada principalmente por materiais celulósicos. É a curva-padrão da ISO 834-1:1999, visto na Figura A.6 e representada pela equação (A.7);

- Curva para incêndios externos: a temperatura dos gases próximos aos elementos estruturais é dada pela equação (A.8):

$$
\theta_{g}=20+660 \cdot\left(1-0,687 \cdot e^{-0,32 \cdot t}-0,313 \cdot e^{-3,8 \cdot t}\right)
$$

- Curva de hidrocarbonetos: utilizada para ambientes em que o material combustível é formado principalmente por hidrocarbonetos, dada pela equação (A.9):

$$
\theta_{g}=20+1080 \cdot\left(1-0,325 \cdot e^{-0,167 \cdot t}-0.625 \cdot e^{-2,5 \cdot t}\right)
$$

A curva da ASTM E119:2000 é definida por número discreto de pontos. Buchanan (2002) cita a equação (A.10) como a que melhor descreve o comportamento da curva americana.

$$
\theta_{g}=20+750 \cdot\left(1-e^{-3,79552 \cdot \sqrt{t_{h}}}\right)+170,41 \sqrt{t_{h}}
$$

Onde:

$t_{h}:$ tempo decorrido em horas.

A Tabela A.1 compara as temperaturas entre a ISO 834-1:1999 e a ASTM E119:2000 para os mesmos tempos de incêndio. 
Tabela A.1 - Temperaturas dos gases no ambiente em incêndio em função do tempo

\begin{tabular}{cccccc} 
Tempo (min) & $\begin{array}{c}\text { ISO 834- } \\
\text { 1:1999 }\end{array}$ & $\begin{array}{c}\text { ASTM } \\
\text { E119:2000 }\end{array}$ & Tempo (min) & ISO 834- & ASTM \\
\hline 0 & 20 & 20 & 70 & 968 & E119:2000 \\
\hline 10 & 678 & 704 & 80 & 988 & 963 \\
\hline 20 & 781 & 795 & 90 & 1006 & 978 \\
\hline 30 & 842 & 843 & 120 & 1049 & 1010 \\
\hline 40 & 885 & 878 & 240 & 1153 & 1093 \\
\hline 50 & 918 & 905 & 480 & 1257 & 1260 \\
\hline 60 & 945 & 927 & & & \\
\hline
\end{tabular}

Graficamente, o comportamento das equações anteriores é mostrado na Figura A.6.

Figura A.6 - Curvas de incêndio-padrão

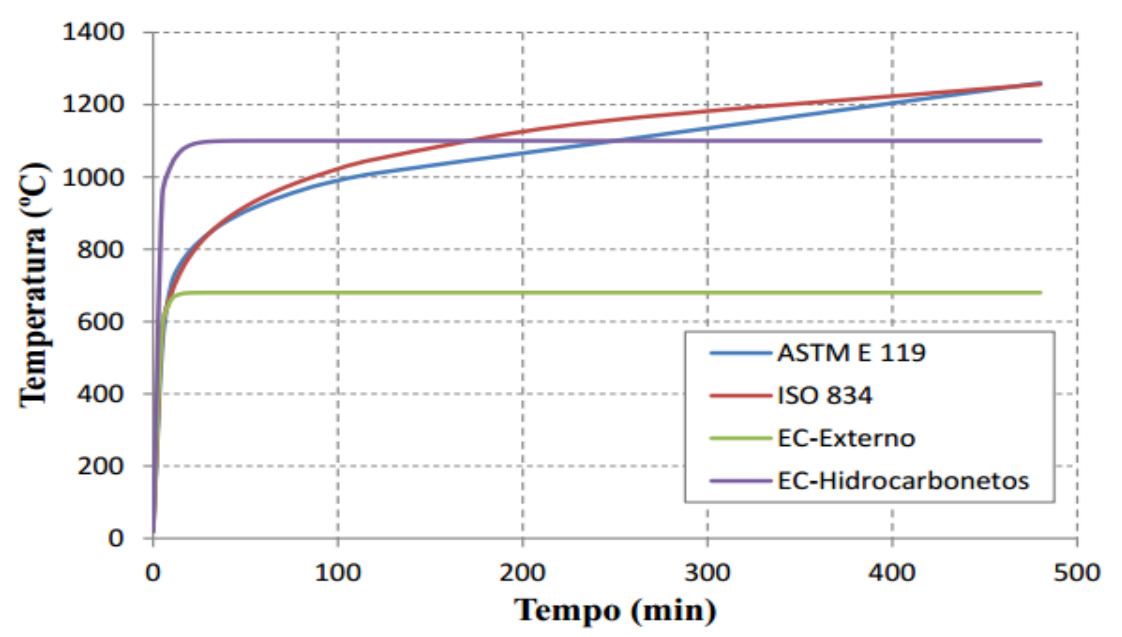

Fonte: Santos (2014)

É relevante salientar, mais uma vez, que as temperaturas existentes nas curvas padrão de incêndio referem-se às temperaturas dos gases no ambiente em chamas. As máximas temperaturas dos elementos estruturais podem ser obtidas experimentalmente, numericamente ou analiticamente, considerando as propriedades dos materiais e os mecanismos de transferência de calor.

Outra consideração importante nestas curvas é a não existência do ramo descendente que caracteriza o incêndio natural, isto é, o resfriamento da estrutura. Moreno Jr. e Molina (2012) comentam que o resfriamento natural da estrutura, em temperatura ambiente, pode levar a uma recuperação da rigidez e da resistência mecânica dos materiais, em relação ao término do incêndio. Cánovas (1988) ressalta que o combate ao fogo nas estruturas, em sua maioria, é 
feito com resfriamento repentino através do lançamento de água. Isto pode causar danos à estrutura semelhantes ao próprio fogo, devido à dilatação dos materiais ao absorver calor e, posteriormente, à contração brusca devido às diferenças de temperatura.

\section{A.4.3. Incêndio Localizado}

Rigobello (2011) descreve este tipo de modelo como aquele em que não há a possibilidade de ocorrência de flashover, ficando a estrutura, sujeita ao aquecimento localizado de seus elementos. Este tipo de situação tem a possibilidade de ocorrência em locais abertos, com grandes dimensões e sem compartimentação, como no caso de estacionamentos, estádios e aeroportos.

A determinação do fluxo de calor dos elementos sujeitos a incêndios localizados pode ser encontrada no Eurocode 1 Part 1-2:2002.

\section{A.4.4. Modelos de Zona}

De acordo com Buchanan ${ }^{19}$ (2000) e Franssen et al. ${ }^{20}$ (2009) apud Rigobello (2011, p.15) são modelos computacionais simples que consideram o compartimento onde ocorre o incêndio dividido em diferentes zonas, sendo que a temperatura destas zonas, por simplificação, admitida como sendo uniforme. Estes modelos baseiam-se nas leis de conservação de massa, energia e momento com o intuito de obter como resultados, a altura da camada, o tamanho, a temperatura e a concentração dos gases por zona do incêndio, além da temperatura das paredes e do piso, bem como, o fluxo de calor ao nível do piso.

Rigobello (2011) comenta que para a fase pré-flashover, comumente utilizam-se modelos com duas zonas, enquanto para a fase pós-flashover, utilizam-se modelos com uma zona, em virtude da maior simplificação.

Uma limitação do modelo se refere à não obtenção da evolução de temperaturas de objetos ou superfícies.

\section{A.4.5. Fluidodinâmica computacional (CFD)}

O CFD é a técnica mais avançada para modelagem de incêndio. Estes modelos permitem a obtenção de resultados com elevado detalhamento em cada ponto do compartimento em

\footnotetext{
${ }^{19}$ BUCHANAN, A. H. (2000). Structural Design for Fire Safety. Chichester: John Wiley \& Sons, Ltd.

${ }^{20}$ FRANSSEN, J. -M.; KODUR, V.; ZAHARIA, R. (2009). Designing steel structures for fire safety. CRC Press.
} 
incêndio estudado, donde é possível obter informações como temperatura, velocidade e concentração dos gases.

Estes modelos baseiam-se no escoamento de fluidos e transferência de calor, bem como, a associação destes fenômenos com a resolução de equações fundamentais da mecânica dos fluidos. Assim, durante a análise de um escoamento, obtém-se numericamente as componentes do tensor de tensões, do vetor de velocidade e a temperatura ou massa específica de determinado ponto, permitindo-se obter a distribuição das temperaturas dos gases no compartimento.

\section{A.5. TEMPO REQUERIDO DE RESISTÊNCIA AO FOGO (TRRF)}

O tempo requerido de resistência ao fogo é definido pela ABNT NBR 14432:2001 como o tempo mínimo que um elemento construtivo deve apresentar resistência ao fogo sujeito ao aquecimento com base em curvas padrão de incêndio. Durante o tempo requerido de resistência ao fogo, o elemento estrutural deve manter a segurança estrutural, a estanqueidade e o isolamento, de forma a garantir a segurança na fuga dos ocupantes da edificação e às equipes de combate ao incêndio, bem como, a minimização de danos a edificações adjacentes e à infraestrutura pública.

Durante um incêndio, a temperatura máxima ocorrente no elemento estrutural não é a mesma das chamas. A temperatura do ambiente depende de fatores ligados à quantidade e distribuição dos materiais combustíveis, ventilação e características térmicas dos materiais de ventilação. Silva (2008) exemplifica o TRRF a partir da Figura A.7.

Figura A.7 - Conceito de Tempo Requerido de Resistência ao Fogo (TRRF)

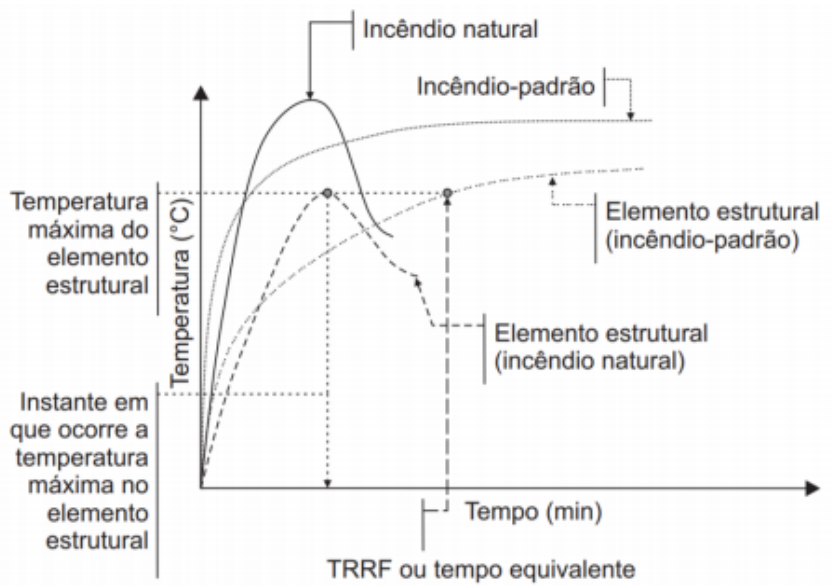

Fonte: Silva (2008)

No Brasil, o TRRF pode ser obtido de forma simplificada a partir de tabelas existentes na ABNT NBR 14432:2001, as quais variam de acordo com o uso da edificação e sua altura. 
Quadro A.1 - Tempo Requerido de Resistência ao Fogo (em minutos), de acordo com a

ABNT NBR 14432:2001

\begin{tabular}{|cccccc|}
\hline Ocupação/ Uso & \multicolumn{5}{c|}{ Altura da edificação (m) } \\
\hline Residencial & 30 & $6<h \leq 12$ & $12<h \leq 23$ & $23<h \leq 30$ & $h>30$ \\
\hline $\begin{array}{c}\text { Serviços de } \\
\text { hospedagem }\end{array}$ & 30 & $60(30)$ & 60 & 90 & 120 \\
\hline $\begin{array}{c}\text { Comercial varejista } \\
\begin{array}{c}\text { Serviços } \\
\text { profissionais, } \\
\text { pessoais e técnicos }\end{array}\end{array}$ & $60(30)$ & $60(30)$ & 60 & 90 & 120 \\
\hline $\begin{array}{c}\text { Educacional e cultura } \\
\text { física }\end{array}$ & 30 & $60(30)$ & 60 & 90 & 120 \\
\hline $\begin{array}{c}\text { Serviços de saúde e } \\
\text { institucionais }\end{array}$ & 30 & 30 & 60 & 90 & 120 \\
\hline
\end{tabular}

Fonte: Adaptado da ABNT NBR 14432:2001

Os tempos entre parênteses podem ser usados em subsolo nos quais a área bruta de cada pavimento seja menor ou igual a $500 \mathrm{~m}^{2}$ e em edificações nas quais cada pavimento acima do solo tenha área menor ou igual a $750 \mathrm{~m}^{2}$.

A IT-08:2011 considera a maioria dos valores semelhantes aos da ABNT NBR 14432:2001. Porém, considera intervalos de altura acima dos 30 metros, e, tempos de resistência ao fogo superiores aos informados pela norma brasileira, conforme indicado no Quadro A.2.

Quadro A.2 - Tempo Requerido de Resistência ao Fogo (em minutos), de acordo com a IT08:2011

\begin{tabular}{|ccccccc|}
\hline $\begin{array}{c}\text { Ocupação/ } \\
\text { Uso }\end{array}$ & $h \leq 6$ & $6<h \leq 12$ & $12<h \leq 23$ & $23<h \leq 30$ & $30<h \leq 80$ & $80<h \leq 120$ \\
\hline Residencial & 30 & 30 & 60 & 90 & 120 & 120 \\
\hline $\begin{array}{c}\text { Serviços de } \\
\text { hospedagem }\end{array}$ & 30 & 60 & 60 & 90 & 120 & 150 \\
\hline $\begin{array}{c}\text { Comercial } \\
\text { varejista }\end{array}$ & 60 & 60 & 60 & 90 & 120 & 150 \\
\hline $\begin{array}{c}\text { Serviços } \\
\text { profissionais, } \\
\text { pessoais e } \\
\text { técnicos }\end{array}$ & 30 & 60 & 60 & 90 & 120 & 120 \\
\hline $\begin{array}{c}\text { Educacional e } \\
\text { cultura física }\end{array}$ & 30 & 30 & 60 & 90 & 120 & 120 \\
\hline
\end{tabular}




\begin{tabular}{ccccccc|}
$\begin{array}{c}\text { Serviços de } \\
\text { saúde e } \\
\text { institucionais }\end{array}$ & 30 & 60 & 60 & 90 & 120 & 150 \\
\hline
\end{tabular}

Fonte: Adaptado da IT-08:2011

O Eurocode 1 Part 1-2:2002 permite o cálculo do TRRF, de forma mais refinada, a partir da seguinte equação:

$$
t_{c}=q_{f i, k} \cdot \gamma_{n} \cdot \gamma_{s} \cdot W \cdot K \cdot M
$$

Onde:

$t_{c}$ : tempo equivalente, em minutos;

$q_{f i, k}:$ valor característico da carga de incêndio, em $M J / m^{3} ;$

$\gamma_{n}$ : coeficiente adimensional que considera a existência de medidas de proteção ativa da edificação;

$\gamma_{s}$ : coeficiente de segurança acerca do risco de incêndio e das consequências do colapso da edificação;

$W$ : fator associado à ventilação e à altura do compartimento;

$K$ : fator associado às características do material de vedação do compartimento, em $\min \mathrm{m}^{2} / \mathrm{MJ}$; $M$ : fator dependente do material da estrutura, sendo, $M=1$ para estruturas com proteção ao fogo através de revestimento e, $M=13,7 \cdot v$ para situações de estruturas de aço sem proteção; $v$ : grau de ventilação da edificação. 


\section{APÊNDICE B - ASPECTOS REFERENTES ÀS PRECRIÇÕES NORMATIVAS NACIONAIS E INTERNACIONAIS}

Neste apêndice são abordados, de forma resumida, sobre alguns aspectos de normas brasileiras e estrangeiras de alvenaria estrutural em situação de incêndio, bem como, comentado de forma bastante sucinta sobre as normatizações nacionais vigentes relativas às elevadas temperaturas.

\section{B.1. NORMAS NACIONAIS}

Comentando, inicialmente, sobre os sistemas estruturais que possuem normatização vigente em situação de incêndio, no caso de estruturas de concreto, é admissível o uso da ABNT NBR 15200:2012, a qual pode ser aplicada para estruturas projetadas de acordo com a ABNT NBR 6118:2014, isto é, para estruturas de concreto simples, armado e protendido com massa específica seca entre $2.000 \mathrm{~kg} / \mathrm{m}^{3}$ e $2.800 \mathrm{~kg} / \mathrm{m}^{3}$ do grupo I de resistência (C20 a C50). Para o grupo II de resistência, a mesma norma prescreve o uso das recomendações do Eurocode 2 Part 1-2:2005. Esta norma é válida também para estruturas projetadas com base na ABNT NBR 9062:2017, caso de estruturas de concreto pré-moldadas.

Para ensaios em situação de incêndio de elementos construtivos estruturais, tais como paredes, lajes, pilares e vigas, a ABNT NBR 5628:2001 prescreve os procedimentos padrões necessários, respeitando a curva padrão de incêndio da ISO 834-1:1999.

Em estruturas de aço ou mistas de aço e concreto, a normatização vigente é baseada na ABNT NBR 14323:2013. Esta norma estabelece os critérios gerais para dimensionamento deste tipo de estrutura em elevadas temperaturas, apresentando propriedades térmicas e coeficientes de redução das propriedades mecânicas, além de um método para obtenção da elevação da temperatura nos elementos estruturais.

A ABNT NBR 14432:2001 estabelece exigências de resistência ao fogo para elementos estruturais e de compartimentação de edifícios para que seja evitado o colapso estrutural. No caso dos elementos de compartimentação, também estabelece o atendimento de requisitos relativos à estanqueidade e isolamento por períodos de tempo pré-determinados, de acordo com o tipo de ocupação e uso, profundidade do subsolo e altura da edificação.

Para casos de determinação da resistência ao fogo de paredes divisórias sem função estrutural, a norma a ser seguida é a ABNT NBR 10636:1989, a qual também segue a curvapadrão de incêndio da ISO 834-1:1999. 
A norma brasileira para o dimensionamento de alvenaria estrutural de blocos de concreto é a ABNT NBR 15961-1:2011. Esta norma especifica os requisitos mínimos exigíveis para o projeto de estruturas de alvenaria. Em seu escopo, a norma comenta sobre a sua aplicação também válida para análise de desempenho de elementos da alvenaria em outros sistemas estruturais, e, a não aplicação para situações que levem a estados-limite gerados por sismos, impactos, explosões e fogo. A segunda parte desta mesma norma, trata dos requisitos exigíveis para execução e controle de obras com alvenaria estrutural em blocos de concreto.

Os procedimentos de ensaio para pequenas paredes de alvenaria estrutural em blocos de concreto são determinados pela ABNT NBR 16522:2016, considerando os esforços de compressão axial, cisalhamento, flexão e flexo-compressão. O modelo de pequena parede deste trabalho é baseado no corpo-de-prova proposto por esta norma.

Para os blocos de concreto, as normas responsáveis são a ABNT NBR 6136:2016 e a ABNT NBR 12118:2013 acerca dos requisitos e métodos de ensaio, respectivamente, as quais também foram seguidas para criação dos modelos de blocos de concreto, em conformidade com os respectivos trabalhos experimentais.

Diferentemente do exposto para os demais sistemas estruturais, não existe uma norma brasileira específica para alvenaria estrutural em situações de incêndio.

A Instrução Técnica 08:2011 do Corpo de Bombeiros do Estados de São Paulo estabelece condições a serem atendidas pelos elementos estruturais e de compartimentação que integram as edificações quanto aos tempos requeridos de resistência ao fogo (TRRF). Isto, com o objetivo de evitar o colapso estrutural por um período de tempo suficiente para possibilitar a saída segura das pessoas e o acesso para as operações do Corpo de Bombeiros. Para dimensionamentos de estruturas não abordadas em normas nacionais, a IT-08:2011 sugere o uso dos requisitos do Eurocode 6:2005.

No Anexo A da respectiva instrução, são indicados os valores de TRRF de acordo com o tipo de ocupação e uso, profundidade do subsolo e altura da edificação. No Anexo B, a instrução indica os valores mínimos que o corpo-de-prova deve atender para os requisitos especificados, como integridade, estanqueidade, isolamento térmico e resistência ao fogo. Para paredes de bloco de concreto, sem revestimento e sem função estrutural, com uma das faces em contato com as chamas, é especificado o tempo mínimo de 1,5 hora. A Tabela B.1 exemplifica um trecho do comentado acima. 
Tabela B.1 - Resistência ao fogo para alvenaria de acordo com a IT-08:2011

\begin{tabular}{|ccccccc}
\hline $\begin{array}{c}\text { Bloco vazado } \\
\text { de concreto } \\
\text { (2 furos) }\end{array}$ & $\begin{array}{c}\text { Espessura } \\
\text { do revest. } \\
\text { (cm) }\end{array}$ & $\begin{array}{c}\text { Duração do } \\
\text { ensaio } \\
\text { (min) }\end{array}$ & $\begin{array}{r}\text { Tempo de atendimento aos critérios de } \\
\text { resistência (horas) }\end{array}$ & $\begin{array}{c}\text { Resistência } \\
\text { ao fogo } \\
\text { (horas) }\end{array}$ \\
\hline $\begin{array}{c}\mathbf{1 4} \text { cm (s/ } \\
\text { revest.) }\end{array}$ & - & 100 & $\geq 1,5$ & $\geq 1,5$ & 1,5 & 1,5 \\
\hline $\begin{array}{c}\mathbf{1 9} \text { cm (s/ } \\
\text { revest.) }\end{array}$ & - & 120 & $\geq 2,0$ & $\geq 2,0$ & 1,5 & 1,5 \\
\hline $\begin{array}{c}\mathbf{1 4} \text { cm (c/ } \\
\text { resvest.) }\end{array}$ & 1,5 & 150 & $\geq 2,0$ & $\geq 2,0$ & 2,0 & 2,0 \\
\hline $\begin{array}{c}\mathbf{1 9} \text { cm (c/ } \\
\text { revest.) }\end{array}$ & 1,5 & 185 & $\geq 3,0$ & $\geq 3,0$ & 3,0 & 3,0 \\
\hline
\end{tabular}

Fonte: Adaptado de IT-02:2011

Leite, Moreno Júnior e Torres (2016) realizaram um estudo sobre os procedimentos de dimensionamento da alvenaria estrutural em situação de incêndio, de acordo com as normas americana, australiana e europeia, em virtude da não existência de normatização nacional vigente. Através deste estudo, os autores propuseram a realização de ensaios dos blocos usuais em território nacional, bem como, dos diferentes tipos de acabamentos, para que possa haver consideração em projetos de alvenaria, num primeiro momento, relativo ao critério de isolamento térmico (I), uma vez que o país não possui em seus laboratórios equipamentos aptos para os demais testes.

Os autores comentam também que, a partir dos ensaios em temperaturas elevadas, seria possível, com simulações numéricas, criar um mapeamento das isotermas dos blocos, o que, por consequência, possibilitaria uma avaliação inicial do critério de resistência mecânica $(\mathrm{R})$ por meio de cálculo simplificado.

Isto, no entanto, não significa que não haja necessidade de ensaios em paredes de alvenaria estrutural. Estes ensaios, em paredes carregadas e em situação de incêndio, têm alta relevância, pois cada país possui especificações de espessura, capacidade resistente, geometria e composições mineralógicas dos agregados utilizados na fabricação dos blocos, evidenciando, portanto, tal necessidade. Os autores comentam que tais ensaios, permitiriam a criação de ábacos que pudessem ser inseridos numa futura normatização nacional, semelhantes aos dimensionamentos internacionais.

\section{B.2. NORMAS INTERNACIONAIS}

Nesta seção estão apresentadas as principais recomendações internacionais para a alvenaria estrutural em situação de incêndio, sendo elas: americana, australiana e europeia. 
Neste trabalho, para alguns parâmetros, foram feitos uso das normas europeia e americana, sendo devidamente referenciadas quando houve tal aplicação.

\section{B.2.1. Código americano}

O código americano é o ACI/TMS 216.1-14, o qual descreve métodos para a determinação da resistência ao fogo de estruturas de concreto e alvenaria, donde inclui-se elementos construtivos, tais como paredes, pisos, lajes vigas, lintéis e colunas.

A verificação das paredes de alvenaria estrutural é feita em função da garantia de valores mínimos para a espessura efetiva cujo valor é determinado de acordo com o tipo de elemento de alvenaria e o tempo requerido de resistência ao fogo.

Para paredes de alvenaria estrutural de blocos de concreto, a ACI/TMS 216.1-14 apresenta a Tabela B.2 para determinação das espessuras equivalentes mínimas, com intervalo de tempo entre 30 e 240 minutos.

Tabela B.2 - Espessuras equivalente mínimas em função do tempo requerido de resistência ao fogo para paredes de alvenaria de blocos de concreto, em centímetros

\begin{tabular}{|cccccccc}
\hline Tipo de agregado empregado no bloco & $\begin{array}{c}\mathbf{3 0} \\
\mathbf{m i n}\end{array}$ & $\begin{array}{c}\mathbf{4 5} \\
\mathbf{m i n}\end{array}$ & $\begin{array}{c}\mathbf{6 0} \\
\mathbf{m i n}\end{array}$ & $\begin{array}{c}\mathbf{9 0} \\
\mathbf{m i n}\end{array}$ & $\begin{array}{c}\mathbf{1 2 0} \\
\mathbf{m i n}\end{array}$ & $\begin{array}{c}\mathbf{1 8 0} \\
\mathbf{m i n}\end{array}$ & $\begin{array}{c}\mathbf{2 4 0} \\
\mathbf{m i n}\end{array}$ \\
\hline Cascalho de calcário ou silício & 5,1 & 6,1 & 7,1 & 9,1 & 10,7 & 13,5 & 15,7 \\
\hline $\begin{array}{c}\text { Pedra calcária, cinzas ou escória resfriada } \\
\text { a ar }\end{array}$ & 4,8 & 5,8 & 6,9 & 8,6 & 10,2 & 12,7 & 15,0 \\
\hline $\begin{array}{c}\text { Argila expandida, xisto expandido ou } \\
\text { ardósia expandida }\end{array}$ & 4,6 & 5,6 & 6,6 & 8,4 & 9,1 & 11,2 & 13,0 \\
\hline \begin{tabular}{c} 
Escória expandida ou pedra-pomes \\
\hline
\end{tabular} & 3,8 & 4,8 & 5,3 & 6,9 & 8,1 & 10,2 & 11,9 \\
\hline
\end{tabular}

Fonte: ACI/TMS 216.1-14, p.21 (medidas convertidas em centímetros)

Para períodos de tempo intermediários, o código determina que a espessura seja determinada por interpolação linear. Para situações de blocos produzidos com combinações de agregados, a espessura também pode ser determinada por interpolação linear, considerando o percentual de volume de cada agregado utilizado na fabricação.

A espessura equivalente das paredes de alvenaria é dada pela soma entre a espessura equivalente do bloco (onde são desconsiderados os vazios) e a espessura equivalente do acabamento, isto é:

$$
T_{e a}=T_{e}+T_{e f}
$$


Onde:

$T_{e}$ : espessura equivalente do bloco;

$T_{e f}$ : espessura equivalente do acabamento.

Para a obtenção da espessura equivalente do bloco, este é obtido a partir da seguinte equação:

$$
T_{e}=\frac{V_{n}}{L \cdot H}
$$

Onde:

$V_{n}$ : volume líquido o bloco;

$L$ : comprimento do bloco;

$H$ : altura do bloco.

O código considera o uso da equação (B.2) para paredes grauteadas ou parcialmente grauteadas. Para paredes totalmente grauteadas, considera-se a espessura equivalente como a própria espessura do bloco. Em situações em que há o preenchimento com material solto, considera-se a própria espessura do bloco para os materiais estabelecidos na norma, como areia, brita e argila expandida.

Para a espessura equivalente da argamassa, são consideradas as seguintes situações:

- Acabamento aplicado na face não exposta ao fogo: a espessura é ajustada por um fator que considera o material utilizado na fabricação do bloco e o material do acabamento, conforme mostrado na Tabela B.3.

Tabela B.3 - Fator multiplicador para a espessura do acabamento

\begin{tabular}{|c|c|c|c|c|}
\hline \multirow[b]{2}{*}{$\begin{array}{l}\text { Tipo de material usado na laje ou } \\
\text { parede }\end{array}$} & \multicolumn{4}{|c|}{ Tipo de acabamento aplicado à laje ou parede } \\
\hline & $\begin{array}{c}\text { Reboco de } \\
\text { cimento Portland } \\
\text { e areia ou } \\
\text { ladrilho } \\
\text { hidráulico }\end{array}$ & $\begin{array}{c}\text { Reboco } \\
\text { de gesso } \\
\text { e areia }\end{array}$ & $\begin{array}{l}\text { Reboco de } \\
\text { gesso com } \\
\text { vermiculita } \\
\text { ou perlita }\end{array}$ & $\begin{array}{l}\text { Drywall (gesso } \\
\text { acartonado) }\end{array}$ \\
\hline \multicolumn{5}{|c|}{ Parede de alvenaria de concreto } \\
\hline $\begin{array}{l}\text { Alvenaria de concreto - Silicioso, } \\
\text { calcário, cal, cinzas, escória de alto } \\
\text { forno resfriada a ar }\end{array}$ & 1,00 & 1,25 & 1,75 & 3,00 \\
\hline $\begin{array}{l}\text { Alvenaria de concreto - feito com } 80 \% \\
\text { ou mais xisto expandido, ardósia } \\
\text { expandida, argila expandida, escória } \\
\text { expandida ou pedra-pomes }\end{array}$ & 0,75 & 1,00 & 1,25 & 2,25 \\
\hline
\end{tabular}

Fonte: ACI/TMS 216.1-14, p. 27 (traduzido para o português) 
- Acabamento aplicado na face exposta ao fogo: deve ser considerado um acréscimo no tempo de resistência ao fogo de acordo com a Tabela B.4.

Tabela B.4 - Tempo adicional atribuído aos materiais de acabamento

\begin{tabular}{|c|c|}
\hline Acabamento & Tempo (min) \\
\hline \multicolumn{2}{|l|}{ Drywall (gesso acartonado) } \\
\hline $3 / 8$ pol. $(9,5 \mathrm{~mm})$ & 10 \\
\hline $1 / 2 \operatorname{pol}(12,7 \mathrm{~mm})$ & 15 \\
\hline $5 / 8$ pol. $(15,9 \mathrm{~mm})$ & 20 \\
\hline Duas camadas de $3 / 8$ pol. (Duas camadas de $9,5 \mathrm{~mm}$ ) & 25 \\
\hline Uma camada de $3 / 8$ pol. $(9,5 \mathrm{~mm})$ e uma camada de $1 / 2$ pol. $(12,7 \mathrm{~mm})$ & 35 \\
\hline Duas camadas de $1 / 2$ pol. (Duas camadas de $12,7 \mathrm{~mm}$ ) & 40 \\
\hline \multicolumn{2}{|l|}{ Drywall tipo "X" (resistente ao fogo) } \\
\hline $1 / 2 \operatorname{pol}(12,7 \mathrm{~mm})$ & 25 \\
\hline $5 / 8$ pol. $(15,9 \mathrm{~mm})$ & 40 \\
\hline \multicolumn{2}{|c|}{ Argamassa de cimento Portland e areia aplicada diretamente sobre o concreto ou alvenaria* } \\
\hline \multicolumn{2}{|c|}{ Argamassa de cimento Portland e areia sobre tela de metal } \\
\hline $3 / 4$ pol. $(19 \mathrm{~mm})$ & 20 \\
\hline $7 / 8$ pol. $(22,2 \mathrm{~mm})$ & 25 \\
\hline 1 pol. $(25,4 \mathrm{~mm})$ & 30 \\
\hline \multicolumn{2}{|l|}{ Argamassa de gesso e areia sobre ripas de gesso de $3 / 8$ pol. } \\
\hline $1 / 2$ pol. $(12,7 \mathrm{~mm})$ & 35 \\
\hline $5 / 8$ pol. $(15,9 \mathrm{~mm})$ & 40 \\
\hline $3 / 4$ pol. $(19 \mathrm{~mm})$ & 50 \\
\hline \multicolumn{2}{|l|}{ Argamassa de gesso e areia sobre tela de metal } \\
\hline 3/4 pol. $(19 \mathrm{~mm})$ & 50 \\
\hline $7 / 8$ pol. $(22,2 \mathrm{~mm})$ & 60 \\
\hline 1 pol. $(25,4 \mathrm{~mm})$ & 80 \\
\hline $\begin{array}{l}\text { Nota: * Para fins de determinação da contribuição da argamassa de ciment } \\
\text { espessura equivalente da alvenaria, será permitido o uso da espessura real do } \\
\text { menor entre os dois. }\end{array}$ & $\begin{array}{l}\text { nd e areia para a } \\
\text { issa ou } 5 / 8 \text { pol., } 0\end{array}$ \\
\hline
\end{tabular}

Fonte: ACI/TMS 216.1-14, p. 28 (traduzido para o português)

- Acabamentos diferentes nas faces da parede: a verificação deve ser feita considerando-se a exposição ao fogo em cada face separadamente, adotando-se como tempo de resistência ao fogo, o menor dos tempos nas situações simuladas. Nesta situação, há, ainda, a necessidade de limitar a contribuição total à metade da contribuição atribuída à parede sem acabamento, caso a espessura equivalente exceda à metade da espessura da parede sem acabamento.

Esta norma faz a consideração para situações de paredes múltiplas, isto é, paredes próximas entre si, conforme visto na Figura B.1. 
Figura B.1 - Paredes múltiplas

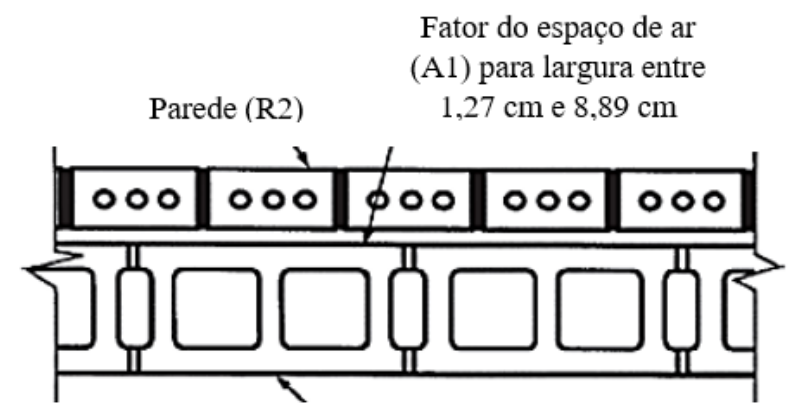

Parede (R1)
R1: tempo de resistência ao fogo da parede 1

R2: tempo de resistência ao fogo da parede 2

A1: fator do espaço de $a r=0,3$

Fonte: ACI/TMS 216.1-14 (medidas convertidas em cm)

A resistência ao fogo é calculada considerando-se a resistência ao fogo de cada parede do conjunto e a influência de eventual espaço entre elas, conforme visto na equação (B.3).

$$
R=\left(R_{1}^{0,59}+R_{2}^{0,59}+\ldots+R_{n}^{0,59}+A_{1}+A_{2}+\ldots+A_{n}\right)^{1,7}
$$

Onde:

$R_{1}+R_{2}+\ldots+R_{n}$ : resistência ao fogo das camadas $1,2, \ldots, \mathrm{n}$, respectivamente, em horas;

$A_{1}+A_{2}+\ldots+A_{n}=0,30$ : fator que considera o espaço entre as paredes (preenchido com ar), com valore entre $1,27 \mathrm{~cm}$ e $8,89 \mathrm{~cm}$.

Situações em que as paredes estejam com distância inferior a 1,27 cm, estas devem ser consideradas como parede única, sem a consideração de ar como elemento resistente entre as mesmas. Caso o espaço seja superior a $8,89 \mathrm{~cm}$, deve ser considerada apenas a parede mais próxima à exposição ao incêndio.

\section{B.2.2. Código australiano}

O código australiano é o AS 3700:2018, e, é o único, dentre os citados neste trabalho, que faz considerações explícitas sobre os critérios de resistência mecânica, isolamento térmico e estanqueidade para o dimensionamento da alvenaria.

Dentre os citados, o critério de resistência mecânica refere-se à estabilidade da estrutura contra o colapso na situação de incêndio. $O$ critério de isolamento térmico remete-se à capacidade resistente da estrutura à passagem de calor, e, por fim, o critério de estanqueidade relaciona-se à capacidade resistente da parede à fissuração excessiva e passagem de gases e chamas. 
Para o dimensionamento quanto ao primeiro critério, a norma considera que a alvenaria é afetada pela expansão térmica dos materiais utilizados na fabricação dos blocos, pelas vinculações nas extremidades das paredes e por sua esbeltez, a qual depende da espessura da parede e da distância entre os apoios verticais.

Em relação ao isolamento térmico, as variáveis envolvidas em relação aos blocos são a densidade, a composição dos mesmos e a espessura. Além disso, influenciam também a existência de acabamentos ou revestimentos e o uso de graute.

Para o critério de estanqueidade, a maior influência provém da espessura dos blocos e da composição dos materiais usados para sua fabricação.

O código permite o dimensionamento da alvenaria estrutural de duas formas, sendo, a primeira a partir de valores tabelados e a segunda, de acordo com valores experimentais fornecidos em ábacos pelos próprios fabricantes de blocos.

Pelo método tabelado, o dimensionamento quanto à resistência mecânica é feito de acordo com a Tabela B.5.

Tabela B.5 - Índice de esbeltez máximo para verificação quanto à resistência mecânica

\begin{tabular}{cccccccc} 
Tipo de bloco & \multicolumn{4}{c}{ Tempo de resistência ao fogo $(\mathrm{min})$} \\
& 30 & 60 & 90 & 120 & 180 & 240
\end{tabular}

1. Alvenaria não armada

\begin{tabular}{cccccccc}
\hline (i) & Blocos de argila & 25,0 & 22,5 & 21,0 & 20,0 & 18,0 & 17,0 \\
\hline (ii) & Blocos de silicato de cálcio com agregado basáltico & & & & & \\
\hline (A) & Menos de 45\% de todos os agregados & 20,5 & 19,0 & 18,0 & 17,5 & 16,5 & 15,5 \\
\hline (B) & Pelo menos 45\% de todos os agregados & 25,0 & 22,5 & 21,0 & 20,0 & 18,0 & 17,0 \\
\hline (iii) & Blocos de concreto com agregados basálticos & & & & & \\
\hline (A) & Menos de 45\% de todos os agregados & 19,5 & 18,0 & 17,0 & 16,0 & 15,5 & 15,0 \\
\hline (B) & Pelo menos 45\% de todos os agregados & 25,0 & 22,5 & 21,0 & 20,0 & 18,0 & 17,0 \\
\hline 2. Alvenaria armada & 36,0 & 36,0 & 36,0 & 36,0 & 36,0 & 36,0 \\
\hline
\end{tabular}

Fonte: AS 3700:2018, p. 57 (traduzido para o português)

Para situações em que o índice de esbeltez exceda os valores da tabela anterior, faz-se necessário o redimensionamento da parede, buscando aumentar a espessura da mesma. Outra possibilidade é a inserção de travamentos na parede, buscando aumentar a rigidez do elemento.

O cálculo do índice de esbeltez em situação de incêndio é feito conforme mostrado na sequência, de acordo com a vinculação utilizada.

- Paredes sem apoio nas laterais:

$$
S_{v f}=\frac{\alpha_{v f} \cdot H}{t}
$$


- Paredes com apoio em apenas uma lateral:

$$
S_{r f}=\frac{0,7}{t} \cdot \sqrt{\alpha_{v f} \cdot H \cdot \alpha_{k} \cdot L}
$$

- Paredes com apoio nas duas laterais:

$$
S_{r f}=\alpha_{k} \cdot \frac{L}{t}
$$

Onde:

$\alpha_{v f}$ : para parede com apoio em toda a extremidade lateral, assume valor de 0,75 ; caso contrário, adota-se 2,0;

$H$ : altura do membro entre os travamentos verticais da parede;

$t$ : espessura total da parede;

$\alpha_{k}$ : para paredes com apoios superior e inferior, assume valor de 1,0; para paredes com apoio inferior, apenas, assume valor de 2,5;

$L$ : comprimento da parede.

Para a situação de paredes com apoio, deve-se utilizar o menor valor obtido pelas equações (B.5) e (B.6).

Ainda, de acordo com o método tabelado, quanto ao critério de isolamento térmico, o dimensionamento é feito de acordo com a Tabela B.6.

Tabela B.6 - Espessura mínima de paredes de acordo com o critério de isolamento térmico, em milímetros

\begin{tabular}{|lcccccc}
\hline \multirow{2}{*}{ Tipo de bloco } & \multicolumn{7}{c|}{ Tempo de resistência ao fogo (min) } \\
\cline { 2 - 7 } & $\mathbf{3 0}$ & $\mathbf{6 0}$ & $\mathbf{9 0}$ & $\mathbf{1 2 0}$ & $\mathbf{1 8 0}$ & $\mathbf{2 4 0}$ \\
\hline Cerâmico & 60 & 90 & 110 & 130 & 160 & 180 \\
\hline Silicato de cálcio & 50 & 70 & 90 & 110 & 135 & 160 \\
\hline Concreto com densidade: & & & & & & \\
\hline (a) $\quad$ Superior a $1800 \mathrm{~kg} / \mathrm{m}^{3}$ & 55 & 80 & 100 & 120 & 150 & 180 \\
\hline (b) $\quad$ Igual ou inferior a $1800 \mathrm{~kg} / \mathrm{m}^{3}$ & 55 & 75 & 90 & 110 & 135 & 160 \\
\hline
\end{tabular}

Fonte: AS 3700:2018 (traduzido para o português)

Para situações de paredes duplas ou com cavidades, a norma australiana faz as seguintes considerações, para o cálculo do índice de esbeltez:

- Paredes duplas com carregamentos axiais próximos entre si, com divergência inferior a $10 \%$, ou mesmo, sem carregamento: calculado considerando a espessura como dois 
terços do somatório das espessuras das paredes e dois terços das condições de apoio da parede não exposta ao fogo;

- Demais casos: baseado na espessura e condições de contorno da parede mais carregada.

Para casos de paredes constituídas por materiais diferentes cujo índice de esbeltez seja determinado de acordo com a primeira situação anterior, deve-se considerar o material menos resistente para dimensionamento de acordo com o critério de resistência mecânica.

O dimensionamento a partir de dados experimentais ocorre através de um grupo de ábacos, os quais são fornecidos, em sua maioria, pelos fabricantes de blocos australianos. Nestes ábacos, os três critérios são considerados, sendo determinado por eles, a respectiva espessura da parede.

Na sequência é apresentado um exemplo de ábaco utilizado na Austrália.

Figura B.2 - Exemplo de determinação da espessura de parede de acordo com o método

$$
\text { experimental }
$$

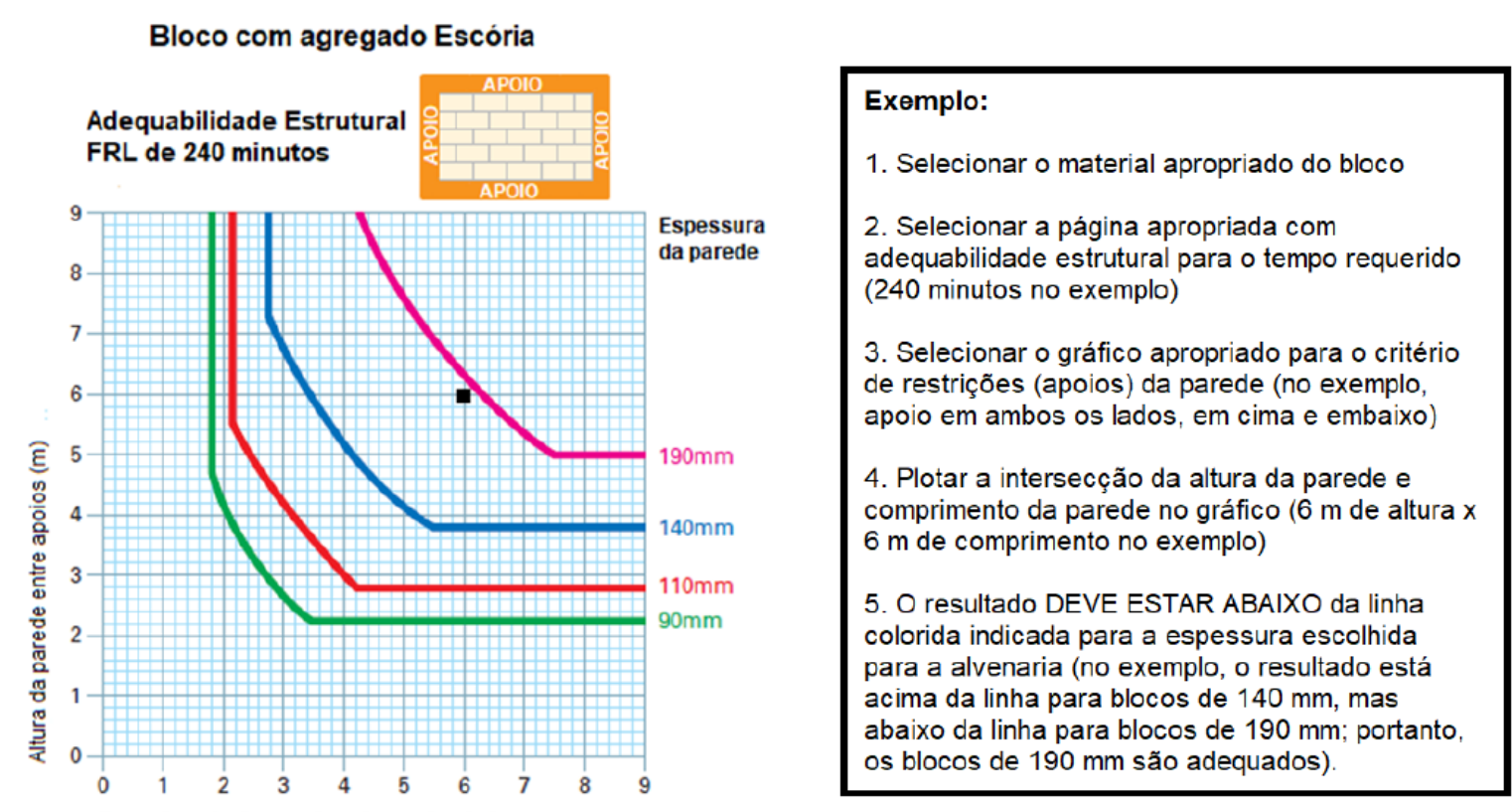

Fonte: Boral Masonry ${ }^{21}$ (2009) apud Leite (2018)

\section{B.2.3. Código europeu}

A norma europeia para alvenaria estrutural é o Eurocode 6:2005, o qual é dividido em três partes. A primeira parte da norma é subdividida em outras duas partes, sendo que a primeira trata das regras gerais para alvenaria armada e não armada e a segunda, do projeto em situações

${ }^{21}$ BORAL MASONRY. Masonry Design Guide. Structural, fire and Acoustics. Book 1. Victoria, Australia, 2009. 
de incêndio. A segunda parte da norma trata das regras do processo executivo da alvenaria estrutural, e na terceira é apresentada uma metodologia para cálculo simplificado de estruturas de alvenaria não reforçadas.

No tocante à Part 1-2 da norma citada, os critérios a serem atendidos pela alvenaria na situação de incêndio são:

- Resistência mecânica (R): função de suporte de carga durante o incêndio por um determinado período de tempo, isto é, não permitir a ocorrência da ruptura.

- Estanqueidade (E): não apresentar fissuras ou rachaduras que permitam a passagem de chamas e gases.

- Isolamento térmico (I): não apresentar um aumento de temperatura superior na face não exposta, em qualquer ponto, a $180{ }^{\circ} \mathrm{C}$, ou, com média nesta mesma face, superior a $140{ }^{\circ} \mathrm{C}$.

- Impacto mecânico (M): um elemento de separação vertical deve suportar uma carga concentrada horizontal com características especificadas na norma.

O Eurocode faz a classificação das paredes de acordo com os critérios citados, não sendo necessário, desta forma, o cumprimento de todos os critérios. Para o dimensionamento de alvenaria estrutural, os três primeiros critérios são considerados básicos em situação de incêndio.

A consideração da junção dos critérios citados é mostrada na Figura B.3.

Figura B.3 - Critérios do Eurocode 6 Part 1-2:2005

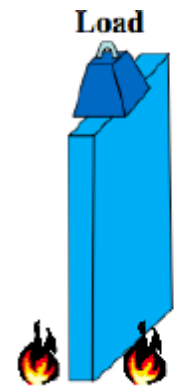

$\mathbf{R}$

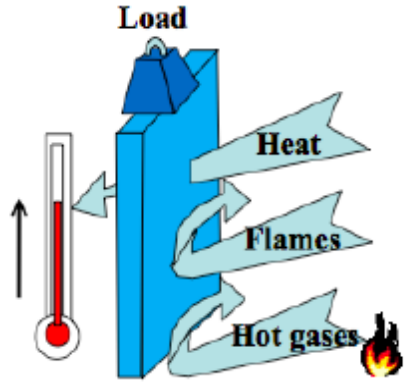

RE

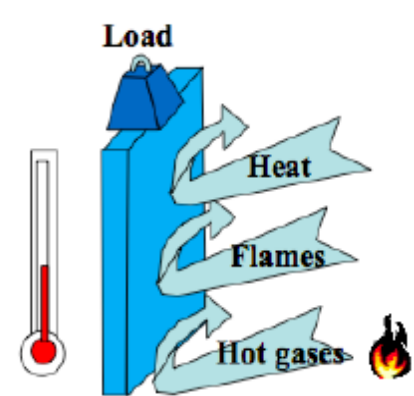

REI

Esta norma permite o dimensionamento da alvenaria a partir de três métodos, sendo eles, os tabulares, os baseados em experimentos e os analíticos.

O dimensionamento da parede pelo método tabular é feito baseando-se, inicialmente, nos critérios anteriormente citados a serem atendidos de acordo com as especificações de projeto. Nas tabelas existentes no Anexo B desta parte do Eurocode, a divisão é feita pela função da parede na edificação e pelo tipo de material do bloco, posteriormente, pela resistência à 
compressão dos blocos $\left(f_{b}\right)$ em função da densidade dos blocos $(\rho)$ e, por fim, em função da relação entre a força solicitante de cálculo da parede em situação de incêndio e a força resistente de compressão de cálculo ( $\alpha$ ).

Na sequência é extraída tabela do código europeu para exemplificar o explicitado acima.

Tabela B.7 - Espessuras mínimas de paredes carregadas para concreto denso e leve pelo critério $\mathrm{R}$

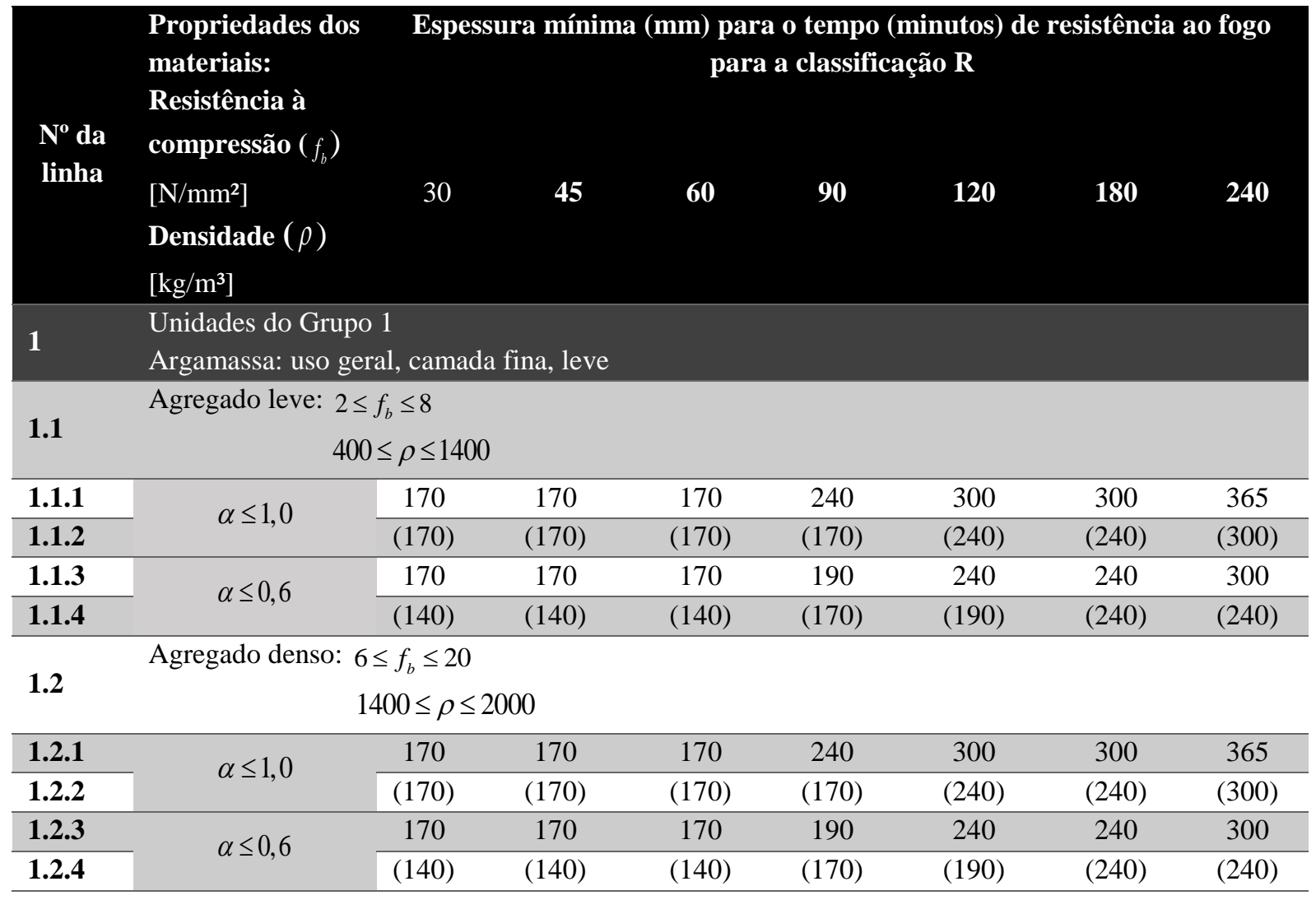

Fonte: Eurocode 6 Part 1-2:2005 (traduzido para o português)

Os valores de espessuras mínimas são indicados nas tabelas em valores únicos ou em intervalos recomendados. Aqueles que aparecem entre parênteses, estão considerados acabamentos (espessura mínima do acabamento de $10 \mathrm{~mm}$ ).

Por ser um código unificado, de acordo com Meyer (2012), a existência desses intervalos deve-se ao fato de não ter sido possível a obtenção de um acordo final sobre os dados tabelados, principalmente devido aos diferentes métodos de ensaio utilizados nos países e às divergências quanto às condições de contorno consideradas.

Quanto ao método analítico, este código apresenta duas formas para o dimensionamento das paredes, sendo a primeira o método simplificado, conforme indicado no Anexo $\mathrm{C}$, e a segunda, o método avançado, existente no Anexo D da respectiva norma. 
Pelo método de dimensionamento analítico simplificado, inicialmente, o código faz a restrição de seu uso às paredes executadas com os materiais mostrados na Tabela B.8.

Tabela B.8 - Intervalo de temperaturas em função dos materiais de execução das paredes

\begin{tabular}{|ccc}
\hline Blocos de alvenaria e argamassa (superfície desprotegida) & \multicolumn{3}{c}{ Temperatura $\left({ }^{\circ} \mathbf{C}\right)$} \\
& $\theta_{2}$ & $\theta_{1}$ \\
\hline Blocos cerâmicos com argamassa comum & 600 & 100 \\
\hline Blocos de silicato de cálcio com uma fina camada de argamassa & 500 & 100 \\
\hline Bloco de agregado leve (pedra-pomes) com argamassa comum & 400 & 100 \\
\hline Bloco normal com argamassa comum & 500 & 100 \\
\hline Bloco celular autoclavado com uma fina camada de argamassa & 700 & 200 \\
\hline
\end{tabular}

Fonte: Eurocode 6 Part 1-2:2005 (traduzido para o português)

Os valores de temperaturas indicados na tabela anterior referem-se a isotermas, as quais devem ser traçadas ao longo da seção transversal da parede para ser realizada a redução da seção resistente. Desta forma, considera-se:

- Área com temperaturas inferiores a $\theta_{1}$ : utiliza-se seu valor integral;

- Área entre $\theta_{1}$ e $\theta_{2}$ : redução da área;

- Área superior a $\theta_{2}$ : desconsiderada.

A Figura B.4 exemplifica esta situação.

Figura B.4 - Redução da área da seção transversal na situação de incêndio

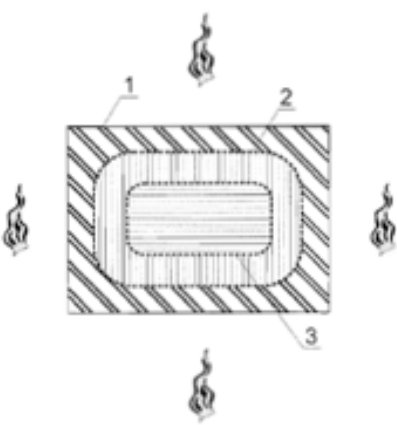

(a) seção transversal de um pilar exposto ao fogo com curvas isotérmicas reais

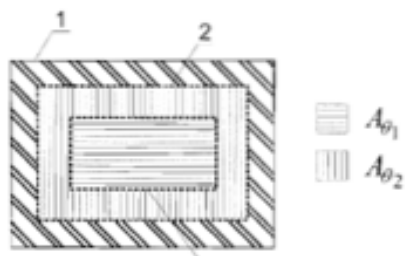

3 (b) seção transversal de um pilar exposto ao fogo com curvas isotérmicas ajustadas para o método simplificado

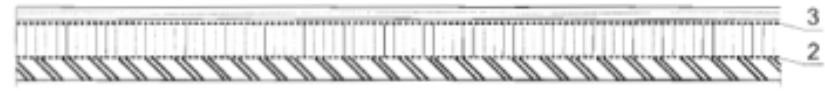

3
Legenda:

1: limite da seção transversal original

2: curva isotérmica para $\theta=\theta_{2}$

3: curva isotérmica $\theta=\theta_{1}$

(c) seção transversal intermediária

Fonte: Eurocode 6 Part 1-2:2005 (traduzido para o português) 
A verificação da seção é feita no Estado Limite Último, sendo as ações combinadas conforme as recomendações usuais. A força solicitante $\left(N_{S d}\right)$ deve ser menor ou igual ao valor da força resistente $\left(N_{R d, f i \theta_{2}}\right)$ :

$$
N_{S d} \leq N_{R d, f i \theta_{2}}
$$

Sendo o valor da força resistente obtido por:

$$
N_{R d, f i \theta_{2}}=\phi \cdot\left(f_{d \theta_{1}} \cdot A_{\theta_{1}}+f_{d \theta_{2}} \cdot A_{\theta_{2}}\right)
$$

Onde:

$A_{\theta_{1}}$ : área da alvenaria até $\theta_{1}$;

$A_{\theta_{2}}:$ área da alvenaria entre $\theta_{1}$ e $\theta_{2}$

$f_{d \theta_{1}}$ : resistência à compressão de cálculo da alvenaria até $\theta_{1}$;

$f_{d \theta_{2}}$ : resistência à compressão de cálculo da alvenaria entre $\theta_{1}$ e $\theta_{2}$;

$\phi$ : fator de minoração da capacidade portante da parede encontrada no item 6.1.2.2 do Eurocode 6 Part 1-1:2005, onde pode ser considerada uma excentricidade adicional $\left(e_{\Delta \theta}\right)$.

O código indica a necessidade da obtenção da distribuição de temperaturas para que as isotermas sejam conhecidas, podendo ser através de ensaios laboratoriais, ou, de base de dados confiáveis, ao longo do período de tempo de exposição ao fogo. 


\section{APÊNDICE C - CARACTERÍSTICAS DA ALVENARIA ESTRUTURAL}

\section{C.1. RESISTÊNCIA À COMPRESSÃO E MÓdULO DE ELASTICIDADE DA ALVENARIA}

O comportamento da alvenaria estrutural está diretamente relacionado às características e propriedades dos respectivos materiais constituintes. Uma forma de estimar a resistência da parede de alvenaria estrutural é a partir das resistências das unidades e da argamassa, principais responsáveis pelo comportamento estrutural do sistema construtivo.

Ramalho e Corrêa (2003) afirmam que a resistência da parede de alvenaria é equivalente ao intervalo entre 50 e 90\% da resistência dos blocos de concreto. A ABNT NBR 15961-1:2011 possibilita a estimativa da resistência característica à compressão simples da parede de alvenaria a partir da resistência de prismas e também de pequenas paredes, conforme mostrado:

$$
\begin{aligned}
& f_{k}=0,70 \cdot f_{p k} \\
& f_{k}=0,85 \cdot f_{p p k}
\end{aligned}
$$

Onde:

$f_{k}$ : resistência característica à compressão simples da alvenaria;

$f_{p k}$ : resistência característica à compressão simples de prismas;

$f_{p p k}$ : resistência característica à compressão simples de pequenas paredes.

Para situações em que seja utilizado argamassamento parcial, a norma determina a correção dos valores anteriormente obtidos, pelo fator de 0,80 .

Para determinação das resistências dos prismas e pequenas paredes devem ser realizados os ensaios prescritos na ABNT NBR 15961-2:2011.

O Eurocode 6 Part 1-1:2005 possibilita a determinação da resistência característica da alvenaria a partir da equação (C.3):

$$
f_{k}=K \cdot f_{b}^{0,7} \cdot f_{m}^{0,3}
$$




\section{Sendo:}

$K$ : constante relacionada ao tipo de alvenaria utilizada;

$f_{b}$ : resistência média à compressão da unidade;

$f_{m}$ : resistência média à compressão da argamassa.

O módulo de elasticidade é uma propriedade relevante, pois é determinante para o conhecimento do mecanismo de ruptura da alvenaria, bem como, quanto às deformações da alvenaria. Apesar de a determinação do módulo de elasticidade ser teoricamente simples, no caso da alvenaria estrutural, esta apresenta resultados bastantes variáveis devido à constituição da mesma.

Oliveira (2014) comenta que alguns pesquisadores chegaram a considerar relações para estimar o módulo de elasticidade a partir da resistência da unidade e do tipo de argamassa. Porém, para uso prático, estas relações entraram em desuso devido à complexidade e imprecisão. Assim, buscou-se maior simplicidade para a estimativa do módulo de elasticidade da alvenaria baseada no produto entre uma constante e a própria resistência da alvenaria.

Colville et al. (1993), através de estudo experimental, propuseram a seguinte relação para o cálculo do módulo de elasticidade de alvenaria de blocos de concreto:

$$
E_{a l v}=666 \cdot f_{a l v}
$$

Onde:

$f_{a l v}$ : resistência da alvenaria determinada por ensaio de prismas.

Em estudo realizado por Hendry et al. (1997), foi proposta a equação (C.5) para o cálculo aproximado do módulo de elasticidade da alvenaria, independente do material utilizado.

$$
E_{a l v}=700 \cdot f_{a l v}
$$

O ACI 530:2011 sugere a equação (C.6) para projetos de alvenaria de blocos de concreto, e, para blocos cerâmicos, a equação proposta por Hendry et al. (1997), mostrada pela equação (C.5).

$$
E_{a l v}=900 \cdot f_{a l v}
$$


De forma semelhante ao ACI, a BS 5628:2005 também estabelece a equação (C.6) para obtenção do módulo de elasticidade da alvenaria, porém, tanto para blocos de concreto quanto cerâmicos ou sílico-calcáreos, independentemente do tipo de argamassa.

O Eurocode 6 Part 1-1:2005 sugere o uso da equação (C.7) quando não houver possibilidade de ensaios. Experimentalmente, o módulo de elasticidade é considerado a um terço da resistência da alvenaria.

$$
E_{a l v}=1000 \cdot f_{k}
$$

Esta norma recomenda a aplicação de um fator de 0,6 ao módulo de elasticidade para a verificação do estado limite de serviço.

No Brasil, a ABNT NBR 15812-1:2010 e a ABNT NBR 15961-1:2011 sugerem o uso das equações (C.8) e (C.9) para o cálculo do módulo de elasticidade de alvenaria de blocos cerâmicos e de concreto, respectivamente.

$$
\begin{array}{ll}
E_{a l v}=600 \cdot f_{p k} & E_{a l v}<12 G P a \\
E_{a l v}=800 \cdot f_{p k} & E_{a l v}<16 G P a
\end{array}
$$

\section{C.2. ADERÊNCIA}

Oliveira (2014) define a aderência como a capacidade de transferência de tensões de tração e de cisalhamento na interface entre dois materiais adjacentes sem que ocorra a separação entre os mesmos. Na alvenaria estrutural, este é um parâmetro de elevada relevância uma vez que a insuficiência de aderência entre bloco e junta pode prejudicar as propriedades da alvenaria (MEDEIROS e SABBATINI, 1993).

Parsekian et al. (2012) consideram como principal fator para uma boa aderência, a compatibilidade entre a argamassa e o bloco. Dentre os fatores preponderantes que interferem para esta compatibilidade, podem ser citados:

- Fator água/cimento, com retenção de água compatível com a absorção inicial do bloco;

- Trabalhabilidade adequada;

- Teor de ar incorporado;

- Condições de cura;

- Tipo de argamassa utilizado; 
- Propriedades do bloco, tais como, índice de absorção inicial (sucção) e condições da superfície (partículas soltas, textura e capilaridade);

- Condições ambientais (temperatura e umidade) durante o assentamento.

De acordo com Carasek (1996) uma forma de estimar a aderência é a partir de três propriedades de interface, sendo elas: resistência de aderência à tração, resistência de aderência ao cisalhamento e extensão de aderência, cujo valor é obtido pela razão entre a área de contato efetivo e a área superficial da unidade. Castro (2003) comenta que o comportamento não linear da resistência de aderência à tração das interfaces unidade-argamassa, na maioria das vezes, é originado por fissuras nas juntas de argamassa.

Para obtenção da resistência de aderência à tração da alvenaria, os dois tipos de ensaios que podem ser realizados são os de resistência de aderência à tração direta e os de resistência de aderência à tração na flexão.

De acordo com Almeida (2002), o ensaio de tração direta é mais adequado para avaliação do comportamento não linear da junta por possibilitar a obtenção de parâmetros relevantes da Mecânica do Fraturamento, em ensaios onde é feito o controle de deslocamento. Porém, o mesmo autor comenta que o ensaio de tração direta é de difícil execução por necessitar de distribuição uniforme de tensão na interface unidade-argamassa e, por necessitar de grande precisão construtiva.

O ensaio de resistência à tração na flexão consiste na imposição da flexão na parede até a ruptura, sendo, desta forma, medida a resistência de aderência no contorno da junta de argamassa. Este valor, porém, não pode ser considerado representativo para todas as juntas (OLIVEIRA, 2014). Apesar de ser um ensaio de execução mais simples em relação à tração direta, há grande dificuldade de correlacionar ambos os valores.

A ABNT NBR 15961-1:2011 estabelece valores característicos que podem ser considerados para a resistência à tração da alvenaria sob flexão, em situações de ações temporárias, como no caso de vento, conforme indicado na Tabela C.1.

Tabela C.1 - Valores característicos da resistência à tração na flexão da alvenaria

\begin{tabular}{|cccc}
\hline \multirow{2}{*}{ Direção da tração } & \multicolumn{3}{c|}{ Resistência média de compressão da argamassa (MPa) } \\
& $\mathbf{1 , 5} \mathbf{a} \mathbf{3 , 4}$ & $\mathbf{3 , 5} \mathbf{~ a ~ 7 , 0}$ & Acima de $\mathbf{7 , 0}$ \\
\hline Normal à fiada & 0,10 & 0,20 & 0,25 \\
\hline Paralela à fiada & 0,20 & 0,40 & 0,50 \\
\hline
\end{tabular}

Fonte: Adaptado da ABNT NBR 15961-1:2011 
Os valores contidos na Tabela C.1 referem-se à área bruta e são válidos para argamassa de cimento, cal e areia e juntas verticais preenchidas. Para outras situações a resistência à tração na flexão deve ser determinada por meio do ensaio de flexão em quatro pontos.

O ACI 530:2011 estabelece os valores apresentados na Tabela C.2 como tensões admissíveis de tração devidas à flexão.

Tabela C.2 - Tensão admissível de tração na flexão da alvenaria

\begin{tabular}{cccc} 
Direção da & Tipo da unidade & \multicolumn{2}{c}{ Traço da argamassa } \\
tração & $\mathbf{1 : 0 , 2 5 : 3 ~ o u ~ 1 : 0 , 5 : 4 , 5}$ & $\mathbf{1 : 1 : 6}$ \\
\hline \multirow{3}{*}{ Normal à fiada } & Bloco maciço & 0,276 & 0,207 \\
\cline { 2 - 4 } & $\begin{array}{c}\text { Bloco vazado não } \\
\text { grauteado }\end{array}$ & 0,172 & 0,131 \\
\cline { 2 - 4 } & $\begin{array}{c}\text { Bloco vazado grauteado } \\
\text { Paralela à fiada }\end{array}$ & 0,448 & 0,434 \\
\cline { 2 - 4 } & $\begin{array}{c}\text { Bloco maciço } \\
\text { Bloco vazado não }\end{array}$ & 0,552 & 0,414 \\
\hline & $\begin{array}{c}\text { grauteado ou } \\
\text { parcialmente grauteado }\end{array}$ & 0,345 & 0,262 \\
\cline { 2 - 4 } & Bloco vazado grauteado & 0,552 & 0,414 \\
\hline
\end{tabular}

Fonte: Adaptado da ACI 530:2011

A ASTM C1072-12:2013, a AS 3700:2001 e a EN 1052-2:1999 indicam ensaios específicos para determinação da resistência à tração na flexão.

\section{C.3. ENERGIA DE FATURAMENTO}

De acordo com Lourenço (1996), a energia de fraturamento pode ser definida como a energia necessária à formação de uma fissura de área unitária ao longo da interface unidadeargamassa.

No estudo dos mecanismos de propagação de fissuras e dos fatores de intensidade de tensão na ponta da fissura, a Mecânica do Fraturamento divide as possíveis formas de ruptura em três modos básicos:

- Modo I (modo de abertura): a fissura que se propaga no plano que a contém, isto é, por abertura normal à face da fissura, não ocorrendo variação angular;

- Modo II (modo cisalhante): a fissura se propaga no plano e ocorre devido ao escorregamento entre as faces na direção do comprimento da fissura;

- Modo III (modo de rasgamento): a fissura se propaga no espaço por cisalhamento fora do plano na direção normal ao comprimento da fissura. 
A Figura C.1 exemplifica os modos comentados anteriormente.

Figura C.1 - Modos de fraturamento
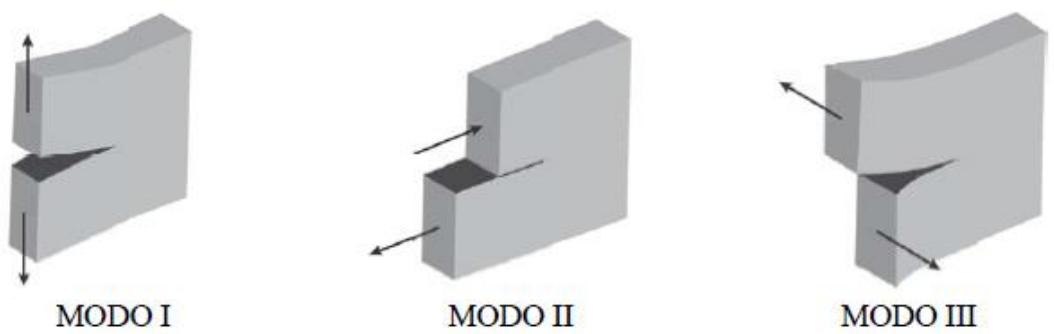

Fonte: Oliveira (2014)

Em alvenaria estrutural, a ligação entre as unidades e a argamassa é normalmente o elo mais fraco nas paredes. Dos modos de ruptura citados, os modos I e II associados à ruptura por tração e por cisalhamento, respectivamente, são aquelas que podem ocorrer na interface da unidade com a argamassa. (ALMEIDA. 2012).

Materiais quase-frágeis, como é o caso do concreto, apresentam diagramas tensãodeslocamento típicos, conforme visto na Figura C.2. De acordo com Lourenço (1996) existe a possibilidade de obtenção do comportamento pós-pico dos materiais quase-frágeis a partir da energia de fraturamento na tração e na compressão através, respectivamente, da integral do diagrama tensão-deslocamento após o pico de tensões.

Figura C.2 - Comportamento típico de materiais quase-frágeis sob carregamento uniaxial e definição de energia de fraturamento no modo I para tração (a) e compressão (b)

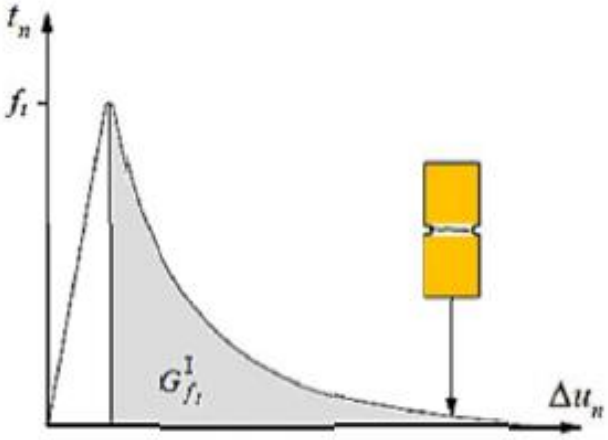

(a)

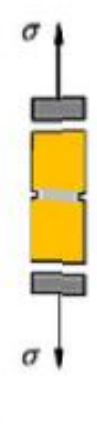

Fonte: Lourenço (1996)

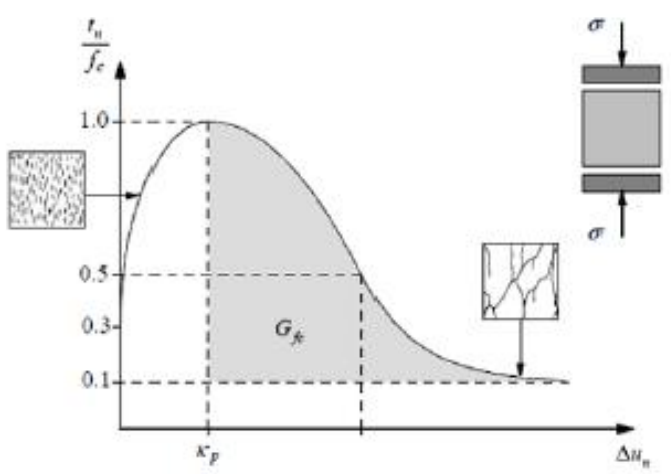

(b)

De forma análoga, no modo II, a obtenção da energia de fraturamento ocorre através da integral do diagrama tensão-deslocamento após o pico de tensões, na ausência de carga normal confinante. 
Figura C.3 - Comportamento da alvenaria sob cisalhamento e definição de energia de fraturamento no modo II

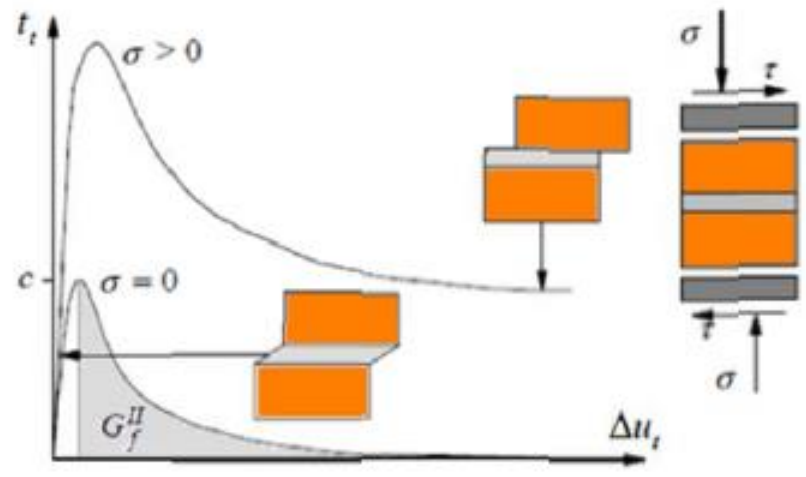

Fonte: Lourenço (1996)

Em modelagens numéricas, ambas as considerações devem ser realizadas quando trabalhado com a estratégia de micromodelagem.

\section{C.4. RESISTÊNCIA AO CISALHAMENTO}

As paredes de alvenaria apresentam um comportamento complexo em termos de resistência ao cisalhamento devido aos diversos planos de fraqueza existentes ao longo das juntas de argamassa. Desta forma, a resistência ao cisalhamento das paredes está diretamente ligada à resistência das juntas.

De acordo com Jukes e Riddington (1997), a lei de atrito de Coulomb representa razoavelmente o comportamento das juntas de argamassa:

$$
\tau_{u}=f_{v 0}+\tan \varphi \cdot \sigma
$$

Onde:

$\tau_{u}$ : resistência ao cisalhamento da junta;

$f_{v 0}$ : resistência ao cisalhamento por aderência inicial, também denominada de coesão;

$\tan \varphi$ : tangente do ângulo de atrito da interface entre a unidade e a argamassa;

$\sigma$ : tensão de pré-compressão normal à junta.

Oliveira (2014) comenta que ao longo dos anos diversos métodos de ensaio para a obtenção da resistência ao cisalhamento vem sendo estudados, porém, a dificuldade está em produzir distribuições de tensões normais e de cisalhamento uniformes em todos os pontos da 
interface. Os ensaios existentes atualmente para obtenção de tais parâmetros buscam obter boas distribuições de tensões, porém, não podem ser considerados ideais.

Dentre os objetivos dos ensaios de resistência ao cisalhamento está a obtenção do diagrama mostrado na Figura C.4.

Figura C.4 - Diagrama de tensão de cisalhamento x deslocamento

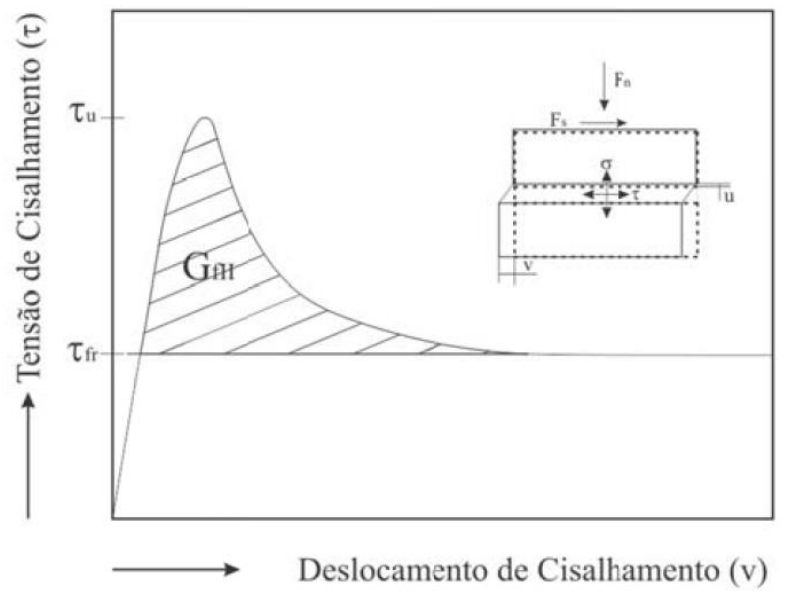

Fonte: Van der Pluijm (1999)

Este diagrama apresenta similaridade com o apresentado na Figura C.4 (a) relativo ao ensaio sob tração. A diferença, entretanto, relaciona-se ao prolongamento da curva que não decresce até zero, tornando-se constante a uma determinada intensidade de tensão de cisalhamento. A variação entre o pico de tensão e o ponto em que se torna constante, entendese como amolecimento da coesão.

A determinação do ângulo de atrito interno do material, bem como a coesão, pode ser feita através da reta tangente do círculo de Mohr, como visto na Figura C.5.

Figura C.5 - Ângulo de atrito e coesão a partir do círculo de Mohr

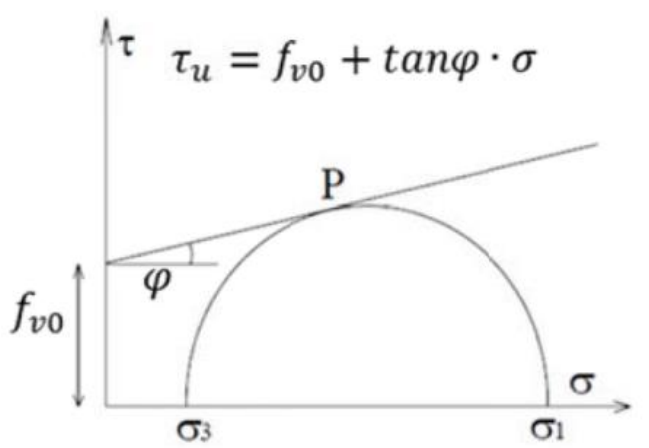

Fonte: Oliveira (2014) 
Outro parâmetro relevante, principalmente em modelagens numéricas, refere-se ao ângulo de dilatância do material, cuja função é avaliar a variação de volume do material devido ao cisalhamento. Este parâmetro pode ser calculado pela relação entre o deslocamento normal plástico e o deslocamento tangencial plástico.

$$
\psi=\arctan \frac{u_{p}}{v_{p}}
$$

Onde:

$\psi$ : Ângulo de dilatância;

$u_{p}:$ deslocamento normal plástico;

$v_{p}:$ deslocamento tangencial plástico.

A Figura C.6 exemplifica a relação mostrada na equação (C.11).

Figura C.6 - Ângulo de dilatância

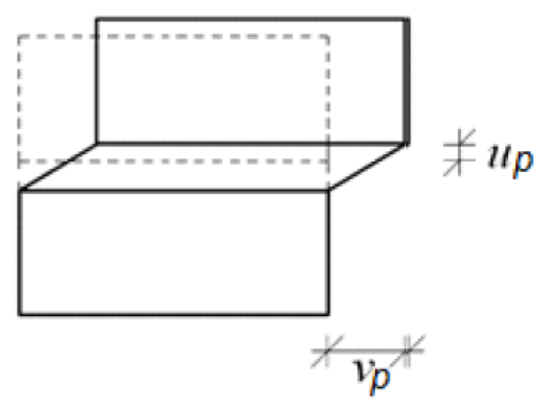

Fonte: Oliveira (2014)

Quanto menor o ângulo de dilatância, maior será a fragilidade do material, ou seja, caso este valor seja muito elevado, maior será a ductilidade do mesmo. Em estudo realizado por Malm et al. (2006) em viga de concreto armado foi verificado que o intervalo entre $30^{\circ}$ e $40^{\circ}$ para o ângulo de dilatância, pouco interferiu nas modelagens das curvas força-deslocamento, conforme visto na Figura C.7.

Para o material concreto, Jankowiak e Lodygowski (2005) concluem que a partir do modelo de dano do concreto (CDP), do ABAQUS, os valores com intervalo de ângulos de dilatância entre $25^{\circ}$ e $40^{\circ}$ foram os que obtiveram melhores concordâncias com resultados experimentais. Malm (2009) verificou resultados melhores para as análises numéricas em vigas de concreto com intervalo entre 35 e $38^{\circ}$. 
Figura C.7 - Curva Força-deslocamento para verificação dos efeitos do ângulo de dilatância

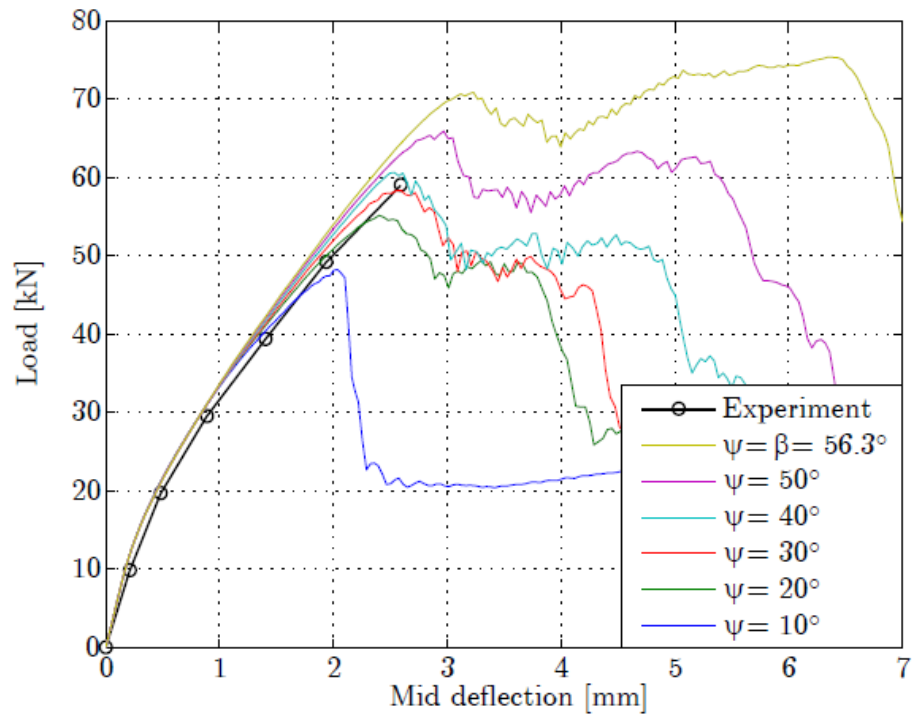

Fonte: Malm et al. (2006)

Dentre os dados relevantes obtidos pelos ensaios de cisalhamento que são relevantes para a modelagem numérica, principalmente na micromodelagem, podem ser citados a resistência ao cisalhamento, energia de fraturamento no modo II, coesão, ângulo de dilatância e rigidez tangencial da junta. 


\section{APÊNDICE D - PROPRIEDADES DOS MATERIAIS DA ALVENARIA ESTRUTURAL DE BLOCOS DE CONCRETO SOB ELEVADAS TEMPERATURAS}

Para a análise de estruturas submetidas a elevadas temperaturas faz-se necessário o conhecimento das propriedades térmicas dos materiais, bem como de suas propriedades mecânicas para as diferentes temperaturas.

Dentre as propriedades térmicas relevantes estão a massa específica, o calor específico, a condutividade térmica e a expansão térmica. Em situações em que se deseja realizar somente a análise térmica, as três primeiras propriedades são essenciais (COSTA, 2008).

A massa específica e a expansão térmica são inter-relacionadas entre si, pois, a variação volumétrica devido à dilatação ou contração dos materiais na ocorrência de variação de temperatura influencia diretamente a relação entre a massa e o volume do material. A expansão térmica, em particular, é importante para análises dos efeitos de $2^{\mathrm{a}}$ ordem, ocorrentes devido às restrições à dilatação térmica.

O calor específico mede a variação térmica de um material ao receber calor, enquanto a condutividade térmica se refere à capacidade do material de conduzir o calor, molécula a molécula. Callister Júnior (2002) comenta que materiais com microestrutura amorfa e porosa, como o concreto, apresentam baixa condutividade térmica devido ao preenchimento dos vazios com ar e água que retardam a absorção do calor.

Em relação às propriedades mecânicas principais, incluem-se as resistências à compressão e à tração, o módulo de elasticidade e as relações tensão-deformação, as quais possuem diferentes valores de acordo com a temperatura em que o material está exposto. Os modelos matemáticos capazes de representar as propriedades mecânicas em função da variação da temperatura, em geral, baseiam-se em análises experimentais ou em modelagens numéricas.

Na sequência, estão comentadas as análises referentes às propriedades anteriormente citadas para os materiais concreto e argamassa. 


\section{D.1. CONCRETO}

\section{D.1.1. Propriedades térmicas do concreto}

\section{D.1.1.1. Massa específica}

Com o aumento de temperatura a massa específica do concreto sofre leve redução devido, primariamente, à evaporação da água livre e, secundariamente, ao aumento do volume devido à expansão térmica, a qual decorre das transformações mineralógicas que os agregados sofrem acima dos $500{ }^{\circ} \mathrm{C}$.

Para a massa específica do concreto, o Eurocode 2 Part 1-2:2004 apresenta as seguintes equações para concretos com agregados silicosos ou calcários.

$$
\begin{gathered}
\rho_{c, \theta}=\rho_{c}, 20^{\circ} \mathrm{C} \leq \theta \leq 115^{\circ} \mathrm{C} \\
\rho_{c, \theta}=\rho_{c} \cdot\left[1-0,02 \cdot\left(\frac{\theta-115}{85}\right)\right], 115^{\circ} \mathrm{C}<\theta \leq 200^{\circ} \mathrm{C} \\
\rho_{c, \theta}=\rho_{c} \cdot\left[0,98-0,03 \cdot\left(\frac{\theta-200}{200}\right)\right], 200^{\circ} \mathrm{C}<\theta \leq 400^{\circ} \mathrm{C} \\
\rho_{c, \theta}=\rho_{c} \cdot\left[0,95-0,07 \cdot\left(\frac{\theta-400}{800}\right)\right], 400^{\circ} \mathrm{C}<\theta \leq 1200^{\circ} \mathrm{C}
\end{gathered}
$$

Onde:

$\rho_{c}$ : massa específica do concreto de densidade normal à temperatura ambiente, em $\mathrm{kg} / \mathrm{m}^{3}$;

$\rho_{c, \theta}$ : massa específica do concreto de densidade normal em função da temperatura $(\theta)$, em $\mathrm{kg} / \mathrm{m}^{3}$.

Graficamente, as equações anteriores geram o gráfico mostrado pela Figura D.1, estando o eixo vertical considerando a massa específica à temperatura ambiente com valor unitário.

Costa (2008) comenta que a redução da massa específica em até $12 \%$ do concreto de densidade normal, a partir das equações mostradas anteriormente, é considerada exagerada, tendo-se observado em diversos trabalhos, uma redução na ordem de $100 \mathrm{~kg} / \mathrm{m}^{3}$. Adicionalmente, comenta que a variação da massa específica sobre as propriedades térmicas apresenta pouca influência, podendo ser considerado como valor constante e igual a temperatura ambiente. 
Figura D.1 - Massa específica do concreto em função da temperatura

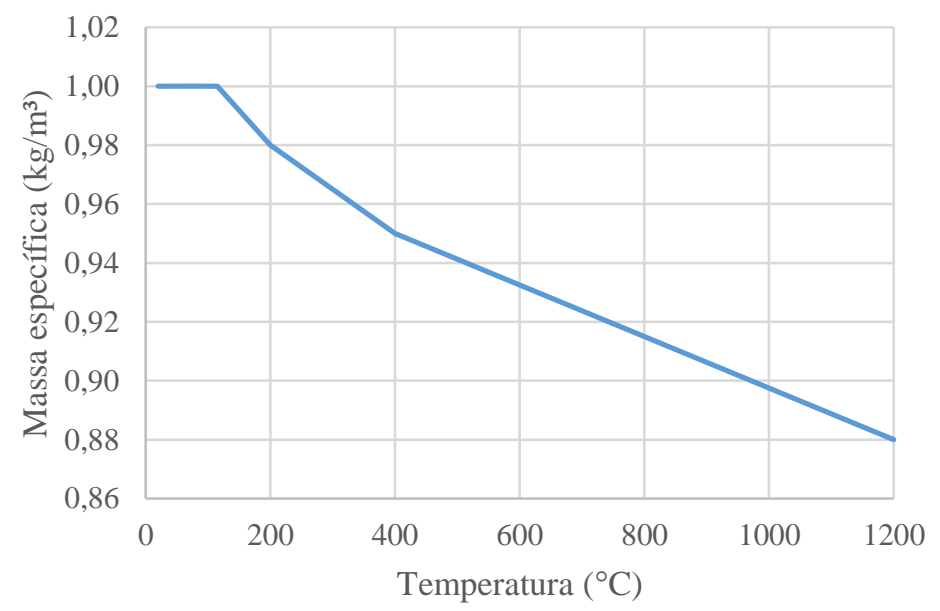

\section{D.1.1.2. Calor específico}

Para o calor específico, as equações fornecidas pelo Eurocode 2 Part 1-2:2004 e pela ABNT NBR 15200:2012 considerando umidade de 0\%, válidas para concreto com agregados silicosos ou calcários são mostradas na sequência:

$$
\begin{gathered}
c_{p}=900,20^{\circ} \mathrm{C} \leq \theta \leq 100^{\circ} \mathrm{C} \\
c_{p}=900+(\theta-100), 100^{\circ} \mathrm{C}<\theta \leq 200^{\circ} \mathrm{C} \\
c_{p}=1000+\frac{(\theta-200)}{2}, 200^{\circ} \mathrm{C}<\theta \leq 400^{\circ} \mathrm{C} \\
c_{p}=1100,400^{\circ} \mathrm{C}<\theta \leq 1200^{\circ} \mathrm{C}
\end{gathered}
$$

Onde:

$c_{p}:$ calor específico por unidade de massa do concreto de densidade normal em função da temperatura, em $\mathrm{J} / \mathrm{kg}{ }^{\circ} \mathrm{C}$.

Para situações em que a umidade for considerada, os valores do calor específico terão os valores mostrados na Tabela D.1 entre o intervalo entre 100 e $115{ }^{\circ} \mathrm{C}$, devendo ser considerado decréscimo linear entre 115 e $200{ }^{\circ} \mathrm{C}$. Os valores até a umidade de $3 \%$ estão 
indicados em ambas as normas citadas anteriormente, enquanto os demais provêm de estudos feitos por Schleich ${ }^{22}$ (2005) e ECCS-MC ${ }^{23}$ (2001) apud Costa (2008).

Tabela D.1 - Valor de pico do calor específico do concreto

\begin{tabular}{ccc}
\hline$c_{p, \text { top }}\left(J / k g \cdot{ }^{\circ} \mathrm{C}\right)$ & $U(\%)$ \\
\hline 900 & 0 \\
\hline 1470 & 1,5 \\
\hline 1875 & 2,0 \\
\hline 2020 & 3,0 \\
\hline \multirow{2}{*}{ Fonte: Costa (2008) } & 5600 & 4,0 \\
\cline { 2 - 3 } & & 10,0 \\
\cline { 2 - 3 }
\end{tabular}

Onde:

$c_{p, t o p}:$ valor de pico do calor específico por unidade de massa do concreto, em função da umidade de equilíbrio do concreto e da temperatura, em $\mathrm{J} / \mathrm{kg}{ }^{\circ} \mathrm{C}$.

A Figura D.2 ilustra os dados mostrados na Tabela D.1.

Figura D.2 - Valor de pico do calor específico do concreto em função do teor de umidade

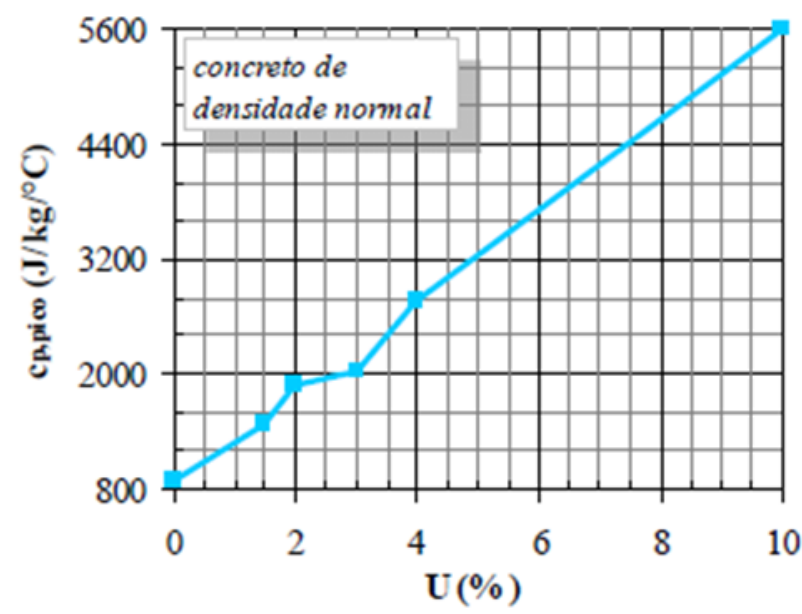

Fonte: Costa (2008)

\footnotetext{
${ }^{22}$ SCHLEICH, J.-B. Properties of the materials. In: Implementation of Eurocodes: Design of buildings for the fire situation: Handbook 5. Luxembourg: KI CTU/CKAIT/RWTH/IET/UOP/TNO/IMK/BRE, 2005. Chapt. 5. p. V-1-V-28. Leonardo Da Vinci Pilot Project CZ/02/B/F/PP-134007.

${ }^{23}$ EUROPEAN CONVENTION FOR CONSTRUCTIONAL STEELWORK (ECCS). Model code on fire engineering. n. 11. Brussels: Technical Committee 3/ECCS, 2001. iii, 125 p.
} 
Graficamente, a variação do calor específico do concreto em função da temperatura pode ser vista a seguir.

Figura D.3 - Variação do calor específico de concreto com agregado silicoso em função da temperatura, de acordo com o teor de umidade

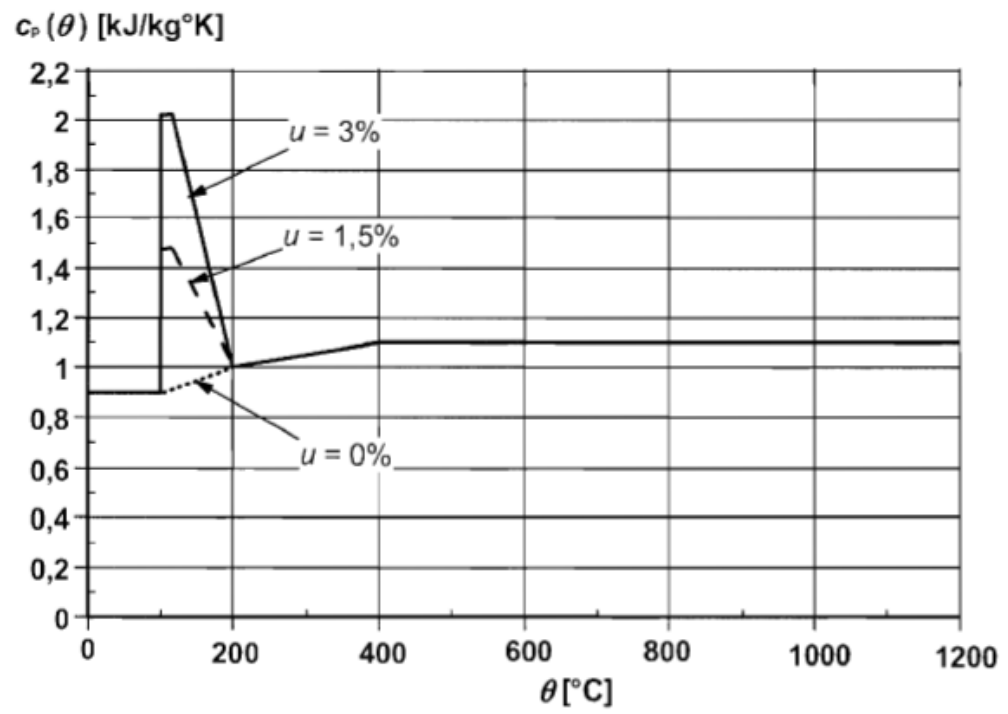

Fonte: Eurocode 2 Part 1-2:2004

\section{D.1.1.3. Condutividade térmica}

A condutividade térmica do concreto está relacionada diretamente aos agregados constituintes do concreto, bem como, à porosidade da pasta de cimento (BAŽANT \& KAPLAN ${ }^{24}$ apud COSTA, 2008; CALLISTER Júnior, 2002).

O Eurocode 2 Part 1-2:2004 fornece equações para os limites inferior e superior para o cálculo da condutividade térmica do concreto, para o intervalo entre 20 e $1200{ }^{\circ} \mathrm{C}$, as quais estão mostradas na sequência, respectivamente.

$$
\begin{aligned}
& \lambda_{c, \theta}=1,36-0,136 \cdot \frac{\theta}{100}+0,0057 \cdot\left(\frac{\theta}{100}\right)^{2} \\
& \lambda_{c, \theta}=2-0,2451 \cdot \frac{\theta}{100}+0,0107 \cdot\left(\frac{\theta}{100}\right)^{2}
\end{aligned}
$$

Onde:

$\lambda_{c, \theta}:$ condutividade térmica do concreto de densidade normal em função da temperatura, em $W / m{ }^{\circ} \mathrm{C}$.

\footnotetext{
${ }^{24}$ BAŽANT, Z. P.; KAPLAN, M. F. Concrete at high temperatures: material properties and mathematical models. Harlow: Longman, 1996. x, 412 p.
} 
A Figura D.4 indica os limites da condutividade térmica com o aumento da temperatura.

Figura D.4 - Variação da condutividade térmica do concreto em função da temperatura

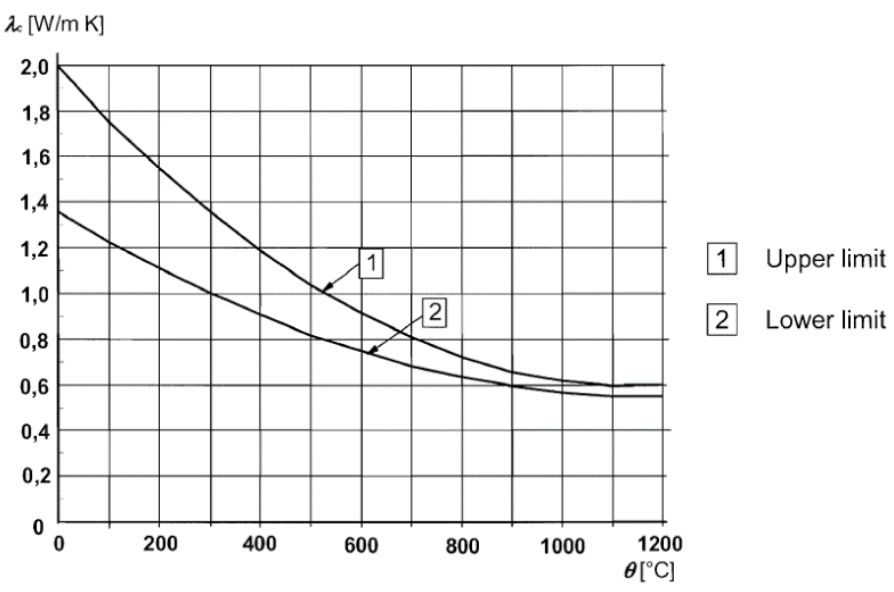

Fonte: Eurocode 2 Part 1-2:2004

A ABNT NBR 15200:2012 indica apenas a equação relativa ao limite inferior fornecido pela norma europeia e, prescreve a possibilidade de uso de valor constante e igual a 1,3 W/m ${ }^{\circ} \mathrm{C}$. Seito et al. (2008) comenta a possibilidade de uso de $1,6 \mathrm{~W} / \mathrm{m}{ }^{\circ} \mathrm{C}$ para cálculos simplificados.

Costa (2008) comenta que parâmetros como a combinação das dosagens do concreto, a natureza dos agregados e a porosidade influenciam diretamente os resultados para obtenção da condutividade. $\mathrm{O}$ consenso comum refere-se à redução da condutividade com o aumento da temperatura. Para a análise do isolamento térmico, o fator determinante relativo à condutividade é o agregado, de forma mais relevante que a própria massa específica do concreto (COSTA, 2008).

Em relação ao tipo de agregado, concretos calcários possuem condutividade térmica mais baixa que concretos silicosos e, agregados leves, possuem condutividade térmica ainda menor (FIB 24:2008).

\section{D.1.1.4. Expansão térmica}

Seito et al. (2008) sugere para o cálculo do coeficiente de dilatação térmica o uso das equações abaixo:

$$
\alpha=\frac{1,8 \cdot 10^{-4}}{\theta}+9 \cdot 10^{-6}+2,3 \cdot 10^{-11} \cdot \theta^{2} \text {, para } 20^{\circ} \mathrm{C} \leq \theta \leq 700^{\circ} \mathrm{C}
$$




$$
\alpha=\frac{14 \cdot 10^{-3}}{\theta}, \text { para } 700^{\circ} \mathrm{C}<\theta \leq 1200^{\circ} \mathrm{C}
$$

Graficamente, as equações anteriores são mostradas na Figura D.5.

Figura D.5 - Coeficiente de dilatação térmica para o concreto silicoso

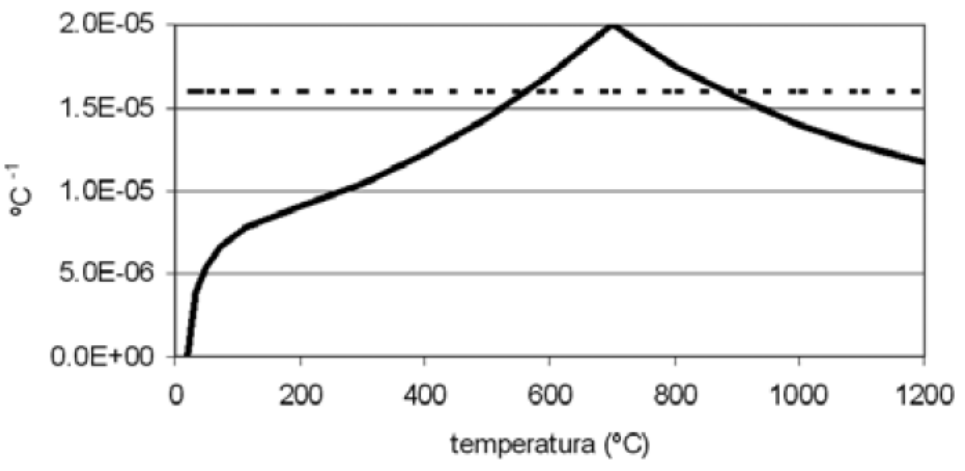

Fonte: Seito et al. (2008)

Drysdale, Hamid e Baker (1994) sugerem o uso do valor do coeficiente de dilatação térmica de $9,0 \times 10^{-6}{ }^{\circ} \mathrm{C}^{-1}$ para unidades de peso normal e $7,2 \times 10^{-6}{ }^{\circ} \mathrm{C}^{-1}$ para unidades leves. Rosemann (2011) sugere o uso do valor de $14,5 \times 10^{-6}{ }^{\circ} \mathrm{C}^{-1}$.

A ABNT NBR 6118:2014 e o Eurocode 2 Part 1-1:2004 indicam o uso de 1,0 x 10-5.

\section{D.1.2. Propriedades mecânicas do concreto}

Para a análise termoestrutural é relevante o conhecimento das resistências à compressão e à tração e do módulo de elasticidade em função da temperatura, além da relação tensãodeformação do material.

Dentre os principais fatores que alteram as propriedades citadas, podem ser citadas:

- Taxa de aquecimento: a velocidade com que ocorre o aquecimento do elemento estrutural;

- Geometria do elemento: a existência de vazios internos ou a sua forma geométrica, propriamente dita, interfere na propagação ao longo do elemento;

- Tipo de agregado: a existência de agregados com diferentes propriedades térmicas entre si, o que irá interferie na resistência do concreto de acordo com a temperatura;

- Tempo de aquecimento; 
- Teor de umidade: como já citado anteriormente, este parâmetro influencia as propriedades térmicas do concreto;

- Resistência: o aumento da resistência do concreto pode causar fenômenos como o "spalling" (lascamento explosivo) devido à menor porosidade, o que dificulta a saída da água livre e aumenta a pressão no interior dos poros;

- Tempo de aquecimento: caso a elevação de temperatura seja finalizada antes do flashover não haverá grandes prejuízos estruturais;

- Taxa de resfriamento: a forma com que ocorre a redução da temperatura, que pode ser lenta ou rápida, o que influencia a resistência residual do elemento estrutural;

- Histórico de carga: o comportamento dos elementos estruturais varia de acordo com o nível de carregamento existente.

Costa (2008) comenta que a determinação das propriedades mecânicas dos materiais a temperaturas elevadas pode ser feita através dos seguintes ensaios:

- Ensaios em regimes de aquecimento constante ("steady state tests"): caracterizados por um período de aquecimento até o nível de temperatura de interesse, estabilizando-a para que ocorra a uniformidade das temperaturas no corpo-de-prova antes da aplicação do carregamento de ensaio;

- Ensaios em regime de aquecimento transiente ("transiente state tests ou non-steady tests”): caracterizados pela variação de temperatura, normalmente, ascendente e linear, e carga monotônica aplicada simultânea ao corpo-de-prova. A aplicação da carga pode ser feita antes do aquecimento (pre-loaded), após o aquecimento, ou após o resfriamento (unloaded).

Britez (2011) relata em seus estudos que o concreto perde cerca de $25 \%$ da sua resistência a temperaturas próximas de $300{ }^{\circ} \mathrm{C}$ e $75 \%$ quando submetidos a temperaturas da ordem de $600{ }^{\circ} \mathrm{C}$.

Cánovas (1988) comenta sobre as alterações relevantes que ocorrem com o concreto na ocasião de elevação da temperatura. Após o início da evaporação da água capilar, a $100{ }^{\circ} \mathrm{C}$, o aquecimento do concreto é retardado até próximo a $300{ }^{\circ} \mathrm{C}$, quando ocorre a evaporação total. No intervalo entre 300 e $400{ }^{\circ} \mathrm{C}$, ocorre leve redução da resistência do concreto devido à perda de água da pasta de cimento, período em que aparecem as primeiras fissuras. Até os $600{ }^{\circ} \mathrm{C}$, tensões internas são criadas devido à diferença de dilatação entre os agregados, onde ocorre o início da desagregação do concreto. 
Landi (1986) reforça sobre a ocorrência da redução da resistência e do módulo de elasticidade do concreto após os $300{ }^{\circ} \mathrm{C}$. Comenta também sobre a possibilidade de lascamento explosivo na ocasião de aquecimento brusco da estrutura, podendo ocasionar a perda do cobrimento nas estruturas de concreto armado, deixando as armaduras diretamente em contato com o fogo.

Dentre os motivos que ocasionam o lascamento explosivo, podem ser citados: pressão interna gerada pela evaporação da água; dilatação do aço ocorrer primeiramente em função da diferença entre os coeficientes de condutibilidade térmica; tensões diferenciais internas que surgem no aquecimento não uniforme da seção; e o quartzo que apresenta aumento de volume ao mudar sua estrutura a partir de $500{ }^{\circ} \mathrm{C}$.

Mehta e Monteiro (1997) observam que no intervalo entre 400 e $600{ }^{\circ} \mathrm{C}$ ocorre a dessecação dos poros, a decomposição dos produtos de hidratação e o início da destruição do gel C-S-H da pasta de cimento, ocorrendo a destruição total a partir dos $900{ }^{\circ} \mathrm{C}$. Os autores comentam também sobre a importância de conhecer a composição da pasta de cimento, pois este é um dos fatores que controlam a resistência do concreto em elevadas temperaturas, uma vez que o calor pode enfraquecer o concreto endurecido, através da desestruturação química da pasta.

\section{D.1.2.1. Resistência à compressão}

A resistência à compressão do concreto diminui com o aumento da temperatura. Esta redução é estimada por meio de coeficientes cuja função é minorar a resistência à temperatura ambiente. Em temperaturas elevadas, a resistência característica à compressão do concreto é determinado pela equação seguinte:

$$
f_{c k, \theta}=k_{c, \theta} \cdot f_{c k}
$$

Onde:

$f_{c k, \theta}:$ resistência característica do concreto à compressão à temperatura elevada;

$k_{c, \theta}$ : coeficiente de redução da resistência à compressão do concreto em função da temperatura, adimensional;

$f_{c k}$ : resistência característica do concreto à compressão em temperatura ambiente, em $M P a$. 
O Eurocode 2 Part 1-2:2004 fornece a Tabela D.2 para os coeficientes de redução da resistência à compressão do concreto em função da temperatura. A ABNT NBR 15200:2012 fornece apenas para concreto de agregados silicosos, os mesmos valores mostrados na Tabela E.2. Estes valores foram obtidos para a situação sem carregamento.

Tabela D.2 - Valores do coeficiente de redução da resistência à compressão em função da temperatura para agregados silicosos e calcários

\begin{tabular}{ccccccc}
$\begin{array}{c}\text { Temperatura } \\
\text { do concreto }\end{array}$ & \multicolumn{3}{c}{ Agregados silicosos } & \multicolumn{3}{c}{ Agregados calcários } \\
\cline { 2 - 7 }$\left({ }^{\circ} \mathbf{C}\right)$ & $f_{c k, \theta} / f_{c k}$ & $\boldsymbol{\varepsilon}_{c 1, \theta}$ & $\boldsymbol{\varepsilon}_{c u 1, \theta}$ & $f_{c k, \theta} / f_{c k}$ & $\boldsymbol{\varepsilon}_{c 1, \theta}$ & $\boldsymbol{\varepsilon}_{c u 1, \theta}$ \\
\hline $\mathbf{2 0}$ & 1,00 & 0,0025 & 0,0200 & 1,00 & 0,0025 & 0,0200 \\
\hline $\mathbf{1 0 0}$ & 1,00 & 0,0040 & 0,0225 & 1,00 & 0,0040 & 0,0225 \\
\hline $\mathbf{2 0 0}$ & 0,95 & 0,0055 & 0,0250 & 0,97 & 0,0055 & 0,0250 \\
\hline $\mathbf{3 0 0}$ & 0,85 & 0,0070 & 0,0275 & 0,91 & 0,0070 & 0,0275 \\
\hline $\mathbf{4 0 0}$ & 0,75 & 0,0100 & 0,0300 & 0,85 & 0,0100 & 0,0300 \\
\hline $\mathbf{5 0 0}$ & 0,60 & 0,0150 & 0,0325 & 0,74 &, 0150 & 0,0325 \\
\hline $\mathbf{6 0 0}$ & 0,45 & 0,0250 & 0,0350 & 0,60 & 0,0250 & 0,0350 \\
\hline $\mathbf{7 0 0}$ & 0,30 & 0,0250 & 0,0375 & 0,43 & 0,0250 & 0,0375 \\
\hline $\mathbf{8 0 0}$ & 0,15 & 0,0250 & 0,0400 & 0,27 & 0,0250 & 0,0400 \\
\hline $\mathbf{9 0 0}$ & 0,08 & 0,0250 & 0,0425 & 0,15 & 0,0250 & 0,0425 \\
\hline $\mathbf{1 0 0 0}$ & 0,04 & 0,0250 & 0,0450 & 0,06 & 0,0250 & 0,0450 \\
\hline $\mathbf{1 1 0 0}$ & 0,01 & 0,0250 & 0,0475 & 0,02 & 0,0250 & 0,0475 \\
\hline $\mathbf{1 2 0 0}$ & 0,00 & - & - & 0,00 & - & - \\
\hline
\end{tabular}

Os valores do coeficiente de minoração são mostrados na Figura D.6, de acordo com a temperatura.

Figura D.6 - Coeficiente de redução da resistência à compressão em função da temperatura para concreto de agregados silicosos e calcários
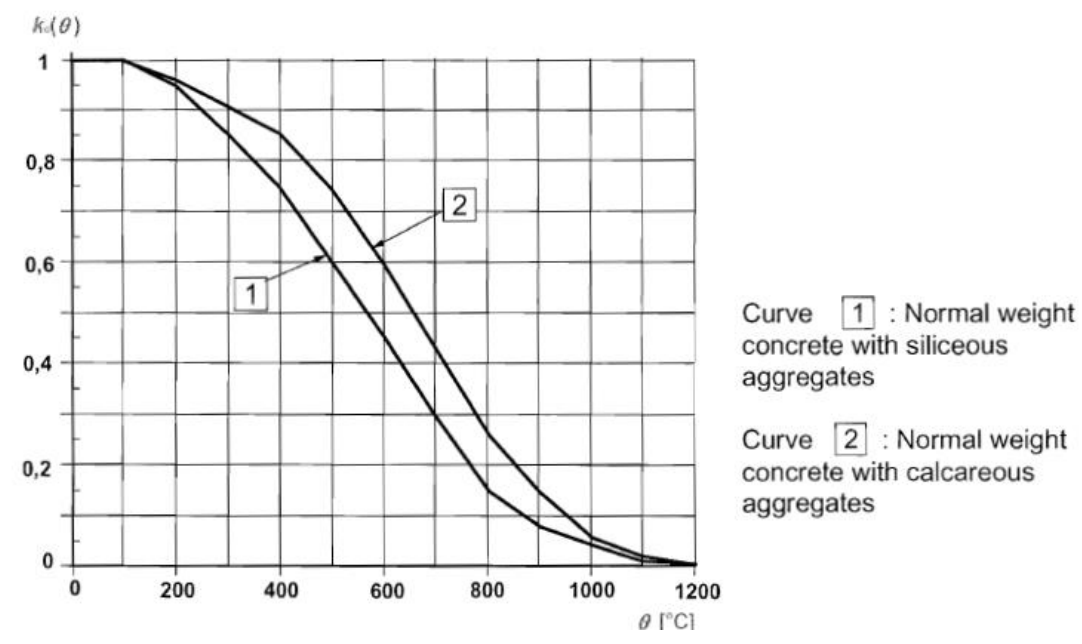

Fonte: Eurocode 2 Part 1-2:2004 
De forma simplificada, o modelo proposto pelo Eurocode 2 Part 1-2:2004 para a resistência à compressão é semelhante ao mostrado na Figura D.7.

Figura D.7 - Modelo matemático para relação tensão-deformação para concreto em temperaturas elevadas

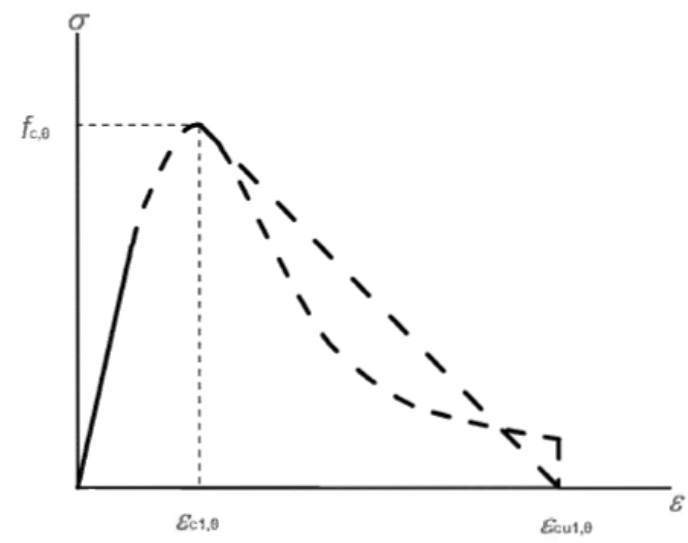

Fonte: Eurocode 2 Part 1-2:2004

O ACI TMS 216.1-14 fornece curvas de redução da resistência do concreto em função da temperatura, tanto para a situação sem carregamento quanto para carregamento de $40 \%$ da carga. A Figura D.8 exemplifica esta curva para concreto de agregado silicoso.

Figura D.8 - Redução da resistência à compressão em função da temperatura para concreto de agregados silicosos

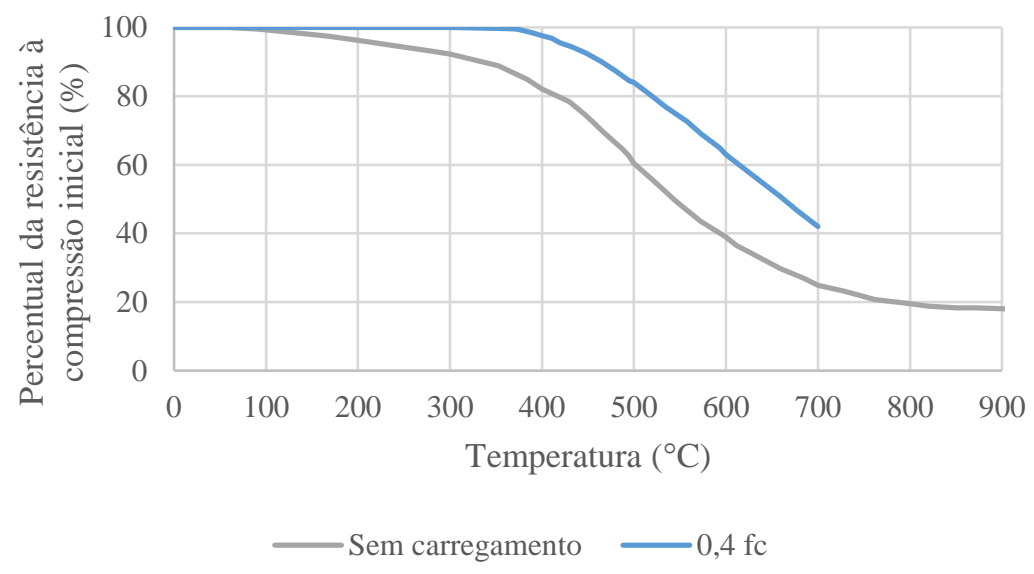

Fonte: Adaptado de ACI/TMS 216.1-14

Purkiss (2007) comenta que o comportamento não-linear quanto à redução da resistência à compressão e do módulo de elasticidade do concreto ocorre devido às mudanças físicoquímicas dos agregados, visto que os silicosos, por exemplo, possuem transformações das fases do quartzo em temperaturas de $570{ }^{\circ} \mathrm{C}$, e, os calcários tem a decomposição próxima de $650{ }^{\circ} \mathrm{C}$, além da ocorrência das fissurações. 
No Brasil, é comum o uso de agregados basálticos, porém, não há definições normatizadas, nacional ou internacionalmente acerca deste tipo de agregado submetido à elevação de temperatura (BRITEZ, 2011). Na literatura, apesar de alguns estudos realizados, não há padronização que possibilite comparações dos trabalhos e conclusões sobre o comportamento do agregado.

Lima (2005) realizou ensaios de concreto submetido a elevadas temperaturas utilizando agregados graúdos basálticos e graníticos. Como conclusão, verificou a ocorrência de lascamento maior nos corpos de prova moldados com agregado basáltico.

\section{D.1.2.2. Resistência à tração}

A resistência à tração é comumente desprezada em elevadas temperaturas, assim como, em temperatura ambiente. Porém, em situações em que esta deva ser considerada, o Eurocode 2 Part 1-2 propõe o uso das equações abaixo para tal estimativa.

$$
\begin{gathered}
f_{c t, \theta}=f_{c t}, \text { para } \theta \leq 100^{\circ} \mathrm{C} \\
f_{c t, \theta}=\left[1-\left(\frac{\theta-100}{500}\right)\right] \cdot f_{c t}, \operatorname{para} 100^{\circ} \mathrm{C}<\theta \leq 600^{\circ} \mathrm{C}
\end{gathered}
$$

Onde:

$f_{c t, \theta}$ : resistência à tração do concreto à temperatura elevada, em $\mathrm{MPa}$;

$f_{c t}$ : resistência a tração do concreto à temperatura ambiente, em MPa.

A Figura D.9 indica a minoração ocorrente em relação ao aumento de temperatura.

Figura D.9 - Coeficiente de redução para a resistência à tração do concreto em elevadas temperaturas

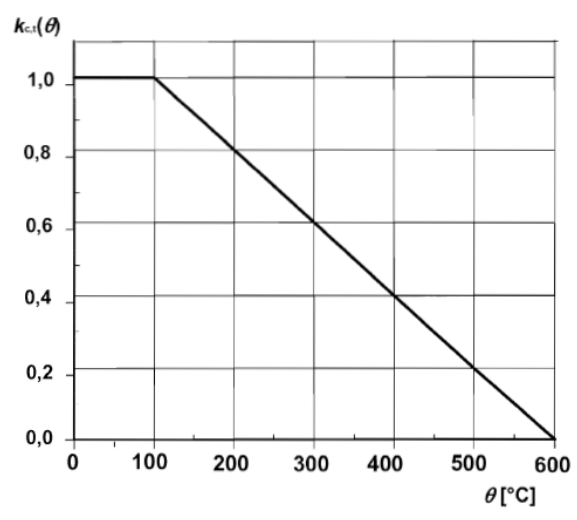

Fonte: Eurocode 2 Part 1-2:2004 


\section{D.1.2.3. Módulo de elasticidade}

A elevação da temperatura reduz o módulo de elasticidade do concreto. De forma análoga à resistência à compressão, a estimativa do módulo de elasticidade em elevada temperatura pode ser feita por meio de um coeficiente de redução, conforme indicado:

$$
E_{c, \theta}=k_{c E, \theta} \cdot E_{c}
$$

Onde:

$E_{c, \theta}:$ módulo de elasticidade do concreto à temperatura elevada, em MPa;

$k_{c E, \theta}:$ coeficiente de redução do módulo de elasticidade do concreto em função da temperatura (adimensional);

$E_{c}:$ módulo de elasticidade do concreto à temperatura ambiente, em $M P a$.

A equação (D.16) é aplicável apenas em métodos simplificados de verificação de estabilidade de elementos, como no caso de análises elásticas.

Para o uso da equação (D.16), o Eurocode 2 Part 1-2:2004 permite o cálculo do coeficiente de redução do módulo de elasticidade em função da temperatura através da expressão abaixo:

$$
k_{c E, \theta}=k_{c, \theta}^{2}
$$

O Eurocode 2 Part 1-2:2004 indica o uso da equação (D.18) para estabelecer o ramo ascendente da relação tensão-deformação do concreto a elevadas temperaturas.

$$
\sigma_{c, \theta}=\frac{3 \cdot f_{c, \theta} \cdot \varepsilon_{c, \theta}}{\varepsilon_{c 1, \theta} \cdot\left(2+\left(\frac{\varepsilon_{c, \theta}}{\varepsilon_{c 1, \theta}}\right)^{3}\right)}
$$

Onde:

$\sigma_{c, \theta}$ : valor da tensão à compressão do concreto à temperatura elevada, em $M P a$;

$f_{c, \theta}$ : valor da resistência à compressão do concreto à temperatura elevada, em $\mathrm{MPa}$;

$\varepsilon_{c, \theta}$ : deformação linear específica correspondente à temperatura elevada (adimensional);

$\varepsilon_{c 1, \theta}:$ deformação linear específica correspondente à tensão de resistência máxima do concreto à temperatura elevada (adimensional); 
$\varepsilon_{c u, \theta}$ : deformação linear específica última do concreto temperatura elevada (adimensional).

A equação (D.18) foi proposta com base em ensaios de corpos-de-prova de concretos usuais aquecidos carregados e não-carregados. Esta relação considera as alterações referentes à resistência à compressão, módulo de elasticidade, e valores de deformações lineares específicas.

Para o ramo descendente, o Eurocode 2 Part 1-2:2004 não estabelece equações ou curvas a serem seguidas. Desta forma, pode-se arbitrar curvas que sejam representativas da plastificação do concreto, ou, utilizar da própria equação comentada anteriormente, ou, ainda, considerar o trecho linear até a deformação última.

Riva (2006) comenta que o trecho entre a deformação de pico e a deformação última não possui grande relevância com base no cálculo da resistência do concreto, sendo mais utilizada para modelagens numéricas não-lineares. Costa (2008) comenta que os parâmetros de deformação fornecidos pelo Eurocode incorporam os efeitos de fluência em altas temperaturas de forma implícita.

\section{D.2. BLOCOS DE CONCRETO}

Os blocos de concreto são compostos por materiais com grande variabilidade quanto à sua composição, como ocorre também no caso do concreto armado. No Brasil, em especial, que possui alta disponibilidade de materiais inertes que podem ser utilizados como agregados em sua fabricação, a variação das propriedades termofísicas é grande para estes materiais, alterando assim, o comportamento quando submetido à elevadas temperaturas.

Atualmente, não há padronização detalhada quanto aos agregados utilizados na fabricação dos blocos de concreto em relação, por exemplo à taxa de elevação de temperatura e a composição dos agregados. As normas internacionais que padronizam os agregados quanto à sua origem também permitem uma alta variabilidade quanto ao comportamento termofísico dos mesmos.

Ingham (2009) comenta que sob baixas temperaturas para um incêndio, na ordem de 250 a $300^{\circ} \mathrm{C}$, os danos às paredes de alvenaria ficam geralmente restritos às mudanças de cor. Entretanto, com a elevação da temperatura, ocorre uma redução progressiva de sua resistência à compressão, principalmente, devido à deterioração da argamassa de assentamento. Com temperaturas entre 600 e $800^{\circ} \mathrm{C}$, a resistência à compressão da maioria das rochas e argamassas é seriamente comprometida. 
Gnanakrishnan e Lawter ${ }^{25}$ (1990 apud Russo e Sciarretta, 2013) comentam que a quantidade de água e a espessura específica dos blocos (isto é, a relação entre a espessura e o volume preenchido) interferem diretamente na capacidade de isolamento das paredes de alvenaria, sendo a relação entre estas propriedades, diretamente proporcional.

Em experimentos realizados por estes autores, verificaram que para o critério de isolamento térmico em paredes com alta capacidade isolante, a falha ocorre, geralmente, devido à perda das propriedades da argamassa. Em relação ao critério de resistência mecânica, os autores ressaltam que paredes estruturais em temperaturas elevadas sofrem colapso devido ao deslocamento horizontal elevado (curvatura ou flecha), dificilmente por esmagamento, ocorrendo geralmente quando este deslocamento alcança cerca de $80 \%$ da espessura da parede.

O Eurocode 6 Part 1-2:2004, em seu Anexo D, apresenta alguns gráficos relativos à esses parâmetros para diversos tipos de blocos estruturais em função da elevação de temperatura. A Figura D.10 exemplifica o comportamento de blocos de concreto com agregados de silicato de cálcio.

Figura D.10 - Variação dos parâmetros térmicos em função da elevação de temperatura de blocos de concreto com agregados de silicato de cálcio

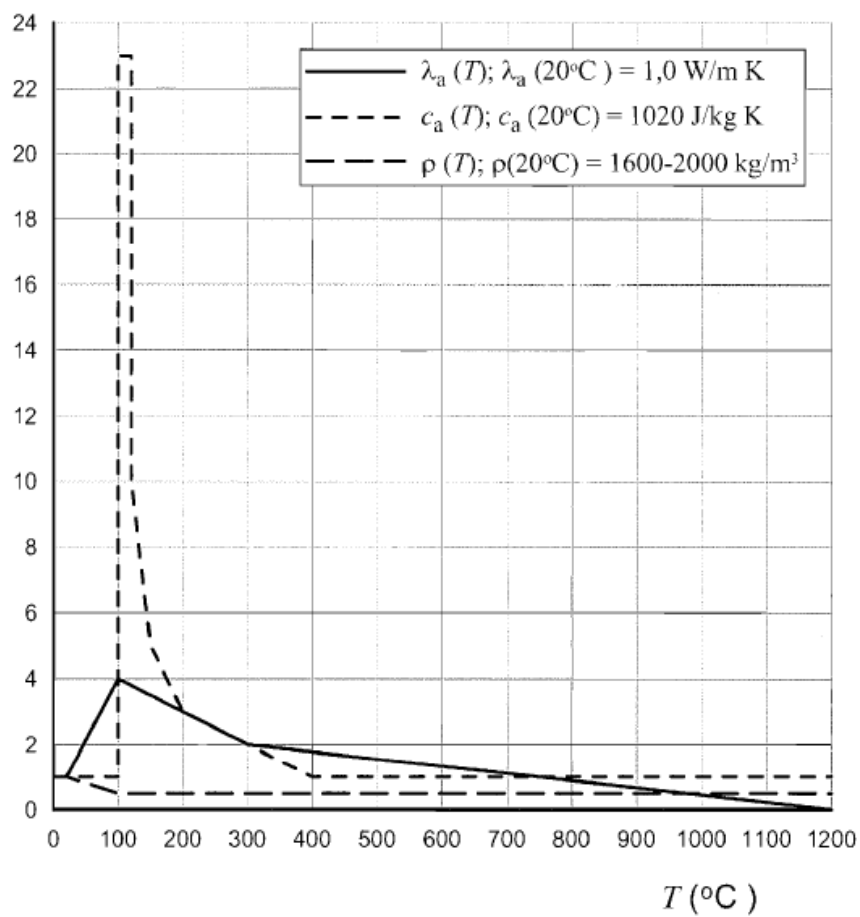

Fonte: Eurocode 6 Part 1.2:2004

${ }^{25}$ GNANAKRISHNAN, N., LAWTHER, R. Performance of masonry walls exposed to fire, in: D. P. Abrams (chairman) ,Proceedingsof the 5th North American Masonry Conference, University of Illinois at UrbanaChampaign, USA, 1990, pp. 901-914. 
Os valores contidos no eixo vertical do gráfico indicam a relação entre o valor em determinada temperatura e o valor de referência à $20^{\circ} \mathrm{C}$.

À temperatura de $100{ }^{\circ} \mathrm{C}$, ocorre aumento brusco do calor específico e posterior queda de seus valores. Nguyen et al. (2009) comenta que este aumento é devido ao calor latente de evaporação da umidade incorporada nos poros do material, o qual é somado ao calor específico do próprio concreto. À mesma temperatura, ocorre o maior valor de condutividade do material, sendo reduzido de forma mais suave posteriormente. Quanto à massa específica, há redução até os $100{ }^{\circ} \mathrm{C}$ e estabilização após esta temperatura.

A Tabela D.3 mostra a compilação dos valores dos três parâmetros comentados, a partir de pesquisas realizadas por outros autores.

Tabela D.3 - Propriedades térmicas para blocos de concreto

\begin{tabular}{cccc}
\hline $\begin{array}{c}\text { Massa específica } \\
\left(\mathbf{k g} / \mathbf{m}^{\mathbf{3}}\right)\end{array}$ & $\begin{array}{c}\text { Condutividade } \\
\text { térmica }(\mathbf{W} / \mathbf{m . K})\end{array}$ & $\begin{array}{c}\text { Calor específico } \\
(\mathbf{J} / \mathbf{k g} . \mathbf{K})\end{array}$ & Fonte \\
\hline $\mathbf{1 8 0 0}$ & - & 1,10 & Chichierchio (1990) \\
\hline $\mathbf{2 0 0 0}$ & - & 1,51 & Chichierchio (1990) \\
\hline $\mathbf{2 1 5 0}$ & - & 1,69 & Chichierchio (1990) \\
\hline $\mathbf{2 2 0 0}$ & - & 1,74 & Chichierchio (1990) \\
\hline $\mathbf{2 3 0 0}$ & - & 1,81 & Chichierchio (1990) \\
\hline $\mathbf{2 0 0 0}$ & 900 & 2,00 & Nahhas et al. $(2007)$ \\
\hline $\mathbf{8 0 0}$ & 1170 & 0,21 & Andreini e Sassu (2011)* \\
\hline $\mathbf{2 2 0 0}$ & 1000 & 1,50 & Bloco Brasil (2016) \\
\hline
\end{tabular}

Nota: * Utilizado concreto leve

Fonte: Adaptado de Rodovalho (2018)

Em relação à expansão térmica, o Eurocode 6 Part 1-1:2005 indica o intervalo de 7 a 11 x $10^{-6} \mathrm{C}^{-1}$. A ABNT NBR 15961-1:2011 indica o valor de 9 x $10^{-6} \mathrm{C}^{-1}$. Já Nadjai et al. (2003) utilizaram o valor de $6 \times 10^{-6} \mathrm{C}^{-1}$.

O teor de umidade apresenta grande influência na condutividade térmica dos materiais porosos como é o caso dos blocos de concreto. Mendes et al. (2001) realizou ensaios em tijolos cerâmicos e argamassa e constatou que quanto maior o teor de umidade, maior foi a condutividade obtida. Para a argamassa com porosidade de $31 \%$, obteve $0,70 \mathrm{~W} / \mathrm{m} \mathrm{K}$ para o estado seco e, 2,95 W/m K para o estado saturado. Com a variação da porosidade para $18 \%$, obteve 1,82 e $2,57 \mathrm{~W} / \mathrm{m} \mathrm{K}$, respectivamente.

Quanto ao resfriamento, Ingham (2009) alerta que o resfriamento com água, como usualmente feito pelas equipes de combate ao incêndio pode colaborar para um eventual colapso das paredes de alvenaria estrutural. Com a alvenaria aquecida, o resfriamento com água causa um choque térmico e eventual contração do material fazendo com que ocorra um intenso 
panorama de fissuração na parede, com muitas fissuras e elevadas aberturas, o que pode colaborar, naturalmente, para o colapso da mesma.

\section{D.3. ARGAMASSA}

Apesar de a argamassa ter pequena representatividade quanto ao volume na alvenaria estrutural (cerca de 7\%), Hendry (2001) e Sabbatini (1986) comentam sua alta relevãncia para o bom desempenho do sistema como um todo.

Na Tabela D.4 estão inseridos alguns valores das propriedades térmicas de argamassas estudados por alguns autores, à temperatura ambiente. Os traços mostrados estão em massa.

Tabela D.4 - Propriedades térmicas da argamassa em temperatura ambiente

\begin{tabular}{|c|c|c|c|c|}
\hline Material & $\begin{array}{c}\text { Massa } \\
\text { específica } \\
\left(\mathbf{k g} / \mathbf{m}^{3}\right)\end{array}$ & $\begin{array}{c}\text { Condutividade } \\
\text { térmica }(\mathrm{W} / \mathrm{m} \mathrm{K})\end{array}$ & $\begin{array}{c}\text { Calor específico } \\
\text { (J/kg K) }\end{array}$ & Fonte \\
\hline $\begin{array}{c}\text { Argamassa } \\
\text { convencional } \\
\text { 1:3:0,8* }\end{array}$ & 1828 & 0,946 & - & $\begin{array}{l}\text { Stancato } \\
(2000)\end{array}$ \\
\hline $\begin{array}{c}\text { Argamassa } \\
\text { convencional } \\
1: 3: 0,62 *\end{array}$ & 1928 & 1,095 & - & $\begin{array}{c}\text { Stancato } \\
(2000)\end{array}$ \\
\hline $\begin{array}{c}\text { Argamassa } \\
\text { convencional } \\
\mathbf{1 : 3 : 0 , 6 3 *} \\
\end{array}$ & 2001 & 1,175 & - & $\begin{array}{l}\text { Stancato } \\
(2000)\end{array}$ \\
\hline Argamassa celular & $600-1000$ & 0,400 & 1000 & $\begin{array}{c}\text { ABNT NBR } \\
15220-2: 2005\end{array}$ \\
\hline $\begin{array}{l}\text { Argamassa de gesso } \\
\text { (ou cal e gesso) }\end{array}$ & 1200 & 0,700 & 840 & $\begin{array}{c}\text { ABNT NBR } \\
15220-2: 2005\end{array}$ \\
\hline Argamassa comum & $1800-2100$ & 1,150 & 1000 & $\begin{array}{c}\text { ABNT NBR } \\
15220-2: 2005\end{array}$ \\
\hline Argamassa & 1500 & 1,500 & 1170 & $\begin{array}{c}\text { Nguyen et al. } \\
\text { (2009) }\end{array}$ \\
\hline Argamassa & 2100 & 1,500 & 800 & $\begin{array}{l}\text { Rosemann } \\
\text { (2011) }\end{array}$ \\
\hline
\end{tabular}

Fonte: Adaptado de Rodovalho (2018)

Para situações com alternância de temperatura, Ayala (2010) fez ensaios em argamassa com traço 1:1:5, em volume, com fator água/cimento de 1,7 e massa específica de $1900 \mathrm{~kg} / \mathrm{m}^{3}$. À temperatura de $200{ }^{\circ} \mathrm{C}$, obteve condutividade de $2,9 \mathrm{~W} / \mathrm{m} \mathrm{K}$, e, para o intervalo entre $400 \mathrm{e}$ $800{ }^{\circ} \mathrm{C}$, obteve valor de $1,4 \mathrm{~W} / \mathrm{m} \mathrm{K}$.

Para a expansão térmica da argamassa, Russo e Sciarretta (2014) utilizaram em suas simulações o valor de $6,6 \times 10^{-6}{ }^{\circ} \mathrm{C}^{-1}$ para corpos-de-prova com resistência à compressão de 10 
MPa. Nguyen et al. (2009) aplicaram o valor de $1 \times 10^{-5}{ }^{\circ} \mathrm{C}^{-1}$ para argamassa com massa específica de $1500 \mathrm{~kg} / \mathrm{m}^{3}$.

Cülfik e Özturan (2012) estudaram a redução da resistência à compressão de corpos-deprova cilíndricos de argamassa com a elevação de temperatura. A massa específica da argamassa era de $2160 \mathrm{~kg} / \mathrm{m}^{3} \mathrm{com}$ taxa de aquecimento entre 2 a $8^{\circ} \mathrm{C} / \mathrm{min}$ até temperaturas de 300, 600 e $900{ }^{\circ} \mathrm{C}$, mantidas entre 1 e 10 horas. Após atingir as respectivas temperaturas, os corpos-de-prova foram resfriados com taxa de $0,4{ }^{\circ} \mathrm{C} / \mathrm{min}$. A Figura D. 11 mostra os resultados obtidos.

Figura D.11 - Resistência à compressão residual da argamassa em função da temperatura

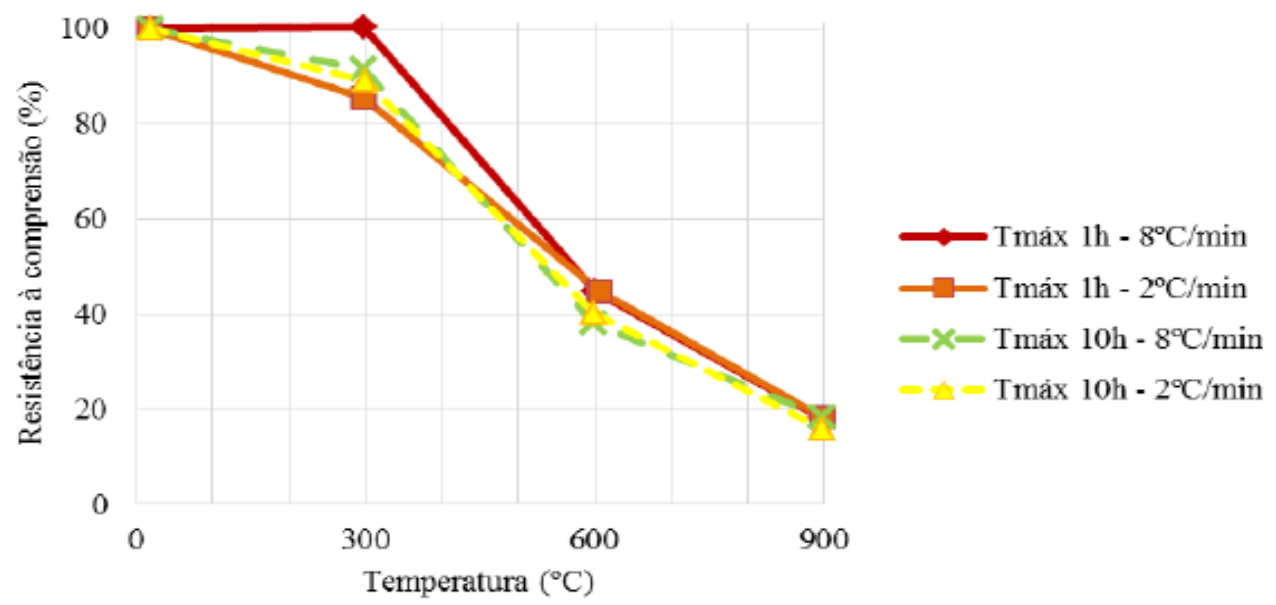

Fonte: Cülfik e Özturan (2012)

Karahan (2010) utilizou amostras confeccionadas com cimento Portland e areia siltosa, com aquecimentos até $400,600,800$ e $1000^{\circ} \mathrm{C}$. O autor adotou três tipos de resfriamento para verificação do comportamento das amostras: resfriamento lento dentro do forno, resfriamento lento ao ar livre e resfriamento brusco. Os resultados estão compilados na Figura D.12.

Figura D.12 - Resistência à compressão residual da argamassa em função da temperatura

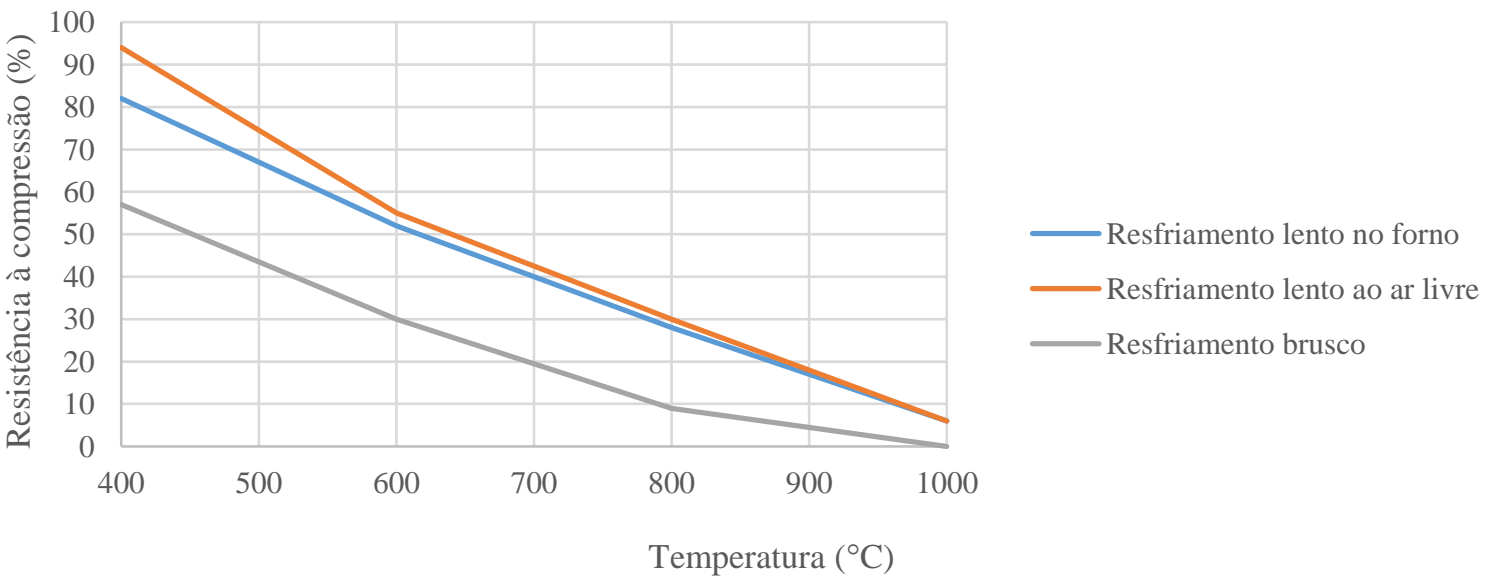


Percebe-se que as reduções utilizando resfriamento lento para ambos os casos atingiram valores próximos, e com maior divergência, aqueles com resfriamento brusco.

O comportamento do gráfico anterior é semelhante ao ocorrente com o concreto visto pelo Eurocode 2 Part 1-2:2004. 


\section{APÊNDICE E - CONSIDERAÇÕES ADICIONAIS SOBRE MODELAGEM NUMÉRICA}

Neste apêndice são apresentadas algumas considerações adicionais referentes aos elementos finitos utilizados no software ABAQUS, além das propriedades de interface existentes. Ainda, comentários gerais sobre os mecanismos de ruptura da alvenaria consideradas numericamente.

\section{E.1. CLASSIFICAÇÃO DOS ELEMENTOS FINITOS DO ABAQUS}

O software possui uma ampla variedade de elementos disponíveis. Dentre os aspectos mais relevantes para definição de acordo com o modelo gerado, podem ser citados:

- Família: se refere ao tipo de elemento, seja unidimensional, bidimensional ou tridimensional. São famílias do software: elementos sólidos, elementos de casca, elementos de viga, elementos de treliça, elementos rígidos, dentre outros (Figura E.1).

Figura E.1 - Família de elementos comumente utilizadas

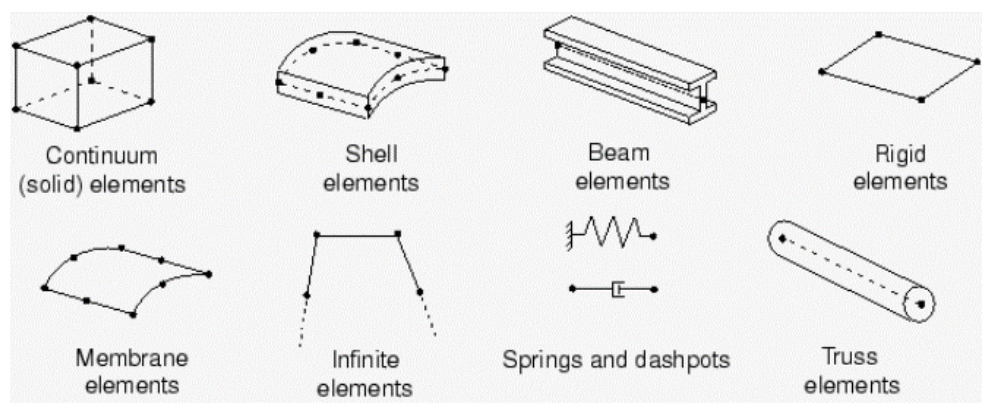

Fonte: ABAQUS (2013)

- Graus de liberdade: se referem às variáveis fundamentais calculadas durante uma análise, as quais incluem translações, rotações, temperatura, empenamento, pressão e potencial elétrico.

- Número de nós: se refere aos pontos no elemento onde são obtidos os dados de interesse. Classificam-se em elementos de primeira ordem ou elementos lineares (Figura E.2 (a)), os quais possuem nós apenas nos vértices e utilizam interpolação linear em cada direção; elementos de segunda ordem ou elementos quadráticos (Figura E.2 (b)), os quais possuem nós no ponto médio e utilizam interpolação quadrática; e, elementos modificados ou elementos de segunda ordem modificados (Figura E.2 (c)), os quais possuem nós nos pontos médios dos lados e utilizam uma interpolação de segunda ordem modificada. 
Figura E.2 - Exemplos de elementos classificados de acordo com o número de nós: bloco linear (a), bloco quadrático (b) e tetraedro modificado (c)
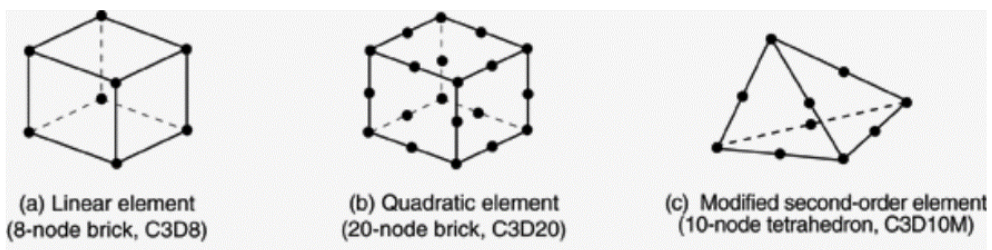

Fonte: ABAQUS (2013)

- Formulação: refere-se à teoria matemática usada para definir o comportamento do elemento, podendo ser o comportamento Lagrangeano ou o comportamento Euleriano.

- Integração: o ABAQUS utiliza técnicas de integração numérica para integrar várias quantidades sobre o volume de cada elemento, avaliando a resposta do material em cada ponto de integração em cada elemento, através da quadratura Gaussiana. Dependendo do elemento utilizado, a integração escolhida pode ser completa ou reduzida. A integração reduzida possui ordem menor que a necessária para integrar a matriz de rigidez do elemento. É utilizada por dois motivos principais:

○ Economia computacional, devido ao menor número de pontos de Gauss;

○ O elemento tende a se tornar mais flexível, compensando o comportamento rígido associado a uma configuração de deslocamento pré-estabelecida.

Neste trabalho fez-se uso do elemento do tipo C3D8R, isto é, elemento finito contínuo (sólido), tridimensional de 8 nós (elemento linear) e com integração reduzida

\section{E.2. PROPRIEDADES DE INTERFACE DO ABAQUS}

Dentre as diversas propriedades de interface do ABAQUS, serão abordadas na sequência aquelas possíveis de serem utilizadas para a modelagem de alvenaria.

- Normal behavior: o contato do tipo "Hard" tem a capacidade de impedir que uma superfície penetre na outra. Esta propriedade permite a ocorrência de separação entre as superfícies após o contato. Para que a transmissão de tensões seja adequada, é necessário a coincidência dos nós das superfícies.

- Tangential behavior: tem a função de reproduzir o atrito ocorrente na ligação entre os materiais, sendo definido pelo coeficiente de atrito estático $(\phi)$. Esta propriedade obedece à Lei de Coulomb, isto é, a resistência ao cisalhamento aumenta conforme ocorre o aumento da tensão de compressão. É possível impor um valor de tensão de cisalhamento máxima, na qual, a partir da mesma, independentemente da magnitude da tensão normal, 
ocorrerá o deslizamento entre as superfícies sem aumento da resistência ao cisalhamento. Outra característica relevante a ser considerada é que a parcela relativa à coesão é desprezada.

Figura E.3 - Tangential behavior

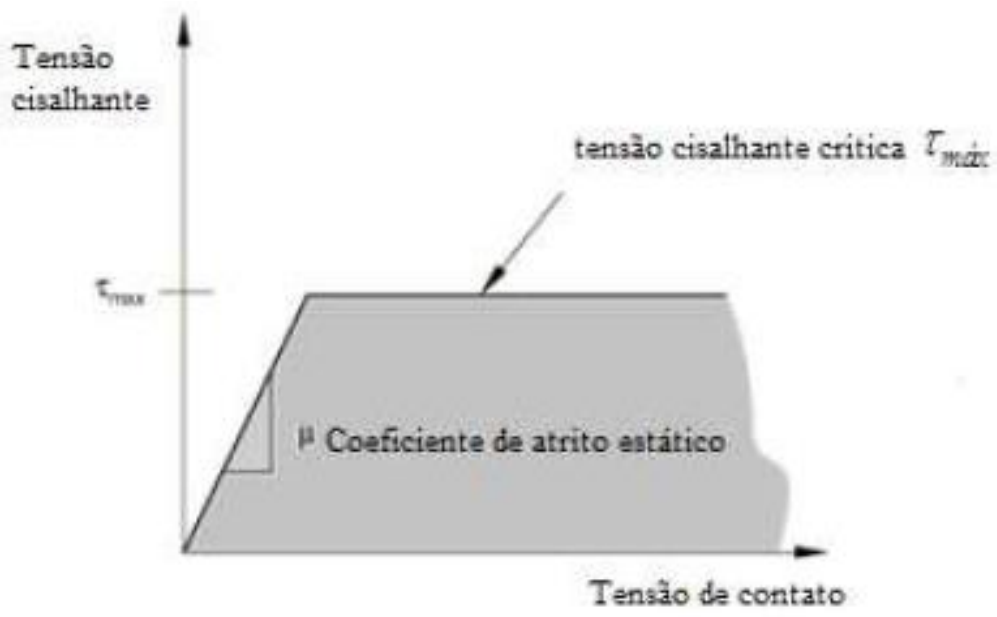

Fonte: Santos (2016)

- Cohesive behavior: é uma propriedade na qual pode ser especificado um valor de rigidez normal e tangencial na interface. Seu funcionamento ocorre como uma borracha de espessura nula. A este contato, pode ser atribuído, conjuntamente, uma degradação de rigidez denominada "Damage".

- Damage: de forma semelhante ao dano do material, tem a função de degradar a rigidez da interface. Para tanto, faz-se necessário o estabelecimento de critérios de inicialização e de evolução da degradação. Para a inicialização, um possível critério é o "Maximum stress criterion", o qual considera o início da degradação quando a equação (F.1) é satisfeita. Para o critério de evolução, um possível critério é o "Exponential damage evolution", o qual representa a evolução do dano de acordo com uma curva exponencial, a qual depende da energia de fratura da interface.

$$
\max \left(\frac{t_{n}}{t_{n}^{0}}, \frac{t_{s}}{t_{s}^{0}}, \frac{t_{t}}{t_{t}^{0}}\right)=1
$$

Onde,

$t_{n}:$ corresponde à tensão normal;

$t_{s}$ e $t_{t}$ : corresponde às tensões cisalhantes; 
$t_{n}^{0}$ : corresponde à tensão normal máxima que ocorreria se a separação ocorresse apenas devido à tensão normal (valor conhecido);

$t_{s}^{0}$ e $t_{t}^{0}$ : correspondem às tensões cisalhantes máximas que ocorreriam se a separação entre as duas superfícies ocorresse apenas devido à tensão cisalhante (valor conhecido).

Conforme indicado ao longo do texto, neste trabalho fez-se uso das propriedades normal e tangential. 


\section{APÊNDICE F - EQUAÇÕES DO MODELO DE GUO (2014) PARA EXTRAPOLAÇÃO DAS CURVAS DE COMPRESSÃO E DE TRAÇÃO DO CONCRETO}

Neste apêndice estão apresentados o equacionamento utilizado para extrapolação das curvas de compressão e de tração dos modelos estruturais, juntamente com as equações para consideração dos modelos de dano dos materiais, utilizadas para cada qual.

Estas equações se referem ao modelo proposto por Guo (2014), também utilizadas por Santos (2016) para representação do modelo estrutural dos prismas e paredes em H.

\section{Compressão:}

Trecho elástico:

$$
\sigma_{c}=E_{c m} \cdot \varepsilon
$$

Trecho inelástico:

$$
\begin{gathered}
\sigma_{c}=f_{b m} \cdot\left[\alpha_{a} \cdot x+\left(3-2 \cdot \alpha_{a}\right) \cdot x^{2}+\left(\alpha_{a}-2\right) \cdot x^{3}\right] ; x \leq 1 \\
\sigma_{c}=\frac{f_{b m}}{\alpha_{d} \cdot(x-1)^{2} \cdot x} ; x>1 \\
d_{c}=1-\frac{\sigma_{c}}{f_{b m}}
\end{gathered}
$$

Sendo:

$$
x=\frac{\varepsilon}{\varepsilon_{c 1}} ; \alpha_{a}=\frac{E_{c m}}{E_{c 1}} ; 1,5 \leq \alpha_{d} \leq 3,0 ; \varepsilon_{\text {inel }}=\varepsilon-\frac{\sigma_{c}}{E_{c m}}
$$

Figura F.1 - Variação do parâmetro $\alpha_{d}$

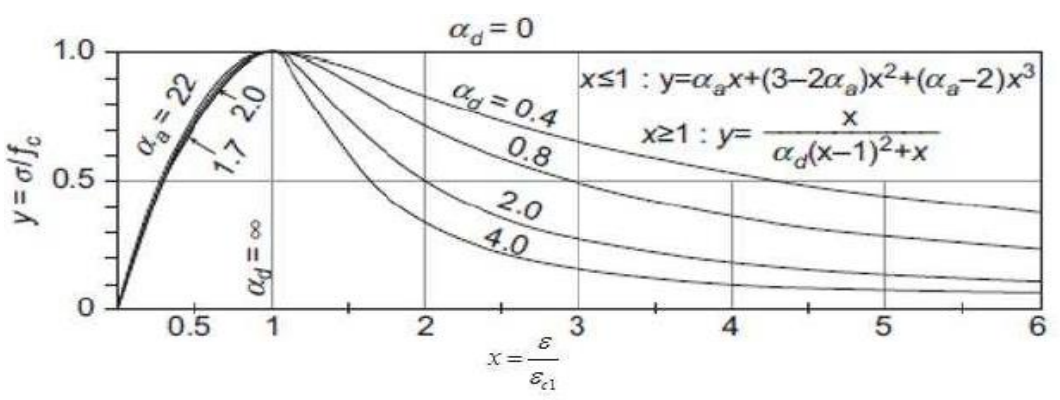

Fonte: Guo (2014) 


\section{Tração:}

Trecho elástico:

$$
\sigma_{t}=E_{c m} \cdot \varepsilon
$$

Trecho inelástico:

$$
\begin{gathered}
\sigma_{t}=f_{b t m} \cdot \frac{x}{\alpha_{t} \cdot[x-1]^{1,7}+x} \\
\varepsilon_{\text {inel }}=\varepsilon-\frac{\sigma_{t}}{E_{c 0}} \\
d_{t}=1-\frac{\sigma_{t}}{f_{c t m}}
\end{gathered}
$$

Sendo:

$$
\alpha_{t}=0,312 \cdot f_{b m} ; x=\frac{\varepsilon}{\varepsilon_{c t}} ; \varepsilon_{c t}=\frac{f_{b t m}}{E_{c m}}
$$

Onde:

$f_{b m}, f_{b t m}$ : tensões de ruptura na compressão e tração, respectivamente;

$E_{c m}$ : módulo de elasticidade inicial (correspondente a uma tensão de $0,3 \cdot f_{b m}$ );

$E_{c 1}$ : módulo de elasticidade secante (considerando a tensão máxima);

$\varepsilon_{c 1}$ : deformação relativa à tensão de ruptura;

$d_{c}, d_{t}:$ danos à compressão e à tração, respectivamente.

Obs.: $f_{b t m}=0,33 \cdot f_{b m}{ }^{1 / 2}$ (baseada em Genikomsou e Polak, 2015) 


\section{APÊNDICE G - INFORMAÇÕES COMPLEMENTARES DAS ANÁLISES NUMÉRICAS}

Neste apêndice constam algumas figuras complementares às análises numéricas realizadas no Capítulo 4.

A Figuras G.1 indica o comportamento do modelo numérico verificado no item 4.1.1 quanto aos deslocamentos no instante da ruptura.

Figura G.1 - Deslocamentos ocorrentes no modelo numérico (a), na direção x (b), na direção y (c) e na direção z (d)
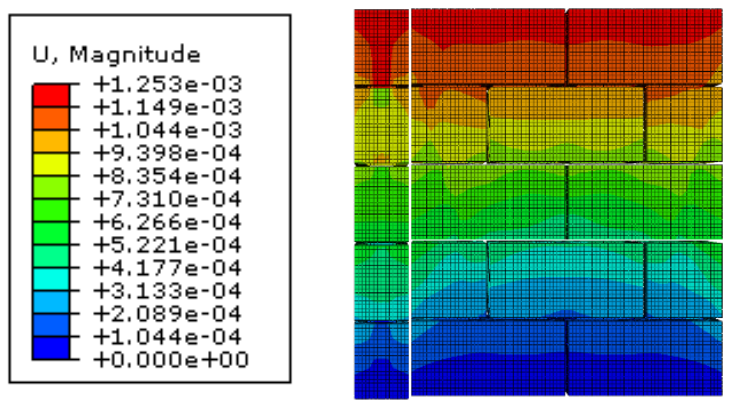

(a)

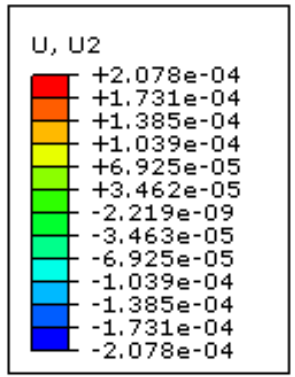

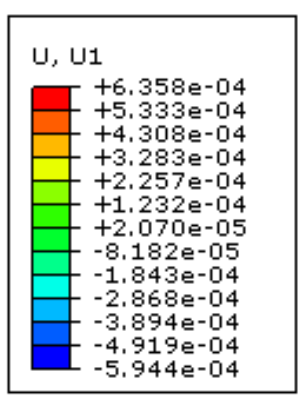

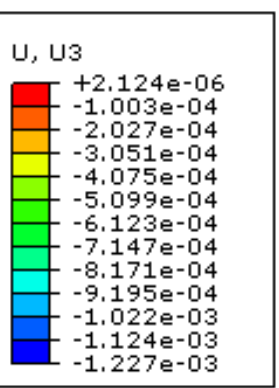

(c)

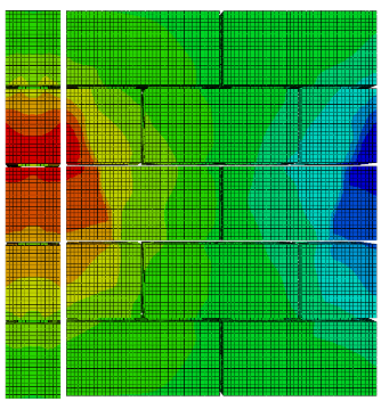

(b)

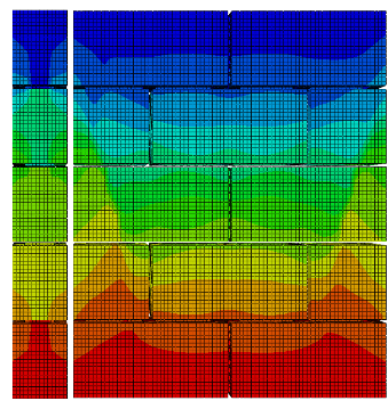

(d)

Os deslocamentos verificados numericamente encontram-se coerentes com os deslocamentos impostos experimentalmente. A referência para todas as situações encontra-se no centro de gravidade da parede. Na direção x (Figura G.1 (b)), verifica-se a expansão da parede para os lados devido ao efeito de Poisson em virtude do deslocamento vertical imposto. Da mesma forma, na direção y (Figura G.1 (c)), ocorre este tipo de situação, com expansão da parede para os lados, já definindo os pontos de ruptura, tanto laterais quanto nas faces. $\mathrm{Na}$ direção z (Figura G.1 (d)), ocorre a redução da altura da parede em virtude do deslocamento imposto, como imposto experimentalmente. 
A Figura G.2 indica o comportamento do modelo numérico verificado no item 4.1.2 quanto aos deslocamentos no instante da ruptura.

Figura G.2 - Deslocamentos ocorrentes no modelo numérico (a), na direção x (b), na direção y (c) e na direção z (d)
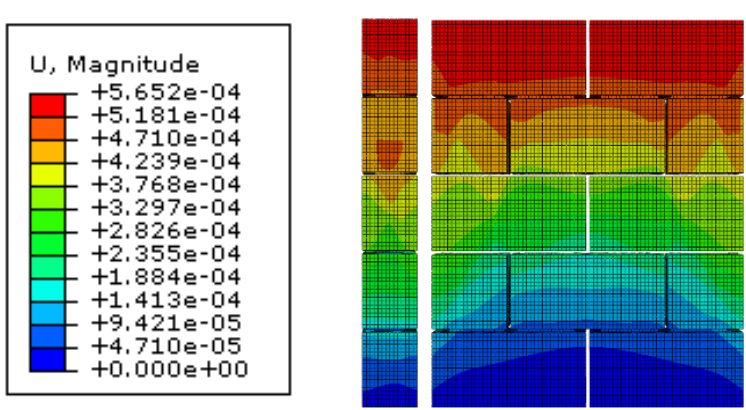

(a)

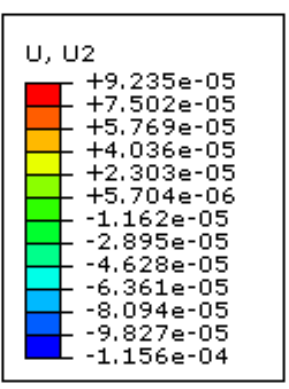

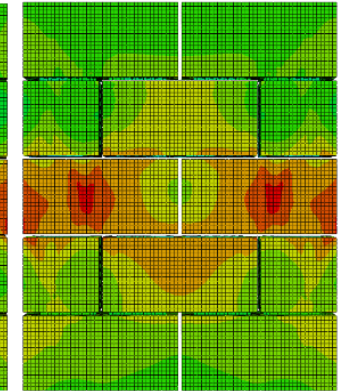

(c)
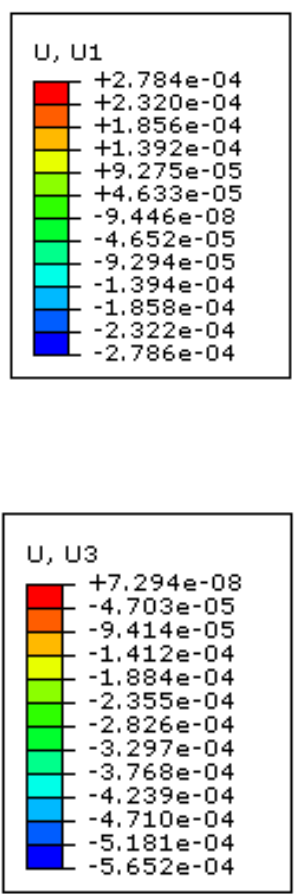

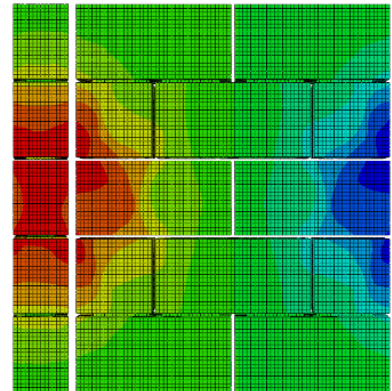

(b)

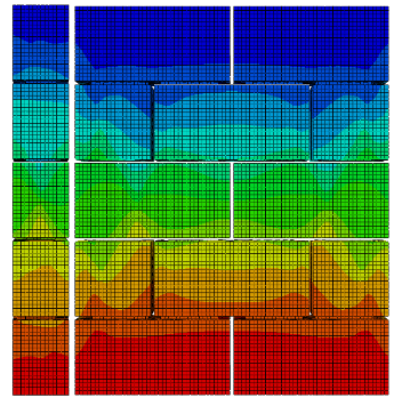

(d)

Quanto aos deslocamentos, verifica-se as mesmas situações analisadas para o modelo com argamassamento parcial, com coerência destes em relação ao procedimento experimental. Na direção x (Figura G.2 (a)), verifica-se a expansão da parede para os lados devido ao efeito de Poisson em virtude do deslocamento vertical imposto. Da mesma forma, na direção y (Figura G.2 (b)), ocorre este tipo de situação, com expansão da parede para os lados, já definindo os pontos de ruptura, tanto laterais quanto nas faces. Na direção z (Figura G.2 (c)), ocorre a redução da altura da parede em virtude do deslocamento imposto, como imposto experimentalmente.

A Figuras G.3 indica o comportamento do modelo numérico verificado no item 4.1.3 quanto aos deslocamentos no instante da ruptura. 
Figura G.3 - Deslocamentos ocorrentes no modelo numérico (a), na direção x (b), na direção y (c) e na direção z (d)
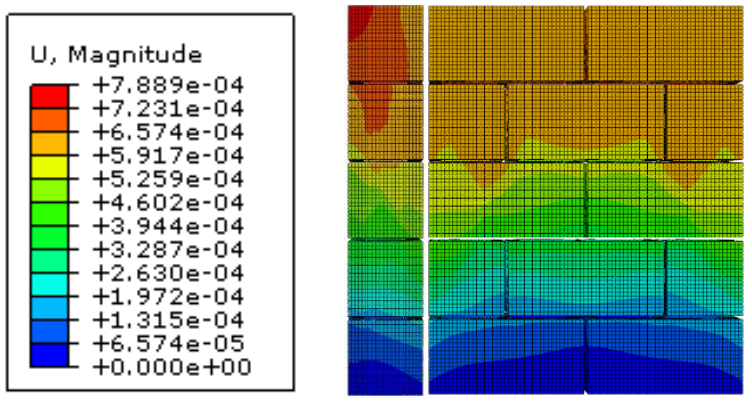

(a)

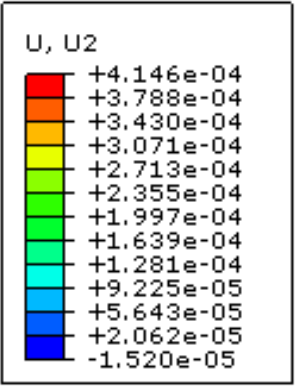

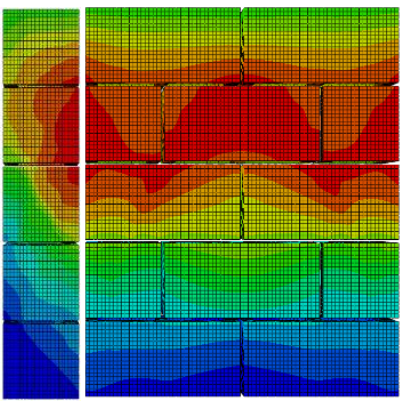

(c)
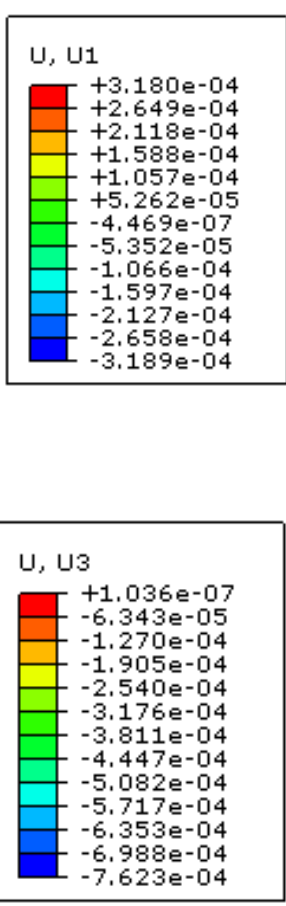

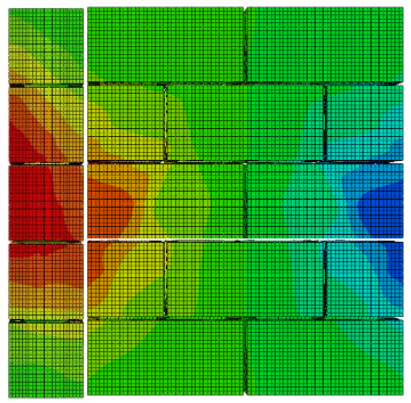

(b)

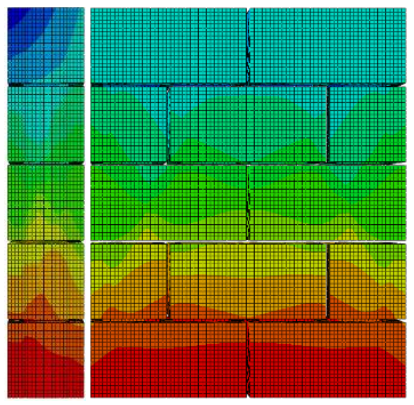

(d)

Quanto aos deslocamentos, na direção x (Figura G.3 (a)), verifica-se a expansão da parede para os lados devido ao efeito de Poisson em virtude do deslocamento vertical imposto. Da mesma forma, na direção y (Figura G.3 (b)), ocorre este tipo de situação, com expansão da parede para os lados, já definindo os pontos de ruptura, tanto laterais quanto nas faces. $\mathrm{Na}$ direção z (Figura G.3 (c)), ocorre a redução da altura da parede em virtude do deslocamento imposto, como imposto experimentalmente.

As Figuras G.4, G.5 e G.6 indicam o comportamento do modelo numérico verificado no item 4.3.2 quanto aos deslocamentos no instante da ruptura para as três condições de contorno analisadas. 
Figura G.4 - Distribuição de deslocamentos na face exposta (1) e oposta (2) para os tempos de 25 (a), 50 (b), 75 (c) e 100 minutos (d) para a condição de contorno CC1

(1)
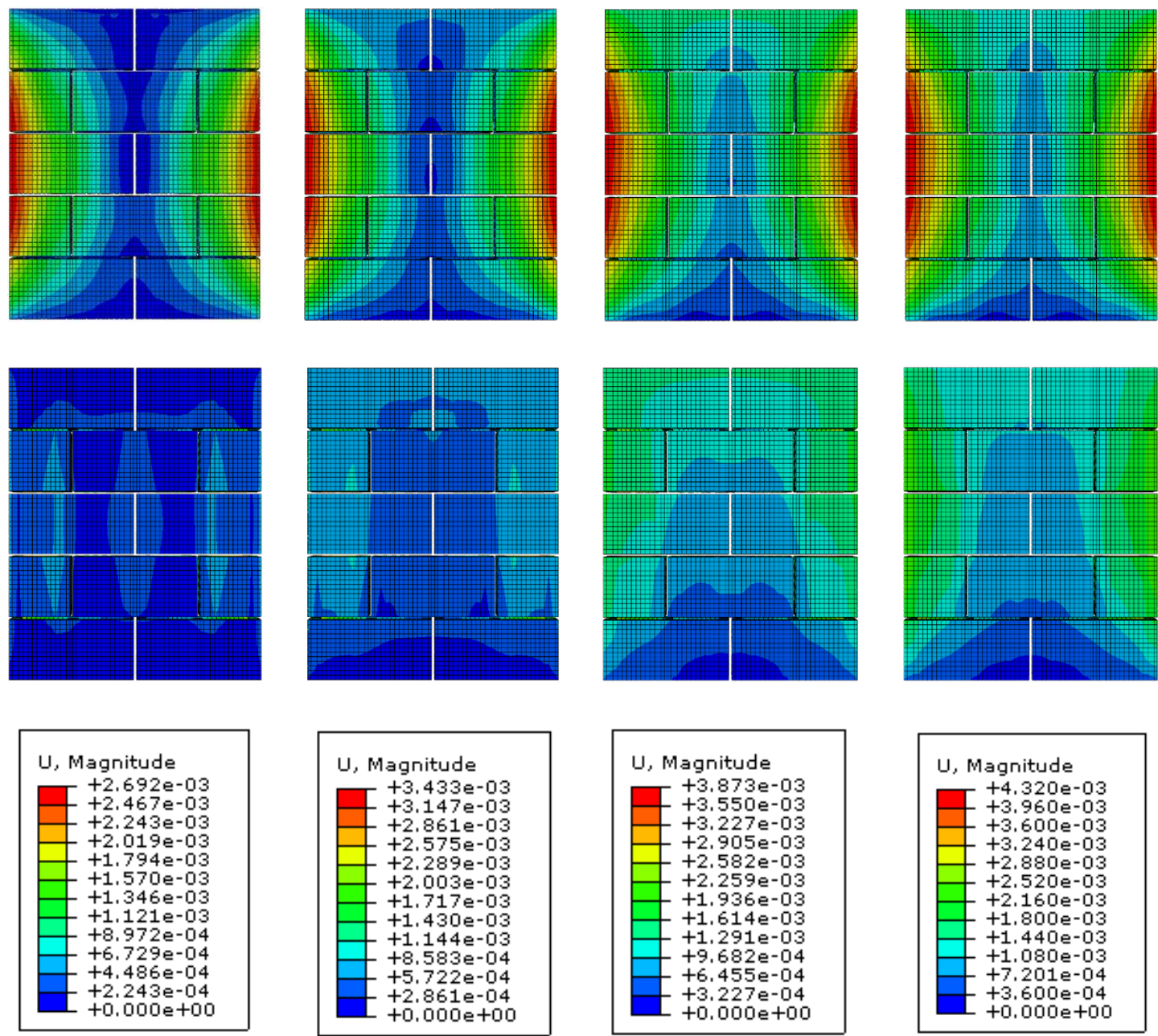

(a)

(b)

(c)

(d)

Apesar da impossibilidade de giro nesta condição de contorno, os deslocamentos da face exposta diferem-se da face oposta em virtude da expansão térmica diferencial, pelo gradiente de temperaturas ao longo da seção transversal. No entanto, conforme esperado, os deslocamentos na superfície superior se queivalem entre as faces. 
Figura G.5 - Distribuição de deslocamentos na face exposta (1) e oposta (2) para os tempos de 25 (a), 50 (b), 75 (c) e 100 minutos (d) para a condição de contorno CC2

(1)

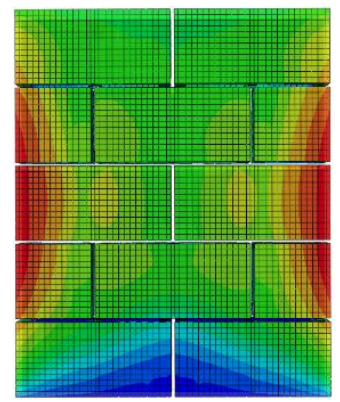

(2)
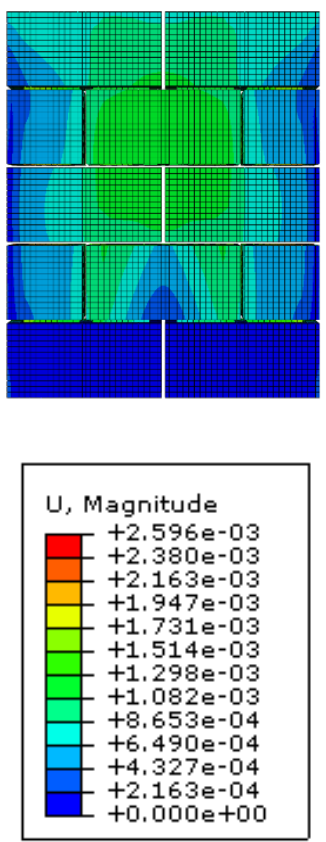

(a)
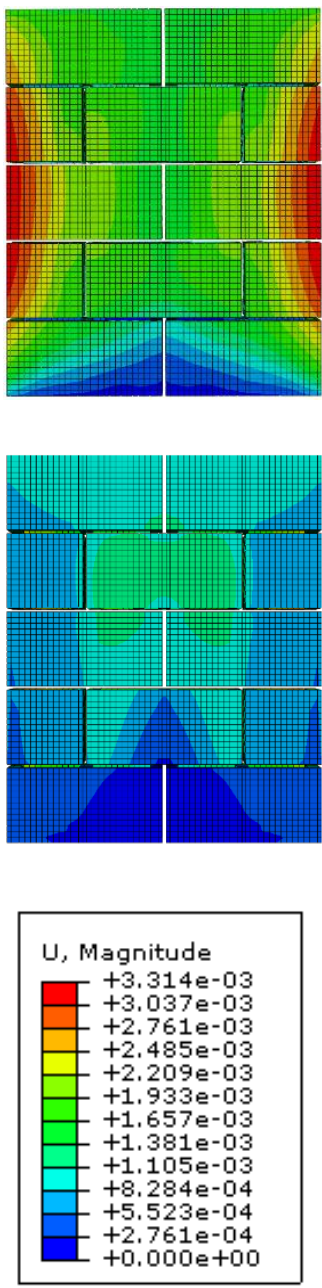

(b)
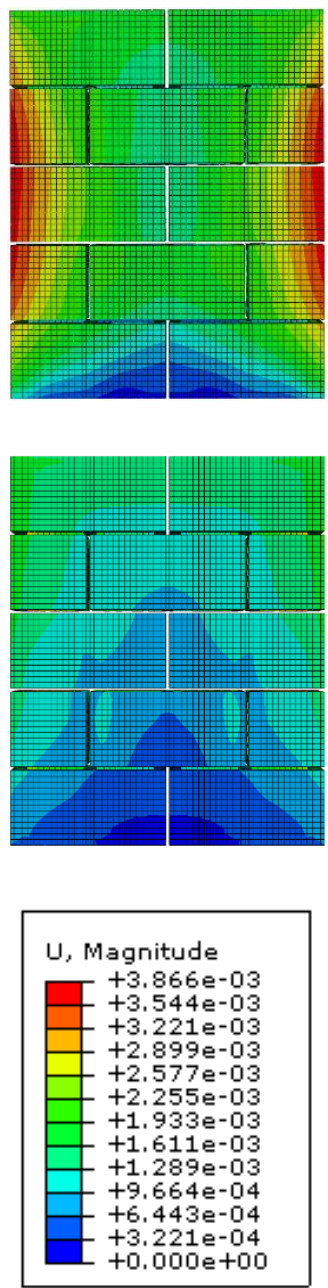

(c)
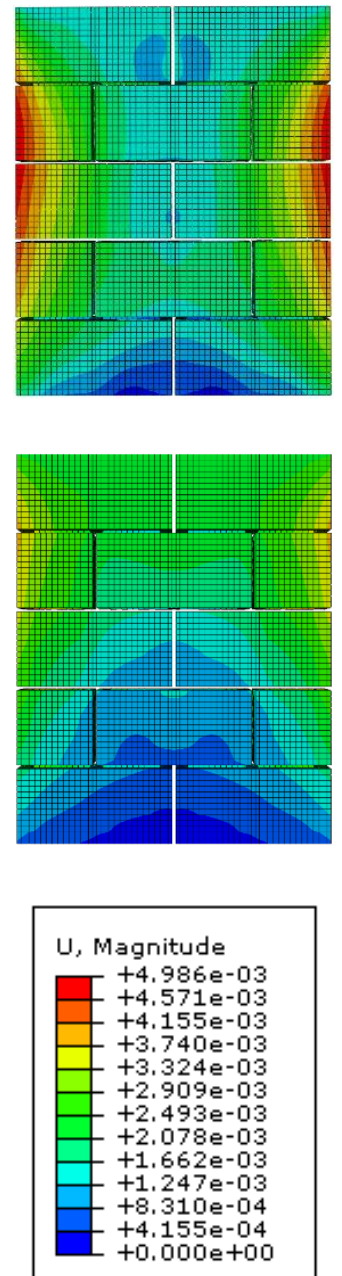

(d)

Para o deslocamento, o comportamento da parede diferencia-se em relação ao caso anterior, pois, com o giro permitido na superfície superior, maiores foram os deslocamentos verificados próximos a esta face, enquanto que na superfície inferior, as primeiras fiadas tiveram menores resultados. 
Figura G.6 - Distribuição de deslocamentos na face exposta (1) e oposta (2) para os tempos de 25 (a), 50 (b), 75 (c) e 100 minutos (d) para a condição de contorno CC3

(1)
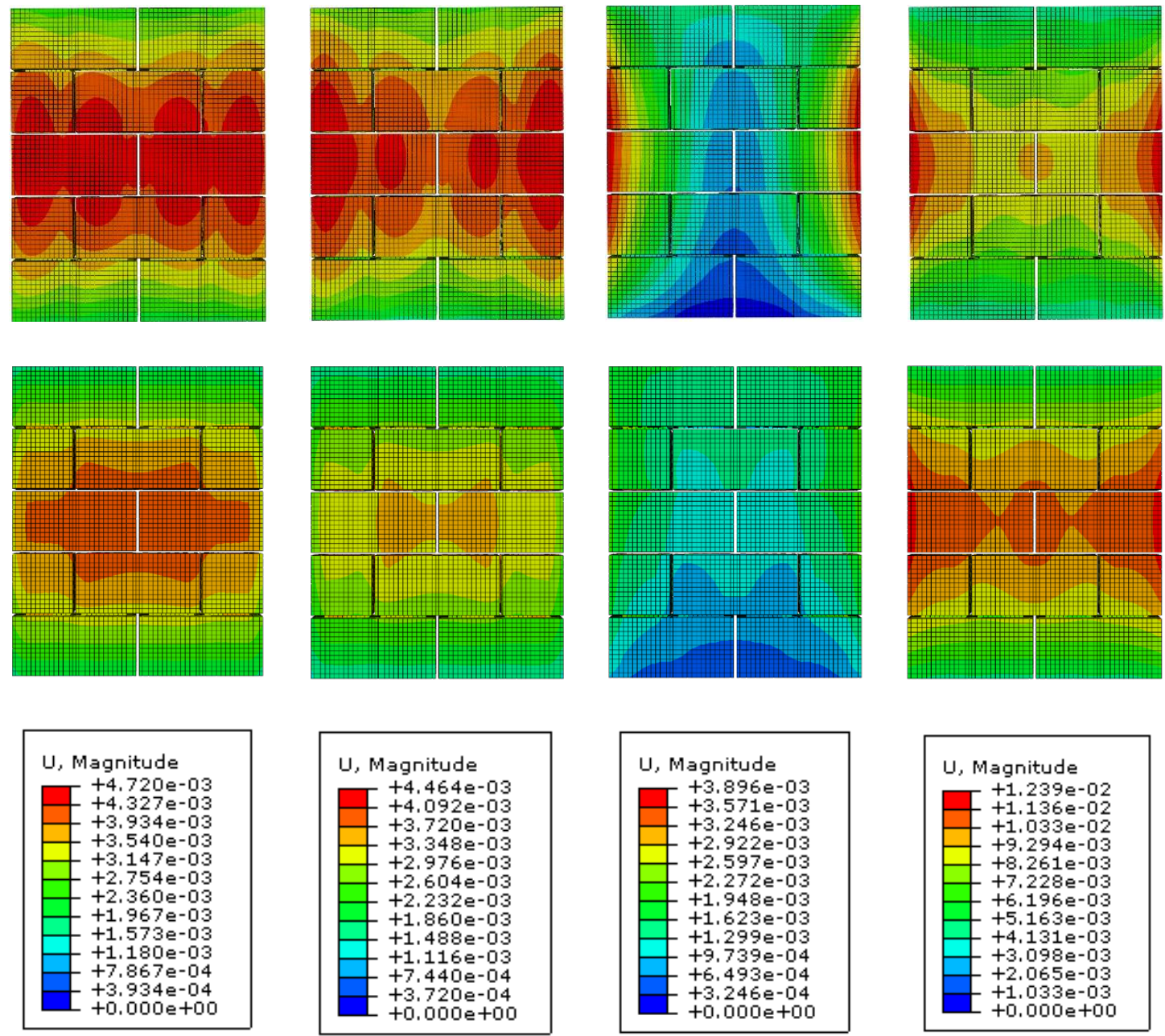

(a)

(b)

(c)

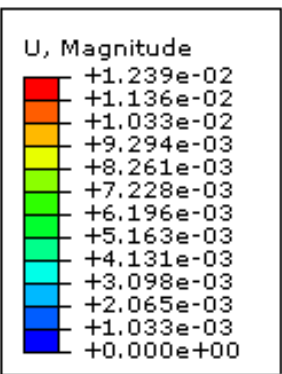

(d)

Quanto aos deslocamentos, verifica-se a inversão de curvatura da parede anterior aos 50 minutos de incêndio. Aos 75 minutos, a parede encontra-se próxima à sua posição inicial, e, aos 100 minutos, com a curvatura totalmente invertida. 


\section{APÊNDICE H - HISTÓRICO DA ALVENARIA ESTRUTURAL E INCÊNDIO NAS ESTRUTURAS}

\section{H.1. Histórico da alvenaria estrutural}

O emprego da alvenaria com fim estrutural existe desde o surgimento das primeiras civilizações, quando se buscava uma maneira de organizar as pedras e montar paredes. Algumas construções milenares, como no caso das pirâmides do Egito, permanecem até hoje como exemplos da história da humanidade.

De acordo com Campos (2008), os assírios e persas utilizavam a alvenaria desde 10.000 a.C. a partir de tijolos secos ao sol. Por volta de 3.000 a.C. já estavam sendo utilizados tijolos de barro queimados em fornos.

Na Pirâmide de Quéops, Egito, construída há cerca de 2600 anos a.C., foram utilizados cerca de 2,3 milhões de blocos, ocupando uma área de aproximadamente 53 mil metros quadrados, cuja altura é de 147 metros. A Figura H.1 indica detalhe dos blocos utilizados.

Figura H.1 - Detalhe da Pirâmide de Quéops, Egito

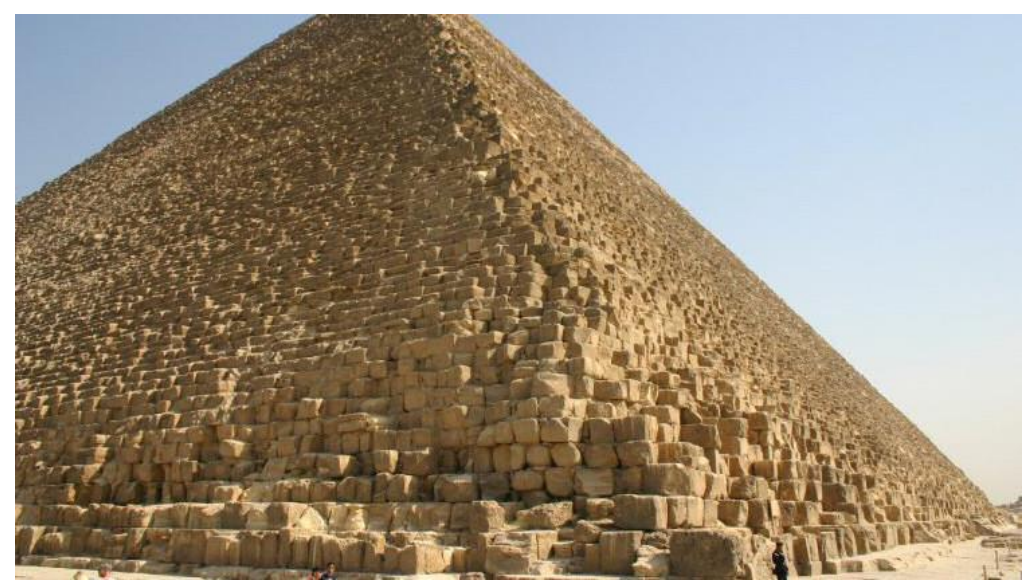

Fonte: https://www.infoescola.com/civilizacao-egipcia/piramide-de-queops/. Acesso em 28/11/2017.

De acordo com Ramalho e Corrêa (2003), uma obra marcante da Antiguidade, do ponto de vista estrutural, é o farol de Alexandria. Este farol possuía entre 120 e 140 metros de altura. Fora destruído por um terremoto no século XIV. Já o Coliseo, construído por volta de 70 d.C., se destaca pelo aspecto estrutural, o qual fora projetado através de suportes constituídos por pórticos formados por pilares e arcos. Este tipo de estrutura possibilitava aos romanos maior liberdade quanto à localização da construção, não necessitando que estes fossem executados em locais com desníveis como ocorria com os teatros gregos. 
Nos séculos XVIII e XIX, com a teoria matemática de Euler, a qual equacionou a carga de flambagem de colunas, bem como, com as primeiras pesquisas experimentais sistemáticas em alvenaria realizadas nos EUA (CAMACHO, 2006), houve considerável avanço do conhecimento em alvenaria estrutural.

No século XIX foi construído o edifício Monadnock em Chicago (Figura H.2), com 16 pavimentos e 65 metros de altura. Suas paredes tinham 1,80 metros de espessura. De acordo com Ramalho e Corrêa (2003), acredita-se que se este edifício fosse projetado com os conhecimentos atuais e com os mesmos materiais, as paredes teriam espessura inferior a 30 centímetros.

Figura H.2 - Edifício Monadnock, Chicago, EUA

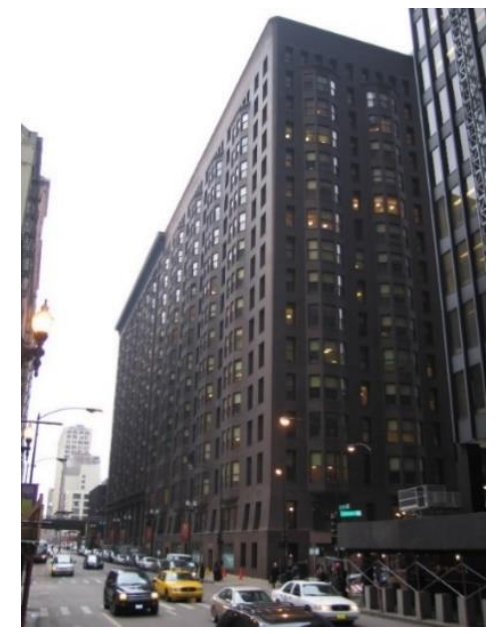

Fonte: https://pt.wikipedia.org/wiki/Edif\%C3\%ADcio_Monadnock. Acesso em 27/11/2017.

A partir do início do século XX, com o advento do concreto e do aço, foram executadas estruturas mais altas, esbeltas e leves (CARVALHO, 2007; RAZENTE, 2004), ficando a alvenaria direcionada para construções de pequeno porte ou utilizada apenas como fechamento. Neste período, as pesquisas e o desenvolvimento da alvenaria estrutural estagnaram.

Apenas em 1951, com a construção do edifício Basiléia, na Suíça, com 13 pavimentos em alvenaria não armada, as pesquisas sobre o comportamento estrutural da alvenaria foram retomadas. Esta construção é considerada como um marco da alvenaria estrutural. Atualmente, o edifício mais alto em alvenaria estrutural é o Hotel Excalibur, em Las Vegas, EUA (Figura H.3). O complexo do hotel é formado por quatro torres principais, com 28 pavimentos, cada uma contendo 1008 apartamentos. As paredes estruturais foram executadas em alvenaria armada de blocos de concreto e a resistência à compressão especificada na base foi de aproximadamente $28 \mathrm{MPa}$. 
Figura H.3 - Hotel Excalibur, Las Vegas, EUA

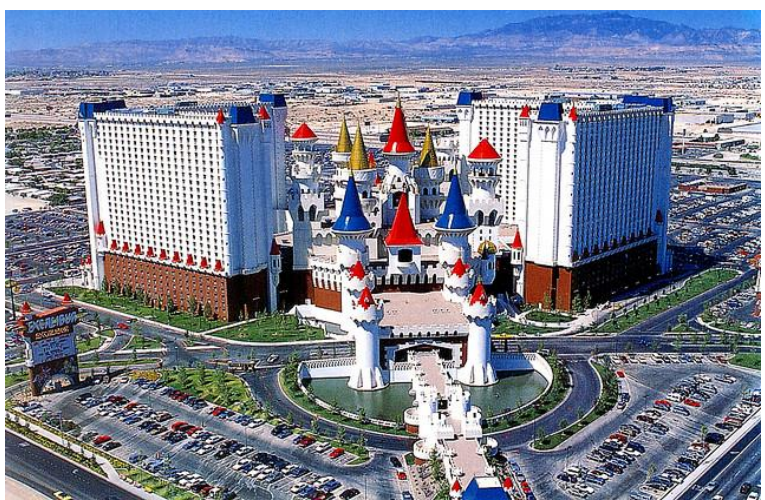

Fonte: https://pt.wikipedia.org/wiki/Excalibur_Hotel_and_Casino. Acesso em 28/11/2017.

No Brasil o histórico da alvenaria estrutural teve início na década de 60, com o Conjunto Habitacional "Central Parque da Lapa" (Figura H.4), onde iniciou-se, também, o "mito" de que a alvenaria estrutural seria viável apenas para edificações populares e de menor vulto. Nos anos seguintes, alguns edifícios de médio e alto padrões foram executados em bairros nobres da cidade de São Paulo, porém, segundo Izquierdo (2011), o sistema construtivo ainda não teve grande aceitação e reconhecimento, como em outros países, principalmente por ser dimensionado empiricamente, não havendo estudos e pesquisas nacionais, cujos dimensionamentos tinham os modelos estrangeiros como base.

Figura H.4 - Conjunto Habitacional Central Parque da Lapa, São Paulo, Brasil

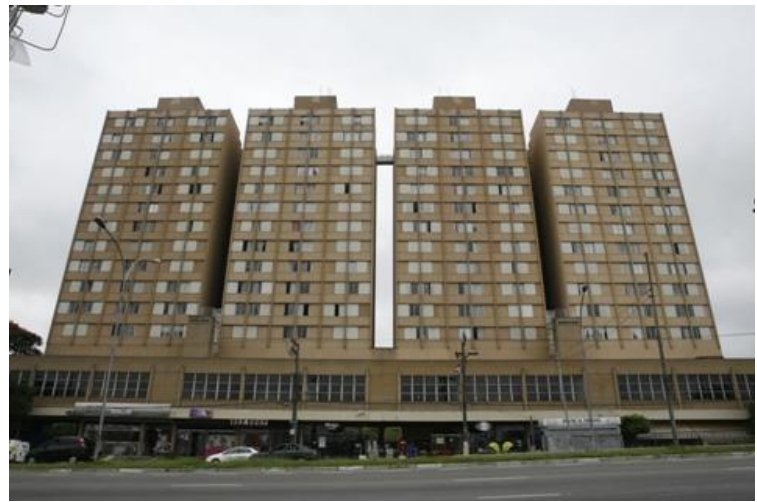

Fonte: http://www.comunidadedaconstrucao.com.br/banco-obras/1/alvenaria-estrutural. Acesso em 28/11/2017.

Com o passar dos anos, os incorporadores passaram a perceber maior viabilidade da alvenaria estrutural devido ao custo competitivo. Com o investimento das indústrias de blocos em novas tecnologias e maior qualidade, houve ganho de confiabilidade e credibilidade do sistema construtivo. Na década de 1970 foram publicadas as primeiras normalizações referentes às classes de resistência, variando entre 4,5 e 20 MPa. De acordo com Ramalho e Corrêa (2003), um fato marcante para a alvenaria estrutural no Brasil ocorreu com a publicação do Manual 
Técnico de Alvenaria, lançado na década de 1990 pela Associação Brasileira de Construção Industrializada, o qual consolidou as práticas executadas nas décadas anteriores.

\section{H.2. Histórico de incêndio nas estruturas}

Ao longo da história, diversos são os relatos e fatos acerca de grandes incêndios que destruíram prédios, vilas e cidades, culminando em perda de centenas de vidas humanas. No ano de 64, tem-se registrado o Grande Incêndio de Roma, sendo a causa do mesmo ainda bastante discutida pelos historiadores. Uma das versões mais aceitas pelos estudiosos, refere-se ao uso do fogo pelos habitantes para aquecimento próprio, e, num pequeno incidente, o fogo se alastrou devido aos ventos fortes e em razão de as habitações serem, em sua grande maioria, feitas de madeira, devastando cerca de um quarto da cidade. A segunda versão refere-se a um incêndio proposital ordenado pelo imperador Nero, com o intuito de criar uma nova cidade mais majestosa. A Figura H.5 ilustra o Grande Incêndio de Roma.

Figura H.5 - Ilustração do Grande Incêndio de Roma

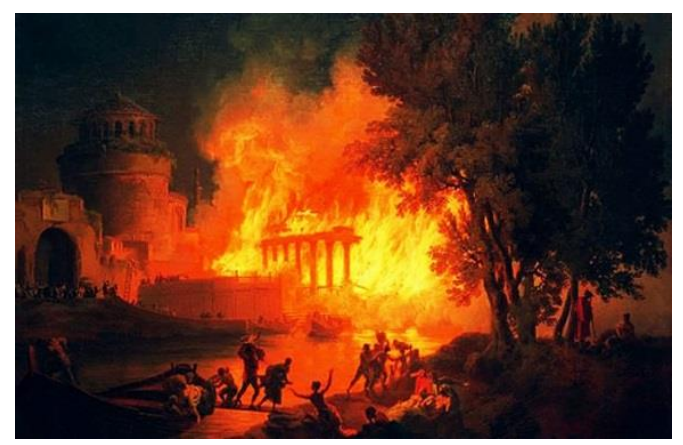

Fonte: http://www.ilmessaggero.it/rubriche/accadde_oggi/grande_incendio_roma_nerone-2567059.html. Acesso em $08 / 01 / 2018$.

Em 1.666, Londres foi consumida por um incêndio que destruiu grande parte da cidade entre os dias 2 e 9 de setembro ${ }^{26}$. $\mathrm{O}$ foco do incêndio iniciou-se em uma padaria, na madrugada do dia 02 de setembro, se espalhando rapidamente, devido aos materiais constituintes das casas, as quais eram construídas de madeira, deixando mais de 100 mil desabrigados. O prejuízo contabilizado foi, na época, de 10 milhões de libras, com destruição de 44 prédios públicos, 87 igrejas, a Catedral de Saint Paul e 13.200 casas $^{27}$. Apesar do tamanho da devastação, o Grande Incêndio deixou apenas 16 mortos. De acordo com Kimura (2009), este incêndio foi o passo

\footnotetext{
${ }^{26}$ Disponível em: http://guiadoscuriosos.uol.com.br/categorias/2846/1/10-incendios-marcados-na-historia.html. Acesso em 08/01/2018.

${ }^{27}$ Disponível em https://www.elondres.com/o-grande-incendio-de-londres-em-1666/. Acesso em 08/01/2018.
} 
inicial para criação de exigências de proteção contra incêndio. A Figura H.6 ilustra este incêndio em Londres.

Figura H.6 - Detalhe de um quadro retratando o Grande Incêndio de Londres

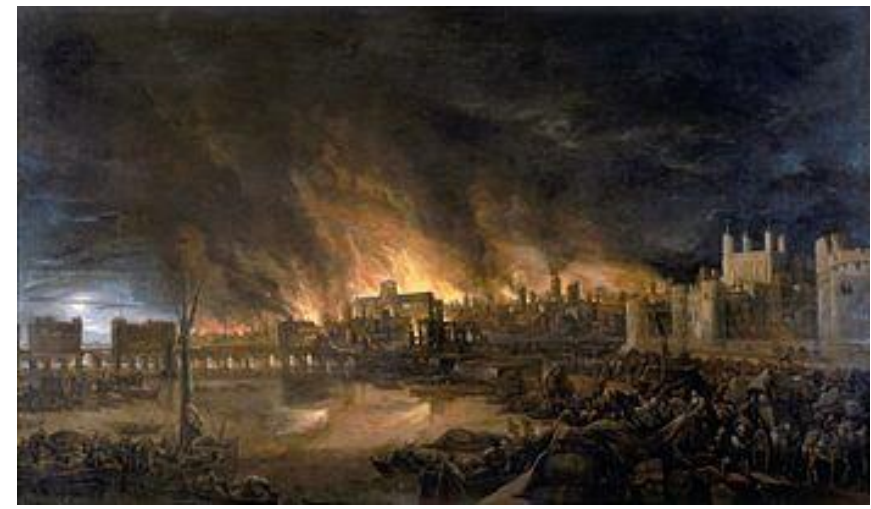

Fonte:

https://pt.wikipedia.org/wiki/Grande_inc\%C3\%AAndio_de_Londres\#/media/File:Great_Fire_London.jpg. Acesso em 08/01/2018.

Em 1871, o fogo deixou 90 mil desabrigados e 300 mortos em Chicago, causando um prejuízo superior a 200 milhões de dólares ${ }^{28}$. De acordo com Santos (2014), a versão mais aceita acerca do foco do incêndio é que este teria se iniciado em um estábulo de uma fazenda, e rapidamente se espalhou por toda a cidade por meio de faíscas que eram conduzidas pelo vento.

No Brasil, tem-se em destaque três grandes incêndios ocorrentes em edifícios, Andraus (São Paulo), Joelma (São Paulo) e Andorinhas (Rio de Janeiro) e, um outro caso em uma boate, em Santa Maria/RS.

Em 1972, um grande incêndio ocorreu no Edifício Andraus (Figura H.7), o qual reunia escritórios empresariais no centro da capital paulista. Foram constatados 16 mortes e 330 feridos neste incêndio sendo a causa mais provável, uma sobrecarga no sistema elétrico. De acordo com Kimura (2009), o edifício não apresentava sistema de segurança contra incêndios, como no caso de chuveiros automáticos, sinalização de saídas de emergência e alarmes de detecção automática.

\footnotetext{
${ }^{28}$ Disponível em: http://guiadoscuriosos.uol.com.br/categorias/2846/1/10-incendios-marcados-na-historia.html. Acesso em 08/01/2017.
} 
Figura H.7 - Incêndio no Edifício Andraus, São Paulo

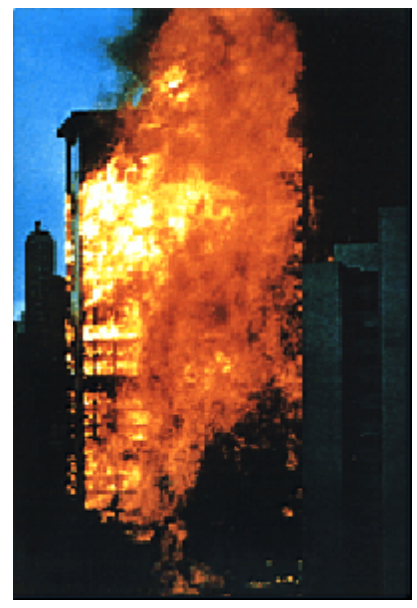

Fonte: http://www.saopauloantiga.com.br/o-incendio-do-andraus-como-nunca-visto-antes/. Acesso em 08/01/2018.

Dois anos mais tarde, ocorreu o incêndio no Edifício Joelma (Figura H.8), de 25 andares, devido à um curto-circuito no décimo-segundo pavimento, também em São Paulo. As salas do edifício eram repletas de materiais que colaboravam com a propagação do fogo, como divisórias de madeira, carpetes, cortinas e móveis de madeira, além dos forros que eram de fibra. Além disso, devido ao telhado ser formado por placas de amianto, isto impossibilitou o pouso de helicóptero em sua cobertura para resgate. O saldo da tragédia foi de 191 mortos e 300 feridos ${ }^{29}$.

Figura H.8 - Incêndio no Edifício Joelma, São Paulo
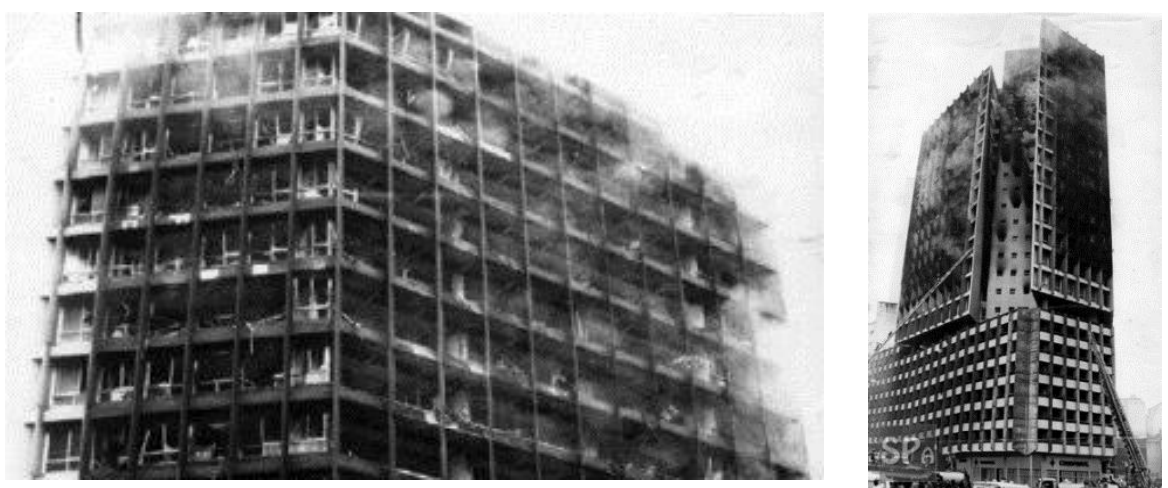

Fonte: http://www.saopauloantiga.com.br/o-incendio-do-edificio-joelma/. Acesso em 08/01/2018.

No Rio de Janeiro, o incêndio com maior destaque foi o do Edifício Andorinhas (Figura H.9), em 1986. Neste caso, foram registrados cerca de 40 feridos e confirmadas 23 mortes. A

\footnotetext{
${ }^{29}$ Disponível em: http://www.alemdaimaginacao.com/Noticias/Os\%20Misterios\%20do\%20Joelma.html. Acesso em 08/01/2017.
} 
falta de água e a dificuldade de acesso ao prédio foram as principais dificuldades dos bombeiros para controlar as chamas ${ }^{30}$.

Figura H.9 - Incêndio no Edifício Andorinhas, Rio de Janeiro

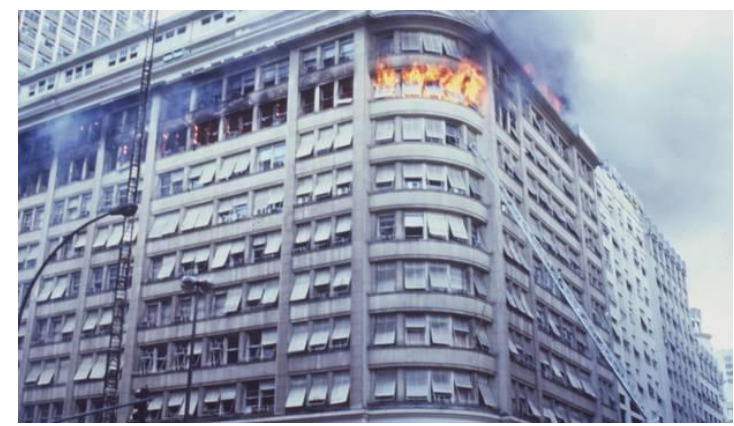

Fonte: http://acervo.oglobo.globo.com/em-destaque/incendio-no-edificio-andorinha-parou-centro-do-rio-deixou-

23-mortos-18686962. Acesso em 08/01/2018.

Mais recentemente, em janeiro de 2013, ocorreu um incêndio em uma discoteca na cidade de Santa Maria no estado do Rio Grande do Sul, deixando 245 mortos. O fogo começou depois que a banda que se apresentava no local acendeu um sinalizador que incendiou o teto de isopor. De acordo com relatório do CREA-RS (2013), o grande número de vítimas foi influenciado pela dificuldade de desocupação, deficiências nas saídas de emergência e excesso da lotação máxima permitida. A tragédia foi classificada como o segundo pior incêndio da história do país. A Figura H.10 indica a destruição do local após o incêndio.

Figura H.10 - Destruição no interior da boate Kiss, em Santa Maria/RS

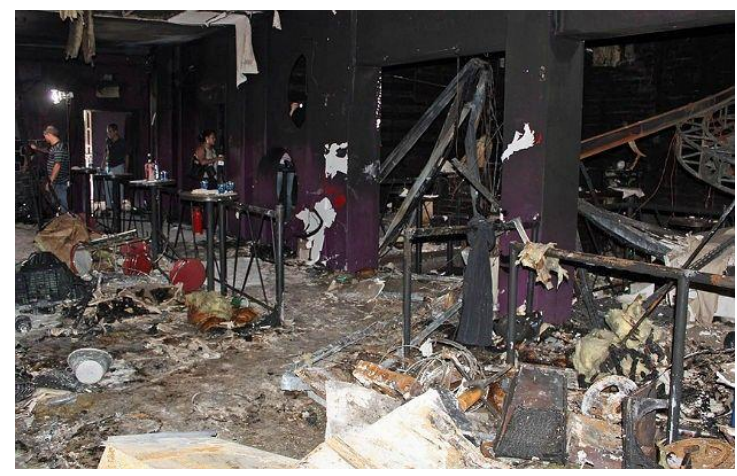

Fonte: http://g1.globo.com/rs/rio-grande-do-sul/fotos/2013/03/fotos-da-pericia-mostram-interior-da-kiss-apostragedia.html. Acesso em 08/01/2018.

\footnotetext{
${ }^{30}$ Disponível em: http://acervo.oglobo.globo.com/em-destaque/incendio-no-edificio-andorinha-parou-centro-dorio-deixou-23-mortos-18686962. Acesso em 08/01/2017.
} 